


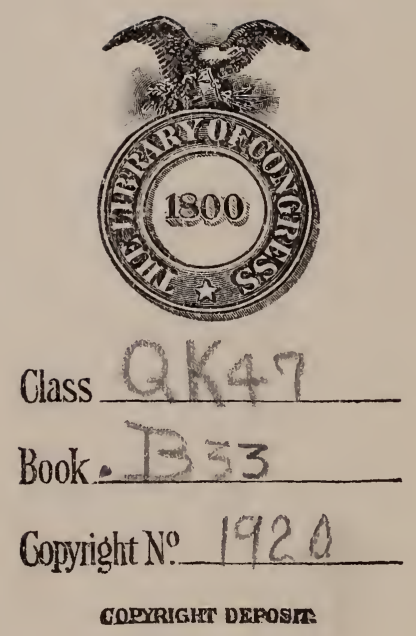




\section{.}





\title{
A REVISION OF
}

\section{Bastin's}

\section{College Botany}

For the use of Students of Pharmacy.

\author{
By \\ WILLIAM BAKER DAY
}

Professor of Botany and Materia Medica in the

School of Pharmacy of the University of Illinois,

FIRST EDITION

with 620 Illustrations

CHICAGO

G. P. ENGELHARD \& CO.

1920 


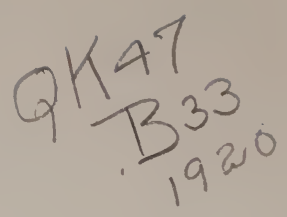

\title{
Copyright 1920
}

By G. P. Engelhard \& Co.

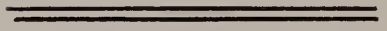

NOV 221920

\author{
DCl.A604442
}




\section{CONTENTS.}

INTRODUCTION.

Definition and Scope of Botany-Departments of Botany-

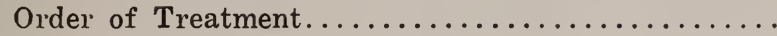

PART I.-ORGANOGRAPHY.

General Considerations-Classification of Plant Organs-

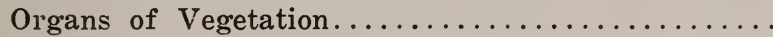

$15-16$

\section{Chapter I.}

THE ROOT.

Definition--Uses of Roots-Structure and Mode of Branching-How Roots Differ Irom Stems-Absorbing Surface Exposed by Roots-Modifications Roots Undergo -.Mycorhizas Shapes of Roots-Classification of Roots -Practical Exercises

\section{Chapter II.}

THE STEM.

Definition-How it Differs from the Root-Uses of the Stem-Buds, Their Nature and Kinds-Different Kinds and Modifications of Above-Ground StemsSize of Stems-Shapes of Stems-Direction of Growth -Duration of Stems-Habits of Growth-Underground Stems-Rhizomes-Tubers-Corms-BulbsLeaf-like Stems-Classification of Stems-Practical

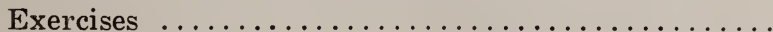

\section{Chapter III.}

THE LEAF.

Definition and Description of Leaves-Prefoliation or Vernation-Phyllotaxy-Duration of Leaves-Position of Leaves-Parts and Structure of LeavesVenation of Leaves-Shapes of Leaves-Simple Leaves-Compound Leaves-Leaf Surface-Texture 
of Leaves-Specially Modified Leaves-Practical Exercises

\section{Chapter IV.}

THE BRANCHING OF ORGANS.

Dichotomous Modes - Monopodial Modes - Practical

Exercises

CHAPTER V.

THE FLOWER.

Nature of the Flower-Reasons why the Flower possesses Special Scientific Interest-The Flower, a Modified Branch .............................

Chapter VI.

ANTHOTAXY.

Definition-Types of Anthotaxy-Forms of Indeterminate Anthotaxy-Forms of Determinate AnthotaxyMixed Anthotaxies-Recapitulation-Practical Exercises

$60-68$

Chapter VII.

PREFLORATION OR FESTIVATION.

Definition and Kinds of Prefloration-Forms of Valvate Prefloration-Forms of Imbricate Prefloration-Contorted Prefioration-Plicate Prefloration-Recapitulation of Prefoliation and Prefloration.-Practical Exercises

\section{CHAPTER VIII.}

\section{STRUCTURE OF THE FLOWER.}

Parts of the Flower-Typical Flower-Deviations from Typical Form-Deviations due to Suppression of Parts -Deviations due to Multiplication of Parts-Deviations due to Anteposition of Parts-Deviations due to Irregularity of Parts-Deviations due to Union of Parts-Practical Exercises .................... 71-76

\section{Chapter IX.}

THE TORUS, CALYX AND COROLLA.

The Torus, or Receptacle-The Calyx-Forms and Modifications of the Calyx-Epicalyx-The Corolla-The 
Complete Petal-Forms of Choripetalous CorollasForms of Gameopetalous Corollas-Practical Exercises

\section{Chapter X.}

THE STAMENS, OR ANDRECIUM.

Structure of the Stamen-Insertion of Stamens-Union of Stamens-The Filament-The Anther-The Connective-The Pollen-Pollinia-Practical Exercises..

Chapter XI.

THE PISTILS, OR GYN AECIUIN.

Structure and Parts of the Pistil-Apocarpous and Syncarpous Pistils-Placentation-The Ovary-The Style - The Stigma-The Ovule-Practical Exercises....

\section{CHAPTER XII.}

POLLINATION AND FERTILIZATION.

Pollination Defined-Cross-pollination the Rule-Agencies of Cross-fertilization-Structure of Anemophilous Compared with that of Entomophilous FlowersMeans by which Self-fertilization is PreventedDiclinism-Dichogamy-Greater Potency of Foreign Pollen - Heteromorphism - Special Contrivances Process of Fertilization - Gametes and Gametophytes-Development of Embryo-Practical Exercises

\section{Chapter XIII.}

THE FRUIT AND THE SEED.

The Fruit Defined-Changes in Process of Development -Agencies of Dispersion-Classification of FruitsDescription of Principal Kinds-Recapitulation of Fruits-

Definition of the Seed-Changes during Development from the Ovule-Structure of the Seed-Parts of the Seed - The Embryo-Kinds of Embryos-Position and Folding of Embryo-The Number of Seeds produced by Plants-Practical Exercises............ 111-130 


\section{PART II.-HISTOLOGY.}

\section{Chapter I.}

THE CELL.

The Cell in General-The Protoplast-Qualities inherent to the Protoplast-Growth of the Cell-Parts of the Protoplast-The Plastids-ChromatophoresChloroplasts-Chromoplasts-Other Cell ContentsStarch - Inulin - Sugars - Other Carbohydrates Fixed Oils and Fats--Proteins-Aleurone-Enzymes -Glucosides-Pentosides-Alkaloids-Tannins-Volatile Oils-Resins, Oleo-resins, Gum-resins and Balsams-Acids-Mineral Substances-Calcium Oxalate Crystals - The Cell Wall-Modifications of the WallCellulose-Ligno-cellulose-Cutin or Suberin-Mucilage-Mineral Substances-Stratifications-Growth of the Wall-Practical Exercises..............

\section{Chapter II.}

THE FORMATION OF CELLS.

Reproduction of Cells-Indirect Nuclear Division or Karyokinesis-Reduction Division-Free Cell Formation-Budding-Direct Nuclear Division-Practical Exercises .......................... 168-175

\section{Chapter III.}

THE TISSUES, THEIR ORIGIN AND CLASSIFICATION.

Definition-Classification of Tissues-Meristematic Tissue-Primordial Meristems-Primary MeristemsPrimary Permanent Tissues-Secondary Meristems -Secondary Permanent Tissues-Parenchymatous Tissues - Parenchyma - Collenchyma-Sclerotic Tissue-Epidermal Tissue-Stomata-Trichomes-Endodermal Tissue - Cork - Prosenchymatous Tissues Bast Fibers-Wood Fibers-Tracheids-Vascular Tissue-Sieve Tissue-Secretory Tissues-Latex Vessels -Secretory Cells-Secretory Passages-Glandular Hairs-Practical Exercises .............. 175-216 
Chapter IV.

THE HISTOLOGY OF THE ORGANS.

The Root-Growth of Roots-Primary Structure-Secondary Changes-Secondary Structure-The StemPrimary Structure-Fern Stems-Monocotyledonous Stems-Dicotyledonous Stems-Secondary ChangesRings of Growth - Bark - The Leaf - Types of Leaf Structure-The Flower--Pollen-The Fruit and the Seed-Practical Exercises................

\section{PART III.-PHYSIOLOGY.}

Chapter I.

Scope of Plant Physiology-Properties or Attributes of Protoplasm-Resemblances and Differences between Animals and Plants................... 254-258

\section{ChAPTER II.}

Constituents of Plants-Food of Plants-Absorption of Water and Soil Solutions-Ascent of Water-Transpiration-Gases in the Plant............ 259-268

Chapter III.

Elaboration of Food-Photosynthesis-Synthesis of Proteins-Distribution and Storage of Food MaterialsDigestion-Symbiosis-Respiration-Growth - Influence of Temperature on the Life of the PlantInfluence of Light on the Life of the Plant....... 268-280

Chapter IV.

Movements of Plants-Locomotion-Movements not Locomotive-Geotropism-Heliotropism-HydrotropismCircumnutation-Nyctitropic Movements-Irritability -Reproduction $280-293$

PART IV.-TAXONOMY.

Chapter I.

Value of Comparative Study-Classification and Naming of Plants-Principal Groups of Plants........ 294-300 


\section{CHAPTER II.}

THE THALLOPHYTA.

Characteristics of the Thallophytes-The Myxomycetes, or

Slime Molds

\section{CHAPTER III.}

THE THALLOPHYTA (CONTINUED).

The Schizomycetes, or Bacteria-The Cyanophyceæ, or Blue Green Algæ-The Flagellata-The Dinoflagellata, or Peridinæ................... 305-312

\section{CHAPTER IV.}

THE THALLOPHYTA-THE ALGE.

The Diatomeæ, or Diatoms-The Heterocontæ-The Chlorophyceæ, or Green Algæ-The Siphonales-The Protococcales-The Volvocales-The Confervales, or Confervoid Algæ-The Conjugales-The Charales, or Stoneworts ....................... 312-332

Chapter V.

THE THALLOPHYTA-THE ALGE (CONTINUED).

The Phæophyceæ, or Brown Algæ-The PhæosporalesThe Fucales, or Rockweeds-The Rhodophyceæ, or Red Algæ ....................... 333-339

\section{Chapter VI.}

THE THALLOPHYTA-THE FUNGI.

General Characters-The Phycomycetes, or Algal FungiThe Zygomycetales-The Peronosporales-Saprolegniales-The Chytrideaceæ-The Ascomycetes, or Sac Fungi-The Erysipheæ-The Plectascales-The Pyrenomycetes-The Discomycetes-The Tuberales-The

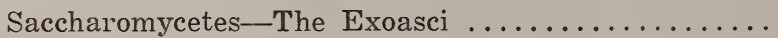

\section{Chapter VII.}

THE THALLOPHYTA-THE FUNGI (CONTINUED).

The Basidiomycetes-The Uredinales-The Ustilaginales - The Gasteromycetes-The Hymenomycetes-The

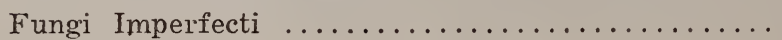


Chapter VIII.

THE THALLOPHYTA-THE FUngi (CONTINUED).

The Lichenes, or Lichens-Nature of Lichens-The Homoiomerous Lichens-The Crustaceous Lichens-The Foliaceous Lichens-The Fruticose Lichens-Classi-

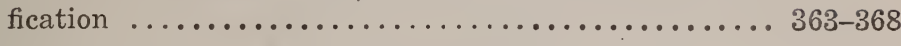

\section{Chapter IX.}

THE BRYOPHYTA, OR MOSS-PLANTS.

Classification-General Characters-The Hepaticæ, or Liverworts-The Ricciales-The Anthocerotales-The Machantiales-The Jungermanniales-The Musci, or Mosses-The Sphagnales-The Andræales-The Bryales .......................... 368-379

\section{Chapter X.}

THE PTERIDOPHYTA, OR VASCULAR CRYPTOGRAMS.

Classification-Characteristics-The Filicineæ, or FernsThe Ohioglossales, or Adder's Tongue Ferns-The Filicales, or Ferns Proper-The Hydropteridales, or Water Ferns-The Equisetineæ, or Horsetails-The Lycopodineæ, or Club Mosses-The LycopodialesThe Selaginallales

CHAPTER XI.

THE SPERMATOPHYTA, OR SEED PLANTS.

Classification-Characteristics-The Gymnospermæ, or Gymnosperms - The Cycadales, or Cycads-The Coniferales, or Conifers-The Gnetales, or Joint Firs.... 396-408

\section{Chapter XII.}

THE SPERMATOPHYTA (CONTINUED).

The Angiospermae, or Angiosperms-General Characters 408-411

Chapter XIII.

THE SPERMATOPHYTA-THE ANGIOSPERM $\approx$ (CONTINUED).

The Monocotyledons-General Characters-The Pandanales-The Heliobales-The Glumales-The PalmalesThe Arales-The Farinales-The Liliales-The Scitaminales-The Orchidales .............408-416 


\title{
ChaPter XIV.
}

THE SPERMATOPHYTA-THE ANGIOSPERM $A$ (CONTINUED).

The Dicotyledons - General Characters - The Archichlamydeæ, or Apetalæ-The Polypetalæ, or Dialypetalæ-The Sympetalæ, or Gamopetalæ-Orders and Families of the Dicotyledons.............417-432

\section{Chapter XV.}

EVOLUTION.

General Considerations-Darwinism-The Struggle for Existence-The Survival of the Fittest-Objections and Difficulties-Continuous Variations-Mutations 432-438

ChaPter XVI.

HEREDITY.

Definition of Heredity-Significance-Mendelism-Mendel's Law of Dominance-Unit Characters-Purity of Gametes-Phenotypes and Genotypes.......... 438-444

\section{Chapter XVII.}

\author{
ECOLOGY.
}

Scope of Ecology-Problems-Ecological Factors-Light -Water - Soil - Wind - Other Plants-AnimalsPlant Societies-Water Plants-Swamp SocietiesNormal Plants-Desert Plants-Seacoast Plants-Succession of Plant Societies - Important Relation to Medicinal Plants ................... 445-455 


\section{PREFACE.}

Introductory courses in botany are well established in the curriculums of pharmaceutical colleges and schools. While the immediate purpose of these courses is preparation for the study of the vegetable drugs, yet their value as a part of the student's general education is not less important. The fundamental facts and principles of botany are the same, whatever application may be made of them; by linking these facts and principles to the student's major subject, pharmacy, a considerable gain in interest is secured.

Bastin's College Botany has served a useful purpose as a textbook in many colleges of pharmacy. It is thirty years since the book was first published. At that time Professor Bastin taught botany and materia medica in the Chicago College of Pharmacy, which later became the School of Pharmacy of the University of Illinois. As a student under Professor Bastin and as his successor in the subjects taught by him in the School of Pharmacy, it has seemed fitting that the writer should undertake the revision of this useful text book.

In this revision, Professor Bastin's plan of dividing the text into four departments has been adhered to. An advantage in this plan, from the point of view of the teacher, is that it permits of the presentation of the subject from any one or more of several sides, to suit the time, facilities and material available. Thus some schools will begin with Organography, others with Histology, yet others with Taxonomy. Or two or more of these subjects may be presented concurrently.

In the choice of illustrative material, an effort has been made to use medicinal plants so far as this was feasible.

Part I, Organography, has required but few changes. In Part II, Histology, many new illustrations have been introduced, and the text has been recast. Part III, Physiology, has been largely rewritten, and Part IV, Taxonomy, has been rewritten and considerably extended.

One hundred and thirty-five figures new to the book have been added, replacing ninety-four of the figures formerly used. Of the new illustrations, sixty are from original drawings by my col- 
league, Professor E. N. Gathercoal, to whom grateful acknowledgment is made. Forty figures are taken from other text books, and due credit has been given in each instance.

It has not been deemed wise to add to the size of the book by including descriptions of processes and methods or by incorporating lists of apparatus, stains, mounting media, etc.; for such, the reader is referred to the many excellent special works on these subjects. The practical exercises in Parts I and II have been retained, as offering useful suggestions for both teacher and student.

August 25, 1920.

WILLIAM B. DAY. 


\section{INTRODUCTION.}

Botany may be defined as the science of plants. In its broadest sense it includes all classified knowledge of vegetable organisms from the lowest to the highest. A science of such scope has, of course, many branches, each of which is the outgrowth of specialized study. For example, plants may be considered with reference to the parts or organs of which they are composed and the changes and adaptations that different organs undergo, as well as the minute structure of these parts, giving rise to the department of morphology, and comprising outer morphology or organography and inner morphology or histology. Included in the latter are embryology, which deals with the origin and development of the individual plant, and cytology, which treats of the structure and behavior of cells themselves. Plants may also be regarded with reference to the functions of the various organs-the way they perform their work of vegetation and reproduction-and this view gives rise to plant physiology; likewise we may compare and classify plants according to their resemblance and differences, thus pursuing the study of plant classification, taxonomy or, systematic botany; once more, we may observe them with reference to the adaptation of the plants themselves or of their parts to their surroundings or environment, this being known as ecology, or we may notice their distribution over the earth's surface or their occurrence as fossils in earth's crust, thus entering upon the study of geographical botany and paleobotany, respectively; and, lastly, we may regard plants in the light of their economic uses or their relations to human welfare, thus leading to the various branches of plant industry or economic botany, including not only the older applied sciences of agriculture, horticulture, floriculture, forestry, pharmaceutical and medical botany, but the newer sciences of plant pathology and plant breeding as well.

For the purposes of this work the subject is treated mainly under four heads, as follows: 
Part I. Organography or Outer Morphology, that branch of structural botany which treats of the organs or instruments with which plants do their work, as roots, stems, leaves, parts of flowers, etc.,forms and modifications.

Part II. Histology, that branch of structural botany which treats of the minute or microscopic structure of plants.

Part III. Physiology, that branch of botanical science that treats of the functions of plants and their organs; that undertakes to explain how the plant and its various parts perform their work.

Part IV. Taxonomy. Under this head is considered the mode of naming and classifying plants, and a brief account of the more important groups of plants is given.

Some subjects which cannot be strictly included under any of the above heads are also briefly treated. 


\section{PART I.}

\section{ORGANOGRAPHY.}

\section{GENERAL CONSIDERATIONS.}

The lowest forms of plant life are so simple in their structure that they can hardly be said to possess distinct organs or parts for the performance of different kinds of work. With them, so to speak, the work of vegetable life is performed without implements, in the rudest manner. But as we pass up the scale of vegetable life we find plants growing more and more complex in their structures, the plant body tends more and more to be differentiated into organs, till at last, when we reach the highest group, the flowering plants, we find it to consist of a variety of parts, each differing from the other in appearance and structure, and each contributing in a somewhat different way to the life of the whole organism. Our study, therefore, of organography will be mainly confined to the organs of the higher plants, where we find them most highly developed.

In flowering plants we observe two kinds of organs; first, the vegetative, or those which are concerned chiefly with the elaboration, transportation and storage of food and which therefore contribute to the vegetative life of the plant; and second, the reproductive, or those whose special function it is to reproduce the species.

The vegetative organs consist of roots, stems, and leaves. All of these organs occur under numerous modifications. The same plant may bear several different kinds of each of them, some adapted to one use, others, perhaps, to quite a different one, so that what is, morphologically speaking, the same organ, may perform a variety of quite distinct functions. It is not Nature's method to create new organs when new uses are required, but to reshape and modify already existing ones, and fit them for the new requirements. If, for example, it is of advantage to the plant 
to climb, a leaf or a branch is converted into a tendril, or if the good of the species requires that it be defended against predacious animals, branches or leaves are modified into thorns.

\section{THE ORGANS OF VEGETATION.}

The flowerless plants below the mosses show, in rare instances, an indistinct differentiation of stem and leaf. In the mosses the distinction becomes sharp and clear, but they do not possess roots. It is not till we reach the Pteridophytes, or highest group of flowerless plants, that we find a complete differentiation of all the vegetative organs. The order of their evolution, therefore, seems to be: First, the shoot composed of leaf and stem, and last, the root. In complexity of structure, roots rank lowest and leaves highest. It must be borne in mind, then, that in discussing these organs of the plant, we are describing types only and that the organs themselves are not immutable, but that various gradations may exist between them.

\section{CHAPTER I.-THE ROOT.}

The root may be defined as the descending axis of the plant; it is that part of the plant-axis which does not bear leaves. Roots are ordinarily subterranean in their habits, and serve the double use of attaching the plant securely to the soil and of enabling it to absorb from it the necessary water and minerals. These are their normal uses, but they sometimes take upon themselves additional functions. The roots of the Carrot, Beet and Turnip, for example, not only subserve these functions, but also that of storehouses for food. These plants are biennials, and during the first year of their growth they store away in their fleshy roots great quantities of nutrient materials, which, during the succeeding year are expended in the production of flowers and fruits. Many perennial herbs, like the Dahlia, though the above-ground parts perish at the close of every season, are able to survive by means of their under-ground parts, because they store away, year by year, in their tuberous roots, the materials necessary for the succeeding year's growth. The famous Banyan tree of India sends downward, from its huge horizontally spreading branches, roots which make their way to the soil, and serve not only the ordinary uses but also 
that of props or subsidiary stems to support the weight of the branches.

But there are many instances of roots whose habits and functions are quite different from the ordinary. The roots of air plants or epiphytes, like those of many tropical orchids, for example, never reach the soil at all, but cling to the bark of trees and absorb moisture from the air; the rootlets that spring out laterally from the stems of the Poison Rhus, Trumpet Creeper and Ivy, Fig. 1, serve purely the use of climbing organs; those of the Mistletoe and Dodder penetrate the bark of the plants on which they find lodgment, and live at the expense of the nutritious juices absorbed from their hosts. Similar parasitic roots, but underground, are formed by many plants, notably the giant Rafflesia of tropical forests.

Roots differ from stems in some importart particulars, notably the following: They are much less regular in their mode of branching, they are simpler in their internal structure, they do not directly bear leaves or leafrudiments, the i $r$ growingpoint is located just back of the apex instead of at the apex, and in consequence of this sub-apical growth, the tip, unlike that of the stem, becomes covered with a protecting sheath or cap of older

Fig. 1.-Portion of stem of Ivy show. ing rootlets.

and thicker-walled cells, technically called the ruot-cap, which affords it a decided mechanical advantage in penetrating the soil.

The absorbing surface exposed by roots to the soil is much greater than is usually supposed. In most plants it is probably comparable in extent with that exposed by the leaves to the air. This great superficial area which roots present to the soil is due partly to their repeated ramifications into fine divisions, and partly to the numerous delicate root-hairs that are found on the ultimate 
branches just back of the growing point. The finer root-branches, together with their attached hairs, are the chief agents by which the plant absorbs water and solutions of minerals from the soil, and on them, therefore, more than on the larger roots, is the life of the plant dependent. The principal reason why transplanting in midsummer is so dangerous to the life of the plant, is that in

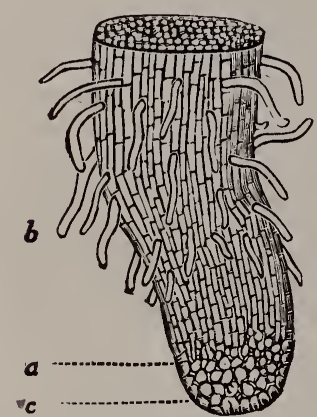

Fig. 2.

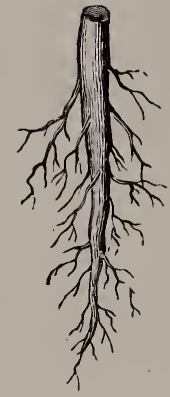

Fig. 3.

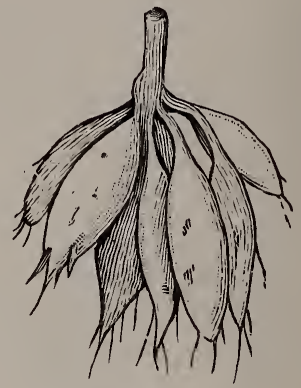

Fig. 4.

Fig. 2.-A root-tip considerably magnified, a, the growing point; b, roothair; c, the root-cap.

Fig. 3.- The tap-root of the common Stock.

Fig. 4.-The clustered and tuberous roots of the Dahlia.

the process of digging up and re-setting, numerous root-tips with their absorbing hairs are broken off and destroyed, so that the leaves evaporate water much faster than it can be taken up by the remaining roots, and the plant, therefore, necessarily withers. As soon as new hairs are formed, the absorption of water is resumed and the plant recovers from its wilted condition. Fig. 2 represents a root-tip considerably magnified, showing its growingpoint $a$, its root-hairs $b$, and its root-cap $c$.

A curious modification of the root is the presence of a fungus, either inside or outside of the root, which replaces the root hairs and carries on their absorbing function. Many forest trees, as well as Heaths and Orchids, have this partnership with a fungus, termed a mycorhiza. It will be more fully considered in a later chapter.

Roots may be classified into primary and adventitious. A primary root is the downward continuation of the embryonic root of the seed. Commonly it is simple, or the branches it produces are small as compared with the main root; in this case it is called 
a tap-root. Fig. 3 represents the tap-root of the common Stock. Sometimes, however, the embryonic root almost immediately breaks up into numerous similar branches, forming multiple primary roots. These may become thickened and tuberous, as in the Dahlia, Fig. 4, or they may remain slender and fibrous, as in the roots of the Plantain.

Not infrequently the primary root disappears altogether at an early stage of the development of the plant, and is replaced functionally by other roots springing out laterally from the stem higher up. This is almost universally the case with the large group of flowering-plants called Monocotyledons, typified by the Lilies, Palms, Grasses and Sedges, and with the higher flowerless plants, such as Ferns, Club-mosses and Horse-tails. Roots of this character and all others which originate laterally from stems, branches or leaves, whether above ground or beneath it, are callerl adventitious rnots. Such are the aerial roots of the Ivv, illustrated in Fig. 1, the roots which spring from the branches and above-ground

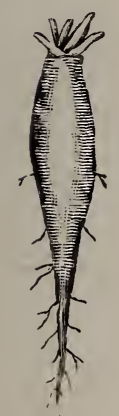

Fig. 5 .

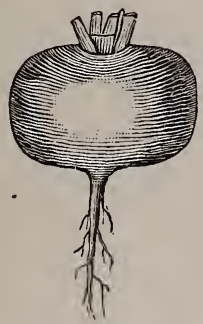

Fig. 6.

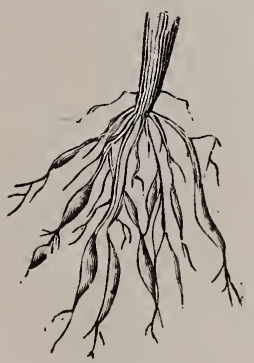

Fig. 7.

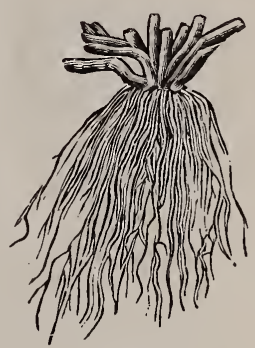

Fig. 8 .

Fig. 5.-Fusiform root of the Radish. Fig. 6.-Napiform root of the Turnip.

Fig. 7.-Nodose roots of the Dropwort. Fig. 8.-Fibrous roots of a Grass.

stems of various species of the Fig, from the joints of some grasses, and from the rhizomes or underground stems of such plants as Podophyllum, Serpentaria and Iris.

It is often convenient to describe roots by their shapes. That of the Carrot, which is thick at the base and tapers gradually to the apex, is called conical; one which is shaped like the root of the Radish, Fig. 5, is called fusiform; one shaped like that of the Turnip, Fig. 6, napiform; roots like those of the Dropwort, Fig. 7, 
nodose; roots like those of the Sweet-potato and Dahlia, Fig. 4, tuberous; and roots which are wholly slender and thread-like, as those of most grasses, Fig. 8, fibrous.

\section{Classification of Roots.}

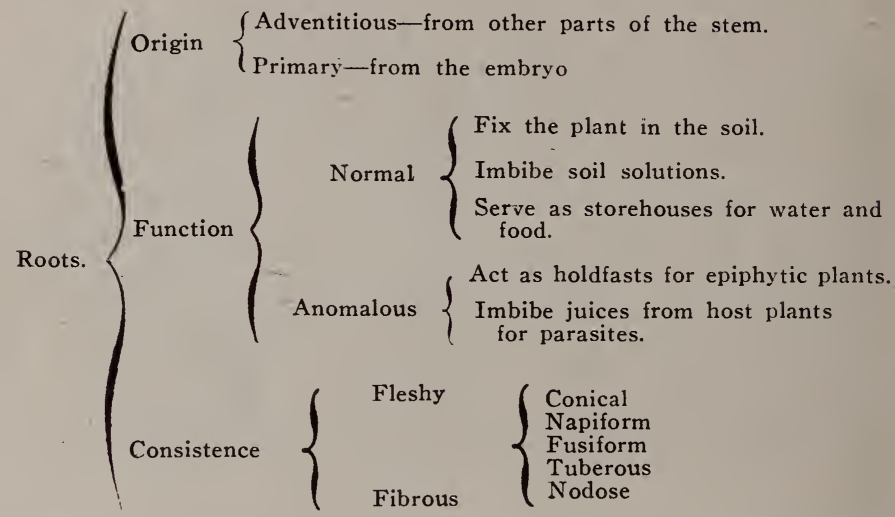

Practical Exercises.

Cause some seeds of common plants, as the Pumpkin, Pea, Corn, etc., to germinate over water so that the roots do not pass into the soil. A convenient way is to fill a wide-mouthed bottle half or two-thirds full of water, and, after fitting a cork to it, fasten by means of wires the seeds to the under surface of the cork, and insert it in the mouth of the bottle, and set the latter away for a few days in a warm place. The seeds will soon germinate, and the forms of their roots, and their structure and habits of growth, may be studied.

Observe and describe the forms and modes of branching of the different roots; by means of the magnifying lens study the root-hairs, observing on what parts of the rootlets they are most abundant; determine whether the roots are primary or secondary in their character, and examine the tips of the roots for the root-cap. Procure specimens of the common Duck-weed, in which the root-cap is highly developed, and examine it with care. As examples of aerial roots, study those of the lvy, and as examples of the roots of parasites, study those of the common Doader or of the Mistletoe, making sections of them and of their host-planis in sucn a way as to observe how the roots penetrate the bark of the host.

Record, in approprate descriptive language, and by means of drawings, the results 'of your observacluals.

\section{CHAPTER II.-THE STEM.}

The stem may be described as that part of the plant which bears all of the other organs. The stem, therefore, is indispensable, there being none of the higher plants that are truly stemless. It is commonly the ascending axis of the plant, while the root is the descending axis. The ordinary functions of the stem are to form 
such a support for the leaves as will expose them to the light and air, to bear the floral organs and convey to them the nutriment they require, and to form a means of communication and interchange between the roots, the organs which absorb the watery solutions from the soil, and the leaves, the organs which utilize these materials in the elaboration of the plant food. But, like other vegetative organs, stems are often modified, as we shall presently see, so as to subserve functions quite different from the normal. Besides bearing roots and leaves-appendages different from itself-a stem, commonly, though not always, bears branches, or appendages essentially like itself. A stem differs from a root not only in the fact that it is leaf-bearing, but in having its branches, for the most part, arranged with mathematical regularity, and that the growing-point is strictly apical instead of subapical. A stem usually increases in length by the growth of a terminal bud, and its branches commonly originate from buds which spring from the angle where the leaf joins the stem. We should first understand the nature of buds.

$B u d s$ are in reality rudimentary stems, with rudimentary leaves compactly arranged upon them. - In the growing season we observe them constantly unfolding. The short bud-axis which bears the minute, closely packed leaf-rudiments is constantly lengthening below, carrying the rapidly expanding leaves farther apart and developing into a leafy branch, while above, the bud is continually being renewed. Such a bud is not covered with scales. Its leaves are all destined to develop into foliage.

On some trees the buds that exist during the season of rest are similar, except as respects the stoppage of their growth, to those of the growing season. Such buds are usually of very small size, and in some cases they are wholly or partially concealed beneath the corky layer of the bark. Buds of this kind are called naked buds.

But most of our northern trees, at the approach of the cold season, form scaly buds, which differ from those of the growing season by having the outer leaf-rudiments transformed into scales which never develop into true leaves, but whose sole function is to protect those within, which in the spring are destined to develop either into foliage or into floral organs. Such buds are usually conspicuous, and they often attain a considerable size, as, for example, in the Hickory.

The scales of scaly buds are admirably adapted for protective 
purposes. They contain but little water, and are therefore bad conductors of heat, thus preventing the occurrence of too sudden changes of temperature in the interior of the bud. In many instances they have either a lining of downy hairs or are covered with an insoluble varnish. They serve to prevent the drying out of the soft and delicate parts within and also in a measure to protect these from being injured by birds or insects.

Fig. 9 represents a twig of the Ohio Buckeye as it appears in the late autumn or early spring. At the apex is a large scaly bud; below, situated in the axils of leaf scars, are smaller axillary buds. Fig. 10 is a longitud-

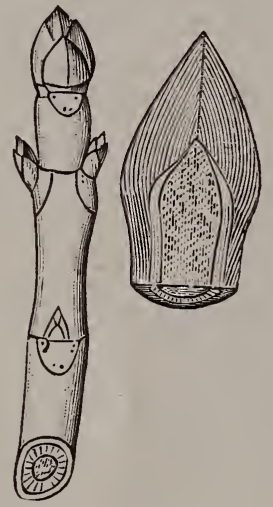

Fig. 9. Fig. 10.

Fig. 9.-Portion of twig of Ohio Buckeye, natural size, with terminal and axillary buds, and leaf-scars.

Fig. 10. - Enlarged view of longitudinal section of a terminal bud of the same tree, showing the manner in which the scales overlap. inal section of one of the large terminal bud of the same tree, showing the very short axis and compactly arranged leaf-rudiments.

Buds normally occur as represented in Fig. 9, either at the ends of the stems, when they are called terminal buds, or in the axils of leaves, when they are called axillary buds; sometimes, however, they occur in other situations on the stem, and occasionally they are formed on roots or even on leaves; in all these cases they are termed adventitious buds.

Examples of buds of this kind occur occasionally on the American Elm when the surface of the stem has been abraded or irritated, causing an extra supply of nourishment to flow to the spot; the compact bunches of twigs sometimes seen on these trees originate from such buds; the shoots which often arise in great numbers from the trunk of a pollarded willow have a similar origin; the leaves of Bryophyllum, when they have been shed, habitually produce marginal buds that, under favorable conditions, root and form new plants (see Fig. 11), and the uccurrence of adventitious buds on the roots of some species of Poplar, causes 
them habitually to send up shoots at a distance from the main trunk.

It often happens, also, that more than one bud is formed in or near the axil of the leaf; extra buds of this kind are called accessory or supernumerary buds. Sometimes they are placed side by side, as on the Apple-tree, and this is more commonly the case, but sometimes they occur one above the other, as on the Butternut and Walnut.

Because of lack of light or of insufficient supply of nourishment, buds frequently fail to develop, remaining quiescent until a favorable opportunity for growth is offered, such as that afforded

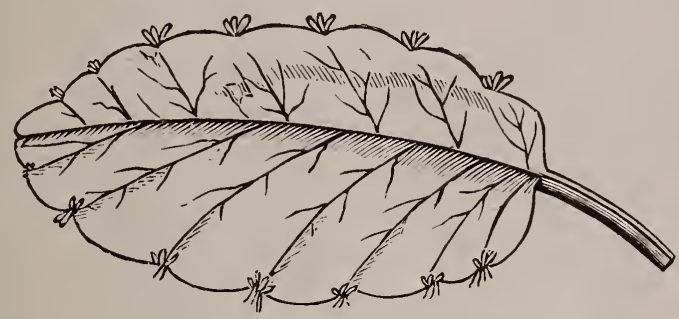

Fig. 11.-Leaf of Bryophyllum, with marginal buds.

by the damage or destruction of the better located buds by late frosts, when these quiescent or latent buds develop into leaves or branches. If no such opportunity offers, latent buds finally disappear, being covered by the bark.

Branches produced from large, strong terminal buds usually grow rapidly during the early summer and then form terminal buds, which thus prevent further growth in length during the remainder of the season. This mode of development is termed definite annual growth. Other stems may continue to lengthen by apical growth during the entire summer, with the result that their soft green tips are killed by the frost and the next year's growth is from axillary buds lower on the stem, where the tissues had matured sufficiently to successfully resist the cold. This is termed indefinite annual growth.

If the development of a stem is entirely from one terminal bud there can be, of course, no branches, and we describe it as a simple stem or, better, as a columnar stem. An instance is the stem of the Palms. If branches are formed freely, but the main stem or trunk dominates the branches, as in the Pines, the stem is de- 
scribed as excurrent or spire shaped. If, however, the main trunk branches freely so as to be soon lost in the branches, we have the deliquescent type of stem, of which the common Elm tree is an excellent example.

Size of Stems. Stems differ widely in this respect. Some, as those of certain mosses, are scarcely the one twenty-fifth of an inch in length, and the diameter does not exceed that of a fine thread, while those of the giant Sequoia of California, and a

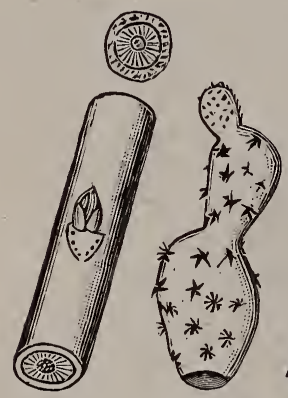

Fig. 12. Fig. 12a.

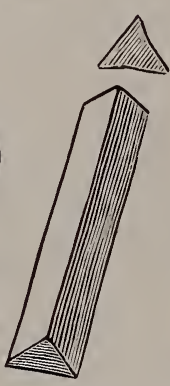

Fig. 13.

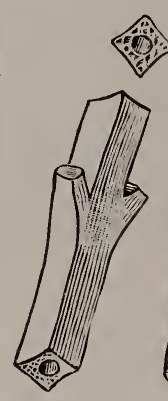

Fig. 13a.

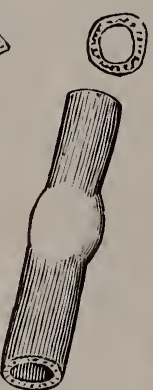

Fig. 14.

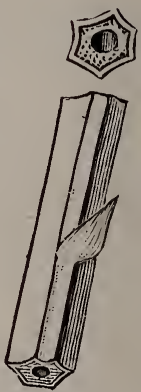

Fig. 15.

Fig. 12. - Terete or cylindrical stem of Basswood.

Fig. 12a.-Flattened stem of Opuntia Cactus.

Fig. 13. - Triquetrous or triangular stem of a species of Scirpus or Rush.

Fig. 13a.-Quadrangular stem of Mint.

Fig. 14. - Jointed stem of Barley.

Fig. 15. - Fluted stem of Parsnip.

species of Eucalyptus in Australia attain the remarkable height of more than four hundred and twenty feet.

Shapes of Stems. In this respect stems differ no less widely. The ordinary or typical form is that of a cylinder, or rather a very much elongated cone; such a stem is described as cylindrical or terete (see Fig. 12); but sometimes it is flattened as in the stems of some species of Cactus, Fig. 12a; sometimes triangular, as in some species of the Rush, Fig. 13; sometimes square or quadrangular, as in many Mints and Scrophularias, Fig. 13a; sometimes jointed, as in the stems of the Grasses, Fig. 14; and sometimes fluted, as in the stem of Valerian and that of the Parsnip, Fig. 15. In the so-called stemless or acaulescent plants, like the Dandelion, the stem is short and broad, forming a disk-like crown, from which the roots shoot downward and the leaves upward; and in the Cactuses, succulent Euphorbias and some other families of 
plants, it assumes a great variety of irregular or oddly grotesque forms.

Direction of Growth. In this respect also there is great diversity. The larger proportion of aerial or above-ground stems are upright or erect, but some are ascending, that is, they rise obliquely upward; some are reclining, or at first erect, but afterwards bending over as if too weak to stand; some are decumbent, or creeping along the ground, but with the apex ascending; some are procumbent or prostrate, that is, lying wholly upon the ground, and still others are repent, or creeping along the ground, rooting as they grow.

Duration of Stems. There are wide differences in this respect also. Some attain their full size in a few days, and in a few days more completely disappear, while there are others that possibly endure for a thousand years, and the vegetable world presents almost every gradation between these two extremes.

A stem which dies down to the ground at the close of the season is called herbaceous; an herb whose life terminates with the season, or which springs from the seed, blossoms, ripens its fruits, and dies completely all in the same season, is called an annual; if, however, the stem dies, but the underground parts retain their vitality, and growth is continued another season, during which the seeds are perfected, and it then dies completely, it is called a biennial; and if by underground parts the life of the plant is continued indefinitely, through a period of years, it is called a perennial herb. An aerial stem that is woody, freely branching from near the ground, and of small size, not more than two or three times the height of a man, is called shrubby or fruticose; if the stem is of small size and woody only at the base, it is described as an under-shrub or as suffruticose; if the stem is woody with a single trunk, and rises not higher than twenty-five or thirty feet, it is called arborescent; and if similar to the last, but of larger size, rising to the height of thirty feet or more, it is termed arboreous.

Kinds of Above-Ground Stems as Regards Habits of Growth. Among the more important of these are the following:

The twining or voluble stem is one which twists or coils about a support, as the stem of the Morning-glory, Fig. 16, and that of the Hop.

The scandent or climbing stem is one that rises by attaching 
itself, by means of special organs modified for the purpose, to some extraneous suppo:t. There are various modes of climbing. The Nasturtium and Solanum jasminoides, for example, climb by means of sensitive petioles, Fig. 18; the true Ivy, and Poison Ivy by means of rootlets; the Grape and Boston Ivy by means of tendrils, Fig. 17 , and some species of the Rose and Bramble climb in a rude

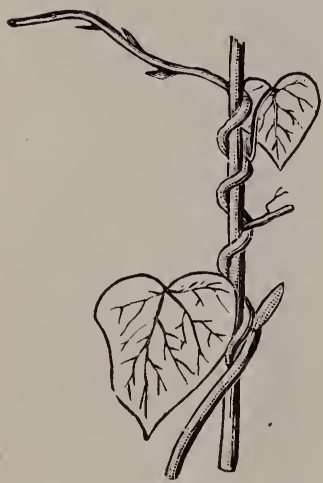

Fig. 16.-Voluble or twining stem of the Morning-glory.

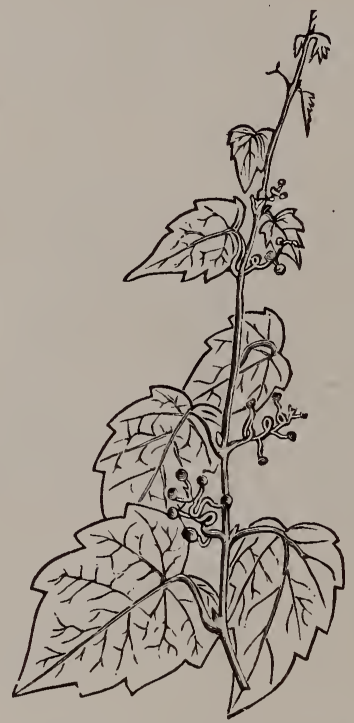

Fig. 17.-Portion of the stem of Boston Ivy, showing branching tendril, provided jasminoides, a leafwith terminal sucker-like discs. climber.

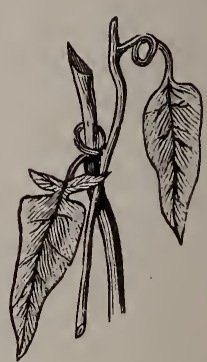

Fig. 18.-Portion

way by means of hooked prickles. Tendrils also may be either modified branches, as in the Grape; modified leaflets, as in the Pea, or modified stipules, as in the Sarsaparilla.

The Culm is the peculiar jointed stem of the Grasses and Sedges. It may be herbaceous, as in Wheat and Rye, or woody, as in the Cane and Bamboo.

The Scape is a flowering stem destitute of true foliage leaves, as those of the Dodecatheon and Dandelion.

The Stolon is a prostrate or declined branch, the end of which, on coming in contact with the soil, takes root, and ultimately gives rise to a new plant. The Currant and Black Raspberry afford examples. 
The Sucker is an aerial shoot that springs from an underground branch. This form of stem is illustrated in the Red Raspberry and Blackberry.

The Runner is such a creeping and rooting stem as that of the Strawberry, Fig. 19.

The Offset resembles a runner, but is shorter and usually gives rise to but one plant. It is illustrated in the common Houseleek.

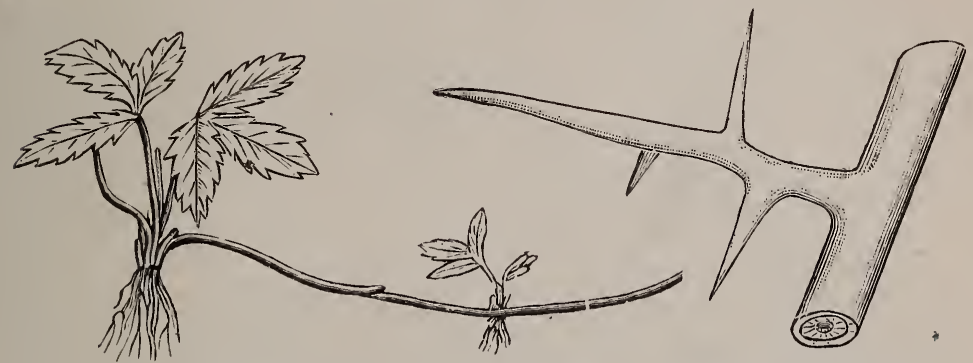

Fig. 19.--Strawberry plant producing a runner.

Fig. 20.-Branching thorn of the Honey-locust.

The Thorn or Spine is a stem modification which is hard, pointed and destitute of leaves, or nearly so; for example, the thorns of the Honey Locust, Fig. 20. Not all spines, however, are modified stems; some are modified leaves or portions of leaves. Prickles are hardened plant hairs and are therefore merely outgrowths of the epidermis.

\section{UNDERGROUND STEMS.}

The stems so far described are all aerial or above ground, but there are also underground ones, which mimic the habits of roots. They may readily be distinguished from the latter by the fact that they bear scales or scale scars, in the axils of which buds not infrequently occur, and also by the fact that the growing-point is situated at the apex instead of just back of it. Its growing end is enveloped in scales, the representatives of leaves; it, therefore, like the above-ground stem, possesses a terminal bud. Various kinds of underground stems are distinguished, the more important of which are the following:

The Rhizome is a creeping, underground stem, which grows horizontally or obliquely, is more or less scaly or marked with the scars of scales, sends off roots usually more abundantly from the under surface, and commonly has its upper surface more or 
less distinctly marked with the scars or withered remains of the bases of aerial stems of previous years. The terminal bud is usually conspicuous. A rhizome may either be slender and extensively creeping, as in Couch-grass and Carex, Fig. 21, or thickened and fleshy, as that of Solomon's Seal, Fig. 22.

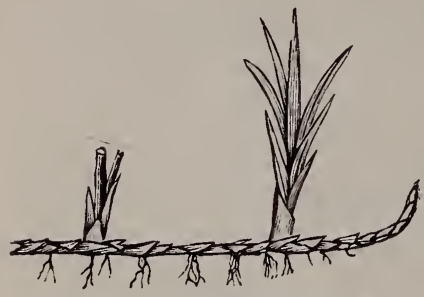

Fig. 21.-Creeping rhizome of a species of Carex.

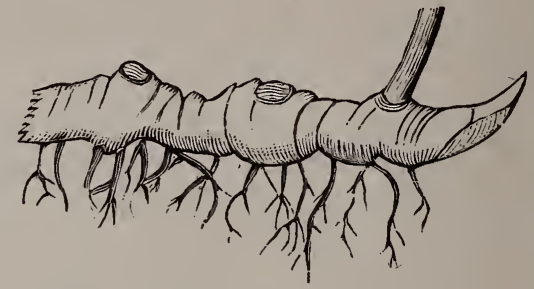

Fig. 22.-Thickened rhizome of Solomon's Seal.

The Tuber is a short and excessively thickened underground stem, borne usually at the end of a slender, creeping branch. The tubers of the Artichoke and Potato, Fig. 23, are examples. The

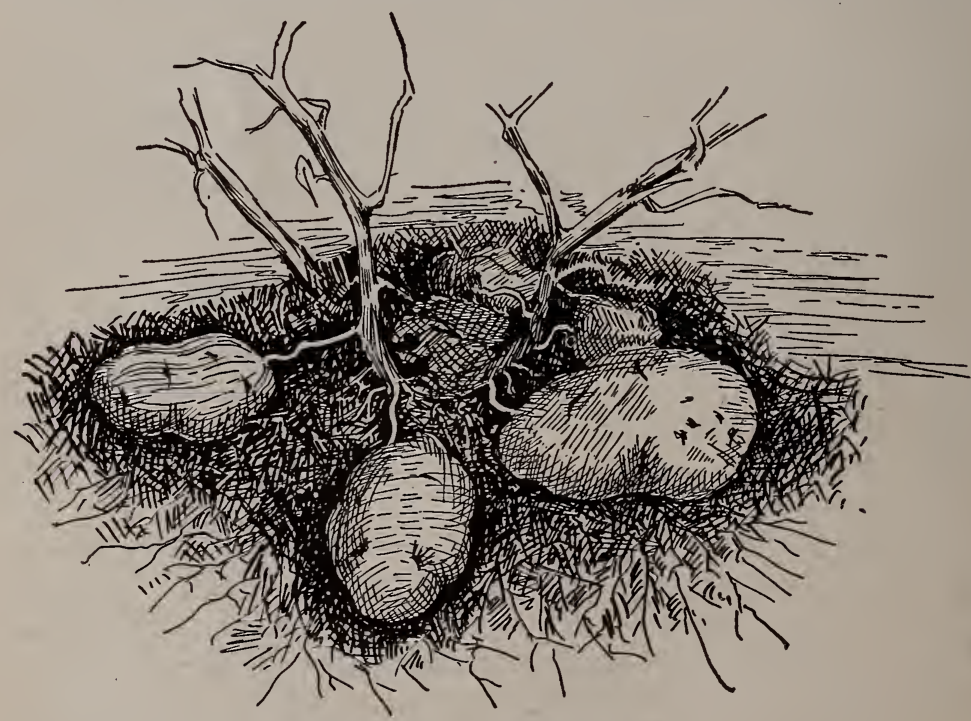

Fig. 23.-Tubers of the Potato. (After Bailey.)

creeping branches usually perish in autumn, setting the tubers free from the parent plant. Since they grow in the spring and produce new plants, they are efficient means of propagating the 
species. They may readily be distinguished from tuberous roots like those of the Sweet-potato, by their "eyes," which are axillary buds.

The Corm is an excessively thickened, erect, underground stem, covered with thin leaf-scales on the surface. The corms of Crocus and Colchicum are examples. Fig. 24 is a longitudinal section of a Crocus corm. At the base is a partially decayed corm of the previous year, and at the apex a large bud.

The Bulb is composed of an excessively short, erect stem, covered with fleshy scales or leaf-bases, which constitute its prin-

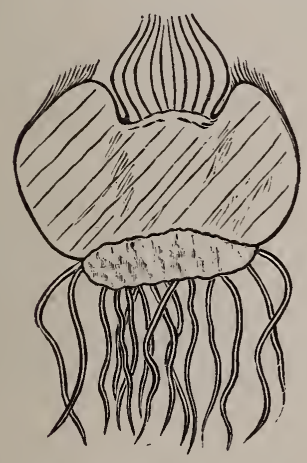

Fig. 24.

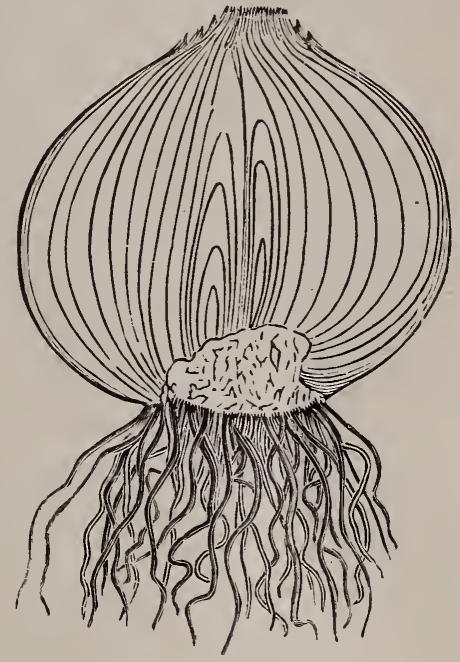

Fig. 25.

Fig. 24.-Longitudinal section of the corm of the Crocus.

Fig. 25.-Longitudinal section of the Onion, showing the structure of a tunicated bulb.

cipal bulk. It is practically a form of bud. A bulb whose leafbases form concentric coatings, is called a tunicated bulb, and one whole scales are imbricated, the outer ones not enclosing the inner, is called a scaly bulb. The Onion, Fig. 25, is an example of the former, and the Lily, Fig. 26, of the latter.

The frequent occurrence of underground stems is evidence of their value to the plants that possess them. Both food and water are stored in these succulent organs and strong buds are developed by them so that the plants so fortunately equipped are not only able to survive the resting season without material injury from 
cold or drouth but in the growing season that follows, they secure the advantages of an early start over their seedling competitors. Practically all the early-flowering herbs are of this kind.

It is an interesting fact, that many of these underground stems,

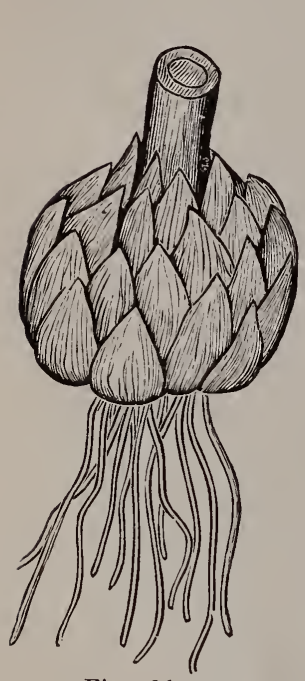

Fig. 26.

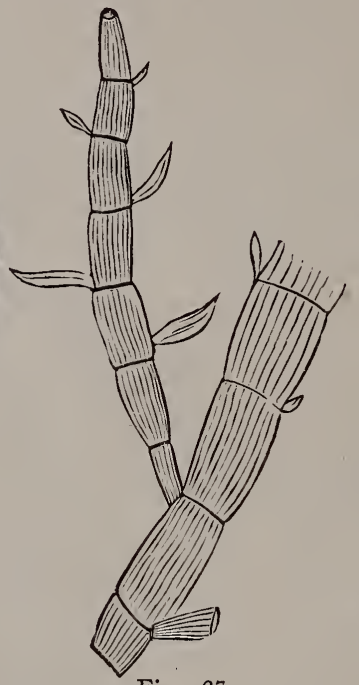

Fig. 27.

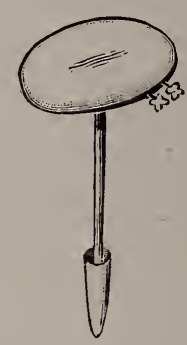

Fig. 28.

Fig. 26.-The s c a 1 y bulb of the Lily.

Fig. 27.-Portion of flattened stem and leaflike branches of Muhlenbeckia.

Fig. 28. - The common Duckweed, the upper disk-like portion bearing marginal flowers, and sending down a root with a prominent root-cap, from the under surface.

rich in stored food, are also supplied with poisonous principles which apparently serve to protect them against destruction by foraging animals or insects.

Thus it happens that many rhizomes and fleshy roots are employed as drugs, and a few poisonous ones, such as Water-Hemlock and Aconite, having the appearance of edible roots when fresh, are occasionally eaten by mistake, sometimes with fatal results.

\section{LEAF-LiKe STEMS.}

Stems occasionally mimic leaves, both in form and function. This is the case with the leaf-like bodies on the stem of the green-house Smilax (Myrsiphyllum). Such stems are called cladophylla, and that they are really stems or branches and not leaves is evidenced by the fact that they occur in the axils of scales; are the product, that is, of axillary buds. Fig. 27 represents a flattened branch of Muhlenbeckia, which performs at once the functions of leaf and stem, though true leaves are borne upon it. The stems of Cactuses also frequently assume leaf-like forms and perform the functions of leaves, the leaves themselves 
being present in the form of spines. Other instances of stems disguised as leaves are afforded by the common Asparagus and the European Ruscus. In Duckweed the functions of leaf and stem appear never to have been differentiated. An organ so constituted, and which is, properly speaking, neither leaf nor stem, is termed a thallus, Fig. 28. It is a rare thing among flowering plants to find leaf and stem thus blended or undifferentiated, but it is very common among flowerless plants.

\section{Classification of Stems.}

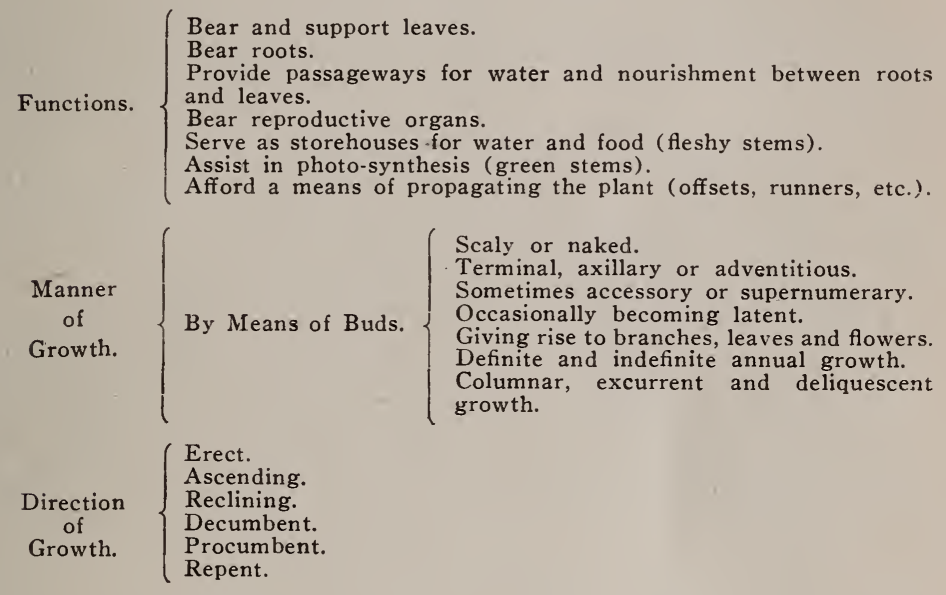

Duration. $\left\{\begin{array}{l}\text { Annual. } \\ \text { Biennial. } \\ \text { Perennial. }\end{array}\right.$

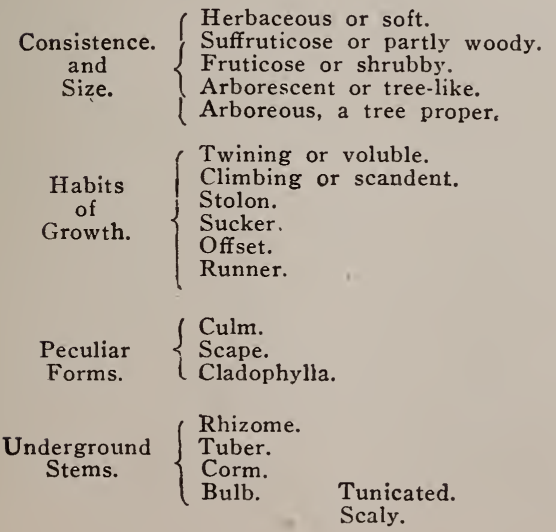




\section{Practical Exercises.}

1. Gather twigs of six or more different trees, such as occur in your neighborhood, for instance, the Sugar Maple, the American Elm, the Bass-wood, the Locust, the Cotton-wood and the Horsechestnut. It will be better for the purpose of this exercise if they be gathered in the late autumn or early spring. Observe the leaf-scars and their arrangement on each twig. Observe the terminal and lateral buds of each, and note in each instance which are the stronger or better developed; note the positions of the lateral buds relative to the leafscars in each case; note which of the trees bear scaly and which naked buds; selecting the twigs that have the largest buds, dissect carefully the terminal buds of each, observing, by means of the magnifying glass, the position, structure and arrangement of the bud-scales and of the true leaves which they enclose; note how the scales are adapted in each case to the purpose of protection, and, lastly, observe the area on the twig ringed by the scars of the budscales of the previous year, and answer, if you can, the question why this part of the twig did not elongate the same as that portion of it which bore the true leaves.

2. Cut off most of the blade of a leaf of the common Begonia, leaving only the basal portion and the petiole, and plant it in damp sand, keeping it moist and at a temperature of about $90^{\circ} \mathrm{F}$., for a few days. If the experiment has been properly conducted, adventitious buds will make their anpearance in the axils of the veins.

Study the supernumerary buds on twigs of the Apple, Lilac and Butternut or Hickory, and note the difference of arrangement.

3. Compare the shapes of the stems of the Bulrush, the Wheat, Peppermint, Yellow Dock, Wild Parsnip, Prickly-pear, Cactus and other familiar plants. Observe the twining stems of the Hop and Morning-glory, and note how they differ in their modes of twining. Observe how the Blackberry, the Wild Clematis, the Poison Ivy, the Virginia Creeper, the Pumpkin, the Pea and the Greenbriar differ in their climbing organs and in their modes of climbing.

Observe the defensive organs of the Gooseberry. Are they all of the same kind or not? Are they modified branches or not? Examine branches of the Barberry and Hawthorn, and determine the nature of their thorns, whether they are modified leaves or modified branches.

4. Pull up the following plants by the roots, and examine the underground parts, determining whether they are roots, rhizomes, corms, tubers or bulbs, and give the reasons for your conclusion: Wild or Indian Turnip, Common Blue Violet, Dandelion, Wild Hyacinth, Blood-root and Sweet-flag. Make a careful dissection of an Onion bulb and a Crocus corm, and ascertain how they differ; also make a careful comparative study of the Sweet-potato and the Irish potato.

\section{CHAPTER III.-THE LEAF.}

Leaves may be defined as stem-appendages which have their origin just back of the apex of the stem, are regularly arranged upon it, and consist of expansions of its tissues.

Foliage leaves, which may be taken as the type, are, in the majority of cases, flattened, bi-laterally symmetrical, expanded organs, green in color and presenting a distinct upper and under surface. They differ usually from stems by maturing or completing their growth first at the apex, and afterwards at the base, but in Ferns and in some compound-leaved Dicotyledons the basal portion matures first while the apex continues to grow. The primary functions of foliage leaves are the elaborating the plant food and the evaporation of water. These functions will be discussed in Part III (Physiology). Morphologically, leaves exist in numerous forms other than that of foliage, and in many instances perform functions altogether different. Several different modifications of 
leaves may often be observed on the same plant. Indeed, there is no organ of the plant body which subserves so many different uses or exists under such a variety of disguises. But, however different their forms and functions may be at maturity, they are alike in the earliest stages of their growth, that is, in the very young bud. All alike begin as minute papillæ or protuberances just back of the growing apex of the stem. Moreover, they always appear in acropetal order, that is, the older ones are lower down, and, as the stem elongates, younger ones are found higher up on the stem.

Prefoliation or Vernation. By this is meant the arrangement of the leaves in the bud, a matter of considerable importance to observe in the study of plants. We may study it from two points

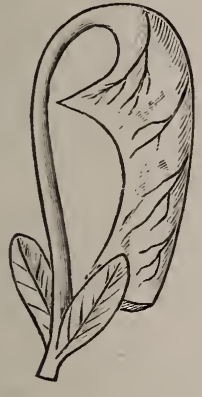

Fig. 29.

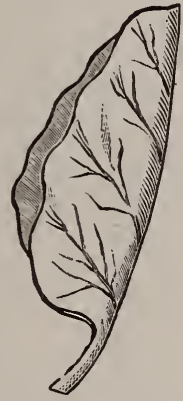

Fig. 30 .

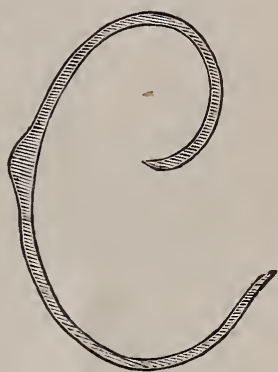

Fig. 31. tion.

Fig. 29.-Young leaf of the Tulip-tree, illustrating reclinate or inflexed verna.

Fig. 30.-Young leaf of Oak, illustrating conduplicate vernation.

Fig. 31.-Transverse section of a young leaf of the Wild Cherry, illustrating convolute vernation.

of view; we may consider the individual leaf, how it is folded, bent or rolled, or we may consider how the leaves are arranged with reference to each other.

Studying the individual leaf, we distinguish the following forms: If the apex is bent inward toward the base, as the leaf of the Tulip-tree, Fig. 29, it is described as reclinate or inflexed; if it is doubled inward on the midrib, so that the two sides are applied to each other, face to face, as in the Oak, Fig. 30, it is called conduplicate; when rolled inward from one margin to the other, as in the Wild Cherry, Fig. 31, it is said to be convolute; when rolled inward from the apex toward the base, as in the Sundew and in Ferns, Fig. 32, it is called circinate; when, as in the Birch, Fig. 33, it is folded somewhat like the folds of a fan, it is described as plicate; when, as in the common Violet, Fig. 34, 
it is rolled inward from each margin, it is termed involute; and when, as in Yellow Dock, Fig. 35, it is rolled outward from each margin, it is called revolute.

It must be borne in mind that in botanical usage the inner surface of the leaf is that which, in the majority of flattened

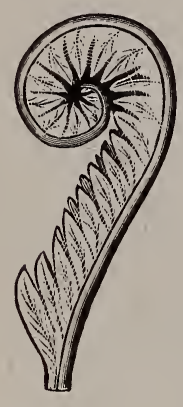

Fig. 32.

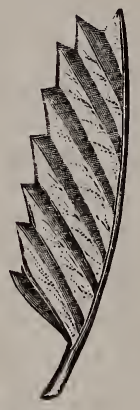

Fig. 33 .

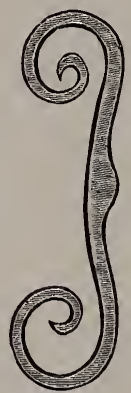

Fig. 34 .

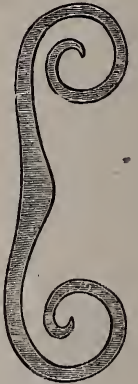

Fig. 35.

Fig. 32.-Young Fern leaf, illustrating circinate vernation.

Fig. 33.-Y Young leaf of the Birch, illustrating plicate vernation.

Fig. 34.- Transverse section of the young leaf of the common Violet, illustrating involute vernation.

Fig. 35.-Transverse section of the young leaf of Yellow Dock, illustrating revolute vernation.

leaves, constitutes the upper surface when fully expanded; it is also called the ventral surface, and the outer is termed the dorsal.

When considered with reference to each other, several distinct

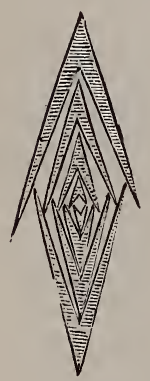

Fig. 36.

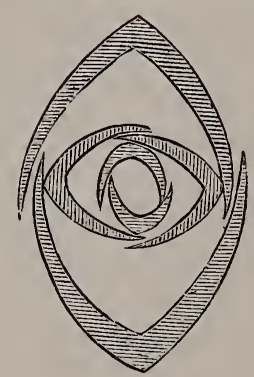

Fig. 37 .

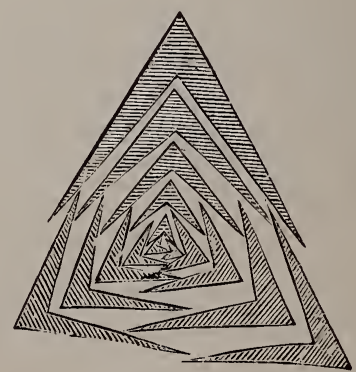

Fig. 38.

Fig. 36.-Diagram illustrating equitant vernation.

Fig. 37.-Diagram of half-equitant vernation. Leaves of Sage.

Fig. 38.-Diagram of triquetrous vernation. Leaves of Sedge.

forms of prefoliation are also observed: It is equitant when, as in the Iris, the leaves are conduplicate, and those exterior override or straddle successively both margins of the ones next interior 
to them, Fig. 36 ; it is called half-equitant when, as in the Sage, the leaves are conduplicate, and each leaf embraces or straddles only one margin of the other, Fig. 37 ; and it is said to be triquetrous when, as in the Sedges, Fig. 38, the leaves are conduplicate, and so arranged that the bud is triangular in cross-section. Other modes of the disposal of leaves with reference to each other will be considered under æstivation or prefloration, when we come to the study of the flower.

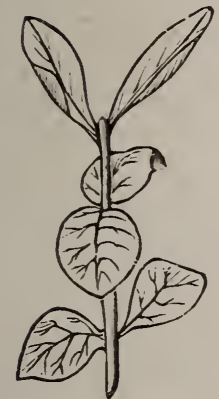

Fig. 39 .
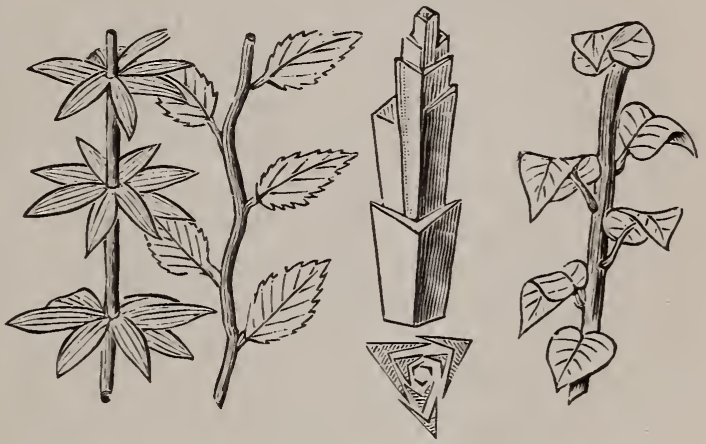

Fig. 40. Fig. 41.
Figs. 42 and 43.
Fig. 44.

Fig. 39.-Branch of Privet, showing the opposite and decussate leaves.

Fig. 40.-Whorled leaves of the Canada Lily. leaves.

Fig. 41.-Branch illustrating the alternate, $1 / 2$ or distichous arrangement of

Fig. 42.- Portion of stem of Carex, with leaves partially cut away, showing the $1 / 3$ or tristichous arrangement.

Fig. 43.-Transverse section of leaves of Carex, showing tristichous arrangement.

Fig. 44.-Branch showing $2 / 5$ or pentastichous arrangement of leaves.

Phyllotaxy. This term has reference to the arrangement of leaves on the stem. It is important to observe that they do not occur at random on a stem or branch, but in a definite order, although the order varies in different plants, and sometimes is different on different parts of the same plant.

There are two general plans of phyllotaxy; first, the whorled or verticillate, and second, the alternate or scattered.

In the whorled plan two or more leaves occur at a node or on the same level, as in Figs. 39 and 40. Where there are but two leaves at a node they are almost invariably situated $180^{\circ}$ apart, that is, the circumference of the stem is equally divided between them, and the leaves are said to be opposite.

Opposite leaves are usually decussate, that is, the second pair 
stand over the intervals between the first pair, as in Fig. 39. Usually, also, when there are three leaves in the whorl, they are one-third of the circumference of the stem apart; when four, onefourth, and so on, and as a general rule also the leaves of successive whorls stand over the interspaces of those immediately below them. Good examples of opposite leaves are those of the Mints, Maples and Lilac, and of whorled leaves in which there are more than two leaves in the whorl, the Galiums, Canada Lily, Leptandra and Silene stellata afford good illustrations.

In the alternate or scattered plan but one leaf occurs at a node, and the leaves succeed each other in a spiral order.

This is much the more common mode of phyllotaxy, and a considerable number of different forms of it are recognized, the greater portion of which may be reduced to a series mathematically represented by the fractions $1 / 2,1 / 3,2 / 5,3 / 8,5 / 13$, etc. In these fractions the numerator represents the number of turns to complete a cycle, that is, to reach a leaf which stands directly above the first; the denominator represents the number of perpendicular rows of leaves on the stem, or, what is the same thing, the number of leaves, counting along the spiral from any one of them, to the one which stands directly above it; and the whole fraction expresses the angular distance measured circumferentially on the stem from one leaf to the next one on the spiral.

It will be observed also that the third fraction of the series is derivable from the first two by adding together the numerators for a new numerator and the denominators for a new denominator; that the fourth is derived from the second and third in the same way, and so on.

Examples of the $1 / 2$ or distichous arrangement occur in the Elm and Basswood, and it prevails in the whole family of Grasses; it is illustrated in Fig. 41. The $1 / 3$ or tristichous arrangement occurs in the Sedges, as shown in Figs. 42 and 43 ; the $2 / 5$ or pentastichous arrangement occurs in many common trees, as the Cherry and Apple, and is illustrated in Fig. 44 ; the $3 / 8$ or octastichous arrangement is observed in Aconite, Osage Orange, Plantain and Holly; the more complex plans are rarer, but the $5 / 13$ is observed in the Houseleek and some other plants, and arrangements represented by this and fractions still higher in the series occur in the cones of various species of Pines, Spruces, etc. Even where the leaves are compactly clustered or fascicled, as in the Larch, Fig. 
45, and some other trees, careful examination reveals the fact that the arrangement is really a spiral one.

It is not uncommonly the case, of course, that in a mature branch we find some slight deviations from regularity in the arrangement of leaves, but these are of such a character that they may readily be accounted for, either by the distortions which stems frequently undergo during the process of growth, or by the failure of some of the leaves to develop.

It will be seen that since branches usually spring from axillary buds, their arrangement must also be regular and correspond in plan with that of the phyllotaxy.

Duration of Leaves. Leaves differ widely as to their period of duration. They are described as persistent or evergreen, if they

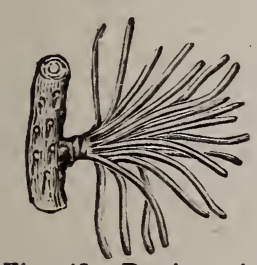

Fig. 45.--Portion of twig of Larch, showing fascicled leaves.

As now in tropical regions evergreen trees are much the more common, while in our own climate they are rare, there is good reason to believe that in the warm ages of the world preceding the ice period, all trees were evergreens, and that our northern trees have become deciduous-leaved by gradual adaptation to the vicissitudes of the climate.

Position. According to their place of insertion on the stem, leaves often differ from each other considerably in form and appearance, and it is often, therefore, convenient to use special terms indicative of their position. Cauline leaves are those which are inserted on the main stem; rameal leaves are those borne on the branches; radical leaves are those which spring from the basal portion of the stem at or just beneath the ground; seminal leaves or cotyledons are those which are borne by the embryo in the seed; and floral leaves are the leaves of the flower.

Parts and Structure of Leaves. A leaf, when complete, consists of three parts, the lamina or blade, the petiole or leaf-stalk, and two small blade-like bodies at the base of the petiole called the stipules. Such a leaf is seen in the Tulip-tree, and is illustrated in Fig. 46. Frequently some of these parts are wanting. The stipules, 
being least serviceable to the plant, are most frequently absent; in this case the leaf is described as exstipulate; not uncommonly the

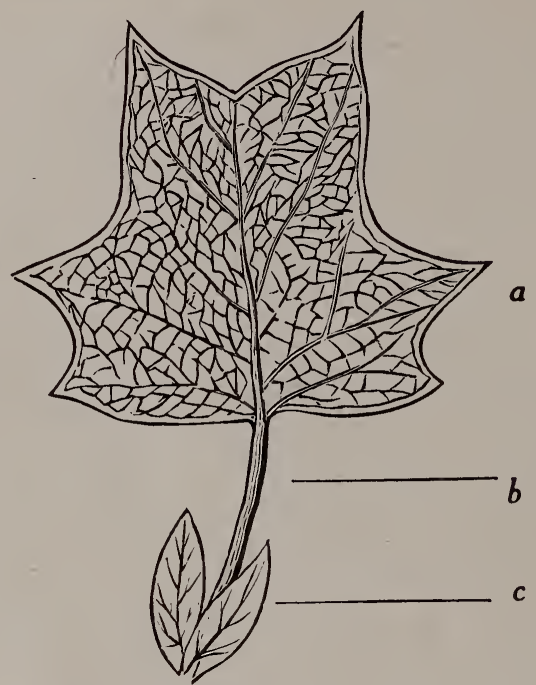

Fig. 46.-Leaf of Tulip-tree, illustrating the parts of a complete leaf. The upper part, $a$, is the lamina, and below is the petiole, $b$, at the base of which are the two stipules, c.

petiole is wanting and the blade is inserted directly upon the stem; it is then described as sessile; sometimes the blade is not merely
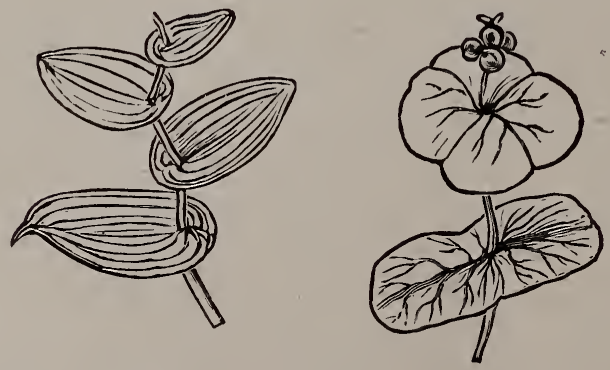

Fig. 47.-Part of stem of Uvularia, illustrating perfoliate leaves.

Fig. 48.-Connate leaves of the Honeysuckle.

sessile, but more or less embraces the stem at the base, when it is called clasping; sometimes it grows quite around the stem, and its 
edges even coalesce on the opposite side, so that the stem appears to grow through its base as in the Bell-wort, Fig. 47, when it is described as perfoliate; sometimes, in the case of opposite leaves, the bases grow together or become coherent, apparently forming a single leaf, with its stem passing through its middle, as in the Cup-plant, the Boneset, and the Honeysuckle, Fig. 48, in which case they are called connate, and sometimes the margins of the leaf grow down the sides of the stem, or become decurrent, as in the Mullein, the Sneeze-weed and the Comfrey, Fig. 49. In some plants, the petiole of the leaf is swollen where it joins the stem, forming a leaf cushion or Pulvinus.

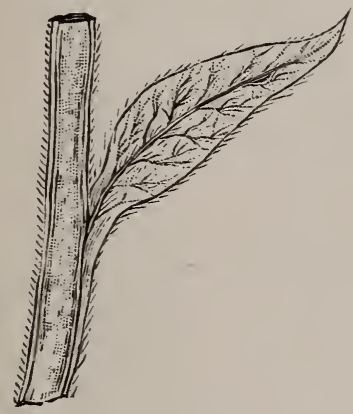

Fig. 49 .

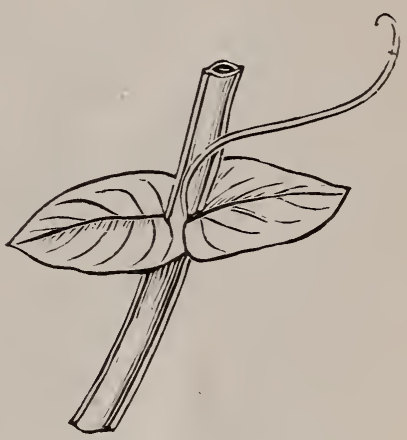

Fig. 50.

Fig. 49.-Decurrent leaf of Comfrey.

Fig. 50.-Portion of stem of Lathyrus aphaca, one of the Pulse family. showing stipules which perform the functions of a leaf-blade while the blade proper is developed into a tendril.

The blade is commonly thought of as the leaf and the other parts as appendages, but even the blade, although the most important part, may be wanting or developed into some form different from the ordinary one, while either the stipules or the modified petiole performs its functions. Lathyrus aphaca, Fig. 50, is an example of a leaf in which the stipules become strongly developed and perform the functions of blades, while the petiole and blade proper are modified into a tendril for the purpose of enabling the plant to climb.

In most of the Australian Acacias, trees which in other countries are noted for their graceful, feathery foliage, both blade and stipules of all but the earlier leaves fail to develop, while the petiole becomes flattened and performs the functions of a blade. These flattened petioles, or phyllodia, as they are called, are simple, 
parallel-veined, and placed with their edges vertical; hence the Australian species present a widely different appearance from the nearly related ones of other countries. Fig. 51 represents one of the earlier leaves of one of these Acacias, showing a widened petiole, and the tendency to develop phyllodia, and Fig. 52 represents a fully formed phyllodium of the same tree.

It is frequently the case, however, that all parts may be pres-

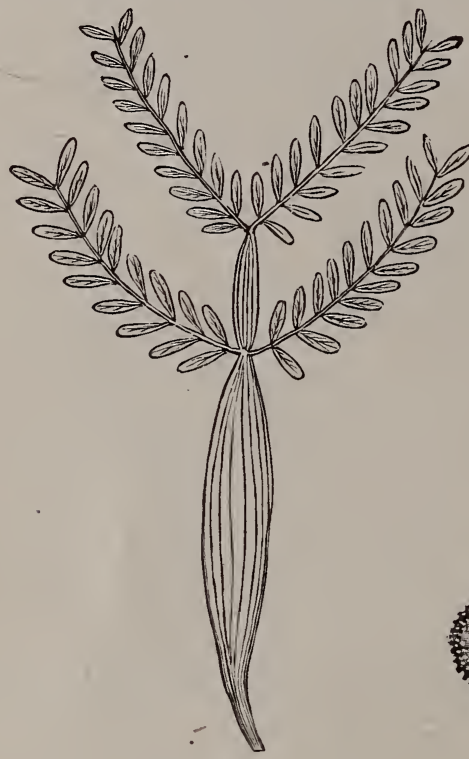

Fig. 51.

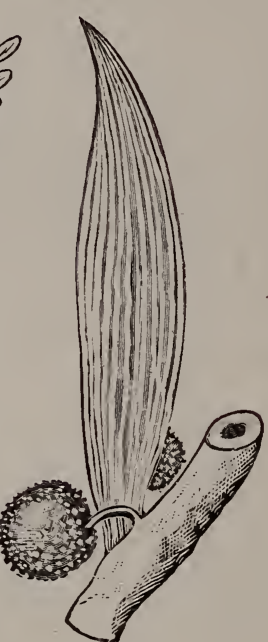

Fig. 52 .

Fig. 51.-Leaf of an Australian Acacia, showing tendency to abortion of leaf-blade and the development of the petiole into a phyllode.

Fig. 52.-Fully developed phyllode of an Australian Acacia.

ent, but, owing to a change in their usual form, or a partial coalescence with other parts, the presence of one or the other of them may be more or less obscured. In grasses, for example, the stipules appear to be united with the petiole to form the sheath which clasps or encloses the stem, but usually their apices are free and slightly project at the junction of the blade and sheath, forming what is called the ligule, Fig. 53.

In the Polygonums the stipules cohere with each other, and form a sheath about the stem. This stipular sheath, which is usually membranous, and may or may not have a free portion, is 
called the ochrea. Not infrequently also the stipules become adnate to the petiole, as in the Rose, Fig. 54, or become converted into spines, as in the Locust, Fig. 55, and in some instances they are changed into tendrils, as in the Green Briar, Fig. 56. In many instances also they are scaly, and after serving the purpose of protection in the bud, fall away when the leaves expand.

Considering the structure of the parts of the leaf, we find the blade and stipules, when normally developed, consist of a tough framework or system of veins, which serves chiefly for support and partly to conduct the nutritive fluids; an intervening soft tissue called the mesophyll, or leaf-parenchyma, and an epidermis

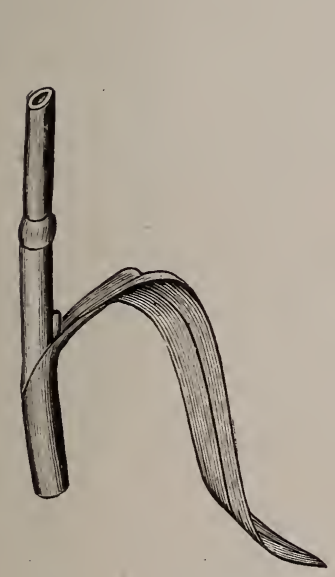

Fig. 53.-Leaf of grass, showing lamina, sheath and ligule.

Fig. 54.-Adnate stipules of Rose.

Fig. 55.- Stipules of the common Locust converted into spines.

which covers the whole. The petiole consists more largely of fibrous tissue, the continuation of the framework of the blade, and possesses comparatively little parenchyma.

The Venation of Leaves. By this is meant the arrangement of the veins or framework. In such simple leaves as many of the Mosses, no veins are present, and the leaf consists merely of a layer of green cells, but in higher plants a venation is always more or less distinctly recognizable. Three different types of it are distinguished: the furcate or forked venation. in which the veins fork or divide once or repeatedly into equal divisions, as 
seen in many ferns and other cryptogamous plants, but seldom in flowering plants, see Fig. 57; the parallel-veined plan, the common form observed in Monocotyledons, as Grasses, Palms, Lilies, etc.; and the reticulate, or net-veined plan, the type which prevails in Dicotyledonous plants, such as the Roses, Maples, Oaks, etc.

Among parallel-veined leaves three different modifications are observed: (1) The type in which the veins run nearly parallel to

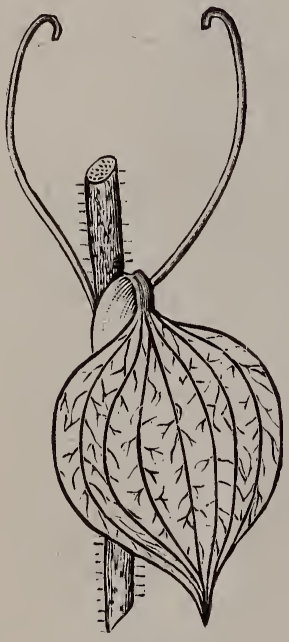

Fig. 56.

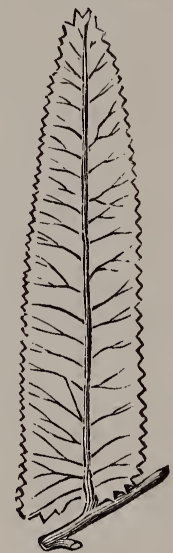

Fig. 57.

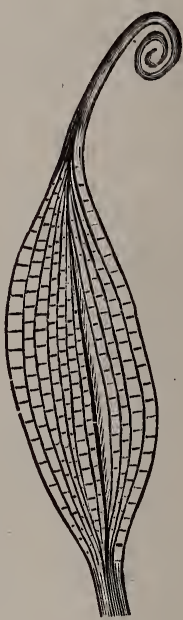

Fig. 58.

Fig. 56.-Stipules of Green Briar (Smilax) developed into tendrils.

Fig. 57.-Pinnule of Osmunda regalis, a Fern, illustrating furcate venation.

Fig. 58. - The leaf of Gloriosa; a basi-nerved leaf.

each other from the base to the apex of the leaf. Such leaves incline to elongated forms, and are well illustrated in most grasses, and in the Gloriosa Lily, Fig. 58. (2) The type in which the veins are straight and radiate from the petiole to the margin of the blade. Such leaves incline to rounded forms, as illustrated in the leaf of the Fan Palm, Fig. 59. (3) The type in which there is a mid-rib or vein running from the base to the apex of the leaf, and straight or somewhat curved veins running from this, nearly parallel to each other, to the margin, as seen in the Banana and the Calla Lily, Fig. 60.

In the reticulate plan the veins branch repeatedly, and the veinlets, or small branches of different veins, run together end 
to end, or anastomose, forming a more or less complicated network. There are also three modifications of this type: (1) The

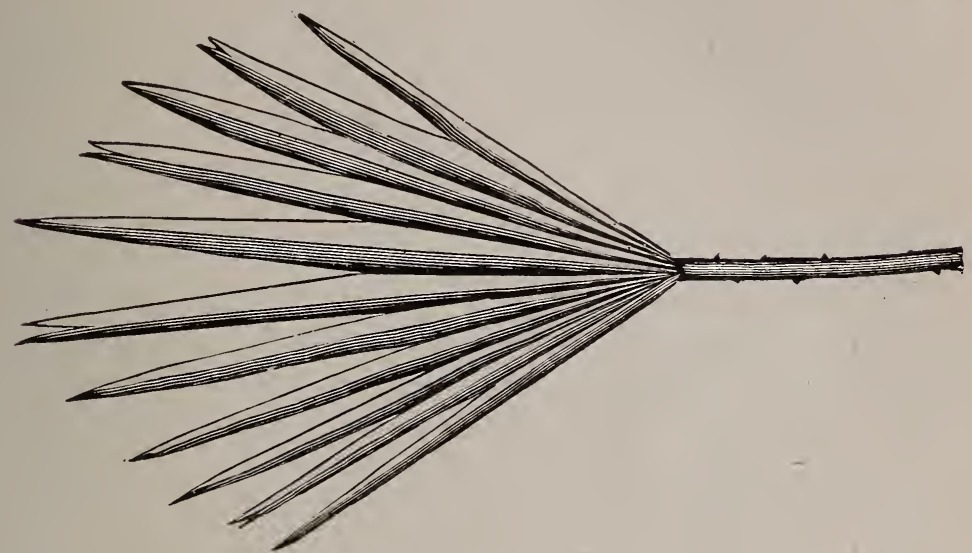

Fig. 59.-The leaf of a species of Palm; a "palmi-nerved" leaf.

pinnately netted or feather veined, in which there is a mid-rib with lateral branches which run toward the margin, branching repeatedly and forming a network, as in Fig. 61 ; (2) the palmately or radiately netted, a reticulate leaf in which there are several ribs

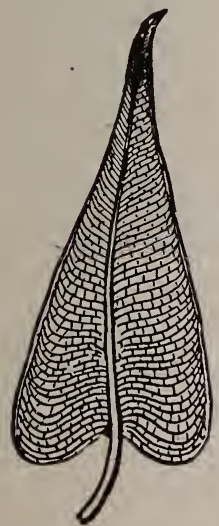

Fig. 60 .

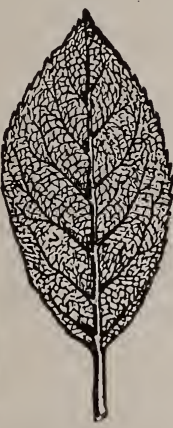

Fig. 61.

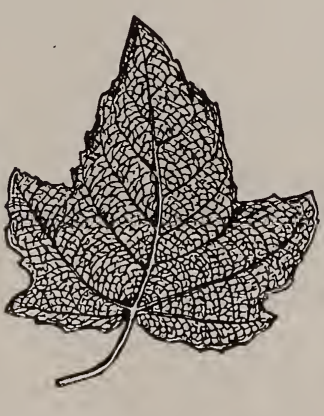

Fig. 62.

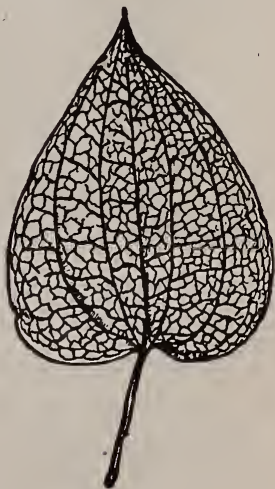

Fig. 63.

Fig. 60.-The leaf of the Calla; a "pinni-nerved" leaf.

Fig. 61.-The leaf of Carpinus; a pinni-reticulate leaf.

Fig. 62.-The leaf of the White Poplar; a palmi-reticulate leaf.

Fig. 63.-The leaf of the Wild Yam; a costate-reticulate leaf. 
radiating from the petiole to the margin, as in the leaf of the White Poplar, Fig. 62, and (3) the costate or ribbed-netted leaf, in which there are several prominent veins or ribs running from base to apex of the leaf, with a network of small veins between, as in the leaf of the Wild Yam, Fig. 63. The first and third varieties incline to elongated and the second to rounded forms, though there are some exceptions to the rule.

\section{The Shapes of Leaves.}

The shapes of leaves are very numerous, and as they often afford characters by means of which plants are distinguished, it is important for the student to be familiar with the more common forms and the terms used in describing them. For the most part

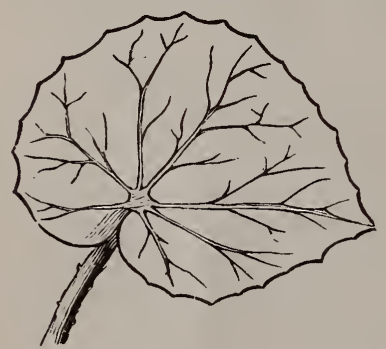

Fig. 64.-Begonia leat, showing inequilateral shape. leaves incline to bi-laterally symmetrical forms, that is, the two sides of the leaf are counterparts of each other in size and shape, but it sometimes occurs, as in the Begonias, Fig. 64 , that one side is much bettor developed than the other. Such leaves are termer inequilateral. It not infrequent?y happens that the bases of simple leaves and the leaflets of compound ol.es show a. slight inequality.

Simple Leaves. A simple leaf is one which has a single blade, which may either be sessile or petiolate; but if the latter, petiole and blade are united directly and not by means of a joint. We may conveniently describe simple leaves and the separate blades of compound leaves as to general outline, apex, base, marginal. indentations, surface and texture.

(a) General Outline. By this we mean the outline form of the leaf, disregarding marginal indentations and slight irregularities. The principal forms are the linear, a narrow, elongated form, with parallel margins, as represented in Fig. 65; the oblong, which is broader, but considerably longer than wide, with sises nearly parallel and ends rounded, Fig. 66 ; the elliptical, somewhat 
longer than wide, with rounded ends and sides, Fig. 67; the oval, or broadly elliptical, Fig. 68 ; the lanceolate, or lance-shaped, Fig. 69 ; the oblanceolate, or inversely-lance-shaped, Fig. 70 ; the ovate, which is shaped like the longitudinal section of a hen's egg, and has the petiole at the larger end, Fig. 71 ; the obovate, or inversely ovate, as in Fig. 72; the spatulate, which is larger and rounded at

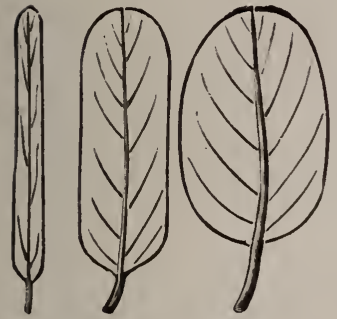

Fig. 65. Fig. 66. Fig. 67.

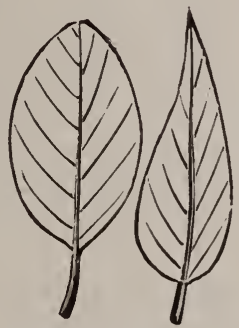

Fig. 68. Fig. 69. Fig. 70.

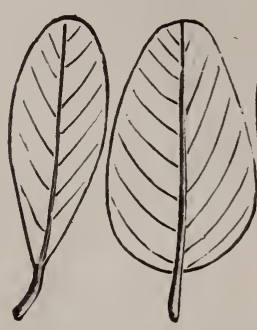

Fig. 71.

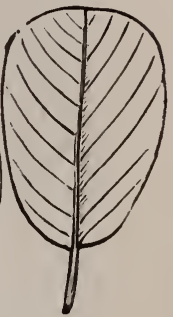

Fig. 72.

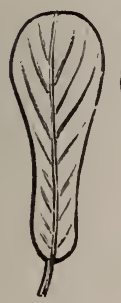

Fig. 73

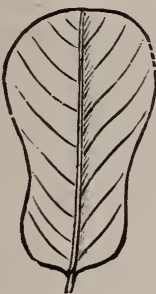

Fig 74.

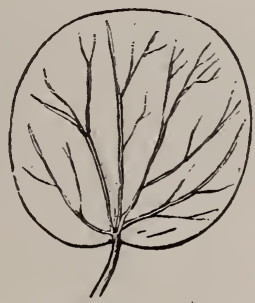

Fig. 75.

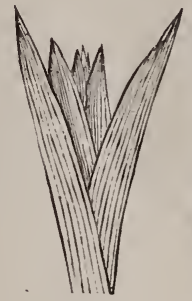

Fig. 76

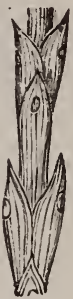

Fig. 77.

Figs. 65 to 77 , inclusive, diagrams illustrating shapes of leaves as respects general outline; 65 , linear; 66 , oblong; 67 , elliptical; 68 , oval; 69 , lanceolate ; 70 . oblanceolate ; 71 , ovate ; 72 , obovate ; 73 , spatulate; 74 , panduriform; 75 , orbicular; 76 , ensiform; 77 , subulate.

the apex, and tapering at the base like the old-fashioned spatula, Fig. 73 ; the panduriform, or fiddle-shaped, Fig. 74 ; the orbicular, which is nearly circular in outline, Fig. 75; the ensiform, or swordshaped, as in the Iris, Fig. 76; the subulate, or awl-shaped, as the leaves of Arbor Vitæ and Cedar, Fig. 77; and the filiform, or thread-shaped, proportionately very long and narrow, as the leaves of Asparagus.

(b) The Apex. As regards the shape of the apex, the following are the more important forms: The obcordate, or inversely 
heart-shaped, Fig. 78; the emarginate, or notched, Fig. 79; the retuse, with a broad, shallow sinus at the apex, Fig. 80 ; the aristate, with the apex terminating in a bristle, Fig. 81 ; the mucronate, with the apex terminating in an abrupt, soft point, Fig. 82 ; the cuspidate, the same as mucronate, but with a hard point; the

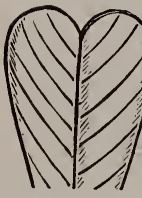

Fig. 78. Fig. 79 .
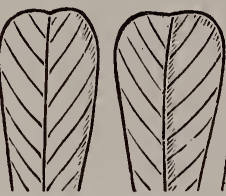

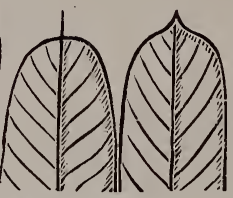

Fig. 81. Fig. 82.
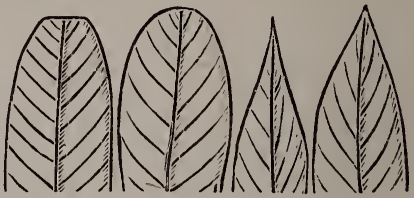

Fig. 83. Fig. 84. Fig. 35. Fig. 86 .

Figs. 78 to 86 , inclusive, diagrams illustrating forms of leaf apices; 78 , obcordate ; 79 , emarginate; 80 , retuse ; 81 , aristate; 82 , mucronate (or if the point be hard, cuspidate); 83 , truncate; 84 , obtuse ; 85 , acuminate; 86 , acute.

truncate, with the apex terminating abruptly, as if cut off, Fig. 83; the obtuse, with a rounded or blunt apex, Fig. 84; the acuminate, or taper-pointed, Fig. 85; and the acute, with an apex which forms an acute angle, Fig. 86.

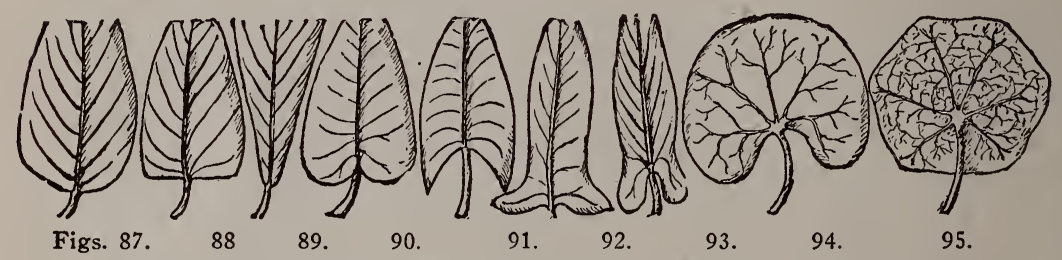

Figs. 87 to 95 , inclusive, diagrams illustrating forms of leaf bases; 87 , rounded or obtuse; 88 , truncate ; 89 , cuneate ; 90 , cordate; 91 , sagittate; 92 , hastate ; 93 , auriculate; 94 , reniform; and 95 , peltate.

(c) The Base. As respects the shape of the base the following are the most common forms: The rounded, or obtuse, Fig. 87; the truncate, Fig. 88; the cuneate, or wedge-shaped, Fig. 89; the cordate, or heart-shaped, Fig. 90; the sagittate, or arrow-shaped, Fig. 91; the hastate, or halberd-shaped, Fig. 92; the auriculate, when there are two ear-like appendages at the base, Fig. 93; reniform, or kidney-shaped, Fig. 94; and the peltate, or shield-shaped, where the petiole is attached near the center of the blade, as in Fig. 95.

(d) Marginal Indentations. Here we may distinguish between indentations that are shallow, extending considerably less than half way to the mid-rib or to the base (if radially indented), and those which are deeper. 
Among the more important forms with shallow indentations are the following: The serrate, or saw-toothed, with sharp teeth

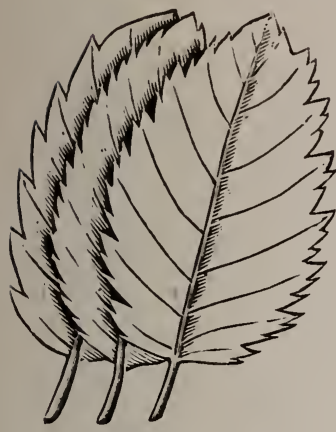

Fig. 96.

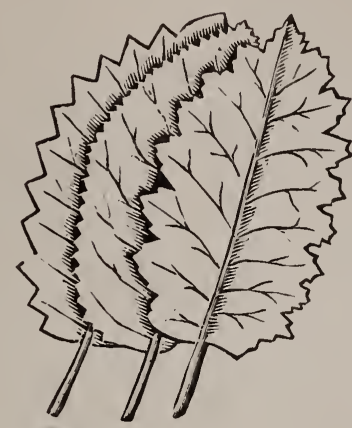

Fig. 97.

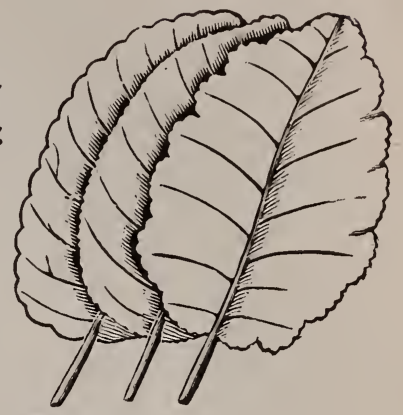

Fig. 98.

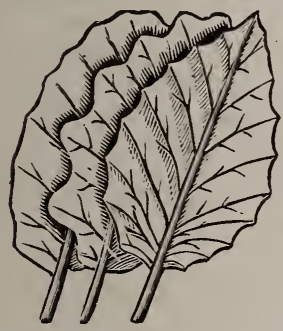

Fig. 99.

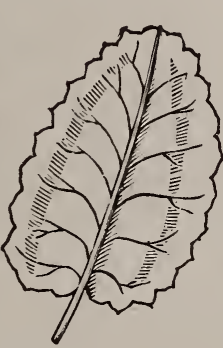

Fig. 100 .

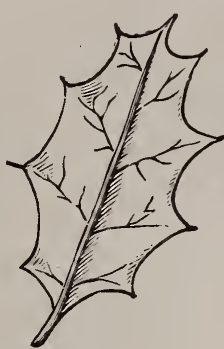

Fig. 101.

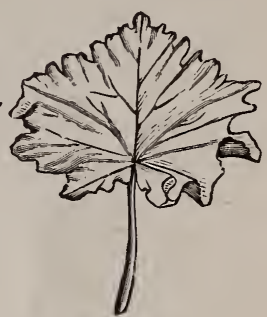

Fig. 102.

Figs. 96 to 102, inclusive, diagrams illustrating marginal indentations of leaves; 96, serrate, serrulate and bi-serrate; 97 , dentate, denticulate and bidentate; 98 , crenate, crenulate and bi-crenate; 99 , undulate, sinuate and repand; 100 , crenate-dentate; 101 , spinose; and 102 , crispate.

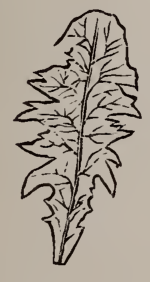

Fig. 103.

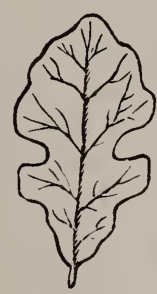

Fig. 104.

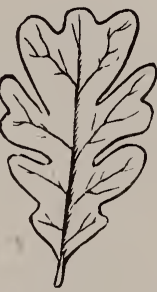

Fig. 105.

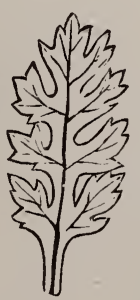

Fig. 106.

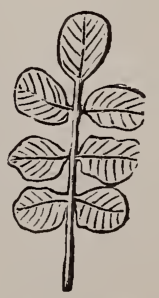

Fig. 107.

Figs. 103 to 107 , inclusive, diagrams illustrating the deeper marginal indentations in pinnately-veined leaves; 103 , runcinate; 104 , pinnately-lobed; 105 , pinnately-cleft; 106, pinnately-parted, and 107, pinnately-divided.

which incline forward like the teeth of a hand-saw, the serrulate, or minutely saw-toothed, and the bi-serrate, or doubly serrate, 
with two sets of teeth, one upon the other, see Fig. 96; the dentate, or toothed with outwardly projecting teeth, the denticulate, or finely dentate, and the bi-dentate, or double-dentate (the three forms are illustrated in Fig. 97); the crenate, or scalloped, the crenulate, or minutely crenate, and the bi-crenate, or doubly-crenate (illustrated in Fig. 98); the undulate, or wavy; the sinuate, or deeply-wavy, and the repand, or undulate-dentate, with a margin like that of an umbrella, Fig. 99. Other forms are the crenatedentate, or scalloped, with the scallops produced into sharp teeth, as in Fig. 100; the spinose, with the margin spiny, Fig. 101; the ciliate, with the margin fringed with hairs; the fimbriate, with the margin cut into slender segments or fringed, and the crispate, with the margin crisped, as in Fig. 102.

The commoner forms with deeply indented margins, are the following: The incised is one in which the margin is jagged, or irregularly and rather deeply cut, as if cut with a knife. The peculiar form of pinnately-incised leaf observed in the Dandelion and some other Compositæ, Fig. 103, in which the teeth are recurved, is called runcinate. The lobed is one in which the indentations extend nearly half way to the mid-rib or base, and in which either the segments or sinuses, or both, are rounded as in the leaves of some Oaks, Fig. 104; the cleft is the same as the lobed, except that the sinuses are deeper and commonly acute, Fig. 105; the parted is one in which the incisions, of whatever form, extend nearly but not quite to the mid-rib, as in the leaf of the Poppy, Fig. 106; and the divided is one in which the incisions extend quite to the mid-rib, but the segments are unstalked, as in the leaf of the Cress, Fig. 107.

It is evident that if the venation is pinnate, the series of forms may be described as pinnately-incised, -lobed, -cleft, -parted or -divided, as in the series of figures from 103 to 107 inclusive. If, however, the venation is radiate, as in the series of figures from 108 to 112 inclusive, they will be described as radiately or palmately-incised, -lobed, etc.

The terms pinnatilobate, pinnatifid, pinnatipartite and pinnatisect are used synonymously with pinnately-lobed, pinnately-cleft, pinnately-parted and pinnately-divided, respectively. The corresponding terms descriptive of the radiate or palmate forms are palmatilobate, palmatifid, palmatipartite and palmatisect.

The number of lobes, segments or divisions may be indicated by appropriate numerical prefixes, thus: Bilobate, trilobate, multi- 
lobate; bifid, trifid, multifid; bipartite, tripartite, multipartite; bisect, trisect, multisect, etc.; and in case it is desired at the same time to indicate the arrangement of the segments or lobes, the

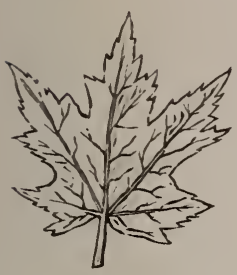

Fig. 108.

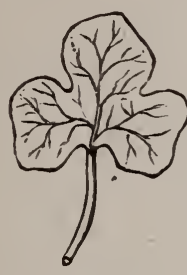

Fig. 109.

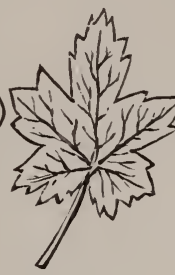

Fig. 110 .

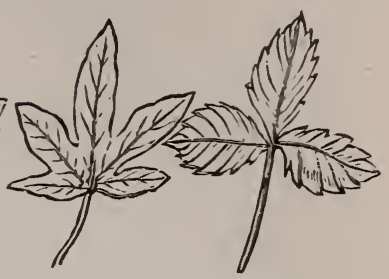

Fig. 111.

Fig. 112.

Figs. 108 to 112 , inclusive, diagrams illustrating the palmately-veined leaves with deep marginal indentations; 108, palmately-incised; 109, palmately-lobed; 110 , palmately-cleft; 111 , palmately-parted, and 112, palmately-divided.

modifying adverbs pinnately and palmately, or radiately, may be used, as pinnately quadrifid, palmately multisect, radiately trilobate, etc.

A leaf which is pinnately-parted in such a manner that the divisions are linear and stand-out from the axis, parallel to each other, as the teeth of a comb, is commonly described as pectinate,

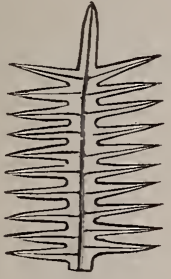

Fig. 113.

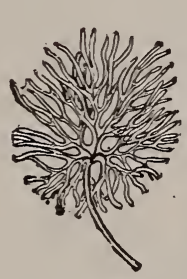

Fig. 114. Fig. 115 .

Fig. 113.-Diagram illustrating pectinate leaf.

Fig. 114.-Palmately-dis sected leaf of the Yellow Water Ranunculus.

Fig. 115.-Pinnately dissected leaf of Chamomile.

see Fig. 113. Leaves which are separated into numerous irregularly branching divisions are described as dissected, and such leaves may be either palmately-dissected, as the submerged leaves of the Yellow Water Ranunculus, Fig. 114, or pinnately-dissected, as the leaves of Chamomile, Fig. 115.

It not infrequently happens that the segments of a deeply indented leaf may again be incised, lobed, etc. Such forms, according to the depth of the incisions, and the arrangement of the segments, are described as bipinnatifid, bipinnatisect, bipalmatisect, etc. 
Compound Leaves. A compound leaf is one whose blade is divided into two or more distinct sub-divisions, called leaflets. These leaflets may possess stalks or petiolules of their own, and in many cases they are fastened to the main axis by means of a joint; but frequently also the leaflets are sessile, that is, attached directly to the main axis. In case, however, the parenchyma of the leaflet is confluent with the axis it is regarded as a divided simple leaf, and not as a compound one. It will be seen, therefore, that the transition from simple to compound leaves is a very gradual one. As a matter of fact, in some instances it is difficult to say whether a given form should be regarded as simple or as compound.

Since the compounding or branching of a leaf always follows

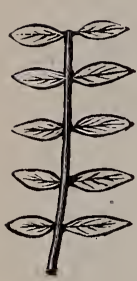

Fig. 116.

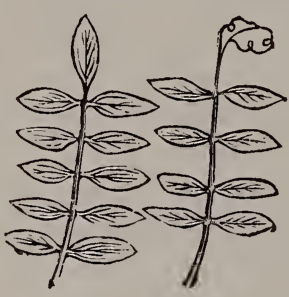

Fig. 117. Fig. 118.

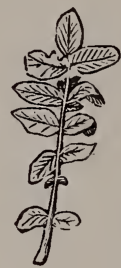

Fig. 119. Fig. 120.

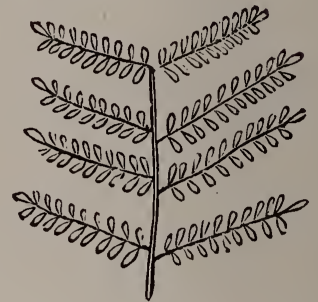

Fig. 121.

Figs. 116 to 121 , inclusive, forms of pinnately-compound leaves; 116, paripinnate; 117 , impari-pinnate; 118 , cirrhosely pinnate; 119 , interruptedly-pinnate: 120 , lyrate; and 121 , bi-pinnate.

the plan of venation, we may have either pinnately or radiately compound leaves.

The following are the most important of the pinnate forms:

The pari-pinnate, or abruptly pinnate, in which the leaf is terminated abruptly by a pair of leaflets, as in Fig. 116; the impari-pinnate, or odd-pinnate, in which the leaf terminates with a single leaflet, as in Fig. 117; the cirrhosely-pinnate, in which the leaf is terminated by a tendril, as in Fig. 118; the interruptedlypinnate, in which, as in the Silver-weed and Potato, Fig. 119, ther are smaller leaflets scattered among larger ones; the lyrate, leaf, in which the terminal leaflet is largest, and the others successively smaller toward the base, as in Fig. 120, and the leaves that are more than once compounded on the pinnate plan. Fig. 121 shows a leaf which is twice compounded; it is called a bi-pinnate leaf; one which is three times compounded on the same plan is tri-pinnate; one that is many times pinnately compounded, multi-pinnate, and 
a leaf which is somewhat irregularly compounded many times on the pinnate plan is termed pinnately-decompound.

A similar series of terms apply to leaves compounded on the radiate plan. Such a leaf, compounded on the plan of three is a palmately-trifoliolate or ternate leaf, as the leaf of the Clover, Fig. 122; one with four radiating leaflets is palmately-quadrifoliolate, or quadrate, as the leaf of Marsilea, Fig. 123; a radiate leaf with five leaflets is palmately-quinquefoliolate, or quinate, Fig. 124, and the Horse-chestnut furnishes an example, Fig. 126, of a palmately-septemfoliolate or septenate leaf, while the Lupine and some other plants produce palmate leaves with a still larger number of leaflets. There are also biternate, triternate, multiternate and ternately-decompound leaves. Fig. 125 is an example of a biternate leaf. The primary divisions of a compound leaf are termed pinnae, the divisions of the pinnæ are tcrmed pinnules and the ultimate divisions or little blades are termed leaflets.

Leaf Surface. In the observation and description of leaves and other portions of the plant body, it is often important to take into account the character of the surface.

Plant surfaces are glabrous, when smooth, or free from hairs or protuberances of any kind; glaucous, when covered with a bloom, as the leaf of the Cabbage; punctate, when dotted with peliucid or other dots; glandular, when bearing glands or secreting vesicles on the surface; rugose, when wrinkled; scabrous, when harsh or rough

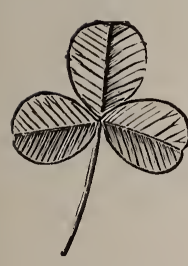

Fig. 122.

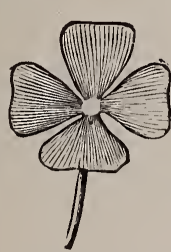

Fig. 123.

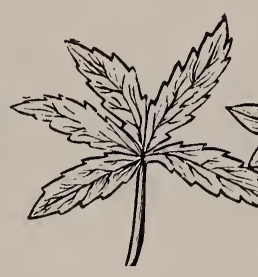

Fig. 124.

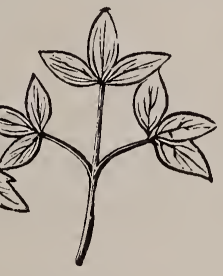

Fig. 125.

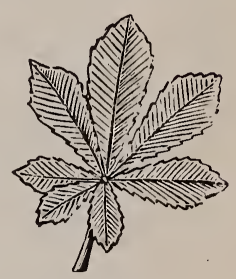

Fig. 126.

Figs. 122 to 126 , inclusive, forms of palmately-compound leaves; 122 , ternate; 123 , quadrate; 124 , quinate; 125 , bi-ternate; and 126 , septenate.

to the touch; verrucose, when covered with protuberances or warts; pubescent, when covered with rather short, soft hairs; puberulent, when minutely pubescent; sericeous, when covered with a pubescence of very fine, appressed, silky hairs; lanuginous, when covered with wooly hairs; tomentose, when covered with matted or felted hairs; villose, when bearing long, soft, shaggy hairs; pilose, when 
bearing long, straight, soft hairs; floccose, when bearing tufted, or cottony hairs; hispid, when covered with stiff hairs or bristles; strigose, when covered with stout, sharp, appressed hairs; spinose, when provided with spines; echinate, when possessing barbed prickles; and aculeate, when prickly.

Texture of Leaves. It is also of some importance to observe the texture or consistence of leaves. They are described as membranous, when thin and pliable; as succulent, when thickened and juicy, as the leaves of Live-for-ever, etc.; as scarious, when dry, like bud-scales; as coriaceous, when thickish and leathery, like the leaves of the great-flowered Magnolia; as herbaceous, when green in color, as most ordinary leaves; and as petaloid, when colored like petals, or of some lively color other than green.

Specially Modified Leaves. Some of these, such as bud-scales and leaf-tendrils, have already been mentioned, but there are many others which, having become adapted to functions altogether different from ordinary foliage, have also acquired forms which in

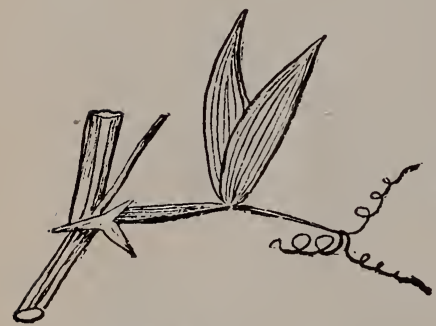

Fig. 127.

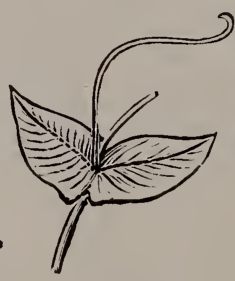

Fig. 128.

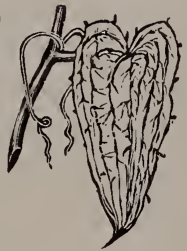

Fig. 129.

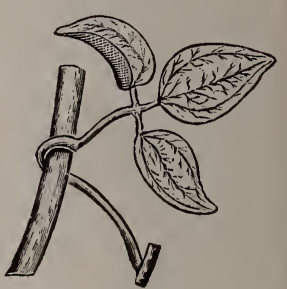

Fig. 130.

Fig. 127.-Leaf of Vetch with upper leaflets developed into tendrils.

Fig. 128. - Leaf of Lathyrus aphaca, with the leaf-blade and petiole developed into a tendril, while the functions of leaf-blade are discharged by the stipules.

Fig. 129.-Leaf of a Smilax, with the stipules developed into tendrils.

Fig. 130.-Leaf of a species of Clematis with petiole serving the function of a climbing organ.

some instances only remotely resemble those of foliage-leaves. The scales of bulbs like those of the Garlic and Lily, and of bulblets like those of some varieties of the Onion, are only leaves surcharged with nutriment stored up to enable the plant to accomplish a vigorous growth during the succeeding season; the spines into which some of the leaves of the Barberry and all of those of most species of Cactus are changed, subserve protective purposes, effectually defending the plants against browsing animals, and the upper leaflets of the common Pea and Vetch, Fig. 127, the entire blade 
and petiole of Lathyrus aphaca, Fig. 128, and the stipules of a Smilax, Fig. 129, are modified into tendrils, and serve the purpose of climbing organs.

Sometimes the petioles, while performing the ordinary function of supporting the blade, also become sensitive or irritable to the touch the same as tendrils, and like them perform the functions of climbing organs, as in the Clematis, Fig. 130, and Solanum

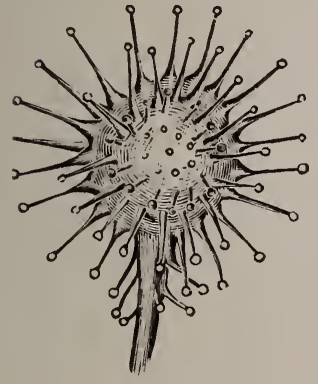

Fig. 131.

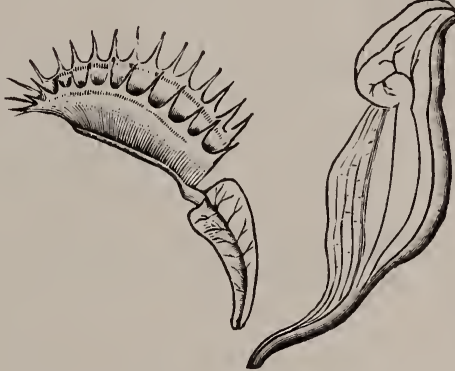

Fig. 132 .

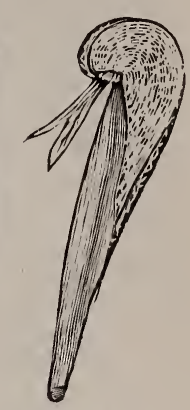

Fig. 134.

Fig. 131.- Leaf of the Sundew serving the purpose of an insect trap.

Fig. 132.-Leaf of Venus' Fly-trap.

Fig. 133.- Leaf of the Northern Pitcher-plant (Sarracenia).

Fig. 134.-Leaf of the California Pitcher-plant (Darlingtonia).

jasminoides, already referred to, Fig. 18; and sometimes they are developed into insect traps of various forms, as in the Sundew, Venus' Fly Trap, the various Pitcher-plants, etc.

Fig. 131 represents the leaf of the common Sundew. The hairs or tentacles distributed over the surface are each tipped with a pellucid drop of sticky material, by means of which small insects which alight on the leaf are secured; the tentacles all then bend over upon the insect, and the leaf itself partially rolls inward so as to envelop him, and by means of a secretion akin to gastric juice, which the secreting glands of the tentacles pour out freely upon the doomed animal, the nutritive portions of his body are dissolved and gradually absorbed by the plant as food.

Fig. 132 represents one of the rosette of radical leaves of the Venus Fly-trap, a plant belonging to the same family as the Sundew. The blade of the leaf consists of two spiny-margined valves, which are movable upon the mid-rib as upon a hinge. The face of each valve is also provided with three sensitive spines, and when an insect, attracted by the glandular secretions on the surface of the lobes, alights on one of them and touches one of the sensitive 
spines, the lobes instantly come together like the jaws of a steel trap, almost invariably securing the intruder, which becomes the food of the plant, and is digested in much the same way as is done by the Sundew.

The leaves of the Pitcher-plant of our northern bogs, Sarracenia purpurea, Fig. 133, also entraps insects, though in a quite different way, and uses them for food. The pitchers are usually found from half to two-thirds filled with water, which is mainly secreted by the plant; the lip of the pitcher has its inner surface clothed with stiff and sharp-pointed bristles, which point downward, and a secretion, enticing to insects, is poured out on the inner surface, particularly about the throat. Insects are thus enticed into the pitchers in great numbers, and owing to the difficulty of getting past the sharp-pointed hairs, they seldom escape, but are drowned in the

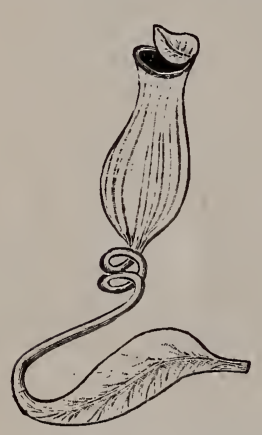

Fig. 135.-Leaf of the East Indian Pitcherplant (Nepenthes). water within the pitcher, and their decaying bodies form a rich manure which goes to sustain the life of the plant. The leaves of Darlingtonia, Fig. 134, a related plant of California, catch insects in much the same way, and make the same use of them. And the East Indian Pitcher-plant, Nepenthes, Fig. 135 , has a leaf, the lower part of which serves as a blade, performing the proper functions of a foliage leaf; the middle portion is developed into a tendril, by means of which the plant climbs, and the apical portion is developed into a pitcher which, like that of Sarracenia, entraps insects which are then digested by the watery secretion and thus utilized for food.

There are several other plants also which possess insectivorous habits, and whose leaves are modified more or less with reference to these habits; among them are the Bladder-worts, which develop little, bladder-like crustacean traps on their leaves; the Pinguiculas, whose leaves are glandular on the upper surface, and which entrap and devour insects somewhat after the manner of the Sundew, though in a ruder fashion, and the Australian Cephalotus, which bears among its ordinary leaves others in the form of very perfect pitchers. 


\section{Practical Exercises.}

1. Compare the following leaf forms and note their resemblances and differences: The scales of a Hickory bud, the fleshy scales of a Lily bulb, the large spines on the Prickly-pear Cactus, the different forms of leaves on the Barberry, the leaves of the Pitcher-plant, the petals of the Rose, and the leaf of the Maple.

2. Determine what organs are represented, respectively, by the tendrils of the Grape, the thorns of the Plum, the flattened joints of the Prickly-Pear Cactus, and the pods of the Pea.

3. Describe the following simple leaves as to their venation, the parts present, general outline, apex, base, margin, surface and texture, using the correct botanical terms: Those of the White Oak, Stramonium, Hard Maple, Bircl, House Ivy, Solomon's Seal, Onion, White Pine, Timothy Grass, and Live-for-ever.

4. Describe the following compound leaves as to the parts present, the plan of compounding, the number of leaflets and the general outline, apex, basc. margin, surface and texture of the leaflets, using the descriptive language of botany: Those of the Pea, the Hemp, Sweet Clover, Common Field-Clover, Meadow-Rue, Locust, Honey-Locust, and Ash .

5. Describe the Phyllotaxy of the Locust, of the Sycamore, of the CrabApple, of the Common Milk-Weed, of the Elm, of the Canada Lily, of the Flax, and of the White Pine.

6. Examine the buds or unfolding leaves of the following plants and determine the vernation: The Hickory, the Custard Apple, the Sweet Flag, the House Geranium, the Oak, the Sycamore, the Plantain, the Maple, the Common Poly. pody and the Ash.

\section{CHAPTER IV.-THE BRANCHING OF ORGANS.}

Not only stems but any organ of the plant-body may branch, and the branching is always according to one or other of two general types, the Dichotomous or the Monopodial. In the former mode the branching takes place by forking, or by the repeated division of the apex of the organ into two equal portions, as illustrated in Fig. 136. Three different varieties of this mode are observed.

(1) The Forked or Bifurcating Dichotomy, in which the branches develop equally, as in Fig. 136;

(2) The Helicoid Dichotomy, in which the branch on one side is invariably suppressed, or less strongly developed than the other, as illustrated in Fig. 137; and

(3) The Scorpoid Dichotomy, in which a branch is suppressed, or but partially developed, first on one side and then on the other, as in Fig. 138.

This plan and its various modifications are more commonly seen in flowerless than in flowering plants. It is the common mode of branching in Marine Algæe, the leaves of some Ferns, and in the stems and roots of Club-Mosses.

In the monopodial type the branches originate as lateral out- 
growt'is, back of the apex of the main stem, as illustrated in Fig. 139. 'There are also several modifications of this type:

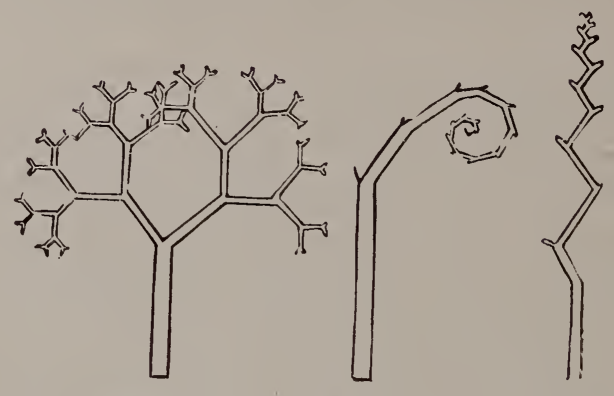

Fig. 136.

Fig. 137.

Fig. 138.

Fig. 136.-Diagram of forked dichotomy.

Fig. 137.-Diagram of helicoid dichotomy.

Fig. 138.-Diagram of scorpioid dichotomy.

(1) The Racemose Monopodium, in which the main axis retains the ascendency over its branches, as in Fig. 139.

(2) The Cymose Monopodium, in which the main axis is soon

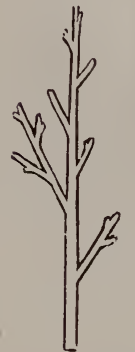

Fig. 139.

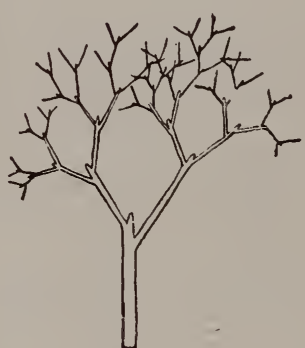

Fig. 140.

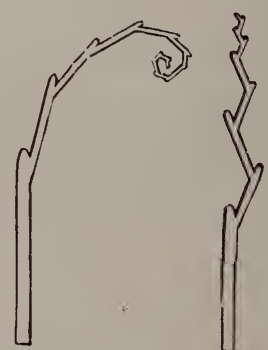

Fig. 141.
Fig. 142.

Fig. 139.-Diagram of a racemose monopodium.

Fig. 140.-Diagram of false dichotomy.

Fig. 141.-Diagram of the helicoid monopodium.

Fig. 142.-Diagram of the scorpioid monopodium.

suppressed and the lateral branches gain the ascendancy. Of the latter kind there are several variations:

(a) The False Dichotomy, represented in Fig. 140, in which the lateral branches develop in such a manner as to resemble true forks, or a genuine dichotomy.

(b) The Helicoid Monopodium, in which the main axis and lateral branches on one side are habitually suppressed, while the 
branches on the other side are developed to form a false axis, as in Fig. 141.

(c) The Scorpioid Monopodium, in which the main axis soon ceases to grow and the branches are suppressed alternately on one side and then on the other, as illustrated in Fig. 142.

The monopodial type of branching is the one seen in the stems of Mosses, in both the roots and stems of Equisetums, in the roots, and sometimes in the leaves of Ferns, and in the stems, roots and leaves of nearly all flowering plants.

\section{Practical Exercises.}

Study carefully, as examples of the various modes of branching, the following, making diagrams of each: (1) The common Liverwort, Marchantia poly. morpha, as an illustration of forked dichotomy; (2) the larger branches of the common Maidenhair Fern, Adiantum pedatum, as illustrating helicoid dichotomy ; (3) the smaller branches of the same plant, as illustrative of Scorpioid dichotomy; (4) the trunk and branches of the Balsam Fir, as illustrating a racemose Monopodium; (5) the branching of the Lilac and Mistletoe, as illustrating the false dichotomy; (6) the arrangement of the flower clusters of the common Day Lily, as illustrative of the helicoid Monopodium, and (7) the flower clusters of the Sundew, as typical of the scorpioid Monopodium.

The student should bear in mind that while in these examples the different modes of branching are clearly illustrated, it is not always equally easy to determine the plan, but sometimes a careful microscopical study of the branches in an early stage of their development is necessary, 


\section{CHAPTER V.}

\section{THE ORGANS OF REPRODUCTION.}

\section{INTRODUCTORY.-NATURE OF THE FLOWER.}

The organs for reproduction in phænogamous or flowering plants consist of flower, fruit and seed. They constitute a mechanism, more or less complex, whose function it is to continue the species. To this end, each part of the mechanism is subservient, and each, therefore, has a meaning which we should endeavor to understand. No part of it is so minute or apparently insignificant as not to deserve careful attention and thorough study. The organs of reproduction are not only interesting in themselves, inasmuch as flowers make strong appeals to everyone's sense of the beautiful, and inevitably awaken in thinking minds a desire to understand their structure, but they also furnish us with the most reliable characters for determining how nearly or how remotely different plants are related to each other; in other words, for classifying them according to their natural relationships.

Perhaps nothing in the vegetable world is more wonderful than the immense variety of flowers. But this multiplicity of forms has not always existed. A careful study of the flora of the past, as revealed in its fossil forms, and a discriminating study of the plants of our own time, necessitates the conclusion that all this variety and complexity have arisen from comparatively few and simple forms. Progressive adaptation to environment has been the law of vegetable life. Plants have been subject to changing conditions of soil and climate. The earth's crust has been slowly elevated in some localities, and depressed in others; large areas of land have been alternately raised above the sea level and then submerged; these things have necessitated profound changes in temperature, in atmospheric humidity, and in other conditions affecting plant growth. Moreover, plants maintain a continual struggle with each other for the occupancy of the soil-a struggle whose conditions vary, not only with the changing physical conditions in the same locality, but with the dispersal of plants by various natural agencies to new localities, bringing them into association with new plants and with new animal friends and foes. All these changes, necessitating changes in the habits of plants, taken in connection with the well-known tendency of plants to 
vary, have led to profound modifications in their structure. The descendants of plants which were alike have come to differ from each other and from the parental forms; from a few kinds, an immense number of species and varieties have arisen.

In the course of the adaptive changes which plants have undergone, the organs of reproduction have, of course, also undergone much modification; but here conservatism is more evident, especially as respects the essential organs of the flower, and changes in them have taken place more gradually than in other parts of the plant. The habits and appearance of related plants may have undergone profound change, while the flowers still bear a strong resemblance to each other in essential points of structure. The Elm and the Nettle, for example, are as different as possible from each other in size and in habits of growth, yet the record of their close relationship is preserved in their flowers.

It is for these reasons-because of the light which flowers throw on the relationships of plants, and the clews they give us to the history of their descent-even more than on account of the appeal which beautiful flowers make to the æsthetic sense, that they command the enthusiastic interest of botanists.

It must not be inferred from this, however, that the scientific study of a flower in any way dulls the enjoyment of it as a thing of beauty. It is a foolish, though popular, error to suppose that such is the case. It would be scarcely less absurd to suppose that the less one knows of art, the more he will enjoy a fine picture or a fine statue. Surely, in the study of flowers, as in every other subject worthy of knowledge, our enjoyment of them will increase as we understand them, and it will be measured by the extent and thoroughness of our knowledge of them.

The older botanists considered the parts of the flower as having been derived from assimilative leaves through modifications or metamorphoses. This assumption was even carried to the extreme of ascribing the origin of ovules to the altered edges, perhaps teeth, of green leaves. In support of this hypothesis, it was argued that, first, the floral parts occur on the stem in the same order as leaves, and develop from it in the same way; second, that in the earliest stages of their growth, they are indistinguishable from true leaves in the corresponding stage of development; third, that, sometimes, when mature, they present every gradation from ordinary foliage, through bracts and sepals to petals and stamens; and fourth, that instances are known of abnormal or monstrous 
flowers, where some or all of the floral organs appear to have reverted to the condition of ordinary green leaves.

However, during recent years it has been clearly established that, at least, ovules and pollen grains are not modified parts of any of the vegetative organs but can be traced through long descent from ancestral but independent structures in the lower plants.

Nature of the Flower. A flower consists, then, of a leafy branch highly modified for the purposes of reproduction. Nature has de. veloped the form, and commonly also, the color of its parts, to suit the requirements of the reproductive process. The flower exists solely for the purpose of producing the seed. To this object its entire mechanism, and even the beauty of its corolla, its perfume and its nectar, are subservient. Even the vegetative processes of the plant, which precede the flowering, have largely for their object the storage of the energy necessary to enable the plant to produce its flower and develop its seed. In many cases, from that time the growth of the plant ceases. During the formation of the flower and the subsequent process of perfecting the seed, its stored-up energies suffer heavy drainage, resulting either in the death of the plant, as in the case of annuals, biennials and some perennials; or in its entering upon a period of rest to recuperate its exhausted vitality.

Let us begin our study of flowers by observing their anthotaxy.

\section{CHAPTER VI.-ANTHOTAXY.}

By Anthotaxy is meant the arrangement of the flowers on the stem. It is often called inflorescence. Flowers may occur singly on the stem, or in clusters, and the latter may have various shapes and characteristic modes of arrangement.

In a flower-cluster, the axis along which the flowers are arranged is called the rachis, or axis of inflorescence; the common stalk of the cluster, the peduncle; the stalks of the individual flowers, the pedicels; and the modified leaves from which the branches of the cluster spring, bracts or bractlets, according as they occur on the rachis or on some of its branches. See Fig. 143. A leafless or nearly leafless stem or peduncle arising from an underground stem and bearing a flower or flower cluster is called a scape.

Since flowers are modified branches and originate from buds 
as do other branches, they follow the arrangement of buds, that is, they are either terminal or axillary, thus giving rise to two distinct types of Anthotaxy, the indeterminate, spikose or axillary type, and the determinate, cymose or terminal type.

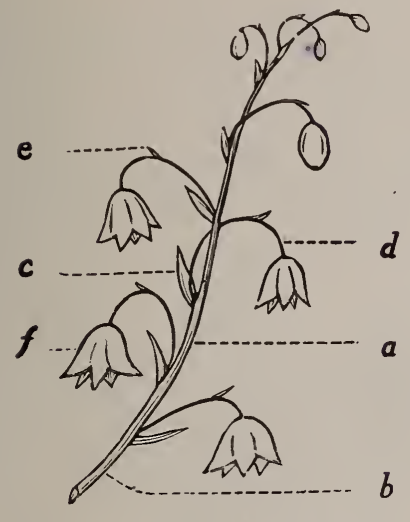

Fig. 143.-A raceme, showing axis of inflorescence, or rachis, a ; peduncle, b; bracts, c ; pedicels, d; bractlets, e; and flowers, f.

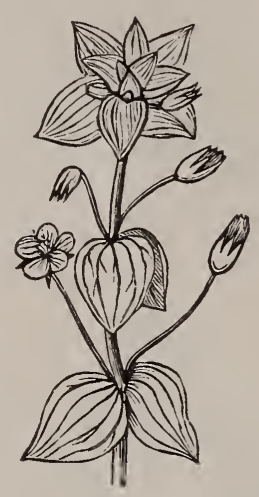

Fig. 144.--Pimpernel, showing solitary indelerminate inflorescence.

An Indeterminate or Ascending Anthotaxy is one in which the flowers occur in succession from the base toward the apex of the
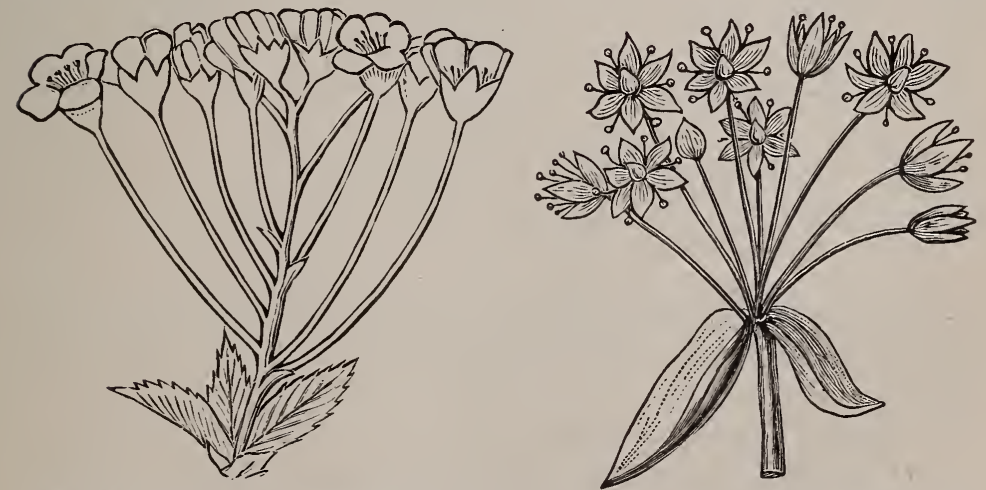

Fig. 145.-Corymb of a species of Cherry Fig. 146.-Umbel of a species of Onion.

main stem. When clustered on this plan, those flowers come into blossom first which are situated lowest down on the rachis, or, in 
the case of a flat-topped cluster, at the periphery. The principal forms of this type are the following:

(1) The Solitary Indeterminate is one in which the flowers occur singly in the axils of ordinary leaves, as in the common Pimpernel, Fig. $14 \dot{4}$.

(2) The Raceme is a cluster in which the flowers are pedicelled and occur in succession along a lengthened axis, blossoming from the base toward the apex, as in Fig. 143. Examples occur in the Choke-cherry and in the Currant.

(3) The Corymb is like a raceme, except that it has the rachis proportionately shorter, and the lower pedicels somewhat length-

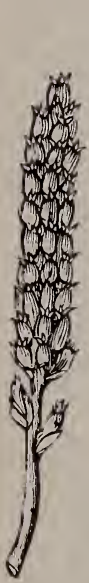

Fig. 147.

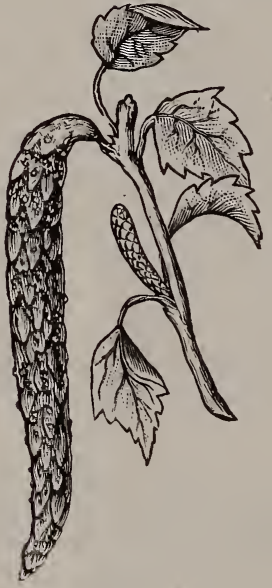

Fig. 148.

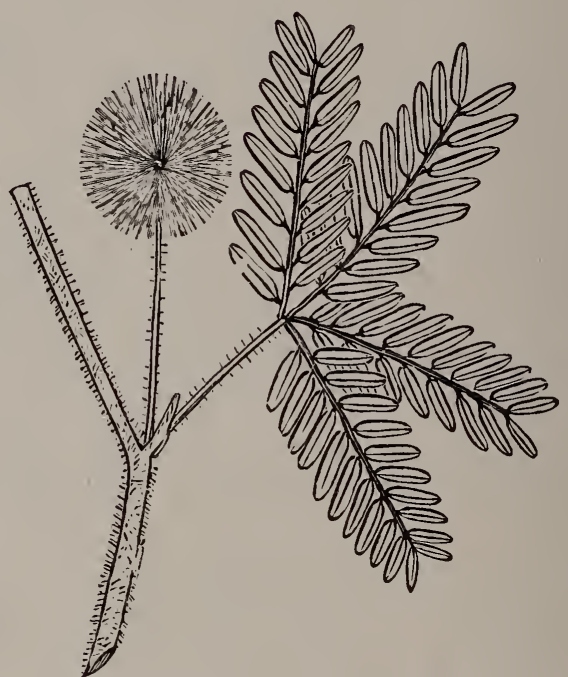

Fig. 149.

Fig. 147.-Spike of Plantain.

Fig. 148.-Catkin of Birch.

Fig. 149.- Head of Mimosa pudica.

ened so as to bring all the flowers to about the same level, as in Fig. 145, which represents the inflorescence of another species of Cherry.

(4) The Umbel resembles a raceme, but has the rachis reduced still more than in the corymb, and the nearly equal pedicels radiate from it like the rays of an umbrella, as in some species of Onion, Fig. 146.

(5) The Spike is like a raceme, except that the flowers are 
sessile instead of pedicelled. Examples occur in the wild Vervains and in the common door-yard Plantain, Fig. 147.

(6) The Catkin, or Ament, is similar to the Spike, having its flowers sessile along a lengthened axis, but it differs from the latter in the fact that it has scaly instead of herbaceous bracts, as the clusters of staminate flowers of the Oak, Chestnut, Hazel and Birch, Fig. 148.

(7) The Head or Capitulum is like a Spike, except that it has the rachis shortened so as to form a very compact cluster of sessile, or nearly sessile, flowers, as in the Clover, Button-bush and Mimosa, Fig. 149. A form of the Head characteristic of the great family Composita. :s known as the Anthodium and simulates a simple

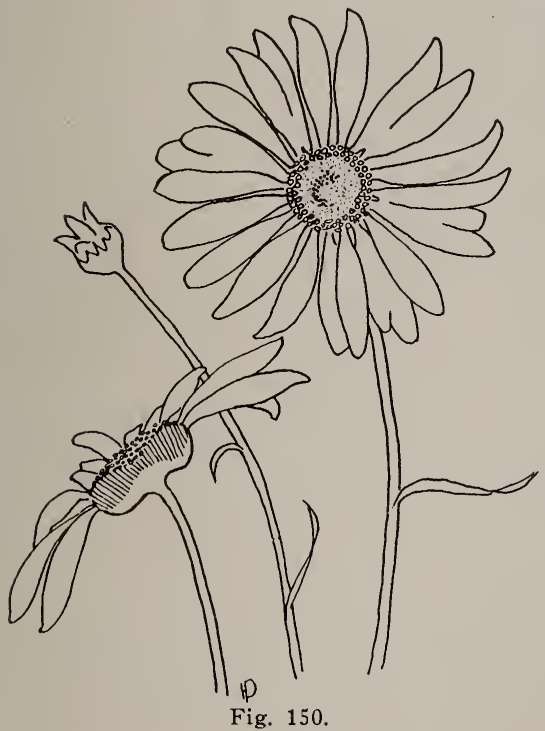

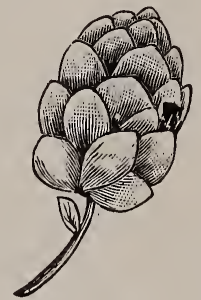

Fig. 151.

Fig. 150.-Head of Daisy. Fig. 151.-Strobile of Hop.

flower, the ligulate ray flowers resembling a corolla, the involucre of green bracts resembling a calyx and the small and usually yellow disk flowers having the appearance of stamens, see Fig. 150.

(8) The Strobile is a compact cluster with large scales concealing the flowers, as in the inflorescence of the Hop, Fig. 151.

(9) The Spadix is a flower-cluster like a spike (or sometimes shortened into a head) that is partially or wholly enclosed in a large bract called a spathe, which springs from its base. The 
inflorescence of the common Calla, the Skunk cabbage and the Indian turnip, Fig. 152, are illustrations.

Several of the forms above described may be more or less compounded. For example, there are compound racemes, compound

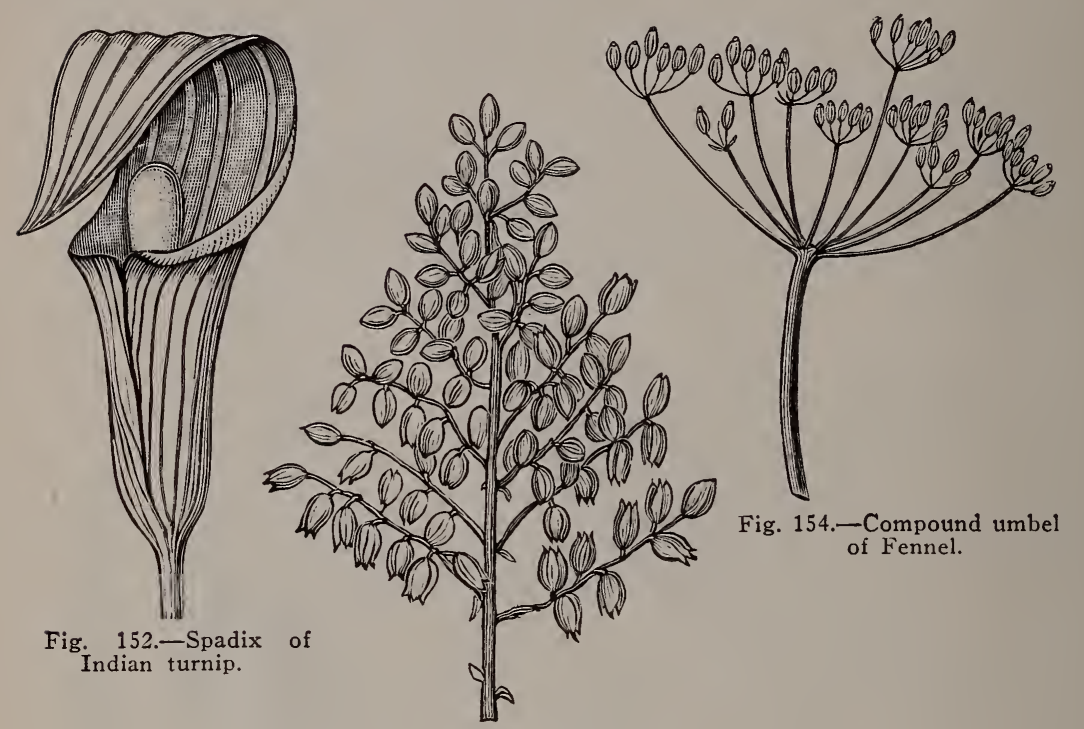

Fig. 153.-Panicle of Yucca.

corymbs, compound umbels, and compound or panicled spikes. The compound raceme, particularly if it is somewhat irregularly compounded, is commonly called a panicle, as in the Yucca, Fig. 153. Fig. 154 illustrates the compound umbel of Fennel, and Fig. 155, the panicled spikelets of the Oat.

The bracts which subtend the heads of the Compositæ, and those which occur in whorls at the base of other compact flower-clusters, as the umbels of many Umbelliferæ, as well as the whorl of bracts which sometimes occurs beneath a single flower, as in the Anemone, are termed the involucre.

A Determinate or Descending Anthotaxy is one in which the first flower that opens is the terminal one on the rachis, and the others appear in succession from the apex toward the base. In case the cluster on this plan is flat-topped, the flowering begins at the center instead of at the periphery, consequently the inflorescence is often described as centrifugal, in distinction from the indeterminate form, which is described as centripetal. 
The principal varieties of determinate anthotaxy are the following:

(1) The Solitary Determinate is one in which there is a single flower at the end of the stem, as in the Wood Anemone, Fig. 156.

(2) The Cyme is a loose cluster on the determinate plan, such as that illustrated in Fig. 157, which represents the inflorescence

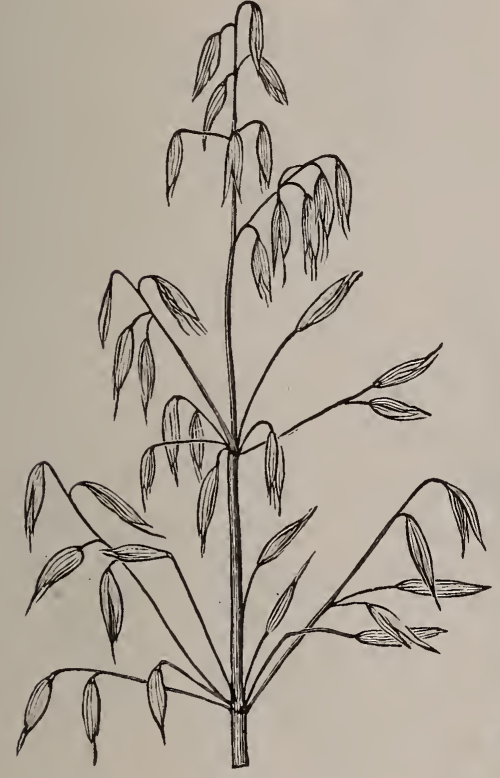

Fig. 155.

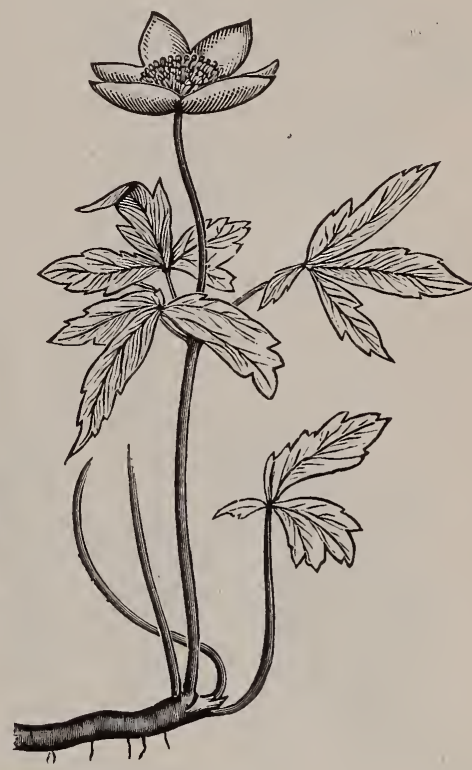

Fig. 156.

Fig. 155.-Panicled spikelets of the Oat.

Fig. 156.-The Wood Anemone, illustrating solitary determinate inflorescence.

of a species of Cerastium. A diffuse and freely branching cyme, like that of the common Elder and the Viburnums, is frequently called a Compound Cyme, and when such a cyme has shortened pedicels and is compactly arranged, as in the inflorescence of the garden Sweet William, it is termed a Fascicle.

(3) A Glomerule or glomerulus, is a dense cluster on the cymose plan, whose flowers are sessile, or nearly so, on a short rachis. It resembles a head, but differs from it in the fact that the inflorescence is centrifugal. The Flowering and Canada Dogwoods both illustrate this form of inflorescence. See Fig. 158. The flower-cluster, as will be seen, is subtended by four conspicuous 
bracts, constituting an involucre; $a$ represents one of the florets of the cluster magnified.

A Scorpioid Cyme is one that imitates a raceme in appearance,

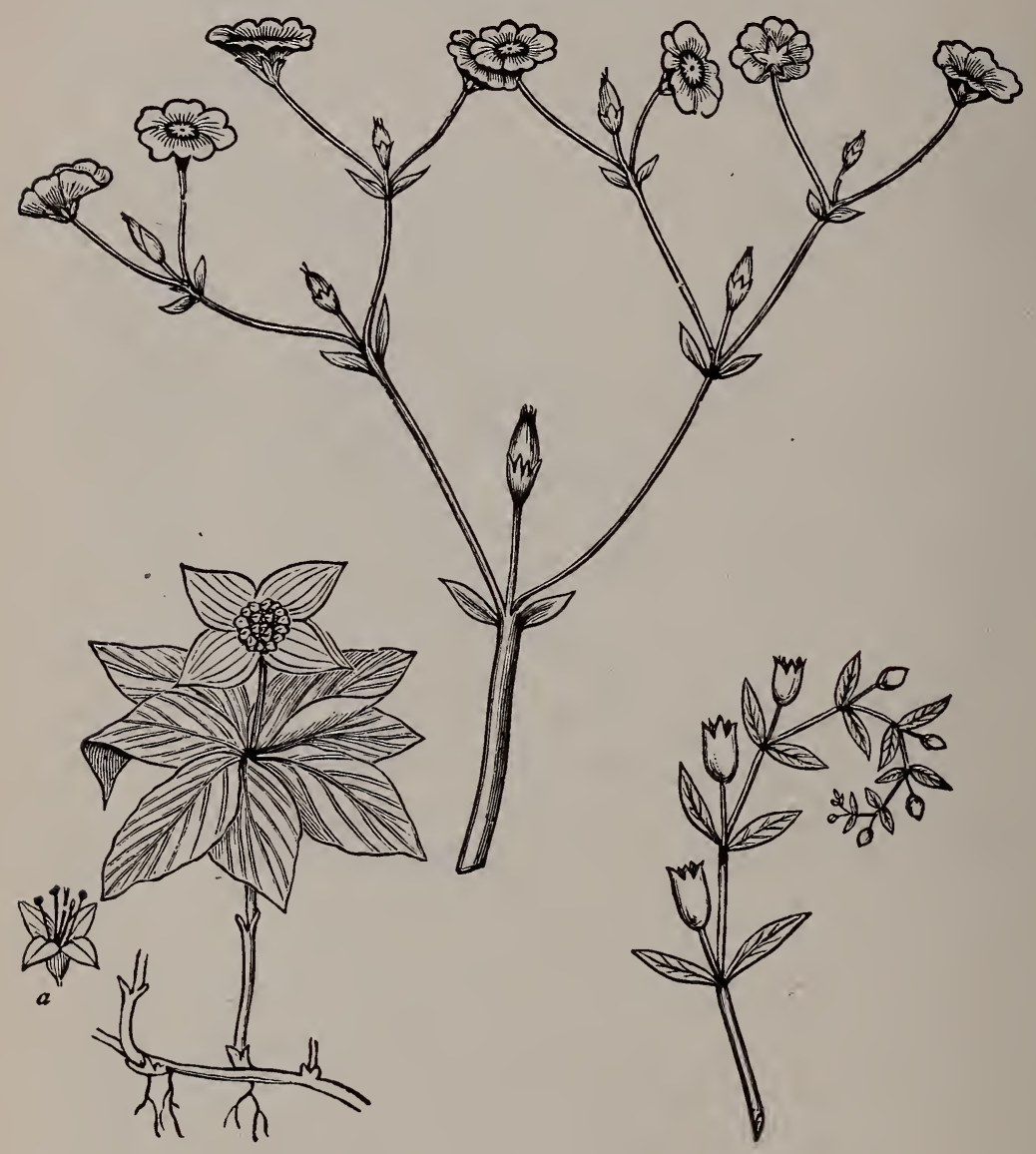

Fig. 158.

Fig. 157.

Fig. 159.

Fig. 157.-Open cyme of a species of Cerastium.

Fig. 158.- Glomerule of the Canada Dogwood.

Fig. 159.-Diagram of Scorpioid Cyme.

having the flowers pedicelled and arranged along a lengthened axis. As in the raceme, the basal flower of the cluster is the oldest, but it is in reality terminal instead of axillary, as shown in the dia- gram, Fig. 159. Such an inflorescence arises either from the sup- 
pression of all the branches on one side, in which case it would properly be called helicoid, or from the alternate suppression of branches, first on one side and then on the other, when it would be, in the strict sense, scorpioid. Owing, however, to the difficulty of distinguishing the two varieties when mature, they are indiscriminately called scorpioid cymes. Such cymes are commonly

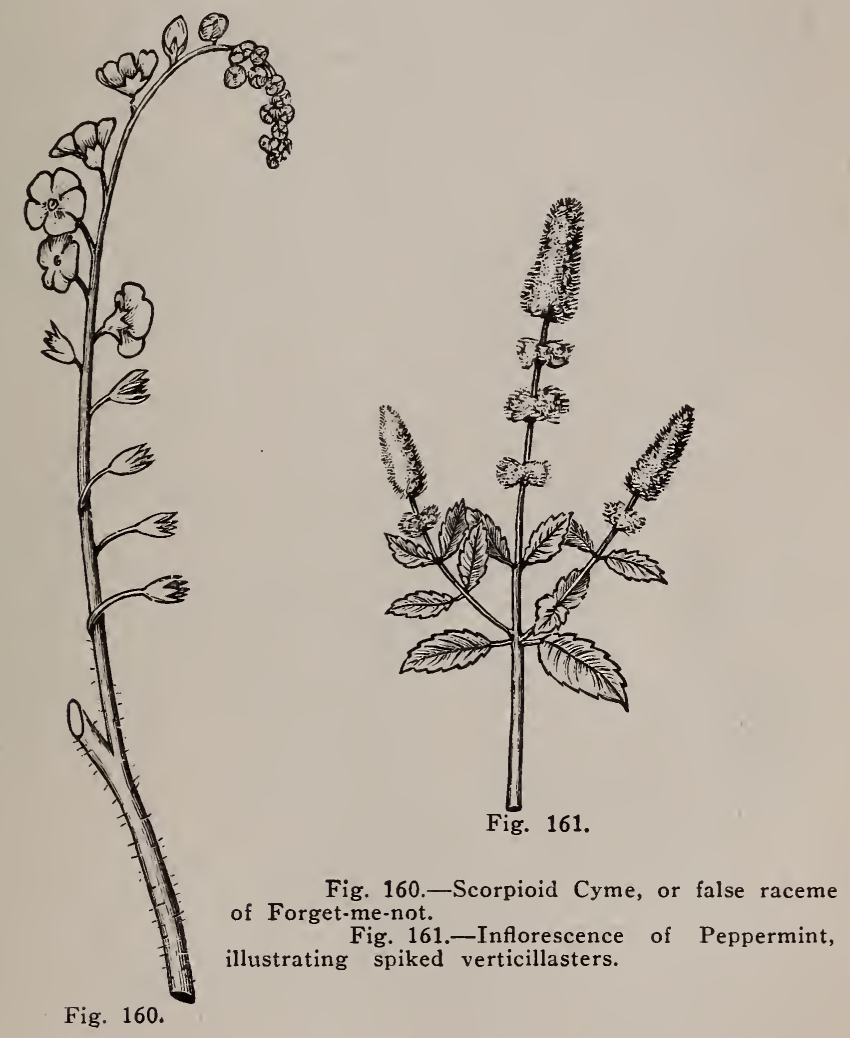

one-sided or coiled in form. They are illustrated in the Sundew, the Heliotrope and the Forget-me-not, Fig. 160. Cymes of this kind also, not uncommonly branch into compound forms.

(5) A Verticillaster is a compact cymose flower-cluster, which at first sight appears like a whorl or circle of flowers about a stem, but which in reality consists of two glomerules situated in the axils of opposite leaves. Clusters of this kind are seen in the Catnip, 
Horehound, Peppermint and other plants belonging to the natural order Labiatæ, Fig. 161.

A Mixed Anthotaxy is one in which the indeterminate and determinate plans are combined. Illustrations of this kind occur in many of the Compositr where the heads of flowers, which of course are indeterminate clusters, are arranged in cymes. In the mints, on the contrary, verticillasters or cymose clusters are often arranged in spikes, as seen in the Peppermint, Fig. 161.

Mixed panicles are of very common occurrence, in fact more common than the purely indeterminate forms. They may be of two kinds, either the primary ramifications may be indeterminate and the secondary or ultimate ones determinate, or the latter may be indeterminate while the former are determinate. A somewhat elongated, profusely branching and compact luster of the former sort, like the inflorescence of the Lilac and Horsechestnut, is commonly called a thyrsus or thyrse.

\section{RECAPITULATION.}

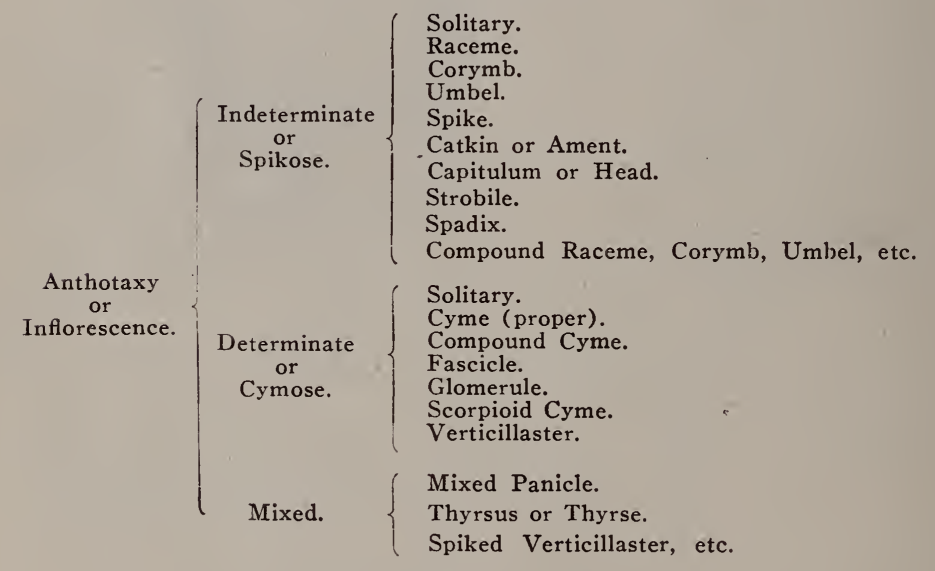

Practical Exercises.

Determine whether the following inflorescences are indeterminate, determinate or mixed, and give the particular names applicable to each: The Currant, the Carrot, the Mustard, the Sycamore, the Red-ozier Dogwood, the Willow, the Frost Grape, the Wheat, the Potato, the common Milk-weed, the Hydrangea, the Burdock and the Harebell. 


\section{CHAPTER VII.-PREFLORATION OR ESTIVATION.}

By prefloration or æstivation is meant the arrangement of the floral organs, particularly calyx and corolla, in the bud. Since these parts of flowers are modified leaves, and flower-buds are structurally similar to leaf-buds, it is not strange that most of the terms explained under the head of prefoliation or vernation are applicable also to the arrangement of the floral organs in the

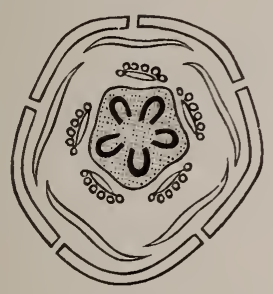

Fig. 162.

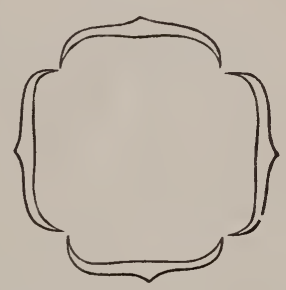

Fig. 163 .

Fig. 162.-Diagram or plan of flower of common Basswood.

Fig. 163.-Diagram of induplicate-valvate prefloration.

bud. These terms need not again be defined, but a few additional forms will be described, all of them relating to the arrangement of the organs with reference to each other.

(1). The Valvate Prefloration. In this, the margins of adjacent members are contiguous merely, that is, do not at all overlap in

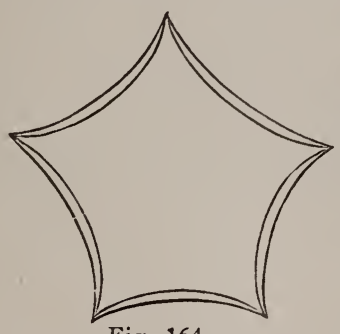

Fig. 164.

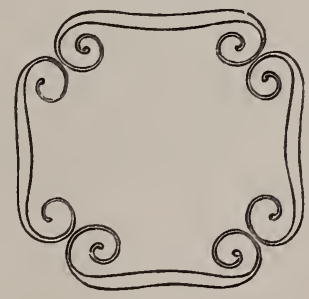

Fig. 165 .

Fig. 164.-Diagram of reduplicate-valvate prefloration.

Fig. 165.-Diagram of involute-valvate prefloration.

the bud. It is seen in its simplest form in the calyx of the Basswood flower, a ground plan of which is shown in Fig. 162. Of this form there are three other modifications: the induplicate-valvate, in which the edges of contiguous organs are bent inward, as in 
Fig. 163; the reduplicate-valvate, in which the edges are bent outward, as in Fig. 164; and the involute-valvate, in which the edges are rolled inward, Fig. 165.

(2) The Imbricate Prefloration. Here the margins of adjacent parts overlap something like shingles on a roof. Of this, also, there are several modifications. The equitant and half-equitant have already been described.

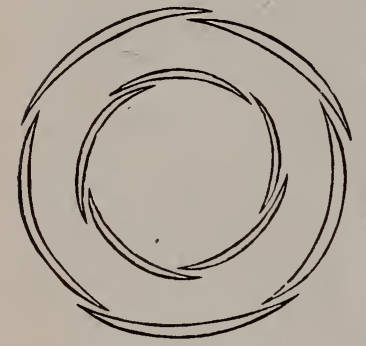

Fig. 166.

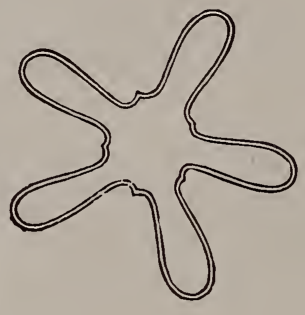

Fig. 167.

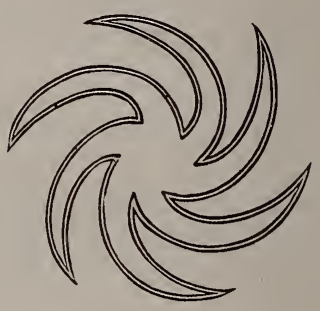

Fig. 168.

Fig. 166.-Diagram. The outer whorl represents imbricate, the inner one, contorted prefloration.

Fig. 167.-Diagram of plicate prefloration of the Harebell.

Fig. 168.-Diagram of supervolute prefloration of Stramonium.

(3) The Contorted Prefloration is that in which the parts are arranged with one edge invariably exterior and the other interior, giving to the bud a twisted appearance, as in the inner whorl, Fig. 166.

(4) The Plicate or Plaited Prefloration. These terms, except when applied to the folding of a single leaf or floral organ, have reference only to those corollas or calyxes whose pieces are united. Such an organ folded lengthwise is called plicate, as the corolla of the Harebell, Fig. 167. In case the organ is both folded and twisted, as in the corolla of Stramonium, Fig. 168, it is commonly called supervolute. 


\section{RECAPITULATION.}

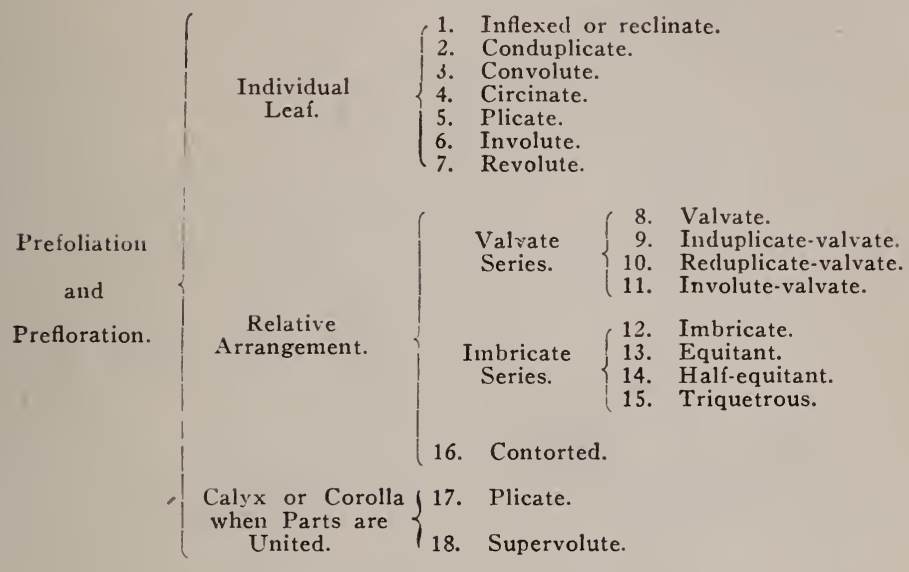

\section{Practical Exercises.}

Examine the flower-buds of the following plants with reference to the prefloration of calyx and corolla; draw a diagram of the arrangement in each case, and apply to each the proper term descriptive of the prefloration: The Apple, the Mustard, the field Clover, the Morning-glory, the Butter-cup, the Geranium, the Buckthorn, the Grape and the Stramonium.

\section{CHAPTER VIII.-STRUCTURE OF THE FLOWER.}

When complete, the flower consists of four sets of organs, the outer set usually leaf-like and green, called the calyx, composed of individual pieces called sepals; the second set, usually delicate and brightly colored, called the corolla, made up of individual pieces called petals; the third set, called the andrœcium, made up of individual pieces called stamens; and the fourth, or central set, called the gynæcium, made up of individual pieces called pistils or carpels. Since the stamens and pistils are homologous with the spore-bearing leaves of the ferns, they are collectively called sporophylls. All of these parts grow from a shortened axis or stem called the receptacle. Fig. 169 is a diagram of a typical flower. The parts are represented as separated in their order from the receptacle:

(a) Represents a set of three pistils, or carpels.

(b) A set of three stamens. 
(c) A whorl of three petals, the corolla.

(d) A whorl of three sepals, the calyx.

(e) The receptacle, the shortened axis to which all these parts are attached; and

(f) A bract below the flower.
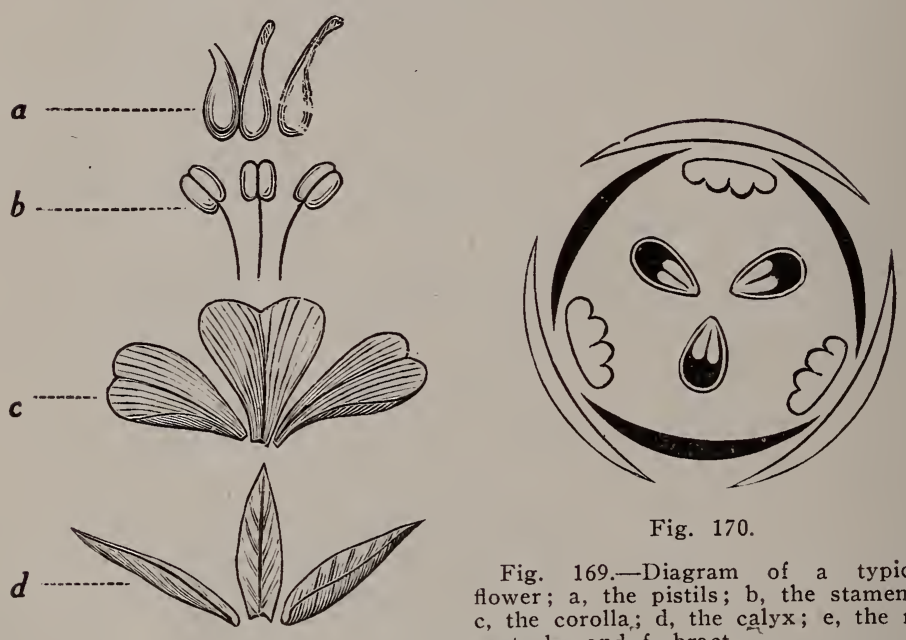

Fig. 170.

Fig. 169.-Diagram of a typical flower; $a$, the pistils; $b$, the stamens; $c$, the corolla; d, the calyx; e, the receptacle, and f, bract.

Fig. 170.-Ground plan of the same

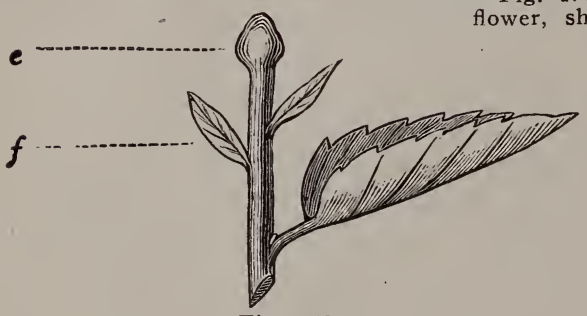

Fig. 169.

Fig. 203 represents the ground plan of such a flower. The first, or outside cycle, represents the calyx, the second the corolla, the third the stamens, and the fourth, or central cycle, the carpels. It will be observed that the successive cycles alternate with each other.

While the floral organs are usually arranged in whorls or cycles, corresponding to whorled leaves, yet the spiral arrangement corresponding to alternate leaves is not infrequent, occurring in all the sets, but more commonly in the inner ones, the sporophylls. By referring again to Fig. 169, it will also be seen that 
in this ground plan a certain number, the number three, prevails throughout. This is called the cycle number or numerical plan of the flower, an important thing to observe in the study of flowers, since in some large groups of plants the same number prevails throughout, as, for instance, the number three, or some multiple of it, in the great group of Monocotyledons, while in Dicotyledons tive or, less commonly, four are the prevalent cycle numbers. A flower constructed on the plan of one, or which possess one sepal, one petal, etc., as is sometimes the case, is called monomerous; one whose parts are in twos, dimerous; one whose parts are in threes, trimerous; one whose parts are in fours, tetramerous; one whose parts are in fives, pentamerous; and one whose parts are in sixes, hexamerous. The commonest of these arrangements are the trimerous, the tetramerous, and the pentamerous. It must be observed that in some cases, owing either to the multiplication, suppression or coalescence of the parts of some whorls, the numerical plan is more or less obscured, but it may in most instances be discovered by careful study.

Such a flower as is represented in Figs. 169 and 170, is trimerous; since, also, it possesses all the parts which properly belong to a flower, it is complete; because it has the same number of parts in each cycle, and these cycles alternate with each other regularly, it is symmetrical; because the parts of each set are similar in size and shape, it is regular; and because it possesses all the parts essential to the production of seed, namely, stamens and pistils, it is hermaphrodite, or perfect; and because it possesses both sets of the floral envelopes, calyx and corolla, it is dichlamydeous. Many typical angiospermous flowers possess two whorls of stamens. The flower of the Trillium, except that its three pistils are partially united, illustrates very well a typical trimerous flower, and the flowers of the Flax and the Stonecrop are pentamerous flowers that closely conform to the typical structure. But, while it is convenient to compare flowers with some such form as we have described as typical, the flowers that differ from this form are far more numerous than those which conform to it. Most of these differences we regard as adaptations which the organs have undergone in relation to the surroundings of the plant, or the conditions of its existence. The selection exercised by insects in visiting flowers for their nectar and pollen, in conjunction with the tendency which all flowers have to vary, has curiously enough been 
proved to be one important agency in producing irregular and unsymmetrical flowers. (See the subject of Pollination.)

The more important deviations from the typical form of the flower described in the foregoing paragraph may be classified as follows :

(1) Suppression or Absence of Parts. A flower may be incomplete in almost any degree. Only a portion of a single whorl may be absent, or one or more entire whorls may be wanting. There are flowers so reduced as to consist only of a single stamen, or of a single pistil, as in the little Wolffia, while others should be considered rather as primitive and simpler forms.

A flower that lacks one of the floral envelopes is called apetalous. Apetaly may result either from suppression of one set of floral leaves or from failure of the perianth to become differentiated into two sets or whorls. A flower that is destitute of both calyx and corolla is termed naked; if it has pistils, but is destitute of stamens, it is called pistillate, or female; if it possesses stamens, but not pistils, it is described as staminate, or male; and if it be destitute of both, it is called neutral. Such showy neutral flowers are seen in the border of the cymes of the wild Hydrangea and Cranberry-tree.

Some plants, as the Begonias, Castor-oil Plant and Maize, bear two kinds of flowers, staminate and pistillate, on the same plant. Such a plant is described as monocious. In the case of some others the staminate and pistillate flowers are borne by different individuals of the same species; this is true of Sassafras, many Willows, the Tree of Heaven, etc. Such plants are diœcious. The Maple is an example of a tree which produces staminate, pistillate and hermaphrodite flowers all on the same tree. Such a plant is termed polygamous.

(2) Multiplication of Parts. This is scarcely less common, and may apply to any of the floral organs. So-called "double" flowers are flowers in which the petals or sepals are multiplied beyond the normal number, as in the cultivated Rose, the Camellia, and the garden Ranunculus. In the Cactuses, the stamens, and in the wild Buttercups, the pistils, are very numerous. Sometimes the multiplication of parts takes place by the formation of new whorls, and sometimes by an increase in the number of parts of the same whorl.

(3) Anteposition of parts. Normally, as has been stated, the whorls alternate, but occasionally they are anteposed, or have the 
pieces of successive whorls placed one in front of the other. In the Barberry and the Blue Cohosh, for example, the stamens come opposite to the petals, and in the Iris the stigmas (which are the upper part of the pistil) come opposite the stamens.

(4) Irregularity of Parts. Irregularity in the size, shape or coloring of parts, particularly of the calyx and corolla, is very common. Flowers which are radially symmetrical and therefore regular are termed Actinomorphic, while flowers which are irreg-
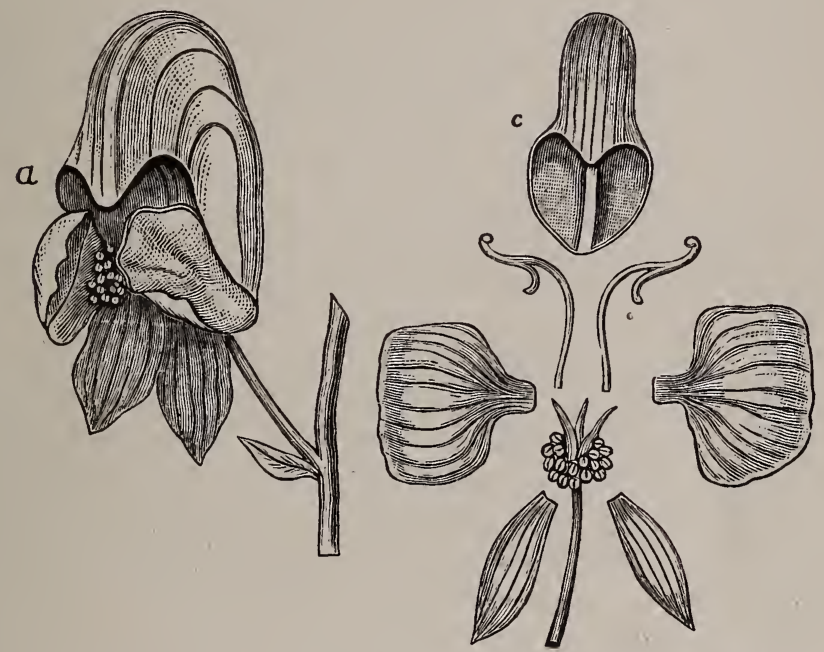

Fig. 171.-Flower of Aconite; a, as it appears when fully expanded; c, with the parts separated, showing the hooded upper sepal, the two large lateral sepals and the two smaller ones; underneath the hood are the two petals.

ular but may be divided in one plane so as to give similar halves, are said to be zygomorphic. In the Figwort and Mint families regularity is the exception and not the rule, and there is no known member of the family of Orchids that is not very irregular. Fig. 171 represents the zygomorphic flower of Monk's-hood or Aconite. In the outer whorl there are five sepals, the upper of which is hooded, and the two lateral ones differ from the two lower in size and shape. From the second whorl, or corolla, all but two pieces are wanting, and these, though really petals, bear little resemblance to ordinary ones in shape. $a$ shows the flower as it appears naturally, and $c$ represents the same with the parts of the calyx and corolla separated, showing their shape and relations.

(5) Union of Parts. The growing together of parts may take 
place in two ways. Either the parts of the same whorl may be united partly or wholly, or parts of different whorls may have become more or less united. The former is termed coalescence, the latter adnation. Coalescence, either complete or partial, may occur between the members of any set of floral organs, and any two sets may become adnate partly or wholly. Even organs so different in their functions as stamens and pistils not infrequently are united, as in the Orchid family. It is to be understood that such union of parts is congenital; it goes back to the development of these parts at the growing point of the floral stem. It would be a misconception to think of these coalesced parts as having been formed separately and then, later, united.

\title{
Practical Exercises.
}

\begin{abstract}
Examine flowers of the following plants: The Tiger Lily, the House Geranium, the Morning-glory, the Butter-cup, and the Rose, and determine (1) the numerical plan of each flower, (2) draw a ground plan of each, representing, as in Figs. 162 and 170, the number and relation of parts, and note in each what deviations occur.
\end{abstract}

\section{CHAPTER IX.-THE TORUS, CALYX AND COROLLA.}

The Torus or Receptacle. This is the shortened axis from which the other floral organs grow. In form it is commonly convex or flat, but sometimes it is conical, as in the Strawberry, sometimes long and beaked, as in the Geranium, sometimes concave or hollow, as in the Rose and Fig, sometimes top-shaped, as in Nelumbium.

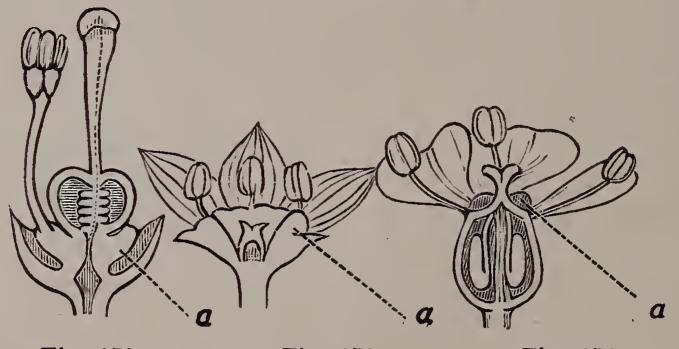

Fig. 172.

Fig. 173 .

Fig. 174.

Fig. 172.-Orange flower, cut lengthwise and deprived of its petals and all but one cluster of its stamens, to show the hypogynous disc, a.

Fig. 173.-Flower of Sumach, cut lengthwise, showing perigynous disc, a.

Fig. 174.- Flower of Æthusa, cut lengthwise to show the epigynous disc, a.

Not infrequently the receptacle produces a fleshy outgrowth from its margin, called a disc. If this remains wholly underneath the pistils, as in Fig. 172, it is said to be hypogynous; if it 
grows up around and partially but not wholly envelops them, as in Fig. 173, it is called perigynous; and if it completely envelops them and become adnate to them, so as to appear to spring from the top of the ovary, as in Fig. 174, it is said to be epigynous.

Since the torus is but a shortened axis, we may expect to find instances which show a lengthening of it. Such an elongation of the torus, when occurring between the calyx and corolla, is termed an anthophore; between corolla and the stamens a gonophore, and between the stamens and the pistil a gynophore. In the Umbelliferæ and some of the Geraniace $x$ there is an upward prolongation of the torus which passes between the carpels and is attached to them. This is known as a carpophore.

The axis of a flower cluster, if very short and resembling in shape the receptacle of a single flower, is also called a receptacle, or a common receptacle. The fioral axes of the Dandelion, Lettuce and Clover are examples.

The Calyx and Corolla together constitute the Perianth or floral envelope. If these two whorls are similar in form and color the term Perigone is applied to them.

The Calyx. This is the outer of the four series of floral leaves, and its parts ordinarily bear a closer resemblance to true leaves than do the other organs of the flower. They are more commonly green in color, and are then described as foliaceous, but in some flowers they have the color of petals or some lively hue other than green, in which case they are described as petaloid. The latter are illustrated in the sepals of the Larkspur, Columbine and showy Lady's-slipper. When the petals are distinct from each other or ununited, the calyx is described as chorisepalous, or, less correctly, as polysepalous, and when they are united either partially or wholly, it is called gamosepalous. In a gamosepalous calyx where the union of sepals is incomplete, the united portion is called the tube, while the free or ununited portion is termed the $\operatorname{limb}$, and the orifice of the tube is called the throat. .

In flowers belonging to the natural order Compositæ, the calyx has its tube united to the ovary, while its limb is produced into a hairy, scaly or spiny crown called a pappus The down, by means of which the ripe fruits of the Dandelion, Thistle and Lettuce are vrafted on the wind, is an illustration. In the Valerian and Teasel families, the calyx-limb forms a pappus in a similar manner.

In form, the calyx may be regular or irregular: regular, if its parts are evenly developed; irregular, if some of the sepals are 
larger or different in shape from others; or in the case of a gamosepalous calyx, if either the tube is unequal-sided or the divisions of the limb are of unequal size or shape. Among the more commonly occurring forms of the gamosepalous calyx are the tubular or tube-shaped, the rotate or wheel-shaped, the campanulate or bell-shaped, the hypocrateriform or salver-shaped, the urceolate or urn-shaped, and the bi-labiate, forms which correspond to those of the corolla, presently to be described.

The calyx very commonly remains after the corolla and stamens have withered, and sometimes endures even until the ripening of the fruit; in either case it is said to be persistent. Not infrequently, however, it falls away at the same time with the corolla and stamens, when it is described as deciduous. More rarely it falls off when the flower begins to open; in this case it is described as caducous; the Poppy and May-apple afford examples.

The calyx often is more or less adherent to the ovary or base of the pistil, and it is a matter of importance in the study of flowers to observe whether such adhesion is present, and to what extent. When free from the ovary or situated wholly beneath it, the calyx is said to be inferior or hypogynous; when its tube becomes adnate to and partially but not wholly envelops the ovary, the calyx is said to be half-superior or perigynous; and when the calyx completely envelops the ovary, so that the limb appears to arise from its very top, the calyx is said to be superior or epigynous. The terms mentioned above are firmly established in botanical nomenclature and are convenient descriptive expressions, yet convey a false impression, for in reality it is the end of the flower axis, the receptacle, that is directly involved. When the receptacle is conical, the ovary, being centermost, will of course be uppermost in the flower and is therefore "superior" while the calyx is "inferior" and the whole flower is "hypogynous." But in other instances the outer whorls spring from a cup shaped receptacle, the hypanthium, in the center of which the pistil is borne; the ovary is free from the hypanthium or but slightly attached to its base, implying a "perigynous" flower, or the hypanthium is grown fast to the ovary so that the floral parts appear to arise from the summit of the ovary, when the flower is "epigynous" and the ovary "inferior." See Figs. 194, 195 and 196.

Sometimes we find exterior to the calyx or even adherent to it a whorl of bracts more or less resembling a calyx in appearance and structure. This is the case with the Hibiscus, the Strawberry 
and the Cinquefoil. Such an organ is called an epicalyx. See Fig. 177.

In some cases bracts situated below the flower become more highly colored than the floral organs themselves, as in the Painted-

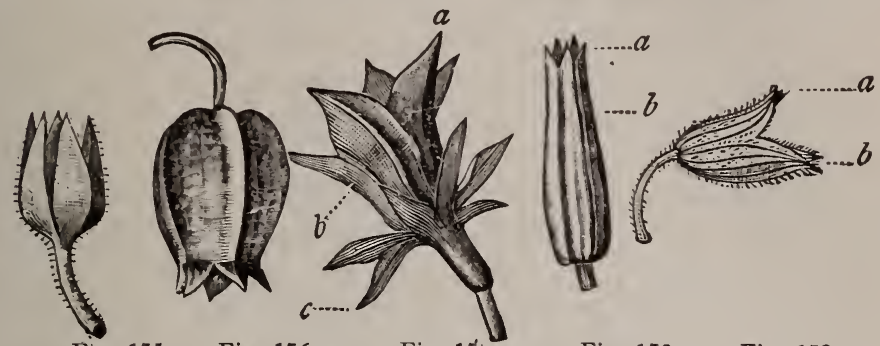

Fig. 175. Fig. 176. Fig. 1\%. Fig. 178. Fig. 179.

Fig. 175.-Chorisepalous calyx of a species of Oxalis, somewhat enlarged.

Fig. 176.-Gamosepalous calyx of a species of Abutilon. The inflated tube is five-winged.

Fig. 177.-Campanulate calyx of a species of Hibiscus. a, one of the divisions of the limb; b, the tube; and $c$, one of the leaves of the epicalyx.

Fig. 178.- Tubular calyx of Saponaria officinalis; $a$, the five-toothed $\operatorname{limb}$; and $b$, the tube.

Fig. 179.-Bi-labiate calyx of Salvia urticifolia, somewhat enlarged; a, threetoothed upper lip; and b, two-toothed lower lip.

cup and in some Euphorbias. These should not be confounded with the floral organs proper.

The Corolla. This is usually the most showy portion of the
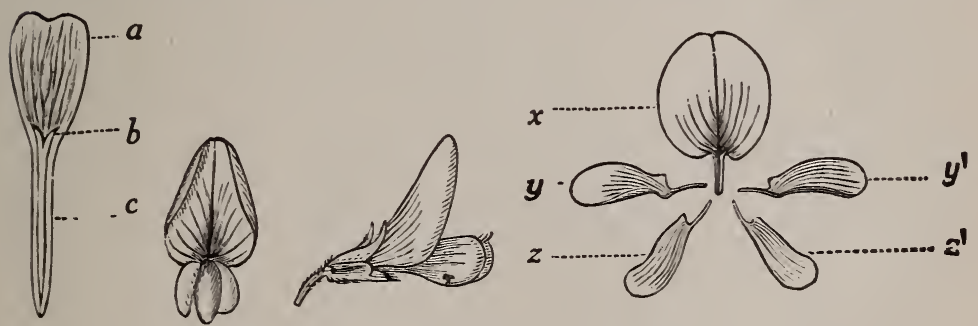

Fig. 181.

Fig. 182.

Fig. 183.

Fig. 180.- Petal of Saponaria, one of the Pink family. a, blade; $b$, corona; c, claw.

Fig. 181.-Flower of Genista, slightly enlarged, in front view.

Fig. 182.-The same in lateral view.

Fig. 183.-The petals of the same separated. $x$ is the vexillum or standard; $y, y^{\prime}$, the alae or wrings; and $z, z^{\prime}$, the two petals which compose the carina or keel.

flower. It is seldom green in color, but, like the sepals of the calyx, its parts often bear more or less resemblance in shape to leaves. In Fig. 180 is shown a petal of Saponaria. The upper or 
expanded portion is termed the limb, blade or lamina. At the junction of the latter with the lower or stalk-like portion are observed two little projections, $b$. These constitute the corona. The stalk, $c$, is called the claw or unguis, and such a petal is said to be unguiculate or clawed. In the great majority of petals, however, the corona is wanting, and in many cases also the claw.

The lamina is most commonly a flat expansion, resembling in this respect the majority of leaf-blades, but this is not always the case; it may be thread-like or filiform, club-shaped or clavate, spurred or calcarate, sac-shaped or saccate, etc. The flattened kinds present almost as great a variety of shapes as those of leafblades, and, like them, may have their margins entire or variously indented, incised, lobed, parted or fringed. The terms already learned in leaf-description are therefore also applicable, for the most part, in the description of petals.

Where the petals are not at all united with each other, the corolla is described as choripetalous, or, less correctly, as polypetalous. If the distinct petals are four in number and arranged in the form of a cross, as they are in the Cress family, it is called cruciform; if the petals are five and short-clawed or clawless and spreading, like those of the wild Rose, it is called rosaceous; if there are five long-clawed petals, having the claws concealed in the tube of a gamosepalous calyx, as in the Pink, it is called caryophyllaceous, Fig. 248; when it is shaped like the irregular flower of the Pea or Genista, it is called papilionaceous, Figs. 181, 182 and 183; when calyx and corolla each consist of three pieces closely resembling each other in form and color, as in the Lily and Tulip, the flower is called liliaceous; and when, as in the Orchidacex, the floral leaves are epigynous, and calyx and corolla are in whorls of three pieces each, and one of the petals, called the lip, has a shape markedly different from the rest, it is called orchidaceous. In flowers like the latter two, where calyx and corolla closely resemble each other, they are commonly not distinguished by separate names, but the two together are called the perianth.

But the petals very often become more or less united. In this case the corolla is described as gamopetalous or sympetalous. The united portion is called the tube, and the free portion, the limb, as in the calyx.

A gamopetalous corolla is called rotate, or wheel-shaped, when the tubular portion is short, and the divisions of the limb radiate from it like the spokes of a wheel, as in the corolla of the Potato, 
Fig. 184; campanulate, or bell-shaped, when shaped like the Harebell, Fig. 185; urceolate, when oblong or globular, with the mouth somewhat contracted, as in the flower of the Wintergreen, Fig. 186; infundibular, or funnel-shaped, when it flares like a funnel,

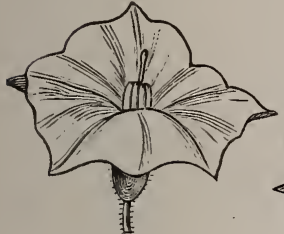

Fig. 184.

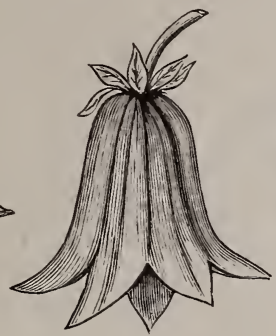

Fig. 185 .

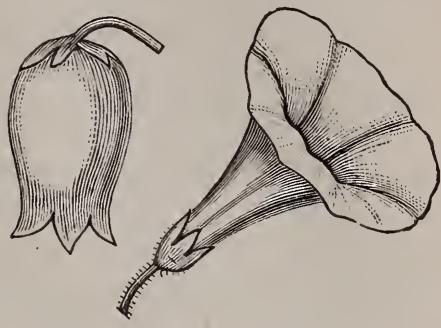

Fig. $186 . \quad$ Fig. 187.

Fig. 184.-Flower of Potato, illustrating rotate corolla.

Fig. 185.- Flower of Harebell, illustrating campanulate corolla.

Fig. 186.-Flower of Wintergreen, illustrating urceolate corolla.

Fig. 187.-Flower of Morning-glory, illustrating infundibular corolla.

as in the Morning-glory, Fig. 187; hypocrateriform, or salvershaped, when the slender, tubular portion is crowned by a limb expanded at right angles to it, as in Phlox, Fig. 188; tubular, when the limb is small or scarcely spreading, and the tube is elongated, as in the flower of Spigelia, Fig. 189; ligulate, when, as in Fig.

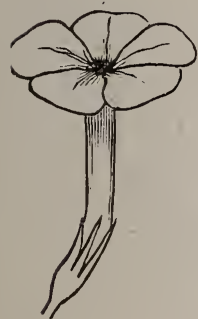

Fig. 188 .

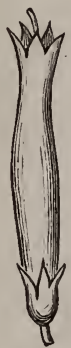

Fig. 189. Fig. 190.

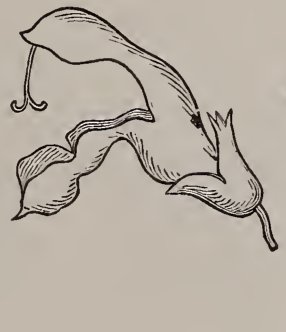

Fig. 191.

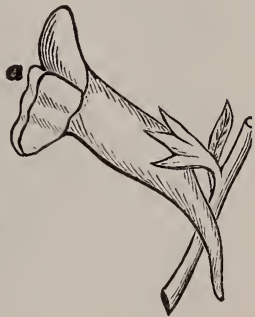

Fig. 192.

Fig. 188.-Flower of Phlox, illustrating hypocrateriform corolla.

Fig. 189.-Flower of Spigelia, illustrating tubular corolla.

Fig. 190.-Flower of Chrysanthemum, one of the Compositae, illustrating a ligulate corolla.

Fig. 191.-Bi-labiate flower of Sage. The corolla is also ringent.

Fig. 192.- Personate corolla of Linaria vulgaris. The corolla is also calcarate at the base. The thickening, a, is called the palate.

190, the lower portion is tubular, but the upper flattened and strap-shaped; labiate, when, as in the flower of the Deadnettle and Sage, Fig. 191, there are two lips; it is also ringent, if the 
lips spread wide apart, as in the last figure; and if they are closed, and have thickened lips, as in Snap-dragon and Linaria, it is personate. A gamopetalous corolla may also be saccate or calcarate, the same as one whose petals are distinct. The corolla of Linaria, Fig. 192, is both personate and calcarate.

The margins of gamophyllous calyxes and corollas may be variously indented or lobed, the same as those of leaves, and the same terms are used in describing them.

\section{Practical Exercises.}

Study the torus, calyx and corolla of the following flowers, observing careiully their structure and describing them fully, using the proper descriptive language of botany: Those of the Petunia, Strawberry, Wild Lupine, Waterlily, Dandelion, Lady's-slipper, Lobelia, Rose, Paeony, and Wallflower. State also, irom your examination of them, which of these flowers have a disk, what its shape is in each case, and whether it is hypogynous, perigynous or epigynous.

\section{CHAPTER X.-THE STAMENS, OR ANDRCECIUM.}

The Andrœcium is composed of sporophylls which are modified for the production of microspores or pollen grains and are therefore termed microsporophylls or, more commonly, stamens.

The stamens are the male organs of reproduction, and each stamen, when complete, consists of a filament, or stalk, which is

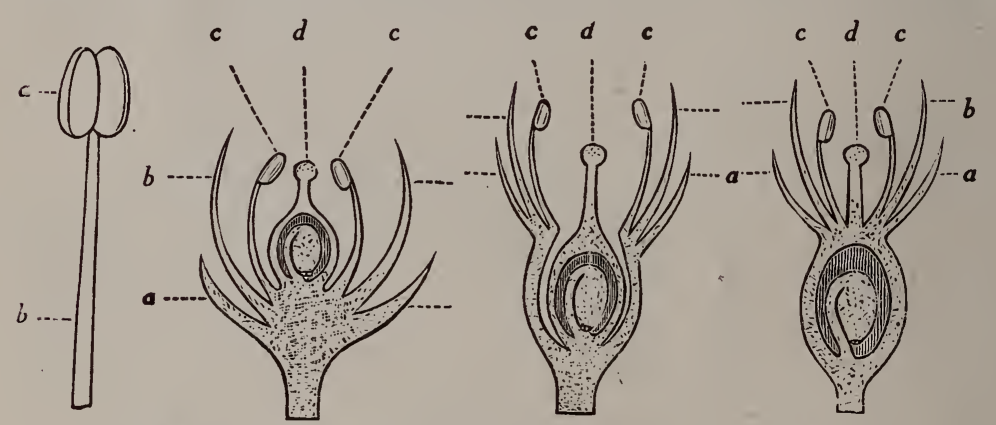

Fig. 194.

Fig. 195.

Fig. 196.

Fig. 193.-A stamen, consisting of a pollen-bearing part, the anther, a, and a stalk or filament, b.

Fig. 194.-Diagram of flower showing hypogynous calyx, corolla and stamens.

Fig. 195.-Diagram of flower showing perigynous corolla and stamens.

Fig. 196.-Diagram of flower showing epigynous calyx, corolla and stamens. In each of these three figures, a represents the calyx; b, the corolla; c, a stamen; and $d$, the pistil.

not essential, and an anther, the essential portion, which contains in its interior a fine powder, the microspores or pollen. See Fig. 193. 
Stamens are said to be definite in number when so few as to be readily counted, as in the flowers of the Barberry, Mustard and Geranium, and indefinite when very numerous, making it difficult to count them, as in the Buttercup, the Rose, and the Water-lily.

As to their attachment, they may be situated on the receptacle, as in the Poppy, when they are said to be hypogynous; or they

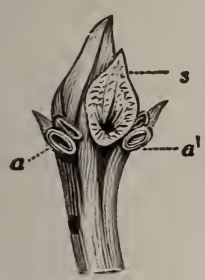

Fig. 197.

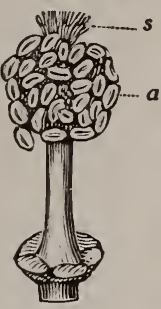

Fig. 198.

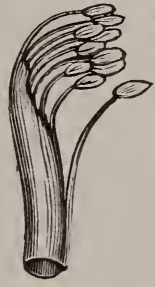

Fig. 199.

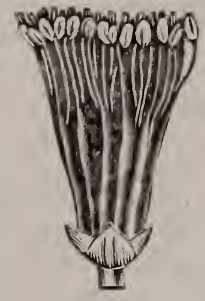

Fig. 200.

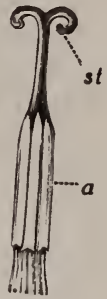

Fig. 201.

Fig. 197.-Gynandrous stamens of the Lady's-slipper, one of the Orchidaceae; $\mathrm{s}$, represents the stigma, and $a, a^{\prime}$, the anthers; they are grown together.

Fig. 198.-Monadelphous stamens of the Mallow; s, the stigmas, and a, the anthers.

Fig. 199.-Diadelphous stamens of the Pea. In this flower, one stamen stands by itself, while the other nine are united by their filaments.

Fig. 200.-Polyadelphous stamens of the Orange.

Fig. 201.- Syngenesious stamens of the Dandelion; a, the anthers; and st, the stigma.

may be borne on the margin of the calyx-tube or of the hypanthium, as in the Apple and Cherry, when they are said to be perigynous; or they may arise from the top of the ovary, as in the Fennel and Madder, when they are called epigynous. See Figs. 194, 195 and 196. In the majority of cases where the corolla is gamopetalous, the stamens are inserted on its tube, as in the Phlox; they are then described as epipetalous. Sometimes they grow fast to the pistils, as in the Orchidacer, Fig. 197, when they are called gynandrous.

Very commonly, stamens may be more or less united with each other. This union may take place by the filaments, or by the anthers, or by both. By their filaments they may be grown together into one or into more than one set. When in one set, as in the Mallow, Fig. 198, they are called monadelphous; when in two sets, as in the Pea, Fig. 199, they are termed diadelphous; when in three sets, as in some Hypericums, triadelphous, etc.; and when in a considerable number of sets, as in the Orange, Fig. 200, they are called polyadelphous. When stamens are united by their anthers, as they are in the Sunflower, Dandelion (Fig. 201), and other Compositæ, they are called syngenesious. 
In some flowers, as in many Mints and Figworts, there are four stamens, two of them longer than the other two; such stamens are said to be didynamous. In the Mustard and other members of the Cress family, there are four long and two short ones; the stamens of such flowers are said to be tetradynamous.

Occasionally the filament is wanting, and the anther is then described as sessile. Sometimes, however, the anther is wanting, or no longer functional; such sterile or abortive stamens are termed staminodia.

The Filament. This is the stalk of the anther. It assumes a great variety of forms in different flowers. Sometimes it is capillary, or very slender and hair-like, as in some grasses; sometimes it is filiform, or thread-like, as in many of the Rosaceæ; sometimes it is petaloid, or petal-like, as in some of the stamens of the White Water-lily; sometimes it is toothed, as in some species of Onion; sometimes it is appendaged, as in the Milk-weed; most commonly it is simple, as in the Geranium, but sometimes it is branched, as in the Castor-oil Plant. Its different forms commonly bear some relation, more or less evident, to the mode of pollination.

The Anther. The anther is usually two-lobed and two-celled, that is, contains two pollen-sacs or thecæ, but occasionally we find it twice as many lobed and celled, and, on the other hand,

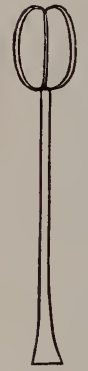

202. 203. 204

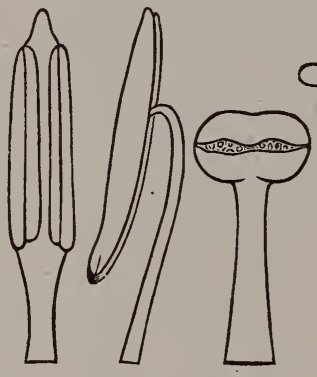

205.

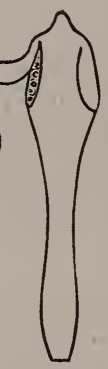

206.

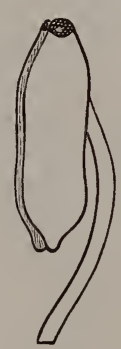

207.

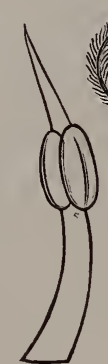

208.

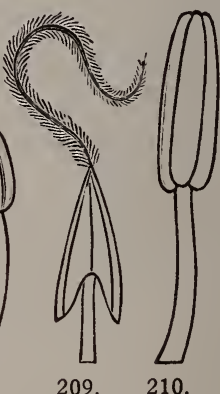

209.

210.

Fig. 202.-Stamen of Saxifrage, showing innate anther.

Fig. 203. - Stamen of Magnolia, showing adnate anther.

Fig. 204.- - Stamen of Agave, showing versatile anther.

Fig. 205.- Stamen of Alchemilla, showing anther dehiscing transversely.

Fig. 206.- Stamen of Barberry, showing anther dehiscing by valves.

Fig. 207.- Stamen of Rhododendron, with anther dehiscing by pores or open. ings at the apex.

Fig. 208.- Stamen of Asarum, with connective prolonged beyond the top of the anther.

Fig. 209.-Upper portion of stamen of Oleander, with connective prolonged and forming a plumose appendage at the top of the anther.

Fig. 210.- Stamen of Butomus, showing four-celled anther. 
we sometimes find stamens where, as in those of the Hollyhock, the two normal pollen-sacs have become confluent into one.

There are different ways in which the anther may be attached to its filament. When it stands erect on the end of the filament, as in Fig. 202, it is described as innate; when the two lobes of the anther appear to grow fast to the side of the filament, or the latter appears to be produced through the middle of the anther, as in Fig. 203, it is called adnate; and when the anther swings freely on the slender apex of the filament, as in Fig. 204, it is called versatile.

It is of importance, also, to observe which way the anther faces in the flower, whether inward toward the pistil, or outward from it, or whether its position is indifferent. Most versatile anthers are indifferent, and other kinds also are frequently so,

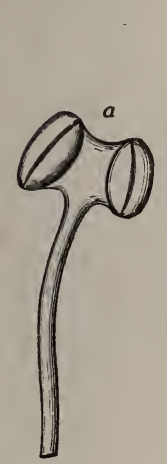

Fig. 211.

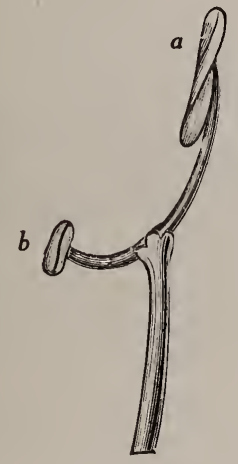

Fig. 212.

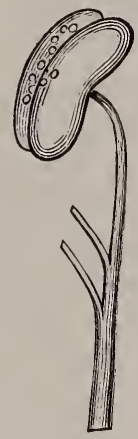

Fig. 213.

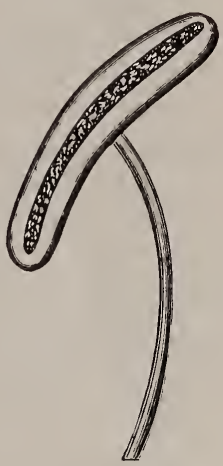

Fig. 214 .

Fig. 211.- Stamen of Calaminth, showing anther with broad connective, a.

Fig. 212.- Stamen of Sage, with elongated connective hinged to the top of the filament. One lobe of the anther, a, contains pollen, the other, b, is sterile.

Fig. 213.- Stamen of Hollyhock, with anther lobes confluent.

Fig. 214.- Stamen of Globe Amaranth, with anther consisting of but one lobe, and that attached by its middle to the end of the filament.

especially when the filaments are long and slender. Anthers which face outward are described as extrorse, while those which face inward are introrse.

Anthers split open or dehisce, in a variety of ways, to shed their pollen. When the dehiscence is lengthwise of the anther, as in Figs. 202 to 204, inclusive, it is said to be longitudinal; when crosswise, as is shown in Fig. 205, it is descirbed as transverse; when it opens laterally by lids, as in the Barberry, Fig. 206, it is called valvular; and when the discharge of the pollen is by pores 
at the apex, as in most members of the Heath family, Fig. 207, the dehiscence is called porous.

The Connective. The connective is that part of the anther which unites the two lobes, or what appears to be the continuation of the filament through the anther. In some anthers, as for example those of Wild Ginger (Asarum), Fig. 208, and the Oleander, Fig. 209, it is prolonged beyond the top of the anther; in others, as in Calaminth and Sage, Figs. 211 and 212, it is broad, or strongly developed transversely, and separates rather widely the two lobes; in the latter the lobes are very wide apart, and one of them becomes abortive, while the other remains fertile; in others still, as the Hollyhock, the connective disappears and the two equal lobes become confluent into one, Fig. 213, and in the Globe Amaranth of the gardens one of the cells entirely disappears, as well as the connective, while the other is attached by its middle to the end of the filament, as in Fig. 214. Such an anther, as the last, has been termed dimidiate.

The Pollen. This appears to the unaided eye as fine, dust-like particles, produced by the mother cells within loculi of the anthers. It is for the production of pollen that the stamens exist, and when it is shed their work is done, and they usually wither away. Each pollen grain is commonly a single cell with two walls, the outer, called the extine, thickened and often peculiarly marked, the inner, called the intine, thin, highly extensible, and inclosing a semi-fluid substance called the fovilla.

Some idea of the variety of forms of these grains may be gained from an inspection of Figures 215 to 221 inclusive.

When a pollen grain is placed upon the stigma of a flower of the same species, the outer coat of the grain bursts, and by the extension of the inner one, a tube is formed which penetrates the tissues of the style. Fig. 220 represents a germinating pollen grain.

Pollen grains are produced in enormous numbers, particularly in plants that are dependent on the wind for the transfer of the pollen from the stamens to the pistils, as in the Pines. It has been estimated that a single plant of the Chinese Wistaria, when well developed, may produce during one flowering season as many as 27,000,000 pollen grains. A common Pine tree, in all probability, produces a vastly greater number than this.

It is to be observed that in plants that are dependent on the wind for the transfer of their pollen, the grains are usually dry 
and powdery; while those that depend on insects for this work, usually produce sticky pollen. In some instances, however, the pollen does not separate into grains, but remains in masses, as in

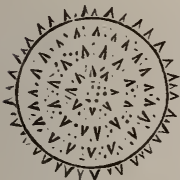

Fig. 215.

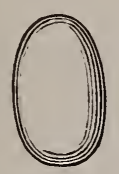

Fig. 216.

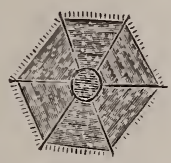

Fig. 217.

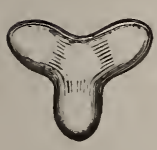

Fig. 218.

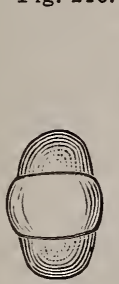

Fig. 219.

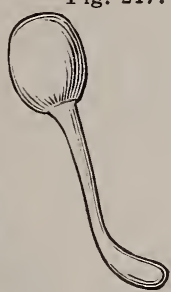

Fig. 220.

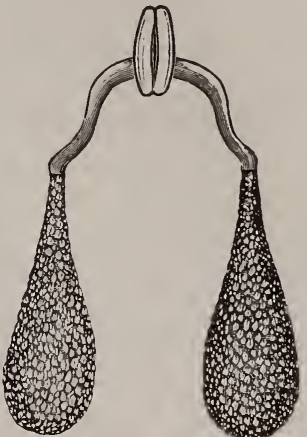

Fig. 221.-Pollinia of the Milik-weed.

Fig. 215.-Spinose pollen grain of the Mallow.

Fig. 216.-Pollen grain of Lily.

Fig. 217.-Pollen grain of Chicory.

Fig. 218.-Pollen grain of Evening Primrose.

Fig. 219.-Pollen grain of Pine.

Fig. 220.-Pollen grain in process of germination.

All highly magnified.

the flowers of the common Milk-weed and those of most Orchidaceæ. These pollen masses are termed pollinia. The pollinia of the Milk-weed are illustrated in Fig. 221.

\section{Practical Exercises.}

Examine the stamens of the freshly opened flowers of the following plants: The Pumpkin, the common Mallow, the Tiger Lily, the Cherry, the Musk Plant, and the Wild Cucumber, and ascertain in each case (1) what parts are present; (2) whether the stamens are distinct or whether they are united to each other or to other organs; (3) whether they are hypogynous, perigynous, or epigynous; (4) whether the position of the anthers is extrorse, introrse or indifferent; (5) whether the anthers are one-celled, two-celled or four-celled; (6) the character of the connective; (7) whether the anthers are innate, adnate or versatile; (8) whether their dehiscence is longitudinal, transverse, valvular or porous; (9) the shape and character of the filaments; (10) the shape and markings of the pollen grains. In order to study the pollen grains, seize by means of a delicate pair of forceps, a stamen whose anther is just dehiscing, tap the latter gently on the surface of a clean sheet of white paper, and then examine carefully the adhering grains by means of a good lens. The pollen grains of many plants are so minute that they cannot be satisfactorily studied in this way; the student had better, therefore, use a microscope for the purpose. 


\section{CHAPTER XI.-THE PISTILS, OR GYN ECIUM.}

The pistil is the female organ of reproduction of the flowering plant. It is composed of one or more sporophylls known as carpels. In the Pine and related plants, it consists of an open leaf or scale, which bears but does not inclose the ovules (see Fig. 222); but in most flowering plants it forms a closed sac which envelops and protects them. Pistils of the former kind are called gymnospermous; they are usually quite simple in their structure (Fig. 222); those of the latter kind are termed angiospermous, and they exist in a great variety of forms. When complete, an angiospermous pistil consists of ovary, style and stigma.

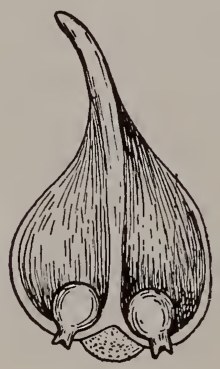

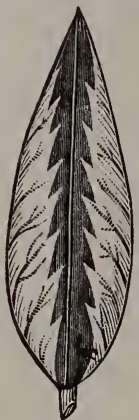

Fig. 223.

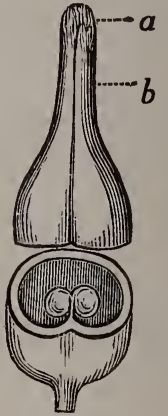

Fig. 224.

Fig. 222.-Scale from a young cone of Pine, bearing two ovules.

Fig. 223.-A leaf folded so as to illustrate the structure of a simple pistil or carpellary leaf.

Fig. 224.-A simple pistil cut transversely to show the cavity of the ovary and the ovules. $a$ is the stigma and $b$ the style.

The ovary, usually the basal portion, is the part which contains the ovule or ovules; the stigma, commonly the apical portion, is the part which receives the pollen, and the style the part which connects the ovary and stigma, Fig. 224. The former two are essential, while the latter is not. When the style is wanting, as is frequently the case, the stigma is said to be sessile.

The pistil is regarded as having been developed from the sporophyll of flowerless ancestral forms rather than as being closely related to foliage leaves. But sporophylls are leaves modified for reproductive functions and, in this sense, pistils are homologous with leaves. If we imagine an ordinary leaf, like that of the 
Cherry, to be folded in such a manner as to bring the upper surface and margins interior, as in Fig. 223, the lower portion would correspond to the ovary, the infolded margins projecting into its cavity to the ovule-bearing portion, or placenta, the apical portion to the stigma, and the narrow upper portion of the leaf adjacent to it, to the style. If the ripe follicle of the Columbine or of the Caltha be opened out, as in Fig. 225, the correspondence in structure to the infolded leaf above described, will be at once evident.

If a Pea-pod be carefully laid open and examined, the young peas will be found to occupy a double row along one of the sutures of the pod, as illustrated in Fig. 226. This portion corresponds to the infolded edges of the leaf, and when the pod splits open it

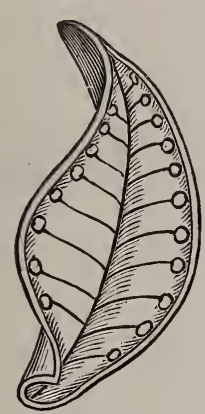

Fig. 225.

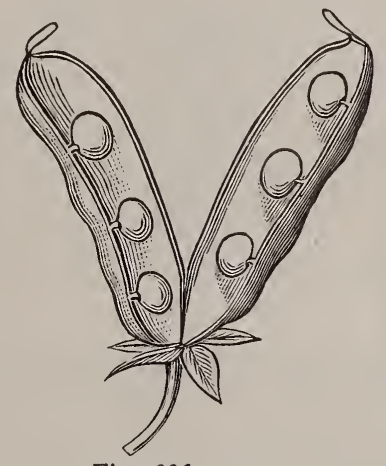

Fig. 226.

Fig. 225.-Follicle of Caltha, opened out to show its resemblance to a leaf.

Fig. 226.- - Pea-pod, laid open to show the placenta, corresponding to the infolded leaf margins, and bearing a double row of ovules.

does so along the line separating these edges. This line is called the ventral suture. 'But in also dehisces along the opposite side, called the dorsal suture, and this corresponds to the mid-rib of the leaf. The pistils of the Caltha, the Columbine and the Pea are each made up of a single carpel. Such pistils are described as apocarpous or simple. Other examples of apocarpous pistils are those of the Buttercup, Blackberry, Golden-seal and Aconite. But pistils, more than any other floral organs, are liable to cohere more or less completely into compound forms. Such pistils are described as syncarpous, or compound, Figs. 227 and 228.

The union may have all degrees of completeness. Sometimes, 
as in Saxifrage, Fig. 229, the ovaries are united below, but distinct above; often they are completely united, while the styles and stigmas are distinct, as in the Flax and Hypericum, Figs. 231 and 228; sometimes the union is complete, even to stigmas. Even in these cases, however, traces of the composite character of the structure usually still remain, either in the lobing of the stigma or ovary, or in the internal structure of the latter organ. If, for instance, the pistil is three-carpelled, the fact may be indicated by the division of the ovary into three cells, or by the fact of its

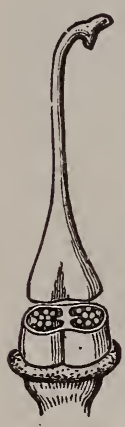

Fig. 227.

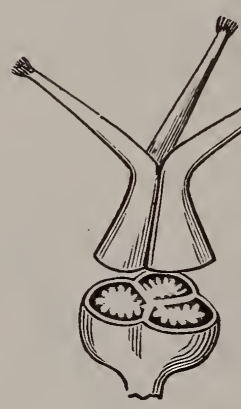

Fig. 228.

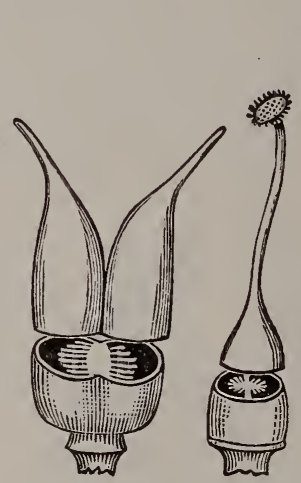

Fig. 229.

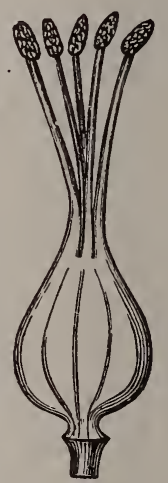

Fig. 231.

Fig. 227.-Syncarpous pistil of Scrophularia, made up of two carpels. The ovary is cut transversely, to show the two-celled ovary.

Fig. 228. - Syncarpous pistil of a species of Hypericum, composed of three carpels.

Fig. 229.-Pistil of Saxifrage, having the two carpels only partialy united.

Fig. 230.-Two-carpelled pistil of Henbane, with the ovary cut transversely to show the placentae.

Fig. 231.-Pistil of Flax, consisting of five carpels, the ovaries united, but the styles and stigmas distinct.

possessing three double rows of ovules on its walls. While, however, the number of cells in the ovary is usually indicative of the number of carpels of which the pistil is composed, it must not be taken as an infallible guide, but other structural points must be taken into consideration, for instances are known where, by the growth of false partitions from the dorsal sutures of the carpels, the number of cells in the ovary has become double the number of carpels. Similarly, though the number of lobes of the stigma usually indicate the number of carpels, this is not always the case.

Placentation. According to the character of the placentation, syncarpous pistils may be divided into four kilids:

(1) Those with parietal placentae. In this case the ovary has 
but one cell or loculus, and the ovules are borne on the infolded edges of the component carpels, as shown in Fig. 232. Here, the number of double rows of ovules corresponds with the number of carpels which compose the pistil. Many apocarpous pistils, as those of the Pea and Caltha, also have this kind of placentation.

(2) Those with axile placentae. In this case, the ovule bearing margins of the carpel grow inward until they meet in the center forming an ovary which usually has as many loculi as there are carpels composing it, as in Fig. 233. Thus the ovary with axile placentæ is a modification of one with marginal placentæ, and, as might be expected, we find every gradation between the

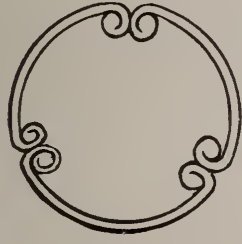

Fig. 232.

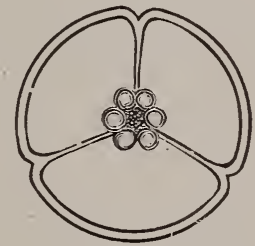

Fig. 233 .

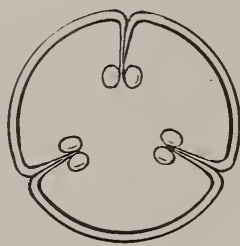

Fig. 234.

Fig. 232.-Diagram of ovary, with marginal placentae.

Fig. 233.-Diagram of ovary, with axile placentae.

Fig. 234.-Diagram of ovary, with marginal placentae, but with the latter extended toward the centre of the ovary, constituting a form intermediate between those represented in Figs. 232 and 233.

two. Fig. 234 represents an intermediate form, in which the marginal placentæ are prolonged inward, but do not meet.

(3) Those with free-central placentae. Here, the ovules are borne on a column which rises free from the bottom of the ovary, as in the Primrose and the Soapwort. This form of placentation is illustrated in Figs. 235 and 236.

The Style. This is the stalk of the stigma, or the part of the pistil which connects the stigma with the ovary. It sometimes contains a narrow canal or passage-way leading from the one to the other, but more commonly this is wanting, and the interior is composed of thin-walled cellular tissues. It most commonly arises from the summit of the ovary, in which case it is described as terminal or apical; in some cases, however, it is inserted on one side, as in the Strawberry, when it is called lateral, or it may even be attached to the base of the ovary, as in Alchemilla, when it is described as basilar. Very commonly the style falls away after the process of fertilization is completed, in which case it is termed deciduous, but sometimes it remains and forms a part of 
the fruit; it is then called persistent. This is the case in Snapdragon and Scrophularia. As regards its form, it may be filiform or thread-like, as in the Fuchsia; clavate or club-shaped, as in the Orange; subulate or awl-shaped, is in Cyclamen; petaloid or petallike, as in Iris. It may also be either simple or branching. In the case of syncarpous pistils, the styles may be united to any degree, from a slight union at the base to one which is complete to the apex. In these cases the terms used in the description of leafmargins may be applied to them to indicate the degree of separation, as trifid, quadrifid, tripartite, quadripartite, trilobate, quadrilobate, etc. So far as the surface is concerned, it may be smooth or it may be hairy, and the hairs may be of various kinds. In the Compositæ the upper part is covered with-rigid, collecting hairs, serviceable in brushing out the pollen from the anthers, and in some members of the Leguminosæ a ring or fringe of stiff hairs, just beneath the stigma, prevents the pollen from falling upon the stigma of the same flower.

The Stigma. This is the part which receives the pollen. It is either destitute of an epidermis or covered with a very thin one, secretes a viscid secretion, and is usually more or less roughened

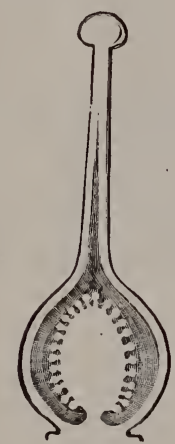

Fig. 235.

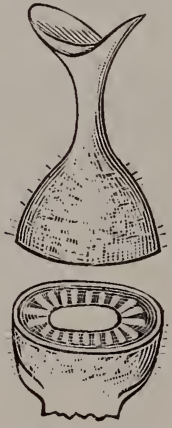

Fig. 236.

Fig. 235.-Pistil of Primrose, with ovary cut vertically to show freecentral placentation. Enlarged.

Fig. 236.-Pistil of Pinguicula, enlarged and cut transversely to show free-central placentation.

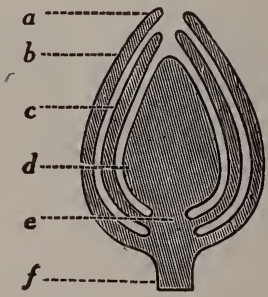

Fig. 237. - Diagram of an ovule in longitudinal section, show. ing its various parts; a, micropyle; b, primine; $c$, secundine; $d$, nucellus; e, chalaza; and $f$, funiculus.

or papillose. This structure doubtless has reference to securing the pollen that is conveyed to it and ensuring its germination. In form and character the stigma differs much in different flowers. It may be terminal, or located at the apex of the style, or it may 
be lateral or confluent down its side; it may be simple or lobed; it may be discoid or flattened and disk-like, hemispherical, globular, filiform, petaloid, plumous or feathery, radiate or rayed like the spokes of a wheel, stellate or star-shaped, cucullate or hooded, flabellate or fan-shaped, rostrate or beaked.

The Ovule. The ovules are the small bodies in the ovary, which, after fertilization, develop into seeds. They are usually borne on a definite ovule-bearing portion of the interior of the ovary, called the placenta, but occasionally they occur without order on any portion of the ovary walls.

A complete ovule, Fig. 237, consists of a nucellus, or body, two coats, the outer called the primine and the inner the secundine, and a funiculus or stalk. The coats do not completely enclose the nucellus, but a little opening for the reception of the pollen tube

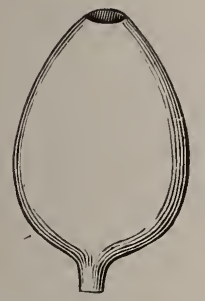

Fig. 238.

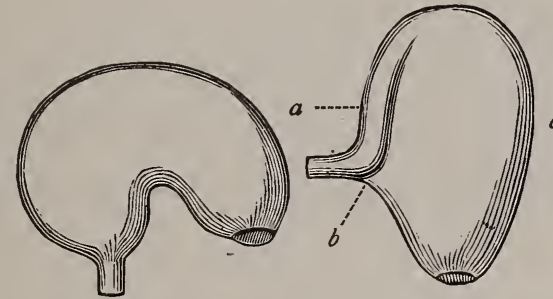

Fig. 240.

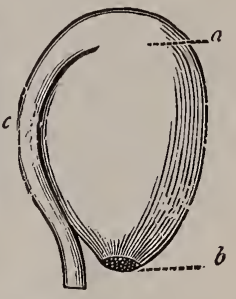

Fig. 241.

Fig. 238.-An atropous or orthotropous ovule.

Fig. 239.-A campylotropous ovule.

Fig. 240.-An amphitropous ovule; a, raphe; b, hilum.

Fig. 241.-An anatropous ovule; a, chalaza; b, micropyle; anl c, raphe.

is left at the apex. This opening is called the micropyle or foramen. The base of the ovule, where the coats are attached to each other and to the nucellus, is called the chalaza. The point of attachment of the funiculus to the rest of the ovule is called the hilum. In some ovules the funiculus grows fast to the ovule for a portion of its length, as in Figs. 240 and 241. The adherent portion is called the raphe.

It is frequently the case that some parts of the ovule are wanting. The funiculus is often absent, and the ovule is then said to be sessile; in gymnospermous plants, like the Pine and Fir, only one of the coats is usually present; and in the Mistletoe and its allies, both coats are wanting.

It is sometimes of importance to observe the position of the ovule in the ovary. It is erect, when it rises upright from the 
bottom of the cavity of the ovary; it is ascending, when it rises obliquely from near the bottom; it is horizontal, when borne on the side of the ovary wall and pointing in a transverse direction; it is pendulous, when directed obliquely downward from near the top of the cavity, and it is suspended, when hanging from the very top of the cavity.

The shape of the ovule itself is also to be regarded. An atropous. or orthotropous ovule is one that is straight, and has the hilum and micropyle at opposite ends, as in Fig. 238; a campylotropous ovule is one whose body is bent so that the hilum and micropyle are approximated, as in Fig. 239; an amphitropous ovule is one that is partly inverted; that is, one that has the funiculus located near the middle of the straight body of the ovule and pointing in a direction at right angles to it, as in Fig. 240; and an anatropous, or inverted ovule, is one whose chalaza is at one end, and hilum and micropyle adjacent to each other at the opposite end, as in Fig. 241. In the latter two kinds, the funiculus is adherent to the body of the ovule for a portion of its length; it is this adherent portion that is called the raphe. Inverted, or partly inverted, ovules are much more common than straight or bent ones.

\section{Practical Exercises.}

Study the flowers of the following plants with reference to the pistils: The Poppy, the Stramonium, the Lily, the Pumpkin, the Rose, the Hollyhock, and the Indian Corn. Determine (1), the parts of the pistil present in each case; (2) whether the pistils are apocarpous or syncarpous, and if the latter, state the degree of union; ( 3 ) the placentation of the ovary-that is, whether it is parietal, axile or free-central; (4) to what degree, if at all, the ovary is adherent to adjacent organs; (5) the position and shape of the style; (6) the position and shape of the stigma; (7) the arrangement of the ovules in the ovary; and ( 3 ) the shapes of the ovules.

In studying the ovules and placentation, the student should make careful longitudinal and transverse sections of the ovaries with a very sharp knife; they may then usually be studied satisfactorily by means of a good lens, but in some cases, where the ovules are quite small, the microscope will be indispensable.

\section{CHAPTER XII.-POLLINATION AND FERTILIZATION.}

Pollination. This consists in the conveyance of the pollen from the stamen to the pistil in such a manner as to produce fertilization, or cause the settling of seed. At one time it was supposed that most flowers possessing both stamens and pistils were selffertilizing-that Nature's design in placing the two organs so near together was to make sure of bringing the pollen in contact with the stigma of the same flower. There are, indeed, some 
instances in which this is the case, and such flowers, since they are habitually self-fertilizing, are called autogamous. But flowers of this kind are now known to be comparatively rare, and crossfertilization, or allogamy, that is, the fertilization of the ovules by pollen derived from another flower, is the general rule. Most flowers are so constructed that external agencies of various kinds are utilized for this purpose, and the appliances by means of which the result is secured and close-fertilization prevented, are sometimes very elaborate and wonderful. Even where the anther and the stigma are in the closest juxtaposition in the same flower, the pollen, in many cases, is effectually prevented from reaching the stigma, while the arrangements at the same time are such as to insure its being brought to it from another flower. It is evident from the pains Nature has taken to secure the result, that some great advantage must accrue to the plant or its offspring from cross-fertilization, and this has also been proved to be the fact by careful and extended experiments. It is proved that there are some plants that utterly refuse to set seed when supplied with only their.own pollen, that there are others which greatly prefer pollen from another plant, and refuse to utilize their own when that from another of the same species is placed upon the stigma, and it is proved that in the great majority even of those plants which are capable of self-feritilization, stronger, hardier and more numerous offspring result from cross-fertilization.

The external agencies utilized by the plant to bring about cross-fertilization are chiefly the wind and insects. Hummingbirds, and some other species of birds that habitually visit flowers, are occasionally of service, and in the case of some aquatic plants currents are made use of; but these agencies are comparatively unimportant.

Flowers whose pollination is effected by means of the wind are called anemophilous. Such flowers differ markedly in appearance and structure from those in which insects are the agents. They are usually provided with stigmas that expose a good deal of surface to the wind; they produce great abundance of dry, powdery pollen; they are without showy floral envelopes; they are without nectar, and they are destitute of perfume. Frequeritly, also, but not always, the pistils and stamens are in separate flowers, thus making self-fertilization impossible.

The difference between the extent of surface exposed by the stigmas of anemophilous flowers and those pollinated by insect 
agency will be seen by reference to Figs. 242. to 247, inclusive. The three figures at the left represent, respectively, the pistils of Wheat, Rush and Hemp, all anemophilous, and the three at the right, the pistils of the Tobacco, Foxglove and Centradenia floribunda, all of which are pollinated by insect agency. The enormous quantities of fine pollen produced by such anemophilous plants as the Pines and Indian Corn, and the great distances to which it is wafted, are facts familiar to every observing mind. The Oaks, Poplars, Birches, Walnuts, Grasses, Sedges, Plantains, Nettle and Hop are examples of wind-pollinated plants.

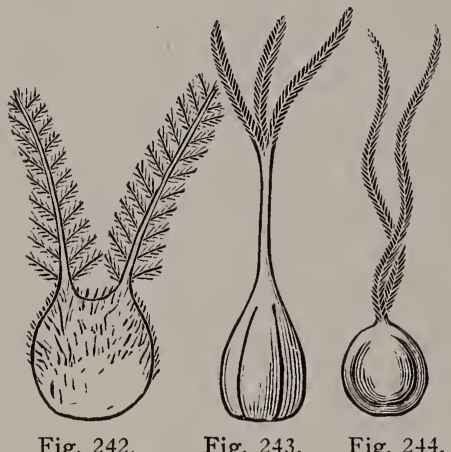

Fig. 242
Fig. 243.

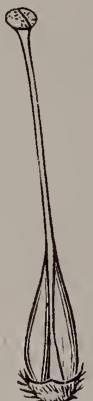

Fig. 245. Fig. 246.

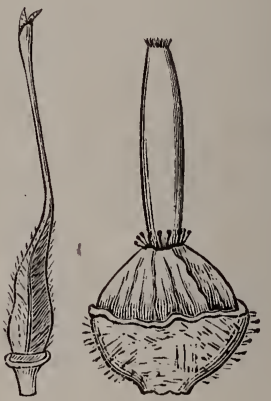

Fig. 247.

Fig. 242.-Pistil of Wheat, showing a pair of long feathery stigmas.
Fig. 243.-Pistil of a Rush, showing three elongated, hairy stigmas.
Fig. 244.-Pistil of Hemp, with two slender and much elongated, hairy or papillose stigmas.

Fig. 245.-Pistil of Tobacco, with small, somewhat two-lobed, capitate stigma.

Fig. 246.-Pistil of Digitalis, showing small, two-lobed stigma.

Fig. 247.-Pistil of Centradenia floribunda (enlarged), showing small papillose stigma.

Flowers which are cross-fertilized by the agency of insects are called entomophilous. They include all those with showy calyx, corolla or bracts, all perfumed flowers, all nectar-bearing, and all irregular flowers. The gay colors and perfumes are to attract the attention of insects, the nectar to reward them for their services, and the irregularities are adaptations of the flower to their visits, the character of the adaptation being such as to render cross-fertilization by their aid more certain. Bright colors and perfume sometimes go together, and the flower offers a double attraction to the insect visitor; but more commonly highly colored flowers are not odcrous, or are but faintly so, and conversely, 
highly odorous flowers are commonly not showy. Flowers with corollas of some shade of red or blue are usually visited by diurnal insects, while those with white or light-yellow corollas are often visited by moths and other insects that fly at dusk, these colors being more readily perceived in the dim light than others. It is by no means true, however, that all white flowers are fertilized by crepuscular insects.

Even the stripes or lines found on corollas are significant; they point to the locality in the flower where the nectar is secreted, and serve the purpose of guiding the insect thither.

The disagreeably odorous flowers are attractive to some insects no less thar the pleasantly odorous ones are to others. The giant flower of Rafflesia, for instance, has a carrion-like odor and a beefy appearance which attract swarms of carrion-flies that are deceived into depositing their eggs upon it, dooming their maggot progeny to starvation; in the process, however, they are likely to bring pollen from another flower and deposit it on the stigma. Some flowers which are visited by night-flying insects withhold their perfumes by day, but dispense them freely at night, as in the case of the night-blooming Cestrum nocturnum. Some flowers, also, that are cross-fertilized by day-flying insects, close at night, doubtless, in some instances at least, to prevent the wastage of nectar and pollen by insects that could not be of service to the plant.

We may briefly summarize, as follows, the different means by which self-fertilization is prevented among entomophilous plants.

(1) By the separation of the flowers into staminate and pistillate forms, that is by diclinism. Diclinous plants are of two kinds: monocious, as the Begonia, where both kinds of flowers occur on the same plant, and dicecious, as most Willows, where the male and female flowers occur on different plants.

(2) By dichogamy, or the maturing of the male and female organs at different periods. This, occurring in flowers which possess both stamens and pistils, is the same in its effects as though the male and female organs were in separate flowers. There are two kinds of dichogamy, one in which the stamens first mature and then afterward the pistils, and the other in which this order is reversed and the pistils are the first to mature. Flowers of the former kind are called proterandrous, while those of the latter are called proterogynous. Examples of proterandry are afforded by the Pinks, Gentians, many of the Compositæ, Umbel- 
liferæ and Labiatæ, the Geranium, Mallow, and many Lobelias and Campanulas. Figures 248 and 249 represent flowers of the common Pink, in different stages of development; in the former

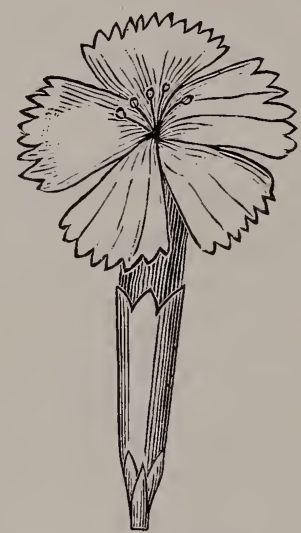

Fig. 248.

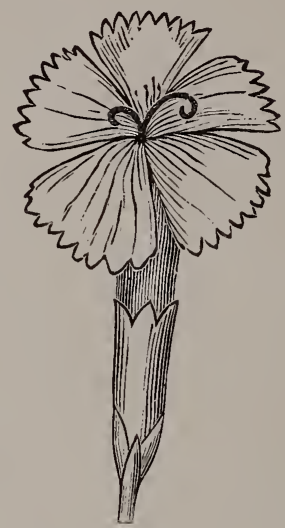

Fig. 249.

Fig. 248.-Flower of Pink in the earlier or staminate stage of development

Fig. 249.-Flower of Pink in the later or pistillate stage of development.

the stamens are ripe, and shedding their pollen; while in the latter and older flowers they are past maturity and have withered, the expanded stigmas taking their place. It is evident that an insect which has visited the younger flower, and become dusted

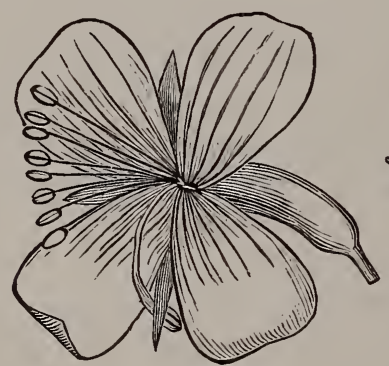

Fig. 250.

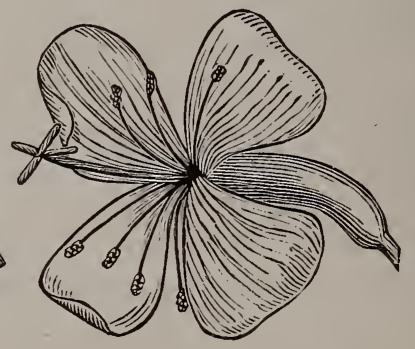

Fig. 251.

Figs. 250 and 251.-Staminate and pistillate stages, respectively of flowers of Epilobium angustifolium.

with its pollen, could hardly fail, when visiting the older, to deposit some of it on the stigmas.

Figs. 250 and 251 represent the proterandrous flowers of the Great Willow Herb, Epilobium angustifolium. The mode of crossfertilization is analogous to that of the Pink just described. 
In Fig. 250, the stamens, which are ripe and protrude from the corolla, stand in such a position that an insect visiting the flower for its nectar must touch them and receive some of their pollen, but the style, crowned by the not yet unfolded stigma lobes, is curved back out of the way. Later, as shown in Fig. 251, the stamens, having shed all their pollen, wither and curve back upon the petals, while the style straightens out and the stigmas unfold, occupying about the same position as the anthers did before. It is clear that here, as in the Pink, an insect flying from a flower in the earlier to one in the later stage of development, will be likely to transfer pollen to the latter flower and fertilize it.

Proterogyny is much less common, though interesting instances

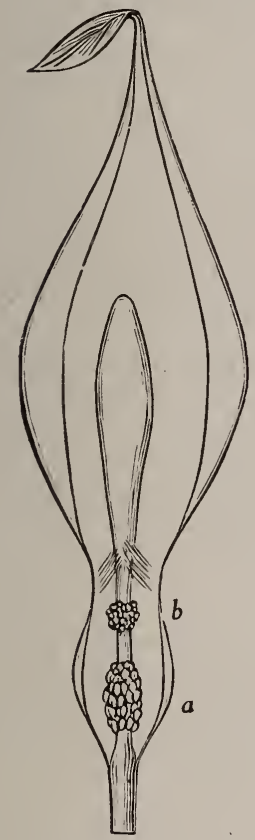

Fig. 252 .

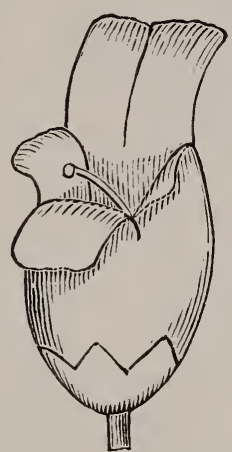

Fig. 253.

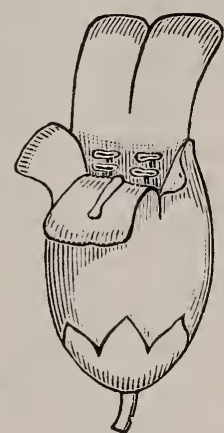

Fig. 254 .

Fig. 252.-Diagram of the inflorescence of Arum maculatum. The spathe is contracted near its middle, and the passage-way obstructed by stiff hairs which point downward. These, being flexible at their base, permit the ingress, but not the egress, of insects. The pistillate flowers are clustered at a, on the base of the spadix, while the staminate flowers are above, at $b$. The former mature first, and after the pollen is shed, the hairs wither, permitting the pollen-dusted insects to escape.

Figs. 253 and 254 represent the pistillate and staminate stages, respectively, of the flower of Scrophularia nodosa. When the flower first. opens, the stigma is mature, and in the way of a visiting insect; after this has withered, the stamens curve upward, and the now ripened anthers occupy a position similar to that previously occupied by the stigma. 
are iound in the Birthwort, in the Arum, in Scrophularia nodosa, and in some other plants. Fig. 252 is a diagram of the inflorescence of the Arum. The large enveloping spathe is contracted near its middle, leaving but a narrow passageway to the cavity below, which encloses the separate masses of staminate and pistillate flowers. This passageway is obstructed by stiff hairs, which point downward. These, being flexible at their base, are readily bent downward and afford but a slight obstacle to the entrance of insects, but they are not so easily forced upward from below, because pressure in that direction brings the distal ends of the hairs into contact with the side walls of the tube. The insects which enter are, therefore, imprisoned. The pistillate flowers are clustered at the base of the spadix, and reach maturity considerably earlier than the staminate ones which are clustered above them. After the stigmas have passed maturity, a drop of nectar is secreted at the bottom of the tube to compensate the flies for their imprisonment; the anthers, now ripened, shed their pollen in abundance; the insects' bodies become thoroughly dusted with it; and, lastly, the hairs that prevented their exit, wither, permitting them to fly away to some other inflorescence of the same kind, carrying with them the fertilizing pollen.

Figs. 253 and 254 represent the pistillate and staminate stages, respectively, in the development of the flower of Scrophularia nodosa. The nectar is secreted in the base of the tube. In the younger or pistillate stage the stigma is exposed at the entrance, in such a position that a visiting insect must come into contact with it in order to reach the nectar; the unripe stamens are bent back out of the way. In the older or staminate stage the stigma lies withered on the lip of the flower, while the four anthers, now ripe, are exposed in the throat, dusting with pollen the insect that visits the flower. It is evident that a bee flying from an older to a younger flower must necessarily effect the cross-fertilization of the latter.

(3) By the greater potency of foreign pollen. It has already been stated that in some cases pollen from the same flower is entirely ineffective.

But even in cases where the flowers are capable of self-fertilization, the pollen from other plants is commonly' more effective than their own; and, as showy or nectar-bearing flowers are almost constantly visited by insects, the chances are that crossfertilization will usually be effected. 
(4) By heteromorphism, or by the existence within the limits of the same species of fiowers of different kinds. In some cases there are two different kinds of flowers,- - one with short stamens and long styles, and the other with long stamens and short styles. Such flowers are called dimorphous. Figs. 255 and 256 represent, respectively, the long-styled and short-styled flowers of Mitchella repens. The flowers occur in pairs, usually grown together, more or less, at the base, as shown in the figures $a, a$. It will be seen

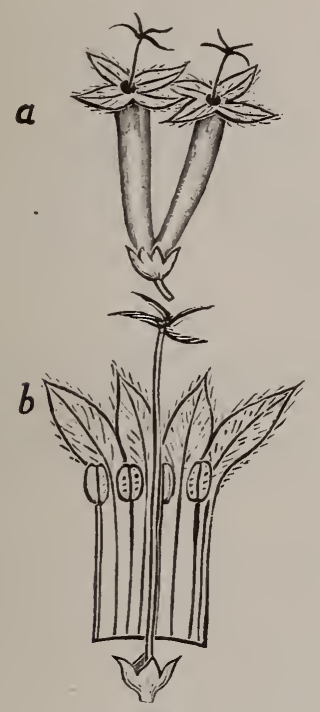

Fig. 255.

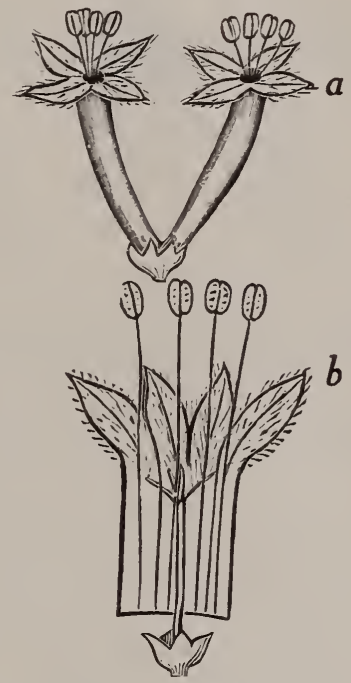

Fig. 256.

Fig. 255.-a, two long-styled flowers of Mitchella repens. b, the tubular corolla of one laid open so as to show the stamens.

Fig. 256.-a, two short-styled flowers of same species; the styles are concealed in the tube of the corolla, while the stamens protrude. $b$, one of the corolla-tubes laid open to show the stigmas.

that the stigmas of the left-hand pair stand at about the same level as the anthers of the right-hand one. The two different kinds of flowers invariably occur on different plants of the same species. The lower figures, $b, b$, represent a flower of each kind, with the corolla tube laid open to show the relative arrangement. It will be seen that a bee visiting one of the short-styled flowers will have her head dusted by pollen from the long stamens as she reaches to the bottom of the cup for the nectar, and that in passing to one of the long-styled flowers she will bring the same parts in contact 
with the stigmas, and therefore probably deposit pollen upon them. At the same time, also, her proboscis is brought in contact with the short stamens in the tube, and its middle portion dusted with the adhesive pollen. If now again she visits a short-styled flower, some of this pollen will in all probability be left upon the stigma.

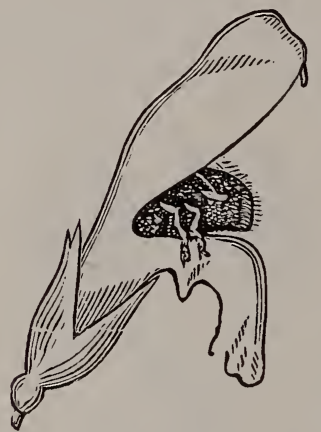

Fig. 257.

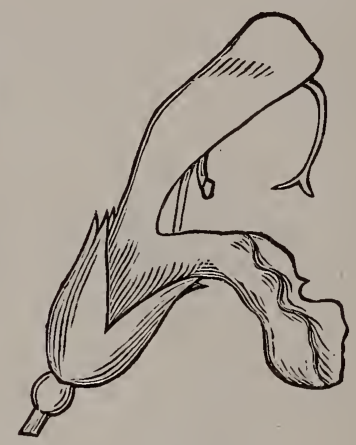

Fig. 258.

Fig. 257.-Flower of the common Sage, in the staminate stage, visited by a bee. The fertile anther lobes are seen in contact with the insect's body, while the stigma is well out of the way, barely projecting from the upper lip of the corolla.

Fig. 258.-Flower of the Sage in the pistillate stage, when the stamens have withered and the style lengthened, so as to occupy a position similar to that of the fertile anther lobes in the previous figure.

In some other cases as in Lythrum salicaria, there are flowers of three different kinds, long-styled, mid-styled, and short-styled ones, which constitute a very effective means of cross-fertilization. by insect agency. Such flowers are called trimorphous.

(5) By special contrivances. Many of these are exceedingly elaborate and wonderful. The flower of the common Sage is an illustration of one of them. The flowers are proterandrous, and are pollinated by bees. Fig. 257 represents one in the staminate stage visited by a bee; the stigma is out of the way, nearly concealed under the arching upper lip of the corolla, while the antherlobes are in contact with the back part of the insect's body as she sips the nectar. Fig. 258 represents a flower of the same plant in the pistillate stage, when the anthers have discharged their pollen and the style has lengthened, unfolding its stigmatic lobes and occupying such a position as to come in contact with the back of the insect when she enters the flower.

The flower has two stamens, separately represented in Fig. 259, inserted in the throat of the corolla in such a position that the 
insect, in order to reach the nectar, must pass between them. Each anther has a long, curved connective, which is pivoted near its middle to the apex of the filament. One lobe, the upper one in the undisturbed flower, is fertile, and the other sterile. Fig. 259 represents them as they are in their normal position, and Fig. 260

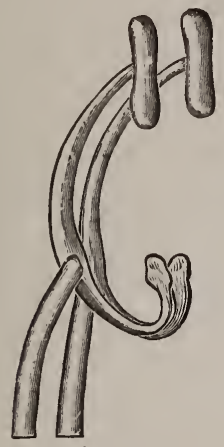

Fig. 259.

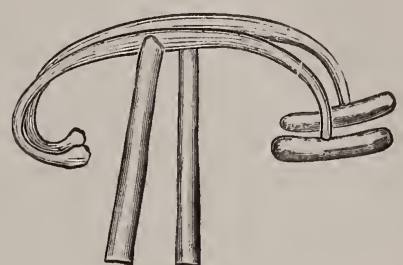

Fig. 260.

Fig. 259.-Position of stamens of Sage, when undisturbed.

Fig. 260.-Positions of anthers, when a bee passes between the stamens to reach the nectar.

as they are when a bee passes between them, butting her head against the sterile lobes, pushing them forward and upward, and turning the fertile lobes backward and downward. It is evident that the insect visiting the flower in its staminate stage will get the back and upper portion of her hairy body dusted with pollen from contact with the fertile lobes, and in flying away to a flower which is in the pistillate stage, will bring the same part of her body into contact with the stigmas.

Another interesting instance among the hundreds that might be mentioned occurs in Habenaria ciliaris, one of our most beautiîul orchids. Fig. 261 represents one of the flowers of this plant. In the center of it is the column of combined pistils and stamens, a. The stigma lies centrally between the anthers, each of which produces a pollinium, which is club-shaped in form, and has at its lower end a sticky disc, as represented in Fig. 262. The delicately fringed lip is connected at its base with the long, tubular nectary, $b$, Fig. 261, which contains the honey secretion. The flowers are visited by butterflies, whose long tongues enable them to probe the bottom of the tube. In this process the visiting insect squeezes the thick basal portion of his tongue between the sticky discs of 
the pollinia, which adhere firmly, and are withdrawn from the anthers when he flies away. The pollinia, when first withdrawn, stand out nearly at right angles to the insect's tongue, but after a few moments, by a drying process which they undergo, they bend obliquely downward and somewhat inward, so that when the next flower is visited, they are brought into contact with the sticky stigmatic surface, and some of the pollen is almost inevitably deposited upon it. By flying thus from flower to flower, a considerable number may be fertilized before finally the pollinia are brushed off, or their pollen exhausted.

While, as has been stated, cross-fertilization is the law, there are a few remarkable instances in which flowers appear to be constructed with special reference to self-fertilization. Some Violets and Polygalas, for example, produce, besides showy flowers that are visited by insects, others that are inconspicuous, closed,

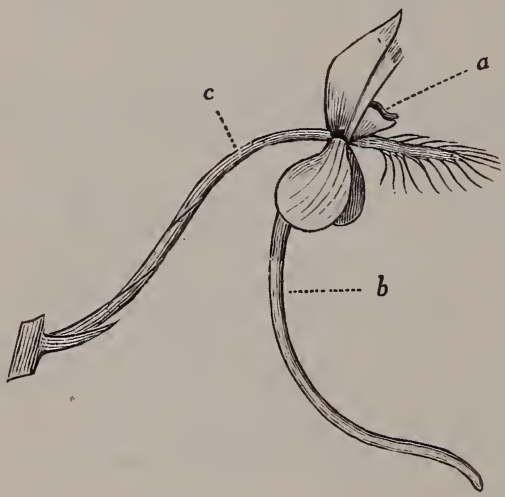

Fig. 261.

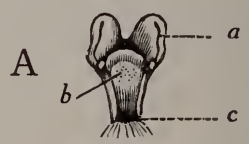

B

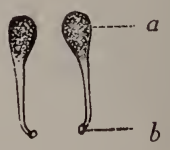

Fig. 262.

Fig. 261.-Flower of Habenaria ciliaris, with three rounded sepals, two strapshaped petals which are fringed at the apex, a fringed lip with the base of which is connected a long tubular nectary, b; a column, a, consisting of a stigma depressed between two anther-lobes, each of which contains a pollinium. c is the ovary of the flower. The flower is magnified about two diameters.

Fig. 262, A and B.-A, Column of combined stigma and stamens, separated from the flower and more highly magnified. a, one of the anthers, the slit showing where the pollinium has been withdrawn; b, the stigma; $c$, opening into the nectary at the base of the labellum. B, The two pollinia still more highly magnified; a, the mass of agglutinated pollen grains; b, the sticky disc at the opposite end of the pollinium.

and often partly concealed beneath the ground, so that insects cannot penetrate them, and in which the pollen falls directly upon the stigma and fertilizes it. Such flowers produce seed abundantly, and yet there is the closest of in-and-in breeding. They 
appear to be a contrivance by means of which the plants are able to produce a greater multitude of seeds with a less expenditure of energy than by the production of an equal number of the ordinary flowers. They seem to multiply in this way as other plants do by means of bulblets or tubers, while the occasional crossing which occurs by means of the showy flowers serves to keep the stock vigorous.

It does not come within the scope of this work to treat this subject more extensively, but those who are interested in it, and wish to pursue it further, should read some or all of the following works: Darwin's "Cross and Self Fertilization in the Vegetable Kingdom"; Sir John Lubbock's "British Wild Flowers in Relation to Insects"; Mueller's "The Fertilization of Flowers"; the portion of Kerner's "Natural History of Plants," and the chapter in Gray's "Structural Botany" which relate to this subject.

Fertilization. By Fertilization is meant the process which takes place subsequent to the deposit of the pollen on the stigma, resulting in the union of the nuclei of the two reproductive cells, the male or sperm cell of the pollen and the egg cell of the ovule.

Attention has already been directed to the fact that pollen grains are a form of spores, termed microspores, and that, like other spores, they possess the power of germination. The immediate stimulus to germination is usually supplied by the sticky secretion of the stigma, though in some instances the germination of the microspores begins before they have left the sporangia, which are here called anther sacs. This secretion of the stigma, which not only stimulates the germination of the pollen grain but also nourishes it during its growth, consists of a solution of sugar varying in strength in different species and suited to the growth of the pollen of that particular species; a fact which explains in part why pollen grains germinate best on the stigmas of flowers of the same species. During the course of germination, the nucleus of the pollen cell divides and two nuclei, known as the generative nucleus and the tube nucleus, are formed. See Fig. 263. The generative nucleus soon divides again, forming two male nuclei, which shortly become primordial male cells, sperms or male gametes. Meanwhile the pollen grain, nourished by the stigmatic secretion, has swollen and ruptured its outer coat and protruded its living contents, enveloped within the thin inner coat, thus forming the pollen tube. This growth is characteristic of the male gametophyte, which, though dependent, minute and usually 
short-lived, is the homologue of the independent and conspicuous gametophytes of the mosses. The pollen tube readily finds its way between the easily separable cells composing the loose, interior tissues of the style or through the tubular passage in the latter, if

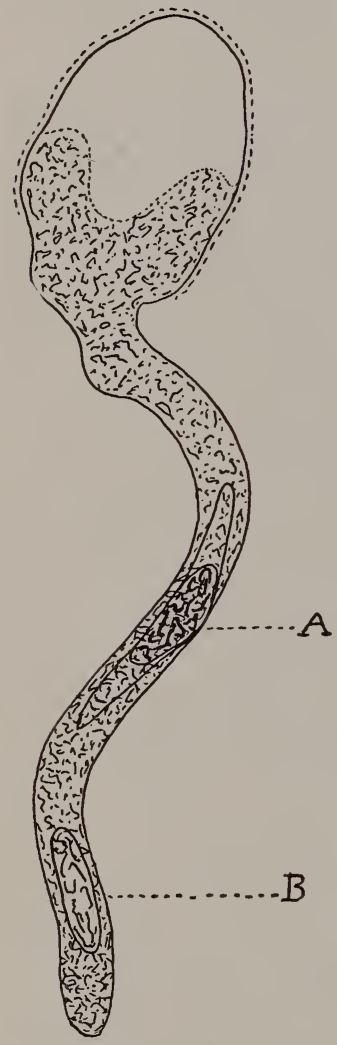

Fig. 263.-Germinating pollen grain of Lilium martagon (after Stras-
burger). A, antheridial mother-cell ; B, vegetative nucleus.

there be one, to the interior of the ovary and enters the micropyle of the ovule. See Figs. 264 and 265. In its descent the tube is assisted by the action of enzymes which it secretes and it is nourished by the cells along its path. It is evident that at least as many pollentubes will be required as there are ovules in the ovary, every ovule requiring one for its fertilization.

The time that it takes for the pollentube to reach the ovule and effect its fertilization varies greatly in different plants. In some it occupies only a few hours, while in others it may require weeks, or even months, as in the Orchids.

We have referred to the anther sacs as spore cases or sporangia and since the pollen grains have been termed microspores we might more accurately name the anther sacs microsporangia; they are borne upon the microsporophylls or stamens.

The ovules are likewise sporangia, and since they contain a larger spore, we may term them megasporangia; they are borne in megasporophylls or carpels.

The megaspore, however, is not only larger than the microspore, but differs further in that it is not discharged from the sporangium but remains imbedded in the tissues of the nucellus. Upon the onset of germination the megaspore also enlarges, its nucleus divides into two nuclei which move to opposite ends of the spore,--here called the embryo sac,while the central part is filled with water.

These two nuclei again divide and the resultant four do like- 
wise, giving eight nuclei, four at each end of the embryo sac. One nucleus from each group, the two polar nuclei, approach the centre of the embryo sac and there fuse into one. This completes the development of the female gametophyte, which is included within the embryo sac and like the male gametophyte is inconspicuous and parasitic. It now contains seven nuclei or primordial cells surrounded by cytoplasm. Toward the micropylar end of the sac

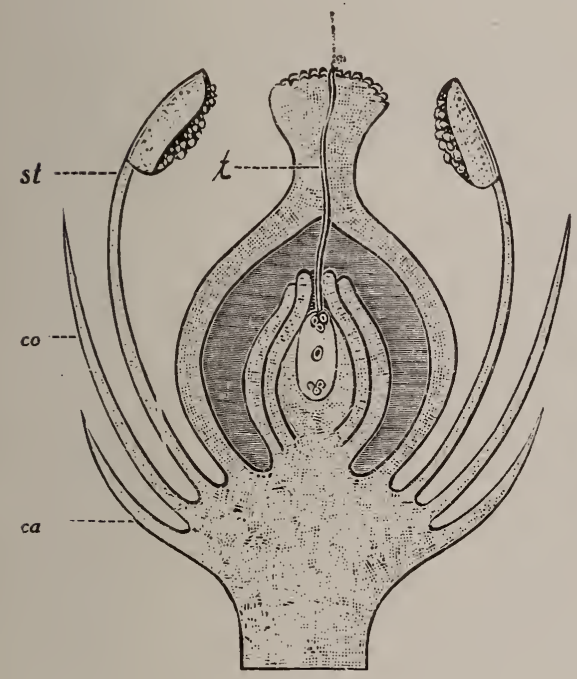

Fig. 264.

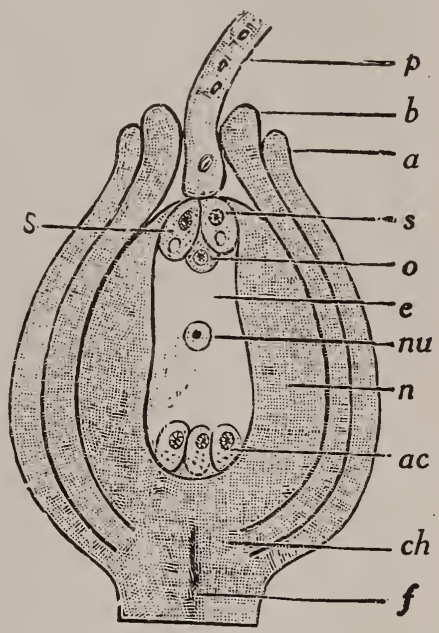

Fig. 265.

Fig. 264.-Diagram of flower in vertical section to show fertilization of ovule: ca, calyx; co, corolla; st, stamen; $p$, pollen grain sending tube, $t$, down through the tissues of the style and into the micropyle of the ovule. In the nucellus of the ovule is seen the embryo-sac with the synergidae, oosphere, antipodal cells and nucleus.

Fig. 265.-Diagram representing an ovule in the process of fertilization: $f$, funiculus of the ovule penetrated by a spiral vessel; ch, chalaza; a, outer integument, or primine; $b$, inuer integument, or secundine; $p$, end of pollen-tube that has penetrated to the nucellus, $n$; e, embryo-sac; nu, nucleus of embryo-sac; $\mathrm{s}, \mathrm{s}$, the two synergidae; o, the oosphere; and ac, the antipodal sells.

are three of these primordial cells; the central one is known as the egg cell, oosphere, female cell or female gamete; the other two are named the synergidæ; these three constitute the egg apparatus. Nearby is the fused nucleus, which becomes the primary endosperm nucleus, and at the other end of the sac are the three remaining primordial cells which soon become surrounded by cell walls and constitute the antipodal cells. (Fig. 265.) While the common type of embryo sac is described above, let it be understood 
that other types containing sixteen, four, and even two nuclei are met with.

The pollen-tube is guided to the micropyle, partly by various mechanical contrivances, such as by papillæ on the placenta, by the position of the funiculi, etc., and partly, also, as it nears its destination, by the stimulating influence of a fluid which escapes from the synergidæ.

It enters the embryo-sac by dissolving its wall, the end of the pollen-tube ruptures, its sperm cells are discharged, one of these male gametes is attracted to the egg cell and fuses with it, forming the fertilized egg (oospore). The second sperm fertilizes the primary endosperm nucleus and the growth resulting gives rise to
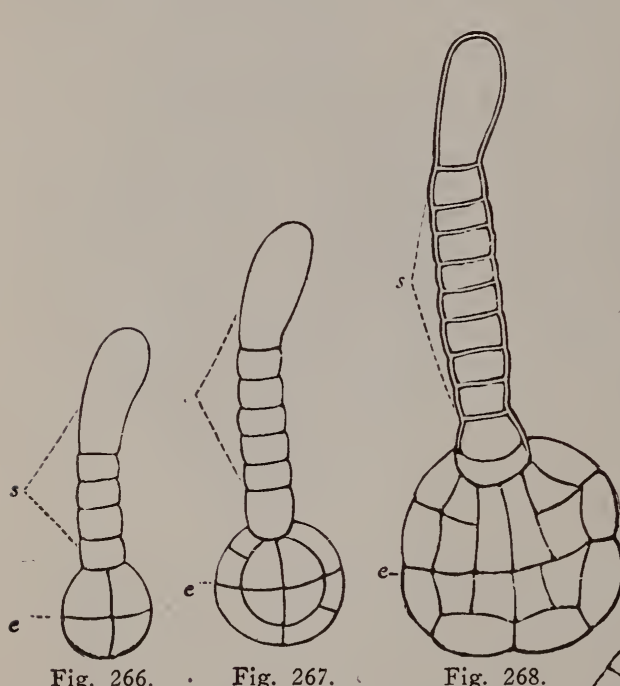

Fig. 266. - Fig. 267.

Figs. 266 to 269.-Diagrams representing successive stages in the development of a dicotyledonous embryo. $s$, in each case is the suspensor or pro-embryo, and e, the embryo. In Fig. 268, the embryo is so far advanced that the first leaves, or cotyledons, c. c, may be recognized; $r$, is the root, and a, the growing apex of the stem.

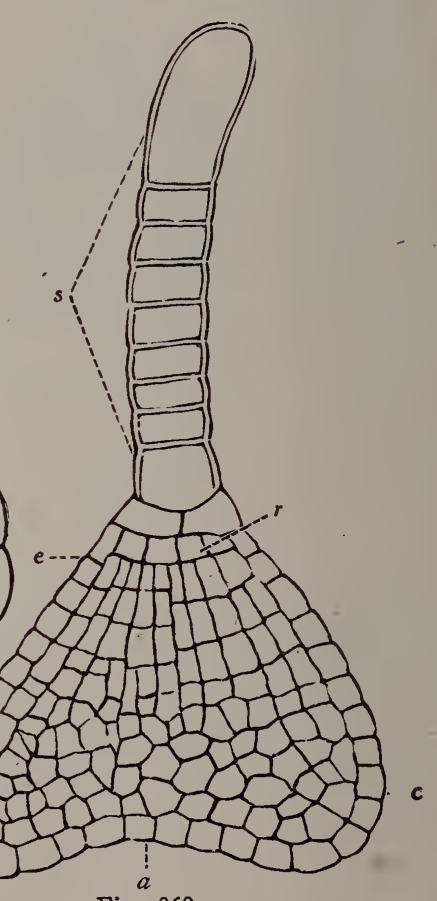

Fig. 269.

the endosperm. From the fertilized egg the development of the embryo (sporophyte) begins. Some of the successive stages in the development of the embryo are roughly illustrated in the diagrams, Figs. 266 to 269 , inclusive.

Cell division is by karyokinesis or indirect nuclear division (see 
page 168), and at first takes place only in one plane, forming a chain or linear series of cells, technically called the suspensor. Then the terminal member of this chain, the embryo-cell, begins to divide in different planes, forming a mass of cells. As celldivision proceeds, the mass gradually becomes differentiated into the various organs of the embryo, a rudimentary root, a rudimentary stem and rudimentary leaves becoming recognizable. It is to be observed that the root end, or radicle, always points toward the micropyle of the ovule.

The remarkable phenomenon known as Parthenogenesis, which consists in the development of an embryo by an unfertilized egg, is known to occur in but few species, chiefly Compositæ.

As already stated, the endosperm originates with the union of the two polar nuclei and the subsequent fusion with a sperm from the pollen-tube; the nucleus resulting from this triple fusion divides, rapidly forming a great mass of free nuclei, which line the wall of the sac. Afterwards, these nuclei become complete cells by the development of cell-walls, and the further growth of the endosperm now goes on by cell-division, which proceeds from without inwards. This is the more usual process. Sometimes, however, the first division of the nucleus results in the formation of two perfect cells, and the development of the endosperm takes place from the very first by cell-division, and not by free nuclear division. In most cases, the embryo-sac enlarges very materially after fertilization and during the formation of the endosperm. Commonly, also, the cells of the latter and of the embryo completely fill it when the seed is mature, but there are instances, of which the Coconut affords a conspicuous example, where only the peripheral portion of the interior of the sac becomes cellular, while the interior remains fluid. The so-called "milk" in the Coconut, is the portion of the cavity of the embryo-sac which has failed to become cellular, while the "meat" that surrounds it is the endosperm.

In most cases, as the embryo-sac and its contents develop, the cellular tissue outside it in the nucellus is absorbed and disappears; but in some instances it remains or even increases in quantity, and is termed the perisperm. In the seeds of Canna, all of the nutritive tissue exterior to the embryo and within the seed-coats is perisperm. The seeds of the Peppers contain much perisperm and a comparatively small quantity of endosperm. Its use to the plant is the same as that of the endosperm, namely, to supply 
food to the germinating embryo. The endosperm that is formed does not always remain until the seed is ripened, but not infrequently, as in the Melon and Bean, it is completely absorbed by the growing embryo, and all within the seed-coats comes to consist of embryo. In a few cases, also, an endosperm is never developed at all. Beside the changes which take place in the interior of the nucellus as the result of fertilization, very important ones also occur outside of it. The ovary always increases in size; sometimes to a remarkable extent, and equally remarkable changes take place in the character and consistence of its walls. Compare, for instance, the ovary of the apple in flower with the ripened fruit, or the pistil of the cherry blossom with a ripened cherry. Moreover, organs exterior to the ovary feel the influence of the process. Even pollination is sufficient, in many caes, to cause the stamens and corolla to wither and fall away before the pollentubes have had time to reach the ovules. It is well known that the period of blossoming may be greatly prolonged in most flowers, if the pollen be prevented from gaining access to the stigmas. The results of the fertilization also often affect organs as far removed from the ovule as the calyx and receptacle, and even the bracts beneath the flower. Indeed, the influence is even more farreaching than this, for the enormous development which the fertilized pistil undergoes, shows that all the nutritive processes in the plant must be more or less deeply affected.

\section{PraCticAL EXERCISES.}

1. Compare the flowers of the Plantain, Indian Corn, Wheat, Timothy Grass and Hazel, all of them anemophilous, with the flowers of the Geranium, Pink, Apple, Buttercup, Poppy, or other entomophilous flowers, and note (1) the difference between the stigmas of the two groups as regards the extent of surface which they expose; (2) the difference as to the abundance and character of the pollen; (3) the difference in showiness, presence or absence of perfume, etc. (4) Observe in the Geranium whether the flower is proterandrous, proterogynous, or whether the maturing of the stigmas and anthers is simultaneous. (5) Observe different flowers of the Pink, and note the difference between the staminate and pistillate stages. (6) Ascertain whether the anthers of the Buttercup dehisce extrorsely or introrsely, and state, if you can, what relation the facts you discover bear to the cross-fertilization of the plant.

2. Examine the flowers of the common Blue Flag; note the position of the nectar, the relative position of the anthers and stigmas, which way the anthers face, and the mode of their dehiscence, and determine, if you can, the manner in which cross-fertilization is effected.

3. Examine the flowers of the common Barberry; observe the relative arrangement of the stamens and petals; observe the structure of the anthers, and their mode of dehiscence; by means of a pin irritate them slightly at the base, and observe the movement; note the shape of the stigma, and the position of the nectar secretion; if possible, observe the flower while it is being visited by an insect, and then explain its adaptations to cross-fertilization.

Other interesting flowers to study for the same purpose are those of the Milkweed, the Cypripedium, the Pea, and the common Mallow.

4. For autogamous flowers examine late in summer the runners concealed 
underneath the leaves of Viola blanda, or of the English Violet (Viola odorata). Examine carefully their structure, and observe in those which have fruited the number of seeds produced.

For the same purpose also study the autogamous flowers of Polygala polygama, and compare them carefully with the showy flowers of the same plant.

5. Take the pistil of Datura Stramonium (or of some other flower whose ovary, style and stigma are rather large), and, immediately after the withering of the corolla, make thin, longitudinal sections through the stigma, style and ovary. Pollen grains will ordinarily be seen attached to the stigma, and pollen tubes may be traced into the style, particularly if the section be heated for a few moments in glycerine. so as to render the cells of the style as transparent as possible. The pollen tube may be distinguished by its more granular contents from the cells among which it has penetrated.

If the sections are fortunately made, the pollen-tube may even be traced into the micropyle of the ovule. But if this cannot be done, some of the young ovules, if removed and carefully examined, will be found to contain the ends of pollen-tubes which have penetrated the micropyle and are in contact with the nucleus of the ovule. If the ovary of almost any species of the Orchidacae be cut open longitudinally a short time after the corolla has withered, numerous pollen-tubes will be seen, appearing under a magnifying glass as delicate, white, silky threads. The ovules of these plants are also favorable for the study of fertilization owing to their small size and the transparency of their parts. Other suitable plants for the purpose are the species of Pyrola, Monotropa, and Torenia Asiatica.

6. To observe the growth of the pollen tubes, germinate fresh pollen grains (preferably Tradescantia, Begonia or Malva) in a ten per cent solution of sugar, prepared by boiling the solution for ten minutes so as to ensure sterilization, and transferring a drop of it with a sterilized needle to the center of a sterilized cover glass. Sprinkle a few pollen grains on this and invert the cover over a ring of the size of the cover or a little smaller, placed on a slide and held in place by a drop of water around its inner edge. Keep in a warm place (preferably a moist chamber) for a few hours and examine with the high power of the microscope. The slide may be kept for several days and the growth of the pollen tubes observed from time to time.

\section{CHAPTER XIII.-THE FRUIT AND SEED.}

\section{I.-The Fruit.}

The fruit consists essentially of the ripened pistil or pistils, but it may also include other organs which grow fast to these in the process of their development.

Its structure, in a general way, resembles that of the pistil from which it is derived. The modifications which it undergoes in its development, in many cases at least, have reference to the dispersion of the seeds when they are ripened.

The kinds of modifications that may take place are chiefly the following:

(1) The loculi or compartments in the ovary, may decrease in number, as in the fruit of the Oak, which in flower is threecelled, but in ripening becomes one-celled. The similar case of the fruit of the Buckeye is illustrated in Figs. 270 and 271. The former figure represents a cross-section of the pistil at the time the flower is in full blossom when it contains three cells with two 
ovules in each cell, and Fig. 271 represents the same at a considerably later period of development, showing the almost complete abortion of two of the cells and of all the ovules but one.

(2) An increase in the number of loculi sometimes takes place from the formation of false partitions, as illustrated in the capsule of Stramonium, which in flower is two-celled, but in fruit becomes four-celled. Fig. 272 .

(3) Alterations in the character of the surface may take place, as is also illustrated in Stramonium, whose pistil, when in

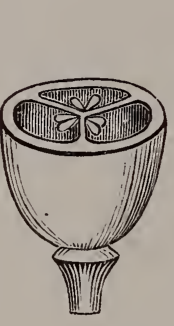

Fig. 270.

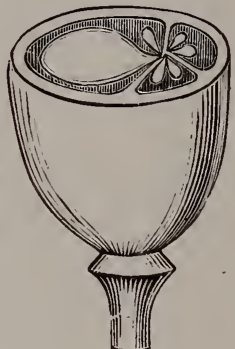

Fig. 271.

Fig. 270.-Ovary of Buckeye when in Flower, cut transversely, showing three loculi and two ovules in each loculus.

Fig. 271.- Ovary of Buckeye, cut transversely at a later stage of development, showing one ovule strongly developed, while the others have ceased their growth.

flower, has only a soft, hairy covering, but in fruit is densely covered with sharp prickles; or in the Maple, whose pistil in flower is merely two-lobed, but, in fruit, develops on each lobe a prominent wing-like appendage, as shown in Fig. 273.

(4) Alterations in the consistency of the ovary wall may take place. These may be of different kinds: (a) They may become thin and papery, as in the Bladder-senna; (b) hard and bony, as in the pericarp of many capsules; (c) tough and leathery, as in the rind of the Orange and Lemon; (d) hard without and soft within, as in the fruit of the Gourd; (e) soft without and hard within, as in the fruit of the Peach and Cherry; or (f) succulent throughout, as in the Gooseberry and Grape.

(5) Organs external to the pistil, but more or less connected with it, often persist and become a part of the fruit. The calyx of the Wintergreen, for instance, grows fleshy, envelops the capsule, becomes red in color, and constitutes the edible portion of the fruit; in Clematis the style persists, becomes long and feathery, 
and serves to waft away the ripened fruit; in the Strawberry the receptacle becomes thick and succulent, and constitutes the edible portion of the fruit, and in the Dandelion and Thistle the modified calyx-limb, or pappus, renders the fruit buoyant and easily wafted by the wind.

Doubtless the reason why fruits often have conspicuous colors is to render them attractive to birds and other animals that can aid in their dispersion. As the seeds of edible fruits are usually indigestible, or difficultly digestible, the fact that the fruits are

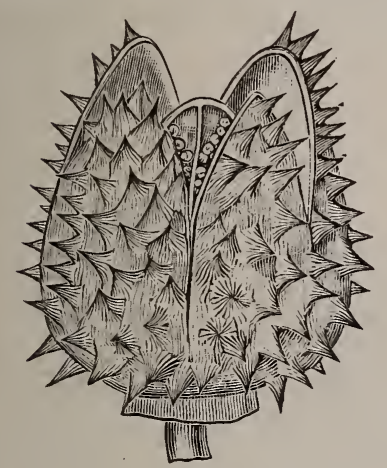

Fig. 272.-Capsule of Stramonium.

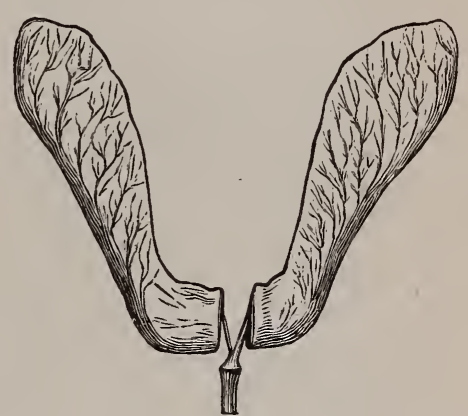

Fig. 273.-Double Samara of Maple.

pleasing to the taste aids the dispersion of their seeds, and secures their deposit under conditions favorable to germination. The hooks and spines which are found on many fruits, or attached to accessory organs, are also means by which plants utilize animals for the dispersion of their seeds.

Dispersion.-The agencies made use of by nature for the dispersion of fruits and seeds may be classified as follows:

(1) The Wind, as when they acquire thin and flattened forms, or are provided with membranous expansions called wings, or have a feathery, hairy or parachute-like pappus, or are otherwise rendered light and buoyant.

(2) Water Waves or Currents, as in the case of the Coconut, which, by its structure, is rendered buoyant, and by reason of its possessing a fibrous husk, and a thick, hard shell, is enabled to resist for a long time the action of salt water.

(3) Explosive Mechanisms. In this manner the seeds of the Squirting Cucumber, Ecballium Elaterium (Fig. 274), are discharged. Many explosive mechanisms are due to Hygroscopism, 
the property possessed by some fruits, by which one part either absorbs water more rapidly than another, or parts with it more readily, thus in some cases causing a strain upon and at last a sudden rupture of the pericarp, scattering the seeds, or else giving rise to movements of a different character which are serviceable in placing the fruit or seed in conditions favorable to germination. To hygroscopism is attributable the violent bursting of the large capsules of the tropical Sandbox tree, Hura crepitans, Fig. 275. When the fruit is thoroughly ripe the segments suddenly separate with a loud report resembling that of a pistol, and the seeds are thrown out with a force which often projects them to the distance

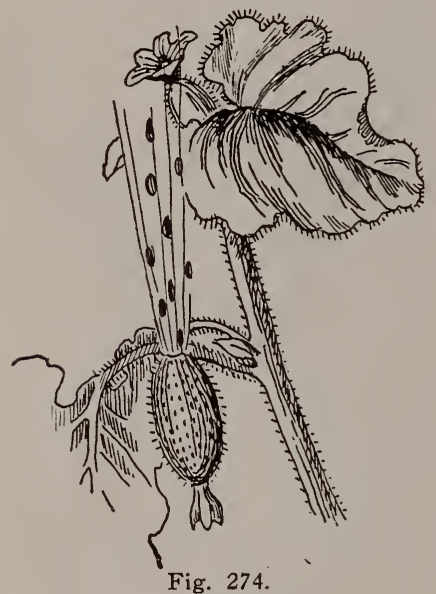

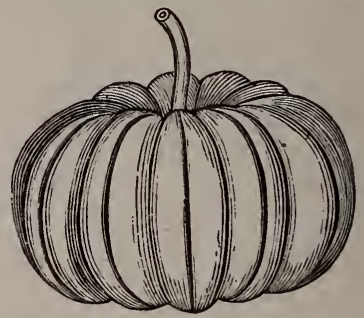

Fig. 275.

Fig. 274.-Fruit of the Squirting Cucumber discharging its seed.

Fig. 275.-Capsule of Sandbox tree, Hura crepitans.

of many yards. The capsules of the well-known Touch-me-not, dehisce with violence from the same cause; and by reason of their hygroscopic properties the awns of some grasses twist and untwist as the quantity of moisture in the air changes, and in some instances the motion thus produced is utilized to drive the fruit into the soil. This is the case with the western Porcupine Grass. In some flowerless plants the same property is taken advantage of for the dissemination of the spores. The hygroscopism of the elaters of Equisetum, and some Liverworts, for example, is the means of ejecting the spores from their cases, and so of scattering them to the wind to be sown far and wide.

(4) Animals. There are many ways in which plants make use of animals for the dispersion of their fruits and seeds. It has already been suggested that this is one of the reasons why 
the fruits of some plants have become edible. Birds and frugivorous mammals are certainly, for this reason, among the most important adjuncts in the distribution of plants. By sparrows and squirrels, doubtless, whole forests have been planted. The

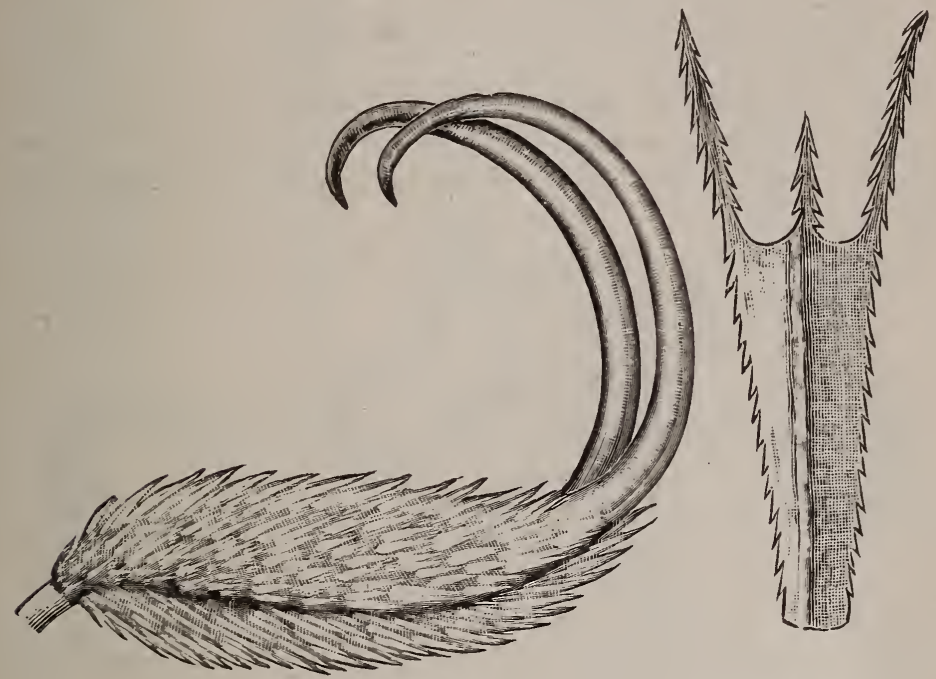

Fig. 276.

Fig. 277.

Fig. 276.-Fruit of Martynia, considerably reduced. When ripe its beak splits into two sharp, hooked hard horns, by means of which it clings to the tails of cattle and horses, and the seeds are thus scattered.

Fig, 277.-Fruit of Bidens connata, magnified about five diameters.

showiness of many ripe fruits is also unquestionably an important aid to the dispersion of their seeds, as it attracts the attention of fruit-eating animals, and causes the fruits to be eaten, or at least to be plucked and tasted. But many fruits and seeds are provided with hooks, spines, barbs, adhesive pericarps, or other means by which they cling to the bodies of animals, and are thus scattered. Fruits of the Burdock, Bidens, Stickseed, Tick-trefoil and Mistletoe are illustrative examples, and many others might be educed. Figs. 276 and 277 represent, respectively, the fruits of species of Martynia and Bidens.

Classification of Fruits.-Although the following scheme of classification does not claim completeness, it includes the most important forms of fruits, and for practical purposes will be found convenient. 
Fruits are primarily divided into two groups, those which are the product of a single flower, and those which are the product of a flower cluster.

The former kind are subdivided into those which are the product of one pistil (either apocarpous or syncarpous), and those which are the product of more than one. The former of these subdivisions is divided into indehiscent forms, or those which do not split open when ripe, and dehiscent forms, those which do. The most important of the indehiscent forms are the following:

(1) The Akene or Achenium. This is a one-seeded, dry, hard, seed-like fruit, like that of the Ranunculus, shown in longitudinal

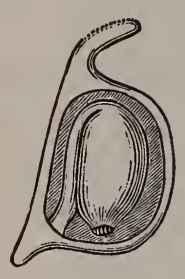

Fig. 278.

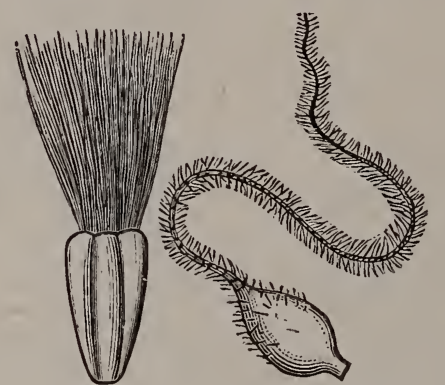

Fig. 279.

Fig. 280.

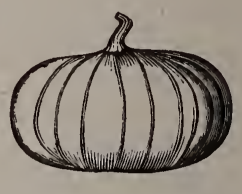

Fig. 281.

Fig. 278.-Superior achenium of Ranunculus, with portions of ovary wall removed to show internal structure.

Fig. 279.- - Inferior achenium of Sow Thistle.

Fig. 280.-Caudate achenium of Clematis.

Fig. 281.-Utricle of Chenopodium.

section in Fig. 278. The akene may either be superior, or free from an adhering calyx, as in the above example, or it may be inferior, that is, having the calyx closely adherent, as in the fruit of the Sow Thistle and other Compositx, Fig. 279. Fig. 280 represents the caudate or tailed achenium of Clematis.

(2) The Utricle. This is similar to an akene, but the pericarp is bladdery and fits the seed loosely; for example, the fruit of Chenopodium, Fig. 281.

(3) The Caryopsis. This resembles the akene, except that the pericarp closely adheres to the seed, as in the Wheat, Indian Corn, Oat, etc., Fig. 282.

(4) The Samara. This resembles an akene, except that it possesses a wing-like appendage. Fig. 283 represents the samara of the Ash, Fig. 284 that of the Elm, and Fig. 273 the double samara of the Maple. 
(5) The Glans, or nut. This is a fruit, like that of the Oak or Hazel, with a thick, hard pericarp, enclosed, or partly so, in an involucre, Fig. 285. In the case of the Acorn, the involucre

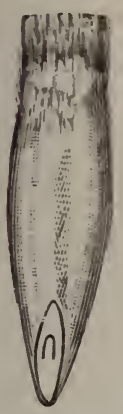

Fig. 282.

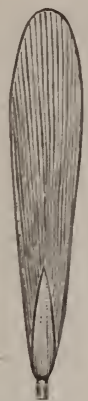

Fig. 283.

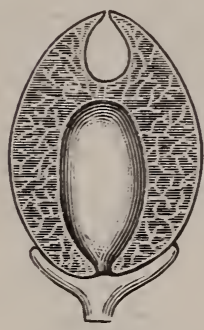

Fig. 284.

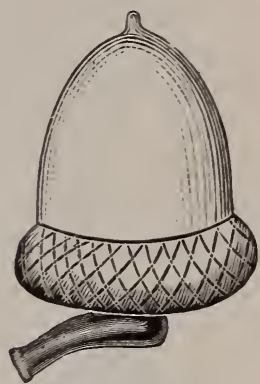

Fig. 285.

Fig. 282.-Caryopsis of the Oat.

Fig. 283.- Samara of the Ash.

Fig. 284.-Samara of the Elm.

Fig. 285.-Glans of the Oak.

consists of a cup-shaped expansion of the axis covered by closely imbricated scales, and is called the cupule.

(6) The Cremocarp. This is the peculiar double fruit produced by umbelliferous plants. Each mericarp, or half of the fruit, structurally resembles an inferior akene, but is longitudi-

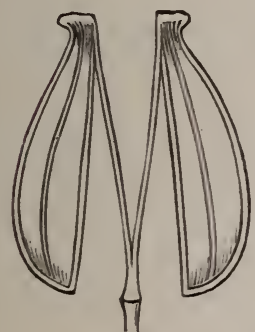

Fig. 286.

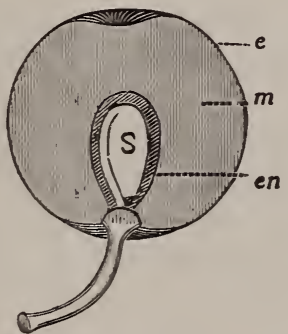

Fig. 287.

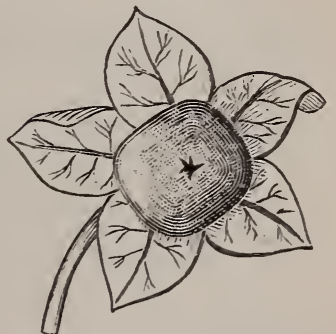

Fig. 288.

Fig. 286.-Cremocarp of Fennel, splitting into two mericarps.

Fig. 287.- Sectional view of drupe of Cherry; e, exocarp; m, mesocarp; en, endocarp, and s, seed.

Fig. 288.-Berry of Belladonna.

nally ribbed, and there are usually oil tubes between the ribs. Fig. 286 represents the cremocarp of Fennel.

(7) The Drupe. This is a one-carpelled fruit like that of the Plum, Cherry and Peach, and is often called a stone fruit. In it 
the wall of the pericarp is differentiated into three portions, the outer or "skin," called the epicarp, the middle or succulent portion, the mesocarp, and the inner portion or hard wall enveloping the seed, the endocarp or putamen. Fig. 287 represents the drupe of the Cherry in longitudinal section.

(8) The Tryma. This is a fruit structurally resembling the drupe, but the mesocarp is harder, more fibrous, the outer husk in most cases ultimately dehiscent, and the cavity containing the seed is usually more or less distinctly two-celled. The fruits of the Hickory, Walnut and Pecan are illustrations. See Fig. 289.

(9) The Berry. This is a fruit which has a thin, membranous rind, and all the rest of the pericarp is succulent. The fruits of

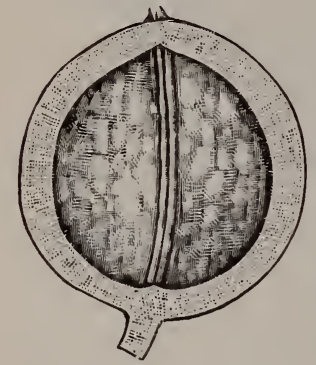

Fig. 289.

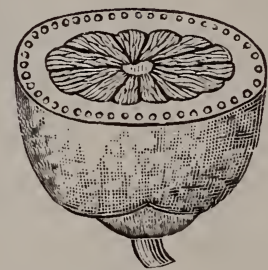

Fig. 290.

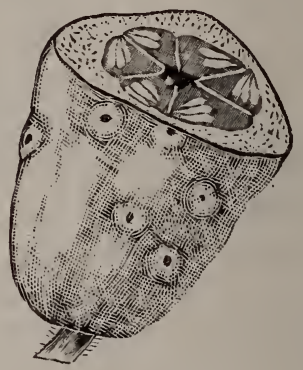

Fig. 291.

Fig. 289.- Tryma of the English Walnut, with portion of sarcocarp removed. Fig. 290.-Fruit of Lemon, cut transversely, illustrating a hesperidium fruit.

Fig. 291.-Cucumber, cut transversely, illustrating pepo fruit.

the Belladonna, Grape and Gooseberry are illustrations. Berries may be one-, two- or even many-celled, and they may be either from an enlarged and juicy pistil or from one which has a surrounding receptacular cup. In the former case the berry is called superior, in the latter inferior. Fig. 288 represents the berry of Belladonna.

(10) The Hesperidium is a fruit like the Orange, Lemon and Lime. It resembles a superior berry, but differs from one in having a leathery rind containing numerous oil glands. See Fig. 290.

(11) The Pepo. This is a fleshy fruit like that of the Gourd, Melon and Cucumber, having a hardened or tough rind, Fig. 291.

(12) The Pome. This is a fleshy fruit, the chief bulk of which consists of adherent, fleshy calyx-tube or receptacle, as the Quince, Pear and Apple, Fig. 292. 
The more important dehiscent fruits which are the product of a single pistil are the following:

(1) The Follicle. This is a one-carpelled, dry fruit, that dehisces along the ventral suture, as the fruit of the Columbine, Fig. 293.

(2) The Legume. This differs from the follicle only in the fact that the dehiscence takes place along the dorsal as well as the ventral suture, forming two valves. This form of fruit is

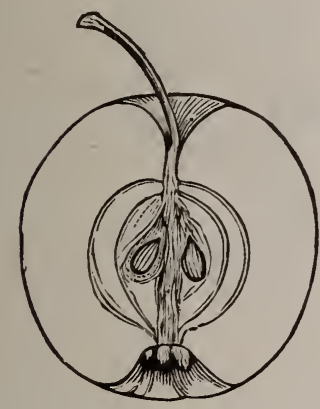

Fig. 292.

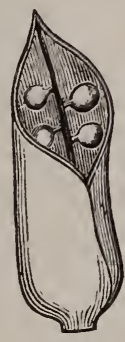

Fig. 293.

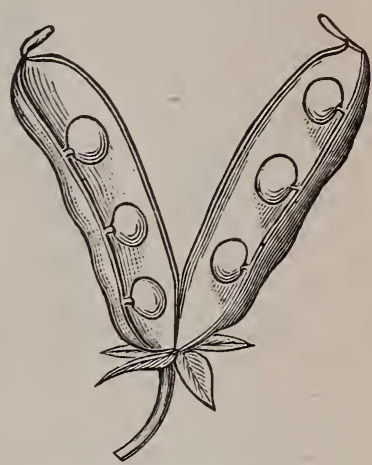

Fig. 294.

Fig. 292.-Sectional view of a pome, the fruit of the Apple.

Fig. 293.-Follicle of the Columbine.

Fig. 294.-Legume of the Pea.

common in the Pulse family. The Pea-pod, Fig. 294, is an illustration.

(3) The Loment. This is a modification of the legume, which, instead of dehiscing longitudinally, breaks up transversely into segments, as the fruit of the Meibomia, Fig. 295.

(4) The Cochlea is a coiled legume like that of the Medicago, Fig. 296.

(5) The Capsule differs from the dehiscent fruits above described in consisting of two or more united carpels. In this form of fruit, several modes of dehiscence are observed. The rupture of the pericarp may take place along the sutures of the carpels, as is more commonly the case, or independently of them; if the dehiscence is sutural, it may be along the marginal sutures only, along the dorsal sutures only, or along both; the splitting may be complete or only partial, and it may begin either at the apex or at the base. Sometimes the valves, in separating, carry the placentæ with them, at other times the latter are left behind, forming 
a central column, which is technically called the columella. The following are the commonest kinds of capsular dehiscence: (a) The septicidal, in which splitting takes place along the septa, or partitions, as in Fig. 297. (b) The septifragal, where the valves break away from the septa, as in Fig. 298. (c) The loculicidal,

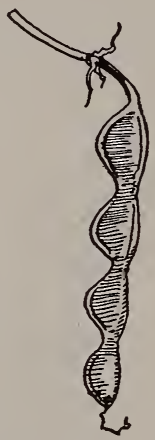

Fig. 295.

Fig. 295.-Loment of Meibomia

Fig. 296.-Cochlea of Med-

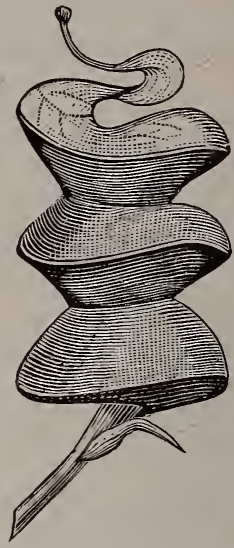

Fig. 296.

where the carpels open by their dorsal sutures into the loculi or cavities of the cells, as in Fig. 299. (d) The marginicidal, when the valves break away along the line where the septa join the outer wall, Fig. 300. All these are forms of valvular dehiscence.

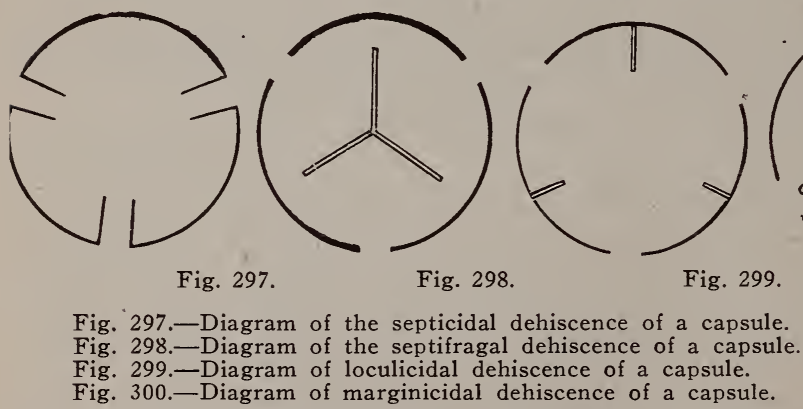

The Violet and Gentian afford examples in which the valvular dehiscence is complete, as shown in Fig. 301, while in the capsule of Lychnis, Fig. 302, it is partial or incomplete, and the partial separation takes place at the top of the capsules. In the capsules 
of the Hare-bell and of Cinchona Calisaya, see Fig. 303, it occurs at the base. (e) The porous. In this form, Fig. 304, the dehiscence takes place by small openings or pores, as in the Poppy. It is really a variety of the valvular dehiscence. (f) The circumscissile is that form in which the upper portion of the capsule

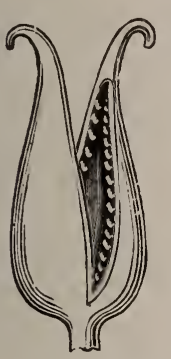

Fig. 301

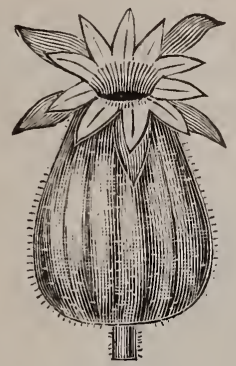

Fig. 302.

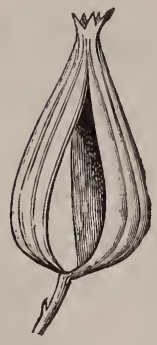

Fig. 303.

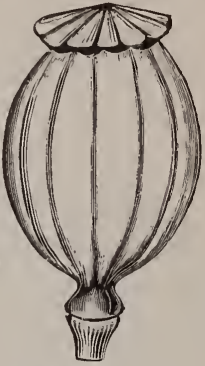

Fig. 304.

Fig. 301.-Capsule of the Gentian, dehiscing septicidally into two halves.

Fig. 302.-Capsule of Lychnis, showing partial dehiscence of capsule.

Fig. 303.-Basally dehiscent capsule of Cinchona Calisaya.

Fig. 304.-Capsule of the Poppy, showing porous dehiscence.

separates from the lower, like a lid, by a transverse dehiscence, as in the capsule of Hyoscyamus, Fig. 305. Such a capsule is often termed a pyxis. (g) The irregular, or that form in which the

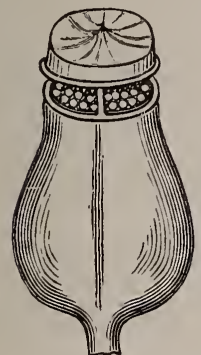

Fig. 305 .

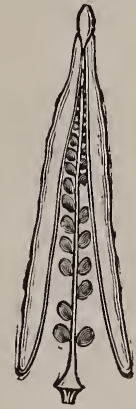

Fig. 306 .

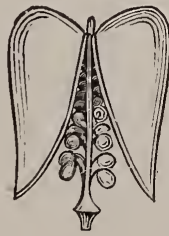

Fig. 307

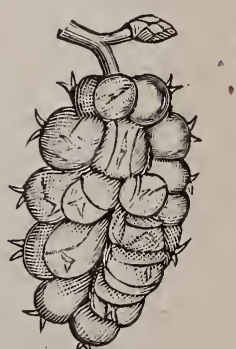

Fig. 308.

Fig. 305.-Pyxis of Hyoscyamus.

Fig. 306.-Silique of Celandine

Fig. 307.-The dehiscing silicle of Shepherd's Purse.

Fig. 308.- Sorosis of the Mulberry.

dehiscence takes place in an indefinite manner or by an irregular rupture of the pericarp, as in the garden Snap-dragon.

The following capsules have peculiarities which make it conven- 
ient to apply special names to them: One which is elongated, two-valved, and the valves of which separate from the base upward, leaving the seed-bearing placentas in place, as in the Mustard and Celandine, Fig. 306, is called a silique; and a shortened silique, like that of Shepherd's Purse, Fig. 307, is termed a silicle.

Fruits that are the product of one flower, but of many separate carpels, are called aggregate fruits.

An aggregate fruit that consists of a collection of small drupes,

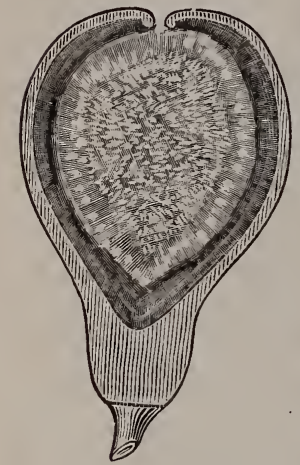

Fig. 309.

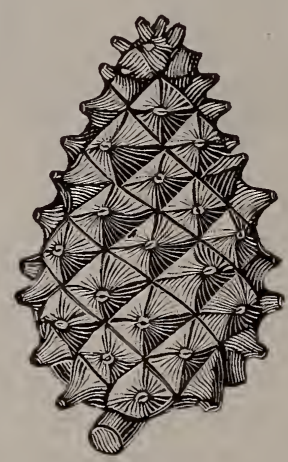

Fig. 310.

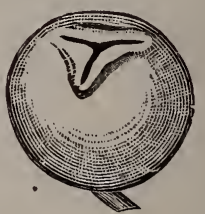

Fig. 311.

Fig. 309.- Syconium of the Fig, shown in longitudinal section.

Fig. 310.-Strobile, or cone of Pine.

Fig. 311.-Galbulus of Juniper.

like that of the Blackberry and Raspberry, is called an etaerio. A strawberry is an aggregation of akenes on a thickened and succulent conical or convex receptacle. A hip is an aggregation, of akenes on a thickened and succulent hollow receptacle. The term is applied to the fruit of the Rose.

Fruits that are the products of flower-clusters instead of single flowers are termed collective or multiple fruits. The most important are the following:

(1) The Sorosis. This is a fruit like those of the Mulberry, Fig. 308, and Pineapple, where the inflorescence in ripening has become fused together into a compact mass.

(2) The Syconium. This is the peculiar fruit of the Fig, the edible portion of which consists of a succulent, hollow receptacle, which incloses a multitude of akene-like nuts, each the product of a distinct flower, Fig. 309. 
(4) The Strobile, or Cone. This is a multiple dry fruit consisting of a scale-bearing axis, each scale enclosing one or more seeds; for example, the cones of the Hop and Pine, Fig. 310.

(4) The Galbulus. This is a cone, the scales of which have become succulent. The so-called Juniper Berry, Fig. 311, is an example.

\section{RECAPitulation of Fruits.}

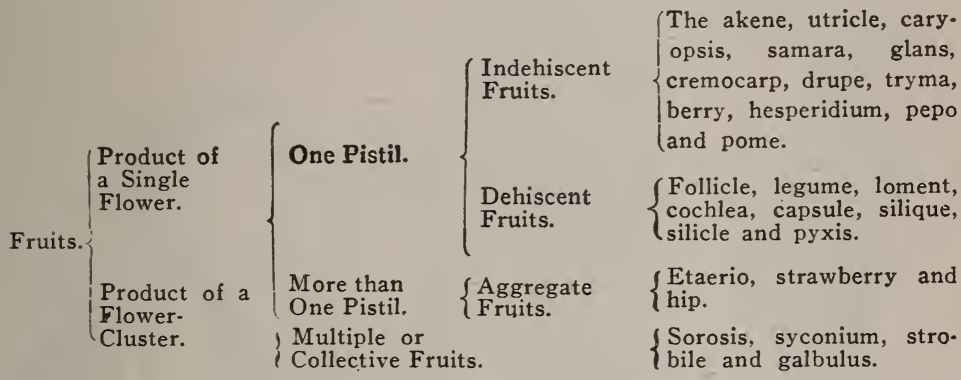

\section{II.-THE SEED.}

The seed is the fertilized and ripened ovule. It ordinarily remains enclosed within the ovary, and is nourished by it until maturity, though the rule has some exceptions. As might have been expected, also, the seed ordinarily bears a general resemblance to the ovule from which it is derived. For example, the coats usually remain to form the coats of the seed; the chalaza and micropyle of the ovule are still recognizable and are called by the same names in the seed; the raphe, if present in the former, is also present in the latter; the position of the seed in the ovary corresponds to that of the ovule; the terms atropous, campylotropous, etc., apply equally well to the seed, and the latter, when ripe, breaks away from the funiculus, if that organ is present, or if not, from the placenta, leaving a scar called the hilum, which corresponds to the part called the hilum in the ovule. But nothwithstanding the structural resemblance in many particulars, the ovule undergoes important changes, not only in size but also in form and structure, in the course of its development into seed. Among the most important of these are the following:

(1) The seed-coats, particularly the outer, frequently undergo considerable modification. While the exterior one of the ovule 
is thin, membranous and smooth, that of the seed, termed the testa or spermoderm, is usually considerably thickened, and acquires various markings or appendages.

If the testa becomes very thick, hard and resistant, it is termed crustaceous; if smooth and shining, it is described as polished; if roughened, it may be tuberculate, pitted, rugose, reticulate, alveolate, fissured, furrowed, hairy, etc.; and if appendaged, the appendages may be in the form of a coma, or long hairs, which nearly or entirely cover the seed, as in the Cotton, or only one end

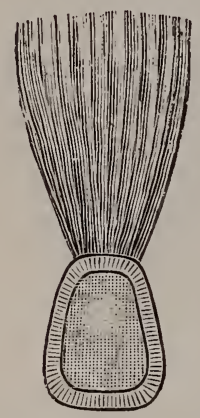

Fig. 312 .

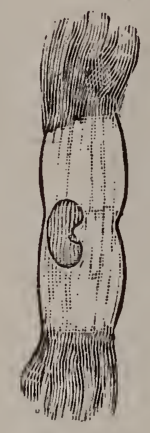

Fig. 313.

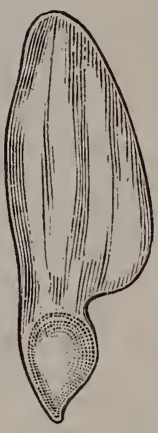

Fig 314.

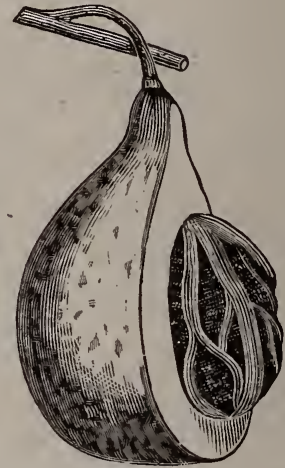

Fig. 315.

Fig. 312.-Comose seed of the Milk-weed.

Fig. 313.- Alate or winged seed of the Catalpa.

Fig. 314.-Alate seed of the Pine.

Fig. 315.-Fruit of Nutineg, with one side removed, to show the seed enveloped in the mace.

of it, as in the Milkweed, Fig. 312 ; or the appendage may be in the form of short silky hairs, as in the seeds of Nux Vomica; of or one or more flattened expansions, called wings, as in the seed of the Catalpa, Fig. 313, and of the Pine, Fig. 314; or it may be an outgrowth from the funiculus or placenta, which more or less completely envelops the seed, and constitutes the aril, as in the mace of the Nutmeg, Fig. 315, the aril of the Water-lily, and that of Celastrus scandens; or, lastly, it may be in the form of a cellular excrescence at the hilum or along the raphe, called the caruncle, or crest, as in the seed of Sanguinaria, Fig. 316. Not infrequently, also, the outer portion of the testa undergoes changes into mucilage, as in the seeds of the Quince and Flax.

The inner coat of the seed, called the tegmen or endopleura, is sometimes wanting; sometimes it coalesces with the outer coat 
and becomes indistinguishable from it. When present, it is usually thin and membranous.

(2) The internal structure of the nucellus undergoes important changes. Some of these were mentioned under the subject of fertilization. It is replaced in the seed by the kernel.

The kernel of the seed, or that portion within the seed-coats, may, as we have already seen, consist either entirely of the

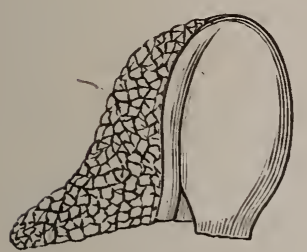

Fig. 316.

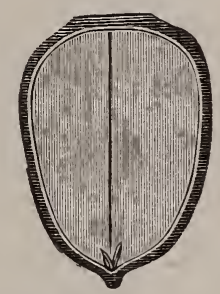

Fig. 317.

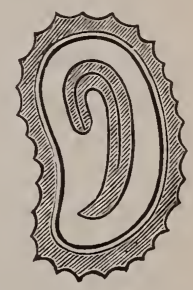

Fig. 318 .

Fig. 316.-Carunculate seed of the Blood-root. Magnified.

Fig. 317.- - Longitudinal section of acorn, showing the exalbuminous seed.

Fig. 318.-Albuminous seed of Hyoscyamus, shown in longitudinal section. Magnified.

embryo, in which case it is described as exalbuminous, as in the Acorn, Fig. 317, or of the embryo, together with more or less nourishing matter called, according to its origin, either endosperm or perisperm, in which case the seed is termed albuminous, as in Fig. 318, which represents a section of the seed of Hyoscyamus. The term endosperm, as already explained, is applied to the nutritious matter developed outside the embryo but within the embryo-sac, while perisperm is applied to the nutritious matter stored up outside of the embryo-sac. Both serve the same purpose, and in the fully developed seed it is often difficult, if not impossible, to distinguish them.

In albuminous seeds the amount of endosperm differs very widely, and in describing it, it is usual to compare its quantity with that of the embryo. If much greater it is copious, or abundant; if about the same, equal; and if comparatively small in quantity, scanty.

The texture of the endosperm differs, also, in different seeds. In some, like the Wheat and Buckwheat, it is farinaceous, or mealy; in the seeds of Barberry and Coconut, it is of a denser consistency, yet readily cut with a knife, and is called fleshy; in some, as the seeds of Poppy and Bloodroot, it is oily; in the seeds 
of Nux Vomica and many others is is horny; in others still, as that of the Ivory Palm, it is so exceedingly hard as to be appropriately called bony; and in the seed of the Nutmeg, since it has an uneven or marbled appearance, and is more or less fissured transversely, it is called ruminated.

The Embryo. This is the essential part of the seed; it is the young plant which is the end and purpose of the entire flower and fruit; it is the finished product of the reproductive process.

In exalbuminous seeds it is usually well developed, while in albuminous ones it is apt to be smaller, and have its parts less perfectly formed, but this general rule has many exceptions.

As respects the position of the embryo in the seed, it has already been noted that the radicle always points to the micropyle. As regards its position with reference to the endosperm, this varies greatly in different seeds. In the seed of the Violet, Fig. 319 , it is straight, and buried in the endosperm. This is true, also of the relatively smaller embryo of Nux Vomica, Fig. 320; in the seed of Hyoscyamus, already mentioned, it is curved within the endosperm; in the seed of Lychnis dioica, Fig. 321, it is curved, but lies

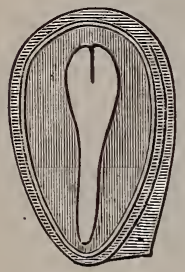

Fig. 319.

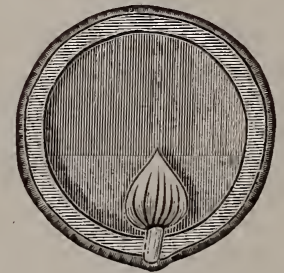

Fig. 320 .

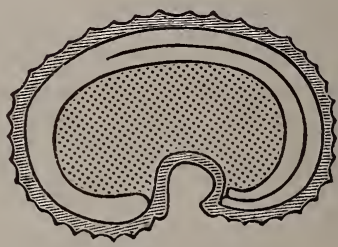

Fig. 321.

Fig. 319.- -Seed of Violet, showing straight embryo buried in the endosperm. Magnified.

Fig. 320.- Seed of Nux Vomica, with one side removed, showing position of embryo. About natural size.

Fig. 321. - Seed of Lychnis dioica, showing embryo curved around the endosperm. Magnified.

on the outside of it, and almost completely surrounds it, while in the Indian Corn, Fig. 322, it is placed to one side of it.

An embryo that is well developed, like that of the Bean, Figs. 323 and 324, possess four parts: an initial stem, termed the caulicle or hypocotyl; at the lower end of this the beginning of the root, called the radicle; near the upper end of the caulicle two thickened bodies more or less resembling leaves and homologous with them, the cotyledons; and between these a small bud called 
the plumule. Thus, in the embryo, all the organs of vegetation are already present.

The cotyledons, although in their nature leaves, and sometimes doing for a time the work of foliage, as those of the Maple and Morning-glory, are commonly thickened and surcharged with nourishment which serves to feed the growing plantlet; in many

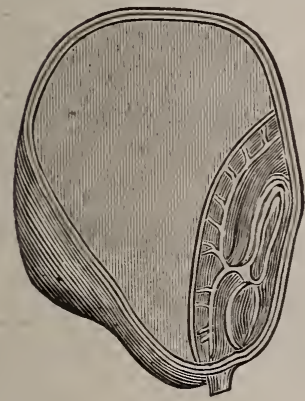

Fig. 322 .

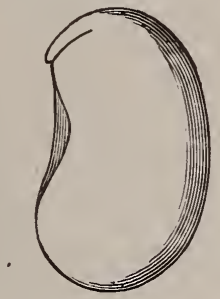

Fig. 323.

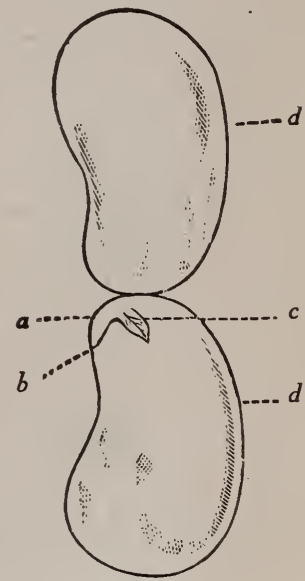

Fig. 324 .

Fig. 322.- Seed of Indian Corn, showing embryo placed to one side of the endosperm. The outer portion of the embryo forms a surrounding sheath known as the Scutellum.

Fig. 323.-Embryo of Bean.

Fig. 324.-The same, with one of the cotyledons turned back to show the plumule. $a$, the caulicle; $b$, the radicle; $c$, the plumule; $d$ and $d^{\prime}$, the cotyledons.

instances this function is the only one they discharge. This is the case with the embryos of the Pea and Oak. In these instances they do not rise above the soil at all in germination, but remain buried in the ground until their supply of nutriment has been exhausted by the growing seedling, when they decay and disappear. Such cotyledons are described as hypogeous, while those which rise above the soil are called epigeous.

Embryos like those of the Bean, because they possess two opposite cotyledons, are called dicotyledonous. Not all embryos, however, are constructed on precisely this plan. Some, as those of Lilies, Sedges and Grasses, have the leaves alternate from the start, and usually the lower one is much the most highly developed, and being the only conspicuous one, besides being folded 
about the rest and concealing them from view, the embryo is called monocotyledonous. Fig. 325 represents the monocotyledonous embryo of Indian Corn. The embryos of some other plants, particularly of many members of the Pine family, have more than two cotyledons in a whorl-sometimes as many as fifteen; embryos of this kind are described as polycotyledonous. Fig. 326 represents the germinating embryo of a species of Pine. There are a few cases in which the cotyledons are aborted or wanting. Such embryos have been called acotyledonous. The seed of the common Dodder contains an embryo of this kind. There is reason to believe, however, that it was once dicotyledonous, for the affinities of that plant, as shown by the structure of its flowers, are with Dicotyledons. The plant is, however, a parasite, and, doubtless, the loss of its cotyledons bears some relation to its parasitic habits. Probably once, like its near relative, the Morning-glory, it pos-

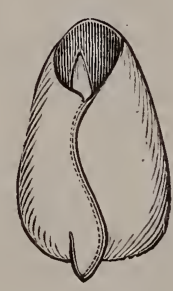

Fig. 325.

Fig. 325.-Monocotyledonous em. bryo of the Indian Corn.

Fig. 326.-Polycotyledonous em. bryo of a species of Pine. (After Sachs.)

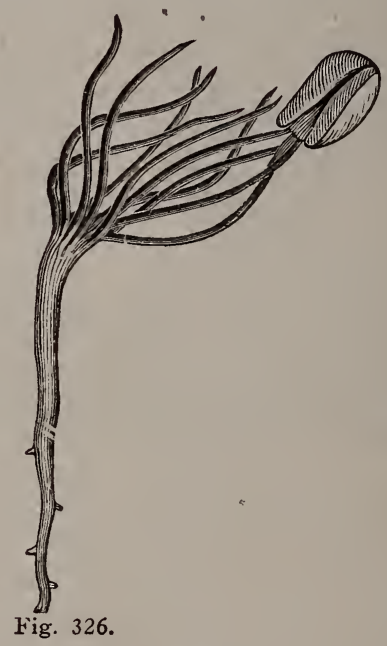

sessed foliage, and obtained its living in a legitimate way, but having acquired the parasitic habit (a habit degrading to plants, animals and men), and having no use for foliage of its own, it lost its leaves, and the degradation of form came, finally, even to affect the embryo and cause the loss of its cotyledons. These probably were once highly developed and did partial duty as foliage, as those of the Morning-glory still do.

There are a few instances, also, where plants whose actual affinities are with Dicotyledons, possess but one cotyledon, the 
other having become aborted, the embryos thus becoming falsely monocotyledonous.

The distinction between monocotyledonous and dicotyledonous embryos is, with these exceptions, one of fundamental importance, -one of the great divisions of the flowering plants, the Monocotolydons, being characterized by monocotyledonous embryos, and another, the Dicotyledons, by dicotyledonous ones.

The individual cotyledons may be folded or bent in various

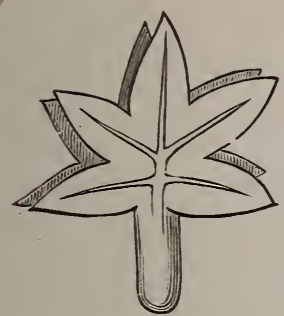

Fig. 327.

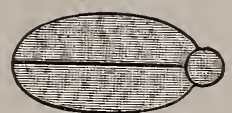

Fig. 328.

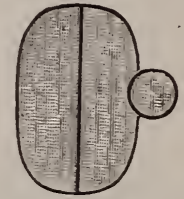

Fig. 329.

Fig. 327.-Embryo of Basswood, showing lobed cotyledons. Magnified.

Fig. 328.-Diagram illustrating accumbent cotyledons.

Fig. 329.-Diagram showing incumbent cotyledons.

ways in the seed, as leaves are in the bud, and their folding may be described in the same way. They also have a variety of shapes, the same as ordinary leaves, though they are much more commonly entire. Occasionally, however, we find them toothed ov lobed, as in the embryo of the Basswood, Fig. 327.

Although we often find the embryo straight, or the caulicle lying in the same line as the cotyledons, in many seeds it is bent so as to lie alongsidr of them. In this case it may be applied to their edges, as shown in the diagram, Fig. 328, which represents a cross-section through the cotyledons and caulicle, in which case it is described as accumbent; or it may be applied to the outer face of one of them, as in Fig. 329, when it is described as incumbent. An illustration of the former arrangement occurs in the seed of the garden Candy-tuft, and of the latter in the seeds of Shepherd's Purse.

The number of seeds produced by some plants is enormously great. A single Poppy capsule, according to Cooke, has been known to contain as many as forty thousand seeds, and the Poppy is certainly much less prolific than many other flowering plants. If all the seeds of almost any ordinary tree were to germinate and reach maturity, and the seeds of all these in turn were to develop, but a few generations would suffice before the earth would be so 
crowded with them that no room would be left for other plants. But, as a matter of fact, only a few of the large number of seeds produced by a plant ever reach maturity. The young plant has to contend with a thousand enemies, in the form of destructive insects, beasts and fellow plants; it must often wage war, also, against unfavorable conditions of soil and climate, against heat and cold, wet and drouth, and be hampered by the shadows cast by its older and stronger brethren. It is fortunate if, in the bitter struggle for existence, it survives to help gladden the earth with bloom and verdure, for the great majority perish.

\section{Practical Exercises.}

1. Study the following fruits, and classify and name them according to the system given you in this chapter: The Watermelon, the Banana, the Raspberry, a grain of Corn, the Butternut, the Almond, the Osage Orange, the Plum, the Sunflower fruit, the fruit of the Locust, that of Stramonium, of Red Cedar, of the Carrot and of the Beet.

2. Study the following fruits with reference to their adaptations for dispersion: The fruit of Dog-bane, of the wild Plum, of Agrimonia, of the wild Geranium, of the Elm, of Cleavers, of the Clot-bur, of the garden Balsam, of the Wild Cucumber (Echinocystis), of the Grape and of the Hound's-Tongue.

3. Examine seeds of the following plants with reference to the surface markings, the coats, the position of the hilum, the micropyle and the raphe: The Bean, the Pea, the Pumpkin, the Almond, the Stramonium and the Nux Vomica.

4. Soak the following seeds for twenty-four hours in tepid water; then remove the seed-coats and study the albumen and embryo: The Bean, the Maple seed, the seed of Hemp, the seed of Morning-glory, the seed of the White Pine, the seed of Indian Corn, and that of the Horse-chestnut. Determine (1) which of these seeds are albuminous and which are exalbuminous; (2) the position of the embryo as regards the albumen in case the seed possesses the latter; (3) the parts of the embryo present in each case; (4) draw a diagram of each, representing the shape and parts of the embryos, and determine whether, in any instance, the caulicle is accumbent. 


\section{PART II.}

\section{HISTOLOGY.}

\section{CHAPTER I.}

\section{The Cell.-The Protoplast.-Other Cell-Contents.-The CELL-WALL.}

The Cell. All plants, whatever their size or kind, are composed of structural units known as cells. While some exceedingly small plants, chiefly microscopic in size, are composed of but a single cell, it is nevertheless a fact that the "higher" plants, those with which in our daily life and associations we have become more or less familiar, are composed of multitudes of cells varying widely

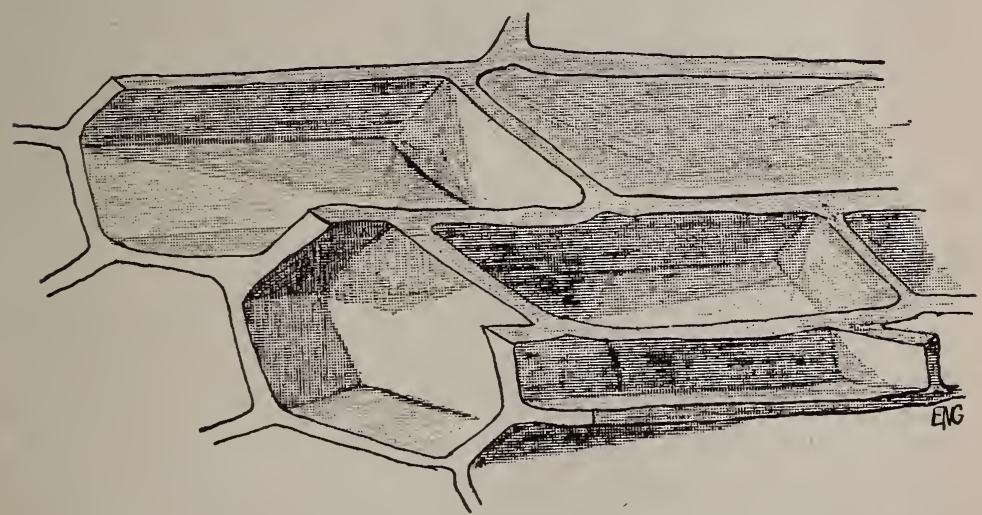

Fig. 330.-Cells of Bottle Cork, illustrating empty, box-like compartments to which the name "cell" was originally applied.

in size, form and structure and wonderfully adapted to the work which they are called upon to perform in the economy of the plant.

The discovery of the cellular structure of plants is credited to Hooke, who in the year 1665, using a microscope which he had made or improved, saw and described the cells in Bottle Cork. The observations of Hooke were confirmed and extended by Malpighi 
and Grew, before the close of the 17 th century. These early investigators devoted their study to the walls of the cells and but little attention was given to the cell-contents until, in 1846, von Mohr discovered the living substance and gave it the name protoplasm.

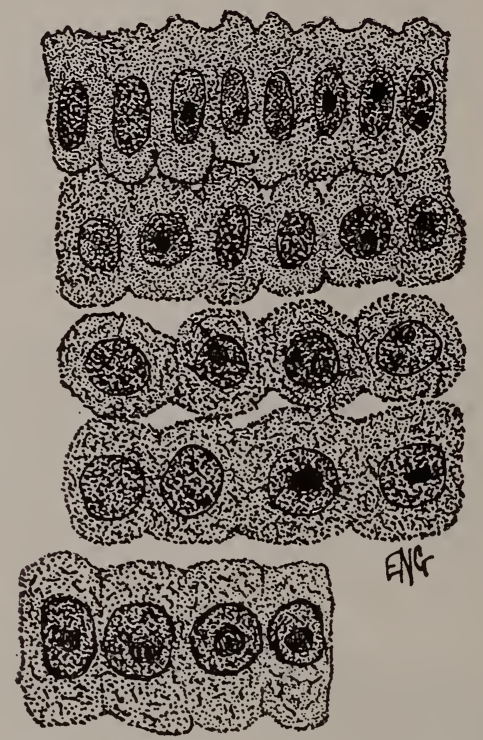

Fig. 331.-Cells from the embryo of Corn, showing typical protoplasts, each containing a nucleus.

Soon afterward came the comprehensive studies of Schleiden which laid the foundations for the modern science of cytology.

The term cell, as applied to the minute box-like compartments (Fig. 330), is fairly descriptive, but in a wider sense cells are much more than empty cavities. Hence the need of a term to distinguish the living or protoplasmic contents of the cell, the wall being of secondary importance in the life of the organism. These living contents have now come to be known collectively as the Protoplast (Fig. 331).

\section{THE PROTOPLAST.}

Protoplasts are, therefore, the living cells of plant structures and alone possess those powers which we characterize as "vital" or intimately associated with life. Most evident among these attributes are: Metabolism, including the building up of food 
products from their elementary substances on the one hand, and, on the other, the utilizing of the energy stored in these foods by breaking them down into simpler compounds with the accompanying release of energy; growth, the power to increase in size by adding new but similar materials; division, accompanying reproduction or regeneration; motion, whether expansion, contraction or streaming, and irritability, the power to respond to stimuli of various kinds, notably light, heat and gravitation. These qualities, of which more will be said in a later chapter, are inherent to the protoplast; all the various and wonderful manifestations of life, even in the largest and most complex plant structure, are but the sum of the activities of its component cells.

If we examine, under the microscope, a section cut from a

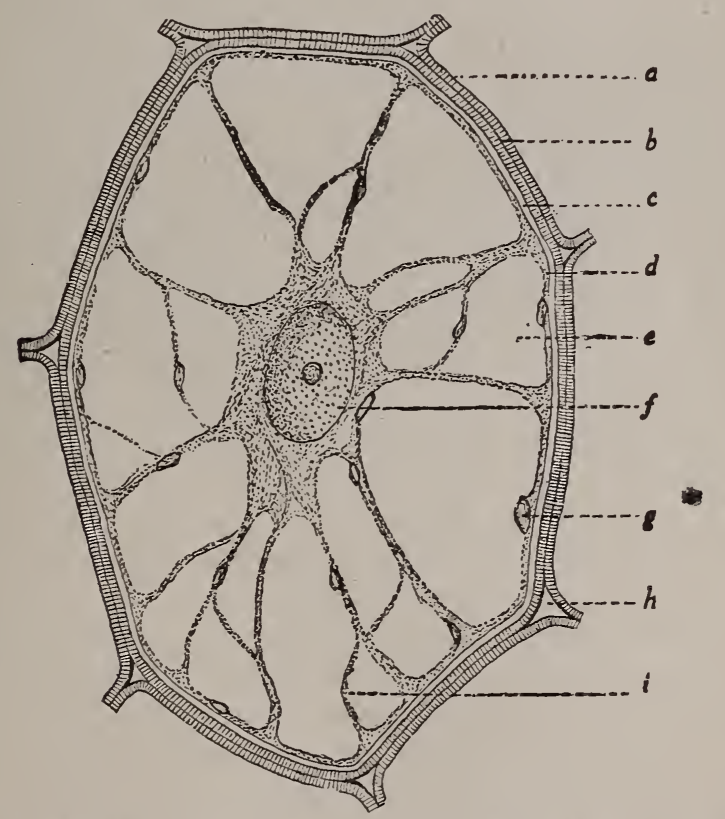

Fig. 332.-Represents diagrammatically a cell, greatly magnified, to show the parts. a, the cell-wall; b, the middle lamella; c, the ectoplasm; d, cytoplasm; e, vacuole; f, nucleus; $g$, chlorophyll granule; $h$, intercellular space; i, cyto. plasmic thread.

young and growing part of a plant, we will find that each protoplast is surrounded by a delicate, transparent and somewhat elastic membrane of cellulose which we call the cell wall. Though each 
protoplast originates and develops its own wall, yet, where cells meet, their walls usually become attached, forming a common wall between adjoining cells, but capable of being separated again through the action of certain solvents or re-agents. In every living cell there may be perceived a protoplast in which, upon closer inspection, several parts or regions may be distinguished: First, the cytoplasm, usually a soft, viscid, slightly cloudy and nearly colorless mass, resembling somewhat the white of an egg in appearance and in consistence. This nearly or quite fills the cell. Its structure is described as foamy and is compared with an emulsion consisting of tiny globules suspended in a fluid, though some investigators contend that this structure should rather be likened to a very delicate, spongy framework distended with liquid contents and containing numerous minute granules known as microsomes. Perhaps both views are approximately correct, under different conditions, for we know that cytoplasm is capable of great variations in consistence, depending upon the amount of water it has absorbed, also that it apparently is able to form within its mass various fibrils, granules and similar structures.

As the cell grows, rifts appear in the cytoplasm. Such gaps are termed vacuoles, though they are not empty but are filled with cell-sap, reserve food and even waste products. (Fig. 332.)

As the cell approaches maturity, the vacuoles increase in size and run.together, eventually leaving only a film of cytoplasm lining the walls. Even this lining disappears at last, the wall meanwhile having become more or less thickened, often with a transformation of the cellulose into some other wall substance.

The protoplasts of adjoining cells are connected together by very thin strands of cytoplasm extending through minute pores in the cell wall and thus affording a means of communication between all the living cells of the plant and, in effect, uniting the protoplasts of the entire plant into one continuous whole.

Concerning the chemical nature of cytoplasm, little has been definitely determined. That it is very complex, exceeding labile or unstable and changing its composition readily and with accompanying release or absorption of energy, we are assured. These characters are distinctively "vital"; they are necessary to the manifestation of life; but, as regards the definite chemical composition of cytoplasm and similar protoplasmic bodies, about all we can say is that these contain several or many protein substances, colloidal and nitrogenous, together with water in varying propor- 
tions, inorganic salts and various food materials. A distinction is here made between protoplasm, which is a definite substance, and cytoplasm, which is composed of protoplasm and various inclusions to be mentioned presently.

Surrounding the cytoplasm closely and also in intimate contact with the cell wall is a delicate protoplasmic film termed the ectoplasm, which is best seen when the protoplast is caused to contract

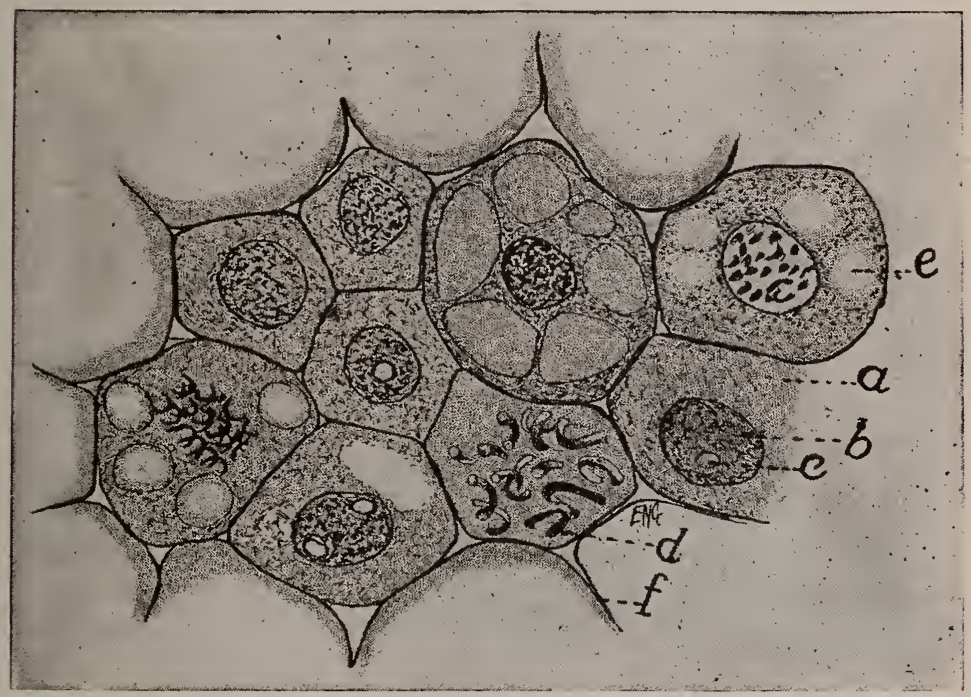

Fig. 333.-Cells from the root tip of the Onion, showing the protoplasts; a, cytoplasm; b, nucleus; c, nucleolus; d, chromosome; e, vacuole; f, cell wall.

by applying salt solution. The ectoplasm controls the passage of materials to and from the protoplast and takes part in building the cell wall. A similar protoplasmic film lines the vacuoles.

The nucleus is imbedded in the cytoplasm, usually toward the center of the cell, and in young cells occupying a half to threefourths of the diameter. The nucleus is roundish or lenticular in shape and is constituted of a network or "reticulum" composed of threads of linin in which granular particules of chromatin are imbedded. These meshes hold a clear, fluid nuclear sap. There is also one or more tiny, globular, somewhat denser bodies termed nucleoli. A nuclear membrane, resembling the ectoplasm, sur- 
rounds the nucleus and separates it from the cytoplasm. (Fig. 333.)

The nucleus is, in a sense, the center of life of the cell, in proof of which we find that, at least in all but the lower unicellular plants, every living cell contains a nucleus. Further, the nucleus divides with accuracy into two equal and similar parts during cell-division. The elaborate precautions for ensuring the accuracy of this division make it seem probable that the nucleus bears the inheritable qualities. In fact, it has been suggested that the

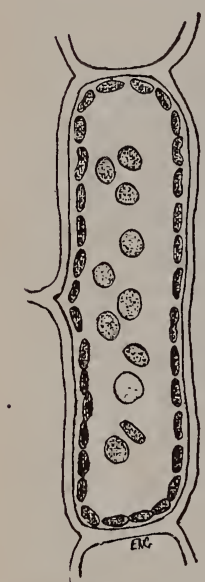

Fig. 334.

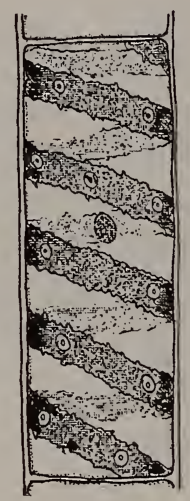

Fig. 335 .

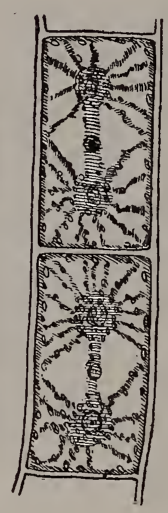

Fig. 336.

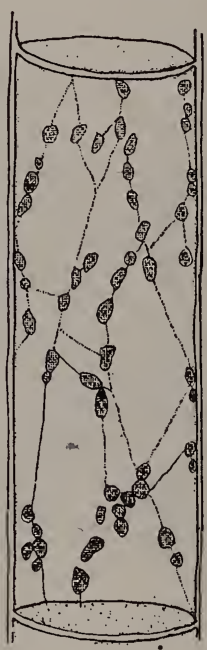

Fig. 337.

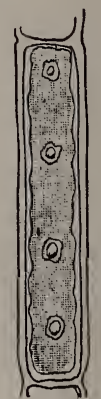

Fig. 338.

Fig. 334.-A cell of Philotria, showing choroplasts of the ordinary lensshaped form.

Fig. 335.-A cell of Spirogyra, showing spiral chlorophyll bands. phyll.

Fig. 336.-Two cells from Zygnema, showing stellate arrangement of chloro-

Fig. 337.-A cell of Oedogonium, showing chains of chloroplasts.

Fig. 338. - A cell of Mesocarpus, showing the chloroplast as a single green
plate.

nucleus controls and regulates the life of the protoplast in a manner remotely resembling the relation of the brain to the body of man. The nucleoli are apparently merely granules of food substance reserved for the nourishment of the chromatin.

Among the other bodies enclosed in the protoplast, the chromotophores are the most prominent: Under this name are included three groups of plastids which apparently originate in the neighborhood of the nucleus and are at first colorless, but more highly refractive than the surrounding cytoplasm. In such 
plant parts as are exposed to sunlight, these plastids develop a green color and are then known as chloroplasts or chlorophyll granules. They are commonly lens-shaped or elliptical and flattened and are found chiefly in the outer portion of the cytoplasm, adjoining the cell wall (see Fig. 334). In the lower plants the chlorophyll may take the form of spiral bands, as in Spirogyra (see Fig. 335), stellate masses, as in Zygnema (see Fig. 336), or a variety of other shapes (see Figs. 337 and 338). Each chloroplast is composed of a colorless, protoplasmic base, infiltrated with a solution of a green pigment, chlorophyll, which, in turn, is composed of several pigments: chlorophyll $a$ and chlorophyll $b$, constituting the green part, and carotin and xanthophyll, the yellow part. This green pigment may be extracted by alcohol, ether or chloroform, leaving the granules colorless. The solution is dichromatic, being a bright green in a thin layer and blood-red in a thick layer when viewed by strong light passing through it. Under the spectroscope it presents a characteristic absorption band in the red part of the spectrum.

The green color of plants is due to chlorophyll, which, however, is frequently masked by other colors dissolved in the sap, as in many Algæ, as well as in our so-called "foliage plants." Under certain circumstances chlorophyll undergoes disorganization; an instance is the production of the beautiful variations of color familiar to us in autumn foliage. If kept away from light, green plants may gradually become yellow or "etiolated"; the blanching of celery is an example. In such parts of plants as are not exposed to light, the chromatophores fail to develop green color and remain as leucoplasts. These are usually globular in shape and may contain crystals of proteid substance.

Chromoplasts differ from the preceding in their color, which ranges from yellow to red, and in their often crystal-like shape, due to the crystallization of their coloring matter. They arise either directly from chromatophores or from chloroplasts, and, like the latter, have a colorless base or stroma. The yellow and orange colors of many flowers and fruits are due to the chromoplasts they contain.

In the peculiar plants known as Fungi, chromatophores of all descriptions are absent.

\section{OTHER CELL CONTENTS.}

Other Cell Contents, sometimes considered as.inclusions in the protoplast, comprise the products of photosynthesis, such as starch, 
sugar and other carbohydrates; fixed oils and fats, especially abundant in seeds; the protein substances, notably aleurone; the inorganic salts, most prominent among which are the various forms of calcium oxalate crystals; the tannins, of frequent occurrence especially in the outer tissues of plants; the volatile oils and resins; the mucilages, the glucosides, the alkaloids and the enzymes.

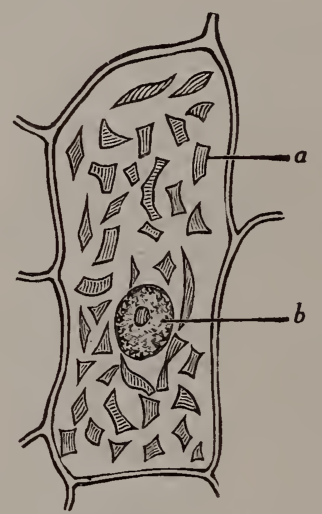

Fig. 339.-A cell from the calyx of the Nasturtium, showing, a, crystal-like chromoplasts, and $\mathrm{b}$, nucleus.

Starch is the first visible product of photosynthesis and is found in chloroplasts whenever these have been exposed to light. This "assimilation starch" represents the transformation of the radiant energy of sunlight into the potential energy stored up in the carbohydrate. Starch is built up from the carbon dioxide of the air and the water from the soil, and appears first as glistening particles imbedded in the chloroplasts. It is generally assumed that glucose is formed primarily, but is rapidly condensed into starch. Almost as fast as they are formed, the granules of assimilation starch are attacked by the enzymes of the protoplast and dissolved, so that their mass does not greatly increase, and upon the approach of darkness, when the production of starch ceases, the tiny starch bodies soon disappear entirely from the chloroplasts. In a soluble form the starch is transported to the storage tissues of the plant, where with the aid of the leucoplasts or "starch-formers" it is deposited as grains of "reserve starch."

All our food and drug starches are reserve starches. Their grains are of definite shape and structure, being built up of layers formed about a centre called the hilum and which may occupy the 
geometric centre of the grain (concentric) or may, more commonly, be situated toward one side (excentric). These layers are due in part to the variation in the water content of the different parts of the grain. The stratifications thus formed are more distinctly seen when the grains are mounted in water and usually show to the best advantage at the moment that the grain swells, when acted upon by alkali or boiling water. Starch solutions, obtained by the action of boiling water, alkalies, acids or digestive ferments, are thick and colloidal, and give at first the characteristic blue color with iodine. This blue color is destroyed by heat but reappears on cooling. Some starches give a purple rather than a blue color with the reagent. Under the microscope, undissolved starch grains in contact with an excess of iodine finally become black.

The starches belong to the class of carbohydrates known as polysaccharoses, the empirical formula usually assigned to these being $\left(\mathrm{C}_{6} \mathrm{H}_{10} \mathrm{O}_{5}\right) n$, in which $n$ may be any number from 20 to 200 . When viewed under the microscope by polarized light, starch grains exhibit a dark cross, the arms of which intersect at the hilum of the grain. Not only do starch grains differ in size, ranging from one to as much as one hundred seventy microns ( 0.001 to $0.17 \mathrm{Mm}$.), and in shape, being spherical, polyhedral, oval, disk-like, elliptical and with various knobs and projections, but they differ also in the form and distinctness of their stratifications as well as in the cleft, which appears in some grains as simple short lines or fissures extending through the hilum but in others is variously branched and stellate. Simple starch grains possess but one hilum, but compound starch grains have two or more hilums with a set of stratifications around each. Large compound starch grains are found in oats and in rice; smaller compound grains occur in many drugs. While these characters of starch grains vary widely in different plants, yet they are fairly constant for each species and hence are of considerable diagnostic value in the study of foods and drugs. (See Figs. 340 to 347.)

Inulin is a carbohydrate which is closely related to starch and isometric with it. It takes the place of that substance in many members of the Compositx. It is abundant, for example, in the roots of Elecampane, Dandelion, Chicory, Dahlia and the Artichoke. It is also occasionally found in members of other families. Inulin occurs in solution in the cell-sap, but if parts containing it be soaked for a time in strong alcohol, and sections of them be 
examined microscopically, sphæro-crystals of it will be observed in the cells, as shown in Fig. 348. Iodine does not stain inulin

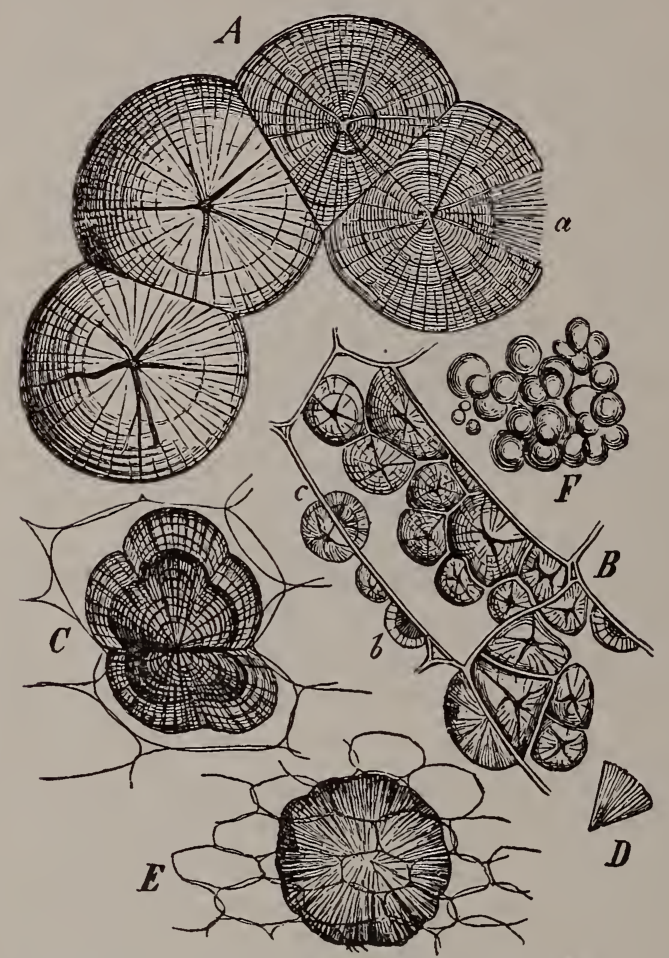

Fig. 348.- Sphaero crystals of inulin; $A$ and F, deposited by crystallization from an aqueous solution. B, from Dahlia tuber. C, E, and F, from Helianthus tuberosus. D, fragment of a sphaero crystal. B, C, D and E, after treatment with alcohol.' (Sachs.)

blue, as it does starch, but, like starch, it is converted into glucose by the action of dilute sulphuric acid.

Sugars. The sugars are sweet and crystallizable principles of plants and occur in solution in the cell-sap. Attention has already

(SEE ILLUSTRATION ON OPPOSITE PAGE.)

Fig. 340.-Manihot starch, showing truncate forms.

Fig. 341.- Corn starch, showing angular and rounded forms.

Fig. 342.- - Starch from the latex of Euphorbia splendens, showing boneshaped and club-shaped forms.

Fig. 343.- Starch from Colchicum corm, showing compound grains.

Fig. 344.-Bean starch, showing characteristic clefts.

Fig. 345.-Wheat starch, showing lenticular grains.

Fig. 346.-Potato starch, showing excentric stratifications.

Fig. 347.-Oat starch, showing compound grains with numerous individual granules. 


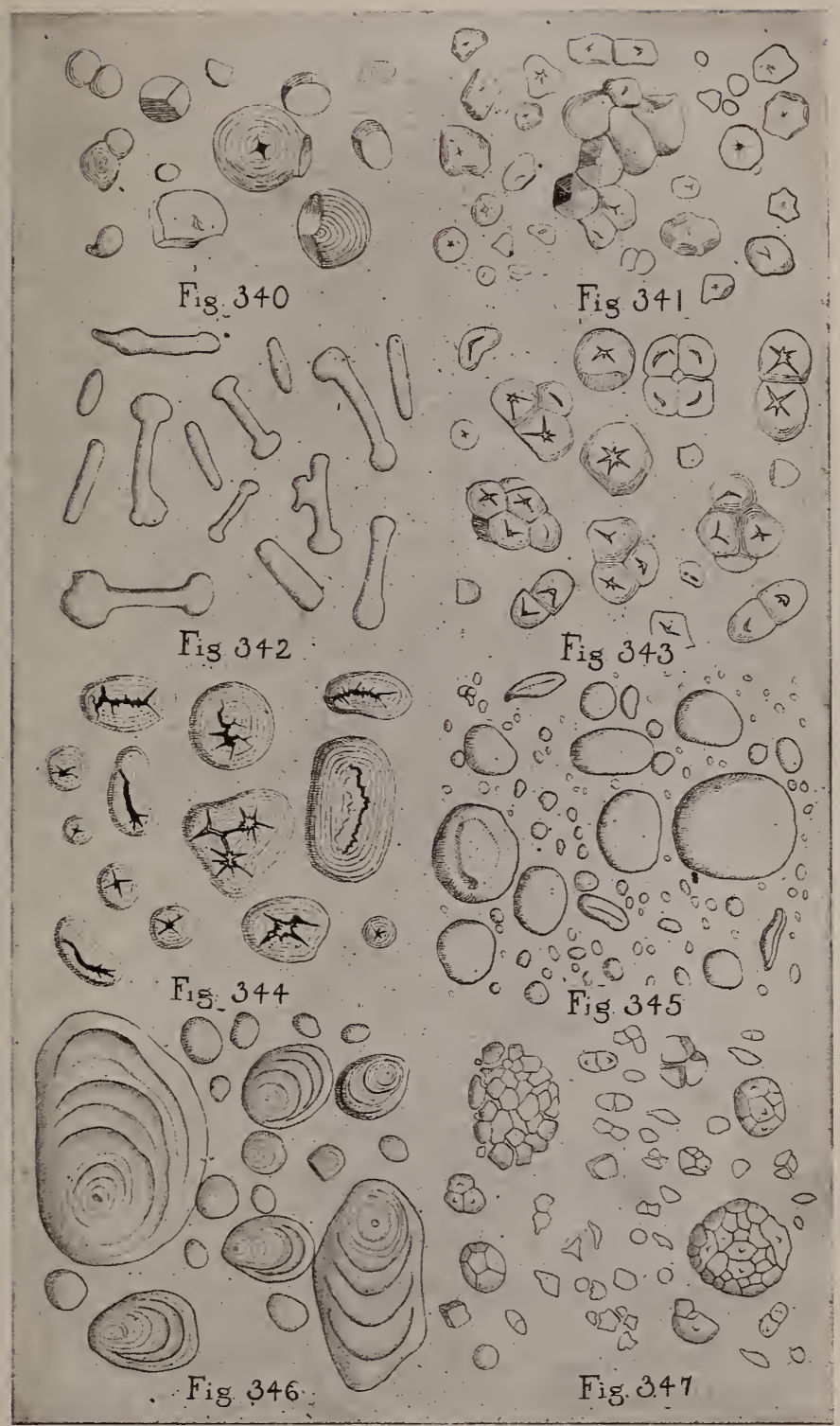


been called to one of the sugars, glucose, which, presumably, is the form in which carbohydrate is first produced in photosynthesis. From this basal photosynthate the more complex carbohydrates, notably starch, are apparently built up.

In general, sugars char when strongly heated, are freely soluble in water but only slightly soluble in alcohol. The sugars are divided into two groups, the monosaccharoses, formerly known as glucoses, and the disaccharoses, formerly known as saccharoses.

The monosaccharoses comprise the simple sugars, that is, those that do not hydrolyze into other sugars. They contain from two to nine carbon atoms in the molecule and classified accordingly as bioses, trioses, tetroses, pentoses, hexoses, etc.

The hexoses are the most important group of monosaccharoses. They have the formula $\mathrm{C}_{6} \mathrm{H}_{12} \mathrm{O}_{6}$ and include two common plant sugars, glucose, known also as dextrose, grape sugar or starch sugar, and fructose, known also as levulose or fruit sugar. Both of these share with the other monosaccharoses certain properties common to the group and may be recognized by their power of reducing an alkaline solution of copper sulphate (Fehling's solution) with the production of a deposit of red cuprous oxide.

As indicated by their names, dextrose rotates the plane of polarized light to the right and levulose to the left. Both are fermentable by yeast. They occur associated together in many fruits. Fructose is considerably sweeter than glucose.

The disaccharoses have the formula $\mathrm{C}_{12} \mathrm{H}_{22} \mathrm{O}_{11}$ and yield upon hydrolysis two molecules of a hexose, not necessarily identical; thus cane sugar hydrolyzes into invert sugar, composed of dextrose and levulose. Cane sugar, known also as saccharose or sucrose (names which are also applied to the class) is the most important member of this group and may be distinguished from the hexoses as well as from most other disaccharoses by the fact that it does not reduce Fehling's solution. It occurs in Sugar cane as well as in Beet root, Sorghum, Sugar Maple,-some palms and other plants, in fact is quite widely distributed. It crystallizes in the form of monoclinic prisms or pyramids. Other disaccharoses are maltose, occurring in germinating cereals, and trehalose, which is found in certain fungi.

Other Carbohydrates. As has already been pointed out, starch and inulin are closely related to the sugars, being, in fact, polysaccharoses. To the carbohydrates belong also pectose, the gums, hemi-cellulose and cellulose. 
Mucilage or gum occurs as cell-contents in relatively few instances. When so occuring, it is stored as a reserve food. Examples are afforded by the medicinal Salep, which is the tuber of an orchid, and by the succulent leaves of the Aloe and the bulb-scales of the Onion.

Far more frequently, mucilage is the result of a metamorphosis of the cell-wall and such "membrane mucilage" will be again mentioned in discussing the wall.

In general, gums or mucilages are characterized by their properties of swelling and at least partly dissolving in water. They are usually grouped according to their composition. Those containing arabic acid and its compounds, of which class Gum Arabic is a type, are completely soluble in water. Those containing bassorin, such as Gum Tragacanth, are only partly soluble. Those containing cerasic acid, such as Cherry gum, form a third class. Cellulose, hemi-cellulose and pectose are cell-wall materials and will be considered later.

Fixed Oils and Fats. These occur in the cells of various parts of plants, but are particularly abundant in certain fruits, as those of the Olive, and in many seeds. They are formed in the protoplast ultimately from glucose. They exist either as tiny drops suspended in the cytoplasm or in somewhat larger globules confined within the vacuoles, and are usually associated with other food substances. They replace starch as a reserve food material, and hence are of great importance to the plant. Chemically considered, they are glycerides of various fatty acids such as oleic, stearic, palmitic or related acids. It is noteworthy that in fats the proportion of oxygen to that of carbon and hydrogen is very smail.

Lecithins are also of frequent occurrence and are related to fats as well as to proteins.

The waxes, which, in their chemical nature, are allied to fats, being compounds of fatty acids with alcohols derived from the higher fatty hydrocarbons, sustain very different relations to the life of the plant. Instead of serving as reserve food-materials, they appear to be purely protective in their function. They occur as excretions on the cuticularized epidermis of many plants. The "bloom" of certain fruits is of this nature, and the glaucous appearance of the leaves and stems of many plants is due to the same cause. The parts covered by it are thus protected from wet and from the spores of destructive fungi; it doubtless serves also 
to check excessive evaporation from the plant. Occasionally, as . in the case of the Brazilian and Andean Wax Palms and the Wax Myrtle of our New England coast, the secretion is sufficiently abundant to be of commercial importance.

Proteins. These are complex nitrogenous substances more or less colloidal in nature and, in plants, mostly stored as reserve food. It would appear that, in the metabolism of the plant, proteins are built up from amides and amino-acids and, when proteins are acted upon by enzymes, the simpler and more soluble nitrogenous substances are again produced. All of these originate in the cytoplasm and, unlike the carbohydrates, do not depend upon photo-synthesis for their formation, hence they occur in fungi as well as in green plants.

The proteins are characterized by their large and complex molecules but differ much in solubility and digestibility.

Hundreds of proteins have been named and grouped under certain general classes; among them are the globulins, which are insoluble in pure water but soluble in neutral saline solutions and coagulated by heat; the albumins, which are soluble in water but coagulated by heat; the glutelins, insoluble in neutral aqueous solutions and in alcohol but readily soluble in dilute acids and alkalies, and the prolamins, which are soluble in alcohol but insoluble in pure water.

In the dry, storage tissues of seeds, reserve proteins are found in characteristic forms known as crystalloids and aleurone grains. Crystalloids are composed of globulins crystallized into cubical or rhombohedral forms and readily distinguished from ordinary crystals by their property of swelling in contact with water. Crystalloids are frequently found imbedded in aleurone grains and occasionally occur suspended in the cytoplasm even in other than storage cells.

Aleurone grains are rounded bodies, formed in the vacuoles of the protoplast and consisting chiefly of globulins. When associated with starch in seeds, they are usually very small and fill in the spaces between the starch grains. In fatty seeds such as the Castor Bean, the aleurone grains are larger and consist of a mass of ground-substance, composed of water-soluble globulins and surrounded by a firmer membrane of similar material. Within such aleurone grains are various inclusions, chiefly crystalloids, globoids and tiny rosette crystals of calcium oxalate. The globoids 
are rounded, as the name implies, and are composeci of calcium and magnesium phosphates in combination with organic substances. (See Figs. 349 to 355 , inclusive.)

The albumins exist in many plant juices. Some of them, such as the ricin of Castor Bean, are powerful poisons and are distinguished as toxalbumins.

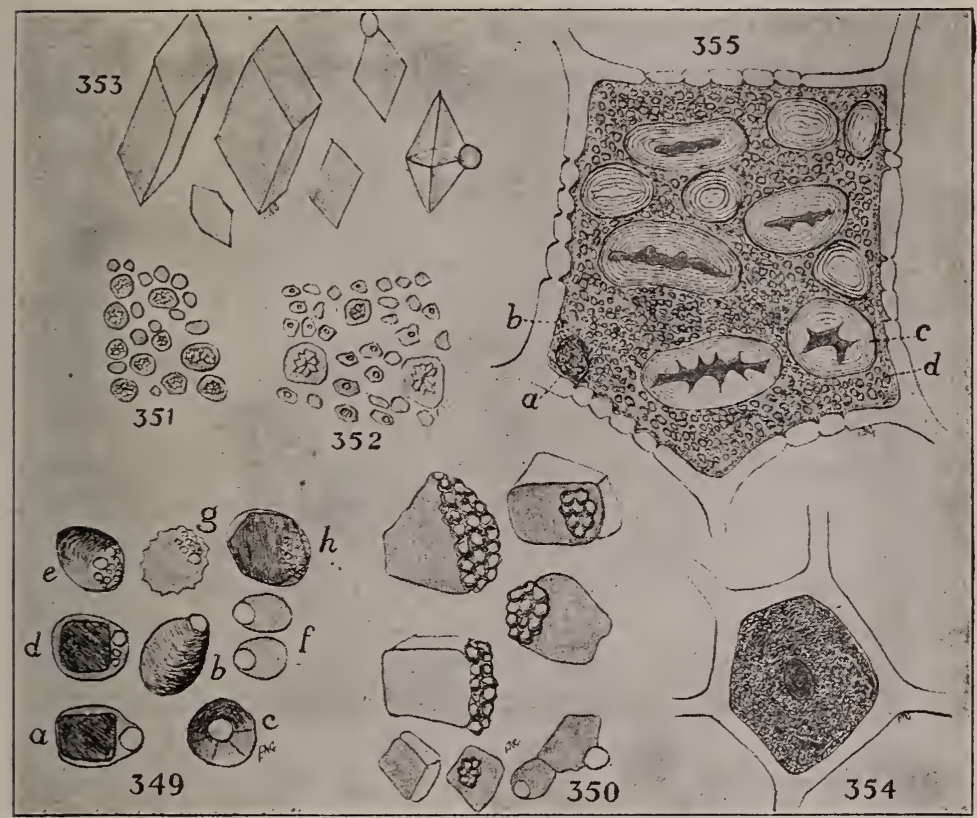

Fig. 349.-Aleurone grains from the Castor bean; a, a grain viewed in direct transmitted light, showing a single crystalloid and globoid. $b$, the same grain in indirect light, showing its ellipsoidal shape. c. the same grain viewed on end, the globoid toward the top. d. a grain viewed in direct light, showing a crystalloid and three globoids. e. the same grain in a different position, slowing several globoids. f, two grains each with a globoid but no crystalloid. g, a grain with crenate or pitted surface and no crystalloid visible. h, a grail: with large crystalloid and numerous small globoids.

Fig. 350.- Aleurone grains from the Brazil nut. Each grain usually contains one crystalloid and one globoid or a globoidal mass. The envelope is very thin.

Fig. 351.-Aleurone grains from Fennel fruit. Globoids are seldom visible, but rosettes of calcium oxalate crystals are present in all but the larger grains.

Fig. 352.- Aleurone grains from Almond. The smaller grains each contain one or more very small globoids, while the larger grains sometimes contain a rosette of calcium oxalate crystals.

Fig. 353.-Aleurone grains from Nutmeg. The crystailoids are very perfectly formed. The globoid is attached at one corner of the crystalloid by a very thin envelope.

Fig. 354.- A cell from the aleurone layer of Wheat. Thie alcurone is in very small angular grains, frequently called "amorphous" aleurone, and surrounds the denser nucleus.

Fig. 355.-A cell from Pea seed inclosing: a, the nucleus; b, ectoplasm; c, starch grains; d, small aleurone grains. 
The gluten of Wheat, which determines the dough-making qualities of flour, is a mixture of a glutelin (glutenin) and a prolamin (gliadin).

The conjugated proteins, highly complex in chemical structure and less readily digestible than the simple proteins, include the nucleins, which contain phosphorus (phospho-proteins) and occasionally iron or sulphur. They are not attacked by pepsin but are dissolved by alkaline solutions.

The protein derivatives result from the hydrolysis or cleavage of the simple proteins when digested by enzymes or dissolved by dilute acids. Peptones and proteoses are soluble and diffusible proteins thus produced, and these are in turn resolvable into amino-acids.

Enzymes are complex organic substances, possibly proteins, of whose composition little is known. They are characterized by their power of bringing about important chemical changes in substances with which they are in contact, without themselves entering into permanent combination or suffering material loss. They are, therefore, organic catalysts, and are, perhaps, the most important of the cell contents. Enzymes are sometimes styled unorganized ferments, as distinguished from organized ferments such as yeasts and bacteria. The distinction scarcely holds, however, since it has been shown that the catalytic power of organized ferments depends upon enzymes which they contain. A better division is that into endocellular enzymes, which cannot diffuse out of the cell, and extracellular enzymes, which can do so. A peculiarity of enzymes is the great amount of material which can be changed or converted by a relatively very small amount of the ferment. Thus diastase, the enzyme obtained from malt, can hydrolyze ten thousand times its own weight of starch, and rennet, an animal ferment, is capable of coagulating a half million times its own weight of casein. Enzymes are sensitive to heat and light. All are destroyed at $100^{\circ} \mathrm{C}$; few can be safely exposed to heat above $60^{\circ} \mathrm{C}$. Like living organisms they have an optinum temperature at which they are most active. Above this point their activity becomes permanently impaired. They withstand low temperatures without injury.

Certain substances stimulate the activity of enzymes. Such activators include a variety of chemical substances, acids, alkalies and salts, and may be separated from the ferment by dialysis. 
The activity of an enzyme may be suspended by the removal of its activator and restored by again adding this to it. In some instances the enzyme is only developed by the action of the activator on an inactive substance, the zymogen formed in the cell. A kinase is a complex organic body, colloidal in nature, which activates the zymogens in living tissues.

Inhibitors of enzyme action are called paralyzers. They may be foreign or be the result of enzyme action itself. Thus alcohol, formed by the action of yeast, will in sufficient strength destroy the ferment that produced it. Antiseptics are paralyzers, notably bichloride of mercury.

Enzymes are usually grouped according to their reactions: The first group includes those enzymes which hydrolyze or cause the addition of water to certain substances, which are then mostly broken up into simpler substances. The digestive ferments fall in this group. Diastase, or amylase, converts starch into glucose; protease, identical with pepsin, changes insoluble proteins into soluble peptones; cytase converts cellulose into soluble forms; lipase digests fats and fixed oils, converting them into fatty acids and glycerin; emulsin and myrosin have the power of hydrolyzing the glucosides amygdalin and sinigrin, respectively, with the production of the volatile oils of bitter almond and of black mustard.

The second group of enzymes cause the splitting of certain substances without the accompanying hydration. The zymases, among which are the enzymes of yeast, represent this class.

The third group are the oxydases or oxidizing enzymes, such as the ferment, produced in the acetic bacteria, which oxidizes alcohol to acetic acid. It is to enzymes of this group that the darkening in color of freshly cut fruits and of mushrooms is due.

The fourth group is the reducing enzymes or katalases, which may reduce nitrates to nitrites, or hydrogen peroxide to water and oxygen.

It must be borne in mind, however, that not only the analytic but the synthetic powers of living cells depend upon the enzymes formed therein, so that the entire metabolism of the plant, its growth and maturation, no less than its senility and decay, are contingent upon these little-known but very necessary agents.

Important industrial processes, such as the making of bread and of cheese, brewing, the "retting" of flax and many others, depend upon enzymes for their operation. 
Glucosides. The glucosides are substances found in solution in the cell-sap, and whose peculiarity consists in the fact that under the influence of enzymes or ferments which occur in the cells with them, they are decomposed into glucose or some similar sugar and another substance capable of still further decomposition. The hydrolysis or splitting of glucosides may also be effected by dilute acids and alkalies.

An example is afforded by Amygdalin, which under the influence of an enzyme, emulsin, hydrolyzes into glucose, benzaldehyde and hydrocyanic acid. This and other cyanogenetic glucosides are widely distributed in the plant world. They are familiar to us in bitter almond and in wild cherry bark. Another rather widelydistributed glucoside, Hesperidin, is often met with in crystalline form, especially in the rind of citrus fruits. The saponins, characterized by their property of frothing in water, are a group of glucosides, members of which are found in a large number of plants. An important medical saponin is Digitonin from Digitalis leaves.

The glucosides are mostly soluble in water; quite a number can be crystallized from their solutions. Many are active medicinal principles; some of them, such as strophanthin, are highly poisonous.

Pentosides, such as Aloin, the cathartic principle of aloes, are closely related to glucosides but yield pentose instead of glucose on decomposition.

Glucosides are usually regarded as reserve food-materials, the sugar part of the molecule being dissociated by hydrolysis for use by the plant, the other part of the molecule remaining in the cell and combining again with sugar when an excess of carbohydrate is available. Probably other functions, such as protection against animals, antisepsis of injured tissues and excretion of sugar in the extra-floral nectaries, may also be served by these very diverse bodies. Glucosides may occur in any or all of the storage tissues of the plant or may be stored temporarily in the leaves, and later translocated to the permanent storage tissues of the cortex.

Alkaloids. These are potent principles of plants, including some of the most valuable of medicines as well as some of the most powerful of poisons. As a class, they are nitrogenous organic bases and combine with acids to form salts, thus showing their resemblance to alkalies, whence the name alkaloid. They are 
formed in considerable variety and through a wide botanical range, though many plants do not possess them at all. It has not been ascertained that alkaloids are of any service to the plant, except, perhaps, as a means of defense against predacious animals and parasitic fungi. They may even be injurious to the plants that produce them. In reserve tissues of the plant, especially in rhizomes, corms, bulbs and roots, alkaloids are usually associated with stored food and larger in amount at the periods when this reserve food is at its maximum, but in the leaves and tops of plants, alkaloids are usually most abundant at the time of flowering or immediately thereafter. In most instances the alkaloids are found in the plant in combination with organic acids, especially tannic and malic acids, or with some characteristic acid, as meconic acid in Opium.

Among the better-known alkaloids are Quinine, from the Cinchona barks; Morphine and Codeine, narcotic principles of Opium; Cocaine, the enslaving alkaloid from Coca leaves; Strychnine, the poisonous alkaloid obtained from Nux Vomica; the even more poisonous Atropine, from Belladonna; Caffeine, found in Tea, Coffee, Cola, Guarana and Mate, and to which the stimulant effect of beverages prepared from these is due; Theobromine, closely related to Caffeine and found in Cacao seeds and hence in Chocolate; Nicotine, the volatile alkaloid of Tobacco, and Muscarine, the deadly poison of some of the Mushrooms.

According to their chemical relationship, alkaloids are classified into several groups, among which are:

The Purine group, including Caffeine and Theobromine, both having but feebly basic properties and apparently decomposition products of proteins, corresponding to urea and uric acid in animals.

The Quinoline group, comprising the alkaloids from Cinchona and Nux Vomica and restricted to the Rubiaceae and Loganiaceae respectively.

The Isoquinoline group, including Morphine and Papaverine, from the medicinal Poppy, and Berberine, restricted to the order Ranales.

The Pyridine group, including the liquid and volatile alkaloids, these being mostly derivatives of Pyridine. Among them are Arecolin, Piperine, Coniine and Nicotine.

The Pyrrolidine or Tropine group, including the solanaceous 
or mydriatic alkaloids, Atrophine, Hyoscine and Hyoscyamine, as well as Cocaine and Pelletierine.

As a class, the uncombined alkaloids are largely soluble in strong alcohol, chloroform or ether, while their salts are most readily dissolved by water or diluted alcohol and are not soluble in chloroform or ether. Among the reagents for alkaloids are phospho-molybdic acid, which precipitates nearly all alkaloids, and potassium-mercuric iodide (Mayer's reagent), which precipitates many of them. Tannic acid as well as iodine also reacts with most alkaloids. Gold and platinum chlorides form characteristic microcrystals with certain alkaloids.

Tannins are astringent substances which, dissolved in the cell sap or deposited in cells in amorphous form, are widely distributed in plants and recognized by their property of striking blue-black or green colors with solutions of iron salts. Tannins are often present in considerable quantities in epidermal cells, especially in winter leaves. Yellowish or reddish-brown substances, at least partly tannin, often fill the cavities of thick-walled cork cells. Excretory tannin products are sometimes found in special cells occurring in rows and following the course of the conducting bundles or in sac-like or tubular cells, various in form and structure, developed in the parenchyma tissue.

The value of tannins to the plant is doubtful. Like glucosides and alkaloids, they may serve in some instances as a means of protection against animal attacks or to repel parasitic fungi, especially when the tannins are situated in the epidermis or the cork.

Chemically, the tannins are divided into tannides, which have the nature of glucosides, and tannoids, which do not yield glucose when hydrolyzed by acids. These groups are further divided into catechu-tannins and gallo-tannins, related to protocatechuic and gallic acids, respectively.

Tannins are soluble in water, alcohol or a mixture of alcohol and ether. Their solutions give distinct color reactions with ferric chloride, ferrous sulphate, copper acetate, and other reagents. They precipitate albumin, gelatine and most of the alkaloids. In alkaline solutions, tannins absorb oxygen and darken in color.

Volatile Oils. Essential or volatile oils are usually the odorous principles of the plants that contain them. Although bearing some resemblance to the fixed oils or fats, they differ from these widely in chemical nature and are themselves, in fact, a most 
heterogeneous group, including mixtures of various principles; terpenes, esters, alcohols, phenols, aldehydes, ketones and lactones, as well as compounds of sulphur and of nitrogen.

While some of these originate in the protoplast as such, others result from the decomposition of glucosides and even through the conversion of the cell-wall substance.

They are often excreted along with resins into secretion reservoirs (see page 211 ).

Some volatile oils are of service to the plant in protecting it against injurious insects or other animals, and perhaps also against destructive fungi, while others, as the floral perfumes, are useful, as we have already seen, in attracting insects to flowers, and so effecting cross-fertilization by their agency.

Volatile oils are widely distributed among the flowering plants and are especially abundant in certain groups, notably the families Coniferæ, Labiatæ, Umbelliferæ, Myrtaceæ, Rutaceæ and Zingiberacex.

Resins, Oleo-resins, Gum-resins, and Balsams. Resins are very common constituents of plants. They appear to be of the nature of excretory products, either occurring normally, or produced pathologically as the result of injuries to the plant. They are either produced in special cells, or groups of cells, called glands, occurring on the surface of plants, or forming the terminal cells of glandular hairs, or else in internal cells which pour their secretions into intercellular spaces, called secretion reservoirs (see page 211). They are, for the most part, amorphous, more or less transparent, readily fusible substances, which cannot be volatilized without change, and which are soluble in alcohol, and in the volatile oils, but not in water. Tschirch classifies resins into the following groups: tannol resins, resene resins, resinolic acid resins, resinol resins, pigment resins and glucosidal resins. When resins are associated with volatile oils, as in Copaiba and common Turpentine, they are called oleo-resins; if they contain benzoic or cinnamic acids, either with or without volatile oils, they are called balsams or balsamic resins, respectively, and if mixed with gums, they are termed gum-resins. The last are often constituents of the milk-juice of plants. Styrax, Peru balsam and Tolu balsam are examples of the balsams, and Gamboge, Myrrh and Asafœtida of gum-resins. Caoutchouc and Gutta-percha are peculiar resinous constituents of the milk-juice of some plants.

Acids. Among the more important of these may be mentioned 
malic acid, a very common acid in fruits, but also found in other parts of plants; oxalic acid, abundant and widely distributed; citric acid, which communicates the acidulous taste to lemons, limes, and other citrus fruits, and which not infrequently occurs;

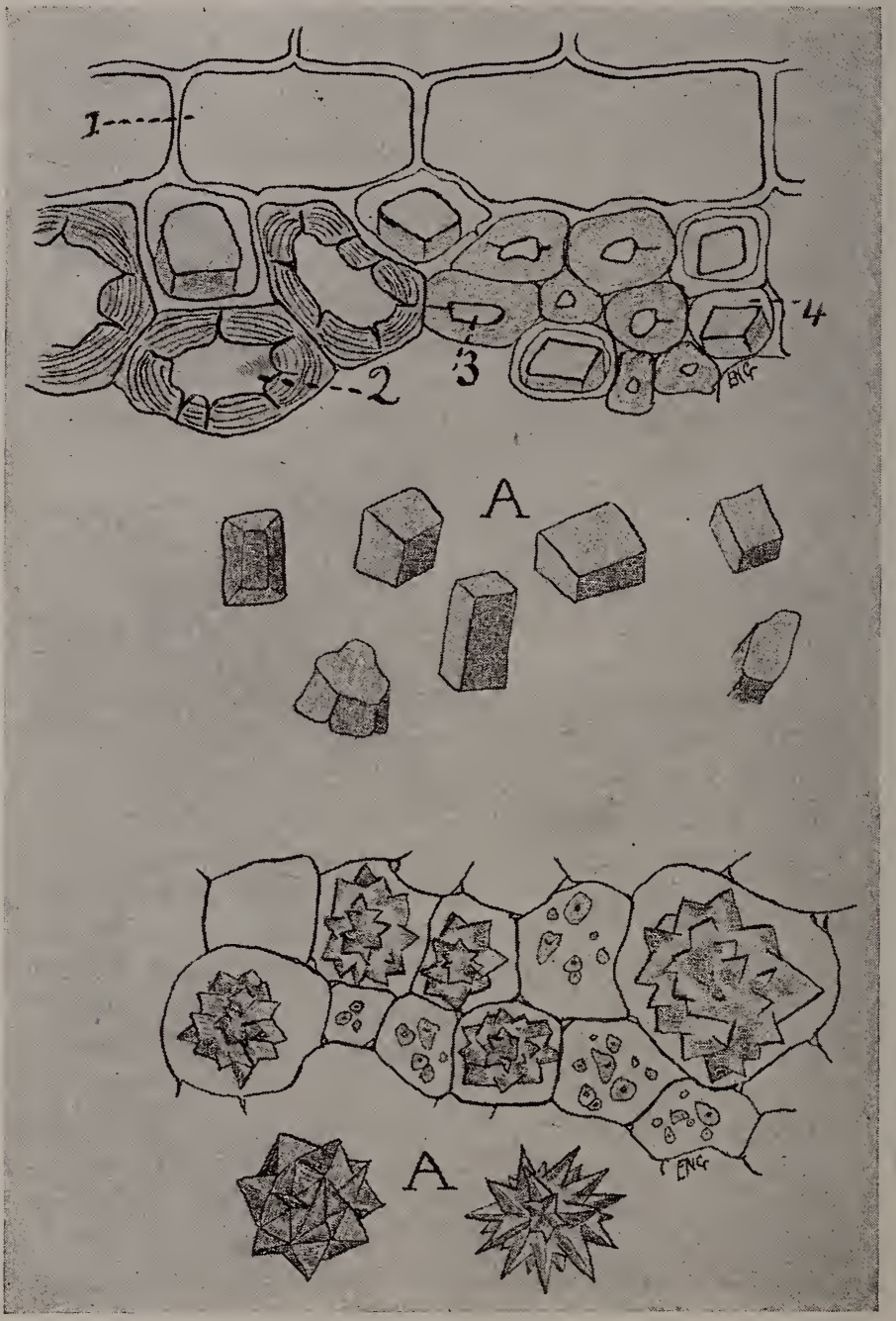

Fig. 356.-(Above.) Section of Witch-hazel hark, showinr hexagonal crystals of calcium oxalate in the cells. A several crystals isolated from the cells. Fig. 357.-(Below.) Section of Riuharb. showing rosette clusters of crystals of calcium oxalate. A, diagrammatic forms of these rosettes. 
also, in other fruits; and tartaric acid, which exists in considerable quantity in grapes, but is not wanting in many other fruits. However, many other acids occur less abundantly. Acids may exist free or in combination with various bases. The acid reaction which many plants exhibit may be due either to the presence of free acids, or to acid salts in solution.

Mineral Substances. The cell sap contains many inorganic substances in solution, such as silica, and salts of potassium, sodium, calcium, magnesium and iron. Silica and salts of calcium may be

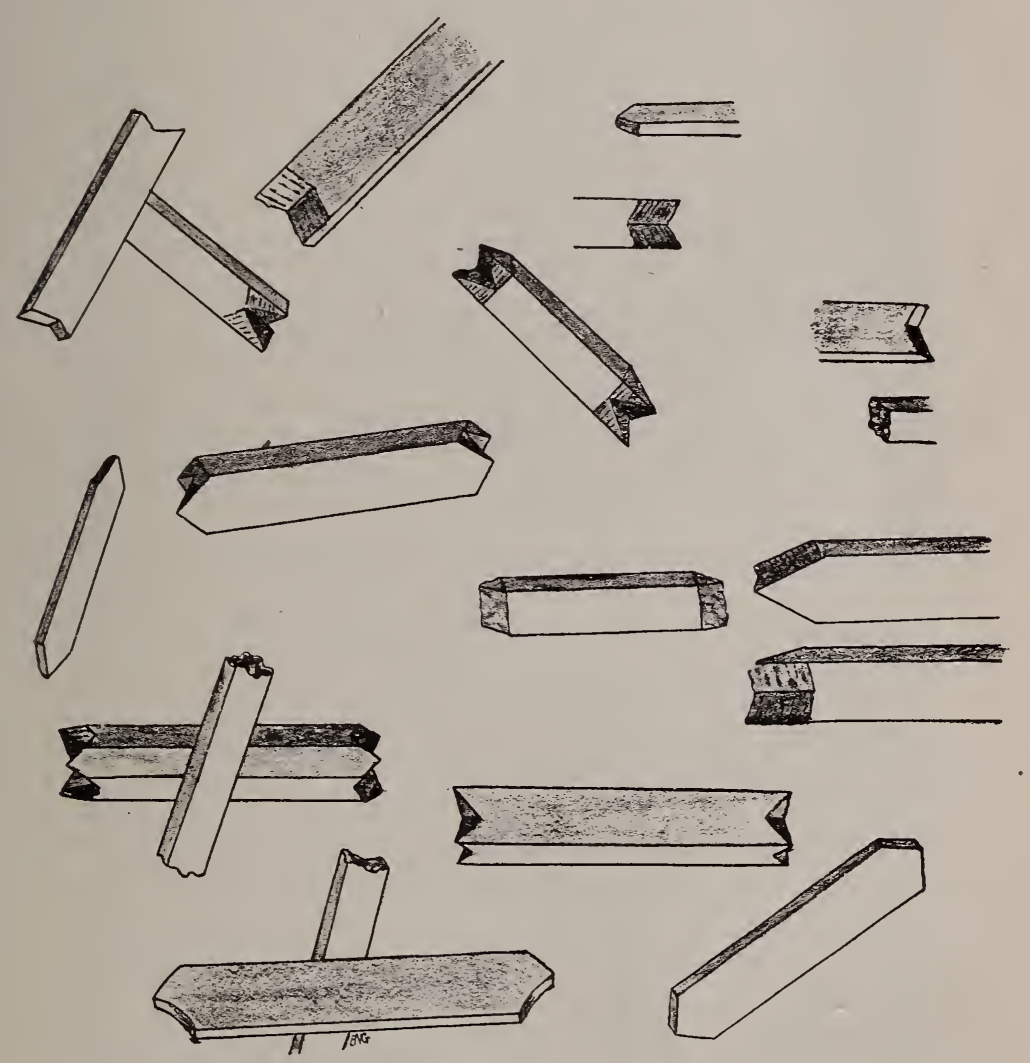

Fig. 358.-Monoclinic crystals, showing hemitrophy, commonly called "twin crystals," from soap-tree bark.

deposited, either in the amorphous or crystalline form, in the substance of the cell-wall. But, besides these, crystals of mineral matter are often found in the interior of cells. 
By far most common among these is calcium oxalate; calcium carbonate occurs much less frequently and other inorganic substances but rarely.

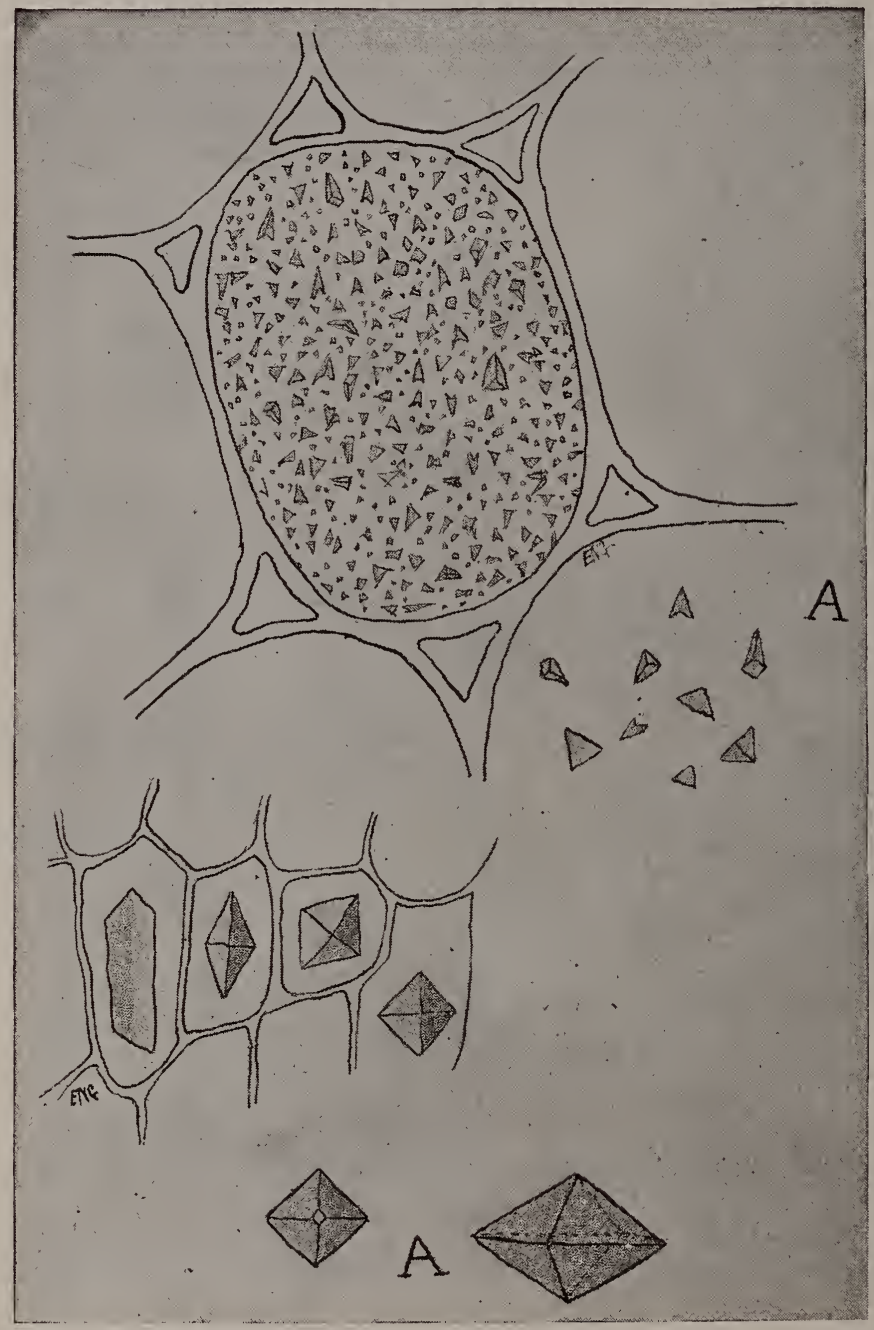

Fig. 359.-A cell from Belladonna root, showing crypto crystals or "crystalsand." A, a more highly magnified view of several of these crystals.

Fig. 360.- Section of Nutgall, showing prismatic crystals in the cells. A, diagrammatic form of these crystals. 
Crystals of calcium oxalate occur chiefly in monoclinic forms and the following types are met with:

(a) Single crystals in pyramids, prisms or somewhat irregular hexagonal shapes (Figs. 356 and 360). Occasionally double or twin crystals occur, notably in Soapbark (Fig. 358).

(b) Needle-shaped crystals or raphides, either solitary or in sheaf-like groups, the latter usually surrounded by mucilage and
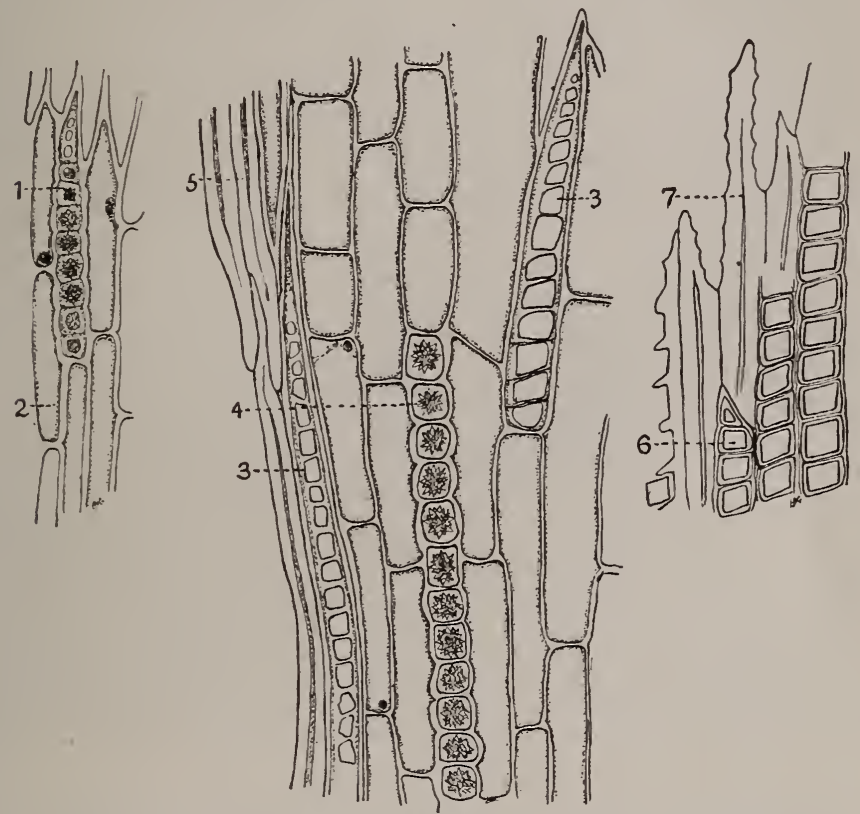

Fig. 361.-Inner bark of Cascara Sagrada: 1, formation of a row of rosette clusters in a single parenchyma cell; 2 , living parenchyma cells; 3 , formation of a row of prismatic crystals in a single fiber cell; 4 , rosette clusters in a row of cells developed from a single cell; 5, developing bast fibers; 6 , crystal fibers containing prismatic crystals, separated by septs; 7 , ends of mature bast fibers.

contained in long, thin-walled parenchyma cells (Figs. 362, 363, $364,365,366$ and 367 ).

(c) Rosette clusters or aggregates, consisting of numerous small pyramids, prisms or hemihedral crystals arranged around a central point or axis, so as to somewhat resemble a rosette or star in appearance (Fig. 357).

(d) Crypto-crystals or "crystal sand," formed of deposits of very minute crystals of arrow-head shape, which occasionally fill parenchyma cells, giving to such cells a dark gray appearance that is characteristic (Fig. 359). 
(e) Crystal fibers, consisting of monoclinic prisms or rosette clusters occurring in a row in a fiber-like cell extending lengthwise. along the groups of sclerenchyma fibers and divided by septa into compartments, each usually holding one crystal (Fig. 361).

Calcium oxalate is recognized by its being insoluble in water,

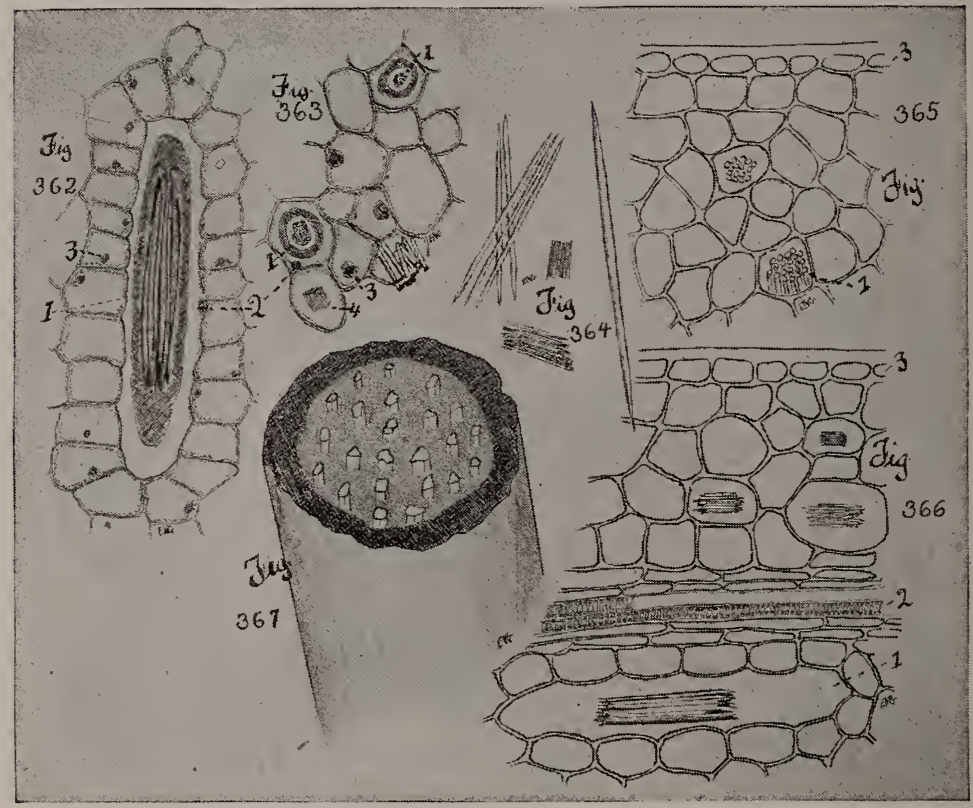

Fig. 362.- Radial longitudinal section of the dried bulb scale of Squill, mounted in alcohol: 1, bundle of raphides enclosed in a hardened and shrunken mass of mucilage; 2 , nucleus and cytoplasm of the large cell, containing raphides; 3 , parenchyma cells, containing nucleus and cytoplasm.

Fig. 363.-Transverse section of same: 1,2 and 2, as under Fig. 362; 4, a bundle of short raphides in longitudinal view.

Fig. 364.-Raphides from Squill separated from the tissues.

Fig. 365.- Transverse section from dried bulb scale of Squill, mounted in water: 1 , bundle of raphides with mucilage coat dissolved awav; 3 , epidermis.

Fig. 366. - Longitudinal section of same: (numbers 1 and 3 as under preceding figure; 2 , wood bundle.

Fig. 367.-Bundle of raphides enclosed in hardened mucilage and separated from cell. The broken raphides project slightly above the cut surface of the mucilage.

alkali or acetic acid, but soluble without effervescence in hydrochloric acid.

Calcium carbonate is present in certain plants belonging to the Urticaceae (Fig. 368) and Acanthaceae in concretions or amorphous masses deposited on a cellulose core and forming the peculiar structures known as cystoliths. Curious stalked cystoliths 
occur in large cells just beneath the upper epidermis in the leaf of Ficus elastica (Fig. 369). Upon treatment with hydrochloric
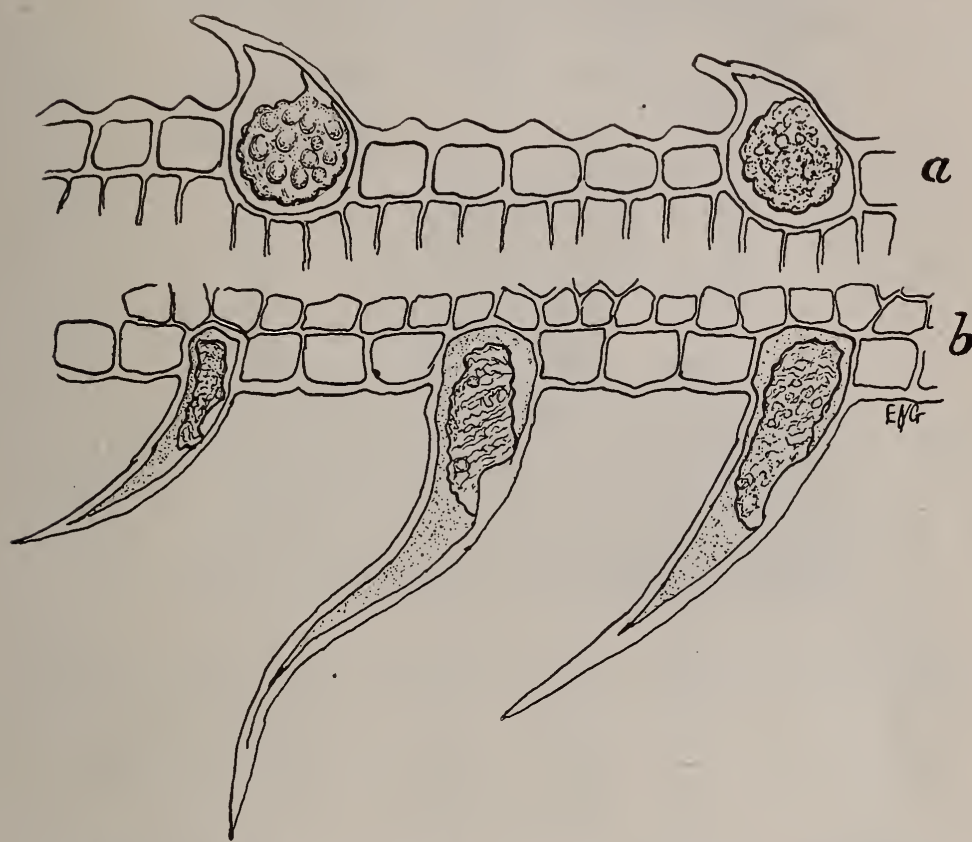

Fig. 368.-Cystoliths in the hairs of the leaf of Hemp; a, upper; b, lower epidermis.

acid the calcium carbonate dissolves, giving off bubbles of carbon dioxide and leaving a skeleton of cellulose.

THE CELL WALL.

While naked protoplasts are found in the earliest stages of development in plants, notably the cells of the embryo-sac (see page 106, Part I), as well as the gametes generally, and while certain kinds of spores of the cryptograms are also of this description, yet these instances must be considered as exceptional, for, as a rule, every plant cell is surrounded by a cell-wall, developed by the protoplast and consisting at first of a delicate film composed essentially of cellulose (see Fig. 333). As growth proceeds, the wall not only becomes thickened to a greater or less extent, but usually unequally so, and this gives rise to markings more or less conspicuous, which may either be irregular in form 


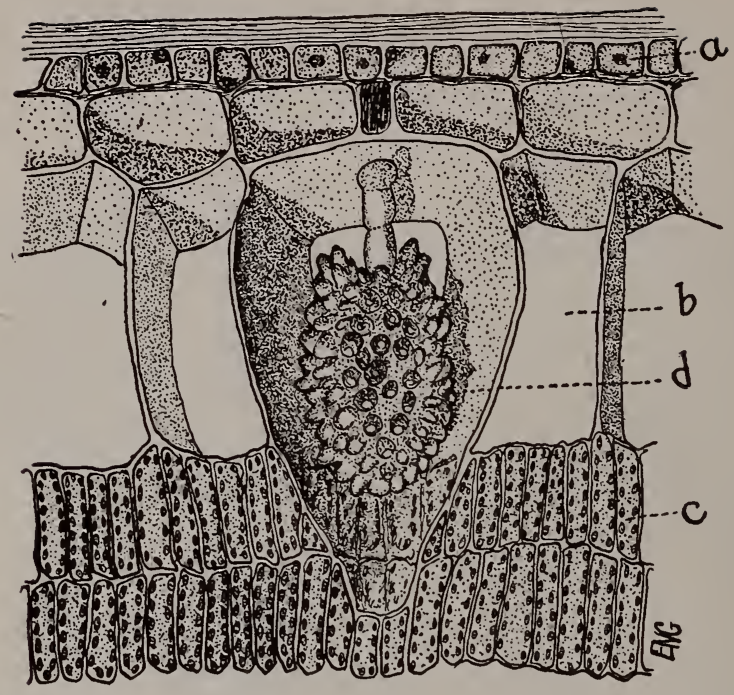

Fig. 369.-Stalked cystolith in the leaf of Ficus elastica: a, epidermis with thickened cuticle; b, water storage cells; $c$, palisade parenchyma; d, cystolith in sac.
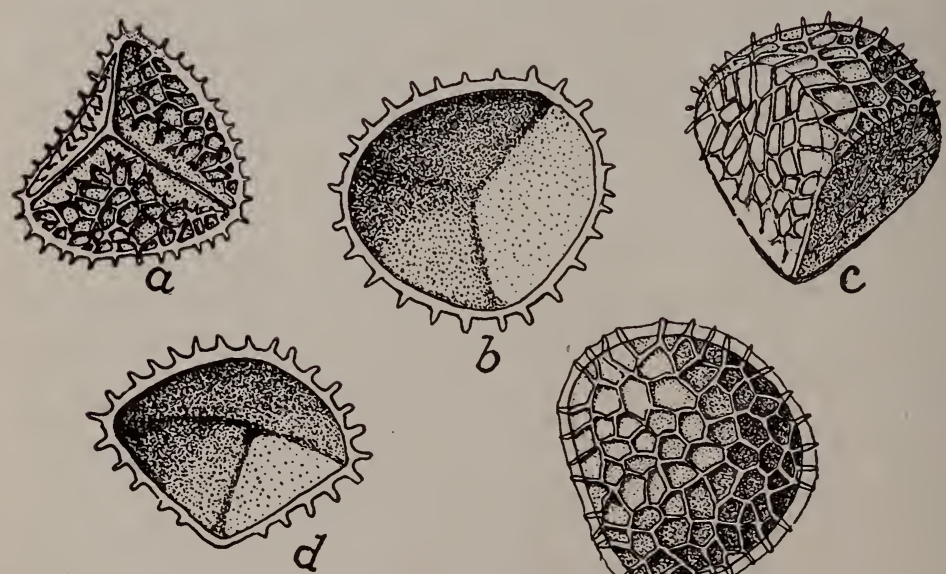

Fig. 370.--Spores of Lycopodium species, showing markizzs in the form of protuberances on the cell wall. $a, c$ and $e$, the whole spores; $b$ and $d$, sectioned spores, showing the interior without cell contents. 
and distribution, or else quite regular and characteristic of certain classes of cells. The markings may take the form of thickenings or protuberances on the outside of the cell-wall, as in the spores of Lycopodium species (see Fig. 370). This cannot well occur, however, except in cells which become independent at or before
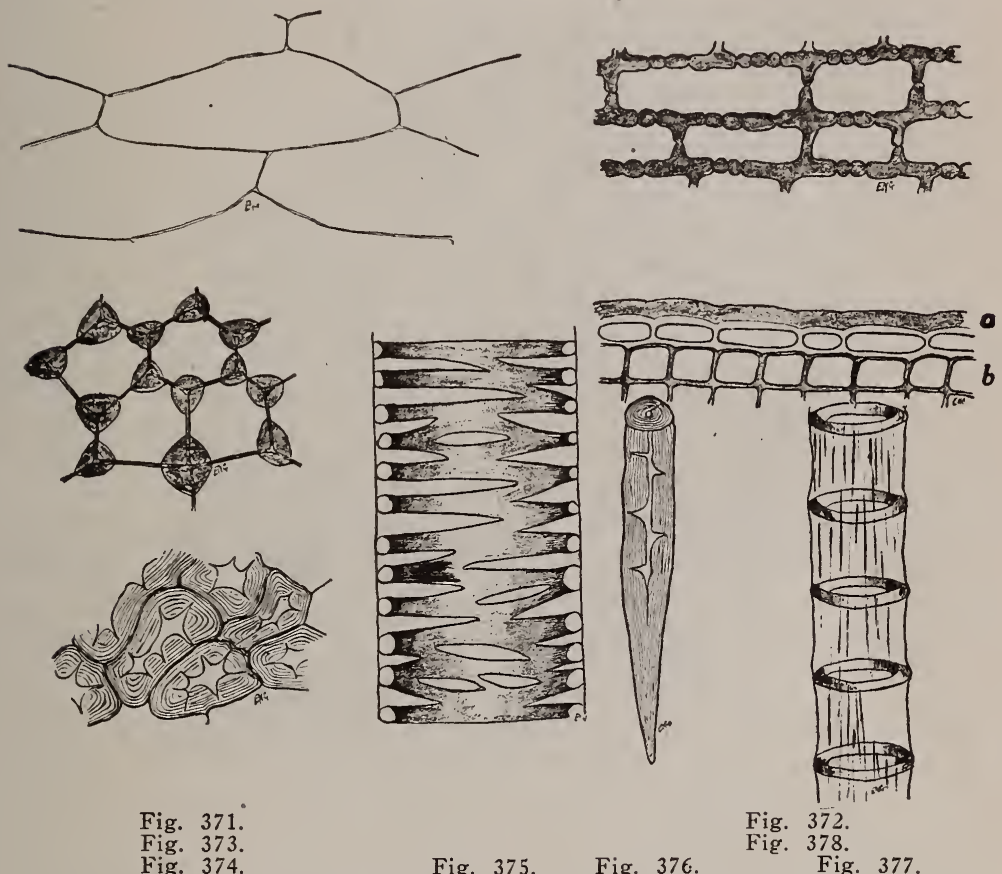

Fig. 371 .

Fig. 373 .

Fig. 374 .

Fig. 375. Fig. 376 .

Fig. 377.

Fig. 371.-Thin-walled parenchyma cells from the tuber of potato, the double wall of cellulose about $0.002 \mathrm{~m} . \mathrm{m}$. thick.

Fig. 372.-Thick-walled parenchyma cells from Cascara Sagrada bark, the double wall of cellulose about $0.001 \mathrm{~m} . \mathrm{m}$. thick and containing prominent pores.

Fig. 373.-Collenchyma cells, cut transversely, from the bark of Abutilon avicennae, the corners of the cells filled with bands or rods of cellulose extending lengthwise of these much elongated cells.

Fig. 374.- Sclerenchyma cells from Cascara Sagrada bark, the walls much thickened and lignified, with stratifications plainly visible, and with distinct pores leading from the cavity of the cell.

Fig. 375 .- Portion of tracheal tube cut longitudinally from the rhizome of Gelsemium sempervirens, showing a thickened lignified wall, but the thickening laid on in anastomosing bands or rods extending tangentially arourd the tube and forming a net-work.

Fig. 376.- Portion, including the end, of a bast fiber from Cinnamon bark, the wall lignified and so thickened as to reduce the cavity of the cell to a tiny canal with branches forming pores.

Fig. 377.- Portion of a cylindrical tracheal tube from the Corn stem, the thin cellulose wall strengthened by thickenings in the form of occasional rings, which are strongly lignified.

Fig. 378.-The epidermis and a layer of cork cells cut transversely from the stem of Solanum dulcamara: a, the outer surface of the epidermis bearing a thick layer of cutin; $b$, the walls of the cork cells infiltrated and covered with suberin. 
maturity. In those cells which are united to form tissues the markings are seen as thickenings on the inner surface of the wall (see Figs. 371 to 378 ). They may form rings, spirals or reticulation, or they may be so arranged that the unthickened portions form circular or oblong disc-like markings. These, in old cells,

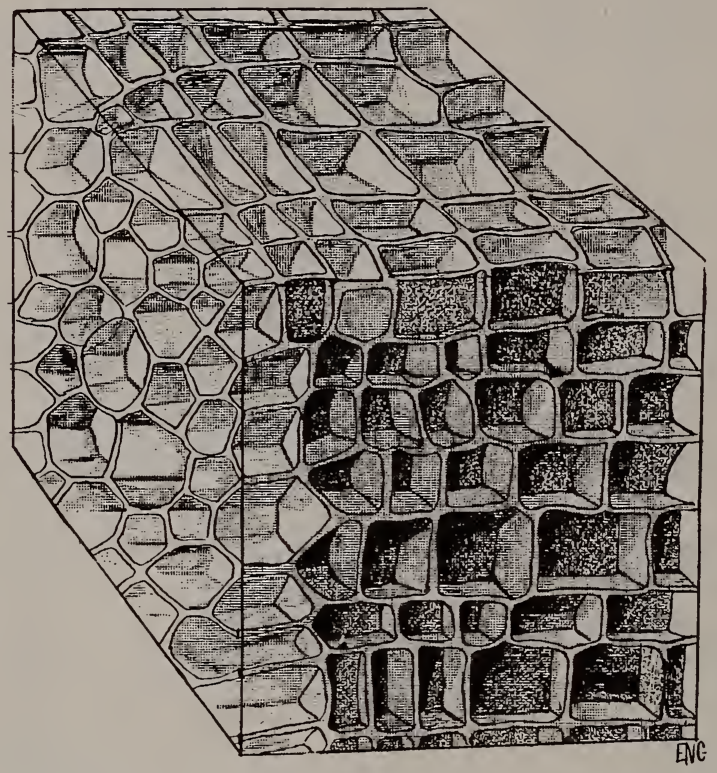

Fig. 379.-Cells of Bottle Cork, showing polyhedral forms.

frequently become perforations. The markings of cells will be more fully described when we come to treat of the different kinds of tissues.

The cell-wall, besides increasing in thickness, grows also in surface area until it reaches maturity. Sometimes the growth is nearly equal in all directions, giving rise to spherical or spheroidal forms (Fig. 333), or if the cells are aggregated into masses, the tendency to an equiaxial growth may be modified by mutual pressure, producing cuboidal or polyhedral forms, Fig. 379; sometimes the growth is greater in one direction than in any other, and elongated cells are the result; or, lastly, by a more exuberant growth in two or more different directions, tabular, star-shaped, or variously branching forms may be produced. Cork and epidermal tissues often afford examples of tabular cells. Fig. 380 represents 
a group of stellate cells from the stem of the Pickerel-weed, and Fig. 381, peculiar branching cells from the stem of the Yellow Water-lily.

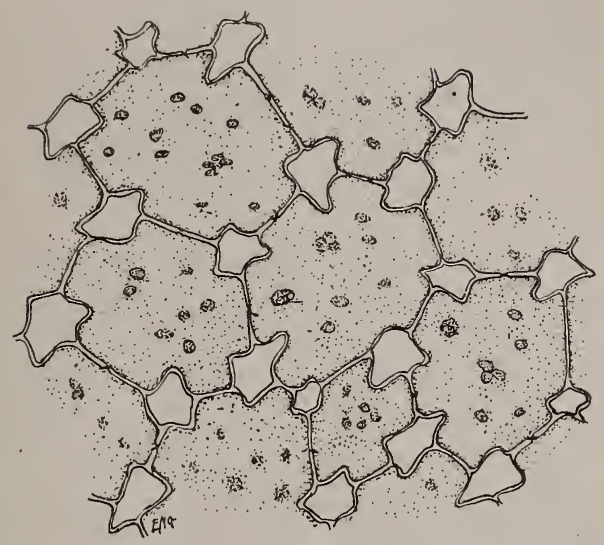

Fig. 380.- Stellate cells from the stem of the Pickerel Weed.

Vegetable cells, on the average, are not more than one fivehundredth or one six-hundredth of an inch in diameter, though

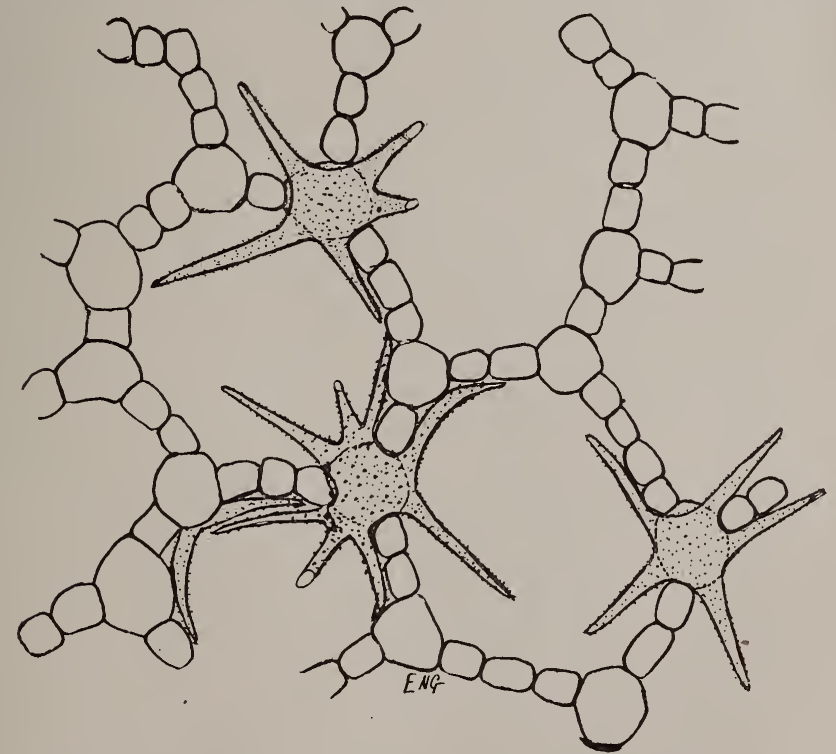
I ily.

Fig. 381.-Branching cells (idioblasts) from the stem of the Yellow Water- 
in some cases they are large enough to be distinctly seen by the unaided eye, as in the flesh of the Water-melon and the pith of the Elder; in rare instances, as in the inter-nodal cells of Chara and Nitella, they may even be upwards of an inch in length. Some, on the other hand, are so small as to be barely visible under the highest powers of the microscope. This is the case with some Bacteria, and there is good reason to believe that there are organisms belonging to this type which no microscope yet made is powerful enough to resolve.

As already stated, the primary cell-wall consists essentially of cellulose. An exception should be noted, however, in the so-called "middle lamella" which unites cell-walls derived from two adjoining protoplasts into a common wall. The substance of the middle lamella appears to be of somewhat different composition, being more soluble in alkalies or chlorine solutions and more readily stained by aniline. In mature tissues the middle lamellæ may remain as such, or may undergo a mucilaginous modification, or may even disappear altogether.

On either side of the middle lamella are formed, first the primary and later the secondary lamellæ. These likewise result from the vital activity of the protoplasts. The primary lamella is usually of cellulose or some related substance, the secondary lamellæ are frequently composed in part of modifications of cellulose. The wall substances, therefore, may be grouped as follows:

Cellulose. Typical cellulose is recognized by its solubility in cuprammonia, its purplish coloration with zinc chloriodide and its blue color when treated with iodine and sulphuric acid. Reserve cellulose occurs in many seeds and is usually more readily acted on by enzymes and therefore more quickly available to the plant as food, than is ordinary cellulose. Amyloid, a closely-related body, is colored blue by iodine alone.

Ligno-cellulose is the material composing "lignified" cell walls. It constitutes the great bulk of the wood of plants. Lignified walls consist of cellulose impregnated with several characteristic substances known collectively as "lignin" and whose chemical nature is not well understood, but which give distinct colorations with certain reagents. Thus, phloroglucin and hydrochloric acid gives a cherry-red color with nearly all lignified walls. It is worthy of note that vanillin and some of the phenols occurring in plants give a coloration similar to that of lignin with the same reagent. With zinc chloriodide, lignified membranes assume a yellow color. 
Cutin or suberin is a waxy substance which may impregnate only the outer portion of the cell-wall, as in the epidermis, where this layer is known as the cuticle, or may encrust the entire wall, as in the suberized cell-walls of mature cork cells. Cutinized or suberized walls are not dissolved by sulphuric acid, but are colored yellowish-brown by zinc chloriodide and yellow by potassium hydroxide. Such walls are practically impermeable to water and afford a protective covering to the plant.

Mucilage. Cellulose walls may be partly or wholly converted into mucilage or gum. Examples are afforded by the seeds of Quince and Flax. If these seeds are placed in water, the outermost cells are observed to swell, become transparent and finaliy dissolve to a thick mucilage. The inner cells of Chondrus and similar gelatinous algæ undergo a mucilaginous modification. In some plants the cells of the pith, medullary rays and other portions of the parenchyma tissues may become mucilaginous. This is the case with the plants that yield the gums, Tragacanth and Acacia. Mucilage occurs also in special cells as well as in passages or canals formed by the cells breaking down (lysigenic) or splitting apart (schizogenic). Such passages will be discussed in connection with the receptacles for secretions (see page 200). Mucilaginous walls may serve for water storage, or to assist in the distribution of seeds, or may constitute a form of stored food.

Mineral substances. All cell walls contain an appreciable amount of mineral matter, which is, however, much greater in the older cells. The commonest mineral substances thus occurring are silica and calcium salts. Beautiful examples of the former occur in the cell-walls of Diatoms, where the silicification is very complete and the silicified walls are often very delicately sculptured. Notable amounts of silica also exist in the walls of many plant-hairs and in the ordinary epidermal cells of the Equisetums and many of the Grasses.

Calcium carbonate, also, frequently occurs in the cell-walls of hairs, as well as in the cells of some seaweeds and in the curious structures called cystoliths, already mentioned. Calcium oxalate occurs occasionally as a crystalline deposit in the walls of thickwalled cells, as in those of Welwitschia (see Fig. 382), but more commonly crystals of this kind are found among the cell-contents.

Stratifications. Thickened cell-walls are seldom homogeneous in structure, but if viewed in cross-section, they have the appearance of being arranged in concentric layers, as in Figs. 374, 376 
and 383. This is called stratification, and the phenomenon is due to the alternation of layers of different water-content and sometimes of different substance. Such thick-walled cells in longitudinal or surface view usually display delicate lines running obliquely, as shown in Figs. 384, 385 and 386.

The term striation has been applied to this form of marking.

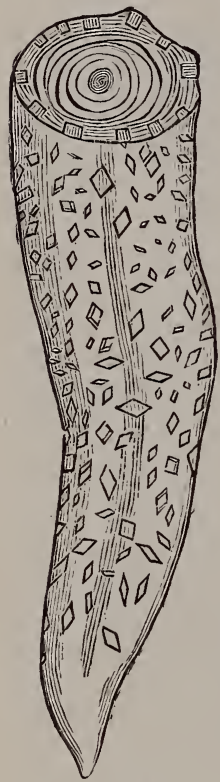

Fig. 382 .

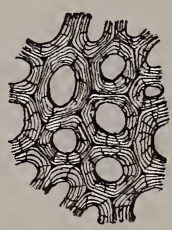

Fig. 383 .

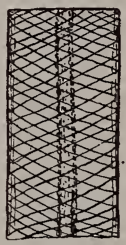

Fig. 384.

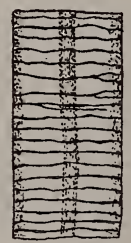

Fig. 385.

Fig. 382-Half of a thick-walled cell from Welwitschia mirabilis, showing crystals of oxalate of calcium imbedded in the cell-wall. (After Sachs.)

Fig. 383.-Transverse section of bast fibers from the stem of Aristolochia Sipho, showing stratification.

Fig. 384.-Portion of bast fiber, showing

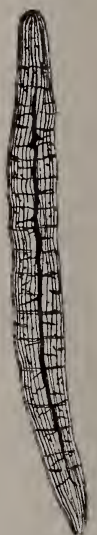

Fig. 386. oblique striation. Highly magnified.

Fig. 385.-Portion of bast fiber, showing transverse striation.

Fig. 386.-Bast fiber from the bark of Cinchona Calisaya, showing longitudinal striae and small tubes connecting the lumen of the cell with the exterior.

In many cases, also, delicate, simple or branching tubes, called pore-canals, will be seen running from the cavity or lumen of the cell through the wall, Figs. 383 and 386 . They doubtless facilitate the circulation of the sap from cell to cell. .

Growth of the Cell Walls. Two theories have been presented to account for the manner of growth of cell-walls. One assumes that new particles of wall material are deposited within the already-formed membrane; this is termed growth by intussusception and satisfactorily explains the growth in surface area which can hardly be accounted for in any other way. In the second, termed growth by apposition, particles or micellæ of wall substance are deposited on the surface of the cell-wall or successive layers 
are superposed on it. It is scarcely open to doubt that the stratified walls such as those of bast fibers are produced in this manner.

\section{Practical Exercises.}

1. Upon the inner (concave) side of the bulb-scale of an onion, outline, with the sharp corner of a razor blade, a small square in the thin skin (epidermis), then strip off, with the forceps, this square portion of the epidermis, and place it in a drop of water at the center of a slide. Smooth out any wrinkles in the specimen by means of a camel-hair brush.

Place a cover-glass over the specimen and examine with the low power of the microscope. A somewhat irregular network is seen, the meshes of which are elongated in one direction. Each of these meshes is a cell.

The cells are made up of an enveloping membrane, the cell-wall and a glairy, viscid mass, the protoplast.

The protoplasts appear colorless, transparent, and only slightly granular. In some a larger, rounded spot is faintly seen. Remove the slide from the stage, take off the cover glass and place a good-sized drop of iodine solution directly on the specimen. Clean the cover and replace it carefully, using the low power, observe that while the cell-walls have been scarcely stained, the contents have assumed a yellow-brown color, showing the cytoplasm and the nucleus in each cell quite distinctly.

Again remove the cover glass and place a drop of zinc-chloriodide on the iodine-stained specimen. Using the same precautions as before, replace the cover glass and notice the effect of the stain. Excepting a thin layer of cutin on the outer surface, the cell walls appear purple-brown, due to the effect of the reagent. This is a test for cellulose, of which these walls are composed.

Make a comparison study of the living cells of yeast, using iodine solution and noting the result as in the foregoing exercise.

2. To observe the motion of the cytoplasm make a study of a young leaf from a growing branch of the Waterweed (Philotria canadensis). Mount the leaf entire in a drop of water. Use the low power first. The motion is usually more rapid in the long cells about the middle of the leaf. The green, diskshaped granules (chloroplasts) move in the stream of cytoplasm and enable us to detect the motion more readily. Place the edge of a piece of filter paper in contact with the water in which the leaf is mounted and on the opposite border of the cover glass put a drop of iodine solution. The iodine will be drawn through and will stain the specimens, but will penetrate but slowly at first. Watch the effect of the reagent. Observe that the motion is stopped and that the chloroplasts are stained. Tiny black spots that may be seen in them are starch bodies.

As a comparison study for the circulation of the cytoplasm, the hairs of the stamens from a young bud of Tradescantia, or a small piece of the green leaf of the Eel Grass (Vallisnaria spiralis) may be used to advantage.

For the further study of chloroplasts, the thread-like cells of Spirogyra (Fig. 335), display the spiral, band-like arrangement while the prothalium of a fern shows large chloroplasts of the usual flattened and rounded type.

An example of leucoplasts may be found in the cells of the cortical part of the Iris rhizome.

Chromoplasts may be studied in the young petals of the common Nasturtium (Tropaeolum) or of the Larkspur (Delphinium).

3. For the study of starch grains prepare a scraping of the inner flesh of a potato. Mount in water and view first with the low and then with the high power. In the field of view are seen numerous colorless, translucent grains, ovate, wedge-shaped, or almost spherical in form, and marked by a hilum, located excentrically, around which the layers of the grain are formed. The layers are narrower near the hilum and broader at the other end of the grain. If sufficient water has been used in mounting, the thickness of the grains may be demonstrated by tapping gently upon the cover-glass The motion of the cover-glass will cause the grains to rotate. It will then be seen that the grain is thicker through at the narrow end. If too great pressure be applied to the cover-glass the grains are fractured, the cracks radiating outward from the hilum, an evidence of their crystal-like structure. The effect of iodine solution should be noted. It may be best observed by allowing a drop of the reagent to run in under the cover-glass. Treatment with potassium hydrate solution causes the grains to swell, at first displaying the stratifications very distinctly, but these soon become lost to view. Note also the effect of boiling water upon the grains by carefully 
heating the starch suspended in a drop of water on the slide. Measurements with the ocular micrometer should be made, as well as drawings of several typical grains, care being taken to show the characteristic shape and form of the grains, and the location of the hilum and the stratifications.

4. Food Starches, particularly those of the arrowroot, pea, bean, wheat, corn, oat and rice, should also be studied and drawings of them made. The prepared starches or the finely ground grains may be employed or the cereals may be softened in water and sectioned. The following descriptions and measurements should be verified:

Arrowroot (Maranta arundinacea) somewhat resembles potato starch, but is smaller. Ovate, pear-shaped and broad fusiform are the chief forms. The hiluni is usually at the broad end and marked by a two-rayed and curved cleft. Length, 30 to 50 microns.

Pea (Pisum sativum) and bean (Phaseolus vulgaris) contain starches that are oval, bean-shaped or kidney-shaped, little flattened and with distinct stratifications. The hilum is replaced by a longitudinal and branched cleft. Length, 30 to 40 microns in the pea and up to 60 microns in the bean

Wheat (Triticum vulgare) starch shows the stratifications little or not at all, and the hilum can seldom be seen. The granules are of two sorts, the larger being the disk-like and flattened and about four times the diameter of the smaller roundish granules. Diameter of large granules, 27 to 40 microns.

Corn (Zea mays) starch is of two sorts. That derived from the horny part of the grain is flattened and angular, that from the mealy part more rounded in outline. Both are similar in size, not distinctly stratified, and with a hilum showing a two, three or four-rayed cleft. Diameter of granules, 15 to 30 microns. Smaller grains are few.

Oat (Avena sativa) starch consists of rounded aggregates up to 60 microns in diameter, which break up readily into numerous small, sharply angular, manysided grains, 2 to 8 microns in diameter. There are also small spindle-shaped forms which are of diagnostic value.

Rice (Oryza sativa) starch is characterized by small polygonal grains, 2 to 10 microns in diameter, which form oval or rounded aggregates of from two to a hundred or more.

Sago, tapioca, salep and cassava starches may also be studied in a similar manner.

5. Drug Starches. Of the many characteristic drug starches only a few are selected for study. The commercial powdered drugs may be used or the pieces of whole drugs may be soaked in water until softened and then sectioned, or the dry drug may be scraped and the scrapings used as powder.

Calumba (Jateorrhiza palmata): The starch grains are variable in form, commonly pear-shaped, but often ovate, oval or roundish, and rarely compound in twos or threes. The hilum is frequently cleft, usually in the direction of the length of the grain. The stratifications are excentric and quite distinct. In size they average from 20 to 40 microns.

Jalap (Exogonium purga): There are present large, single starch grains of oval, circular or slightly flattened form, with broadly cleft hilum located excentrically and with distinct though delicate stratifications, also compound grains in twos and threes, showing similar structure. Pasty, swollen grains are common, these being probably due to the application of heat in drying the drug. The grains of Jalap starch measure 15 to 45 microns in diameter.

Ginger (Zingiber officinale): Grains biconvex, roundish, varying to three or four cornered, slightly longer than wide, each grain with a pointed end in which is located the hilum. Both the hilum and stratifications are difficult to see, the latter showing best in the larger grains. Length, 15 to 30 , occasionally up to 50 microns.

Colchicum Corn (Colchicum autumnale): Starch grains are of two sorts, the single grains being globular or egg-shaped in form, mostly with a stellately. cleft hilum, and faint but visible stratifications. The compound grains are in twos and threes and are similarly marked and of the same shape except when flattened by contact. Diameter of the largest grains about 20 microns.

Ipecac (Cephaelis Ipecacuanha): Grains mostly compound in twos, threes and fours, but numerous single grains are also present. The single grains are roundish in form with centric hilum and very faint stratifications. The hilum is frequently two or three-cleft. Each part of the compound grains displays similar markings. The single grains are from 6 to 13 microns in length; the compound attain a length of nearly 20 microns.

Orris (Iris florentina, rootstock): Starch grains elongated, oval or ovate, truncated, sometimes curved or lobed. Hilum located excentrically at the larger end of the granule and having usually a two-branched cleft extending 
toward the smaller truncated end. Stratifications not distinguishable. Length, 25 to 50 microns.

6. Inulin may be viewed to advantage in sections of Taraxacum root or of Dahlia root which have been kept for a time in strong alcohol. Since inulin is soluble in water, the sections should be mounted in alcohol or glycerin. The inulin appears in sphaero-crystals. Note the effect of iodine solution and also of hot water on these crystals.

7. For the study of aleurone grains, remove the testa (shell) of the Castor bean (Ricinus communis) and with a razor or sharp knife make very thin sections of the kernel. Mount in glycerine and examine. The cells are filled with very small roundish granules. These are the aleurone granules. Run in under the cover-glass a drop of water and notice that when water acts on the specimens, globules of fixed oil are liberated and the aleurone grains gradually dis solve. This oil occurs as one of the cell-contents associated with the aleurone. Test another section with iodine solution and note the result.

Examine now a section of this seed which has been prepared by staining with an alcoholic solution of eosin for several hours previous to use. Mount the specimen in oil of cloves. Upon viewing with the high power some of the aleurone grains display a crystalloid of the same proteid substance as the granule itself and often one or more rounded bodies located at one end of the granule, the globoids. The crystalloids and globoids are surrounded by envelopes of amorphous proteid substance.

Compare sections of the kernel of the Brazil nut (Bertholletia excelsa) similarly prepared and stained. Sections cut from near the surface but just under the cork tissue ("peel") of the Potato will show protein crystals of cubical form in the cells with starch grains. Sections of Fennel fruits (Foeniculum vulgare) may also be compared. (Fig. 351.)

8. For the study of calcium oxalate crystals select a piece of the medicinal Squili, soften and prepare a thin section of the bulb-scale. View first with the low, then with the high power. Notice that the raphides occur either singly or in bundles, the latter being sheaf-like in form and grayish, owing to their cutting off most of the transmitted light. The solitary crystals are the larger in size, often extending through several cells, apparently piercing the transverse walls. The bundles of crystals are usually surrounded by a mucilaginous covering soluble in water and which upon treatment with eosin solution is stained red. Make a drawing of each of these kinds and compare with them the raphides of the medicinal Ipecac and Sarsaparilla roots. Examine Soap Bark (Quillaja), making a scraping or thin section, mounting in water and observing the peculiar twin crystals. Rosettes crystals may readily be studied in the medicinal rhubarb, in which they are abundant, giving to the drug its charac teristic grittiness. They may be viewed to advantage by mounting a scraping of the drug or a small quantity of the powder in chloral hydrate solution.

Raphides are also abundant in the Evening Primrose, the Calla Lily, the Indian-turnip and most other members of the Arum family, as well as in many liliaceous plants.

Sphaero-crystals are abundant in the Yellow Dock and in the Hollyhock and most other Malvaceous plants.

Other forms may be found in the stems of the Cactuses, in the stems and leaves of the Begonias, in the leaves of the Century Plant, etc.

Cystoliths of great beauty are obtained by making thin cross sections of the leaves of the common Nettle and of Ficus elastica. (Fig. 369.)

These crystals may also be studied to advantage by means of polarized light.

The following tests may be applied to determine the nature of the crystals:

Acetic acid has no effect on silica and calcium oxalate, but calcium carbonate dissolves with effervescence. Hydrochloric acid has no effect on silica, but dissolves calcium oxalate without effervescence, and calcium carbonate with effervescence.

9. To observe some of the various kinds of cell-walls and shapes of cells, examine a transverse section of the young stem of the Elder (Sambucus canadensis), mounting the section in water.

Notice that the stem is made up of cells differing from one another in size, shape, in the nature of their contents, and in the color and thickness of the walls. Cells of similar kind are arranged in groups or layers, and occupy definite portions of the stem.

The outermost part of the stem is the epidermis, and beneath this is the cork, which may have replaced the epidermis, and is composed of several layers of tabular cells regularly arranged in radial rows. The walls of these cells are ycllowish-brown in color, and a re incrusted with suberin

Within the corky layer is located the middle bark, composed of cells which are iso-diametric, or nearly so, and have cellulose walls. Prove this by applying 
the zinc-chloriodide test. The outermost cells of this layer have very thick walls.

The inner bark is composed of cells of two kinds. One has excessively thickened walls and a small cell cavity. These are the bast fibers. Their walls are lignified. To confirm this, mount a section of the stem in phloroglucin and hydrochloric acid. The walls of the bast fibers will be colored red, as will also the walls of the cells in the circle of wood surrounding the pith. Between the wood and the bast are severa layers of cells with cellulose walls. These constitute the phloem and cambium parts of the stem. In the vicinity of the bast in this stem are found glands filled with a transparent brown resin and others filled with tannin.

The cells composing the wood are found, upon careful examination, to be of two kinds: tracheal tubes, with large cavities and relatively thin walls, and wood-fibers, with smaller cavities and thicker walls. Note also that the woody zone does not form a continuous circle, but is divided into numerous wedgeshaped parts, by rays of brick-shaped cells extending in a radial direction.

Occupying the center of the stem is a pith, which consists of large, thinwalled iso-diametric cells. Usually tannin and resin sacs like those seen in the bark occur in the pith also.

In the same manner, applying the reagents as before, examine tangential and radial longitudinal sections. Pay particular attention to the markings upon the cell-walls. Note especially the thin places (pores) in the walls of the pith cells, and the spiral and dotted markings upon the walls of the ducts. Compare the shapes of the cells as seen in the longitudinal sections with those seen in the transverse section.

\section{CHAPTER II.-THE FORMATION OF CELLS.}

Most cells have the power of reproduction, or of giving origin to new cells. This may take place either by cell division, which directly increases the number of cells, or by the formation of spores, which in turn give rise to new cells.

Indirect Nuclear Division or Karyokinesis: In the higher plants, at least, cells increase in number by repeated and successive division. In this manner certain cells, styled primordial cells, give rise not only to the groups of similar cells known as tissues, but also to the aggregations of tissues comprised in the organs of the plant.

Typical cell-division, in the vegetative cells of the higher plants, may be briefly outlined in two series of changes: those involved in the division of the nucleus and those resulting in the partition of the protoplast, usually through the formation of a cell-wall separating the two daughter cells. The close inter-relation between these two series of changes adds to the difficulty of a clear understanding of this phenomenon.

The successive changes in the nucleus are as follows (see Fig. 387) :

The threads forming the reticulum of the resting nucleus are shortened and thickened, while the chromatin particles swell and become disk-shaped. The thickened skein thus formed and repre- 
senting the reticulum is converted into a definite number of "chromosomes" which assume the form of hooked rods of L or U shape and which are then arranged in a plane with the curved ends facing the plane and thus forming the "equatorial plate."
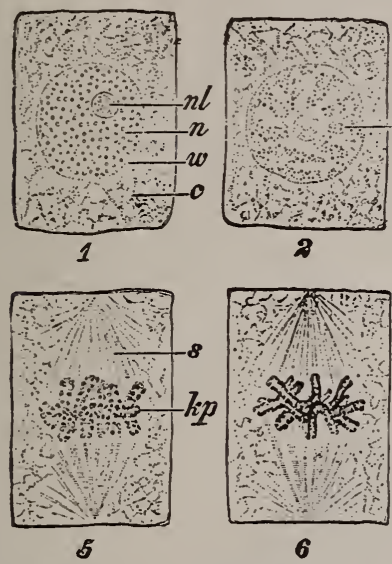

6
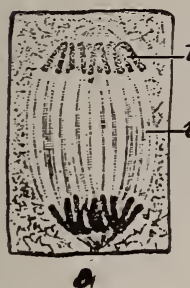

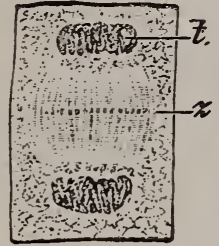

10
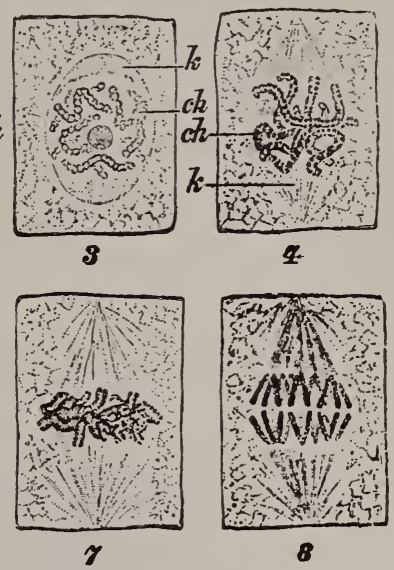

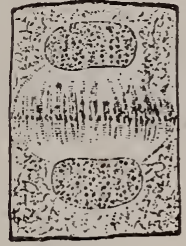

11

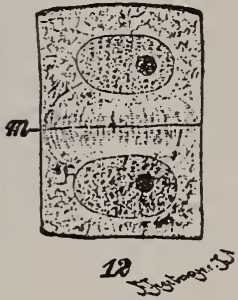

Fig. 387. - Successive stages of nuclear and cell division in a meristematic cell. n, nucleus; nl, nucleolus; w, nuclear membrane; e, crtoplasm; ch, chromosomes; $k$. polar caps; $s$. spindle; $\mathrm{kp}$, nuclear plate; $\mathrm{t}$, voung daughter nucei: $v$, connecting fibrils; $z$, cell-plate; $\mathrm{m}$. new cell-wall. In 1 , the resting nucleus; 2 and 3 , separation of the chromosomes: 4 , chromosomes with transverse discs; 5 , the arrangement of the chromosomes to form the cell-plate and their longitudinal fission; 3.5 show the formation of the spindle from the polar caps; 6 , the longitudinal fission of the chromosomes; 7 , beginning of their separation.to either pole; 8, the complete separation of the daughter chrom.somes; 9 , passage of the daughter chromosomes to either pole; $10-12$, formation of the daughter nuclei; in 9-11 the origin of the connection fibrils and of the cell-plate is seen, while in 12 the new cell-wall is formed. (Strasburger.)

Meanwhile each chromosome has split lengthwise into halves, which pull away from each other in opposite directions.

While these changes are taking place, the delicate protoplasmic membrane surrounding the nucleus has developed fibrils at opposite sides, forming the "polar caps." Similar fibrils within the nucleus are attached to the chromosomes and facilitate the 
construction of the equatorial plane. These protoplasmic threads soon extend from the polar caps to the chromosomes and also as continuous fibrils from pole to pole, giving rise to the "nuclear spindle."

The split chromosomes are now moved along the fibrils of the spindle, but in opposite directions, as above mentioned, to the poles, where they constitute the chromosomes of the "daughter nuclei" and, uniting with one another, resume the reticulate structure characteristic of the resting nucleus. The nucleoli take no active part in this process; apparently they serve chiefly for nourishment and to provide material for the fibrils. The form of nuclear division above outlined is termed indirect nuclear division, mitosis, or karyokinesis.

Its undoubted advantage is in making sure of an equal division

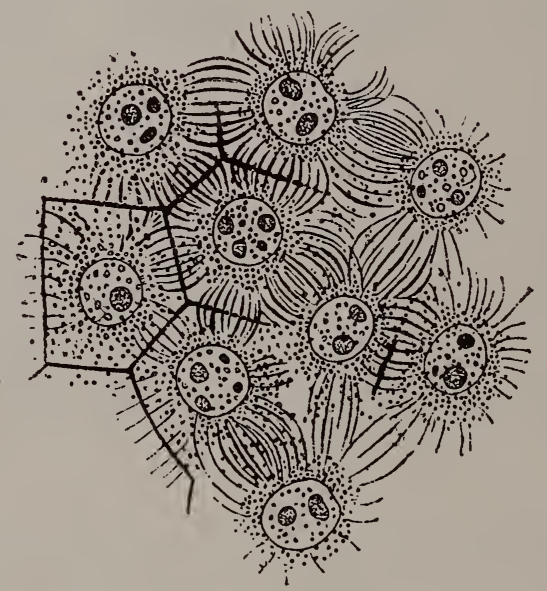

Fig. 388.-Commencing development of partition-walls between the nuclei produced by successive divisions in the embryo-sac of Agrimonia eupatorium (after Strasburger).

of the nuclear substance between the two daughter cells, especially an equal distribution of the chromosomes, which evidently transmit the characters of the parent cell to the offspring.

After the formation of the two daughter nuclei, the fibrils of the spindle expand so as to give the mitotic figure a barrel shape, with the nuclei at the heads of the barrel. Along a plane passing through the middle of the barrel-shaped figure, the fibrils are thickened and finally fused, forming the "cell-plate," which is at 
first a homogeneous protoplasmic membrane, but later splits into two layers, between which the new cell-wall forms.

The segmentation of the mother cell into the two daughter cells is now complete and the remaining fibrils gradually merge into the cytoplasm of the new-formed cells.

A modification of the process above outlined occurs in the course of the growth of the endosperm in the embryo-sac of angiosperms, where by rapid division after fertilization a large number of nuclei are formed, each connected with its neighbors by a spindle of fibrils, but with at first no permanent cell-plates; at a later stage of the growth of the embryo, cell-walls are developed and the subsequent multiplication of cells is through the typical division already described (Fig. 388).

Another modiscation of the typical form of nuclear division is observed in the reproductive cells constituting the so-called "sporogenous" tissues, which give rise to spores. Of such nature are the "mother cells" of the anther, where the pollen grains (microspores) are formed. This is termed reduction division.

While in the vegetative reproduction, above described, there is but one thread in the reticular skein, and this, presumably, bears all the transmissible characters, in reduction division there are two parallel threads forming the skein, one of these supposedly bearing the paternal, the other the maternal characters. In suitably stained preparations these threads are seen to be composed of alternating colored (chromatin) and colorless (linin) bodies.

After passing through some intermediate phases the double threads divide transversely into segments, and since each of these segments represents a pair of chromosomes, they are, of course, but half as numerous as the single chromosomes formed in the vegetative cells of the same plant. Several more phases follow, but finally the paired chromosomes are lined up at the equator of the cell, the paternal members of the pairs are drawn to one pole, the maternal members to an opposite pole. On the way to the pole each chromosome divides longitudinally, and, arriving at the pole, the split chromosomes spin a nuclear reticulum which becomes enclosed in a nuclear membrane and forms the nucleus of the "daughter" cells.

The split chromosomes then reappear, the halves are separated in a manner similar to ordinary nuclear division and formed into nuclei of the granddaughter cells, there being now four of these, 
which have been produced from the original mother cell and which now become the spores or gametes (Fig. 389).

As distinguished from these forms of cell-division we find in some of the lower plants other processes, among which are:

Free Cell Formation, where the nuclear division of the ordinary
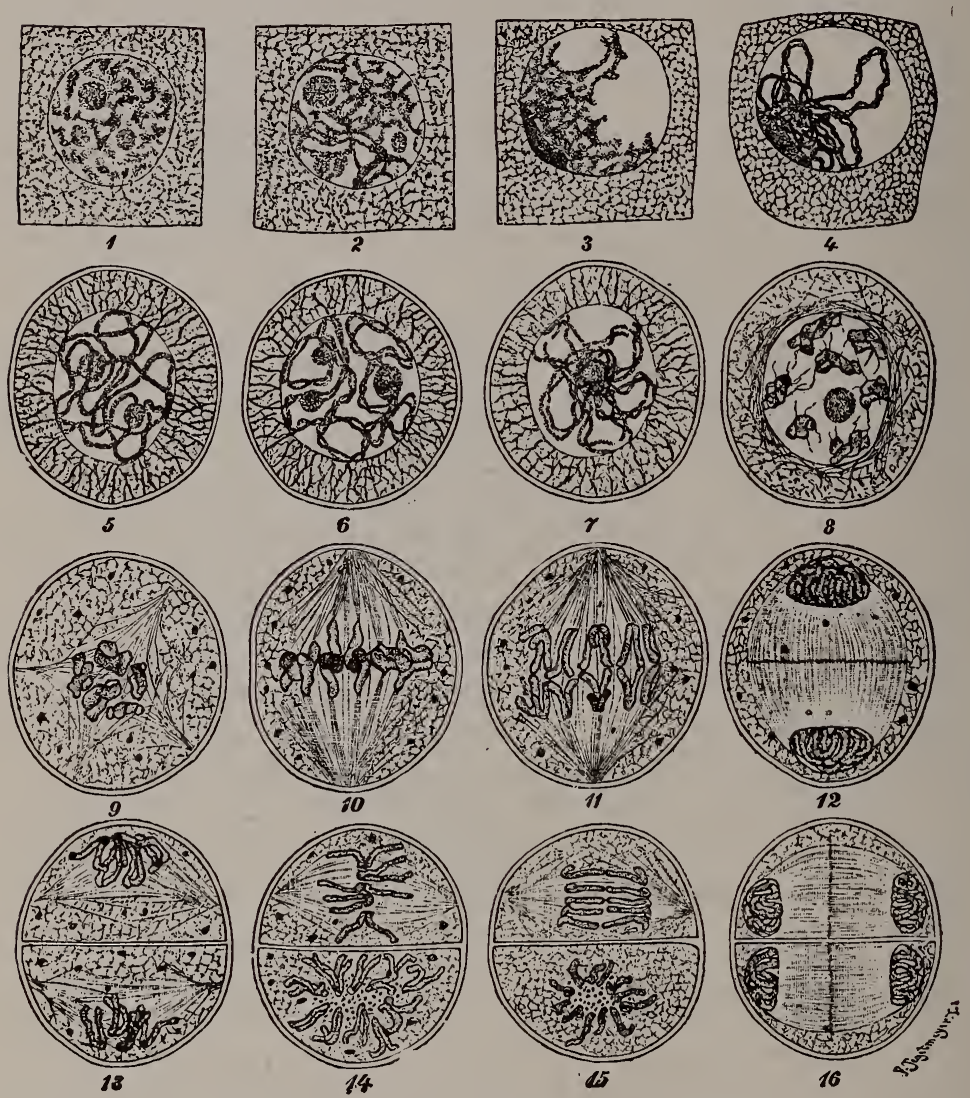

Fig. 389.-Dividing polien mother cells of a Lily, somewhat diagrammatic. 1 , mother cell, with resting nucleus; 2 , the separation of the chromosomes; 3 , the condition of contraction known as synapsis; 4, double filament in process of fusion; 5, spirem consisting of an apparently single filament derived from the fused double filament; 6 , reappearance of the longitudinal split, the spirem still unsegmented; 7 , spirem transversely segmented, into paired chromosomes; 8 , diakinesis; 9, multipolar spindle; 10, spindle of the mother nucleus, the nuclear plate composed of paired chromosomes; 11, reduction divisisn, the separating chromosomes showing partial separation of their longitudinal balves; 12 , young daughter nuclei; 13, the longitudinal halves of the chromosomes (daughter chromosomes) are arranged in pairs on the nuclear spindles; 14 , the spindles of the daughter nuclei; 15 , separation o fthe daughter chromusomes; 16 , young stage of the grand-daughter nuclei. (Strashurger.) 
type is followed by the formation, in the cytoplasm of the mother cell, of a wall surrounding each nucleus, the walls of adjoining cells not being in contact with each other. The spores of the Ascomycetes illustrate this method of cell formation (Fig. 390).

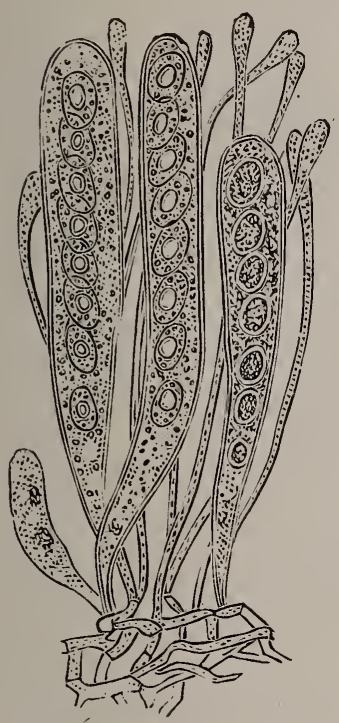

Fig. 390 .

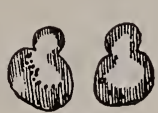

Fig. 391.

Fig. 390.-Small portion of sporocarp of Cup Fungus, showing asci containing asco spores produced by free cell formation.

Fig. 391.- Various stages of cell budding in Yeast Plant (after Reess).

Budding-is another method of cell division. In this, a minute protuberance is formed on the surface of the cell; it gradually increases in size until it may be as large or nearly as large as the parent cell, when usually it separates through constriction and becomes an independent organism. The Yeast plant affords an cxample of this mode of propagation (Fig. 391). The spores known as conidia, produced by other Fungi, originate similarly (Fig. 392).

Direct nuclear division, alto termed amitotic division or fragmentation, occurs but seldom and is observed chiefly in old cells. It comes about through a constriction of the nucleus, resulting in its division into two sometimes unequal nuclei and is not followed by cell-division such as attends indirect nuclear division.

It will be seen that in all cases new cells are formed from preexisting ones; that living organisms are derived from antecedent 
living organisms. The spontaneous generation of living protoplasm from inorganic matter has never yet been observed.

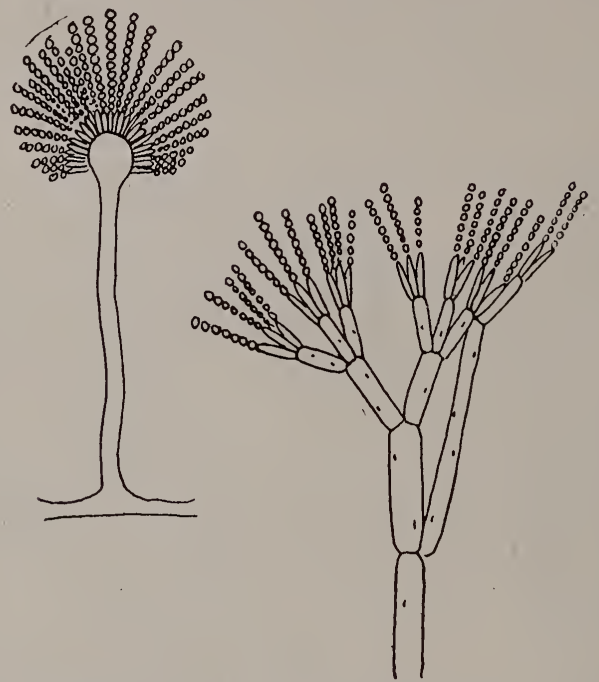

Fig. 392.-Conidiophores of Aspergillus herbariorum (at left) and Penicillum crustaceum (at right).

\section{Practical Exercises.}

1. Sterilize by boiling in water several pieces of blotting paper. After these have cooled but are still moist place on them a few small onions and cover with a bell jar. When the onions have sprouted and the roots are about an eighth of an inch long, cut off several roots and "fix" them in Flemming's fixative. Imbed in cellodin or paraffin and cut longitudinal sections, or if this is not feasible, cut transverse sections, free-hand, by holding the roots between pieces of elder pith. Stain the sections with Flemming's triple stain (safranin, gentianviolet and orange G.), dehydrate and mount in Canada balsam. (For details of these processes see Stevens' Plant Anatomy, third edition, pp. 258 to 278). The sections should show nuclear cell division and should be compared with the description given in the text (p. 169), also with the description of a typical cell (p. 132).

2. Select a young staminate flower bud of Begonia and make thin sections with a moistened razor across the upper part of the bud, including the tips of the contained anthers. Pick out several of the thinnest sections, including the anthers, and transfer them carefully to a drop of water on a slide. With the aid of a magnifier remove all but the thinnest sections of the anthers themselves. Cover and study under the microscope. With the low power, observe the two cavities in each of the two anther sacs. Later these coalesce. Note the isolated rounded cells either in the cavities or floating in the water. These are the pollen mother-cells.

3. Select another staminate flower somewhat older than the preceding and prepare sections in the same manner. Stain with iodine solution. With the aid of the low power find some of the pollen mother-cells floating in the water, and focus on them with the high power. Observe the contents of each mother cell, four small pollen grains. Note the form of the grains, the nucleus in each grain and the readiness with which the cytoplasm takes the stain. Compare several fully developed pollen grains from the ripe anther of a full-blown flower.

4. Make a culture of yeast by preparing a broth consisting of three tablespoonfuls of mashed potato and one tablespoonful of sugar in a pint of water. Bring to a boil and when cool add a piece of yeast cake and set the culture 
aside in a warm place for several hours until the formation of numerous bubbles indicates that the yeast is "working."

Examine a drop of yeast under a magnifying power of 600 or 700 diameters. Budding cells will be observed, with the buds in various stages of development. Make drawings of some of them.

Obtain a piece of porous tile; place one end of it in a small dish containing water. The portion not immersed will be kept moist by capillary attraction. On this portion place a little yeast; cover the whole with a bell jar; keep in a moderately warm place for a few days, and then examine the yeast. Some cells will probably be found in which the protoplasm has broken up into several small, rounded masses, presenting an example of internal cell-formation.

Obtain in spring or early summer, when vegetative growth is rapid, some filaments of Spirogyra; examine them microscopically by daylight, and note that the cells all appear well developed, and no signs of cell-division are observable. This is because in these plants the cell-division takes place in darkness. Let the filaments remain in water in a dark room until after midnight; then place them in 60 per cent alcohol, which will stop their growth and kill the protoplasm. Now study them microscopically, and cells will be found in all stages of division, some in which the nucleus has just divided, and an annular protuberance on the interior of the cell-wall (the beginning of a cellulose septum) has made its appearance; others in which the division is nearly completed, and still others in which the separation into two cells is quite complete, but the new cells have not yet attained their full growth.

Make drawings of different stages in the process.

The little red Cup-fungus, Peziza coccinea, is not uncommon in our woods. Make a thin, vertical section of the "cup" or hymenium of one of these plants, and examine with a magnifying power of 300 or 400 diameters. Numerous elongated cells, each containing a number of oval spores, called ascospores, will be observed. Some of the latter may be seen escaping from the top of the asci, or mother cells. Draw one of the asci with its contained ascospores.

\section{CHAPTER III.-THE TISSUES, THEIR ORIGIN AND CLASSIFICATION.}

While it is true that all the essential phenomena which we call "vital" are manifested within the compass of a single cell, it is true, also, that the manifestation is feeble in comparison with that exhibited by cell aggregates, where there is division of labor among the cells. All the higher plants are such aggregates or collections of cells. A Rose-bush, for example, is made up of milkions of them, and its life is not the mere aggregate life of cells precisely alike, but rather that of sets of cells that have grown to differ from each other in form and function, some being specialized for one use, and others for another, but all subserving the life of the whole organism. These cell-groups, which differ from each other in ways more or less important, but each of which is composed of similar cells, are called tissues. The lowest plants can hardly be said to possess tissues, since they are either one-celled or are collections of precisely similar cells; but as we study plants in the ascending scale, we find a more and more complete differentiation of the cells, until, in the ferns and flowering plants, we find a great variety of tissues.

Tissues may conveniently be classified into five groups, the 
meristematic, the parenchymatous, the mosenchymatous, the sieve and the secretory.

Meristematic Tissue. As already pointed out, tissues arise by repeated cell-division. This process must underlie the development of all new plant parts. Cell-division begins at certain points, usually the apical cells, at the end of the stem or branch, or just back of the cap of the root. From these apical cells are formec' by cell-division a mass of undifferentiated tissue known as the primordial meristem. From this is developed the primary meristems, which in turn give rise to primary permanent tissues. Meristems, then, precede the formation of the permanent tissue, whose cells are mature and fully differentiated. We may therefore regard meristematic tissue as simply the embryonic or undifferentiated tissue from which all the later tissues are derived; yet it is sufficiently characteristic to be entitled to a place as a definite tissue.

If we study a longitudinal section of the growing tip of a young stem or shoot, or a young root just behind its cap, we will observe that the cells of the growing plant are very small, much alike, densely filled with cytoplasm. and contain relatively large nuclei (see Fig. 333). We will find no sharp demarcation between this homogeneous mass of cells and somewhat differentiated layers which closely border upon it. As we pass back from the growing point, however, the tissues become more distinctly differentiated. Evidently, then, the cells originate in the growing point, where they are exceedingly minute and densely filled with cytoplasm; then they absorb water osmotically, their walls are stretched by the expanding sap-cavity, new wall substance is deposited, the cell grows, extending in the direction of the least pressure; at length the cell is full-grown, is many times larger than its original size, its wall is tightly stretched and in close contact with adjoining cells; it has attained certain distinctive size, shape and wall-markings and has become one of the units of a permanent tissue.

As already stated, primary meristems are located, with few exceptions, at the apices of plant organs and give rise to primary permanent tissues; secondary meristems, on the other hand, form from living primary permanent tissues and give rise to secondary permanent tissues. The former determine the growth in length of a stem or root, the latter control its later growth in thickness. A good example of a secondary meristem is afforded by the so-called "cork-cambium" or phellogen that forms in the cortical paren- 
chyma and gives rise to the cork, which is purely a secondary tissue (see Figs. 420 and 421).

Parenchymatous Tissues. Tissues whose cells generally retain to maturity the characters of living cells, that is, they possess cytoplasm and nuclei as well as more or less plastic material, are known in general as parenchymatous tissues. Their cells are usually isodiametric or nearly so, at least they are as a rule not greatly elongated, and are mostly joined together by their flattened sides, therefore not fibrous nor interwoven. Ordinarily, the cellwalls of these cells are thin and composed of cellulose. However, here, as alsewhere in nature, many gradations and transitional forms occur, so that hard and fast lines are difficult to draw. Included in this group are Parenchyma, Collenchyma, Sclerotic, Epidermal, Endodermal and Cork tissues.

Parenchyma, the simplest form of permanent tissue, is the most abundant as well as the most important of all the tissues. The cell-walls are thin, and frequently, though not always, composed of unmodified cellulose. In form, the cells are commonly spheroidal or polyhedral, and the longitudinal diameter rarely much exceeds the transverse (see Fig. 393).

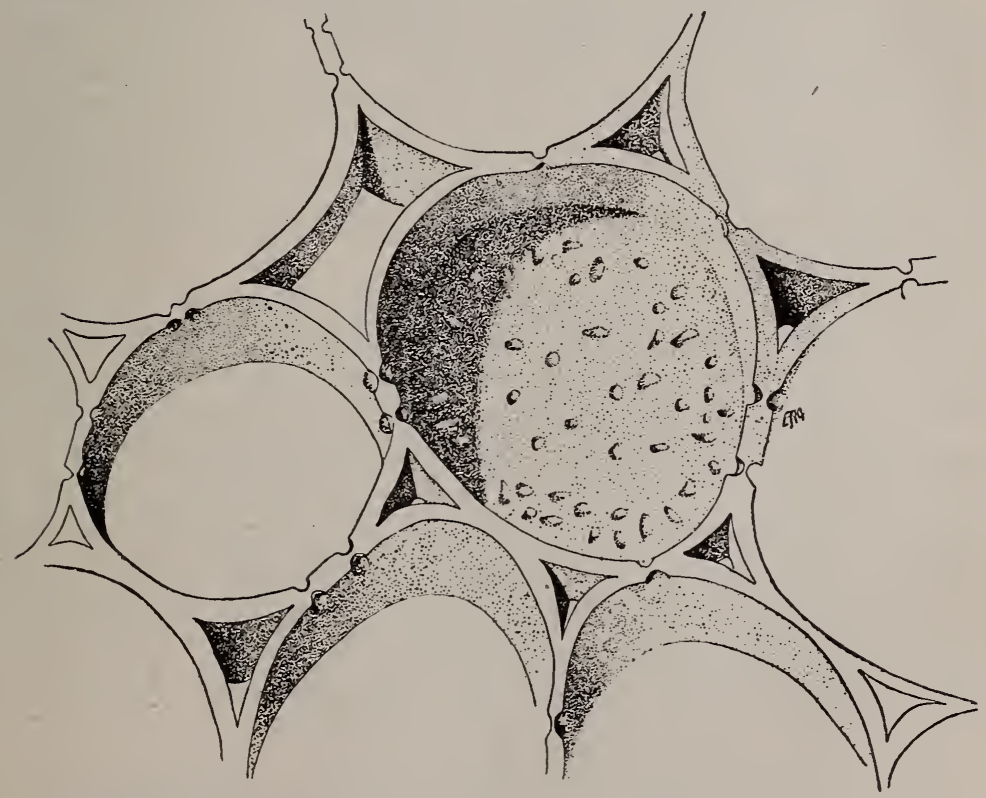

Fig. 393.-Typical parenchyma from rhizome of Podopinyllum. 
Parenchyma includes most of the softer tissues of plants, such as the green cells of the leaf, the thin-walled cells of the pith, a considerable portion of the cells of the bark, frequently those of the medullary rays, etc. Not infrequently the cell-walls are so unequally thickened as to present the appearance of markings or sculpturings of various kinds; indeed, they are seldom of uniform thickness, but commonly their membranous character and transparency makes them appear so. Forms of parenchyma are shown in Figs. 371, 372, 380, 393 and 394.

The very loosely arranged green cells that occur in the interior of leaves constitute the spongy parenchyma (Fig. 415); the more compactly arranged and somewhat elongated ones found next the upper epidermis of most flattened leaves, the palisade parenchyma (Figs. 369 and 415); parenchyma like that illustrated in Fig. 394 is called pitted parenchyma; that in which the cells take starshaped forms, as shown in Fig. 380, is called stellate parenchyma; and the green cells with internally folded walls, found in the interior of Pine leaves, are called folded parenchyma (see Fig. 489).

Parenchyma tissues, being widely distributed, perform various functions. The chlorophyll-bearing parenchyma of leaves is the chief photosynthetic tissue; the conducting parenchyma, associated with the vascular bundles, conveys elaborated foods in solution; in the reserve parenchyma of the fleshy parts of plants, foods are stored, usually as cell contents, as already noted, but occasionally as thickened walls, notably in the seeds of the date and the vegetable-ivory nut.

Collenchyma is a tissue nearly related to parenchyma, from which it differs chiefly in the peculiar thickenings of its cell-walls. The cells composing collenchyma tissue are closely connected, are from three to eight sided, several times longer than wide and with horizontal or obliquely-pointed ends. The cell-walls are thinnest at the ends and at the middle of the sides and are thickest at the angles, where three or four cells meet, the thickened walls being whitish, lustruous and delicately stratified. In typical collenchyma this thickening is due to deposits of cellulose and the cells usually contain cytoplasm, nuclei and more or less chlorophyll. No sharp lines of distinction can be drawn between parenchyma and collenchyma, as there exists every gradation between these tissues.

Collenchyma is never found elsewhere than in close proximity to the epidermis, or rarely in similar relations to the endodermis, 
and one of the uses which it serves is evidently that of giving strength and resistance to these portions of the plant. Being unlignified and elastic, it is well adapted for young and growing parts. Sometimes it forms a continuous zone beneath the epider-

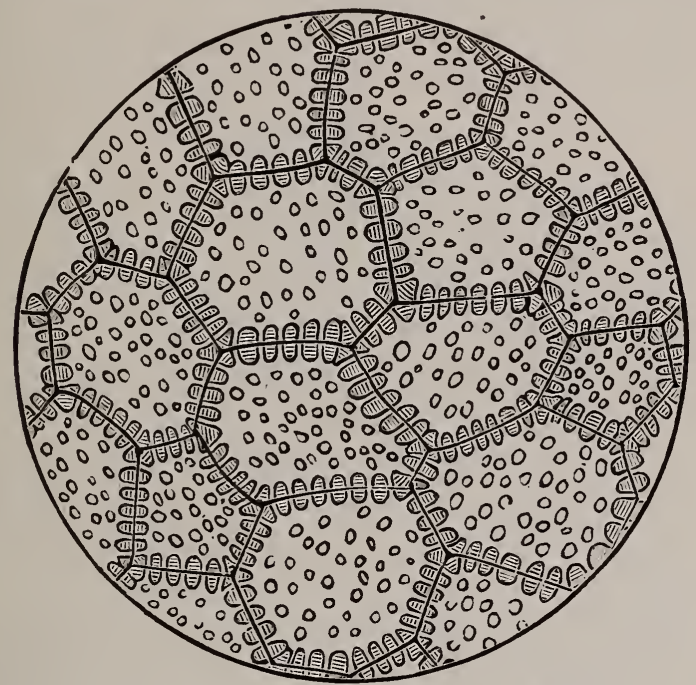

Fig. 394.-Pitted Parenchyma from the pith of the stem of the American Papaw.

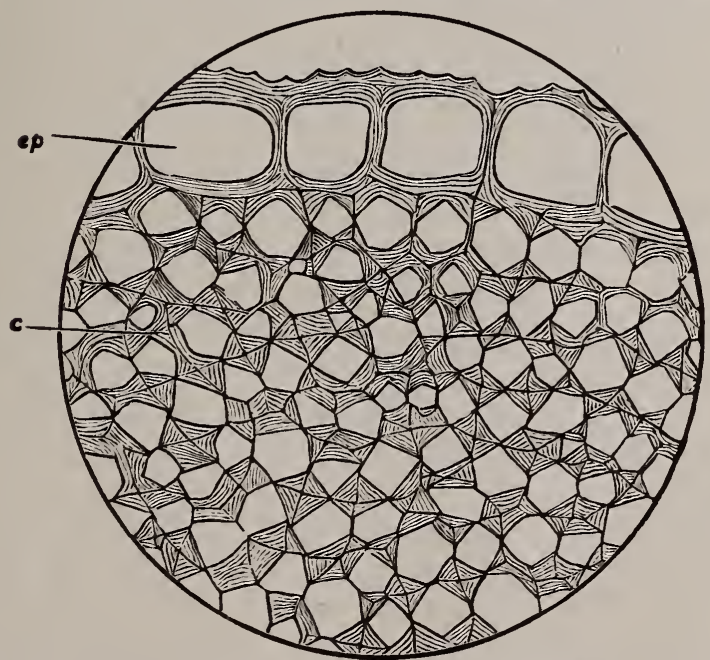

Fig. 395.-Portion of epidermis of collenchyma from stem of Yellow Dock. Transverse section, ep, epidermis ; c, collenchyma. 
mis; at others, it occurs in longitudinal bands. The tissue is illustrated in Figs. 373, 395 and 411.

Sclerotic Tissue. The cells of this tissue are commonly called stone or grit cells. It differs from ordinary parenchyma in having the walls of the cells excessively thickened-so much so, frequently, that the cavity of the cell is nearly obliterated. Every gradation, however, may be observed between these and ordinary parenchyma

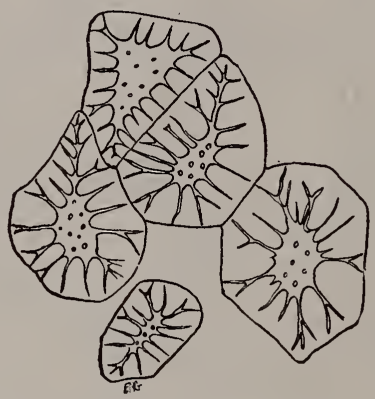

Fig. 396.-Sclerotic cells from the flesh of the Pear.

cells. In sclerotic tissue the cell-wall is usually lignified, and the thickening is in layers, presenting the appearance of stratifications. There are also delicate tubes or pore-canals radiating from the cell-cavity to the outer portion of the cell-wall.

These are the cells which give the great hardness to the outer coats of many seeds, and the shells of nuts. They constitute the gritty particles that occur in the flesh of some fruits, as that of the Pear. They occur in Cinnamon and Cinchona barks and in Tea leaves, and are, in fact, seldom entirely absent from the more highly organized plants. See Figs. 356, 374, 396, 397, 398 and 399.

Stone cells are sometimes grouped with wood fibers and bast fibers under the general name of Sclerenchyma or of Stereome. In this event the stone cells are distinguished as Short Sclerenchyma, the fibers as Long Sclerenchyma, the distinction being based on the fiber-like form and the greater length $(0.5$ to $2 \mathrm{~mm}$.) of the latter.

Epidermal Tissue. All of the higher forms of plants possess an outer layer of cells sharply defined by their shape, size and often color from the tissues within, and constituting the epidermis.

This tissue consists usually of but a single layer of tabular or plate-like cells arranged compactly side by side, with no inter- 
cellular spaces except where stomata and water-pores are situated. Occasionally we find underlying and strengthening layers constituting a hypodermis (see Fig: 400). A typical epidermal cell such as occurs on the more permanent aerial parts of the plant is a little longer than broad, has a comparatively thin inner wall,

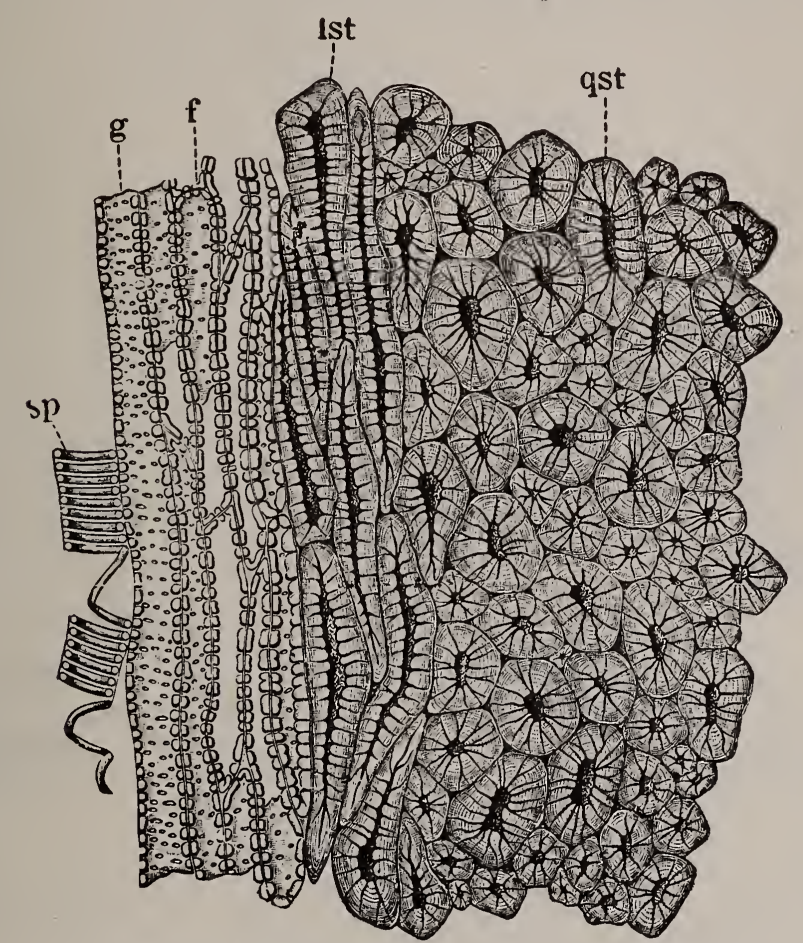

Fig. 397.-Sclerotic cells from the shell of the Cocoanut (Winton)

somewhat thickened and often wavy side walls and a very thick outer wall. The thickening of the outer wall is due to an adhering film of cutin, coating its outer surface. This film is the cuticle (Figs. 369 and 378). It is usually distinctly stratified and is occasionally coated over with a reinforcing layer of wax or even of silica. On the floral parts and in the epidermis of young roots it is commonly absent. The nearly or quite waterproof cuticle is an effective means of preventing loss of water, while it is scarcely less efficient against the attacks of parasitic fungi.

Epidermal cells usually contain cytoplasm and often have 
coloring matter dissolved in the cell-sap. Chlorophyll is rather seldom present except in guard cells. Not infrequently the epidermal cells of the upper surface of leaves show a lens-shaped swelling or papilla; these possibly act as condensing lenses to collect the light-rays and thereby promote photosynthesis. Similar but rather more elevated papillæ characterize the velvety surface of

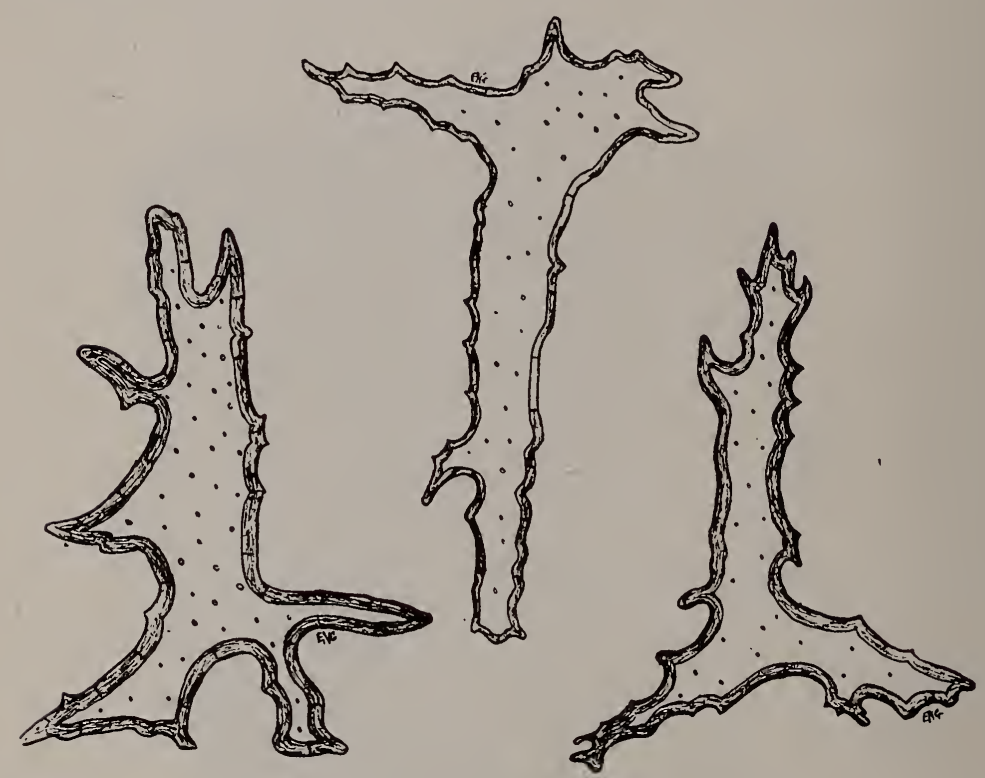

Fig. 398.-Sclerotic cells from Tea leaves.

many petals (Fig. 406). In certain tendrils, the epidermal cells possess a tactile sense that is remarkable.

The hypodermis may assume some of the functions of the epidermis, restricting the latter to the protective and waterproof functions merely, as in some Pine "needles" (Fig. 489). In other instances the hypodermis serves only a mechanical purpose, but most commonly it is directly concerned with the storage of water.

The epidermis remains, as a living tissue, until it is cut off from its supply of water by the development of cork (Fig. 378).

Stomata are composed of modified epidermal cells, usually crescent-shaped and chlorophyll-bearing, occurring in pairs with the concave sides facing so as to leave an opening between. Each cell is called a guard-cell and the entire organ is a stoma (Fig. 
402). In the tissue directly beneath the stoma is always found an intercellular space which communicates with intercellular air passages throughout the leaf. (Fig. 403.)

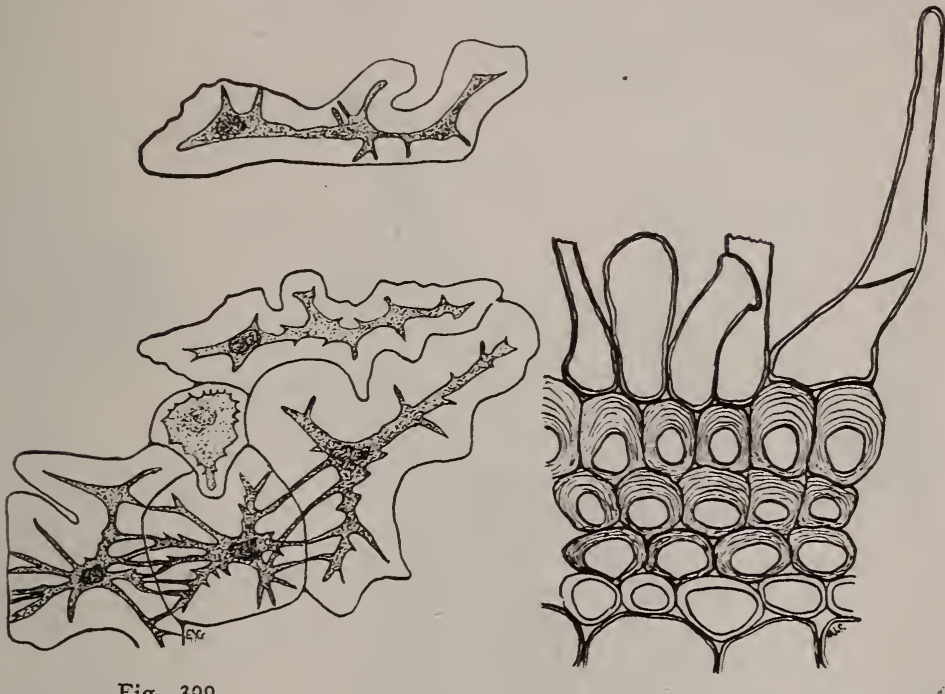

Fig. 399.-Sclerotic cells from Wild Cherry bark. hairs and a four-rowed hypodermis.

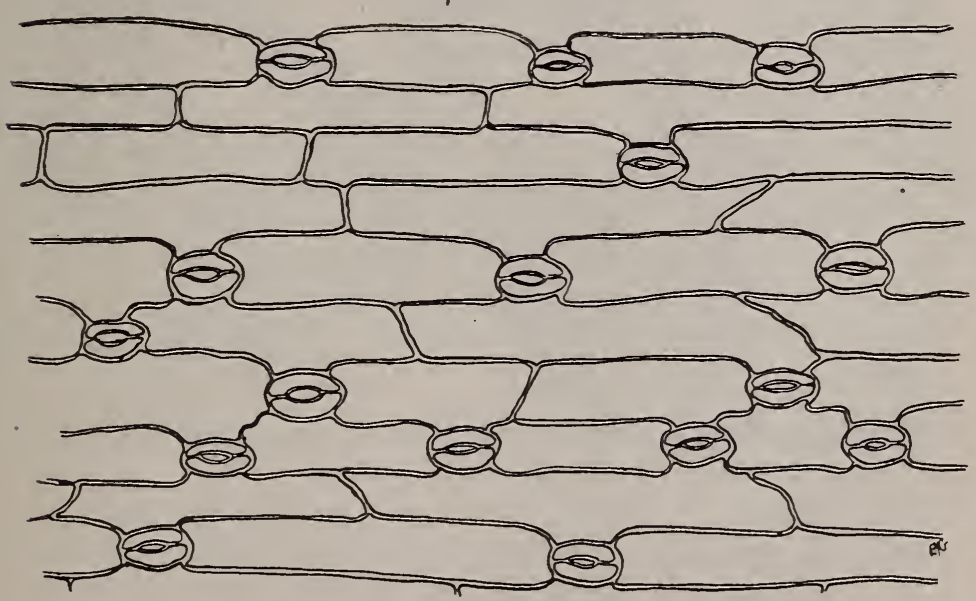

No. 401.-Epidermis of Tulip leaf, showing a surface view ef epidermal cells and stomata in a monocotyl leaf. 
Stomata are the most common upon the green parts of plants, especially leaves, but may occur upon any of the plant organs except roots. In leaves, stomata are usually more numerous upon the shaded surface. As a rule, the stomata are arranged in rows

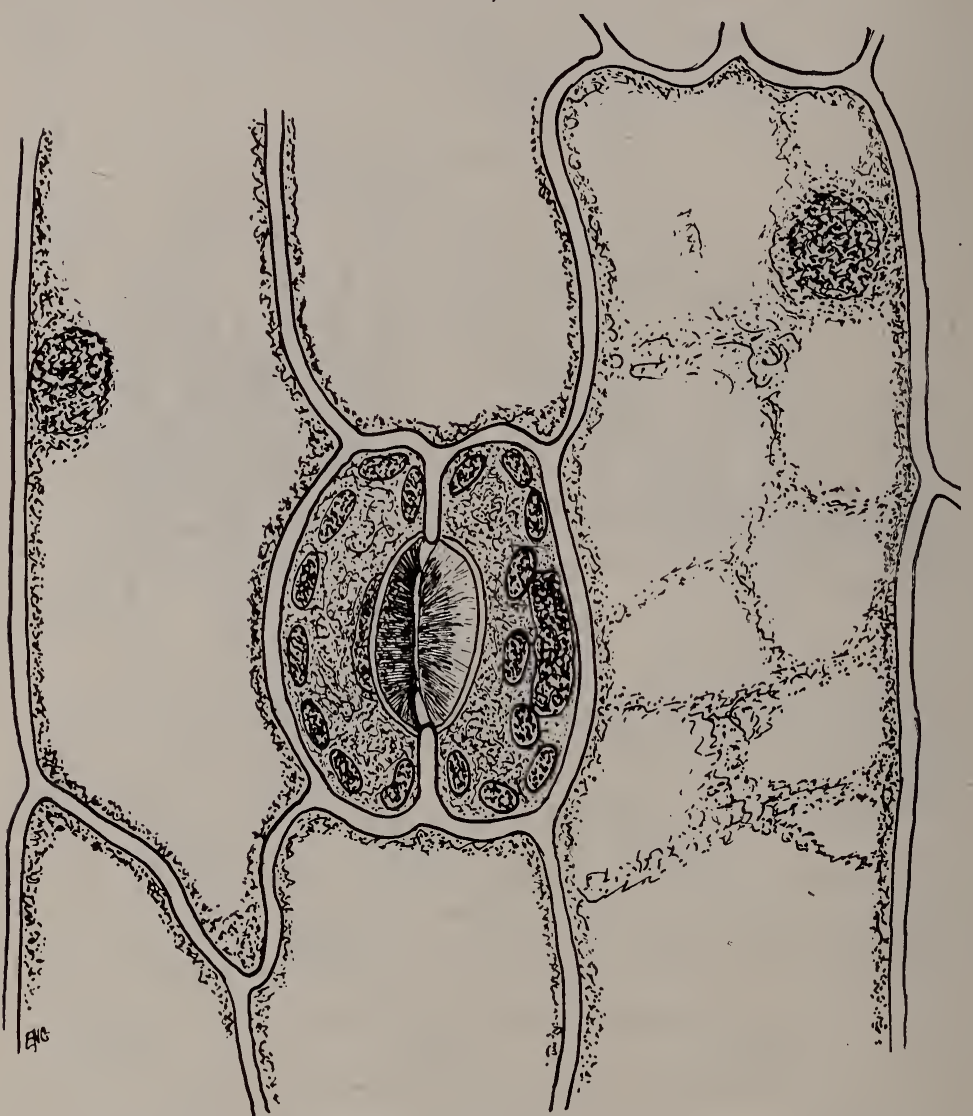

No. 402.-Epidermis of Tulip leaf, showing a surface view of a stoma under high magnification.

in Monocotyledons and are irregularly arranged in Dicotyledons (see Figs. 401, 402, 403, 404, 405).

The number of stomata varies much in different species of plants. On the under surface of bifacial leaves the number will average from one hundred to three hundred in a square millimeter, but in some plants the number may reach seven hundred, indicat- 
ing that a half a million stomata may be present upon a square inch of leaf surface.

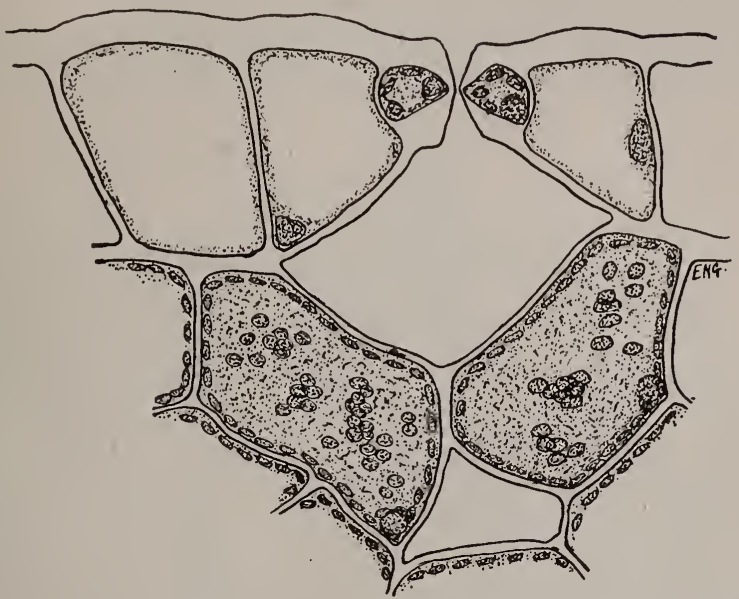

No. 403-Epidermis of the Tulip leaf in transverse section, showing a stoma and adjacent epidermal cells, also intercellular spaces and chloienchyma.

Stomata have the power of opening and closing under the influence of light, warmth and moisture, and act as automatic

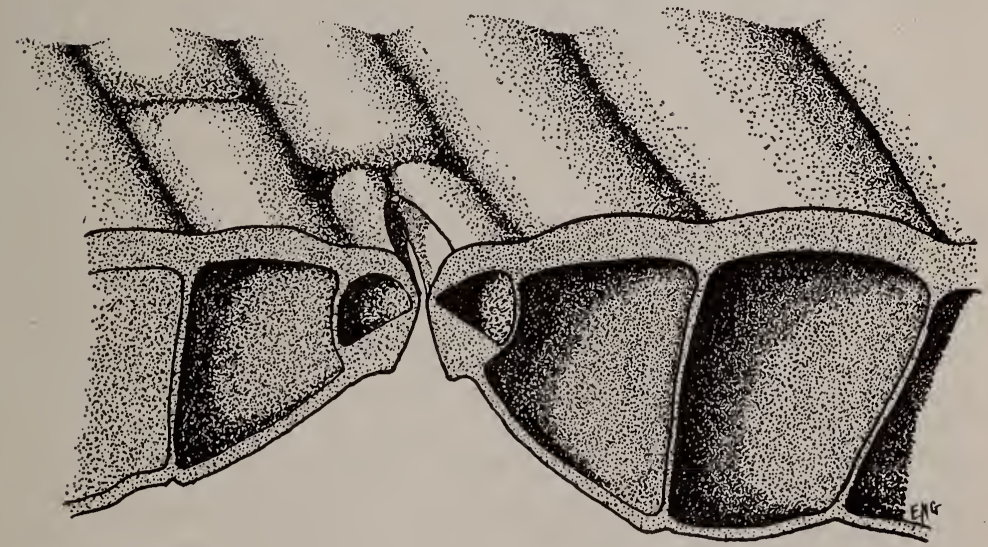

No. 404.-Epidermis and stoma of the Tulip leaf in perspective view.

valves to regulate the amount of moisture given off by the leaf as well as to allow free access of air to the interior. 
Stomata are formed by division of the epidermal cells, first a stoma mother cell is produced, then this divides into the two guard-cells which split apart, providing the pore.

Water-pores or hydatodes are also openings in the epidermis, bearing some resemblance to stomata, but differing from them in

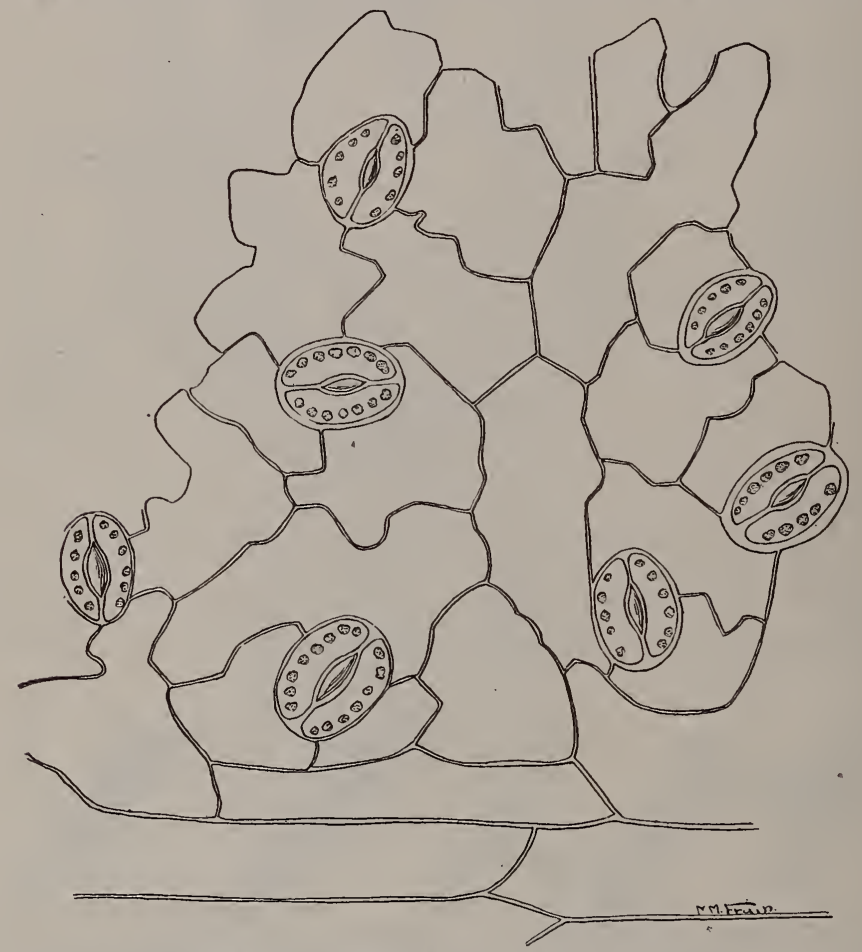

No. 405.-Epidermis from the lower surface of Stramonium leaf, showing cells and stomata under high magnification.

the fact that the guard-cells are immovable, and the opening, therefore, does not increase or diminish, and also in the fact that water, instead of gaseous matter, commonly fills the orifice or oozes out upon the surface. Their distribution is also different from stomata. While the latter are most abundant between the veins on the under surface of leaves, water-pores occur at the extremities of veins on the margin of the leaf and usually toward the upper side. Fig. 407.

Trichomes or plant-hairs are modifications of epidermal cells, being formed by such cells projecting or lengthening outward. 
They occupy a position intermediate between papillæ, which represent only slight projections of the epidermal cells, and various emergences in which the tissues underlying the epidermis are more or less deeply involved. Trichomes vary in character; some are single-celled, others are many-celled; some are simple in shape,

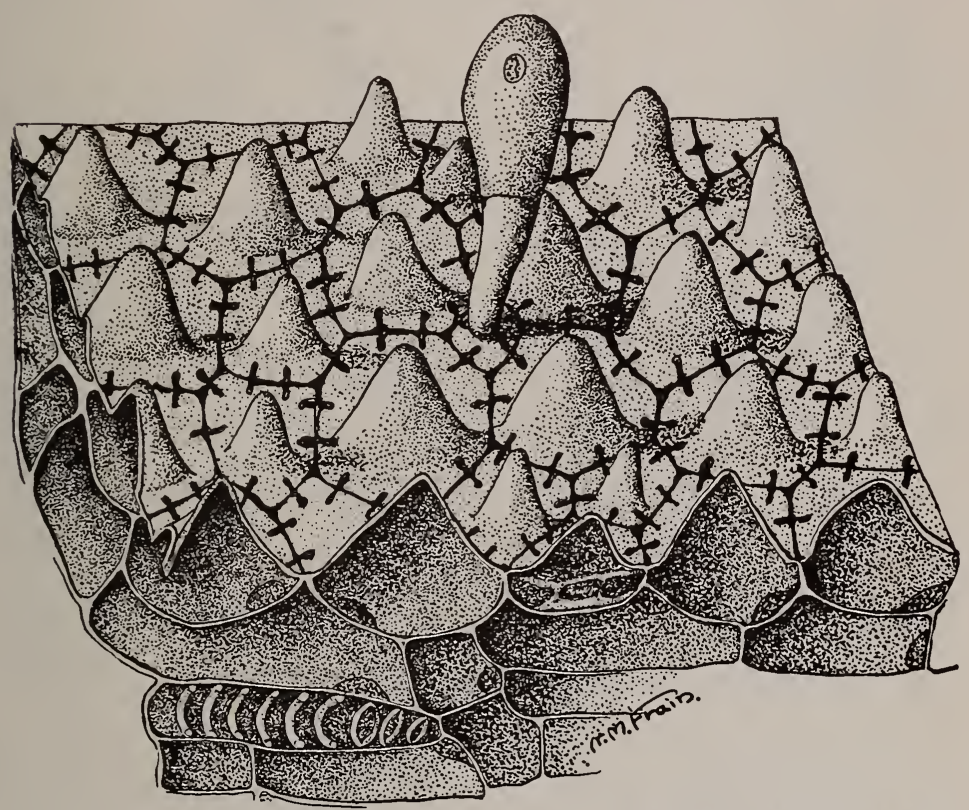

No. 406.-Epidermis of the petal of Cranesbill, showing epidermal cells with folded walls and papillae, also a glandular trichome.

others are variously branched and forked; some are microscopic in size, others, like cotton, are more than an inch in length. They may be borne upon any organ of the plant, that is, upon root, stem or leaves, and they usually occur without definite order.

Unicellular trichomes, or those consisting of but one cell, are the more common. These, though usually undivided, may be forked, branched or stellate (Figs. 408, 409, 410 and 411). Multicellular trichomes, those built up of several or many cells, may be moniliform (necklace-like) clavate (club-shaped), capitate (with a gland-like head), hooked, stellate, peltate, etc. (Figs. 411, 412, $413,414,415,416$ and 417). The cell-walls of plant-hairs may consist of unmodified cellulose or may be cutinized, silicified or even lignified. The cell-contents may include protoplasm, cell-sap 
and, in the glandular trichomes, oil, resin, wax or irritating substances. Trichomes which have lost their living contents and have

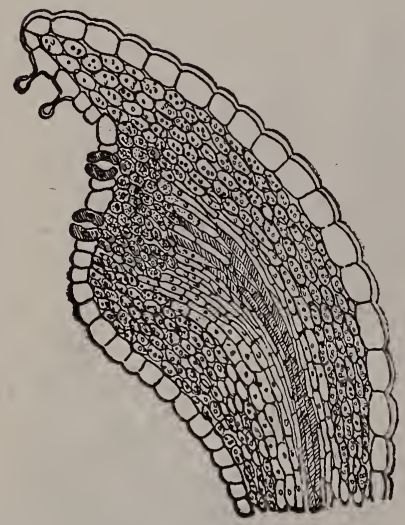

Fig. 407.

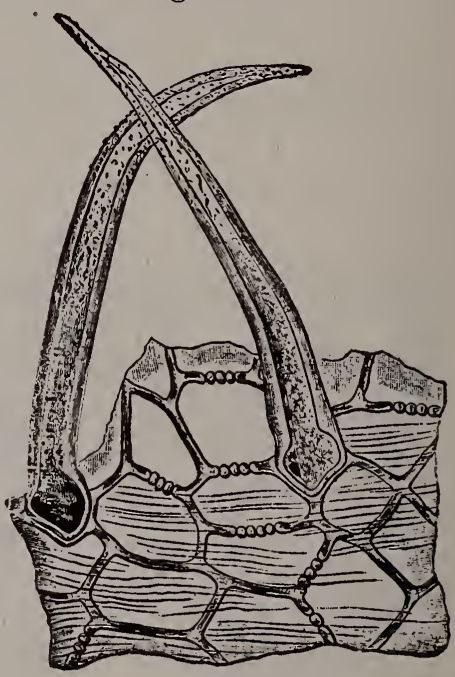

Fig. 408.

Fig. 407.-Section of leaf of a species of Saxifrage, showing two water-pores at the extremity of a vein. Above them are two hairs, to which usually a deposit of calcium carbonate clings, on evaporation of the water excreted by the pores. (Modified from Vines.)

Fig. 409.- Simple unicellular hairs from Vaccinium Aictostaphylos leaf. (Mueller.)

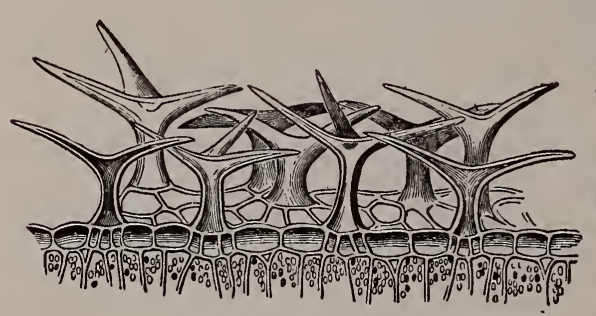

Fig. 409.

Fig. 409.-Branched unicellular hairs from Aubretia deltoidea. (Kerner and Oliver.)

Fig. 410.-Spiral unicellular hairs from Centaurea Ragusina. (Kerner andOliver.)

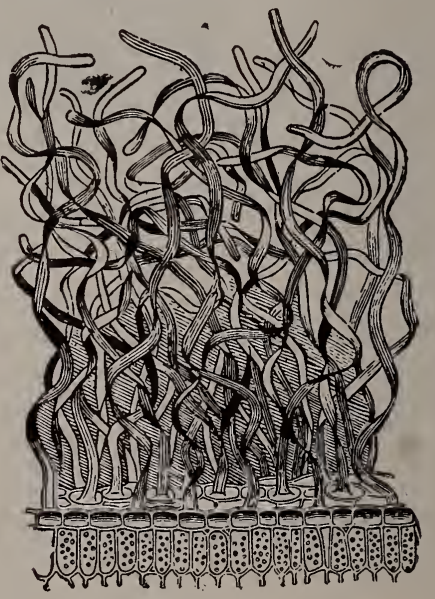

Fig. 410.

become filled with air, being therefore white in appearance, are not uncommon. 
Most important to the plants are the trichomes growing near the tips of the roots, for these, by osmosis, absorb water and nutritive substances from the soil.

Trichomes afford an important means of lessening water loss through transpiration, particularly when felted or woolly; they

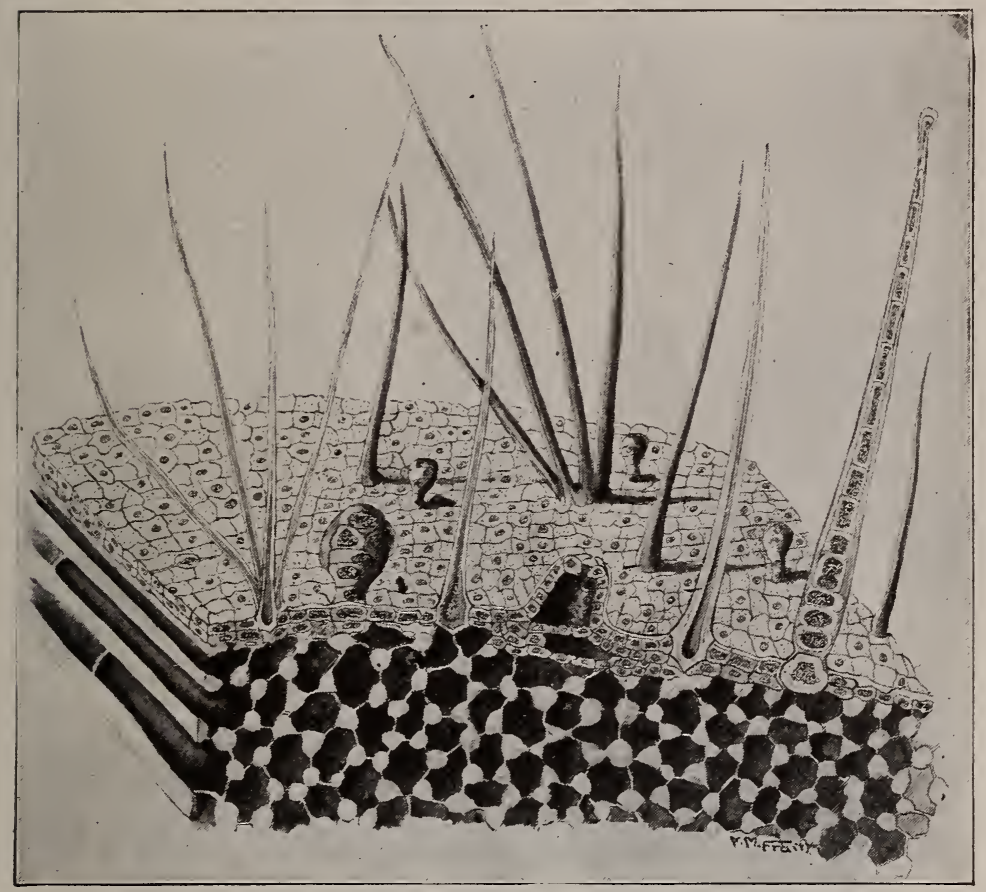

Fig. 411.-Epidermis and sub-epidermal collenchyma from the petiole of Abutilon avicennae. showing simple and multicellular hairs.

may also become a means of seed distribution,- especially hairy outgrowths of the seed coat, like those of the Milkweed; they may serve for defense against insects or herbivorous animals, - the prickles of the Cactus species being notable instances, or as an aid in climbing, or they may serve for the secretion of various principles, such as the perfume of flowers. Secreting hairs are distinguished as "glands," but this term includes also protuberances of quite complex structure but of similar function.

As their form, size, contents and cell-walls are ofter characteristic, trichomes are of great value in the recognition of drugs, 
especially as they usually retain their identity, even after the plant or organ bearing them is powdered.

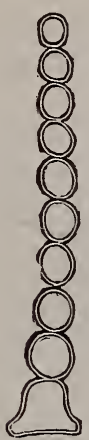

Fig. 412.

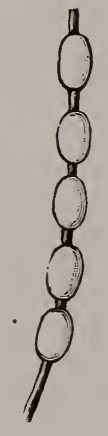

Fig. 413.

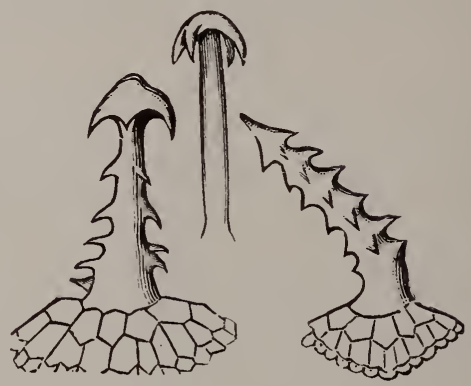

Fig. 414.

Fig. 412.-Moniliform hair from the stamen of Tradescantia.

Fig. 413.-Moniliform hair of Mirabilis Jalapa.

Fig. 414.-Different kinds of barbed hairs from leaf of Mentzelia ornata.

Endodermal Tissue. This tissue consists of a single layer of compactly arranged cells which surround and form a protecting sheath to either single fibro-vascular bundles or, more rarely, to groups of them. This sheath is known as the endodermis. The

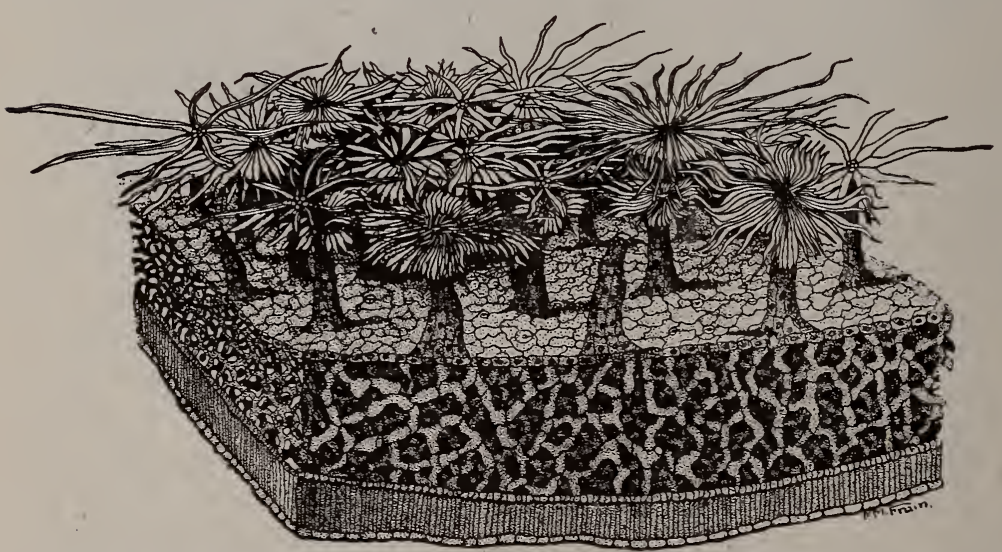

Fig. 415.-Leaf of Shepherdia canadensis, showing palisade and spongy chlorenchyma and epidermis with many peltate trichomes.

cells composing it are commonly elongated, four-sided prisms, with square or oblique ends and often with cutinized walls. The cutinization is usually most evident in the radial walls-those which 
are common to adjoining cells. In one type of endodermis this portion of the wall is more or less wrinkled or folded. Besides its protective function the endodermis also serves to restrict the translocation of food substances to certain paths and to prevent their escape from the conducting bundles into the surrounding tissues. See Figs. 418, 460 and 461.

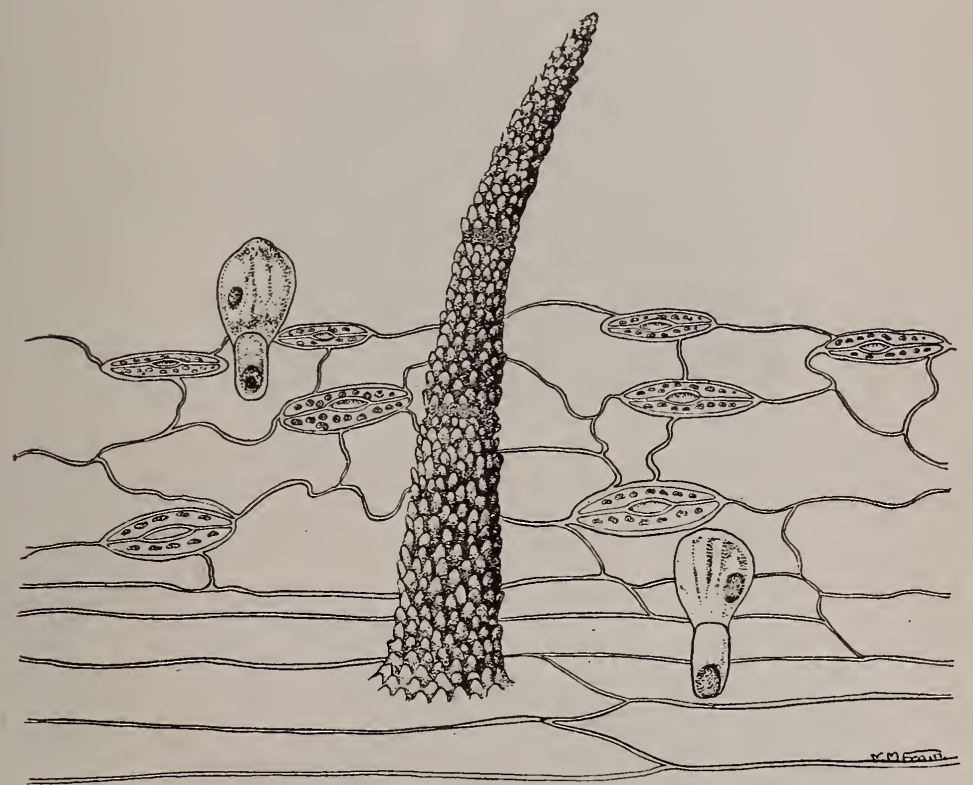

Fig. 416.-Epidermis of Stramonium leaf, showing verrucose and glandular multicellular hairs.

Cork or Suberous Tissue. The cells composing this tissue are rectangular, usually tabular, and placed in rows one behind another with their side walls forming continuous lines corresponding to radii of the stem. Ordinarily no intercellular spaces exist in cork tissue. Cork cells originate in a secondary meristem, the phellogen, the cells of which divide tangentially in a very regular manner (Figs. 420 and 421). The cells of the phellogen and those cells within it contain cytoplasm. The mature cork cells exterior to it have lost their living contents and are filled with air (Fig. 419). The walls of the mature cork cells consist wholly or in part of suberin, a substance nearly identical with cutin; occasionally they are lignified, resembling sclerotic cells (stone-cork). The 
cork cells of different plants may vary characteristically in size arld shape, as well as in the thickening and color of their cell-walls.

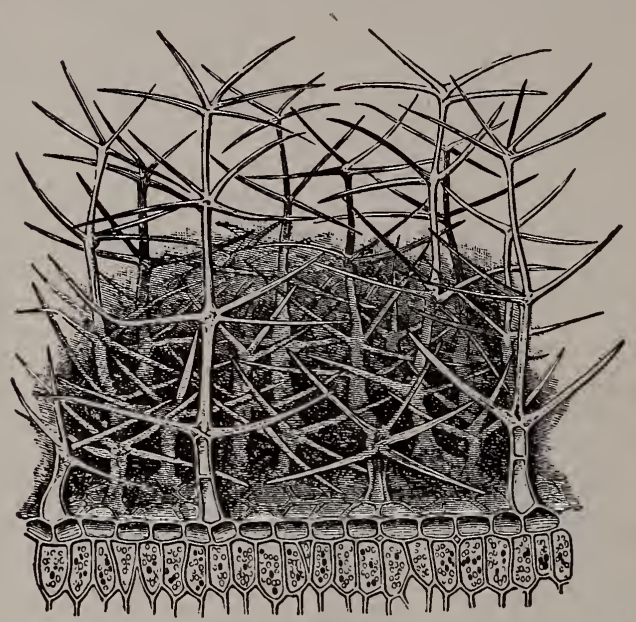

Fig. 417.-Branched multicellular hairs of Mullein leaf. (Kerner and Oliver.)

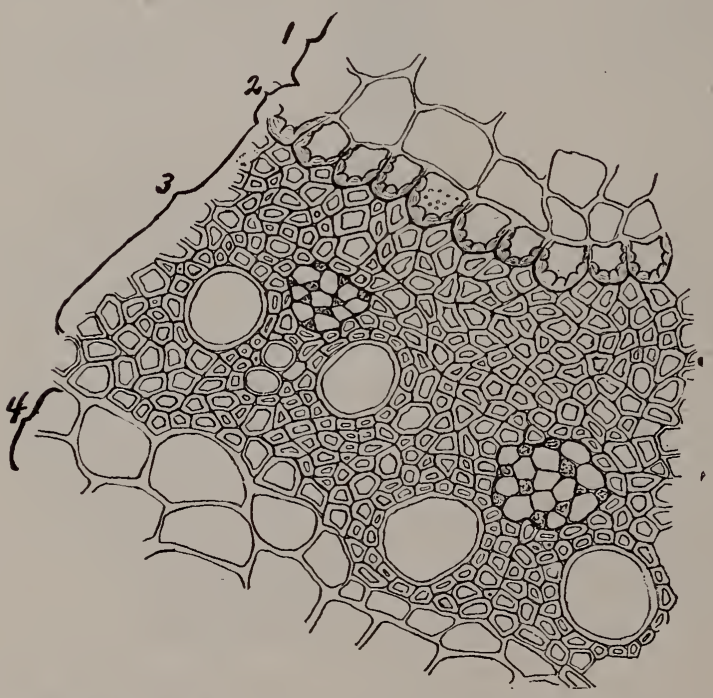

Fig. 418.-Transverse section of Couch-grass rhizome, showing the endodermis (2) adjacent to the wood bundles ( 3 ) and parenchyma ( 1 and 4).

Cork is a secondary tissue located just under the epidermis, which it frequently replaces. It may extend backward into the 
middle and even the inner bark. Normally, cork occurs abundantly in the perennial stems and roots and rarely in the leaves of dicotyledons, less frequently in monocotyledons and very seldom in cryptogams.

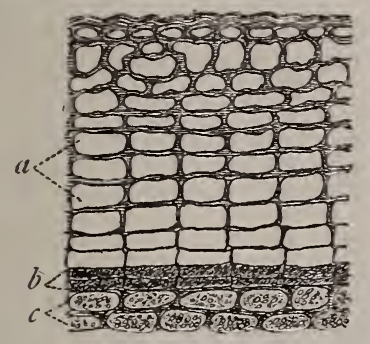

Fig. 419 .

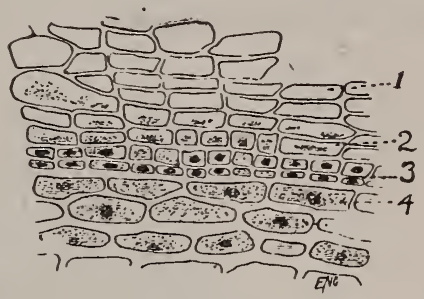

Fig. 420.

Fig. 419.-Section of branch of Currant, showing cork cells, and the way they are formed. c, chlorophyll-bearing parenchyma; b, cork-cambium; a, mature cork cells.

Fig. 420.-Section of bark of Cascara Sagrada, showing, 1, mature cork cells; 2. immature cork cells; 3 , phellogen; (4) mother cells.

The function of cork, like that of the epidermis, is to protect the tissues lying beneath from too great evaporation or from injury; "Wound Cork," which forms when the living tissues inte-

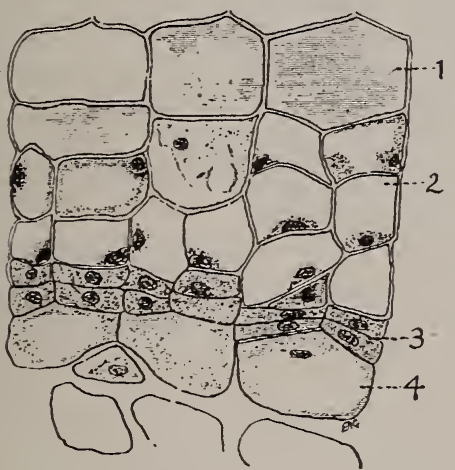

Fig. 421.

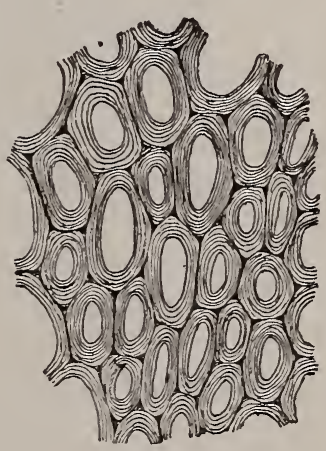

Hig. 42?.

Fig. 421.-Section of stem of Elder, showing, 1, mature cork cells; 2, immature cork cells; 3 , phellogen; 4 , mother cells.

Fig. 422. - Transverse section of bast cells from the stem of Menispermum canadense. The middle lamella is shaded dark, and the walls of the thickened fibers show concentric lamination.

rior to the epidermis are laid bare, serves this purpose of protection very effectively. Leaf scars are also protected by a growth of cork. 
Prosenchymatous Tissues. Those tissues are often grouped as Prosenchyma, whose cells, at maturity, lose their nuclei and protoplasmic contents, and therefore their distinctively living character, and have their walls thickened by secondary deposits, usually of lignin. Such cells are for the most part elongated and obliqueended or taper-pointed and are joined together by their sides and

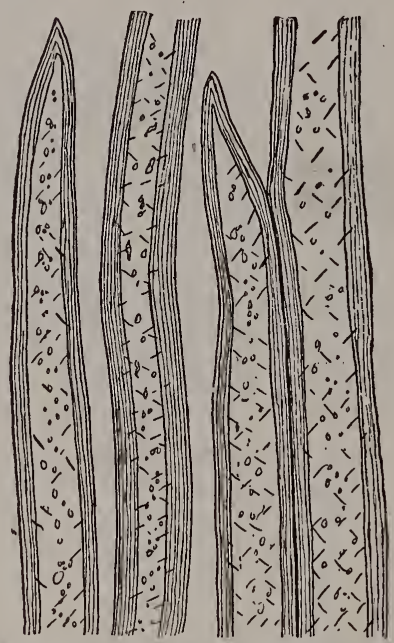

Fig. 423.-Longitudinal view of small portions of the long bast fibers from the stem of the same plant, showing oblique markings in the cell walls.

by their oblique and tapering ends. They sometimes contain starch and traces of proteid matter, but take no active part in the nutritive processes of the plant. These tissues serve chiefly for strengthening or support, and hence are called mechanical tissues. They are also serviceable in conducting the sap. Both in the shape of their component cells and in their physiological functions there are many transitional forms or gradations between the tissues of the parenchymatous and the prosenchymatous groups. The latter includes Bast, Libriform, Tracheary and Vascular tissues.

Bast or Sclerenchyma Fibers. These consist of greatly elongated, usually taper-pointed, but sometimes forking or sparingly branching cells, very thick-walled, tough and flexible. Their walls, when mature, are strongly lignified, frequently unequally thickened, and often marked with delicate, oblique, slit-like markings (Fig. 376). They are usually highly refractive and lustrous. Living contents are absent from typical mature bast fibers, in fact 
the thickening of the walls is frequently so excessive as to almost obliterate the cell cavity.

In longitudinal section, typical bast fibers show their distinctive elongated fusiform shape with their tapering ends fitting closely together and firmly united (Figs. 376 and 423). In transverse section these cells appear as polyhedral plates set in close contact with each other so as to resemble a mosaic.

Bast fibers constitute the tough and stringy tissues in the liber or inner bark of Dicotyledons, such as the Bass-wood, Flax and

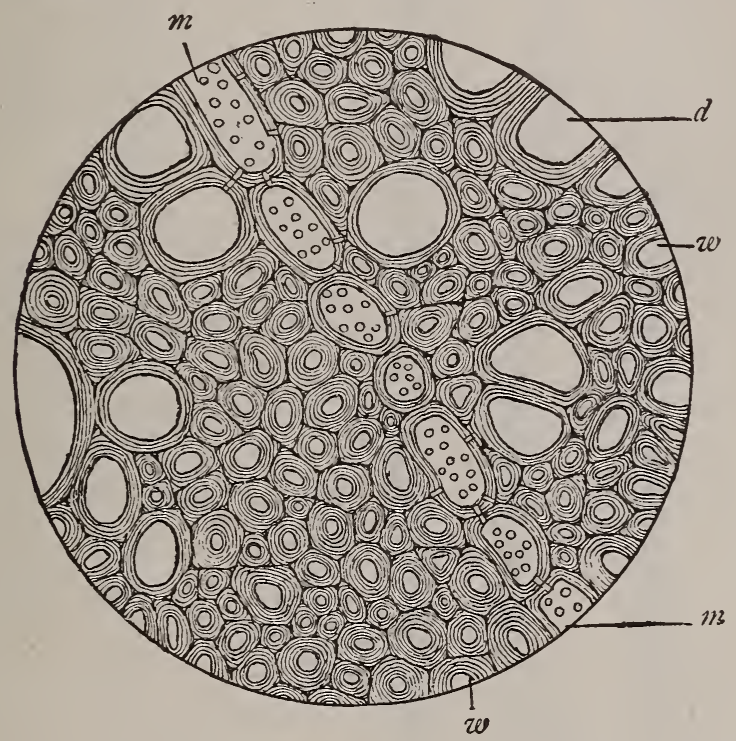

Fig. 424.-Portion of transverse section through woody part of stem of Pilocarpus pinnatifolius. $\mathrm{m}$, $\mathrm{m}$, medullary ray cells; $\mathrm{w}$, w, wood fibers; $\mathrm{d}$, a tracheal tube.

Leatherwood. The value of Flax for the production of textile fabrics depends upon the presence of the fibers.

Though bast fibers, in the strict sense of the term, are confined to the bast or phloem portion of fibro-vascular bundles, fibers structurally indistinguishable from them often occur elsewhere in the plant. Examples of these are the fibrous tissue that surrounds and strengthens some fibro-vascular bundles, as those of Maize (Fig. 471); the strengthening cylinder immediately underlying and supporting the epidermis of some plants, as that of the stems of many Monocotyledons and Ferns; and the fibrous strengthening 
cylinder sometimes found imbedded in the parenchyma of stems, considerably beneath the epidermis and outside of the fibro-vascular bundles, as in the stem of the Pumpkin. The terms "sclerenchyma or "sclerenchyma fibers" may, therefore, be applied to all

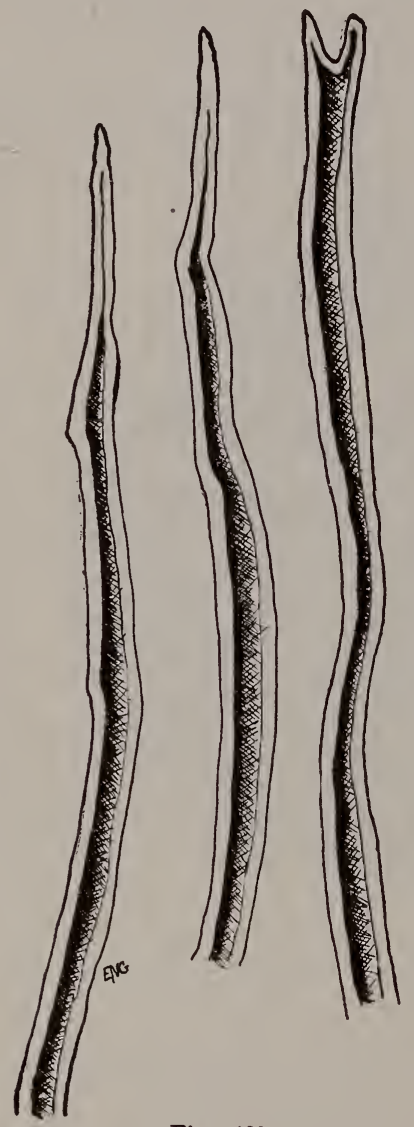

Fig. 425.

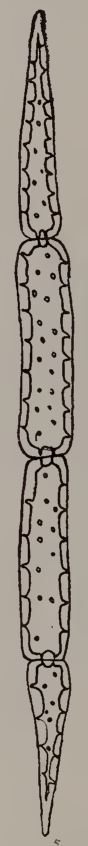

Fig. 425 .

Fig. 425.-Simple wood fibers isolated, showing an end and about one-third the length of each fiber.

Fig. 426.-Wood parenchyma cells from Red Oak. showing fiber-like form.

these, and in this sense are used in this work. Fibrous cells, unthickened and unlignified and with or without living contents, are sometimes associated with the bast. Occasionally these become septate.

Bast is a typical mechanical tissue. It serves to strengthen and support the organs in which it is found. It is admirably adapted 
to this purpose by reason of its ductility and supporting power, the latter being comparable to wrought iron.

Libriform Tissue or Wood Fibers closely resemble bast fibers and by some authors are considered as sclerenchymatous fibers, along with bast. They differ from bast fibers chiefly as regards their position in the plant, for while bast fibers, as has already been stated, are located only outside the fibro-vascular bundle,
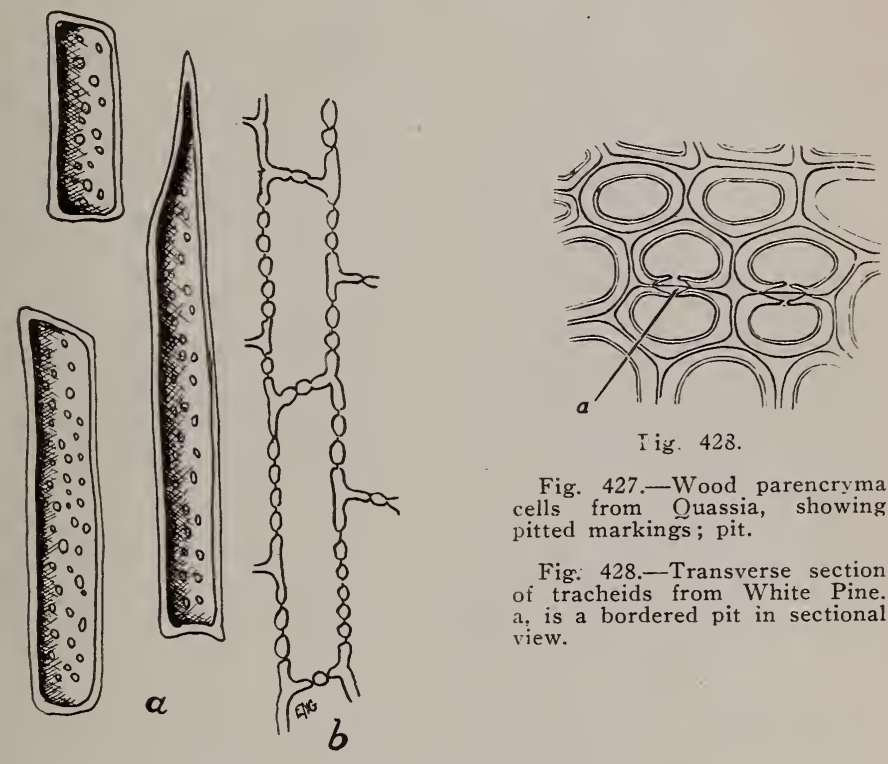

Fig. 427.-Wood parencryma cells from Quassia, showing
pitted markings; pit.

Fig: 428.-Transverse section of tracheids from White Pine. $a_{\text {, is a bordered pit in sectional }}$ view.

Fig. 427.

wood fibers are always found constituting a part of the xylem, or woody portion of the bundle. As between typical fibers of the wood and of the bast, fairly well-marked differences exist, but the two grade into one another very closely. From their resemblance to bast (or liber), wood fibers are sometimes termed libriform cells. They constitute the great bulk of the wood of most plants and abound particularly in the stems of Dicotyledons. The cells are compactly arranged, long-fusiform in shape, rarely forked or lobed at one or both ends, more or less compressed laterally by mutual pressure, so as to appear angular in cross-section, and like bast fibers, they are so placed together as to splice one over the other, forming a hard and strong tissue, Fig. 424.

Wood fibers exist in several modifications. The common or 
typical form is slender-fusiform, thick-walled, with a continuous cavity, and the walls sometimes marked with oblique or other markings, but frequently without them, Fig. 425. Another form, much less common, is distinguished by the possession of transverse septa, Fig. 426.

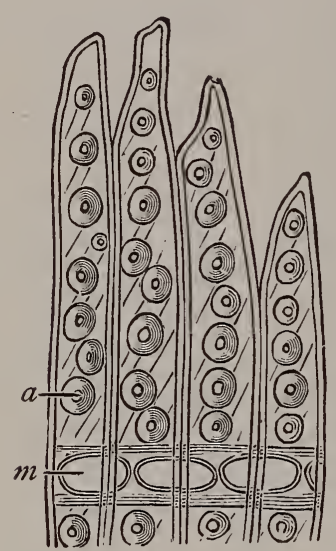

Fig. 429.

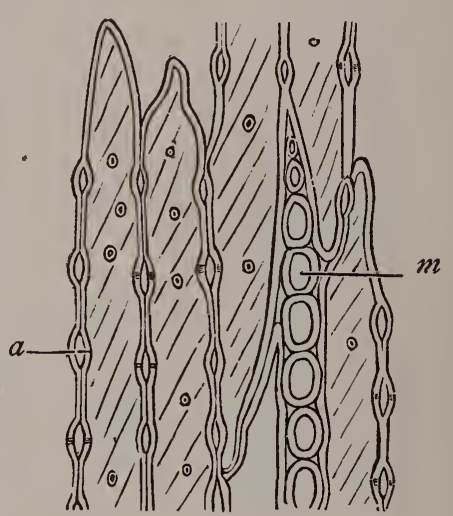

$\mathrm{Fi}_{\varepsilon}$. $43 \%$.

Fig. 429.-Longitudinal radial view, showing numerous bordered pits. a, a bordered pit; $\mathrm{m}$, one of a row of medullary ray cells.

Fig. 430.-Longitudinal tangential section, showing medullary-ray cells and tracheids. In this view the pits appear lenticular in shape, and on the margins of the cells. $a$ is one of the pits and $m$ a medullary-ray cell.

Tracheids are of elongated tapering forms, therein resembling wood-fibers, but they are usually of larger caliber and have relatively thinner walls, sometimes spirally thickened, sometimes marked with various and characteristic sculpturings, thereby resembling tracheal tubes. In fact, tracheids occupy an intermediate position between wood-fibers and tracheal tubes and grade into one or the other of these forms very closely. When tracheids occur in association with wood cells, as is most commonly the case, they are usually larger than these in transverse diameter, and have less tapering, merely oblique or even square ends, though there are some exceptions to these rules. When arranged end to end in linear series, they are indistinguishable from tracheal tubes, save by the imperforate transverse or oblique partitions.

In the Pines and related plants a peculiar kind of tracheid composes the wood, giving to coniferous woods peculiarities which enable us to readily recognize them. If a radial section of the 
wood of the common White Pine be made, the elongated, fusiform cells of the woody zone will be seen to possess numerous rounded pits, each of which, in this view, looks like two circles, one within the other. They occur mostly on the radial walls of the cells, as

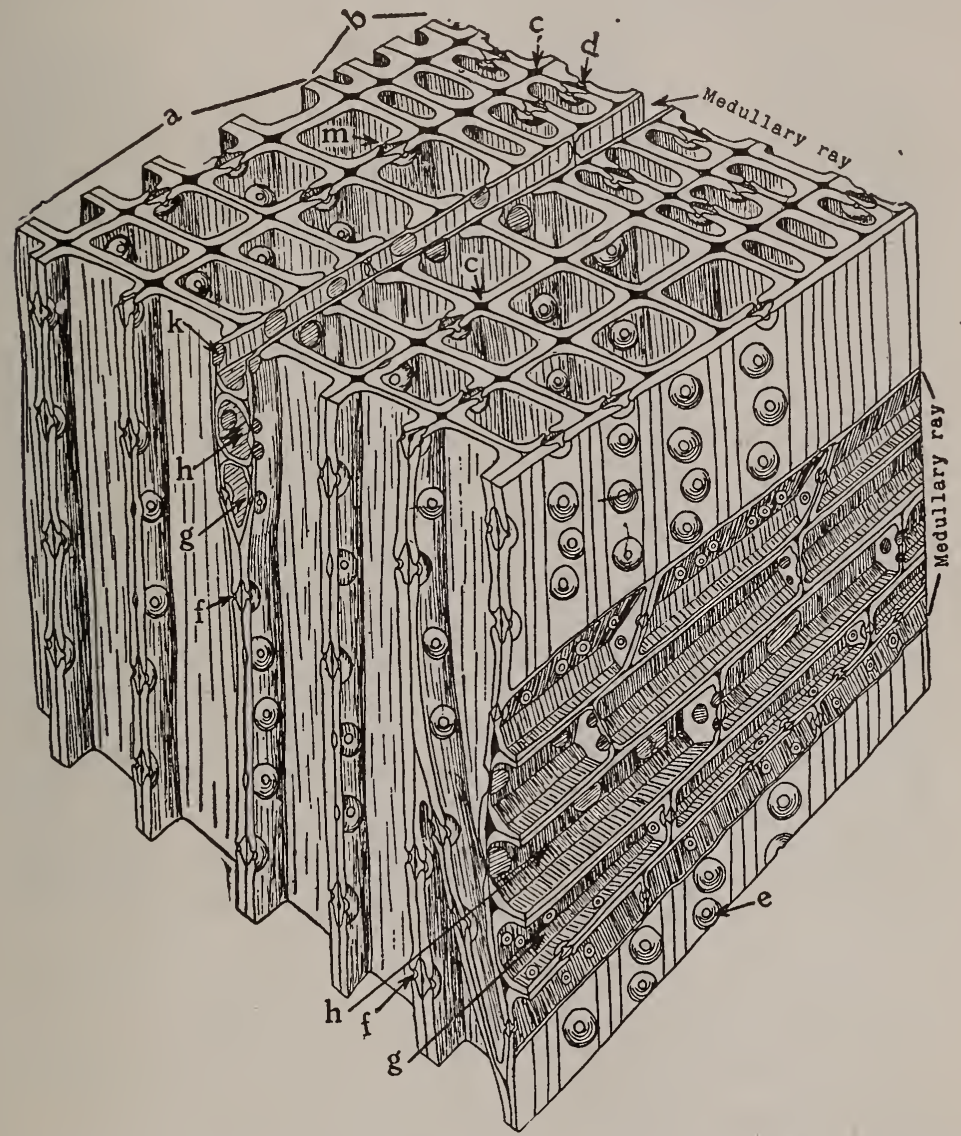

Fig. 431.-Diagrammatic representation of a block of pine wood, highly magnified. a, early growth; b, late growth; c, intercellular space; d, bordered pit in tangential wall of late growth; $m, f$ and $e$, bordered pit in radial wall of early growth from different points of view; h, row of meduilary cells for carrying food; $g$, row of medullary ray cells for carrying water; $k$, thin place in radial wall of ray cells that carry food. (Stevens.)

is shown by comparing the radial, transverse and tangential sections. The comparison will also show us that the bordered pits, as they are called, are lenticular areas in the common wall between 
two adjacent cells. These areas have their lateral walls perforated centrally with a circular or oblong perforation. It is this which, in the radial view, gives rise to the optical impression of an inner circle in each pit. The perforation, however, does not extend,

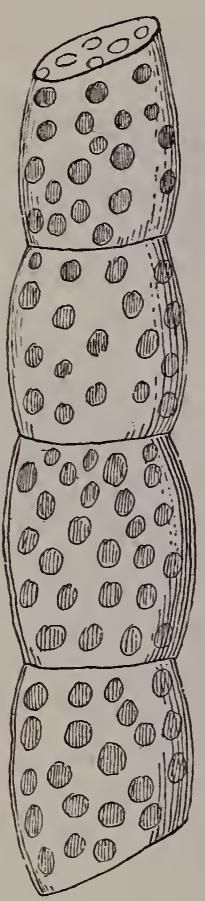

Fig. 432.

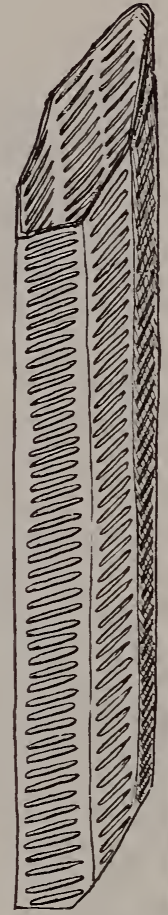

Fig. 433 .

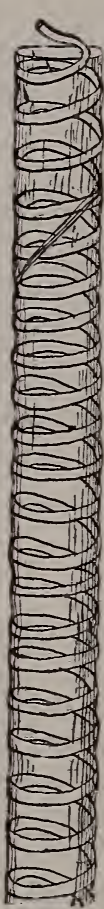

a

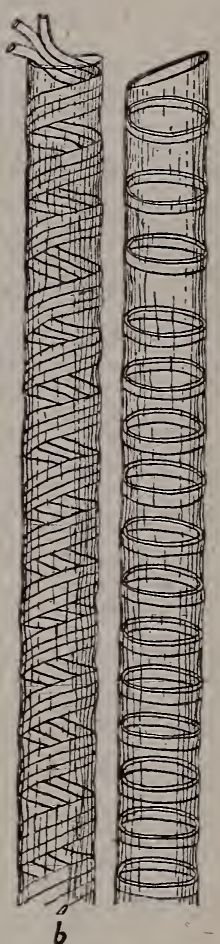

Fig. 435

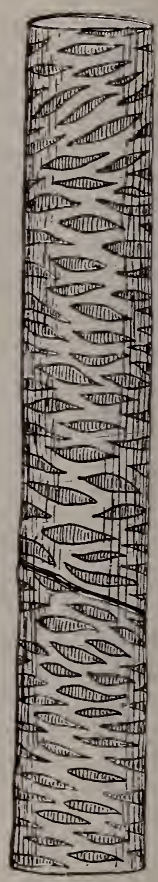

Fig. 436.

Fig. 432.-A dotted or pitted tracheal tube from Milk-weed.

Fig. 433.- Part of a scalariform tracheal tube from a fern.

Fig. 434.- Spiral tracheal tubes; $a$, one with a single spiral band; b, one with a triple spiral.

Fig. 435.- An annular tracheal tube from house Geranium.

Fig. 436.-A reticulate tracheal tube from house Geranium.

except in very old wood, completely through the common wall from one cell to the other, but there still remains stretched across the cavity of each area a delicate separating membrane. The structure will be understood by references to Figs. 428,429 and 430 , which represent small portions, respectively, of transverse, radial and tangential sections of White Pine wood, and Fig. 431, which is a 
diagrammatic representation of Pine wood showing the cellular structure in three dimensions.

The parenchyma cells, with bordered pits, which occur immediately within the bundle sheath in the leaves of Pines, may be regarded as transition forms between ordinary parenchyma and the tracheids just described. Indeed, by-some they are classed as tracheids.

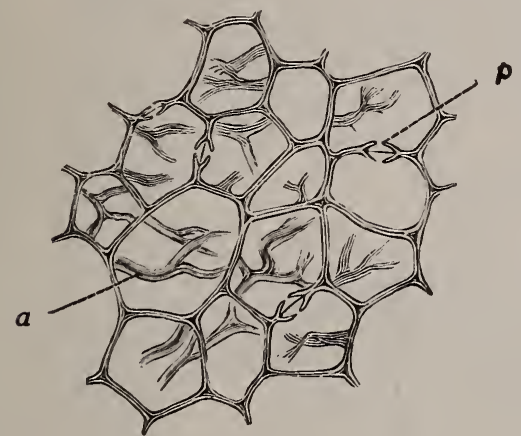

Fig. 437 .

Fig. 437.-Transverse view of trabecular tracheids from leaf of common Juniper; $p$, a bordered pit; $a$, thickening crossing the lumen of the cell.

Fig. 438.-Longitudinal view of the same, magnified to the same extent. The letters also refer to the same structures.

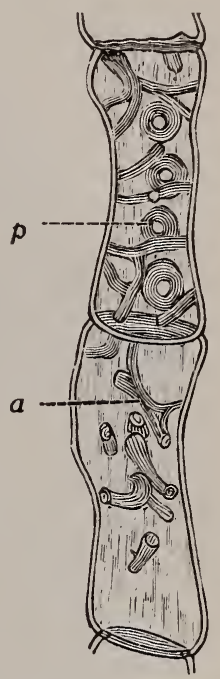

F:g. 438.

Just as wood fibers grade into vessels they also, on the other hand, approach parenchyma, and we frequently find among the woody tissues rows of rather thin-walled cells, like those represented in Fig. 427, the end ones taper-pointed, the middle ones blunt-ended, and together forming a combination shaped like a wood cell. Such tissue is termed wood parenchyma, and the name happily expresses its intermediate character.

Vascular Tissue. These cells, variously known as ducts, tracheai tubes or vessels, differ from tracheids mainly in being composed of two or more cells which have become confluent end to end, forming tubes of varying length. Their diameter is commonly large, compared with that of the other wood cells of the same plant, and they are usually much longer. When mature, their walls are lignified, their lumen commonly filled with air, though sometimes with cell-sap, and they are destitute of cytoplasm. The 
thickenings, which constitute the markings, are on the internal surface of the wall, and the different kinds of tracheal tubes are named from the character of these markings.

The following kinds are the most important:

The Dotted or pitted are characterized by rounded or oblong, thin areas or pits scattered over the wall, as in Figs. 432 and 440.

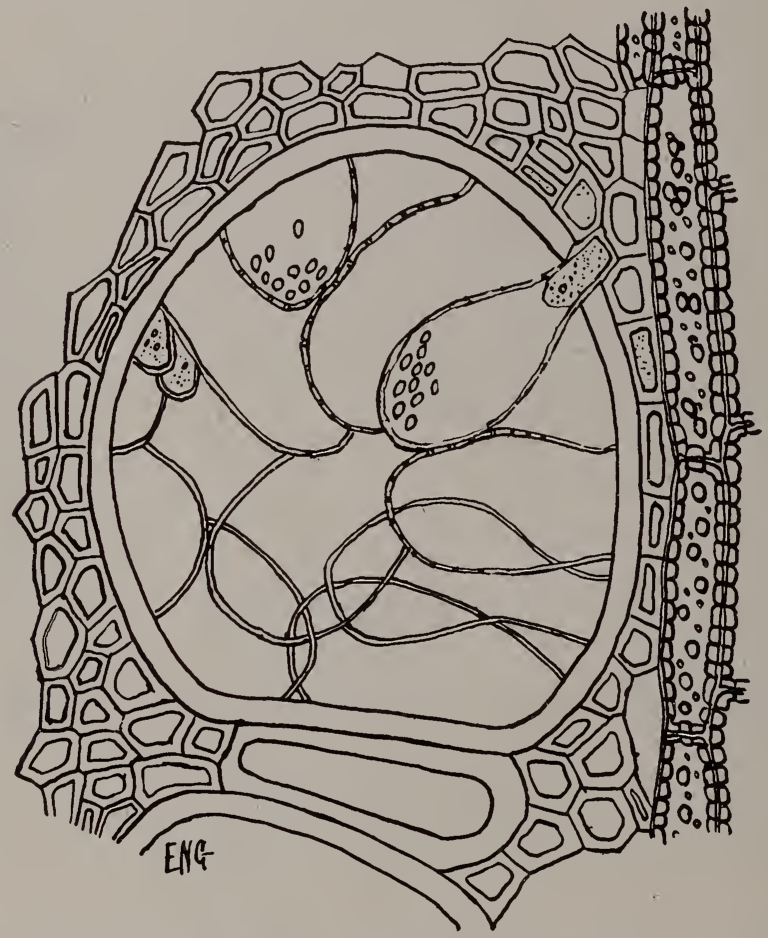

Fig. 439.-Transverse section of the wood of Vitis vinifera, showing large vessel filled with old tyloses. At the left a young tylose growi g out of a wood parenchyma cell. (After Reess.)

The Scalariform differs from the dotted chiefly in the fact that the pits are greatly elongated in a transverse direction, giving rise to markings which bear some resemblance to the rounds and spaces of a ladder; hence the name; Fig. 433.

The Spiral are those in which the markings consist of spiral thickenings. The spirals may be loosely or compactly arranged; they may be single, double, treble, or even sextuple. The rest of the wall on which they are borne is usually thin, so thin that when a stem or other organ containing them is torn asunder by a longi- 
tudinal strain, the cell-wall is ruptured, and the spirals are drawn out, sometimes to great length, and appear to the naked eye like spider lines. Two of these tubes are shown in Fig 434, $a$ and $b$.

The Annular are those in which the thickenings take the form of rings, Figs. 377 and 435. Transition forms between these and spiral vessels are often met with. For example, one end of the tube may possess a spiral, while the other is annulate.

The Reticulate vessel is one in which the thickenings take the form of a reticulum or network, as in Figs. 375 and 436 . Intermediate forms between this and the spiral are also sometimes seen, and gradations occur between this and the dotted vessel.

The Trabecular is a rarer form, in which the thickenings cross the lumen of the cell. On either side of the central fibro-vascular

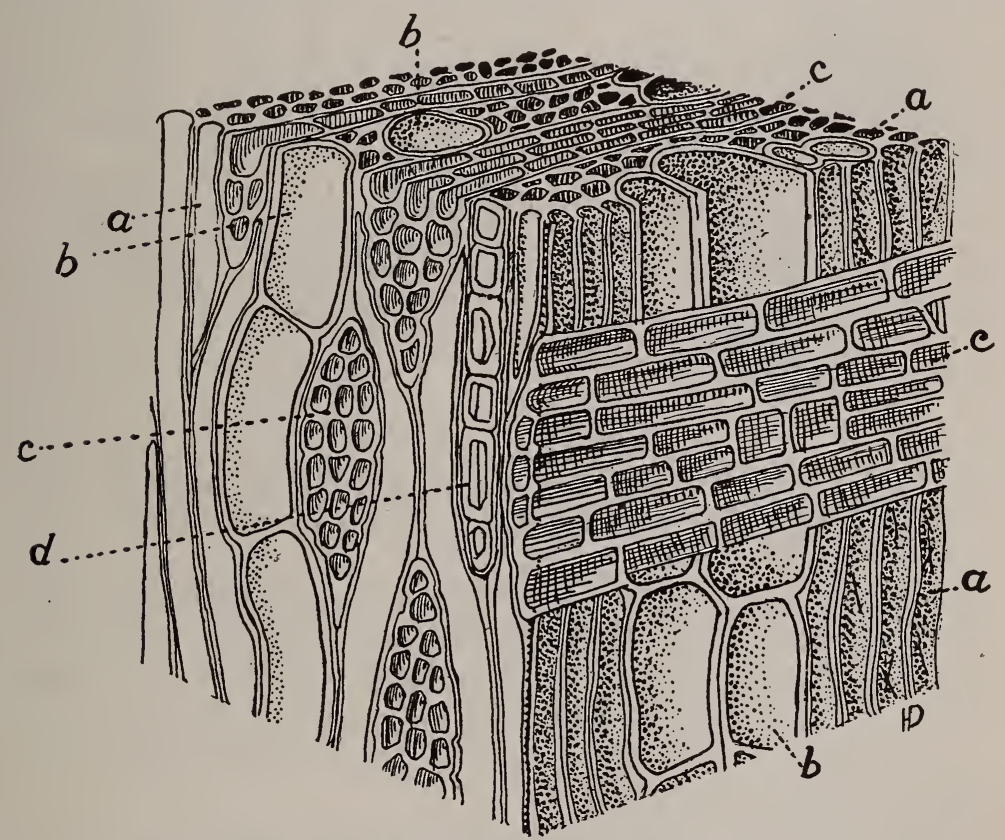

Fig. 440.-Ouassia wood, showing the structure. a, wood fibers; b, tracheal tubes; c, medullary rays; d, wood parenchyma, bearing prismatic crystals of calcium oxalate.

bundle in the leaf of the common Juniper occur tracheids having thickenings of this character. Fig. 437 represents some of them as they appear in transverse section, and Fig. 438 some of the same in longitudinal view. 
Occasionally parenchyma cells lying alongside the tracheal tubes, force their way through the thin places in the walls of the tubes and more or less completely fill the cavity. These are termed tyloses (see Fig. 439).

In wood fibers the mechanical function predominates and the conducting work is secondary, but with tracheids and tracheal tubes the reverse is true. Tracheary cells serve only incidentally to support the plant, their prime purpose being to convey water

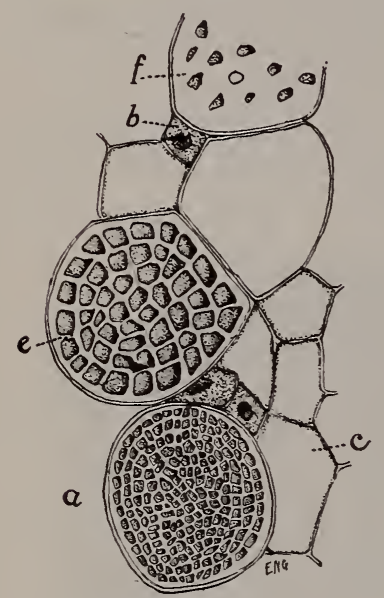

Fig. 441.

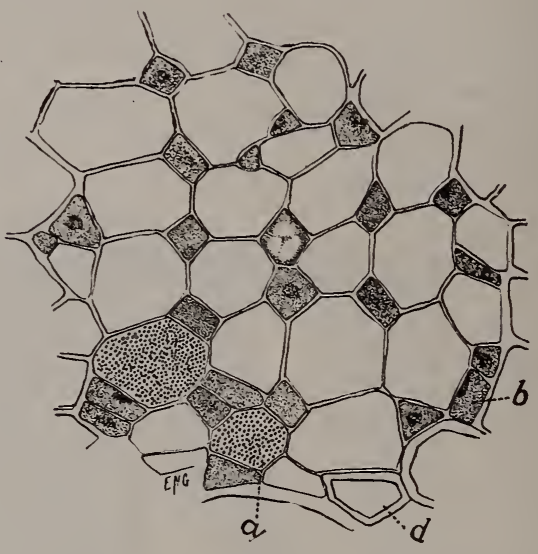

Fig. 442 .

Fig. 441.-Phloem tissue from Pumpkin stem, showing. a. e and $f$, sieve plates; $b$, companion cell; c, parenchyma cell in transverse sect:on.

Fig. 442.-Pbloem tissue from Corn stem, showing, a, sieve plate: $b$, com. panion cell, and d, zylem.

and watery sap, while the conduction and storing of the elaborated foods are carried on chiefly by the parenchyma cells. Fig. 440 shows the relation of wood fibers, tracheal tubes, and wood parenchyma to the medullary rays in Quassia wood.

Conducting tissues, both woody and parenchymatous, are sometimes grouped as Mestome.

Sieve Tissue. This includes the different varieties of Sieve Cells, which are the essential feature of the phloem of fibro-vascular bundles. They consist usually of elongated, thin-walled and blunt or somewhat oblique-ended, relatively large cells, arranged in longitudinal rows and having areas with sieve-like perforations, technically called sieve-plates, on some portion of their surface. Accompanying them may be elongated parenchyma cells, with liv- 
ing contents known as companion cells. The sieve and companion cells, with parenchymatous elements (cambiform cells or leptomeparenchyma) that may also be present, constitute the phloem (leptome) of the vascular bundles (mestome strands).

In some forms of this tissue, as in the stem of the Pumpkin, where it is abundant and well developed, the ends of the cells, and not the sides, have the most prominent sieve plates. Figs. 441, 442 and 443 . In others the plates are more prominent on the side walls than on the end partitions, but not infrequently they occur on both, as may be seen in some of the sieve-cells of the Pumpkin.

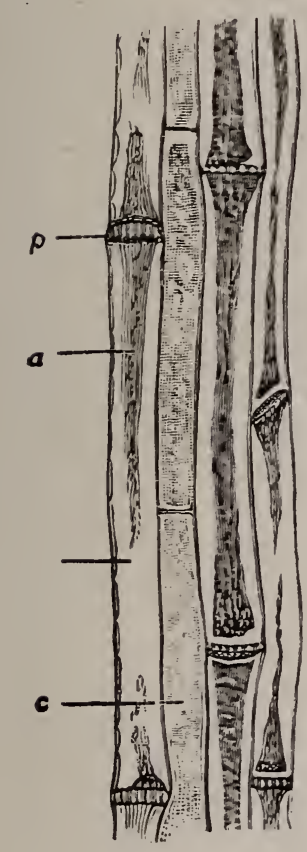

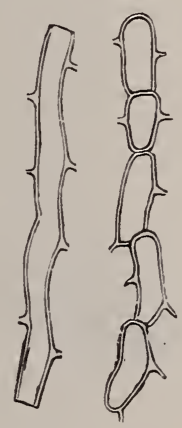

Fig. 444.

Fig. 444.-a, row of latex cells from rhizomes of Sanguinaria; $b$, portion of latex tube, com posed of several confluent latex cells from the same plant.

Fig. 443.-Longitudinal view of sieve tissue from Pumpkin. s, a sieve-cell; p, a thickened sieve-plate; attached to either surface of the sieve-plate are masses of albuminoid matter, d, shrunken by treatment with alcohol; c, companion cell.

Fig. 443.

Mature sieve-tubes usually contain a thick, slimy, albuminous fluid composed partly of the cytoplasm lining the tube and partly of watery or somewhat mucilaginous material. When the sieve tubes are cut and exposed to air or when they are treated with strong alcohol this fluid coagulates and is then most abundant and dense next to the transverse plates, as shown in Fig. 443, which represents a longitudinal view of sieve-tissue from the Pumpkin stem 
after having been treated with alcohol. In places the albuminoid matter is shrunken away from the sieve-plate. From mature sieve tubes the nucleus has disappeared; the cytoplasmic filaments are continuous from one cell to the next through the perforations in the plates; thus the protoplasts are connected, forming an organic whole, and the sieve cells, during the growing season, at least, form long, continuous tubes, through which nutritive mate-

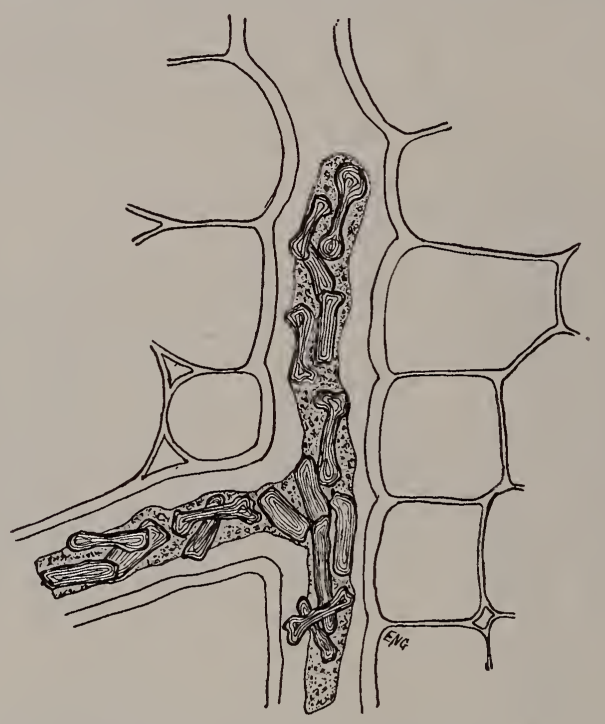

Fig. 445.-Branched latex vessel from Euphorbia splendens, containing bone-shaped starch grains embedded in the latex.

rials circulate in the plant. The sieve-plates are usually much thickened, often with a deposit of a peculiar lustrous, gelatinous character called callus, which may line the pores only or may cover the whole plate. The rest of the cell-wall remains very thin and is composed of unmodified cellulose. The function of this tissue is, presumably, the distribution of nitrogenous food substances through the plant. The non-nitrogenous foods, carbyhydrates especially, are apparently conveyed by the sap.

Secretory tissues serve the special function of forming and storing secretions. By the term "secretion" as used in this connection is meant those substances formed during the life of the plant which are not, so far as we know, used by the plant as food, nor in the construction of the cell-walls. Such secretions include 
the volatile oils, resins and balsams, and a variety of other substances. The latex or milk-juice of plants, while containing food substances, consists largely of waste products, and is therefore included here.

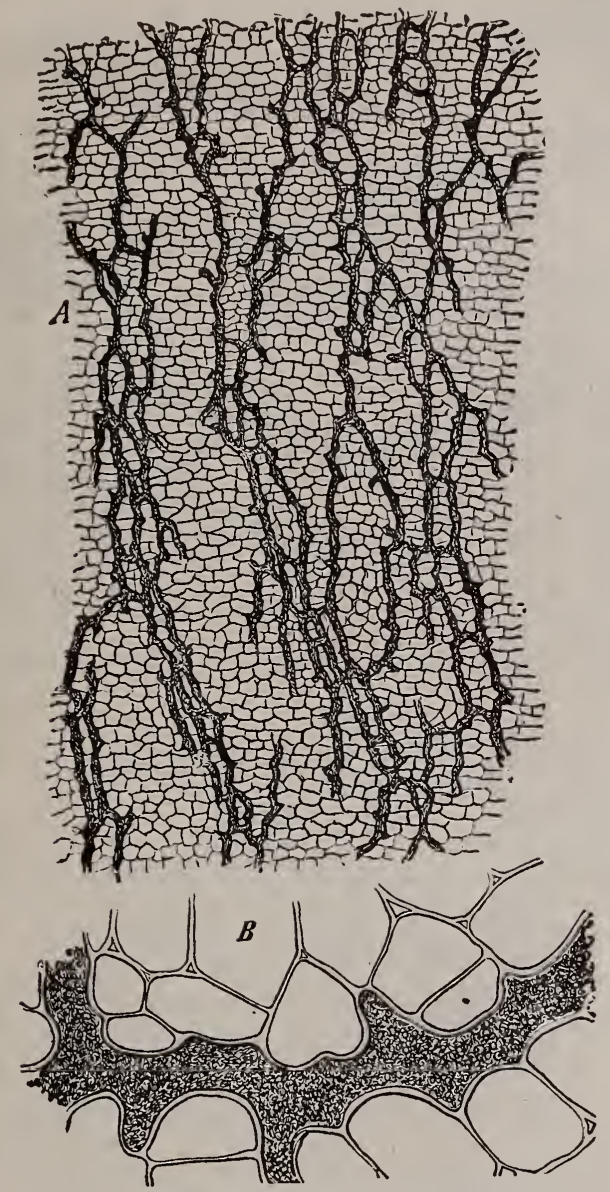

Fig. 446.-Laticiferous vessels from the bark of the root of Scorozonora his panica; a, as seen under low power, and, b, under high power. (After Sachs.).

The substances above mentioned may occur in plants in specially modified cells, as the glandular trichomes already noticed; in tubes or sacs, which may be either single cells or formed from rows or groups of cells which have become confluent through the breaking away of their walls (see Figs. 444 and 445), as in many 
milk-vessels and resin receptacles; and in passages formed by the splitting apart of cells (intercellular spaces), as in many oilglands, resin and balsam passages. Such intercellular passages

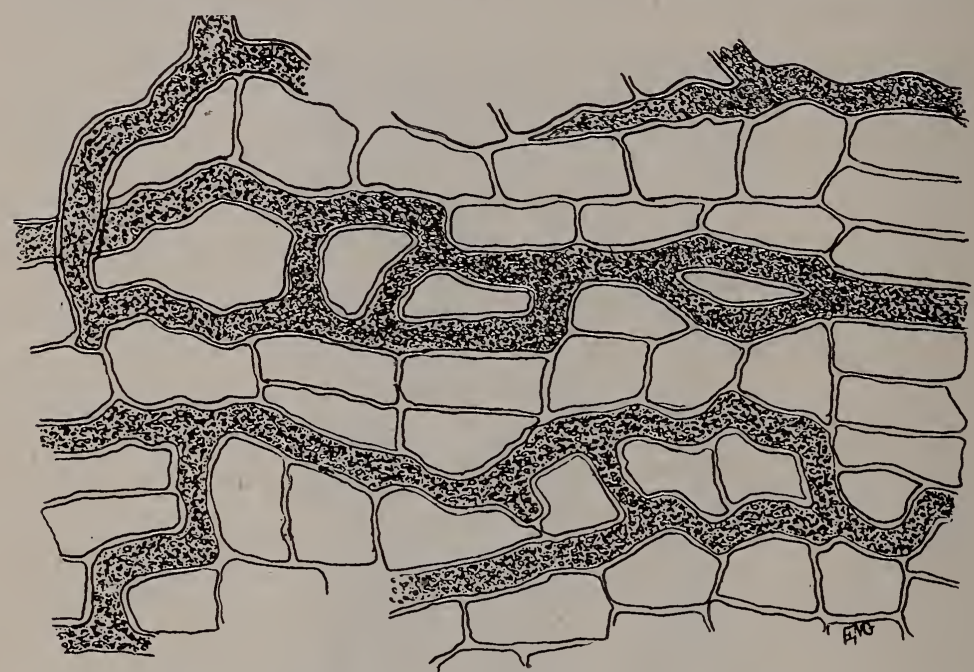

Fig. 447.-Latex tubes from the cortex of Dandelion root, under high magnification.

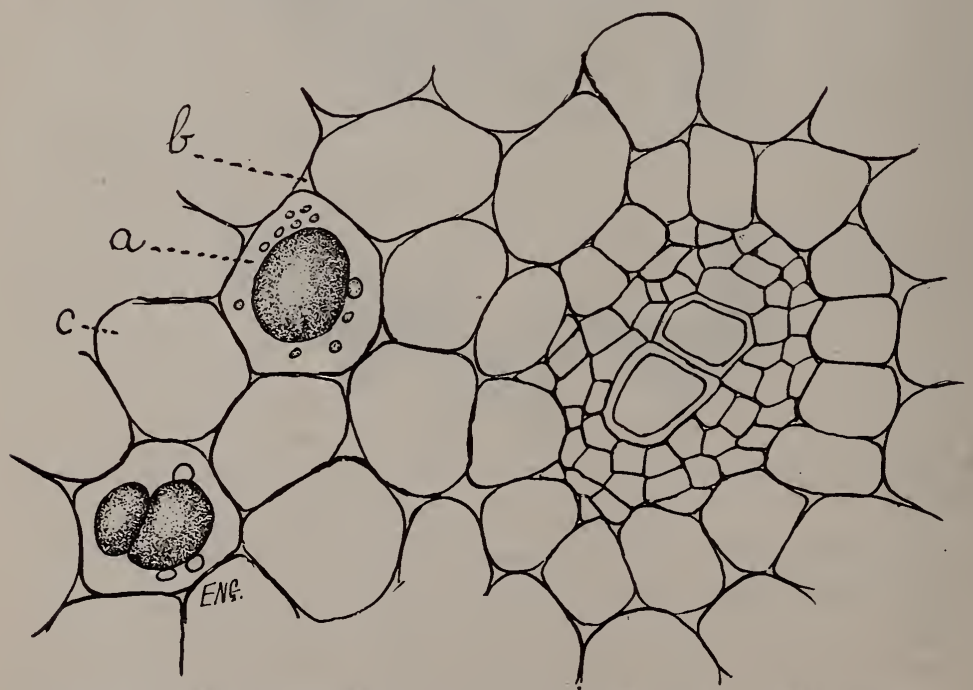

Fig. 448.- Section of the cortex of Ginger, showing olcoresin sacs. a. oleoresin sac; b, intercellular space; c, parenchyma cell. 
are usually surrounded by a layer of secreting cells, which secrete the contents of the passage or receptacle.

Many plants, when wounded, emit a milky fluid, varying in color, copiousness, consistency and chemical composition in differ-

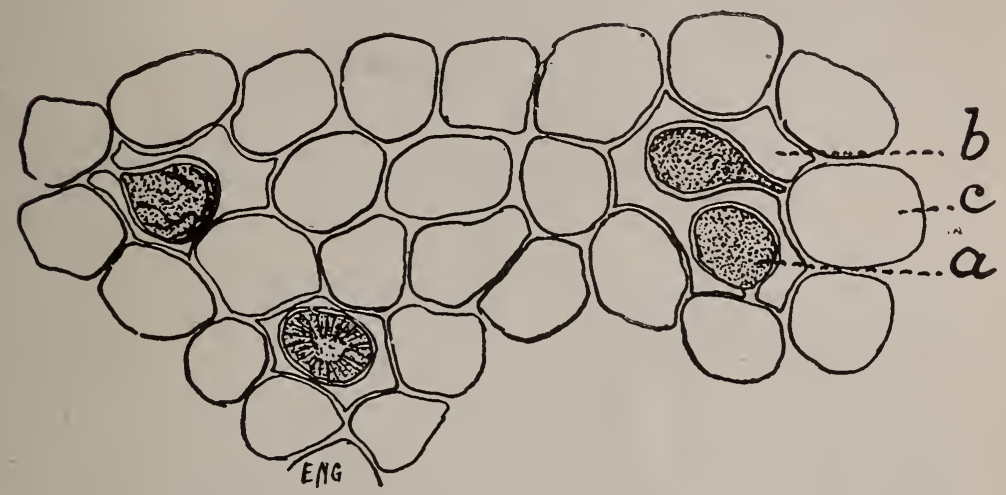

Fig. 449.-Oleoresin glands in Male Fern rhizome. a, stalked oleoresin gland; $b$, intercellular space; $c$, parenchyma cell.

ent plants. The vessels which contain this fluid, or latex, are called laticiferous vessels and may occur in any organ of the plant.

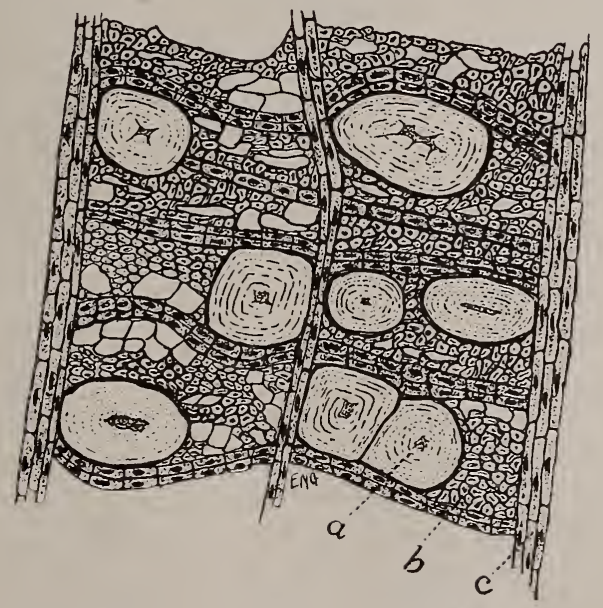

Fig. 450,-Mucilage sacs of Elm bark, transverse section; a, mucilage sac; b, bast bundles; c, medullary ray.

Three kinds are distinguished-the simple short cells (Fig. 444); tubes which consist of single, greatly elongated, and usually 
branching cells, which originate in the growing tissue and follow the extension and branching of the organ in which they occur, as in the Euphorbias and Asclepiads (Fig. 445); and vessels which consist of coalesced cells, forming an irregular network, as in the Dandelion and other Cichoracer (Figs. 446 and 447). The latex cells have cellulose walls which are smooth and elastic. They are living cells with cytoplasm and nuclei lining the inner surface of their walls.

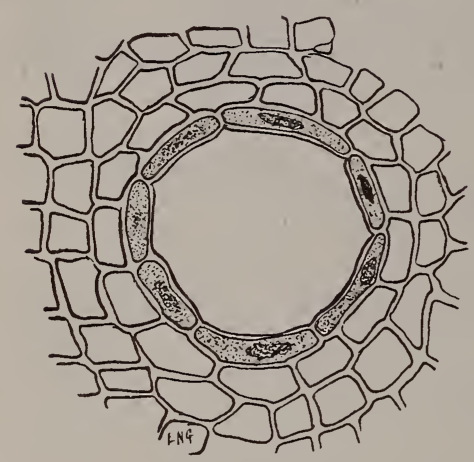

A

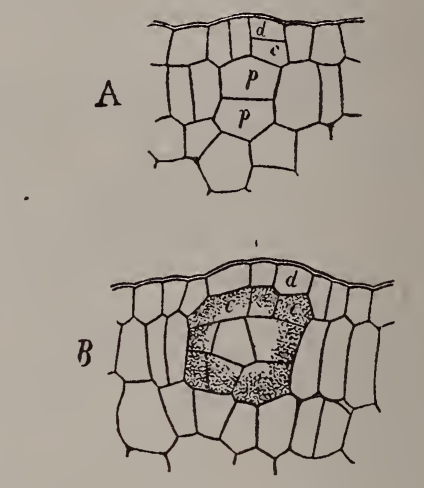

Fig. 451.

Fig. 451.-Schizogenic mucilage passage from the stem of Rhamnus Purshiana.

Fig. 452.-Formation of a lysigenous gland in the leaf of Fraxinella. $A$ and $B$, early stages of development; c, a mature gland containing a large drop of secreted
oil. (Sachs.)

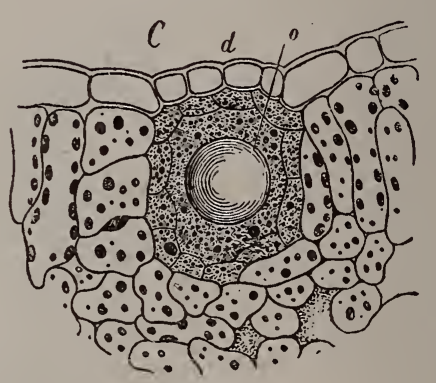

Fig. 452.

Secretory Cells are for the most part slightly modified parenchyma cells, rather seldom suberized, and known under the general name of "secretory sacs." The oleoresin sacs of many spices, such as Ginger (Fig. 448) and Pepper, the volatile oil cells of the Star Anise and the peculiar internal glands of Male Fern rhizome (Fig. 449) are examples of secretory cells. It is convenient to classify them according to their contents. Thus some contain crystals, and are called crystal cells; in many of these the protoplasmic and other contents have almost, if not completely, disappeared, and the 
cell is nearly or quite filled with the crystals (Fig. 359). Other cells, on account of their resinous or balsamic contents, are called

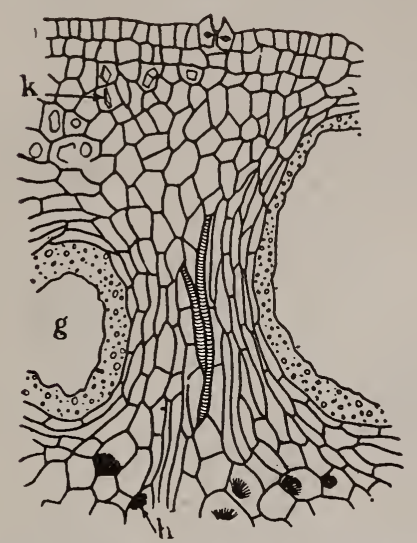

Fig. 453.-Cross-section through a portion of orange peel, showing the cav ity of an interior, globular gland at (g); crystals of hesperidin at (in); calcium oxalate crystals at (k). (Tschirch and Oesterle.)
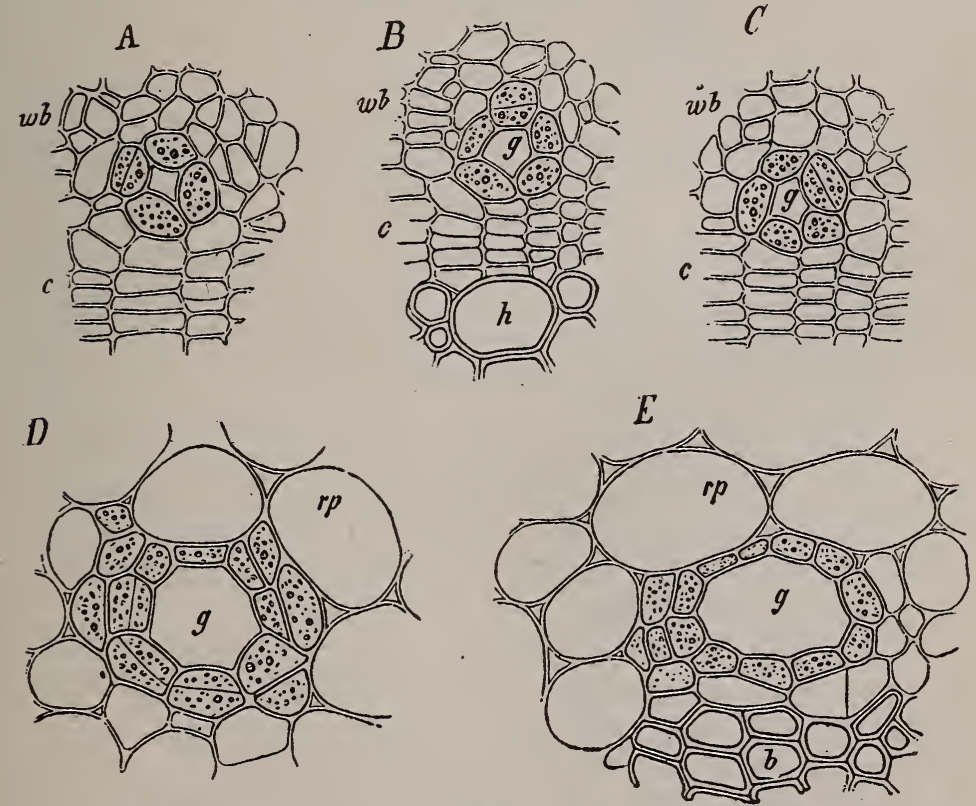

Fig. 454,-Resin canals in the young stem of the Ivy (transverse section). $A, B, C$, young canals (g) at the boundary of the cambium (c) and soft bast (wb); h, wood. D and E, larger and older canals (g) lying at the boundary between the bast (b) and the cortical parenchyma (rp). (Sachs.) 
resin sacs; others, containing mainly tannin, are called tannin sacs; still others that contain volatile oil are termed oil sacs; and those that contain an abundance of mucilaginous or gummy mat. ter are named mucilage sacs (Fig. 450).

Secretory Passages may be either intercellular spaces or canals formed by the fusion of rows of cells. They may contain volatile oils, oleoresins, balsams, mucilage or other secretions and are

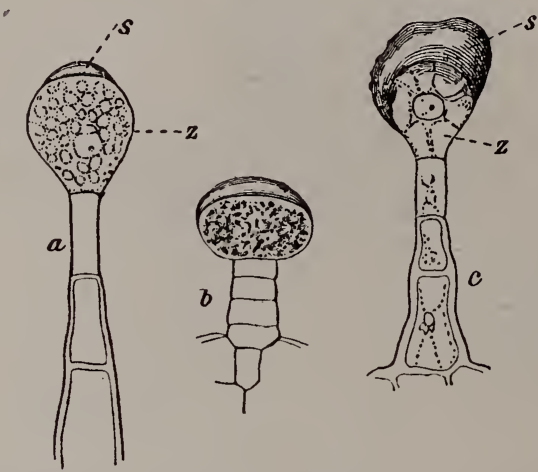

Fig. 455.-Glandular hair from leaf of House Cieranium, showing a singlecelled gland; a, stalk of the hair; $z$, secretory cell; s, secretion cavity of the cuticle formed by distension. (Haberlandt.)

formed in different ways; sometimes by the splitting of the common cell-wall which separates adjacent cells, a mode of formation described by the term schizogenous (Figs. 451 and 454 ) ; sometimes by the rupture and destruction of certain cells, a process described as lysigenous (Figs. 452 and 453). In some instances, passages originate in a schizogenous manner but their later development is lysigenous. The oil tubes characteristic of the umbelliferous fruits, Anise, Fennel and Caraway, and the oleoresin passages of the Pine trees, from which we obtain Turpentine, are examples of secretory passages (Fig. 454).

Glandular hairs consist essentially of a secretory gland borne upon a stalk of varying length. The gland may be one-celled (Fig. 455 ) or several celled (Fig, 456). (Refer also to Figs. 411 and 416.) In glands which secrete volatile oil or resin, the secretion originates in the cell-wall, appearing between the cellulose layer and the cuticle, and finally breaks through the latter and escapes. Related are the nectaries which secrete the sugary nectar that 
serves to attract insects to flowers, the digestive glands of insectivorous plants, and the mucilage hairs or "colleters" on many leaf buds.

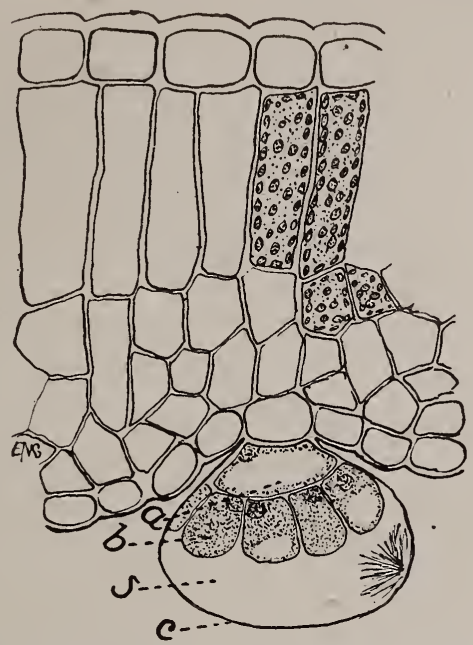

Fig. 456.-Glandular hair from leaf of Peppermint, showing a many-celled gland; a, short stalk; $b$, secretion cells; $c$, much distended; s, secretion cavity.

\section{Practical Exercises.}

1. For the study of meristematic tissue, examine sections cut lengthwise through the embryo of a grain of corn and which have been prepared by staining with rosanilin and mounting in balsam. The cells are rectangular in shape, nearly isodiametric and average about fifteen microns in diameter. The nucleus is stained more deeply than the surrounding cytoplasm and the cell-wall is very thin and delicate.

Compare the sections of the onion root tip properly fixed, stained and mounted. (See Fig. 333.)

2. For the study of parenchyma examine a transverse section of the rhizome of May Apple (Podophyllum peltatum). This is a dicotyledonous stem and exlibits a large central pith surrounded by about sixteen or more small woodwedges separated by broad medullary rays, and outside of the woo: a rather thick bark. The pith, medullary rays and middle bark consist of parenchyma tissue. With the low power observe the shape and comparative size of the cells of these parts and the nature of their cell contents. Cellulose walls are indicated by the purple color with zinc chloriodide and liquefied walls by the cherry red color with phloroglucin solution. In a similar manner study a longitudinal section of the rhizome and make a drawing.

3. From a stem or petiole of the Pickerel Weed (Pontederia cordata) remove one of the membrane-like plates which are found extending across the large air passages. Under the microscope this plate will be seen to consist of stellatelyshaped parenchyma cells, joined together by the projecting ends of neighboring cells and having intercellular spaces in the angles. Notice that attached to or suspended from this tissue are oval cells containing raphides and globular cells filled with a brown resin.

4. For the study of collenchyma examine a transverse section of the petiole of the Yellow Dock (Rumex crispus). Mount in water and view with the low power. Notice that the outer side of the petiole is ribbed. Underlying 
the epidermis at each of these ribs is collenchyma tissue. Compare the appearance of the collenchyma cells with the description given in the text. Test with iodine solution and notice whether cell-contents are present. With the high power examine the cell-walls and notice whether stratifications are visible. Apply the zinc-chloriodide test for cellulose.

Examine a longitudinal section and state how the length of these cells compares with their breadth.

Excellent examples of collenchyma tissue are also afforded by the petioles of the Burdock, Pie Plant, Grape or Begonia.

5. For the study of sclerotic tissue make a scraping of the flesh of the Pear (Pyrus communis) and mount in water. View with the low power. Little bunches of grayish, thick-walled cells will be found imbedded in the soft, thinwalled parenchyma cells of the fleshy part. Rather firm pressure with the point of a knife is required to break up these groups into their component cells. Apply the phloroglucin test. The walls of the sclerotic cells are colored red. Notice the great thickness of the wall and the small lumen of these cells. Simple and branched pores extend from the lumen through the wall.

For a tissue consisting entirely of sclerotic cells examine the shell of the Coconut (Cocos nucifera), taking two sections, one tangential and one radial to the surface of the shell.

7. Make thin sections of the shell of a Hickory nut, some of them parallel with the surface, and others at right angles to it; treat the sections with hot Schulze's fluid; rinse, stain with methyl-green, mount in water, and jar the cells apart by tapping the cover-glass with a needle; then study the cells with the high power. Observe the excessively thickened walls, and the concentric and radial markings.

8. The sclerotic cells of the Tea Leaf (Thea sinensis) are striking and characteristic. They occur imbedded in the parenchyma tissues adjacent to the inidrib, and may be seen to good advantage in a transverse section of the leaf, especially when the latter is stained with phloroglucin solution. Examine such a section, stain as indicated, and draw one or more of the peculiar sclerotic cells.

9. With the forceps remove a small piece of the epidermis, or with a razor cut a surface section including only the epidermis from the under side of a leaf of the Tulip (Tulipa gesneriana). Mount the specimen in water and view first with the low, then with the high power. Notice the shape and arrangement and contents of the epidermal cells. Observe the stomata and note how these differ in size and shape from the other epidermal cells. Notice that the guard-cells of the stomata are the only epidermal cells which contain chlorophyll.

10. For a sectional view of the epidermis, study a transverse section of the leaf of the Tulip. Notice particularly the shape of the epidermal cells, the thickness of the cuticle, the location of the stomata and the nature of the opening between the guard-cells. Notice that the stomata never occur above a vein, but only where the underlying parenchyma cells are loosely arranged, and that beneath each stoma is an intercellular space.

11. Examine in the same manner a surface section from the lower face of the Stramonium leaf (Datura stramonium). Compare the arrangement of the epidermal cells and stomata in this, a dicotyl leaf, with that of the tulip, a monocotyl. Notice the altered form of the epidermal cells and the absence of stomata where the epidermis overlies a vein of the leaf. Compare a similar section from the upper surface of the leaf. In which section are the stomata more numerous?

12. Examine a transverse section of a young stem of Velvet Leaf (Abutilon avicennae). Notice the two kinds of trichomes present. Determine the character of the cell-walls and contents of each, applying appropriate tests. Notice the relation between the plant-hairs and the ordinary epidermal cells.

13. Compare the plant-hairs of the Mullein leaf (Verbascum thapsus), examining in the same manner.

Mount a few hairs of absorbent cotton. Notice the ribbon-like appearance and the characteristic spiral twisting of the collapsed plant-hairs. Observe that each of these hairs is composed of but a single cell. Apply the test for cellulose.

14. Study the cork cells of the stem of the Elder (Sambucus canadensis) in transverse and longitudinal sections. Notice the shape and arrangement of these cells and especially the cell-contents in the phellogen layer after testing with iodine solution. Describe the thickness and color of the walls. Test for wallsubstance.

Study sections of a bottle cork (Quercus suber), cut radially, tangentially and transversely. Refer to Fig. 379. Notice that the cells are not of uniform size, but that the large, rather thin-walled, cubical cells pass into flatter cells, giving the appearance of a dark zone, which, like the annual rings in woods, marks the limit of a year's growth. Treat the section with potassium hydrate 
solution and warm the slide. How are the cell-walls affected? In a similar manner examine the cork cells of the Potato (Solanum tuberosum), and of Red Cinchona Bark (Cinchona succirubra).

15. For the study of typical bast fibers, examine transverse and longitudinal sections of the stem of the Sunflower (Helianthus annuus). The bast layer is located in the inner bark and the fibers are grouped into crescentshaped bundles, which lie opposite and outside the wood-wedges. Apply the phloroglucin test. Describe the individual fibers as to shape, thickness of wall and markings. Notice also the relative size of the.cell-cavity. In a longitudinal section observe the shape of the bast fibers and the manner in which their ends overlap. Compare fibers obtained by macerating the bark in Schultze's fluid. In a similar manner study transverse and longitudinal sections of Cinchona bark, and notice how these bast fibers differ from the preceding in size, shape, markings and relative arrangement.

16. Compare the textile fibers of Flax, Hemp, Jute and Ramie with the trichomes constituting cotton, the hairs of wool and the threads of silk.

17. For libriform tissue examine a transverse section of the root of Gelsemium sempervirens, staining with phloroglucin. The walls of the cells composing the woody zone are stained red, indicating that these membranes are lignified.

Observe that these cells are of various sizes and forms. Those with a large rounded cavity and thin walls are the tracheal tubes. The smaller and more nearly square cells with relatively much thicker walls, which form a tissue filling in between the tubes, are the wood fibers, while extending through these in radial rows of one to six cells in width are the medullary rays, composed of tabular, radially extended and lignified parenchyma cells. In a longitudinal section stained with the phloroglucin reagent observe the shape of the wood fibers, their relative arrangement, and the oblique slit-like markings on their walls.

18. In a similar manner study the Quassia wood (Picrasma excelsa), staining with iodine. The fibers are stained brown, the medullary rays yellow and the starchy contents of the wood-parenchyma are stained black. Compare tangential and radial sections of the latter as regards the position and appearance of the medullary rays.

19. For the study of tracheids examine a radial section of Pine wood, staining with phloroglucin. Observe that the section is entirely composed of tracheids except where these are crossed by medullary rays. The tracheids are of typical shape and are marked by one or two rows of pitted markings, each of which appears as of two concentric circles. Within the inner circle is the thinnest portion of the wall, consisting of a delicate membrane, unequally thickened and partly lignified, forming the bottom of the so-called "pit." The portion between the circles is the wall of the pit, while the cell wall beyond shows the maximum thickening. The pits are, then, thin places in the wall, and each might be compared with a very wide-angled funnel, having the neck removed, and the larger opening closed by a membrane. In contiguous cells the pits are directly opposite, so as to resemble two such truncated funnels placed top to top, with only a diaphragm between. In the older cells this separating membrane is frequently absent.

Compare a tangential section. Notice that the markings upon the tracheids appear disk-like and only on the lateral walls, while the under or upper walls are rarely so marked. Observe that the medullary rays in this section appear as short fusiform groups of cells lying between the tracheids.

Take next a transverse section. In this view the tracheids appear roundish or nearly square in form. The appearance of the pits resembles that in the tangential section, but they are few and difficult of observation Notice that the tracheids are arranged in radial rows constituting the wood wedges, these being separated by medullary rays. Annual rings are distinctly visible in this section. These rings are made evident by the contrast caused by the small, thickwalled cells of the fall growth, being immediately succeeded by the much larger and thinner-walled cells formed during the following spring.

20. In the preceding studies we have had occasion to observe the shape of the tracheal tubes in both transverse and longitudinal section. For a study of the characteristic markings upon their walls examine the fo'iowing: Corn (Zea mays) stem-pitted, annular and spiral markings. Brake Fern (Pteris aquilina) rhizome-scalariform markings. Podophyllum rhizome-reticulate markings.

21. For the study of sieve tissue examine a transverse section of the stem of the Pumpkin (Cucurbita pepo). Stain with phloroglucin solution. Notice the presence of large tracheal tubes in the xylem. On either side of the xylem layer is located a crescent-shaped phloem mass. Th two phloem strands curve around the xylem until they almost encircle it. Stain another section with eosin or with methyl blue. If the latter stain is used, mount the specimen in glycerinc. The albuminous contents of the sieve tubes are stained blue and the plates are 
distinctly seen. Many of the sieve tubes display no plates for the reason that the section has been made above or below the plane in which the plates of these cells were located. The companion cells are here much smaller than the sieve tubes. Compare longitudinal sections similarly stained, where plates can be observed on the lateral walls.

22. Examine a longitudinal section of the fruit of Osage Orange (Toxylon pomiferum). In the parenchyma are located many latex-tubes, which the coagulated and yellow-colored milk-juice renders distinctly visible. The tubes consists of elongated, simple or branched cells.

23. In a similar manner study the milk-vessels of Dandelion (Taraxacum officinale) as displayed in the bark of the root. The vessels in this root are formed through fusion of rows of cells and are branched, the branches anastomosing freely.

24. Study the mucilage sacs of Althea root (Althea officinalis), mounting the sections in glycerine and alcohol. Test with zinc chloriodide. Compare sections of Slippery Elm bark (Ulmus fulva).

25. Make a study of the resin-passages of the root of the American Spikenard (Aralia racemosa), examining transverse and longitudinal sections. These passages occur in the bark parenchyma and each passage consists of an inter. cellular space surrounded by secreting cells.

\section{CHAPTER IV.-THE HISTOLOGY OF THE ORGANS.}

The Root.-The growth in length of roots is accomplished by $\lambda$ meristem located near the apex of the plant organ. This tender growing-point is protected by the root cap-a covering of loose, parenchyma tissue. Such a meristem is composed of embryonic tissue, the cells of which are capable of dividing rapidly and in all three planes of growth-radial, tangential and transverse. These cells are polygonal in shape with thin cellulose walls, and are filled with cytoplasm and contain relativly large nuclei. This is the primordial meristem. A short distance back from the growing point, it is differentiated into three parts, known as primary meristems, from which the primary permanent tissues are developed (Fig. 458). From the outermost of these, the protoderm, the epidermis is developed. In the younger portion of the root the epidermis is characterized by bearing numerous blunt, single-celled and thin-walled root-hairs, through which the plant obtains its supply of water and nutritive substances from the soil. As the root lengthens the older hairs die off and new hairs arise from the epidermis lower down toward the apex. A cuticle is lacking from this youngest portion, but as we pass further backward, we find that the epidermis of the older part of the root is strongly cutinized and is frequently reinforced by one or more layers of cells comprising the hypodermis.

The second of the primary meristems is the middle layer and is called the periblem. From this originates the primary cortexcomposed usually of parenchyma and extending from the epidermis 
on the outside to the endodermis on the inside. The third primary meristem is located at the centre and is called the plerome. It gives rise to the stele or central cylinder, which is surrounded by a sheath of a single layer of compactly-arranged cells somewhat flattened in a radial direction, often suberized or lignified and

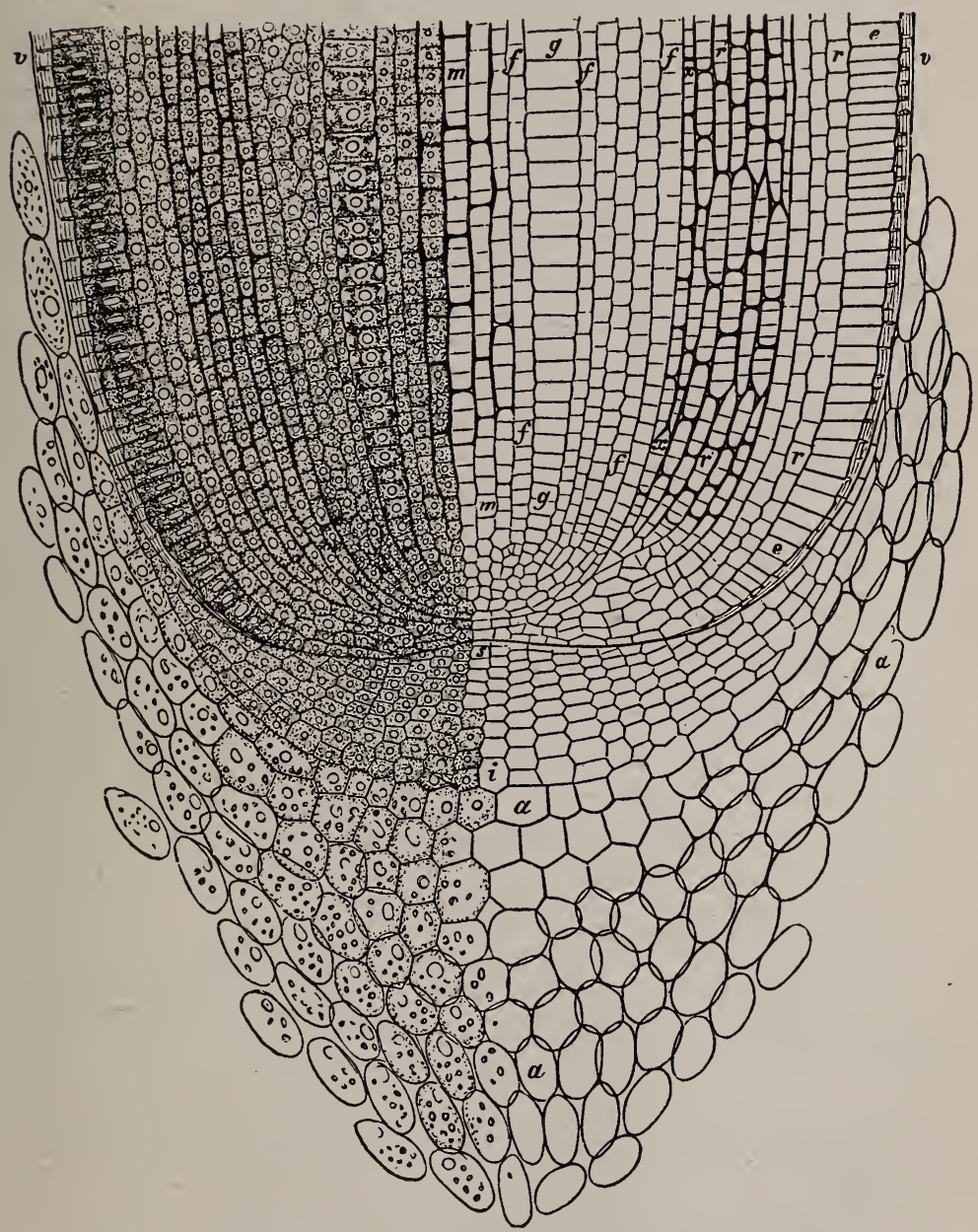

Fig. 458.-Longitudinal section through the root apex of Corn. a, older portion of root-cap; $i$, younger part of same; $s$, apex of growing-part; $e$, external layer of tissue of root-the cell-walls are thickened ( $v$; ; $r$, young cortex; f, cells of axial vascular bundle; $g$, flattened cells of a large vessel, which will subsequently form long cylindrical segments with bordered pits; $m$, parenchyma of the pith in the axial strand (highly magnified). (Sachs.) 
constituting the endodermis or starch sheath. The stele consists of mestome strands of tracheal tubes and sieve tissue, known as hadrome (xylem) and leptome (phloem), respectively, which are imbedded in fundamental tissue forming what is called a radial vascular bundle.

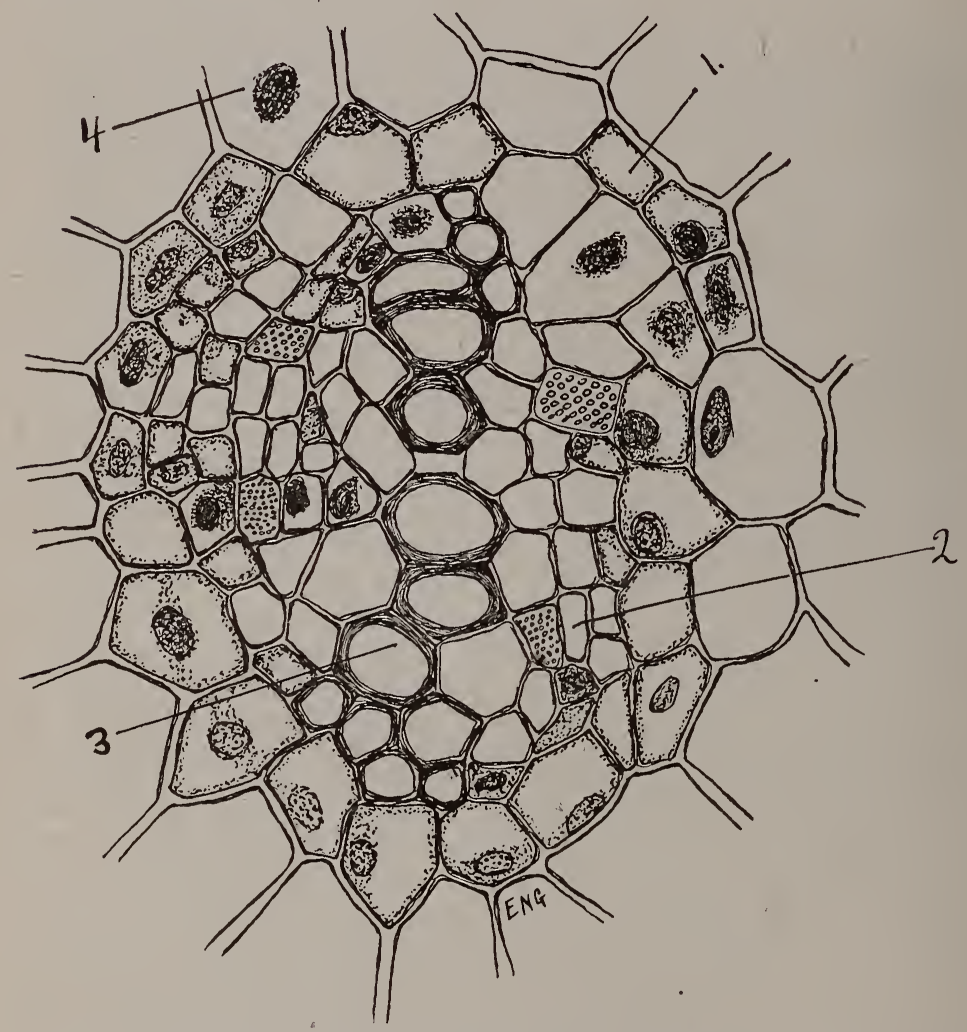

Fig. 459.-Two-rayed vascular bundle from a young root of Podophyllum 1, endodermis; 2, phloem tissue; 3 , tracheal tube of the xylem; 4, cortical parenchyma.

The structure above outlined, having developed from the primary meristems, is called the primary structure (Figs. 458, 459 and 460 ).

The roots of Club-mosses, Ferns and nearly all Monocotyledons conform in a general way to this description and undergo littlechange with age, excepting the cutinization or lignification of certain tissues. The roots of Dicotyledons and Gymnosperms, how- 
ever, may have a later growth in thickness, due to the development of secondary meristems and giving rise to a secondary structure (Fig. 463).

One of these secondary meristems is the phellogen, or corkcambium, which develops in the cortex just beneath the epidermis, or at times in the epidermis itself, and through division of the cells in tangential and radial directions produces a layer of cork. Since the walls of the cork cells are suberized and impervious to water, the sap supply of the epidermis and sometimes of the primary cortex is cut off and these tissues gradually die and are

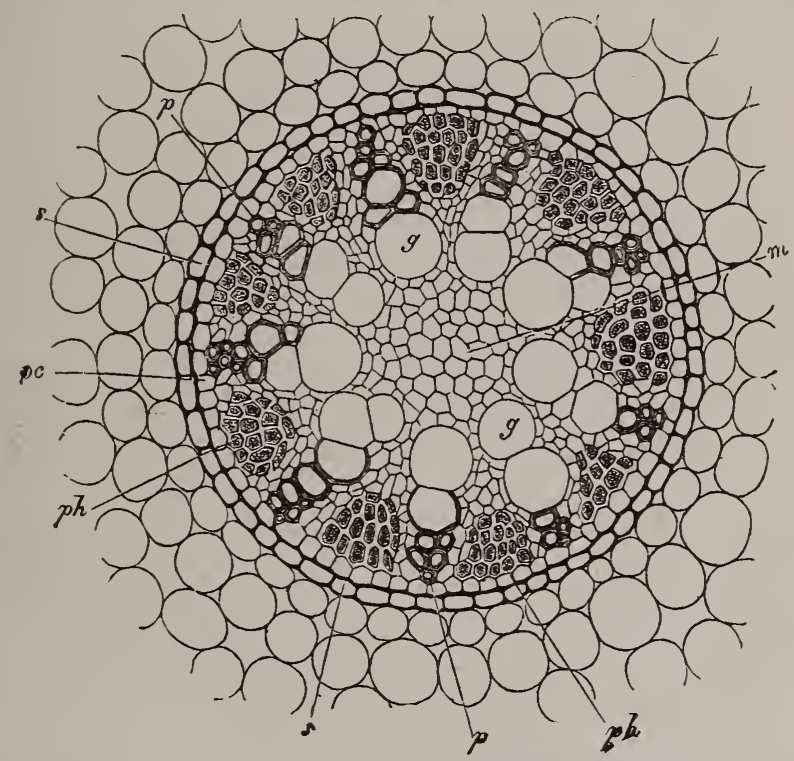

- Fig. +60.-Radial vascular bundle from Calamus root; $s$, endodermis; pc, procambium; ph, phloem strand; $g$, xylem ray; m, central parenchyma. (Sachs.)

thrown off, leaving the cork as a permanent protective covering for the root.

The other secondary meristem is the cambium, which develops from procambium cells situated between the primary xylem and the primary phloem and produces the most striking changes in the structure of the root. On the inner face of these cambium strands not only new tracheal tubes, but also tracheids, wood fiber's and wood-parenchyma may form, giving rise to a xylem of more complex composition, the secondary xylem. The activity of the cam- 
bium is mostly on the xylem side so that the xylem increases in thickness and pushes out the phloem until the xylem has assumed a cylindrical form and is separated from the surrounding cylinder of phloem by the layer of cambium that lies between. Strips of parenchyma tissue, the cells of which are more or less flattened and are elongated in a radial direction, divide the xylem into wedge-shaped portions. These parenchyma rays are formed at the cambium. They are called medullary rays. Thus, when the secondary structure is completed, the original radial vascular. bundle of the stele has been changed into a circle of open collateral bundles, each consisting of a xylem and phloem strand with a

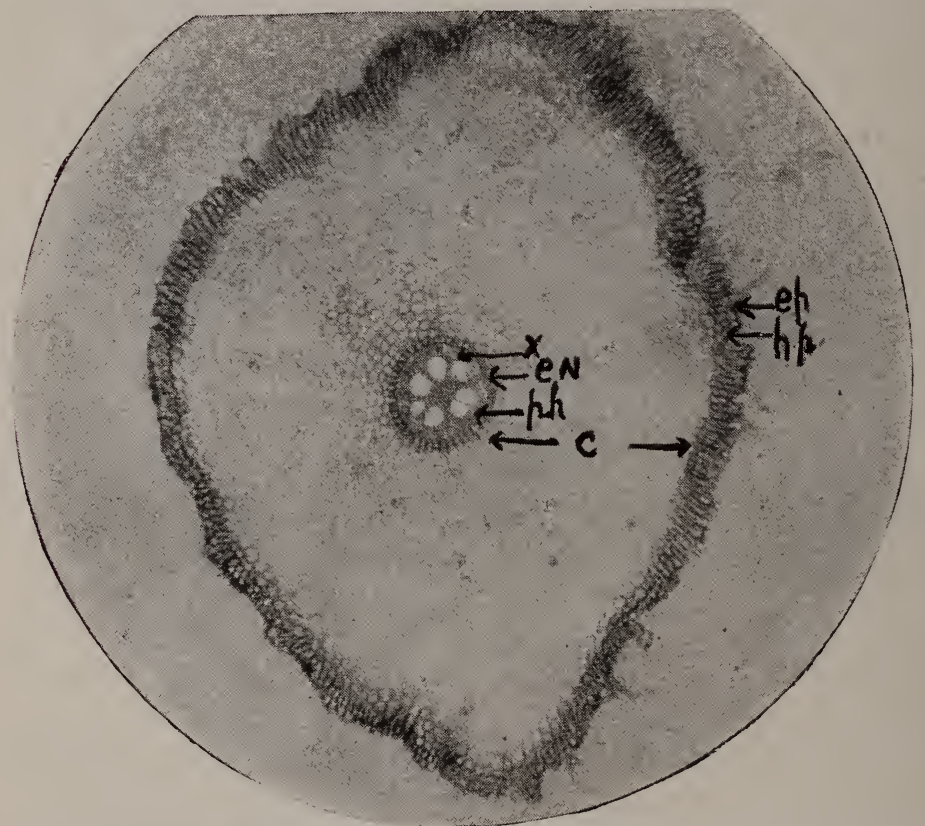

Fig. 461.-Transverse section of the root of Blue Flag (photo-nicrograph). ep, epidermis, with an occasional, nearly obliterated root-hair; hp, hypodermis of two or three rows of rather thick-walled cells; c, cortex of loosely arranged parenchyma; en, endodermis; ph, phloem strand; $x$, xylem ray.

cambium between and in that sense "open" to further growth in thickness. These wood bundles are separated by medullary rays. The cambium crosses these rays, forming a complete circle. As growth proceeds annual rings may form in a manner to be explained under stem structure.

The growth from the outer face of the cambium develops not 
only new sieve tissue, but also bast fibers, medullary rays and occasionally sclerotic cells. In the course of this growth the tissues of the cortex and the epidermis are replaced by cork and secondary parenchyma. As a result, we have a complete bark, replacing the original cortex. Meanwhile, the endodermis has disappeared. A pith is absent from the root except near where the root and stem join.

Branches of the root originate from the cells of the pericycle situated just within the endodermis; the rootlets extend outward through the cortex, being assisted by the digestive action of an enzyme. Each develops its own root cap and corresponds in structure with the parent root.

The roots of vascular cryptograms, except Lycopodiacex, differ from those of flowering-plants in the fact that they increase in length by the division of a single sub-apical cell instead of a mass

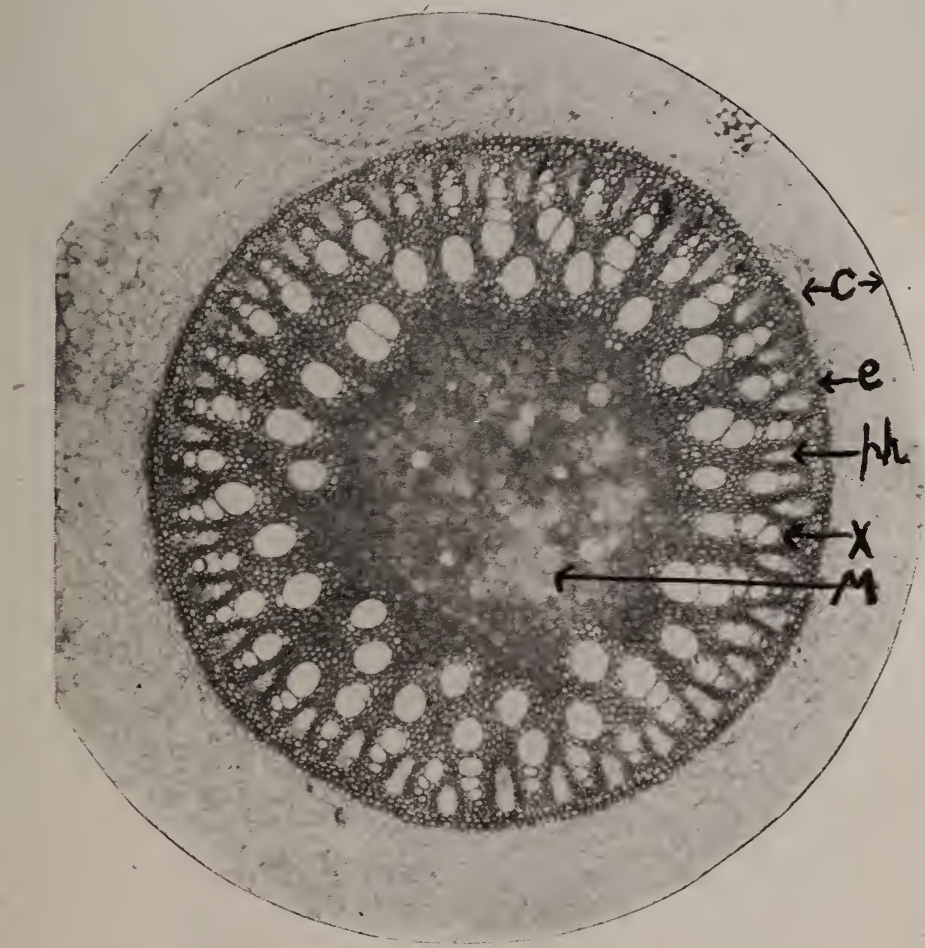

Fig. 462.-Large radial fibro-vascular bundles from Sarsaparilla rcot (photomicrograph). c, small portion of cortex; e, endodermis; ph, phloem strand; $x$, xylem rays; in, central parenchyma. 
of such cells. The roots of Lycopodiacex differ from those of Ferns and flowering-plants in the fact that their mode of branching is dichotomous. In the higher plants and in Ferns root-branches always originate as lateral outgrowths.

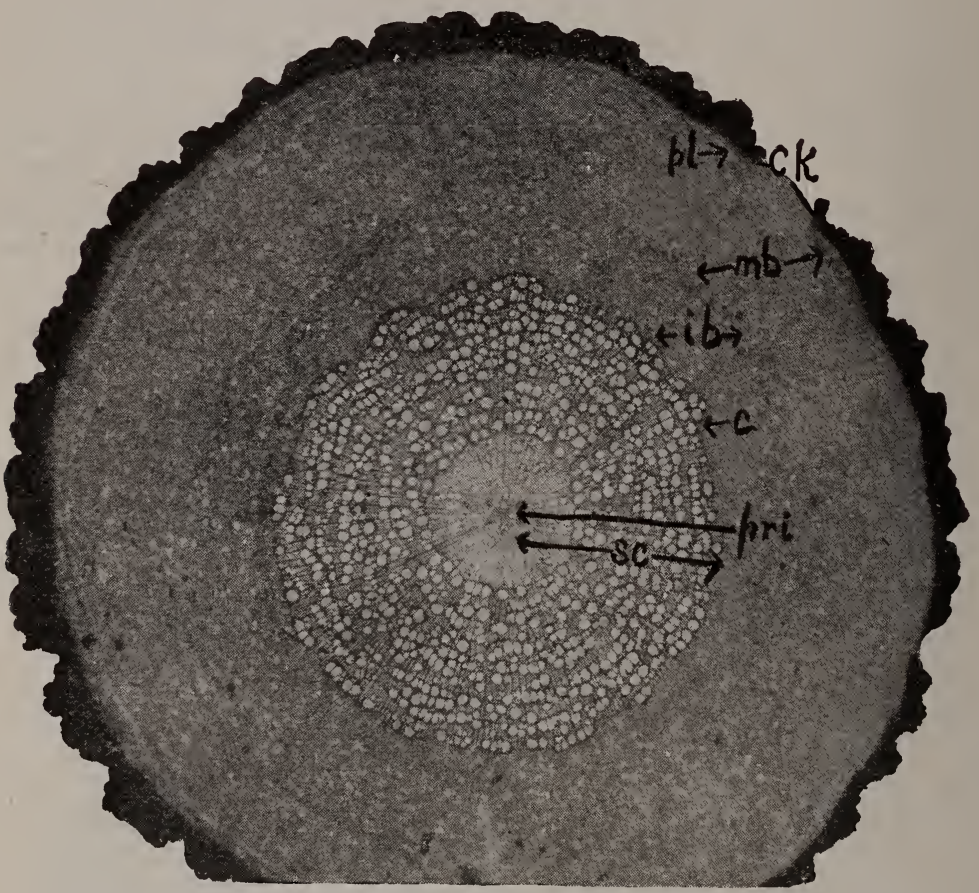

Fig. 463.-Transverse section of the root of Black Indian Hemp (Apocynum cannabinum), (photo-micrograph), showing the secondary development of a root. ck, cork; pl, phellogen or cork cambium; $\mathrm{mb}$, middle bark; ib, inner hark, including the phloem; c, cambium; sc, secondary wood of several years growth; pri, primary wood, represented by a minute star at the center.

Plants below vascular cryptogams do not possess true roots, but many of them produce outgrowths of much simpler-structure, destitute of vascular tissues, which serve the purpose of securing the plants to the soil or rocks. Such organs are called rhizoids.

The Stem.-The stem originates in a primordial meristem which displays the same structure and develops the primary meristems as does that of the root. However, a cap is lacking, the primordial meristem being located at the apex, though the region of growth may extend back through several internodes (Fig. 464).

Primary structure.-Except for the presence of stomata and 
the variety of its trichomes, the epidermis of the stem differs little from that of the root. In herbaceous plants the epidermis is commonly persistent, while in woody-stemmed plants it is usually

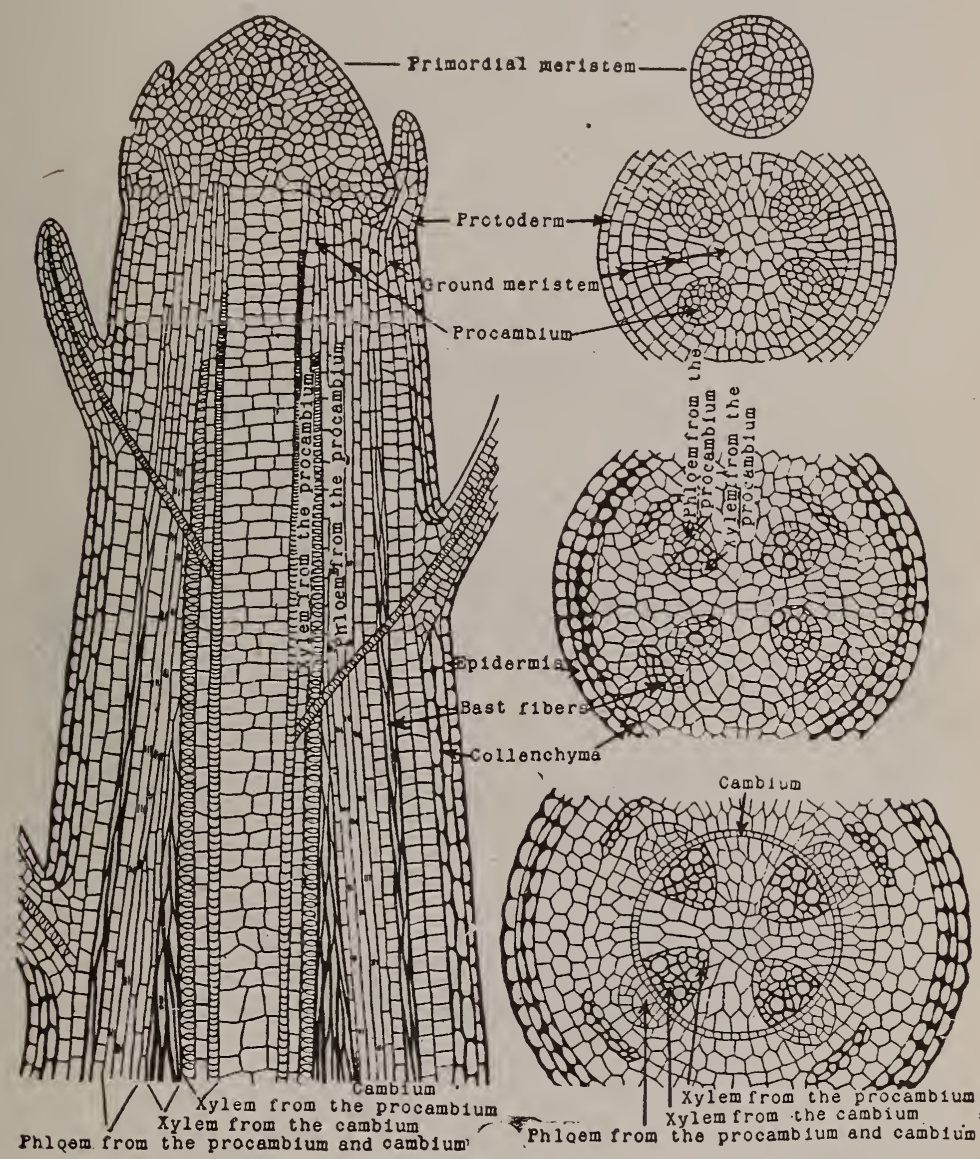

Fig. 464.-Diagram, showing the evolution of tissues from the primordial meristem down to the beginning of cambial activity. In the longitudinal diagram, at the bottom, the initial $C$ of the work cambium stands directly beneath this tissue, which is radially but one cell in thickness. (Stevens.)

replaced by cork. The primary cortex here resembles that of roots save that the stem-cortex may comprise chlorophyll-bearing cells and that its tissues are usually more varied and complex than are those of the corresponding portion of the root, thus collenchyma is commonly present and serves to strengther the young stem 
until the development of bast and xylem. Sclerotic cells are also frequently met with.

The endodermis, which marks the inner boundary of the cortex, is composed of cells rich in starch and known as the starch sheath.

All the tissues within the starch sheath are included in the stele.

The pericycle, or outer part of the stele, may contain bast fibers, either forming a continuous ring or in separate groups or

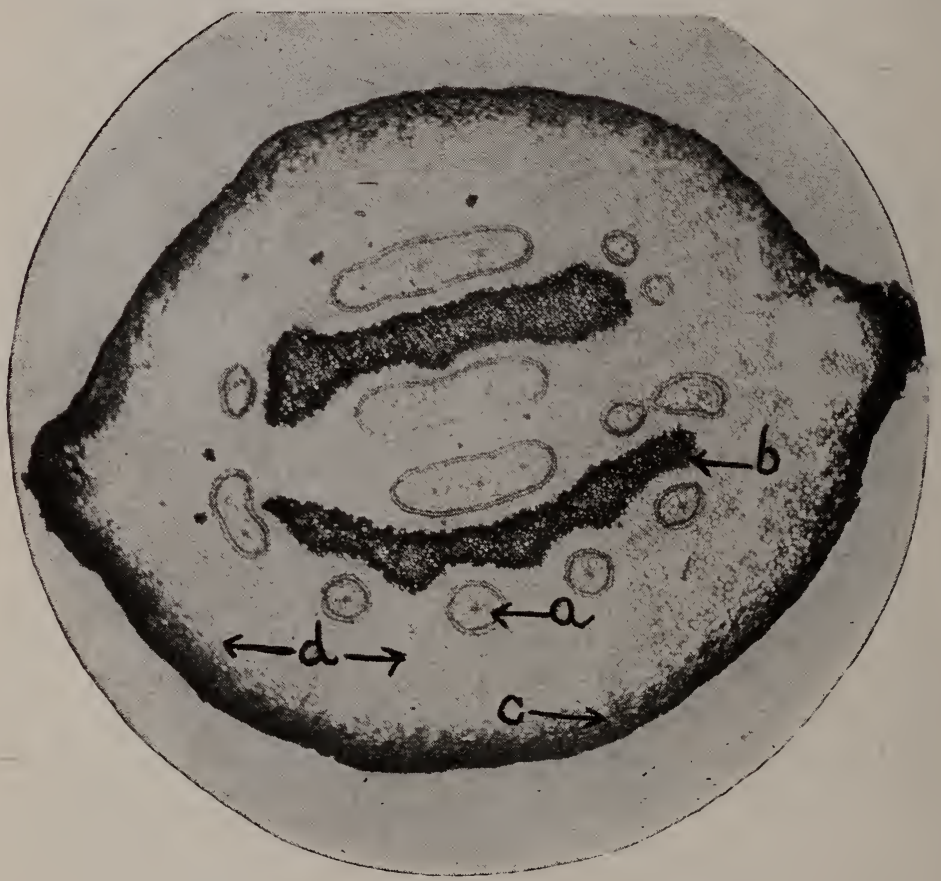

Fig. 465.-Transverse section of tine rhizome of Brake Fern (photo-micrograph). $a$, one of the several lepto-centric bundles; b, sclercnchyina strand; c, suberized parenchyma; d, starch-bearing parenchyma.

strands. Associated with these, sclerotic cells are often found. Bast and sclerotic together constitute the stereome.

Within the pericycle are the vascular bundles (mestome strands), their structure and arrangement being characteristic of the principal kinds of stems, namely Ferns, Monocotyledons and Dicotyledons.

The Fern Type. In the Ferns and their allies, the bundles 
(mestome) are usually of the concentric (hadrocentric) variety, consisting of xylem (hadrome) surrounded by phloem (leptome) associated with more or less parenchyma tissue and surrounded by an endodermis. In some cases there may occur within the stele but a single bundle, from which branches are given off to the leaves; in others, there may be two or more bundles placed side by side; and in still others, and this is the commonest arrangement, they are disposed in a single circle. But when distributed circularly, they are never radially elongated, as are the bundles in the stems of Dicotyledons, and if viewed in transverse section they appear either circular, or more or less lengthened in a tangential direction. In the smaller strands the xylem consists of scalariform tracheids, chiefly, while in the larger bundles there are parenchyma cells associated with the tracheids, and in a few instances tracheal tubes. The fundamental parenchyma sometimes contains stereome either as clusters of stone-cells, or masses of sclerenchyma fibers, as in the rhizome of Pteris aquilina, Fig. 465. The cortex also usually consists mainly of parenchyma, passing toward the exterior

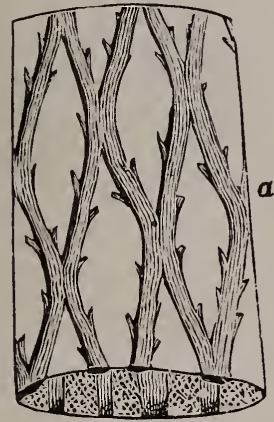

Fig. 466.

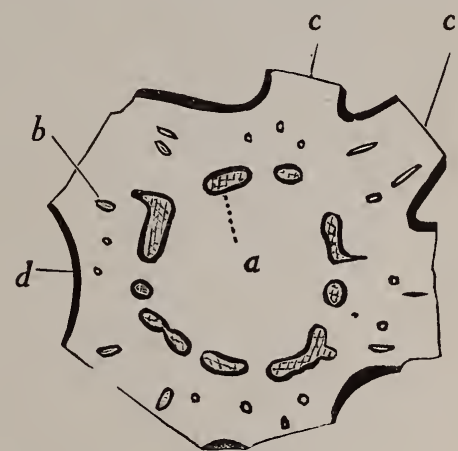

Fig. 467.

Fig. 466.-Longitudinal view of the rhizome of Aspidium, with the cortical portions cut away to show the cylinder of anastomosing bundles; a, one of the branches of a bundle passing off to a leaf. Magnified about five diameters. Sornewhat diagrammatic.

Fig. 467.- Transverse section of rhizome of Aspidium, showing arrangement of bundles; $a$, one of the bundles of the primary circle; $b$, one of the branches passing off to a leaf; c, c, places where leaves have been cut away; $d$, thickwalled hypodermal cells. The unshaded portion is mainly parenchyma. Magnified about five diameters.

into a thick-walled hypodermis. The fern structure is illustrated in the rhizome of the medicinal Male Fern, Dryopteris Filixmas. Here the principal bundles, which are from eight to twelve in number, are circularly arranged about a central parenchymatous 
area which contains no bundles. Each bundle of the circle sends thick anastomosing branches to those adjacent to it, so that as a whole they form a netted cylinder, the stele. From this numerous smaller bundles pass outward through the cortex to supply the leaves (Figs. 466 and 467).

In the stems of a few Ferns there is more than one circle of bundles. In the stems of Lycopodiums and Selaginellas there may be a single bundle, and this may be either concentric or radial, or

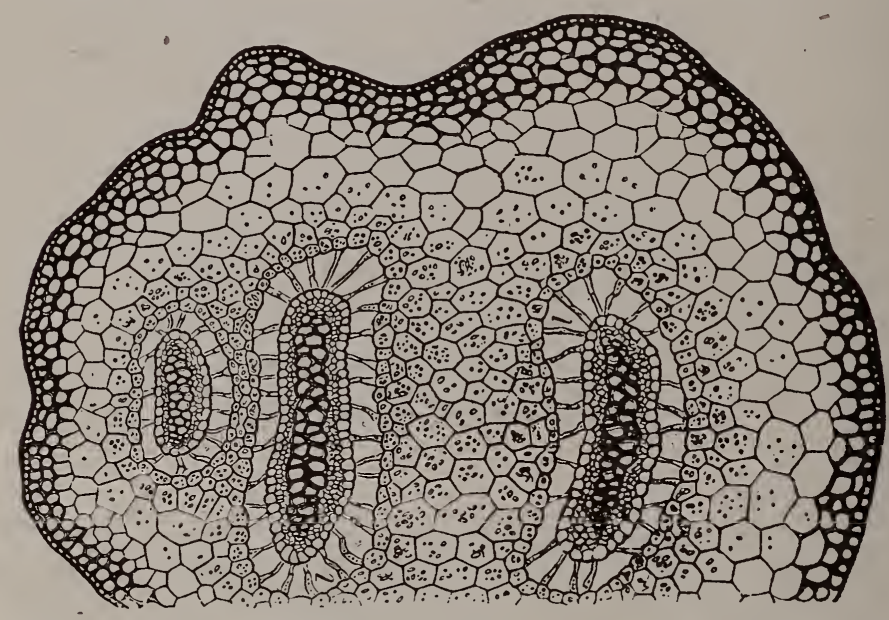

Fig. 468.-Transverse section of the stem of Selaginella inaequalifolia, showing three fibro-vascular bundles separated from the fundamental tisste by intercellular spaces. (Sachs.)

there may be two or more concentric bundles placed side by side, as in Fig. 468. In the stems of Equisetums, a transverse section of the internode shows a single circle of poorly developed collateral bundles surrounding a central hollow and having an endodermis on both inner and outer sides. Within each bundle at the inner side is an intercellular space, produced by the breaking down of the earlier formed xylem elements. - A longitudinal section shows that the bundles run parallel in the internodes, but anastomose at the nodes where the bundles are received from the leaves.

Monocotyledon Type. Here the stele contains a large number of bundles, usually of the collateral kind, and possessing no meristem tissue. .They are, therefore, closed bundles. As viewed in a cross-section of the stem, they are scattered with little or no apparent order through the fundamental tissue. The phloem part 
of each bundle usually faces radially outward toward the periphery of the stem, and the xylem inward or toward the centre. The bundles of the stem are all continuous with those of the leaves and since the latter are usually broad and sheathing, the bundles are very numerous. From the leaves, the bundles pass obliquely downward, or sometimes nearly horizontally inward, in a radial direction, toward the center of the stem; thence they bend in a downward direction, and then, in a long curve, sweep gradually outward toward the circumference of the central cylinder, where they finally terminate, after coalescing with other bundles which originate from leaves higher up. The bundles do not all penetrate

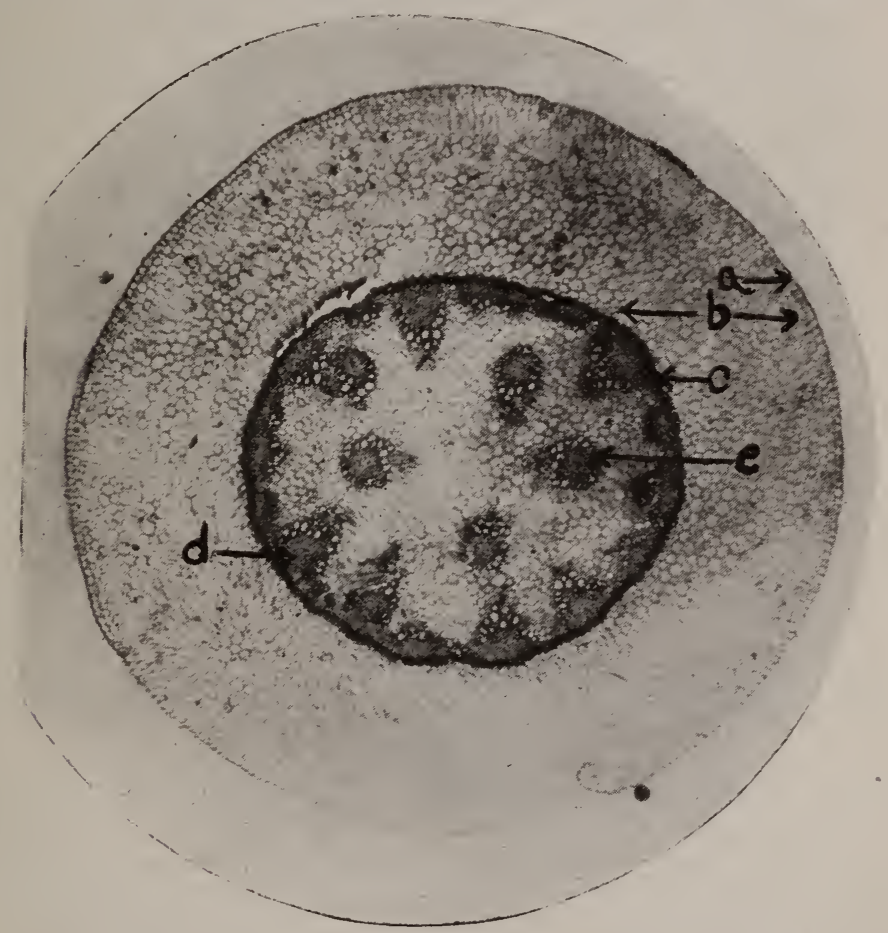

Fig. 469.-Transverse section of the rhizome of Lily-of the-Valley (photomicrograph). a, epidermis; b, cortex of parenchyma; $c$, endadermis; $d$, fibrovascular bundle with V-shaped xylem; e, fibro-vascular bundle with xylem surrounding the phloem (hadrocentric bundle).

the cylinder to the same depth, some bend downward soon after entering it, others pass nearly or quite to its center. Hence the irregular arrangement observed in cross-section. It is evident also 
that the bundles will be more numerous and crowded toward the periphery of the cylinder. The fact that stems of this type are denser exteriorly than they are in the center, is thus, in part at least, accounted for. In some plants the central portion of the

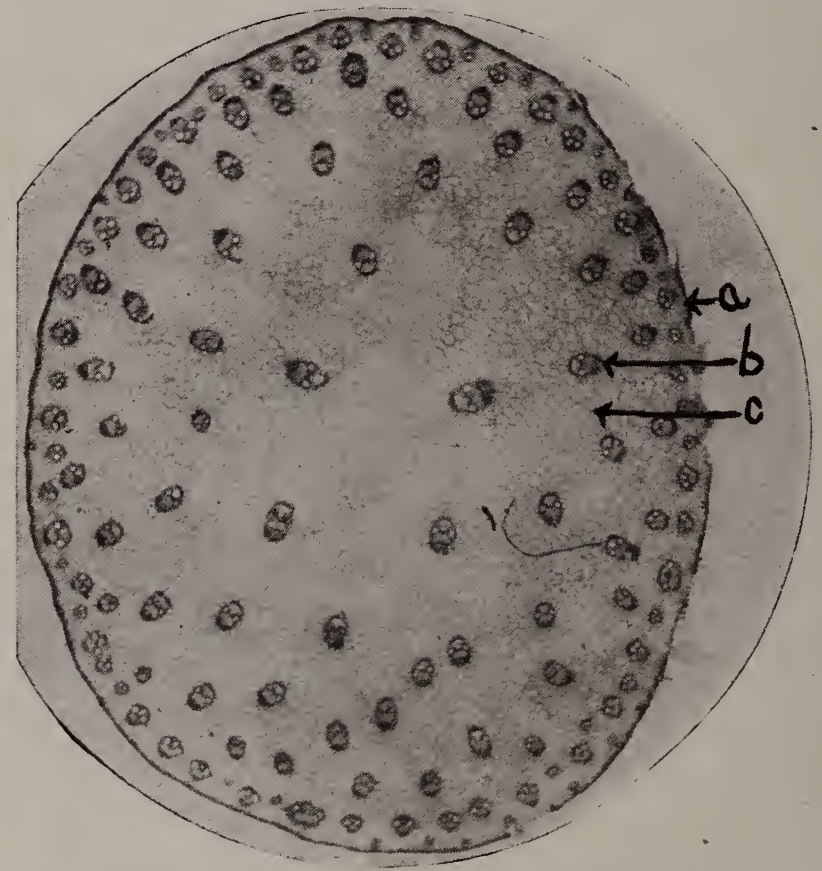

Fig. 470.-Transverse section of Corn stem (photo-micrcgraph). a, the epidermiis; $b$, one of the many scattered fibro-vascular bun:les (cicsed col. lateral type); $c$, the fundamental parenchyma.

stele is destitute of bundles, and the thin-walled parenchyma of this region may even disappear at an early stage in the development of the stem, leaving a hollow, as in the stems of most Grasses. The bundles attain their best development in the middle portion of their course. In their progress downward and outward they become thinner and less vascular; hence, in viewing a cross-section of a stem of this kind, the best developed bundles are found to be those farthest interior, while the more imperfect ones are the ones crowded together toward the outside of the cylinder. The main points of structure in stems of this type are-illustrated in Figs. 469 to 473 , inclusive. 
Since the bundles do not possess a meristem layer, no increase in the thickness of the stem can take place except by the direct growth of the cells formed at the primary meristem. Accordingly, the majority of stems of this type do not increase in thickness

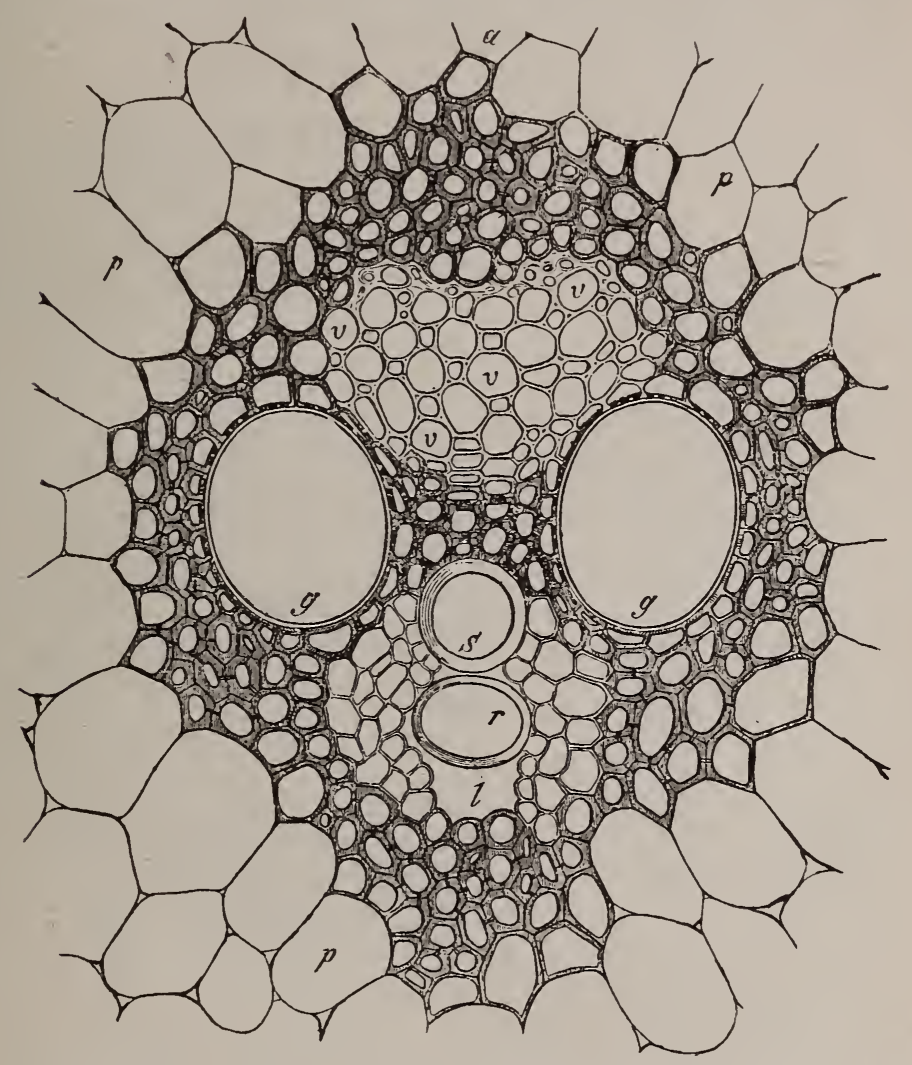

Fig. 471.-Transverse section of a closed fibro-vascular bundle of the stem of Zea Mays. It consists of yxlem ( $g, g, s, r, 1)$ and phloem $(v, v)$. The surrounding thick-walled tissue is the bundle sheath. $p, p$, thin-walled parenchyma; g, g. two large pitted vessels; s, spiral vessel; r, isolated ring of an annular vessel; 1, air cavity produced by rupture during growth. (Sachs.)

except when quite young. This is true eren when they live on from year to year; the stem of a Palm, for example, having the same diameter when two feet high that it has after reaching the height of one hundred feet. The growing area of the stem is confined to the apex or its immediate vicinity, and does not extend downward as a meristem cylinder between wood and bark, as it 
does in the stems of Gymnosperms and Dicotyledons. In fact, in Monocotyls no true bark is found, nor is there a true pith, nor medullary rays, nor rings of growth.

There are some exceptional Monocotyledons, however, like the Yuccas and Dracænas, whose stems do increase in diameter from

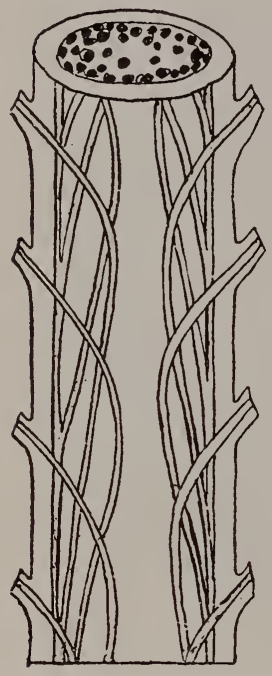

Fig. 472.

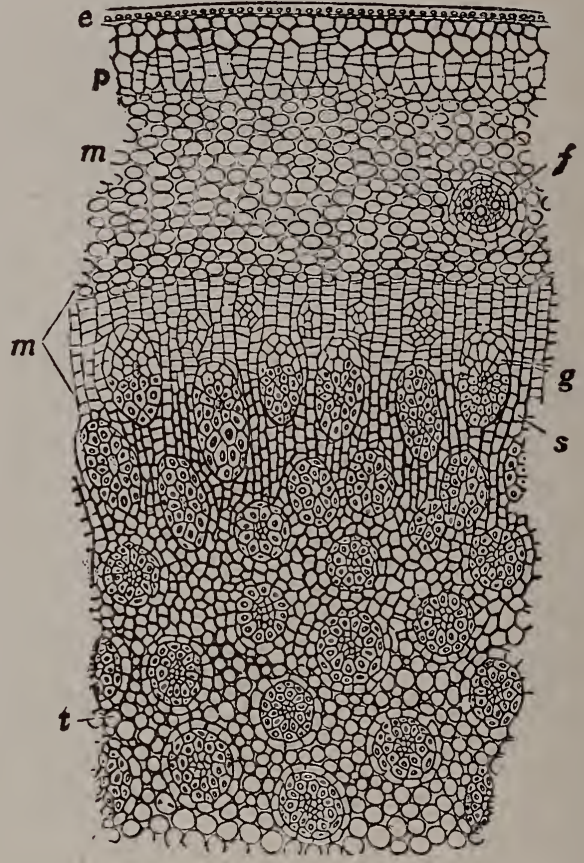

Fig. 473.

Fig. 4i2.-Diagram showing course of bundles longitudinally in Monocotyledon type of stem.

Fig. 473.-Part of transverse section of stem of a Dracrena, showing its mode of increasing in thickness. e, epidermis; $c$, corky layer; $p$, cortical parenchyma: $\mathrm{f}$, a procambium bundle passing outward to a leaf; $\mathrm{m}$, meristem layer, in which vascular bundles are forming; $g$, newly formed bundle, the upper or outer part of which still consists of thin-walled cells; s. secondary fundamental tissue, with radially arranged cells; t, primary fundamental tissue. (After Sachs.)

year to year by means of a meristem zone in the thick primary cortex. In this layer secondary bundles are formed resembling those first formed in the stele of these and other. Monocotyledons. This mode of growth will be understood by reference to Fig. 478 . 
It should also be observed that there are a few anomalous Monocotyledons that have their bundles arranged in a manner quite different from that which has been described. In the common Yam and a few other plants the above-ground stems have the bundles arranged in a circle about a central pith, as in most Dicotyledons and Gymnosperms; and in some instances, as in Ruppia and its allies and in some Potamogetons, there is a single axile bundle which sends out branches to the leaves.

Dicotyledonous Stems possess bundles of the open collateral type-i.e., comprising phloem (leptome), cambium and xylem (hadrome). These vascular bundles are arranged in a circle and separated from each other by the fundamental tissue composing the medullary rays and the pith.

The secondary structure of dicotyledonous stems, resulting in growth in thickness, is due to the development of the cambium, which, as in the corresponding structure of dicotyledonous roots, forms new xylem on one face and new phloem on the other.

At this point it becomes necessary to distinguish between the terms applied to the vascular bundles and their parts. Let it be understood, then, that mestome strand is not identical in meaning with fibro-vascular bundle although the terms are often employed synonomously. A mestome strand includes only the conducting elements of a fibro-vascular bundle, namely, the sieve-tubes, companion cells, and cambiform cells, constituting the leptome, and the tracheal tubes, tracheids and wood parenchyma, comprising the hadrome. Bast fibers (stereome) being mechanical elements are expressly excluded from the mestome, as are also, for the samc reason, the libriform cells of the xylem.

In dicotyledonous stems the course of the bundles from the leaves is inward and usually obliquely downward, and, having entered the stele, their course lies directly downward, keeping at about the same distance from the center of the stem. A crosssection of the stem, therefore, shows a circular arrangement of the bundles, which are of the collateral variety. They are usually shaped like a wedge, and radiate from a central portion of the fundamental tissue called the medulla or pith, toward which each presents its thinner edge. Separating the bundles laterally, and connecting the pith with the primary cortex are plates of fundamental tissue called medullary rays. The inner or thinner portion of each wedge-shaped bundle is composed of xylem, and the outer or broader portion of phloem tissues, and these are ordinarily 
separated from each other by a tangential layer of meristem tissue called the fascicular cambium. This is usually continued from one bundle to the next across the intervening medullary ray, and is here called the interfascicular cambium. The cambium thus forms, in most cases, a narrow zone, separating the phloem and exterior tissues, which constitute the bark, from the xylem and interior tissues, which constitute the woody region of the stem. These facts will be understood by reference to Figs. 474, 475 and 476 and their accompanying descriptions.

In woody stems of this kind, every year during the season of growth, and for a time even in herbaceous stems, the cells of the cambium-layer divide in a tangential direction, and those interior and next to the wood are developed into xylem, and so add to the thickness of the woody region, while those exterior are developed into phloem elements, and increase the thickness of the bark.

The activity of the cambium results most largely in the formation of new wood (secondary xylem), both as a part of the primary bundles (proto-xylem) and by the interposing of secondary bundles between these. Along with the secondary bundles, new (secondary) medullary rays are formed. This accounts for the various lengths of medullary rays sometimes seen in transverse sections of woody stems. Usually the medullary rays extend but a short distance vertically ( $1 \mathrm{~mm}$. or less), though in some instances they run from node to node.

The interior and older xylem tissues of woody stems commonly become strongly lignified and conspicuously different in color from the rest, owing to infiltrated coloring matter. This portion of the

Fig. 474.-Portion of the young stem of Elder in tiansverse, radiallongitudinal and tangential-longitudinal views, showing primary structure of the dicotyl stem. (1) epidermis; (2) sub-epidermis (the mother cells of the phellogen); (3) collenchyma; (4) parenchyma of the middle bark; (5) crystal cells, containing crypto-crystals; (6) resin tube; (7) bast fibers; (8) phloem: (9) cambium just developing; (10) tracheal tubes. of the prinary wood; (11) parenchyma of the pith. $T$, added to a number indicates that the tangential view is presented, and $R$ added to the number indicates the radial view of the tissue.

Fig. 475.-Portion of the stem of Elder in transverse, radial-longitudinal and tangential-longitudinal views, showing secondary structure of the dicotyl stem. (1) epidermis, (2) mature cork cells, (3) immature cork cells, (4) phellogen or cork cambium, (5) collenchyma, (6) parenchyma of the middle bark, (7) crystal-cells containing crypto-crystals, (8) bast fibers of prinary structure, (9) sieve-tissue of the phloem, (10) medullary ray, (11) cambium, (12) wood fibers, (13) tracheal tubes, (14) primary xylem, (15) parenchyma of the rith. $T$, added to a number, indicates that the tangential view is presented, and

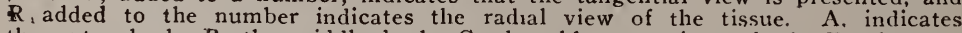
the outer bark, B, the middle bark, C, the phloem or inner bark, $D$, the secondary xylem, and $E$, the pith, except that the primary xylcm appears in this region also. 


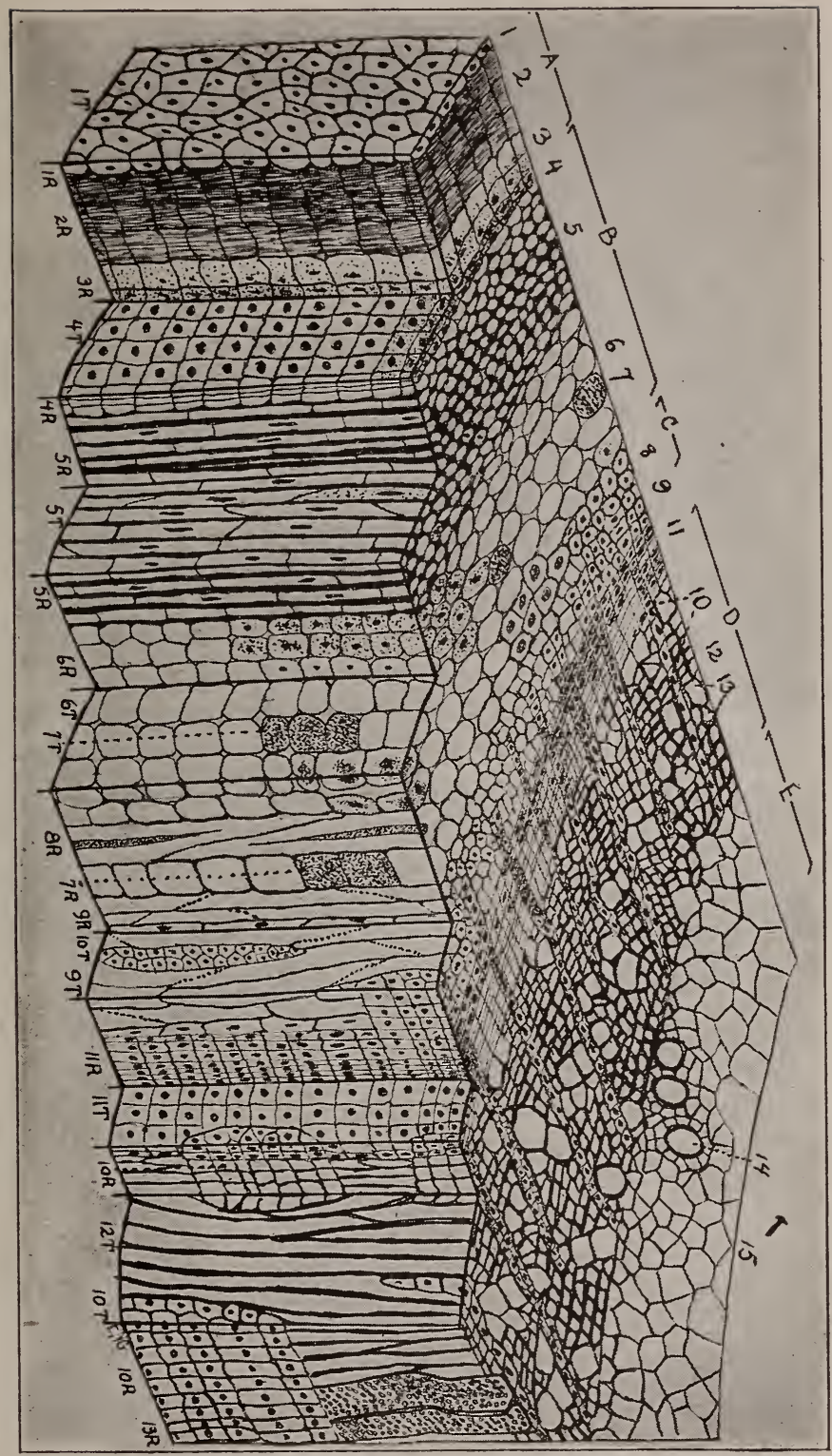

Fig. 474.

For description see page 232 . 
PART II.-HISTOLOGY.

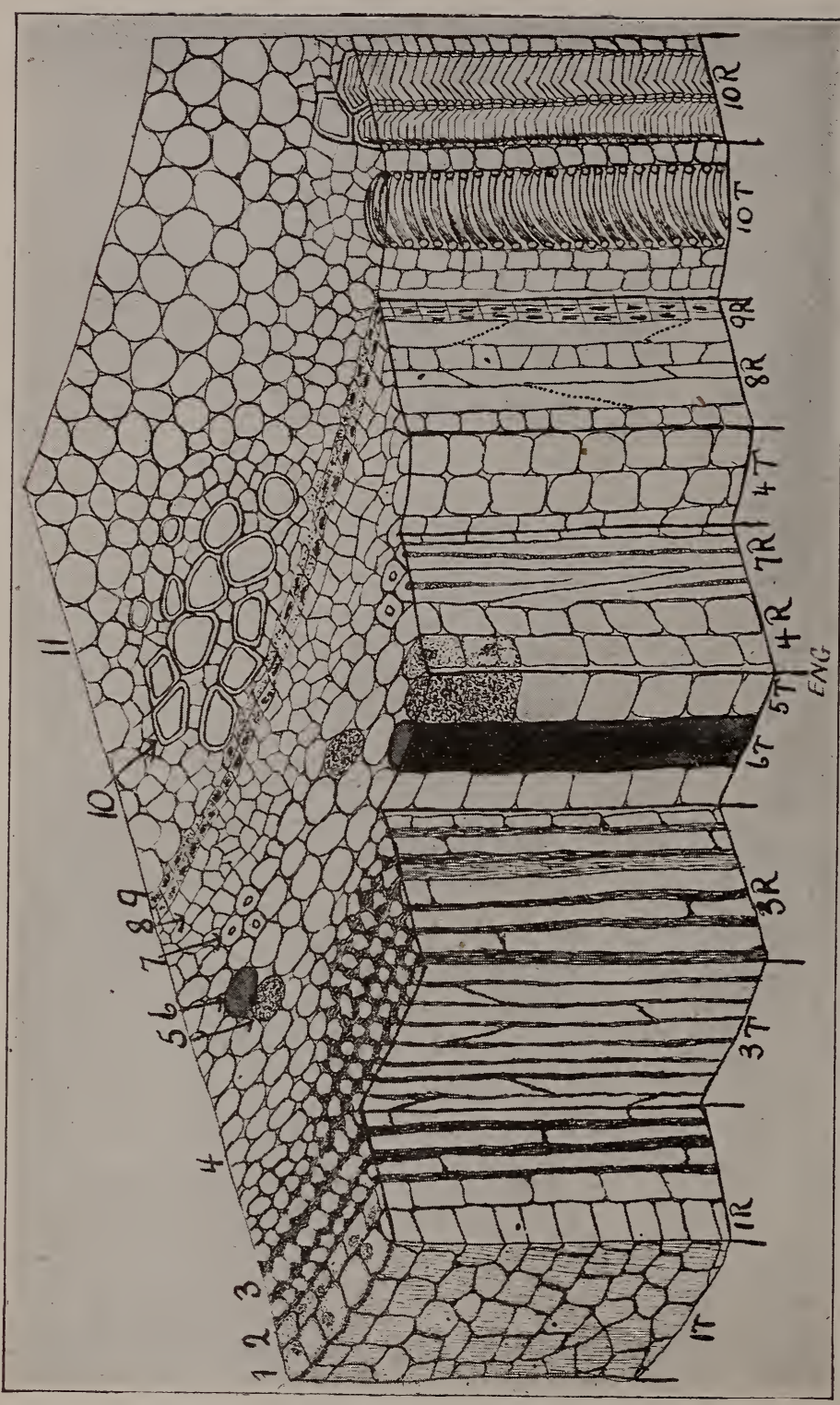

Fig. 475.

For description see page 232. 
wood, which has ceased to take any important part in the vital processes of the plant, is called duramen, or heart-wood, while the exterior zone of thinner-walled, uncolored and active cells is called alburnum, or sap-wood.

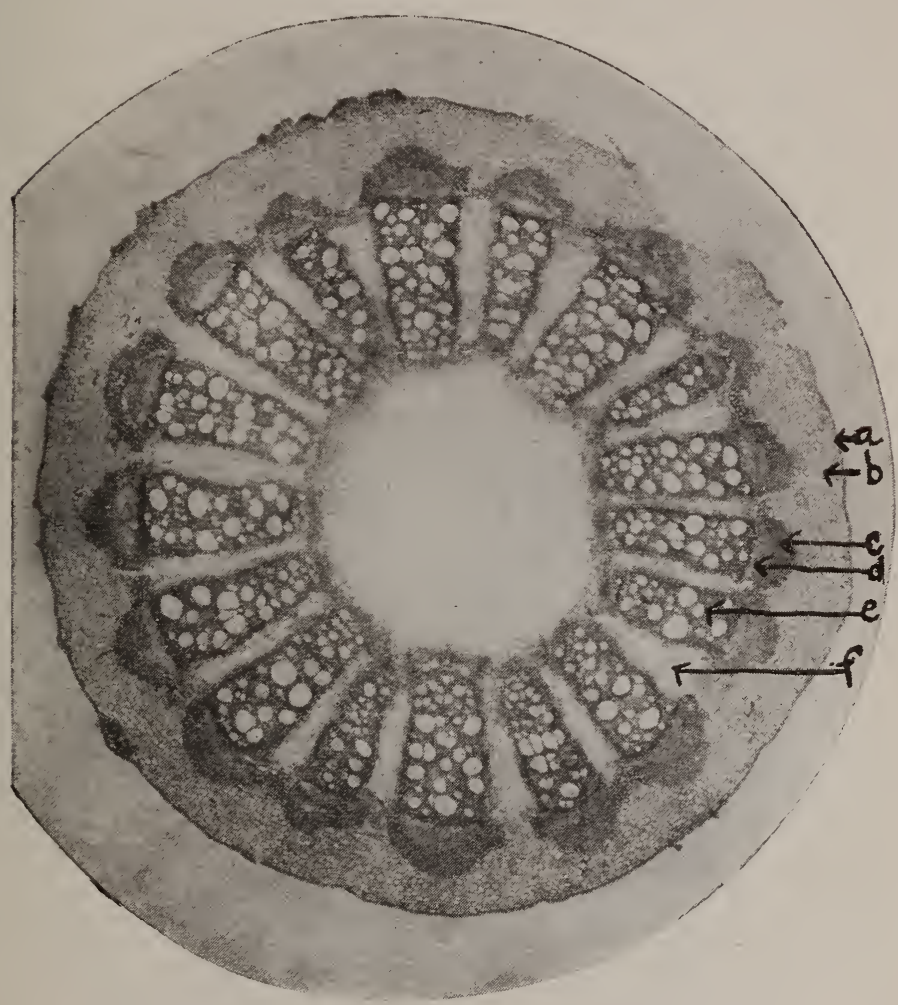

Fig. 476.-Transverse section of the rhizome of Menispermum canadense (photomicrograph). a. epidermis; b, parenchyma of the middle bark; c, crescentshaped mass of bast; $d$, phloem and cambium; e, xylem ray; f, medullary ray.

In both stems and roots of Dicotyledons there may be distinguished in the secondary xylem, produced each year, two wellmarked parts, an early growth containing relatively more and larger tracheal tubes and a later growth in which the tracheal tubes are fewer and smaller and the wood fibers predominate. This difference in structure results from the need of water-conducting tissue at the time when the leaves are growing, while after. this need has been supplied, chiefly strengthening tissue is formed. 
Only the newer wood is connected with the vascular bundles of leaves and capable of supplying them with water. Thus are formed the rings of growth which are observed in the wood of trees that inhabit climates where there is a decided change of seasons, so as to produce periodical cessation of growth, and these rings are directly due to the juxtaposition of the small cells formed in the latter part of the season of growth and the larger ones formed at the beginning of the succeeding season. This will be understood by reference to Fig. 479. In climates where there is during the year one period of growth and one of rest, there will usually be formed one ring each year, and the number of rings in

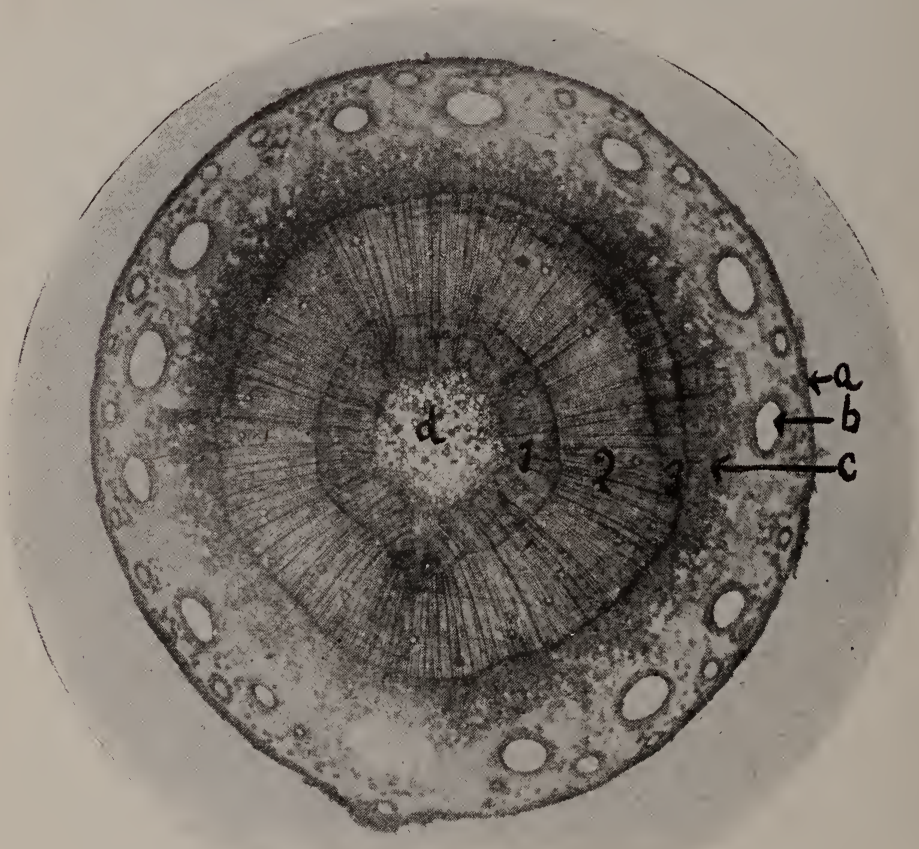

Fig. 477.-Transverse section of a young stem of Pine (photo-micrograph) $\mathrm{a}$, cork; $\mathrm{b}$, one of many oil-vessels, embedded in the parenchyma of the middle bark; c, the inner bark, including the phloem and medullary rays; (1), (2), (3), the first, second and third year's growth of wood (the specimen was gathered in early summer), showing small scattered oil tubes, the medullary rays, the xylem rays and two annual rings; $d$, the pith.

the wood, therefore, becomes an index, approximately, at least, of the age " of the stems. Sometimes, however, rings are due to other causes. Periods of drought in midsummer, accidental losses 
of large branches possessing a great amount of leaf-surface, or other causes seriously interfering with regular growth, may result in the formation of two or more rings during a season. They must
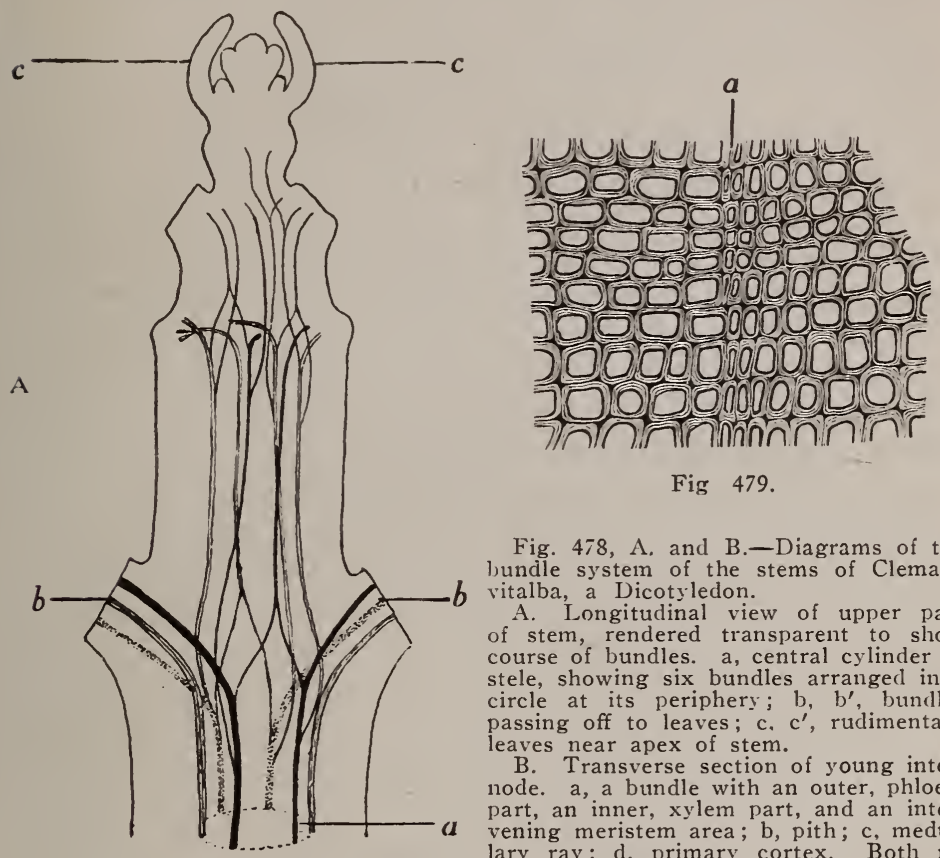

Fig 479.

Fig. 478, A, and B.-Diagrams of the bundle system of the stems of Clematis vitalba, a Dicotyledon.

A. Longitudinal view of upper part of stem, rendered transparent to show course of bundles. a, central cylinder or stele, showing six bundles arranged in a circle at its periphery; $b, b^{\prime}$, bundles passing off to leaves; c. $c^{\prime}$, rudimentary leaves near apex of stem.

B. Transverse section of young internode. a, a bundle with an outer, phloem part, an inner, xylem part, and an intervening meristem area; $b$, pith; $c$, medul. lary ray; $d$, primary cortex. Both reluced from figures by DeBary.

Fig. 479.- Small portion of transverse section of wood of White Pine, showing part of a ring of growth, a. The small cells at a, were produced near the close of the season's growth, and the large cells immediately to the left were produced in the spring of the succeeding season.

B

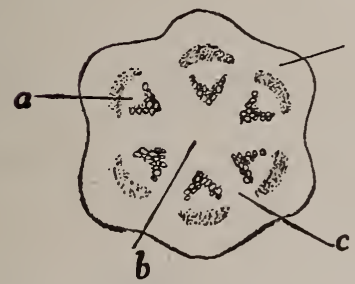

Fig. 478.

not be relied on, therefore, as indicating with absolute accuracy the age of trees.

The bark of Dicotyledons and Gymnosperms, when all the parts are present, consists of three layers, known as the outer bark, including the epidermis and the cork, the middle bark, chiefly parenchyma, and the inner bark or liber.

The epidermis has already been described. In perennial stems 
it seldom persists for more than two or three years. When it first reaches maturity it forms, except where the stomata occur, a continuous covering, though minute elevations may be discernible here and there on the surface, even before the close of the first year's growth. These are due to the growth of cells at certain points beneath. During the second year, the continuity is ruptured by fissuring at these points, and the cells from beneath protrude, giving to the surface a freckled or spotted appearance. These spots are technically called lenticels. They consist at first of loose parenchyma which soon breaks down, leaving a pore or opening surrounded by a layer of cork. Through this pore, air is supplied. Lenticels thus replace the stomata as these are destroyed or rendered useless by the development of the bark. See Fig. 480.

Sooner or later, however, a corky layer or periderm is formed by the division of cells in a tangential direction. This periderm may be formed superficially either by the division of the cells of the epidermis itself, as in the Willow, Apple and Oleander, or, as is more commonly the case, by the division either of the parenchyma cells in immediate contact with the epidermis, or of those forming the second or third layer beneath it. In this case, the epidermis and the one or two layers of parenchyma that are thus cut off from supplies of nutriment by the formation of cork interior to them, die and disappear, and the cork and the secondary merrstem (phellogen), in which new cork cells are formed, now constitutes the periderm. It increases in thickness by the formation of new cells in the phellogen by tangential division, but at intervals rows of cells divide in a radial direction, thus enabling the layer to keep pace, for a time, at least, with the growth of the stem in circumference. Examples of plants that form a periderm of this character are the Beech, Chestnut, Hazel and Bass-wood.

The middle bark beneath this layer consists largely of parenchyma cells, the outer layers of which are rich in chlorophyll. It is hence often called the green layer of the bark, for it is this which in young shoots, before the formation of a periderm, communicates the green color to the surface, the cells of the epidermis being transparent. Some stems remain green for years because of the delay to form a periderm, and the persistence of the epidermis. The Canada Moonseed (Menispermum canadense) affords an example.

Not infrequently there occurs at the junction of this layer with the bast a ring or zone, it may be more or less interrupted, 
consisting partly of bast fibers and partly of stone cells, the socalled "mixed ring." Sometimes where this zone crosses the medullary rays it dips inward toward the centre of the stem, thus presenting a scalloped appearance when viewed in cross-section. Cluster's of stone cells may also develop elsewhere.in this layer, and it may contain latex vessels, crystal sacs, secretion passages, etc. In stems where the layer persists, new cells are also formed either along the continuations of the medullary rays or elsewhere, so that it keeps pace with the general expansion of the tissues of the stem.

It is by no means always the case that the periderm originates at or near the exterior. In many woody stems it originates internally, in the deeper layers of the middle bark, or even in the innermost layer of cells where it joins the zone of bast fibers just described, or if that is not present, where it joins the other tissues of the inner bark. Thus, when the periderm is formed, not only may the epidermis disappear but also the greater part or even the whole of the middle bark, leaving only the inner bark covered with a periderm. The Juniper, Currant, Honeysuckle, Deutzia, Philadelphus and Barberry are examples of plants that form a periderm in this manner.

In the majority of woody stems when they become old, whether the periderm is at first produced superficially or from more deeply lying tissues, secondary formations of periderm occur in succession interior to those first formed, and the layers of dead tissues exterior to them, stretched by the growth of the stem, become ruptured or fissured in various ways and peel off from the surface. These secondary layers of periderm may be formed in the middle bark or in the older portions of the bast; hence, in the large trunks of many of our forest trees all tissues exterior to the liber have disappeared, land, in the strict sense of the term, nothing of the bark but the inner layer is left.

The liber is always present and always constitutes the most important portion of the bark. Although, as we have seen, its outer layers may peel off while being renewed from within, it always consists, when first formed, of the phloem of the fibrovascular bundles, together with that portion of the medullary rays which separate these parts of the bundles laterally. It consists, therefore, largely of sieve and parenchyma tissues, with bast often intermingled. It not infrequently also contains other tissues, such as latex tissues, secretion cells, etc. The soft tissues of this layer 
are particularly rich in albuminoid and other nutritious matters, and in medicinal barks it constitutes the area in which the active principles are usually found in greatest abundance.

Since in perennial stems this layer increases in thickness year by year by growth in the cambium, it often, though not always, presents the phenomenon of rings of growth similar to those seen in the woody part of the stem.

It is not always the case that the stems of Dicotyledons conform fully to the type which has been described. Cucurbitaceous plants, like the Pumpkin and Melon, have so-called bi-collateral bundles, that is, collateral bundles with an internal phloem; moreover, these bundles are arranged in two circles instead of one. Other curious deviations from the typical form occur in the stems of many tropical climbers known as "lianas."

The stems of Gymnosperms show, for the most part, the same arrangement of the bundles as those of Dicotyledons. They differ from the latter mainly in the fact that the tissues, particularly those of the xylem, are less complex. In most cases the tracheal tubes and wood fibers which are so abundant in the xylem of Dicotyledons are few in number or altogether wanting, these tissues being replaced, as we have seen, by disc-bearing tracheids. (Fig. 477).

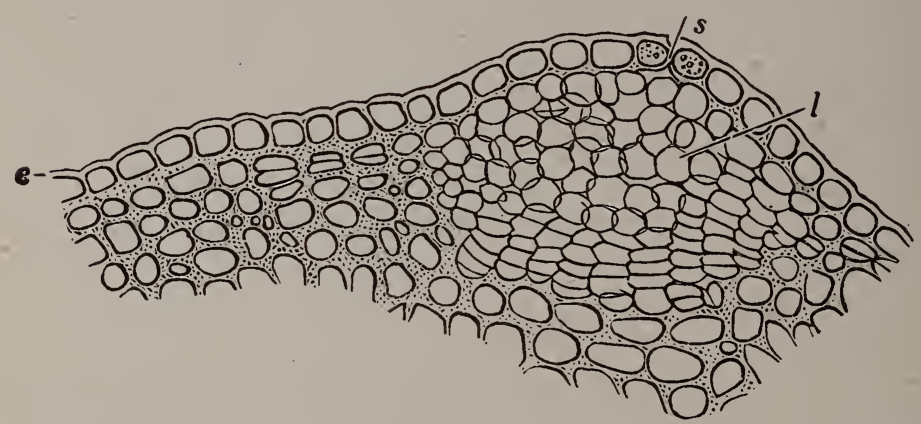

Fig, 480-Transverse section through lenticel of the White Birch. s, stoma; 1, cells of the lenticel which, by their rapid increase in the inner layer, have caused an elevation of the epidermis, but have not yet burst through it; 2 , epidermis. After DeBary. .

The Leaf.-Leaves are specially modified expansions of the stem and in their incipient formation from the latter they develop from a primordial meristem (Fig. 481) with three primary meristems just as stems do (Fig. 482). From this growth arise the 
corresponding layers: epidermis, mesophyll and vascular bundles of the leaf.

The epidermis of the leaf has substantially the same structure as that of the stem, except that it is usually more abundantly

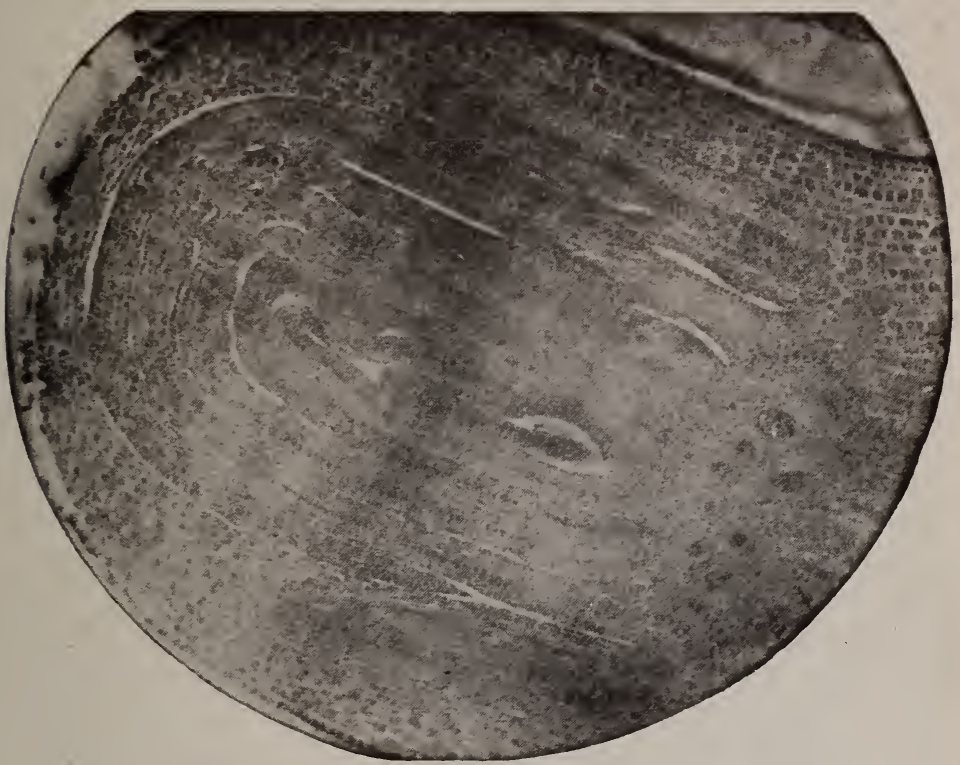

Fig. 481.-Meristematic leaf structure of Corn in the plumule of the embryo; longitudinal section (photo-micrograph).

supplied with stomata, particularly on its under surface. Here they are often very numerous. The leaf of Osmunda regalis has 21,000 to the square inch, that of the Apple upwards of 150,000 , and that of the Olive tree more than 400,000 . The ordinary epidermal cells are also more apt to have lobed or irregular forms than those of the stem, as illustrated in Fig. 405.

The vascular bundles of the leaf are usually composed of much the same elements as those of the stem with which they are continuous, except that in their finer ramifications they become much depauperated, being often reduced to scarcely more than a row of tracheids surrounded by elongated parenchyma cells constituting the bundle sheath. They follow the course of the veins and are a constituent part of them, though the veins include other tissue: than those which properly belong to the vascular system (mestome). The bundles are usually collateral and destitute of a func- 
tional cambium; the phloem portion faces the lower or outer surface, while the xylem faces the upper or inner surface. In the petiole there is either one large bundle or, more commonly, a mass composed of several pursuing a parallel course, at the stem end, becoming a part of its vascular system, and in the blade spreading out in various ways, according to the plans of venation already described.

In the forked type, seldom seen except in Ferns and their allies, the bundles may spread out from the base of the leaf and run toward the margin, in which they terminate without anastomoses, or they may diverge from a median group of bundles or mid-rib, as shown in Fig. 483.

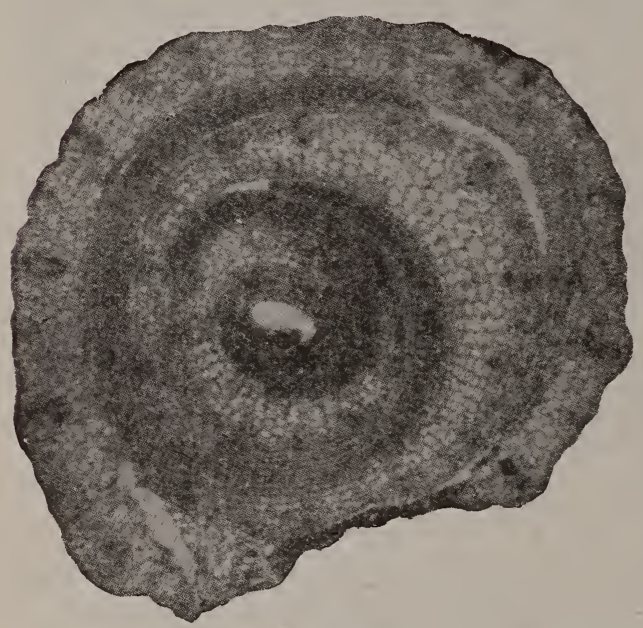

Fig. 482.-Meristematic leaf structure of the Corn in more advancedstage; transverse section of the terminal bud (photo-micrograph).

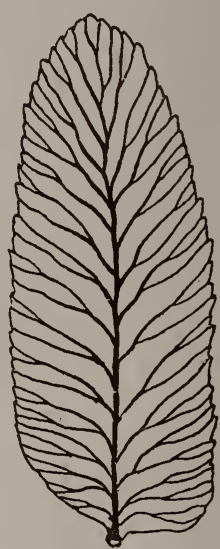

Fig. 483.-Leaflet of Osmunda regalis, showing arrangement of vas. cular system.

The parallel type is, as we have already seen, the prevalent one in Monocotyledons and Gymnosperms, though in exceptional instances it occurs among Dicotyledons, as in Eryngium yuccaefolium.

It presents interesting variations. In the Pines a single median bundle is present, or two bundles enclosed in a common sheath but unconnected by cross-veins, run parallel to each other from base to apex of the leaf. In Welwitschia and most Monocotyledons the bundles run nearly parallel to each other from base to apex or margin, or from a median group of bundles, forming a mid-rib, to 
the margin. Adjacent bundles are connected laterally by minute branches. The ends of the veins seldom terminate free, but curve toward each other and become united near the margin. See Fis. 484. A few exceptional Monocotyledons belonging mainly to the Yam, Arum and Smilax families, have the bundles reticulately arranged, as in most Dicotyledons.

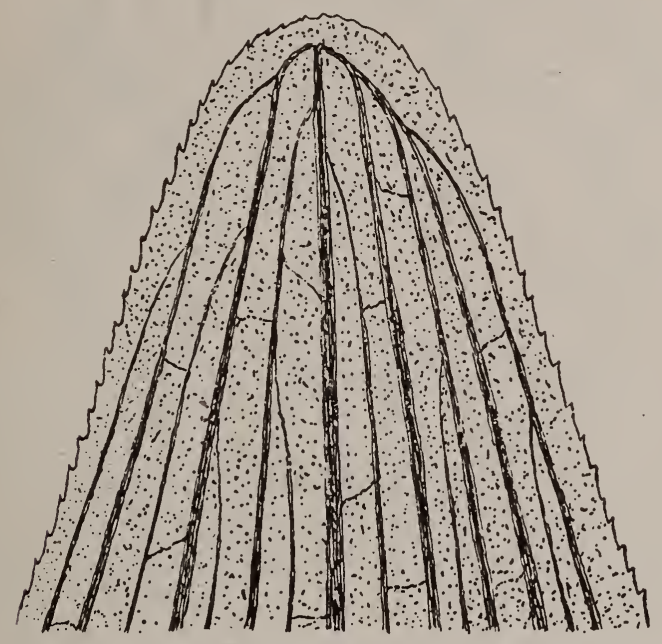

Fig. 484.-Apical portion of leaf of Smilacina stellata, showing the arrangement of vascular bundles.

In the reticulate type the bundles that enter the blade branch freely through it, running in all directions and anastomosing to form a net-work. The net-work may be fine or relatively coarse, but the meshes are seldom very rcgular, except in some Ferns which exhibit this type of venation. In many cases there are bundles which end free in the interior of the meshes, as in Fig. 485 ; in others these are wanting, but some of the veins terminate free in the margin; in still other cases both modes occur in the same leaf. Compare Figs. 485 and 486 . The main veins from which branches diverge to form the reticulum may be pinnately, radiately or costately arranged. In netted leaves the veins are usually more prominent on the dorsal surface of the leaf.

As regards the arrangement of the mesophyll of the leaf three different types are distinguished: the dorsi-ventral, the isolateral and the centric. 
The dorsi-ventral is much the more common. In this there are usually two or more layers of parenchyma, rich in chlorophyll

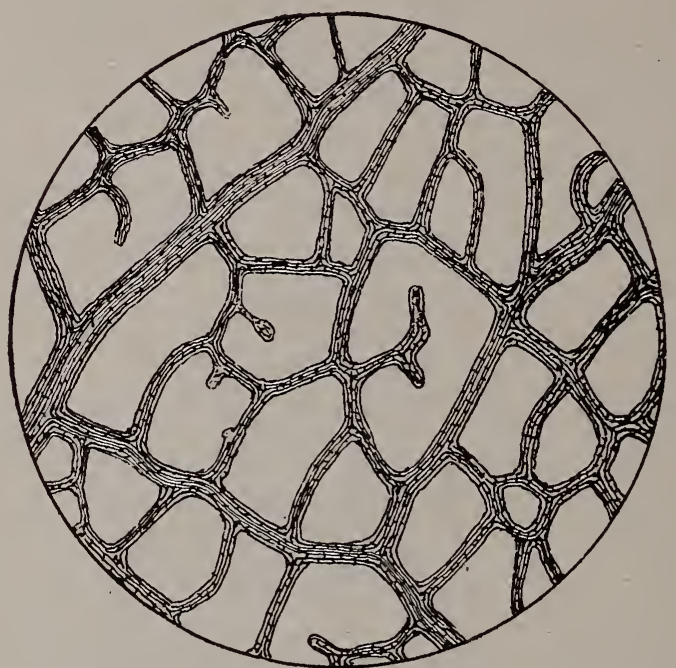

Fig. 485.-Part of vascular system of leaf of Cobaea scandens.

(chlorenchyma) compactly arranged next the upper epidermis, or next the hypodermis, if the latter is present. These cells are elon-

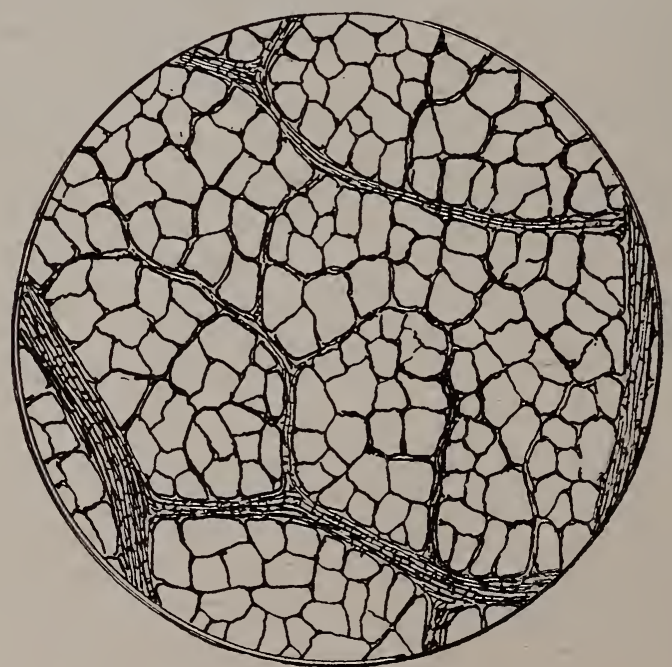

Fig. 486.- Part of vascular system of Bass-wood leaf. 
gated in a direction perpendicular to the surface of the leaf, and hence the name palisade parenchyma has been applied to them. The other parenchyma cells of the leaf are usually very loosely arranged, being separated from each other by large intercellular spaces. They are hence called spongy parenchyma. The spongy parenchyma is the chief transpiring tissue and is protected by its position from too bright light and from too great evaporation. In leaves of this class, the color of the upper surface, owing to the compact arrangement of the chlorenchyma cells next to it, is usually a much deeper green than that of the lower surface. (See Figs. 487 and 488.)

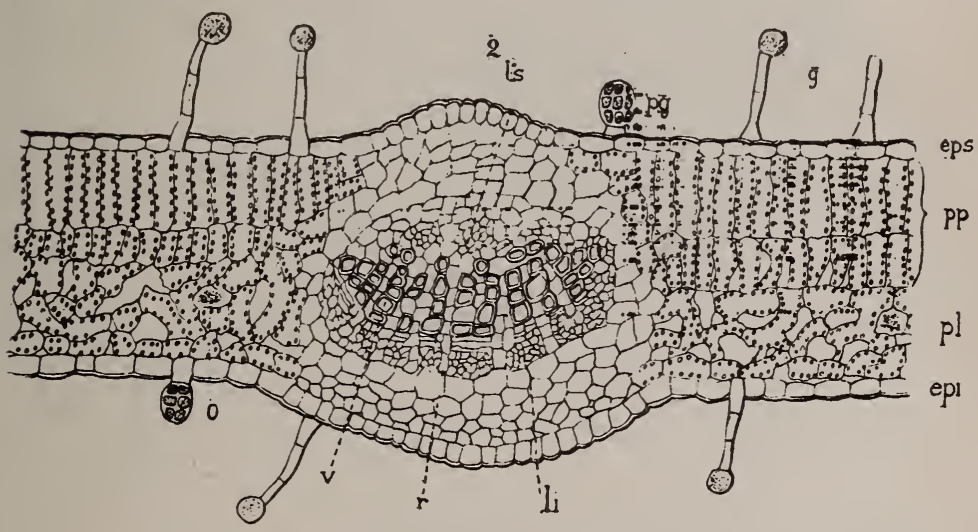

Fig. 487.-Transverse section of Belladonna leaf. eps, upper epidermis, and cpi, lower epidermis with glandular trichomes; pp, palisade parenchyma; pl, spongy parenchyma; o, crystal cell; $v$, xylem of the midrib; $r$, meduliary ray; ls, and li, phloem. (Godfrin and Noel.)

Isolateral Leaves differ from the preceding in having the palisade cells symmetrically distributed upon both -sides of the spongy parenchyma, the latter occupying the interior of the leaf. Similarly, too, stomata are equally numerous upon both surfaces. (See Fig. 488a.)

Centric leaves have but one kind of mesophyll cells and the veins are at the center, as in the Pines. Such leaves are cylindrical or of a similar shape and io not present a distinct upper and under surface. (Fig. 489.)

In all leares, the stomata are placed directly over intercellular 
spaces, so that there is free communication between the interior of the leaf and the outside. Collenchyma is frequently met with;

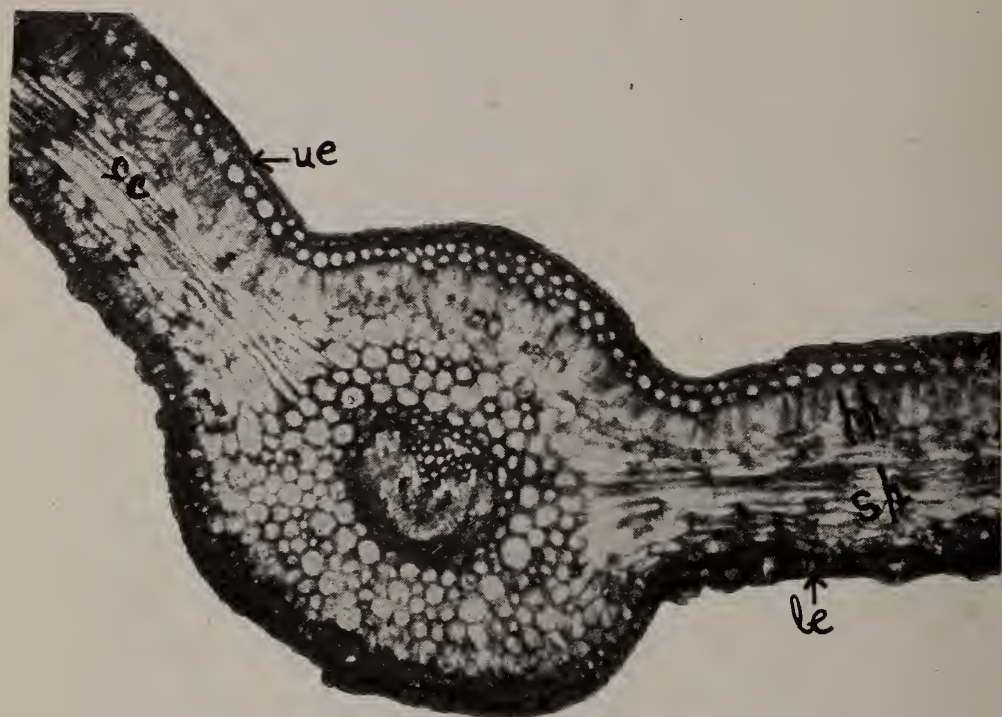

Fig. 488.- Transverse section of a leaflet of Cycas revoluta (plioto-micrograph). ue, upper epidermis with one row of sub-epidermal cells; le, lower epidermis with sunken stomata; $p p$, palisade parenchyma; sp spongy parenchyma; cc, conducting cells.

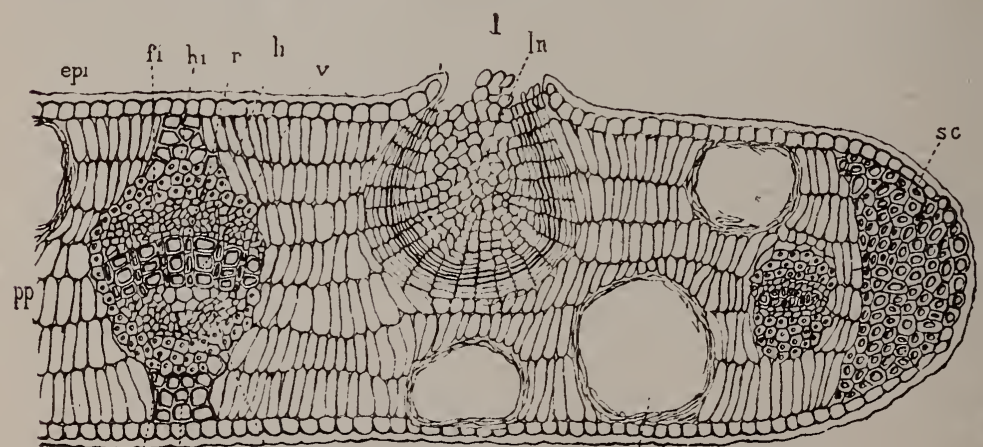

epe fo he le

Fig. 488a.-Portion of a transverse section of Eucalyptus leaf. epi, epidermis of inner surface; epe, epidermis of outer surface; pp, palisade parenchyma extending from epidermis to epidermis; f, oil gland; ln, lenticel; sc, bundle of sclerenchyma at the leaf margin; hi, and he, hypodermis beneath the epidermis at the principal veins; fi and fe, bast fibers on the inner and outer faces of the fibrovascular bundles; $\mathrm{li}$ and le, phloem on the inner and outer faces of the xylem which consists of vessels, v, separated by medullary rays, $r$. (Godfrin and Noel.) 
strands of stereome often accompany the bundles, usually adjoining and outside of the phloem. Peculiar, branched sclerotic cells sometimes occur in the mesophyll, notably in Tea.

The Flower.-Morphologically, flowers may be considered modified branches, the parts of the flower being analogous to leaves arranged upon a shortened stem (the receptacle). Floral leaves

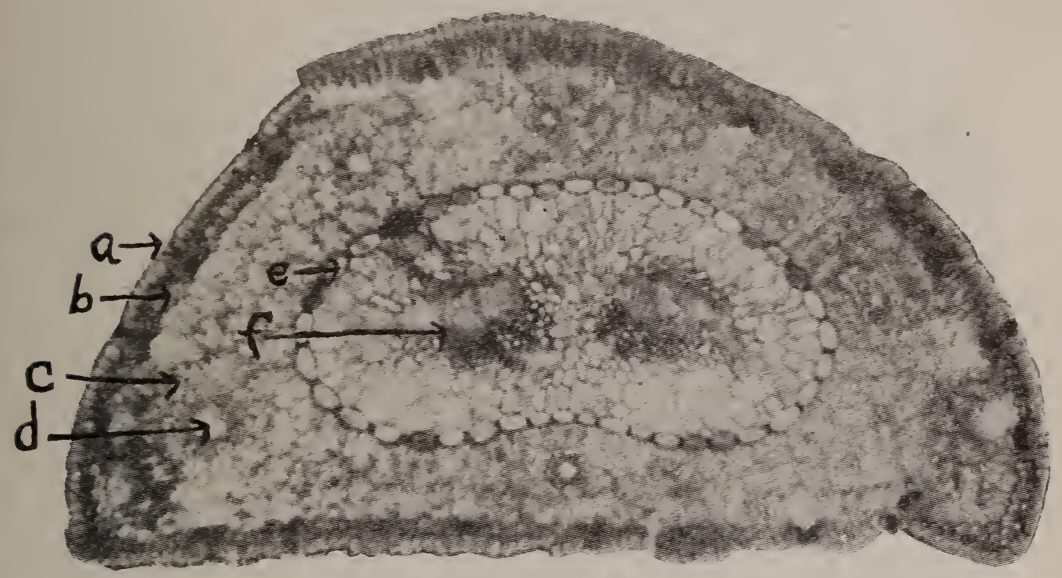

Fig. 489.-Transverse section of Pine leaf (photomicrograph). a, the epidermis with sunken stomata; b, sub-epidermis; c, chlorenchyma, with infolding walls; d, oil-tube; e, endodermis; $f$, one of the two fibro-vascular bundles, showing phloem above and xylem below.

therefore resemble foliage leaves and, like the latter, their histological elements consist of a framework of bundles, parenchyma filling the spaces between these, and a surrounding epidermis.

The receptacle and peduncle likewise resemble the leaf-bearing stem.

The sepuls are usually green, and bear the closest resemblance to assimilative leaves. When green, they bear stomata on the outer face. Trichomes are frequently present.

The petals are destitute of chloroplasts and are usually colored either by chromoplasts or by substances dissolved in the cell-sap. The velvety appearance possessed by many petals is due to papillæ, very short cell projections. The mestome or conducting strands of petals are greatly attenuated and their mesophyll is reduced to a thin layer of branching, spongy parenchyma cells. In fact, as compared with foliage leaves, the whole structure of the petal is much more delicate (see Figs. 406 and 490). 
The Stamens consist of parenchyma covered by an epidermis and bearing a slender bundle or mestome strand passing through the filament and connective. The pollen sacs possess a fibrous hypodermal layer, the endothecium, which determines their dehiscence. The tapetum which lines the pollen sacs during their

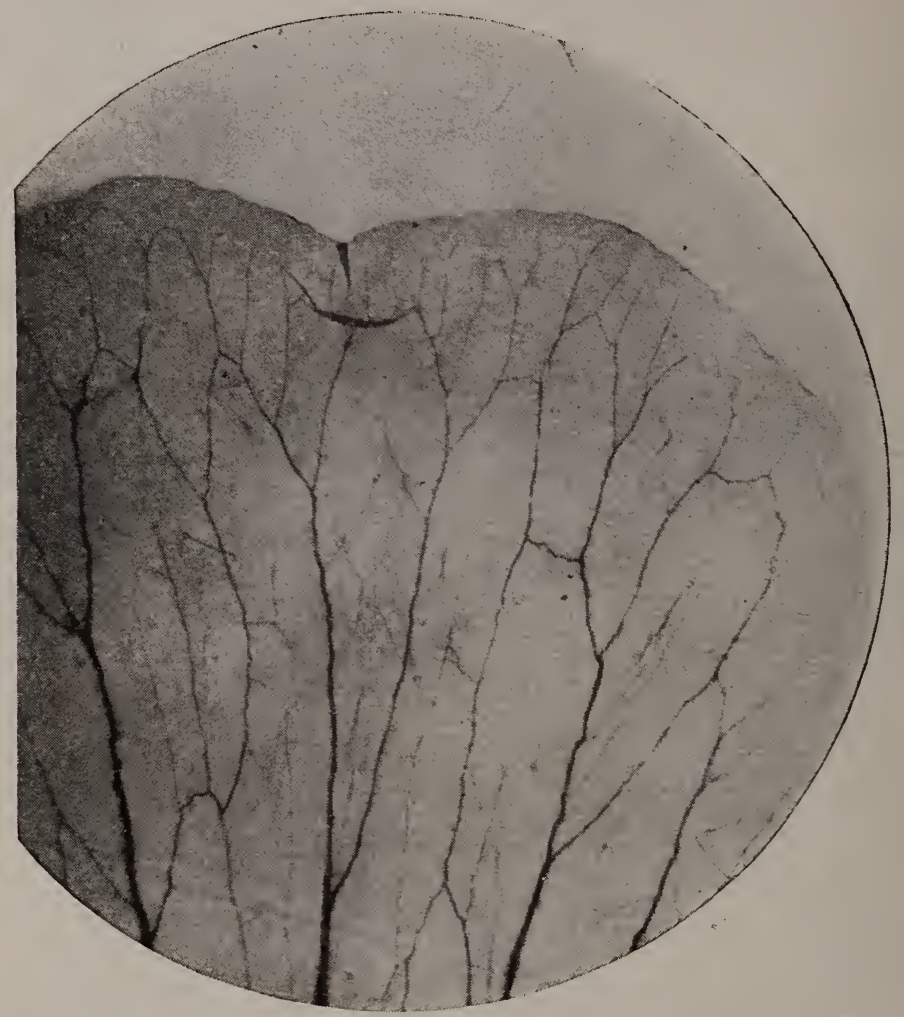

Fig. 490.-Petal of House Geranium, showing the delicate, anastomosing venation.

development nourishes the pollen grains and disappears at their maturity. The pollen grains are either single cells or groups of few cells, containing cytoplasm and surrounded by an outer and an inner wall, the outer wall being thickened externally by various and peculiar markings. Besides cytoplasm and nuclei, pollen grains contain stored food, commonly oil or starch. (See Fig. 491.)

The cells of the Stigma secrete a viscid, saccharine substance, and are frequently prolonged upward, forming papillæ. 
The Style consists in its interior portion of a loose conducting tissue, or may even be tubular, thus favoring the passage of the pollen tube.

The Ovary consists of tissues which are as yet in an undeveloper condition, but which later form characteristic parts of the fruit. Upon the inner surface of the ovary is borne the Placenta, through which pass mestome strands whose branches lead to the ovules. The structure of the ovule has already been described (page 93). It is joined to the placenta by a stalk which contains a strand of conducting tissue.

The Fruit and the Seed. Since the fruit includes not only the ripened pistil or pistils but also such adhering portions of the perianth or of the receptacle as may develop along with the pistil and remain attached to it, it is evident that fruits may vary widely in character, botanically, yet they present no new tissues histologically. The fruit may possess: (1) An epidermis of the usual kind and bearing some or all of the usual appendages, stomata being, however, much less common than in leaves. (2) A hypodermis, underlying the epidermis and sometimes quite distinctive. (3) Sclerotic tissue, varying greatly in character and amount in different fruits, being very abundant in hard, dry fruits and often absent in others. (4) Parenchyma tissue, especially abundant in fleshy fruits and which may contain the various cell contents. Secretion receptacles, oil tubes, latex vessels, oil cells, etc., may be associated with the parenchyma or extend through it. (5) Vascular bundles (mestome), usually slender and destitute of fibers, extending through the parenchyma.

The portion of the fruit enclosing the seed is called the pericarp, and three parts of it are distinguished: (1) The epicarp, the outer part, consisting practically of the epidermis only. The mesocarp or sarcocarp, which, when present is the middle layer, and is the fleshy part of many fruits. (3) The endocarp or inner part, which may include the inner epidermis and sclerotic tissue.

The seed is composed of: (1) The seed coat (spermoderm), which includes the testa, or outer coat, and the endopleura, or inner coat. These coats are made up of an epidermis, seldom bearing stomata, but frequently trichomes, the latter being often characteristic, as in Nux Vomica and Gossypium. Quite frequently, too, the epidermis is mucilaginous in nature, as in Linum, 
and Sinapis. Sometimes the epidermis may be more or less lignified, as in Amygdala. In addition to these features, peculiar markings are often formed through the arching of the thickened outer wall (cuticle) of the epidermal cells, as in Staphisagria.

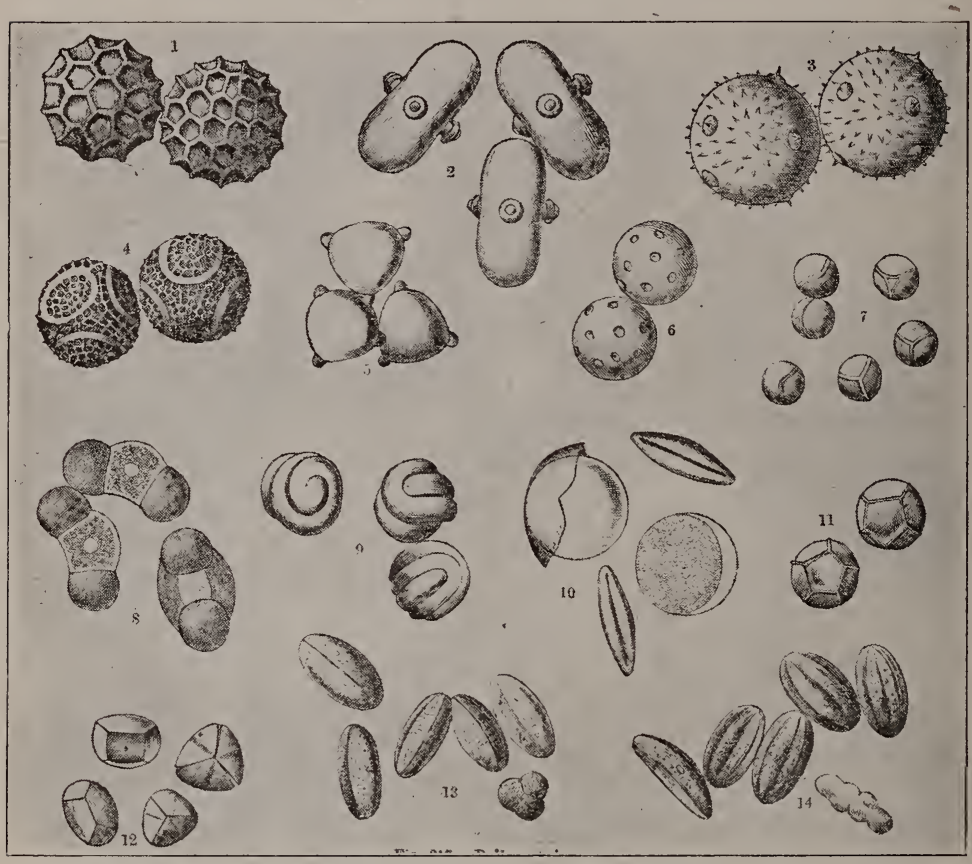

Fig. 491.-Pollen-grains: 1. Cobea scandens. 2. Morina Persica. 3. Cucurbita Pepo. 4. Passiflora Kermesina. 5. Circæa alpina. 6. Convolvulus sepium. 7. Cannabis sativa. 8. Pinus Pumilio. 9. Mimulus moschafus. 10. Albucca minor (dry and moistened). 11. Dianthus Carthusianorum. 12. Corydalis lutea. 13. Gentiana rhotica. 14. Salvia glutinosa. (Kerner and Oliver.)

The side walls of these cells are in some cases characteristically sinuous, as in Stramonium and the seeds of the Grasses. Underlying the epidermis are sclerotic tissue, pigment cells and parenchyma in varying amounts. (2) The kernel, located within the seed-coats, and consisting of the embryo only or of the embryo and the surrounding endosperm. The tissues composing the embryo are meristematic, but parenchyma constitutes the storage portion and its cells are filled with nutritive contents, such as starch, aleurone and fixed oil. The cells composing the endosperm are usually thin walled and stored with food, but may in some cases 
be thick-walled and horny, as in Nux Vomica and Coffee, where the walls consist of reserve cellulose. Similar to the endosperm but differing in origin is the perisperm or nucellar tissue, usually insignificant but in some cases, notably in Pepper and Cardamom, composing the bulk of the starchy part of the seed.

\section{Practical Exercises.}

1. For the study of Dicotyl stem structure, make sections transverse and lungitudinal of a stem of Menispermum canadense, selecting one that has attained a season's growth. This is selected for the first study, because the bundles are sharply distinct from the other tissues, the medullary rays being broad, unlignified and composed of thin-walled cells, and various kinds of tissues are well developed. It also affords a simple and easily understood example of stem structure. The sections should be cut thin, and care should be taken that the longitudinal ones run as nearly lengthwise of the grain as possible. To get a clear understanding of the structure, some of the longitudinal sections should be radial and others tangential. A radial section, it will be remembered, is one which passes through the middle of the stem lengthwise, - that is, along the medullary rays, - while a tangential section is made to one side of the center, so as to cross the direction of the medullary ravs. The sections used for immediate study should be placed on a slide, treated with a drop of phloroglucin solution, and then, after the solution has had time to thoroughly penetrate the tissues, but before the liquid has evaporated from the cells, put on a drop of chloral hydrate solution, cover the section with a cover-glass and examine. The tissues of the xylem, the bast cells of the phloem and other lignified tissues will, hy this process, be stained a bright red, while the unlignified tissues, such as most of the pith cells, the medullary ray cells, the cortical parenchyma, the sieve tissues and the cambium cells will not be stained.

Some of the longitudinal sections should be treated with Schulze's maceration fluid for the purpose of isolating the tissues and studying them in detail.

After the structure and arrangement of the tissues of this stem are well understood, similar studies, for the sake of comparison, should be made of twigs of the Bass-wood, Apple, Maple, Witch Hazel, or other common woody plants, and the resemblances and differences of structure carefully noted and described by the aid of drawings.

The stems of several herbaceous Dicotyledons, such as those of the Begonia, Buckwheat, Datura, Cow Parsnip and Common Milkweed, should now be studied in the same way.

Make similar studies, also, of the stems of aquatic Dicotyledons, such as the Water Chinquepin, the White Water-lily, the Yellow Water-lily, etc.

In what respects do the bundles of the above-named stems of herbs and aquatics differ from those of the woody stems you have studied?

2. For the study of Monocotyledon stem structure, first make thin sections of the stalk of the common field Corn, treating the sections in the same way as it was directed to treat those of Menispermum. Note the distribution of the bundles, and then study their structure, the relative arrangement of xylem and ihloem, the tissues composing each, and determine whether or not they are separated from each other by a cambium area; study what tissues of the stem are lignified, and what ones unlignified, and note the tissues of the hypodermis, observing whether they are fibrous or not, the extent to which their walls are thickened, etc.

Now compare with this, sections of the stems of other herbaceous Monocotyledons, such as the Spiderwort, Canada Lily, Tuberose, and Wheat.

Compare, also, sections of the stem of a woody Monocotyledon, as that of Smilax or Rattan, and note carefully the structural differences.

Lastly, compare sections of aquatic Monocotyledons, such as Pickerel Weed, Bulrush, and Calamus.

3. For the study of the Fern stem, make similar studies of the rhizome of Pteris aquilina, of Aspidium marginale, and of Polypodium vulgare.

4. For the study of root structure, first make sections of the rootlets of the Sweet Flag or Calamus, or of the Virginia Spiderwort, preparing sections as before. Identify the xylem (hadrome) rays and the alternating phloem masses (leptome); determine the number of strands of each, and the kinds of 
cells which compose them. Identify the pericambium and the endodermis, and study the character of the cells which compose each.

With these, compare sections of the roots of other Monocotyledons, such as those of Indian Corn, Amaryllis, Indian Turnip and Calla, making drawings and descriptions of the central stele in each case.

Make similar sections and studies of the root of some herbaceous Dicotyledon, such as that of the common Buttercup, or of the American Cowslip, and of some Fern, such as Osmunda cinnamomea, and observe that in all essential respects the structure is the same as that of the roots previously studied.

liow cause a few beans or peas to germinate, and make transverse sections of the primary root in different stages of its development. Note that, when young, its structure corresponds with the rest, but afterward it undergoes important secondary changes. By means of a series of sections, study the successive stages of these changes, recording your observations by aid of drawings.

5. For the study of the arrangement of the bundles in leaves, obtain the following: the fork-veined leaflets of the Cinnamon Fern or of the Maiden-hair Fern; the parallel-veined leaves of the Lily-of-the-Valley or of Solomon's Seal; and the reticulate leaves of the Wild Cranberry, of the Maple and of the Wild Cucumber (Echinocystis). In order that the finer ramifications of the veins may be distinctly sc $\mathrm{n}$, it is best that the leaves should first be bleached and then stained. Soak them for a few days in alcohol to remove the chlorophyll, then transfer them to Labarraque's solution, and let them remain until colorless, but not so long as to cause their disintegration. They must now be soaked for some time in clean water, or better, be allowed to remain for some hours in running water, until the last traces of the odor of chlorine have disappeared. They should then be allowed to stand for a little time in water slightly acidulated with hydrochloric or nitric acid, and then transferred to a very dilute aqueous solution of methyl-green and permitted to remain until the veins have become distinctly stained. They may then be rinsed in clean water and examined. The lignified tissues of the veins are more deeply stained by this process than the rest of the structure, and the mestome strands may, therefore, be readily traced. Such preparations may be mounted in balsam, and if the preparations are not much exposed to light, the aniline stain will persist for years.

6. For tre study of the internal structure of bifacial leaves, take almost any flattened leaf, like that of the Currant, Beech, or American Elm, and place it between two pieces of Elder pith and make thin slices transversely, with a razor, transferring the sections to water as fast as made. By aid of a camel's hair brush, float some of the thinnest ones upon a slide, cover with a cover-glass and examine. Observe the vertically elongated palisade cells beneath the upper epidermis, the loosely arranged parenchyma farther interior, and the somewhat more compactly arranged parenchyma next the lower epidermis. In the lower epidermis, also, a sectional view of stomata may be obtained. Observe that these each communicate with a large intercellular space. Study the sestion of a vein, and observe what kind of bundle it represents, also the position of the phloem, as respects the lower epidermis.

The leaf of the Sago Palm (Cycas revoluta) shows the typical dorsiventral structure, though it is much more woody than are ordinary leaves. This lignification, however, gives rigidity and enables one to prepare sections more readily. Using the method described above, cut sections crosswise and lengthwise of the leaf and parallel with the upper surface. In the transverse section, observe that the epidermis is covered by a thick cuticle, more noticeable on the upper surface, while the upper epidermis is reinforced as well by a lignified hypodermis. The underlying palisade parenchyma is rich in chlorophyll. If leaves that have been kept in alcohol are used, the green color will have disappeared but the plastils remain. The spongy parenchyma is not typical in this view. The stomata are peculiar in structure owing to the "vestibule" in front of each pair of guard cells, Fig. 488. In the longitudinal sections the intercellular spaces in the spongy parenchyma are evident, while the tangential (surface-parallel) section shows the intercellular spaces in the palisade tissue. Examine a surface section from the lower side of the leaf and notice the appearance of the stomata in this view.

By a similar method, the structure of isolateral leaves may be studied. For this purpose, leaves of the Wax-plant (Hoya caruosa), or of the garden Portulacca, may be used. Here, it will be observed, no distinct palisade tissue is developed, and there is little difference of structure between the upper and under sides of the leaf

Now compare with these the leaf of the common White Pine, making thin cross-sections of it and studying it with care. Observe the excessively thickwalled epidermal cells, the well-developed hypodermis, the large intercellular spaces beneath the stomata, the peculiar chlorophyl-bearing parenchyma cells with internally folded walls, the scattered resin-passages, and the pitted paren: 
chyma cells and fibro-vascular bundles, both enclosed within the bundle slieatli. Fig. 489.

7. For the study of sepals and petals with reference to the venation, the presence or absence of stomata, the character and distribution of the coloring matter and the cause of the velvety appearance which some parts possess, the flowers of Tropeolum majus, of Torenia Asiatica, and of the common Pansy may be selected. Cross-sections may be made in the same manner as was directed for ordinary leaves.

8. As a study of fruit, examine common Garden Pepper (Capsicum annuum). This fruit has a thick pericarp enclosing a large cavity divided below into three compartments by a central placenta which bears numerous seeds. In the upper part of the fruit these three compartments become confluent and the placenta changes to the parietal type.

A section through the pericarp displays an epicarp consisting of epidermis having a very thick outer wall (cuticle), a mesocarp composed of several layers of collenchyma the walls of which are suberized, and parenchyma containing drops of oil and red chromoplasts, to which the red color of the fruit is due. The unripe fruit is green in color and in it this layer contains chloroplasts and sume small starch grains. The inner part of the mesocarp is marked by a row of very large, empty cells (giant cells). Then follows the endocarp made up of alternating groups of elongated cells with a wavy outline, one group consisting of lignified sclerotic cells having distinct pores while the adjoining group is thin-walled.

A transverse section of the seed shows a spermoderm possessing a peculiar epidermis. The outer wall of these epidermal cells remains thin while the inner and side walls are excessively thickened and lignified. These thickenings of the inner wall project inward into the cell-cavity in oddly-curved masses, giving rise to intestine-shaped convolutions which are highly characteristic.

The parenchyma of the endosperm is rich in aleurone and fat. The embryo is of similar tissue but more delicate.

Compare surface sections of the outer and the inner epidermis from the pericarp and the epidermis of the seed, staining for lignin.

9. Study the fruit of the Fennel. This is a cremocarp, and is composed of two plano-convex half-fruits termed mericarps. Each mericarp is marked by five obtuse ridges, and between these are from six to eight oil tubes. Each mericarp contains a single seed. A transverse section of the mericarp displays the following structure: The epidermis is narrow, inconspicuous, destitute of trichomes and with few stomata. Enclosed within it is parenchyma tissue con. taining the oil-glands, which are intercellular spaces lined by specially modified cells of a deep brown color. Extending through the parenchyma, and underlying each ridge, lies a vascular bundle, and two more lie near the flat (commissural) surface on the inner side of the mericarp.

The endosperm is hard and is composed of thick-walled parenchyma cells filled with aleurone and fixed oil. The embryo is of similar tissue. 


\section{PART III.}

\section{PHYSIOLOGY.}

\section{CHAPTER I.}

SCOPE OF PLANT PHYSIOLOGY.-PROPERTIES OF PROTOPLASM.

Plant Physiology treats of the functions of plants, or in other words, of the way plants do their work, whether of vegetation or of reproduction. We have already touched upon this subject. In Parts I and II, where we described the mechanism of plants, we had, incidentally, more or less to say about the functions of parts and of various processes that go on in the plant. What was there said need not here be repeated, but it remains still to be explained how the plant, as a whole, performs its functions; how it absorbs, digests and circulates its food; how, through the organs it possesses, it makes use of the chemical and physical forces of nature to maintain its life, to build up its tissues and to reproduce its species.

All the activities which a plant exhibits are due to the wonderful substance, protoplasm, the appearance and structure of which have already been described. While the protoplasm lives the plant goes on building up its tissues, appropriating constituents of the soil and air to repair its wastes, and exhibiting all the profoundly interesting phenomena which belong to life; but when it dies, the intricate structure which it had built up, and of which it formed a part, falls rapidly into ruins, and the complex molecules constructed by its agency speedily decompose into simpler forms.

The properties or attributes of protoplasm, that is, those which serve to distinguish it from all other substances, have already been mentioned in part, but may be more fully stated as follows:

1. Contractility or mobility, the power to change its form by virtue of forces which reside within. 
2. Irritability, or the power to respond to stimuli, such as heat, light, moisture and gravity.

3. Conduction, the power of transporting substances in definite courses through itself; including the absorption and excretion of such substances. Since these substances are necessarily conveyed in aqueous solution, the property of conduction implies also permeability to water, perhaps the most noteworthy single character of living protoplasm.

4. Metabolism, the sum of the changes, chemical and physical, which take place in the protoplasm. Metabolism may be constructive or destructive. Constructive metabolism (anabolism) comprises the building up of complex substances from simpler compounds. Photosynthesis, whereby the active energy derived from the sun is stored up as potential energy in the form of carbohydrate, is an anabolic process. Destructive metabolism (katabolism) comprises the breaking down of complex substances into simpler forms, with the accompanying release of energy. Respiration is a typical katabolic process. We know little of the actual mechanism of metabolism but we have reason to believe that the enzymes secreted by the protoplasm are intimately connected with it and perhaps govern it.

The constructive and destructive processes are going on constantly and, of course, simultaneously.

When, as is usually the case, the constructive process overtops the destructive and more material is added than is given off, we have growth, to which, in turn, development and reproduction are closely allied. If, on the other hand, the waste exceeds the repair, we have decay, which if carried on too far, results in the death of the organism.

These properties not only sharply distinguish living from nonliving matter, but all living protoplasm, both animal and vegetable, possesses them in a greater or less degree. They are interdependent, being closely bound up one with another. Thus the power of contractility lies at the foundation of all movements in animals and plants. Motion is a less conspicuous phenomenon in plants than in animals, but it is no less real. The higher plants show it in the.slow movements of all young and growing organs, in the movements of the living matter within the cells, in the bending of organs toward or from the light, or toward or from the earth, and, more conspicuously, in such movements as those of the upper internodes of climbing plants, of tendrils, of the leaves of some Mimo- 
sas, of Venus' Fly-trap, etc., but they arc destitute of the power of locomotion, or of moving from place to place as the higher animals do. On the other hand, while some of the lower forms of animal life are fixed, some of the humblest of plants are conspicuously locomotive. Moreover, the modes of locomotion are, in many cases, identical with those observed among the simpler forms of animals. The Slime Molds, for example, move from place to place by a slow, creeping process, accompanied by constant changes of form, precisely as in the case of the Amoba and kindred animal organisms, and Protococcus, in one stage of its life history, Pandorina and Volvox move by means of cilia the same as the Infusoria; so do likewise the zoöspores of many cryptogams.

As regards irritability, that which plants exhibit is, of course, less in degree than that which, in the higher animals, rises into sensibility and sensation, but it can hardly be doubted that it is the same in kind.

In animals this property is mainly concentrated in a highly specialized tissue called nerve tissue; hence its phenomena are strikingly evident, while in plants it is diffused through all the living tissues, and is in most cases but feebly manifested. But these differences do not hold when we come to compare the lowest forms of animal life with plants. In the lowest animals there are no nerve cells; the property of irritability is diffused, as in plants. The Dionæa, the Sundew and the Sensitive Plant exhibit a degree of irritability which equals, if it does not exceed, that shown by the lowest animal types. Moreover, every gradation is observed between the irritability of a tendril or a radicle and that shown by the higher animals. The conclusion therefore is irresistible, that the property is fundamentally the same in animals and plants - that irritability is an endowment of all living protoplasm.

Respiration, also, which is essentially an oxidation process, involving the taking in oxygen and throwing off carbon dioxide, is much less evident in plants than it is in animals, though certainly it is no less real. It is a less noticeable phenomenon in plants, partly because, being less active organisms, they waste less rapidly than animals do, and the respiratory process is consequently slower; partly, because it is not carried on by means of a special breathing apparatus, as it is in those animals with which we are best acquainted, but more, perhaps, because in ordinary green plants the process is masked in the daytime by the photosynthesis which goes on at the same time. In the latter process, 
carbon dioxide is utilized for the production of food, in quantities larger than that given off in respiration; and the amount of oxygen which is consumed in respiration is more than counterbalanced by that set free in photosynthesis. For this reason, it is difficult, in the daytime, to demonstrate the respiratory process in green plants. But at night, photosynthesis, being dependent on sunlight, is suspended, while respiration, which goes on continuously, can readily be discovered by appropriate experiment.

The facts of respiration in plants have also been demonstrated by experiments on fungi and other plants destitute of chlorophyll, as well as on seeds, roots and other chlorophylless parts of green plants, and which, therefore, cannot make use of carbon dioxide. Here the consumption of oxygen and liberation of carbon dioxide is found to go on continuously, as in fact it does in all living cells.

All living organisms are also in substantial agreement as legards destructive metabolism. In both animals and plants the energy which is required for carrying on the various phenomena of life is derived from the breaking down of complex into simpler matters by processes of oxidation. In both, complex compounds with much potential or passive energy become simpler compounds with little or no potential energy, and the difference becomes kinetic or active energy in the form of heat, electricity and motion, giving rise to the various activities of the organism. Here lies the significance of the respiratory process. In this transfer of matter from a higher to a lower potential, oxygen is consumed, and gaseous carbon dioxide escapes as one of the products of the change. The organism is therefore in many respects comparable to an engine in which the latent energy of the fuel is converted into work, while during the process, the wood or coal passes into carbon dioxide and water which are no longer available as sources of energy.

The products of metabolism are not always the same in the plant as in the animal, but the differences are only such as can readily be accounted for by differences of habit; indeed, they are scarcely greater than those existing between animals of widely different habits.

The divergence between plants and animals is perhaps widest in the matter of photosynthesis or constructive metabolism. Green plants have a power not possessed by most animals, of raising inorganic matter into complex organic compounds. Thus they derive their sustenance directly from the inorganic world. From 
the interaction of water and carbon dioxide they form a carbohydrate, and then, by bringing this into other combinations, or causing it to pass through other chemical changes, they use it to build up their tissues. This the animal cannot do; he is dependent for his sustenance on already organized matter. $\mathrm{He}$ is, in fact, indebted for his very existence to the constructive work of the plant. But this distinction, which separates with apparent sharpness the chlorophyll plant from the ordinary animal, is not universal. Most parasitic and saprophytic plants, being destitute of chlorophyll, are, like the animal, dependent on organic food materials for their existence. Moreover, chlorophyll plants are not green throughout; a part of the cells contain green coloring matter, but another part, often the larger part of the plant, contain none whatever. These cannot manufacture their own food-materials; they are dependent for their sustenance on the organic matters elaborated by the green cells. In the way they are nourished they agree essentially with animals, yet their origin is the same as that of the chlorophyll-cells with which they are associated; both are products of cell-division from the original germ-cell.

Lastly, as regards the modes of reproduction. Here again the parallelism between animals and plants is very complete and striking. Among both are found organisms which reproduce by cell division, in its various modifications of budding, fission and internal cell-formation. Many animals bud and branch like plants, and some of these approach so nearly to plants in appearance and habit of growth that it requires careful observation to distinguish them. The lowest animals, like the lowest plants, reproduce by cell division only; organisms a little higher in the scale, in each kingdom, reproduce by conjugation or the union of two similar cells; and the highest animals, as well as the highest plants, reproduce by fertilization, or the union of two different cells.

Plants and animals, therefore, resemble each other fundamentally; the protoplasm, which constitutes the physical basis of life of both, has in both the same essential properties. We must regard plants and animals as two branches of a common trunk. The first living being that made its appearance on our globe was probably neither distinctly plant nor animal, but a bit of undifferentiated protoplasm. From such a form, as a common trunk, have diverged the two great branches of the tree of life, each of which, by countless ages of growth, and repeated branching, has given rise to an innumerable and richly varied series of forms. 


\section{CHAPTER II.}

CONSTITUENTS OF PLANTS.-FOOD OF PLANTS.-ABSORPTION OF WATER

AND SOIL SOLUTICNS.-ASCENT OF WATER.-TRANSPIRATION.GASES IN PLANTS.

Constituents of Plants. By dessicating a plant at a temperature too low to cause chemical decomposition, we find it loses greatly in weight, owing to the evaporation of water, which always forms a large part of the substance of the living plant. The amount, however, varies greatly in different plants, and in different portions of the same plant. In aquatics, it often reaches 95 per cent, while in the wood of some trees, it may fall as low as 20 per cent. The average for herbaceous plants is probably not far from 75 per cent. It pervades all parts of the organism. The vacuoles of every protoplast contain water in greater or less quantity. In dry seeds this amount may be very small, but in active and growing parts the protoplasm must have sufficient water to maintain it in a semifluid condition. Indeed, naked cells live only in water or in wet places, and when the protoplasts of any plant are thoroughly dry their life is usually extinct. The wilting of plants when deprived of water is familiar, and the crispness of leaves and other soft parts is due to the water that fills their cells.

The food of the plant must be supplied in watery solution in order to be usable; the waste products are excreted through the same medium, and even the raw materials, both the gases from the air and the soil substances, are brought to the protoplasts in aqueous solution. Growth, also, is dependent on water supply.

If the dried plant be burned, the larger portion of its substance will pass off in the form of gases, consisting of watery vapor, carbon dioxide, etc., while another portion, varying in amount according to the nature of the plant, will be left behind as ash.

Quantitative determination of the ash shows a variation in amount in the different organs of the plant; the ash yield of leaves is greater in proportion to weight than that of woody stems or roots. Therefore ash determinations are of value in establishing the purity of many drugs. However, the character of the soil and other external conditions may influence the amount as well as the composition of the ash, which also varies with the species of the plant; thus samples of Digitalis leaves give an ash content ranging from seven to fourteen per cent, while Henbane leaves normally 
yield from twenty to thirty per cent of ash. Guaiac wood, noted for its hardness and weight, yields not more than three per cent, and Gum Arabic scarcely more, about four per cent.

Qualitative analysis shows the ash of plants to consist chiefly of Potassium, Sodium, Calcium, Magnesium and Iron, among the metals, and Chlorine, Sulphur, Phosphorus and Silicon among the non-metals.

In that portion of the dessicated plant which passed off as carbon dioxide and watery vapor when the plant was burned, we would find the elements Carbon, Hydrogen, Oxygen and Nitrogen. Of these, carbon in the form of charcoal is most familiar. Ordinarily carbon constitutes about half of the weight of the dried plant.

Carbon, oxygen, hydrogen, nitrogen, potassium, magnesium, phosphorus, sulphur and iron are essential to all plants. The first three are the constituents of all carbohydrates, as starch, cellulose, sugar, etc.; in addition to these, protoplasm contains, as essential constituents, nitrogen and sulphur. Potassium and phosphorus, though not properly constituents of protoplasm, are always found in relation to it, and closely associated with the activities of the plant. The former appears to be essential to the formation of starch, and to be concerned, also, in its transfer from one part of the plant to another, while the latter, though its functions are not well understood, enters as an essential constituent into some of the important organic compounds of the plant, as, for example, nuclein and chlorophyll. In the form of the phosphates, it also . promotes the process of metabolism in the cells, and, probably by rendering albuminoid matters more soluble, aids the transfer of these important substances. Calcium is necessary for the higher plants, though fungi can develop without it, and sodium chloride is commonly required by seaweeds.

Among the non-essential constituents is silicon, which occurs in the form of silica, is widely distributed and in some cases is very abundant, as in the Diatoms, Equisetums, and many Grasses, but it appears to have but little physiological importance. Its chief service seems to be mechanical, affording strength or protection to the organ which secretes it.

Among the other occasional constituents of the ash of plants occur Aluminium, Manganese, Fluorine, Bromine, Iodine, Lithium, Barium, Strontium, Copper, Cobalt, Nickel, Tin, Zinc, and several others, but most of them, when present, exist in very small quantities. 
Food of Plants.-The young plant, when it begins to germinate from the seed, is still practically dependent on the food-stores laid up for it by the parent plant. It is incapable, that is, of deriving its sustenance directly from the soil. Its cells, besides containing protoplasm, are heavily charged with nourishing matters, such as starch, sugar, oil and reserve proteins which the protoplasm makes use of for the purposes of growth. It may also, as we have seen, have an outside supply laid up for it in the form of endosperm or perisperm, which serves the same purpose. When the seed is placed in favorable conditions, as when lodged in moist, warm soil, the dormant protoplasm of the embryo becomes active, water is greedily absorbed by it from the outside, the stores of reserve materials are rapidly changed by the aid of ferments present, into soluble forms, and these are applied to the formation of new cells.

As the plant increases in size, sending its radicle into the ground, and its plumule, and perhaps also its cotyledons, into the air, its food-stores diminish pai $i$ passu and are finally exhausted, and the plant now becomes entirely dependent on the soil and air for its sustenance. In the meantime, it has developed rootlets and numerous root-hairs as absorbent organs, and expanded to the air a few green leaves which are to utilize the absorbed materials. It is evident that its food must now be elaborated from the inorganic materials. It must, of course, take in the elements mentioned above. But it no longer has them supplied in such complex forms as those in which they were stored in the seed. On the other hand, none of them, save oxygen, can the plant utilize in the elementary form; and even its consumption belongs largely, if not wholly, to the respiratory rather than to the assimilative process. They are absorbed in the form of compounds. Thus the carbon is derived from carbon dioxide; the hydrogen, mainly, at least, from water; most of the nitrogen from ammonia, ammonium salts and the nitrates; the sulphur from the sulphates; the phosphorus from the phosphates; chlorine from the chlorides; potassium from its phosphate, chloride, sulphate and probably also the silicate; sodium, mainly from its chloride, and calcium, magnesium and iron from the sulphates, carbonates, nitrates and phosphates of these elements.

The carbon dioxide, made use of by the plant in the elaboration of food, is obtained from the air. Oxygen is taken by land plants partly from the air, and partly from solution in the water that permeates the soil. The mineral salts required by plants exist in 
minute quantities in the dust of the atmosphere, yet in proportion large enough to supply the needs of epiphytes; but they occur in still greater abundance in most soils, which is the source whence the great majority of plants obtain their supplies. Besides these inorganic salts there are in most soils various decomposing organic matters, which many plants are able to appropriate; but that these are not absolutely essential to plant life, is shown not only by the

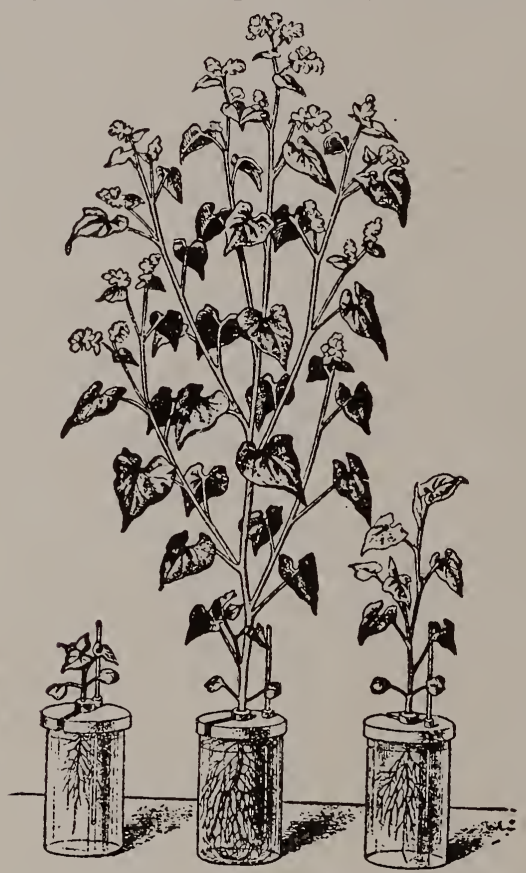

Fig. 492.-Buckwheat plants in water culture. To distilled water in the middle jar were added all the mineral salts needed by the plant. To that on the left, all except potassium; to that on the right, all except iron. In the latter case, the upper, less shaded leaves are white, not green, in the"plant. (Ganong.)

fact that Cactus plants and House-leeks grow on bare rocks, or in arid sands, but also by experiments like the following: If the root of a germinating Bean be placed in a solution containing, in 1,000 parts of water, about two parts each of potassium nitrate, iron phosphate and calcium sulphate, and its leaves be exposed to the sunlight and air, care of course being taken that a suitable temperature be maintained, it will grow nearly, if not quite, as well as if planted in the soil. (See, also, Fig. 492.)

Absorption of Water and Soil Solutions. The great importance 
of an adequate supply of water to enable the plant to live and grow has already been indicated. The amount needed depends upon the species of plant and the conditions surrounding its growth. So we have plants which flourish only in moist places, other's adapted to dry soil; some that do best in the shade, others that need sunshine. Temperature and winds also affect the water needs of the plant. Unicellular plants and those of few cells can absorb water throughout their surfaces; but in larger plants a specialization among the cells is necessary and certain exterior protoplasts are fitted for the purpose of absorbing water from the soil. These cells are chiefly the root-hairs, which are borne just back of the growing tip of the root. Root-hairs are cylindrical in form and each consists of a single protoplast, surrounded by a

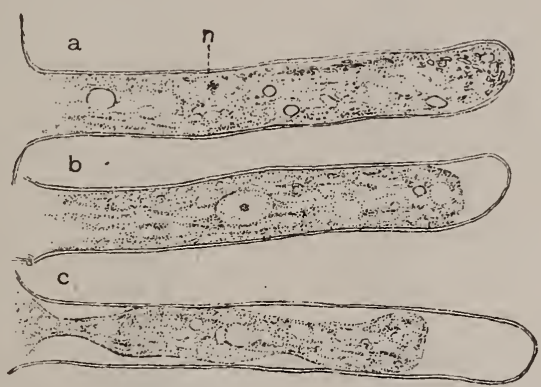

Fig. 493.- Root hairs from the root of a mustard seedling. a, in a state of turgor; b, the beginning of plasmolysis after immersion in weak salt-solution; c, later stage of plasmolysis; n, nucleus. (Gager.).

delicate cellulose wall. The protoplasts contain sugar solution in the vacuoles, and their outer membrane, ectoplasm, presses closely against the cell wall. Fig. 493.)

Having in mind the absolute necessity of water for maintaining life and the dependence of all the vital functions upon it, it is evident that the process by which water is secured is of great importance. It is well known that if two miscible liquids of different densities are placed in contact with each other in such a manner as to mingle as little as possible, they will, nevertheless, after a short time be found to be uniformly mixed. In the same manner a soluble solid when placed in a liquid, without stirring, will in the same way diffuse in time throughout the liquid. The solution of sugar in water is an example of this phenomenon, which is termed diffusion. Gases diffuse in a similar manner. If, between the two miscible fluids or two solutions of different densities, we interpose a porous membrane, the diffusion proceeds as 
before but the current passes more rapidly from the rarer to the denser solution than vice-versa. However, the diffusion continues until a condition of equilibrium is established. Such diffusion through a membrane is termed Osmosis. (Fig. 494.)

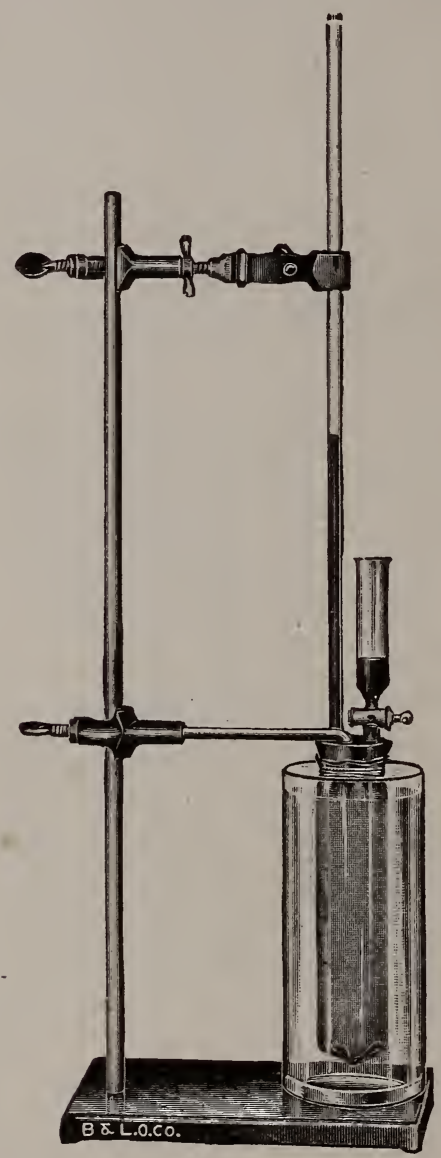

Fig. 494. An osmoscope, for demonstration of osmosis. The osmotic membrane is supplied by a parchment-paper cup, whose top is closed by a rubber stopper through which is passed a piece of barometer tubing and a funnel with stopcock. The cup is filled with molasses and the jar surrounding it with water. As osmosis proceeds, the molasses rises in the tube and when it reaches the top can be dropped back again by opening the stop-cock of the funnel. (Ganong.)

If a membrane in the form of a small cup or bag of soaked parchment is tied, securely on the end of a long piece of glass tubing and a solution of sugar is poured into this tube and the 
parchment then immersed in a vessel of water, the tube being properly supported, a striking phenomenon will be observed; the liquid will rise steadily in the tube, against the force of gravity, and, if the bag is relatively large and the tube of small caliber, the liquid will mount quite rapidly to a height of several feet. Evidently the rise is due to a strong current from the water into the sugar solution, - an illustration of an osmotic process which has an obvious connection with the absorption of soil solutions by root-hairs as well as the rise of the sap in the stem. It will be noted, however, that the intake of the water by the sugar solution is accompanied by a slower but discernible outflow of the sugar solution into the vessel of water. Herein the osmotic power of the root-hair differs from that of the parchment, for the former does not lose its sugar to the soil. The explanation is found in the protoplasmic lining of the living root-hair which permits the passage of water, while preventing the passage of sugar. A membrane of this kind is called semi-permeable, in distinction from a permeable membrane such as parchment. By appropriate chemical treatment, semi-permeable membranes may be made artificially, which have an osmotic effect closely resembling that of the living root-hair.

The root-hair thus acts in a manner not unlike a pump, absorbing water and weak soil solutions by means of its osmotic powers and passing this watery liquid on to the conducting tissues of the plant, where it rises as sap. It will be noted that the roothairs do not lose their sugar to the sap, for the same reason that they do not lose it to the soil, namely, the operation of the semipermeable living membrane, completely surrounding the vacuoles which contain the sugar solution. Consideration of the osmotic properties of the protoplasts involves not only the production of Turgor or fullness, caused by the absorption of water to the fullest capacity of the cells, but also the converse condition of plasmolysis which is produced when the cell loses its water through contact with a denser solution. An illustration of the latter is obtained by treating root-hairs or other protoplasts with a five-per cent solution of common salt, whereupon the outflow of water occurs more rapidly than the intake, since the salt solution is denser than the cell sap, with the result that the protoplasmic lining is loosened from the cell wall and the protoplasm shrinks and ultimately collapses. (See also Fig. 493.)

The absorption of water by the plant is aided in various ways: 
(1) By the branching of the root into numerous fine divisions which develop near their tips great numbers of root-hairs. (2) By the fact that the root-hairs are in intimate contact with numerous earth particles, and even grow fast to them. (3) Each earth particle, even when the soil is dry, is enveloped in a closely adhering film of water, and as each particle is in contact with adjacent ones, the whole virtually forms a complicated network of capillary tubes through which water is drawn from a distance, in proportion as that adjacent to the root-hairs is absorbed. (4) The liquid of the lesser current, from the interior of the cells outward, may be of indirect service, on account of its acid properties, in bringing mineral matters into solution, which are afterward absorbed by the plant.

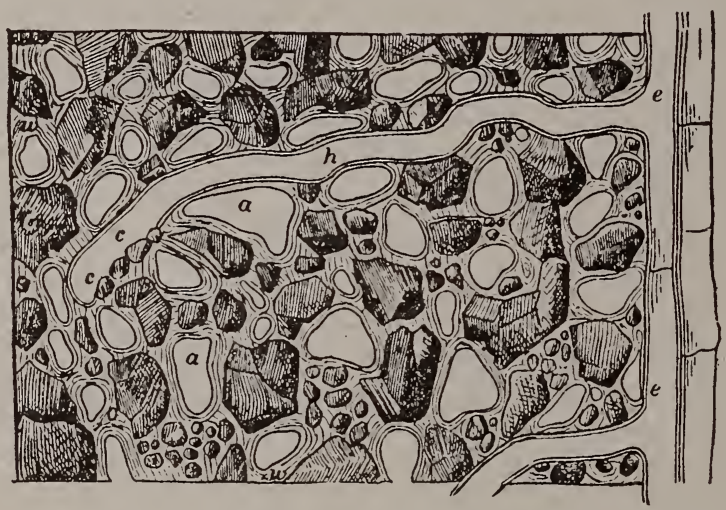

Fig. 495.-Diagram to illustrate a root-hair (h) in the soil, and its relation to the soil-particles, the capillary film of water (w), and the air spaces (a); c, epidermal cell of the root, of which the root-hair is an outgrowth, or branch. (From Gager, after Sachs.)

Ascent of Water. We have already noted that an important function of the fibro-vascular bundles is the transportation of sap. The water supplied through the'root-hairs, with its weak content of soil solutions, is passed inward from the root-hairs and soon reaches the tracheal tubes and tracheids which form a part of the stele of the root. These water tubes are practically continuous throughout the plant, starting near the tips of the smallest branches of the root and extending through the stem and its branches into the veins of the leaves, where they finally end in the mesophyll. Important factors in the ascent of this watery sap are: Root pressure, due to the osmotic action of the root-hairs; this continues even after the hairs are so turgid as to be capable 
of holding no more water, when pressure exerted by their walls forces the water into adjacent cells, from which it streams into the water tubes; Transpiration, or the evaporation of water by the leaves, in a manner to be discussed presently; Osmotic action of the cells of the mesophyll which exerts a pull upon the slender water columns in the tubes; and Capillarity, due to the minute diameter of the water tubes themselves.

Transpiration. While a part of the water supplied to the plant by its roots is used in development of new parts and in elaboration of food, by far the larger amount is evaporated from the leaves and the other green parts-a process known as transpiration, since it implies the giving off of water in the form of vapor. The familiar facts concerning the wilting of leaves and cut flowers are instances of the loss of water through transpiration, followed by the collapse of the turgid cells and resulting in the loss of the rigidity of the soft tissues. The necessity for transpiration is evident, for by its aid the protoplasts secure the soluble mineral substances required in metabolism and which can enter the plant only in very dilute solutions from the soil, and also because only through the evaporation of water can the temperature of parts exposed direc'ly to the sun's rays be kept within suitable limits. A green leaf may often take up many times more solar energy than it can possibly utilize in its constructive processes. If this energy were allowed to accumulate as heat in the leaf, it would be rapidly fatal to the protoplasts. But the heat not employed in metabolism is used in evaporating water and the leaf is thus kept cool. It is noteworthy that the evaporation of water does not take place in epidermal tissues, which, in fact, are especially protected against it, but in the intercellular spaces, the exits from which are guarded by the stomata and the amount of transpiration thus regulated to suit the needs of the plant.

Gases in Plants. The plant is very largely dependent upon gases for the raw material from which its food is made, as well as for its respiratory processes. But the very structure which enables it to have access to the air, whence these gases are obtained, also exposes it to unfavorable conditions of temperature and humidity. Hence the need for a special mechanism which may provide means of securing the necessary carbon dioxide for photosynthesis and oxygen for respiration, while, at the same time, safeguarding the transpiration of water. This protective function is supplied by the cuticle, a waterproof coating over the epidermis, while the 
aerating function is cared for by the stomata and the intercellular spaces whose outlets they guard. In older parts of the plant the cork answers the purpose of the cuticle; but the pores in the cork, the lenticels, though not useless, can scarcely be compared with the stomata. The whole substance of the plant is permeated by a complete network of intercellular spaces, with some part of which every protoplast is in contact. Thus a ready access to the gases circulating through the leaf is provided and through the delicate cell-walls, constantly kept moist by the water held in the vacuoles, these gases, in solution, are supplied to the protoplasts within. Not only does the air which fills the intercellular channels contain varying amounts of oxygen and carbon dioxide, but it is also well charged with watery vapor.

In the living plant these gases are never absolutely quiescent, or in a state of perfect equilibrium. Owing to the metabolic activity of the protoplasts, to the evaporation constantly going on, to the varying temperature of the air, causing expansion or contraction of the gaseous contents of the plant, and to the mechanical agitation caused by the wind moving among the leaves and branches, the gases in the plant are in constant movement, though the movements are by no means regular or uniform.

\section{CHAPTER III.}

ELABORATION OF FOOD.-PHOTOSYNTHESIS.-SYNTHESIS OF PROTEINS. -DISTRIBUTION AND STORAGE OF FOOD MATERIALS.-DIGESTION.SYMBIOSIS.-RESPIRATION.-GROWTH.-INFLUENCE OF TEMPERATURE ON THE LIFE OF THE PLANT,-INFLUENCE OF LIGHT ON THE LIFE OF THE PLANT.

Elaboration of Food. It is, as has already been seen, one of the functions of living organisms to take in materials different from themselves, change them in chemical composition, and appropriate them to their uses. Some require that the materials be in a complex form, others are able to make use of those which are relatively simple. Organic beings cannot create energy; they can only dispense or apply to serviceable ends that which is supplied to them. Animals and chlorophylless plants are dependent for their vitality on the energy supplied by the oxidation of the complex food-mate- 
rials which they take into their bodies, but chlorophyll plants are able to do an additional work. They can make use of the energy of the sun's rays in constructive work. By its aid plants construct, from raw materials supplied by the earth and air, complex organic matter, which is afterward used, partly by themselves and partly by other plants and animals, in carrying on their vital processes and building up their tissues. The utilization of the sun's rays by the plant is accomplished by the agency of the chlorophyll. This green coloring matter, this verdure which in grass and leaf. gives the chief glory to the summer landscape, has other uses than merely to please the eye of man. By means of it, organic beings are able to draw perpetual supplies of power from the sun; without it, it is difficult to conceive how life, save possibly in some of its lowest forms, could exist upon the earth. Since this process is one of synthesis, the putting together of simpler molecules to build up the more complex, and as light is necessary for its accomplishment, the descriptive name Photosynthesis is applied to it. It requires not only the presence of light, preferably moderate sunlight, but also a suitable temperature, an adequate supply of water and free access of air, containing about three parts of carbon dioxide in ten thousand, which is the approximate amount usually present. Evidently it occurs only in the chloroplasts, for only the green coloring matter of these, chlorophyll, has the power of absorbing from sunlight certain rays, chiefly red and blue-violet, as may be demonstrated by a spectroscopic examination of the sunlight that has passed through it. The fact that certain rays are thus absorbed gives us some idea of the source of the energy which is stored up in the process.

The precise function of chlorophyll is to apply the energy of the sun's rays to the production of some form of carbohydrate, which is not starch, but some related body, such as glucose. The exact composition of this carbohydrate, we do not know, nor do we know precisely the process of its formation, or of the production of protein matter from it, but we know it is built up from carbon dioxide and water.

Since the molecules of carbon dioxide and water contain more oxygen than is required in the construction of the molecule of a carbohydrate, a portion of it escapes from the plant as free oxygen. Suppose, for example, the carbohydrate be represented by the formula $\mathrm{C}_{6} \mathrm{H}_{12} \mathrm{O}_{6}$ we may express the formation of its molecule by the following equation: $6 \mathrm{CO}_{2}+6 \mathrm{H}_{2} \mathrm{O}=\mathrm{C}_{6} \mathrm{H}_{12} \mathrm{O}_{6}+6 \mathrm{O}_{2}$. In this case, 
it will be seen, six molecules of oxygen, or as much as is contained in the carbon dioxide used, become free, and it is evident that an amount equivalent to this would be set free in any case, whatever the carbohydrate formed. The equation, however, must not be taken to express the process which actually takes place, for the reactions are probably much more complicated than this would imply. A recently advanced hypothesis, which is favored by many botanists, suggests that the first interaction is between carbon dioxide and water, forming formaldehyde and hydrogen peroxide. Immediately following this first step, the formaldehyde is polymerized or condensed by the action of the protoplasm in the plastid, while, through the agency of an enzyme in the cell, the hydrogen dioxide is decomposed into water and free oxygen. The intervening stages between formaldehyde and carbohydrates are not understood; sugar is the simplest substance so far detected and there is probably a simple hexose such as glucose.

The reducing power which the chlorophyll plant possesses is of the highest significance, so far as the maintenance of life is concerned. Animals are continual consumers of oxygen and generators of carbon dioxide, and if there were no means of setting free again the oxygen they are continually bringing into combination, the atmosphere would soon become poisonous and unfit to sustain animal life; but plants, by feeding upon the carbon dioxide which animals exhale, and restoring the oxygen which they consume, maintain the atmosphere at nearly a constant composition, and the balance of life is kept in equilibrium.

An interesting calculation based on the foregoing equation, indicates that for the production of one gram of glucose, 750 cubic centimeters of pure carbon dioxide are required and that this amount is normally present in two cubic meters of air. And the same volume of pure oxygen will be released. It has been further estimated that 750 cubic centimeters of carbon dioxide are used by a square meter of green leaf each hour on a bright summer day. On this basis and allowing for the cessation of photosynthetic work at night and during the winter, it has been calculated that it requires about 150 square meters of leaf at work during the summer to balance the respiration of a man for a year.

Attention has already been called to the fact that starch is the first visible product of photosynthesis and that it occurs in the chloroplasts during the height of the photosynthetic process and can be detected by the employment of iodine solution, which turns 
it blue (see Fig. 496). Since the formation of sugar precedes that of starch and since an excess of sugar in solution in the cel: sap interferes with the activity of the chloroplasts, it would appear that starch represents the production of carbohydrates in excess

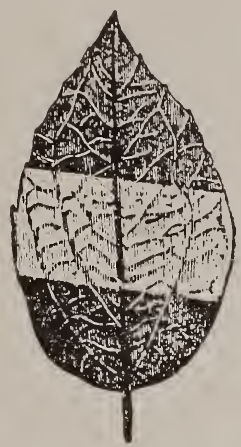

Fig. 496.-Accumulation of starch in the illuminated portion of a leaf. The light-colored portion was shaded by tinfoil and the starch has been stained by iodine. (Palladin.)

of the immediate requirements of the protoplasts and that, stored in this insoluble form, it permits the photosynthetic action to go on freely while other conditions are favorable. Starch, then, is to be regarded as stored carbohydrate, wherever it appears. It is one of the most important of the reserve food-materials of the plant. Stored away in various parts of the vegetable structure, it is so much capital which the plant may draw upon in case of need, to build up new tissues, to repair losses and wastes, or to carry on the exhaustive work of reproduction.

The power to utilize starch for the building up of the tissues is not the exclusive property of the green cells, as is that of the first formation of carbohydrate, but it is possessed to a greater or less extent by all the living cells of the plant. Tissue construction from starch is also not dependent upon light. A potato will sprout in a dark cellar, and the sprouts will continue to grow until they have exhausted all the reserve food-materials in the tuber; but when this is done they die, for they cannot, without the aid of the sun's radiant energy, construct new materials; no new carbohydrate can be formed, as we have seen, in the absence of light.

The Synthesis of Proteins. Proteins contain nitrogen, which carbohydrates lack. While nitrogen exists in abundance in the elemental form, which constitutes four-fifths of the atmosphere, 
yet plants, with possibly few exceptions, cannot utilize or "fix" the free nitrogen of the air but require that it be supplied to them

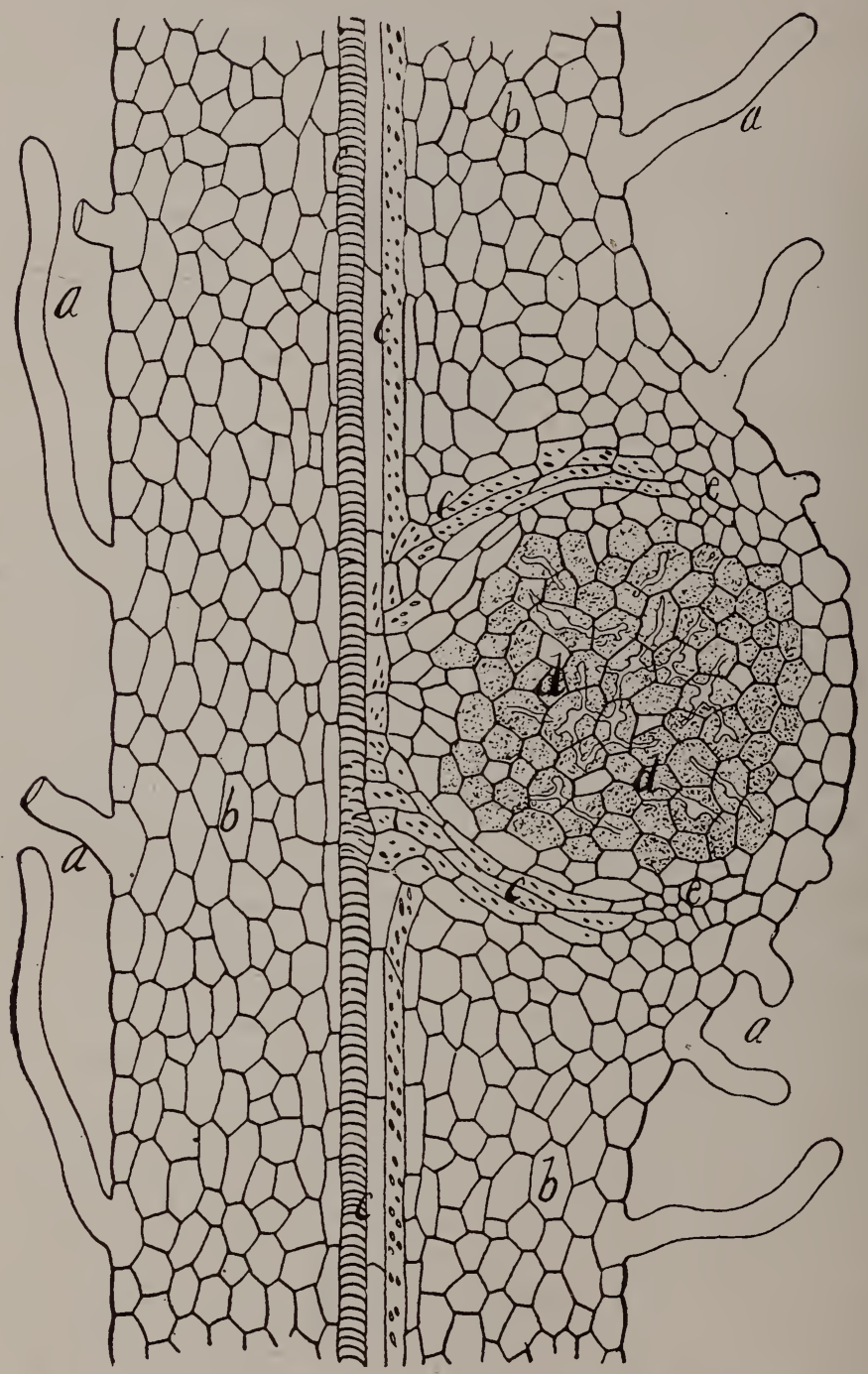

Fig. 497.-Longitudinal section through Red Clover rootlet, showing tubercle formation due to the root nodule microbe, Rhizobium mutabile. The tubercle is only partially developed. $a$, root hairs. These do not develop on the nodule. $\mathrm{b}$, the normal root parenchyma. c, vascular tissue. d, infected area, also showing the infecting strands. The cells are filled with bacteria. e, apical areas, the growing areas of the tuhercle. (Schneider.) 
in combination in the form of nitrates,- chinefly the nitrates of the alkalies or alkaline earths. Green plants use best the nitrates of potassium or calcium; fungi prefer ammonium nitrate. Of two groups of nitrogen-fixing bacteria, Nitrosomas changes ammonia into nitrites, while Nitrobacter oxidizes nitrites into nitrates. The bacterium-like organisms found in the root nodules of the Leguminosæ are able to fix the nitrogen of the air so that it may be utilized by the plant. (Fig. 497.)

We know but little of the synthesis of proteins. Evidently it is independent of the synthesis of carbohydrates, for the fungi, though lacking in chlorophyll, are able to grow and thrive in media containing carbohydrates and certain ammonia salts but destitute of proteins. Apparently light is not necessary to protein construction, which may, therefore, take place in the protoplasts of any part of the plant. The plant is able to store up a reserve supply of proteins, just as of other food products, and to utilize these for food when occasion arises.

As with proteins, so with fixed oils and fats, we know that these are important reserve foods of the plant but we know little or nothing of the manner of their formation. Presumably, they are formed in the protoplasts from starch and therefore, indirestly, from glucose.

The Distribution and Storage of Reserve-Materials. The manufacture of plant food, whether carbohydrate, protein or fat, goes on, under favorable conditions, in excess of the immediate needs of the plant and results in the storage of a reserve supply in various parts, such as fleshy underground stems and roots, seeds, the medullary rays and middle bark of stems, and the region adjacent to the buds. In the histological part of this book we have already considered these various kinds of food reserves. They must be transported in solution from the protoplasts where they were formed, to those where they are to be stored. Thus the starch granules formed in the chloroplasts under the influence of light, undergo solution in darkness, and disappear. Probably this solvent process is in continual operation during the day, but, owing to the fact that the formation is more rapid than the solution, the latter process cannot be directly observed. In undergoing solution, the starch is changed into sugar, which, in its various forms, is a highly diffusible substance. It may thus be conveyed to parts very remote from its place of formation. The 
transformation is brougnt about by the agency of diastase, or some similar ferment.

In the form of sugar, it may be conveyed to growing parts and applied to the construction of tissues, or it may be carried to various parts of the plant, as seeds, tubers, etc., and laid by as reserve material. In this case it is sometimes stored as sugar, for example, in the Sugar Beet; sometimes it is laid up in the form of cellulose, as in the Ivory Palm (Fig. 498) and Nux Vomica;

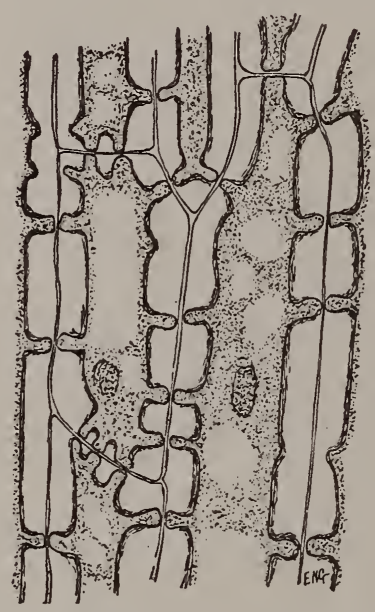

Fig. 498.-A section through the horny albumen of a seed, showing walls thickened by a deposit of cellulose which later is used as food for the seedling.

sometimes it goes to the formation of reserve proteid material, such as aleurone grains, etc.; but it is more commonly either re-converted into starch, or else stored in the form of fixed oil.

When starch, fats or proteins are to be conveyed from the tissues where they are held in reserve to growing parts, they are again brought into solution by the agency of a ferment.

This process is digestion just as truly as that of animals, though in plants occurring within the cell only. However, the glands of insectivorous plants such as Sundew, Venus' Fly Trap and the Pitcher plants closely parallel the action of the alimentary tract of animals. When food has been digested, it is not yet a part of the living material of the plant, but must still be assimilated or incorporated into the living protoplasm. Concerning this assimilation we know but little, for although digestion can be car- 
ried on in a test tube and even carbohydrates can be produced artificially, no one has yet succeeded in producing protoplasm synthetically. Only living protoplasts are able to accomplish this. The dictum, "Omne vivum e vivo" (All life from life) still holds. Of the food thus assimilated, a part is subsequently employed to furnish energy, through the process of respiration, a part is transformed into plastic materials for the construction of the cell walls, a part goes to form various cell contents and secretions, and a part remains as protoplasm itself.

Symbiosis or Mutualism. While green plants are fully equipped to elaborate their own food, many do not depend entirely on their photosynthetic mechanism but supplement it to a greater or less extent, or even replace it altogether, by securing elaborated food from their neighbors or their surroundings. Saprophytic plants obtain their food from partly decomposed or decaying animal or vegetable matter in the soil. Chlorophylless plants are saprophytes, except a few that are parasitic in habit, and most chlorophyll bearing plants make use of decomposed organic material in the soil to a considerable extent; hence the importance of manures and fertilizers, especially to young and rapidly growing plants. It has been shown that not only nitrogenous compounds but even carbohydrates can be absorbed from the soil by green plants.

Parasites absorb food from another plant, termed the host plant. The Dodder is a familiar example. It develops no foliage leaves and forms no chlorophyll. The Mistletoe is typical of another group which are only partly parasitic, as they form chlorophyll and bear green leaves. In fact, it has been pointed out that the Mistletoe, remaining green in winter, actually supplies food to its host during the period in which the latter, having lost its leaves, is unable to supply itself. A similar arrangement exists among other green plants, Castilleja and Comandra are instances of it; both are parasitic on the roots of other plants (semiparasites). The close physiological association of two plants to their mutual advantage is well illustrated in the lichens, composite plants of fungi and algæ. The alga, having chlorophyll, supplies the food and is held in a sort of slavery by the fungus. Such arrangements are termed symbiosis and the plants concerned symbionts. An interesting example is also afforded by certain fungi which live symbiotically with the roots of forest trees and of other highly-organized plants, forming a felt-like mass of fungal filaments around the epidermis of the root or even pene- 
trating the latter and ramifying through its tissues. (Fig. 499.) Such Mycorhizas are found chiefly in soils rich in humus, and the fungal hyphæ answer the purpose of root hairs, especially in securing for their host the organic compounds of the humus. The nitrogen-fixing bacteria, already mentioned, afford further examples of symbiosis. The subject is of great and increasing economic importance.

Respiration in plants, as in animals, consists essentially in the oxidation of organic materials, whereby complex molecules are

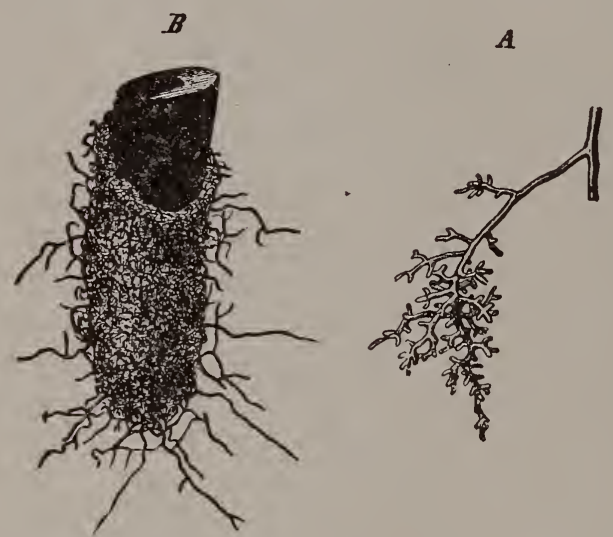

Fig. 499.-Epiphytic mycorhiza of Fagus sylvatica. (A) twice magnified; (B) tip of root partially denuded of the investing mantle ( $x 30)$. (Pfeffer.)

broken down to simpler forms and energy is released. The organic materials consumed in this process are known as foods, a term which is by some extended to include the mineral salts, and even water, since these are needed for the growth and repair of plants. In a more restricted sense, however, foods are comparable to fuel, and like the latter, supply, through oxidation, the energy needed to maintain the vital processes of the plant. This form of destructive metabolism, though often overtopped and largely concealed by the photosynthetic operations is, nevertheless, just as necessary to the life of the plant as it is to the animal. In both animals and plants the end-products of respiration are carbon dioxide and water, which, in the plants, may be given off through the intercellular canals and the stomata, or may be used at once in the converse process of photosynthesis. While this exchange of gases is analogous to the breathing of animals, it is well to dif- 
ferentiate between the two, recognizing that plants have no mechanism comparable to the lungs of animals, and restricting the term respiration to the process carried on in every living protoplast.

Respiration is evidently a chemical process, but a complex one. The oxygen does not unite immediately with the organic material, as in combustion, but is first absorbed in aqueous solution by the protoplast and acts through its agency, with the assistance of an oxidizing enzyme. The actual liberation of energy in the protoplast is very gradual, and while partly manifested as heat and thereby serving to maintain the normal temperature of the plant, it is chiefly employed in the series of transformations which constitute the processes of metabolism already discussed. Not all respiration requires the presence of oxygen, for certain bacteria and fungi secrete a ferment which can break down complex organic compounds, rich in oxygen, with the release of energy and the formation of carbon dioxide and water. Such decomposition is termed anærobic, for air is not necessary for its maintenance. Both ærobic and anœrobic kinds of respiration are forms of fermentation and depend upon the action of enzymes, as already stated.

Growth is the increase in size and substance, either of the whole plant or of any of its parts. It comprises three phases; first, the formation of new parts; second, the enlargement of these new parts to their full size; third, the ripening of these parts for their functions, whatever they may be. Growth goes on during the entire life of the plant, in at least some of its parts. Thus a tree continues to put forth leaves and new stems so long as it lives, even though it may not noticeably increase in size. At times, even, the growth of one part may cause decrease or loss at another place, as shown by the sprouting of potatoes or other fleshy underground stems, where the reserve food supply is consumed and the storage tissues depleted to enable the sprouts to be formed. While in the simpler and smaller plants, growth may occur throughout the plant at one time, in the larger and more complex structures the growth is confined to certain regions known as growing points. Here, new cells are formed through cell division, and this increase in the number of cells, constituting the first phase of growth, is succeeded by the enlargement of the new cells, illustrating the second stage, which, in turn, is followed by the thickening of their walls and the secretion of certain substances in the protoplasts, 
fitting them for their work in the plant, and constituting the third stage of growth.

In order that the cell may grow it must be supplied with nutritive materials, with which to increase its substance as well as to consume in furnishing the needed energy; it must have a sufficient amount of oxygen, for respiration is necessary for the release of energy; it must have an adequate supply of water, for only turgid cells can grow; it must possess or form osmotic substances within the cell, for osmosis is necessary to turgor and therefore to growth, and finally, it must have the proper amount of heat, for the chemical changes constituting metabolism take place only within certain ranges of temperature. When these conditions are met, the young cell, formed at one of the growing points, osmotically absorbs water containing nutritive materials in solution, and the resulting hydrostatic pressure stretches the cell wall, which is rapidly added to by the deposit of new wall material secreted by the cytoplasm. Meanwhile the cytoplasm increases in amount, and thus keeps pace for a time with the growth of the cell, but, presently, vacuoles form in it and are filled with sap. By the time the cell has reached its full size the vacuoles occupy the larger part of it and the cytoplasm is restricted chiefly to the living film lining the wall. The cell wall usually continues to increase in thickness after its growth in area has ceased.

Growth is not uniform in rate; it commonly begins slowly, gradually accelerates its speed and then slows down until it ceases. These changes in growth constitute what is called the "grand period," and are noticeable not only in the cells, but in the larger structures, roots, stems and other plant organs as well. Thus, in roots, the new cells at the growing point (primordial meristem) divide soon after they formed, but those farthest from the apex gradually cease to divide and then pass through the stages above outlined, at length becoming a part of the permanent tissues, in which the power of further growth has been lost. Finally, growth in different cells, tissues or organs of the plant is not uniform. The unfolding of leaves from the bud, the twining of stems and the curving of other parts, is directly due to such unequal turgidity or growth, which will be discussed in connection with movements of plants.

Influence of Temperature on Growth. The vital processes of the plant can only go on within certain limits of temperature. If it 
be too low, the seed will not germinate or the bud unfold, and if it be increased beyond certain limits, life is at first suspended and then destroyed. For each species of plant there is a minimum temperature below which activity ceases, an optimum temperature at which its activities are greatest, and a maximum temperature which cannot be exceeded without stopping the vital processes. These temperatures differ for different plants. Some, as the Redsnow plant of the Arctic regions, thrive at a temperature very near the freezing-point, while others, as the Vanilla plant, cannot flourish except in the tropics.

A very low temperature as well as a very high one may cause the death of a plant, but the facility with which it is destroyed by either will depend upon the amount of water in its tissues. Dry seeds and spores have in some instances been found to endure an extremely low temperature without destruction of their vitality, while the vigorously growing plants of the same species were unable to endure even a slight frost. Similarly, a seed will endure a temperature many degrees higher than will the actively growing plant which springs from it.

It seems evident that when plants are killed by frost, it is on account of the formation of ice crystals by the withdrawal of water from the protoplasm, thus seriously disturbing the equilibrium of the protoplast, and probably setting up destructive chemical changes. The life of a plant that has been frozen may, however, often be saved by thawing it very slowly, when if rapidly thawed it would perish. Much, though, depends upon the habit of the plant. The fact that physical and chemical changes are promoted by heat and that these changes constitute the metabolism of the plant but are controlled by the living protoplasm, no doubt accounts for the importance of heat as a factor in growth. Few actively growing plants can endure a temperature higher than $122^{\circ} \mathrm{F}$. Most of them grow best at a temperature of about $85^{\circ} \mathrm{F}$.

Influence of Light on the Life of the Plant. It has already been shown that green plants are dependent on light for their photosynthetic power, and as all other organisms are dependent, in the long run, on the work done by green plants, light is indirectly essential to all life. Those organisms, however, which do not contain chlorophyll are not directly dependent upon light, hence may thrive in darkness. Give a fungus the decaying organic matter on which to grow, and it will flourish in the blackness of the deepest recesses of a cave. Even those cells of the chlorophyll 
plant which do not contain green coloring matter are able to discharge their vital functions in darkness as well as in the light. Light is essential only to the construction of organic out of inorganic matters; it is not necessary for carrying on the oxidizing changes that take place in the plant. A seed will germinate in absolute darkness, but the seedling will cease growing and perish as soon as it has exhausted the nutrient matters which were stored up for its use. A potato tuber permitted to grow in a dark cellar will apparently make a very vigorous growth, but when the shoots have exhausted all the nourishment stored up in the tuber, growth ceases, and if a comparison be made between the dry weight of the tuber at the beginning, and that of the sprouts and exhausted tuber at the close of the experiment, it will be found that there has been no increase; no new material has been added. Moreover, in plants thus growing in darkness, chlorophyll very rarely develops; both leaves and stem have a blanched appearance instead of the normal green.

Indeed, it is a matter of common observation that plants often grow more at night than during the day. In rapidly growing plants, such as cucumbers or melons, this is especially noticeable after a warm summer night. Not only do plants in semi-darkness "reach out" toward the light and thereby lengthen their stems, but at night photosynthesis ceases and the plant can devote its energies entirely to growth. Again, an excess of light, like an excess of heat, may injure the plant, and the amount of light best suited to the growth of the plant varies with the species. Hence we have shade-loving plants, and for the successful cultivation of some of our valuable crops, such as Tobacco, as well as for Golden Seal and Ginseng, the grower must provide artificial shade.

Light, also, by influencing the growth of the plants, or by the stimulant effects it exerts upon the living matter of their cells, gives rise to certain movements; but these may be more appropriately considered under the subject of the movements of plants, which will be taken up presently.

\section{CHAPTER IV.}

MOVEMENTS OF PLANTS. - LOCOMOTION. - GEOTROPISM. - HELIOTROPISM.-IRRITABILITY.-REPRODUCTION OF PLANTS.

Movements of Plants. Although some plants, like the so-called Rose of Jericho, wither during the dry season and are blown by the 
wind, often to great distances over the sandy plains, but resume their verdure and send forth blossoms when they reach moist soil, or at the advent of the rainy season, strictly spontaneous movements of transition or locomotion are confined, as we have already stated, to the flowerless plants, and are most conspicuous among the lowest forms. They are exhibited chiefly by isolated cells, or by small colonies of cells. This is not because the protoplasm of higher plants has really less activity, but rather because it is mainly confined within rigid walls, so that the young and growing parts, or those, at least, in which the cell walls are thinnest, are the only ones free to move.

Locomotion in plants exists under several modifications, the amceboid, the ciliary, and a creeping motion of ill-defined character, such as that observed in many Diatoms, Desmids, etc. Plants that exhibit amceboid movements are unicellular and destitute of a cell-wall. The movement is a slow, creeping one, accompanied by constant changes of form, or the throwing out of processes resembling the pseudopodia of Rhizopods. It is undoubtedly the most primitive form of locomotion, and is exhibited only by the simplest living forms, or by more complex ones in the earlier stages of their development. It is illustrated in the Myxomycetes, Fig. 506.

Ciliary motion is accomplished by means of delicate hair-like or lash-like projections of the protoplasm, called cilia. In these organs, the ordinary protoplasmic contractility has acquired a high degree of development to suit them to the functions of locomotion, and by their rapid bending to and fro, the cell to which they are attached is propelled through the water in which it lives. While amceboid movement is slow and creeping, this is conspicuous for its rapidity, and is to be regarded as a higher development. It is observed in many mature plants belonging to the lower orders, examples of which are illustrated in Fig. 513 and in the reproductive spores of the great majority of flowerless plants. See Figs. 505, 527, 539, 594.

Morements not Locomotive. First to be noticed among these are the movements of the cytoplasm within the cell. In some cells, for instance those of the stems and leaves of Chara and Nitella, the leaves of Vallisneria, many hairs, such as the stinging hairs of the Nettle, those on the filaments of Tradescantia, etc., the phenomena are conspicuous, and there are few things more wonderful than to watch them under the microscope. Though movements are more obvicus in these examples, there is no doubt that they 
take place more slowly in all living cells. As regards their nature, they are streaming movements in the bands and plates of cytoplasm that cross the cell, or gliding movements of the great mass of the cytoplasm around the interior of the cell, or sometimes crossing from one wall of the cell to the other. In cells containing chloroplasts the latter very commonly assume a different position, in strong light, from that which they occupy when the light is greatly diminished. These changes of position are due to the movements of the cytoplasm in which they are imbedded. In strong light they ordinarily gather along the side walls of the cell, or those which are perpendicular, or nearly so to the surface of the organ, while in dim light or darkness they congregate along the outer and inner walls. In Fig. 500, $a$ is a cell from the spongy

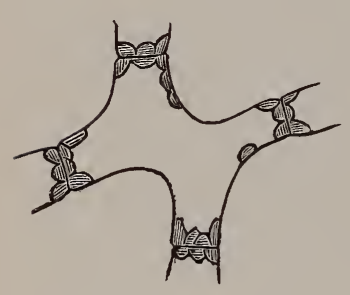

a

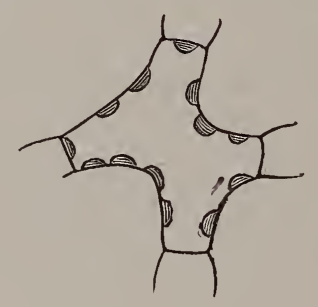

$b$

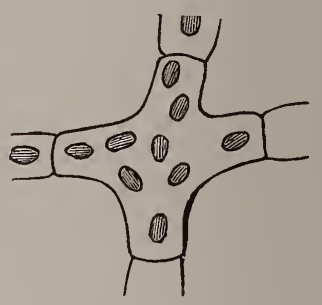

c

Fig. 500.-Cells of the lowermost layer of spongy parenchyma from the leaf of Oxalis Acetosella, seen in a direction at right angles to the surface of the leaf. a, plane position of chloroplasts in diffused light; b, profile position after short exposure to the sun; c, position after longer exposure to the sun. (After Sachs and Stahl.)

parenchyma of the leaf' of Oxalis acetosella that has been exposed to weak or diffused daylight; the chloroplasts are nearly evenly distributed along the walls parallel to the surface of the leaf. $b$ shows a similar cell from a part of the leaf which has been exposed for a short time to direct sunlight; the chloroplasts are here seen distributed along the walls which lie perpendicular to the epidermis. $c$ shows the position of the chloroplasts in a cell which has been exposed for a longer time to direct sunlight. They are now massed together along the walls perpendicular to the surface of the leaf.

Geotropism. By this is meant those movements of growth, the direction of which is determined by the stimulus produced by gravity on the growing organs. It has been ascertained by planting a germinating seed on the rim of a wheel which was made to rotate in a vertical plane with a velocity sufficient to produce a 
considerable centrifugal pull at the circumference, that the stem grew inward toward the center of the wheel, or in a direction opposed to the pull, while the root grew outward from the center, or in the same direction as the pull, indicating that in the ordinary growth of plants, gravity is the cause of the downward trend of the root, and also that of the upward trend of the stem. This conclusion is confirmed by other experiments. The condition of the growing tissues of the root is such that when that organ is stimulated by a constant downward pull it grows downward, while the different condition of the tissues of the stem causes that organ to grow in the opposite direction under the influence of the same stimulus. Under ordinary conditions, other forces, as we shall presently see, more or less modify the action of gravity; still it is mainly this which determines the position of the various organs of the plant with respect to the horizon. It is not only the chief cause of the downward growth of the main root of a tree, and the upward growth of the stem, but it has much to do with the horizontal or oblique growth of the branches and leaves, and if any young and growing organ be by any cause diverted from its wonted direction, it tends to resume its normal direction again when the disturbing cause is removed. An organ which grows directly downward or in the direction of the pull of gravity is said to be positively geotropic; one which grows directly upward, or in opposition to that pull, is said to be negatively geotropic, and one which assumes a position at right angles, or nearly so, to the pull is said to be transversely geotropic. (Fig. 501.)

Heliotropism or phototropism includes movements caused by the stimulant effects of light. The effect may be either to cause the organ to curve toward the source of light, or to bend away from it. In the former case the plant or organ is said to be positively heliotropic, and in the latter, negatively heliotropic or apheliotropic. Plants growing in the open sunshine of course always have one side more strongly illuminated than the other, but owing to the diurnal motion of the earth, the effect of which is to cause the direction of the light to constantly change, and owing also to the slowness with which most organs respond to the stimulus, movements of this character are not ordinarily conspicuous. It would not be difficult to prove, however, that the position which leaves and some other organs assume is due in part at least to the stimulant effects of light. In the case of a few plants, like the sunflower, when they are young and actively growing, the sensi- 
tiveness to light is so great that the leaves and stem follow the sun during his daily course. When, however, we cultivate a plant in such a way that it receives its light chiefly from one direction, as for example when a house-plant is grown in a window, helio-

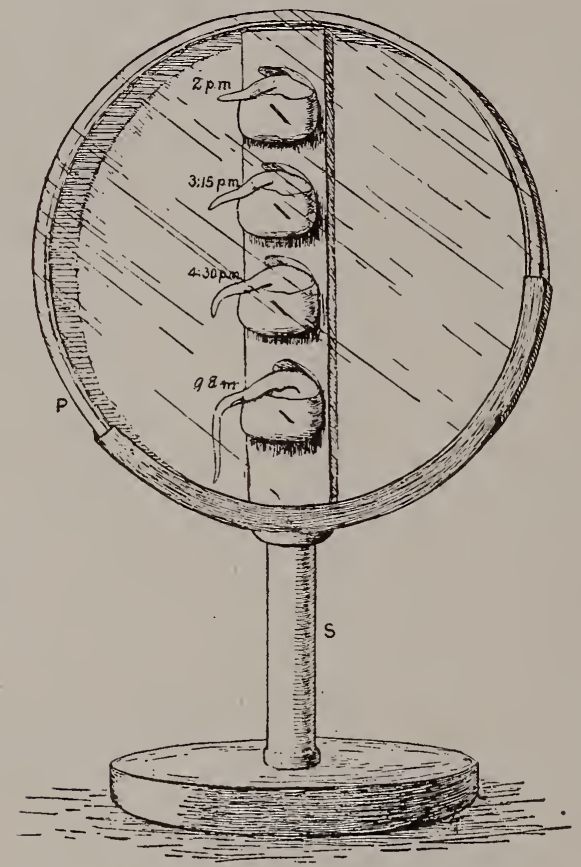

Fig. 501.-Experiment to demonstrate positive geotropism in the root of a seedling of Lupine (Lupinus albus). S, metal stand; P, Petri dish, with edges lined with moist filter-paper. The seedling is pinned to a strip of sheet cork. The four views are of the same seedling at the successive bours as indicated. (Gager.)

tropic movements are very noticeable. The stems, branches and petioles bend over toward the more strongly illuminated side, and the leaf-blades place themselves in a plane at right angles to the rays which fall upon them. If a seedling plant of almost any kind that has an erect habit, be fastened upright in a glass of clear water and placed in a window so that one side is presented toward strong light and the other toward darkness, in a few hours the stem will be bent perceptibly toward the light and the root away from it. The utility of these movements in enabling the plant to adjust the position of its organs in such a manner as to make 
them of the greatest service, is clearly evident. It is not always the case, however, that homologous organs behave alike under the same stimulus. The young shoots of the Ivy, when grown in a window, bend away from the light instead of toward it. But here also the movements are of advantage to the plant in enabling it to bring its rootlets into contact with walls, tree-trunks, etc., and so to climb. The negatively heliotropic movements of the rootlets of this and other root climbers, and of the tendrils of the Virginia Creeper and a few other climbers, subserve the same end.

But movements of heliotropism are not confined to multicellular organs; they are often observed in organs composed of a single cell, or even in unicellular plants. The root-hairs of many plants, for example, are negatively heliotropic, while the spore-bearing hyphæ of some molds are positively so, and if certain minute Algæ, such as Desmids, which are endowed with the power of locomotion be placed in a glass of water having one side exposed to strong light and the other to comparative darkness, it will be found, after a time, that the Algæ have accumulated on the illuminated side of the glass.

Experiment proves that the rays most concerned in producing heliotropic movements are those toward the violet end of the spectrum.

The phenomena of heliotropism are similar, in all essential respects, to those of geotropism, except that the force which causes the movement is light instead of gravity. In the one case it is the direction of a pull, in the other the direction of an ether vibration, which, acting upon the irritable living matter of the cell, brings about changes that cause the organ to place itself in a different position.

It has been found also that movements are sometimes produced by the ultra-red or dark heat rays of the spectrum, some organs moving toward the source of heat, and others away from it. The phenomenon is called thermotropism.

Hydrotropism is a term applied to organs which, like young roots, have been found to curve toward a moist surface. It is a source of great advantage to a plant, since, by means of it, its roots are, so to speak, able to seek out the moisture and avoid the dryer and ordinarily less nutritive portions of the soil. (Fig. 502.)

Circumnutation. This term was first applied by Darwin to the revolving movements observed in the tips of the young and growing shoots, roots and leaves of the higher plants. The movement 
consists in a bowing of the organ successively to all points of the compass, thus causing its tip to describe a figure approximating a circle, or, more commonly, an ellipse. It is caused by the formation, lengthwise of the organ, of a line of growtr: which travels laterally around the organ.

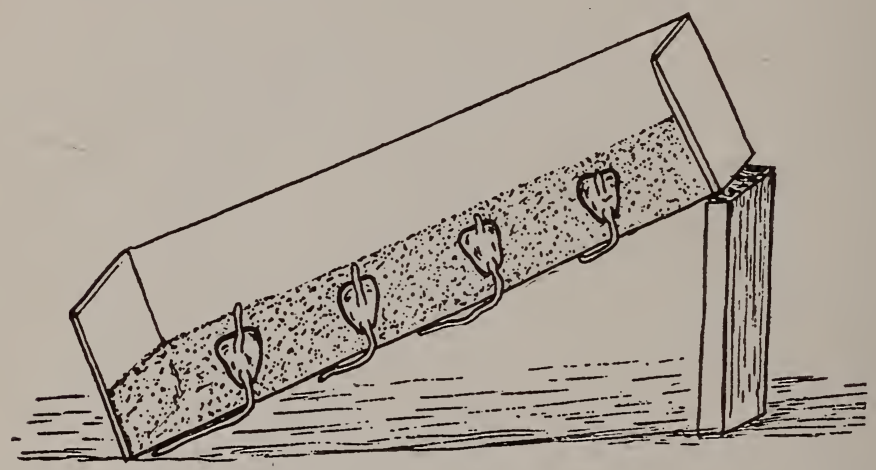

Fig. 502.-An experiment to show the effect of moisture upon the direction of the growth of roots. The box containing moist sawdust in which the Corn is planted has a bottom of wire netting. After the roots grew through the meshes, thus coming in contact with dry air, they changed their direction and grew along the bottom of the box, thus keeping in contact with moisture. (Martin.)

The circumnutating movements of the growing radicle doubtless aid it in penetrating the soil; those of the upper internodes of twining plants are the means by which they climb; the corresponding movements of some other climbers constitute an efficient means by which they are able to bring their climbing organsrootlets, sensitive petioles or tendrils-into contact with a support, and so secure a hold by which they may raise themselves toward the sunlight; and the tendrils themselves are also commonly endowed with circumnutating movements which serve the same useful purpose. This is the most important of all the plant movements. It is also regarded by Darwin as the fundamental form, of which the others are modifications. The phenomena of geotropism, heliotropism, etc., are caused by the modification of this primitive form by external stimuli of various kinds, as gravitation, light, heat, etc.

Nyctitropic, or Sleep Movements. The leaves of Oxalis, of Clover, of the Acacias, and the compound leaves of many other plants, have been observed to assume positions quite different at night from those they occupy during the day. See Figs. 503 and 
504. By day the leaflets are expanded so as to expose as large a surface as possible to the light, but at night they droop and become pendant from the axis on which they are borne, or, in some instances, fold together so as to present to the sky as little surface as possible. These movements are serviceable to the plant in preventing excessive radiation of heat at night. In many plants the combined upper surfaces of the leaves amount to an enormous

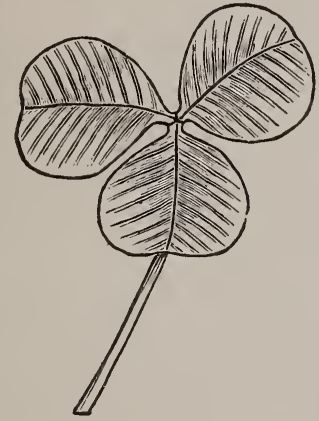

Fif. 503.

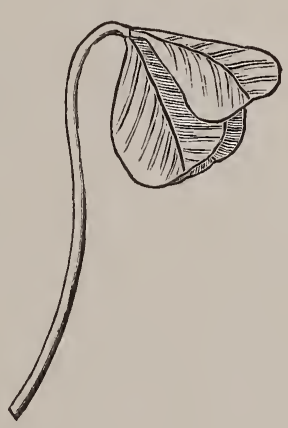

Fig. 504.

Fig. 503.-Leaf of White Clover with the leaflets in their diurnal position. Fig. 504.- Leaf of White Clover with leaffets in the position which they assume at night.

total, and if this be spread out to the sky, on a clear night, the loss of heat by radiation must be very great-so great, in fact, that serious injury to delicate tissues would often result, especially in the case of plants inhabiting dry regions, or open plains. Experiment has proved that when the leaves of nyctitropic plants are pinned out horizontally, so that they cannot close, they do suffer injury from this cause, the leaflets often turning brown and dying after a night's exposure.

The cotyledons of many germinating seeds of dicotyledonous plants exhibit nyctitropic movements in a conspicuous manner. Sometimes they droop at night like the leaflets of Oxalis, while in other cases they rise from the horizontal to the vertical position: closing over the plumule, and thus protecting it, as well as their own upper surfaces.

The flowers of many plants also show similar movements Some open in sunshine and close at night, or in cloudy weather; others, like the Evening Primrose and the White Lychnis, have the opposite habit of opening by night and closing by day. Some 
flower's have very regular hours of opening and closing; for example, according to Linne and De Candolle, the Purple Morning-glory opens at 2 A. M.; the White Water-lily at 7 A. M.; the Blue Passionflower at 12 M.; the common Evening Primrose at 6 P. M., and the Night-blooming Cereus between 7 and 8 P. M. Sometimes the movements appear to be dependent on variation in the intensity of light; at others they seem to be quite independent of it, as in the case of the Goat's-beard (Tragopogon pratensis), which opens in the morning and closes at or before noon.

The opening and closing movements of the floral organs are accomplished, like those of ordinary leaves, by unequal growth, or, sometimes, mainly by unequal turgescence of the upper and under surfaces of each organ, or of its basal portion.

So far as the utility of these floral movements are concerned, they mostly have reference in some way to cross-fertilization. The closing of a flower at night, or when the sky is darkened at the approach of a storm, serves to prevent the wastage of its nectar and pollen by dew and rain, and the closing at night, in some cases at least, prevents the access of night-flying insects that could not be serviceable to the flower in cross-fertilization, while in the reverse case of flowers that open by night and close by day, they are mostly adapted to cross-fertilization by night-flying insects, and it is an obvious advantage to them to protect themselves, by closing, from unserviceable day-flying insects.

Besides these, there are other more conspicuous movements observed in some plants, the use of which is not so well understood. The Telegraph Plant (Desmodium gyrans), a native of India, affords a conspicuous example. The plant has compound leaves, with the leaflets in threes, two small lateral ones, and a much larger terminal one. The lateral leaflets are in constant motion, sometimes moving up and down, and sometimes circularly. The motions are often rapid, particularly in bright sunshine, and they are frequently unequal and jerky.

These movements, as well as those described as nyctitropic, are also to be regarded as modifications of circumnutation.

Irritability. Attention has already been called to various phenomena under this head, such as the sensitiveness to contact shown by the leaves of the Sensitive Plant, by those of Venus' Fly-trap, by the stamens of the Barberry, etc. Phenomena like these are by no means exceptional, though in many cases much less conspicuous. In fact, all the spontaneous movements of plants that have been 
described are evidences of irritability. They take place, that is, in response to a stimulus of some sort communicated to the living protoplasm. The irritant or stimulant influence may be gravita. tion, light, heat, chemical agents, electricity, or mechanical shock, pressure or contact.

If we experiment upon a mass of naked, living protoplasm, such as, for example, the plasmodium of one of the Myxomycetes, we find that a shock causes it to contract, whether the shock be that produced by a mechanical blow, or that caused by a current of electricity. Also, if we strike a young and growing shoot a smart blow, it will respond to the stimulus by slowly bending, the character of the movement it undergoes depending on the force and direction of the blow. Facts like these, and numerous similar ones, justify the conclusion already stated, that irritability is a property common to all living protoplasm.

Among the more interesting phenomena of this kind are the sensitiveness of tendrils and other climbing organs. Take, for example, the tendril of the Passion-flower. When young, it is straightened out and somewhat hooked at the apex, and is carried around in a circle by circumnutating movements. If, in the course of these, it fails to be brought into contact with an object suitable for it to cling to, it soon coils up into a close spiral, loses its sensitiveness, and finally withers away. But if the hook at its extremity comes into contact with the stem or branch of another plant or other suitable object, it is likely to catch upon it, the irritation of the contact causes it to bend around it and clasp it firmly, ultimately, if the shape of the object permits, forming two or three coils about it. The rest of the tendril then forms a double spiral, a part of which winds in one direction, and the rest in the opposite direction, and at the same time its tissues acquire great firmness and elasticity. The spiral coils thus formed serve the double use of drawing the plant closer to its support, and of acting as a spiral spring to prevent it from being torn away by a sudden strain, such as that produced by a gust of wind.

The tendrils of some species of Ampelopsis, as we have seen, are apheliotropic, and by virtue of this property, and since walls, tree-trunks, etc., are nearly always less strongly illuminated than the sky, they bend toward such surfaces. If they are able to reach them, the sensitive tips of the branches are irritated by the contact, and they enlarge, become flattened into sucker-like discs, which, by means of a cement they secrete, become glued to the 
surface, affording them a secure hold upon it. The tendrils and their branches then coil into spirals, and acquire great firmness and elasticity, in the same manner as those of the Passion-flower above described. The plant is thus enabled to climb over perpendicular walls of rock, the sides of buildings, etc., objects to which most tendril- and leaf-climbers are unable to cling. A portion of Ampelopsis Veitchii is shown in Fig. 17, Part I.

Not less wonderful is the sensitiveness of young roots, by reason of which they are able, during their progress through the soil, to avoid obstacles or turn aside from their course to reach supplies of moisture.

Experiment proves that plants, like animals, may have their sensitiveness impaired or destroyed by exposure to anæsthetics like ether, chloroform, etc.

If the Sensitive-plant be placed in a bell-jar under which a little chloroform is permitted to evaporate, its leaves very soon cease to respond to the touch; if the exposure be long continued, it fails to recover sensitiveness, and dies; but if it be of short duration, it soon comes to itself and the possession of its normal powers. This affords another proof that irritability in the plant is essentially the same thing as irritability in the animal.

That all the protoplasts constituting the living portion of the plant are connected by delicate threads of protoplasm passing from cell to cell through the cell-walls, has already been shown. It is reasonable to assume that these threads conduct irritant impulses and serve thereby as a nervous mechanism, rudimentary indeed, but sufficient for the purpose of plants, whose responses to stimuli are exceedingly slow, as compared with those of animals.

Reproduction. All plants possess the power of giving rise to new individuals, and this may take place in either one of two general ways, (1) by some form of cell division, and (2) by the union of two cells, at first distinct. The former mode is called asexual, and the latter, sexual reproduction. In the asexual mode we may distinguish between vegetative reproduction, in which the parent plant throws off or separates from itself ordinary vegetative cells, and spore-reproduction, which consists of the separation of specialized cells called asexual spores. The vegetative mode is represented in a very simple way by many of the low forms of plant life. The Red Snow-plant of the Arctic regions and the Bacteria multiply with astonishing rapidity by the simple process 
of fission. Except that the cells become independent of each other, instead of remaining together to form colonies, the process resembles the cell-multiplication which takes place in the higher plants during growth. In the yeast and its allies, new individuals are formed by budding or by internal cell-formation. Most plants, even those belonging to the higher orders, have the power to multiply vegetatively. The Common Liverwort (Marchantia), for example, produces on the surface of its fronds, little cup-like organs from which rounded masses of green cells are set free to give rise to new individuals; the Tiger Lily reproduces by means of bulblets formed in the leaf-axils; and many plants multiply, as we have seen, by bulbs, tuber's; stolons, offsets, etc.

Spore-reproduction by the asexual process is exemplified in many flowerless plants. The spores which are produced in such enormous numbers on the gills of the common Mushroom, many of the motile spores so commonly produced by the fresh-water Algæ, and the ordinary spores of Equisetums, Club-Mosses and Ferns, are all products of this process. The spores are commonly borne in a special organ, called a sporangium.

There are also two principal modes of sexual reproduction. The simplest is by conjugation, which means the union of two similar gametes or sexual cells.

The second mode is by fertilization, or the union of two sexual cells, or gametes, one of which is usually of larger size and passive, the egg cell; and the other, smaller and commonly active, the sperm cell. This mode is much the more common, and it exists in many varieties. It is the only sexual mode observed in all the higher types of plants. The description of its different modiflcations is, however, reserved for Part IV, where they will be treated of in detail in our study of the principal types of plant life.

There are few things in nature more wonderful than the results produced by fertilization. These, as we well know, are not confined to the immediate effects upon the fertilized cell itself, resulting, in the case of flowerless plants, in the production of one or more spores, or in the case of flowering ones, in the development of an embryo, each capable of giving rise to a new plant; but the effects reach to adjacent organs, and often modify them in a profound manner. When Apple, Pumpkin or Melon blossoms are fertilized, not only do the ovules undergo great changes of structure and size, but the entire ovary walls undergo a very remarkable development. In the Strawberry the influence extends to the 
receptacle, and in the Checkerberry to the calyx, in each case resulting in an extraordinary development of the organ.

In the case of other organs the effect of fertilization may be of the opposite character, namely, to cause their rapid withering and decay, probably by a diversion of nutriment from them to other parts. This is nearly always the case with the corolla, and frequently also with the calyx, as every gardener knows, for if he wishes to prevent, as long as possible, his flowers from withering, he pinches off the anthers before they are ripe, or takes some other means to prevent fertilization.

How far these effects are the result, more or less remote, of the stimulant effects of the fertilizing material on the egg-cell, and how far they are due to the stimulant effects of the pollen-tube on other tissues with which it comes in contact, is not yet known; but there are numerous facts to show that the effects cannot all be due to the fertilization of the ovule.

The question naturally arises, why two modes of reproduction, the asexual and the sexual, should exist among plants.

Comparing the two processes, we find that the asexual mode is simple, and involves little expenditure of energy on the part of the plant, while the other often requires for its consummation complicated machinery, and is an expensive process, a heavy draft on the vitality of the plant. Why, then, does the sexual mode exist? Science cannot yet give a complete answer to this question, but it may be partly answered by observing the difference between the offspring produced by the two processes. That of the asexual presents very little variation from the parental form. If we wish to perpetuate a fine variety of fruit, we do not sow the seeds, but rather multiply the plant by grafting, budding, layering, or by some other process of division, imitating nature's modes of asexual multiplication. Should we plant the seeds, we would probably obtain a variety of fruits, those from different seeds differing more or less from each other and from the parent form, and all, very likely, inferior in excellence to the fruit we wish to perpetuate. Now, variation, which in this instance we wish to avoid, is of immense advantage to plants in their struggle for existence. The physical conditions of the earth's surface are slowly but constantly changing, and by variation, plants are constantly adapting themselves to these ever-changing conditions. Those varieties best adapted to the existing conditions are the ones to survive; those unfitted for them must perish. 
The reason of the greater variation in sexually generated offspring is to be sought for in the double parentage. The offspring of two individuals, or the product of two distinct lines of descent, must occasionally, at least, possess stronger characters-characters better adapted to insure the survival of the individual-than would be possible where the selection is made from one individual, or from one line of descent. Hence, the adoption and continuance of the more costly process of sexual reproduction is not an instance of extravagance on the part of nature, but is rather a wise economy of her forces-an investment which brings a profitable return. (See, also, Chapters XV and XVI of Part IV.) 


\section{PART IV.}

\section{TAXONOMY.}

\section{CHAPTER I.-CLASSIFICATION AND NOMENCLATURE.}

Value of Comparative Study. Taxonomy is that department of botany which treats of classification, or the arrangement of plants in groups according to resemblances and differences. The study of plants in their relationships to each other, distinguishing between differences which are superficial and those which are deeplying, and noting how even the most diverse forms resemble each other fundamentally, is not only of engrossing interest, but one of the most necessary parts of botanical training.

It is not possible, either, to understand any one plant thoroughly, or even any one plant-organ, except by comparative study. We shall get, for example, a far more comprehensive view of the nature and functions of the leaf, if we compare the different modifications of it which occur on the Oak with those of the Pea, the Pitcher-plant, the Venus' Fly-trap, and the Clematis, than we should if we studied any one of them separately; so also we shall know more about the Rose plant if we study it in comparison with the Indian Corn, the Pine, the Fern and the Moss.

Moreover, it is a matter of great interest and importance to the student to obtain a clear conception of the vegetable kingdom as a whole, as a great system of life. Of course, it is not possible, even if it were desirable, within the limits of an ordinary lifetime, to become acquainted with all of the two hundred thousand or more species of plants known to science; but to get some accurate knowledge of the principal types, and of their relations to each other, to become thoroughly acquainted with a few of the representative forms of each type, and to be well acquainted with the flora of one's own neighborhood, is both possible and of great importance to every intelligent man. 
Classification and Naming of Plants. All plants are more of less nearly related to each other, not only in structure and function, but without doubt also genetically or by descent.

The forms that gladden the face of the earth to-day are the descendants of the luxuriant vegetation of the far-off Carboniferous Age, whose remains, in the form of coal, supply the civilized man of the present with fuel to warm his dwelling and drive his machinery; the coal plants, in turn, were descended from the still more remote and simpler vegetation of the Silurian seas.

We shall best understand what plant classification means, the relation of past to present forms, and of present forms to each other, by means of a symbol-by picturing to our minds the system of life as a great tree. This tree began its life in the very remote past, in some very simple form, probably a shapeless bit of living jelly. From this as a common trunk, as time rolled on, branches diverged, which have continued to develop and ramify, and spread wider and wider, until the present time. Some branches, however, that throve for a time, were overshadowed by others, and finally decayed and died; but there still remain innumerable twigs and small branches of the.wide-spreading top; all else is buried in the debris of the past, its outlines only being traceable in the fossil remains which have been preserved to us. On examining the living twigs that remain, we naturally find them distributed into groups and clusters of various sizes. The members of a cluster of twigs we may trace back to a common branch, those of adjacent clusters similarly converge to other branches, and these again converge to larger ones, and so on. It is the business of the systematic botanist to move about among these twigs and branches of the great tree of vegetable life, and discover their real relationship to each other, to trace back the branches as far as possible toward the common trunk.

Thus botanical classification has for its object the discovery of such natural or phylogenetic relationship.

Looking about among the varied forms of vegetation, the botanist finds plants that closely resemble each other in form, structure and habits of growth, and which are distinguished from other forms by some constant structural difference. For instance, the Smooth Rose, wherever found, maintains its essential characteristics, and differs constantly in some particulars from the Dog Rose, the Carolina Rose, the Prairie Rose, etc. Such a form is typified by one of the twigs of our figurative tree, and we call it a 
species. Species often resemble each other, as do the different species of Roses just mentioned. Such a group of species we call a genus, and that to which the roses belong we name the genus Rosa. Just as the species naturally fall into genera, so these, in turn, form higher groups, called families. The genus Pyrus, for example, which contains the Apple, Pear and Quince, resembles the genus Rosa in certain important and constant particulars in which it differs from all other plants. The same is true of the genus Rubus, which contains the Raspberries and Blackberries, the genus Cratrgus, which contains the Hawthorns, and so on. These genera, therefore, are placed together in the family $R$ osacex. Similarly, families which resemble each other form orders, orders are grouped into classes; classes into divisions, and these are the primary divisions of the plant kingdom.

It must not be understood that groups of the same name are always equal either in the sense of being equally numerous in subdivisions or individuals, or in the sense of being marked off with equal distinctness from other groups; on the contrary, they are often very unequal in both senses, as we should naturally expect if we bear in mind our figure of the tree. Some species for example, are rare, they contain but few individuals, and these may not fall into distinct sub-groups or varieties; while others are exceedingly numerous, and may be broken up into many varieties; some species, at least so far as existing forms are concerned, are sharply marked off from other species, while others shade so insensibly into other species, by reason of connecting forms, that it is often difficult to draw the line between them. So it is also with the larger groups. When genera are large, they are often conveniently divided into sub-genera; large families are commonly divided into sub-families, and these, perhaps, again into tribes. Classes, also, are often divided into sub-classes. The terms race and variety are applied to sub-divisions of species.

The relation of the principal groups may be represented in the descending scale as follows:

Division,

Class,

ORDER,

FAMILY,

GENUS,

Species,

VARIETY. 
In the classification of plants in a natural system, no one character or set of characters can be relied upon to the exclusion of the rest. The whole structure and development of the plant should be taken into account, in assigning it to its place in the system. It must not be understood, however, that all characters are of equal value, for this is far from being the case. For example, the cycle number of the flower is of much more value in classification than the shape of the petals, and the structure of the pistil has more significance than the character of the stem, whether it be herbaceous or woody. Moreover, the same characters do not always have the same value in some groups that they have in others. The shapes of leaves, for instance, in some genera afford convenient and reliable means of distinguishing species, while in others, these organs are so inconsistent in form as to be nearly worthless for the purposes of classification. In general, however, it may be said that characters drawn from the reproductive organs are of more value than those drawn from the vegetative, and those derived from structure are of more importance than those derived from the habits of the plant. The Elm and the Nettle, for example, resemble each other in important structural features, and belong to the same natural order, but their habits are widely different, the one being a pernicious pasture-weed, the other, one of the most magnificent and valuable of our forest trees.

In the naming of plants, the binomial plan of nomenclature, first brought prominently into use by Linnæus, is now universally adopted. This consists in applying the name of the genus and following it with the name of the species. According to this plan, the generic name must never be duplicated or applied to more than one genus, but the same specific name may be used again and again, providing it is appropriate and is not applied to more than one species of the same genus. The names, with rare exceptions, are either of Latin origin or latinized from other languages. Solanum tuberosum, for example, is the name of the Potato plant, and Gentiana crinita, of the Fringed Gentian. The usage, it will be seen, is analogous to that employed in naming persons, except that the order of the names is reversed, the generic name corresponding to the surname, and the specific to the christian or given name. The plan has also obviously the same advantages.

As to the origin of botanical names, some have come down to us from remote antiquity. Of these Petroselinum and Mandragora 
are examples. The larger proportion, however, are of modern invention. Some of these were applied because of some useful property, real or fancied, which the plant was regarded as possessing; for example, Scrophularia, because the plant was believed to be useful in scrofula; and Serpentaria, because the plant was thought to be a remedy for the bites of poisonous serpents. Sometimes they were given in allusion to something in the appearance, habit, structure or behavior of the plant. Podophyllum, for example, has reference to the shape of the leaf; Dendrobium, to the epiphytic habit of the plant; Utricularia, to the fact that most of the species have small bladders on the leaves; and Impatiens, to the fact that the ripe capsules rupture explosively when touched.

Very commonly, also, names were applied in honor of some naturalist, either the botanist who discovered or first accurately investigated and described the plant, or some other naturalist of eminence; for example, Linnæa was named in honor of the great Swedish naturalist, and Claytonia in honor of Clayton, an early American botanist.

The first or generic name of the plant is always a noun, and should begin with a capital letter; the second, or specific name, may be either a qualifying adjective or a noun; it is much more commonly the former, and then should begin with a small letter, as in Bartonia verna and Lithospermum canescens.

When the specific name is a noun, it may either be a proper name in the genitive case (corresponding to our English "possessive"), as Carex Asa-Grayi (Gray's Sedge), and Iris Hookeri (Hooker's Iris) ; or it may be a common noun in the genitive, as Polygonum dumetorum (the Polygonum of the thickets), and Salix desertorum (the Willow of the deserts). In the first case, it should begin with a capital; in the second, with a small letter; but names which have previously been used as the names of genera, and have been reduced to those of species, are capitalized, whether they were originally proper names or not; the following are examples: Arisæma Dracontium, Inula Helenium and Aristolochia Serpentaria. In zoology, the principle of beginning all specific names with a small letter is generally accepted; many botanists are adopting the same practice.

In cases where species are sub-divided into varieties, the latter are designated by an additional name, as in the following examples: Glycyrrhiza glabra typica, Prunus Amygdalus dulcis and Chenopodium ambrosioides anthelminticum. 
A recognized rule among botanists is that the name which should finally attach to a plant is that which was first published. The publication, however, to be authoritative, must be accompanied by an accurate description of the plant. By general consent, botanists have accepted the first edition of Linnæus" "Species Plantarum," published in 1753, as the starting point for the publication of both generic and specific names. Of course, it has very often happened in the history of the science, that several different botanists have investigated and named the same plant, and the question which name should be adopted is sometimes a difficult one to determine; some authors will perhaps adopt one name, and others another. To save confusion, in descriptive works it is customary to indicate, usually in abbreviation, the authority for the name. For example, Digitalis purpurea, L., Grindelia cuneifolia, Nutt., and Rhamnus Purshiana, D. C., the abbreviations standing for Linnæus, Nuttall and De Candolle, respectively. When a species is transferred from the genus under which it was first published, the original specific name is retained with its authority; thus our Evergreen Wood-fern was named, by Linnæus, Polypodium marginalis. The newer genus Dryopteris was later split off from the genus Polypodium. Asa Gray reclassified this plant under Dryopteris and we now have it named Dryopteris marginalis (I.) A. Gray.

The names applied to groups of plants higher than genus, have the adjective form, and qualify the word Plantæ understood; for example, Angiospermæ (meaning plantæ angiospermæ, or angiopelmous plants), is applied to one of the main divisions of flowering-plants, and Rosciceæ (meaning plantæ rosaceæ, or rosaceous plants), is applied to the family which includes the Roses, Brambles, and Cinquefoils. Such names begin with a capital.

Names applied to families are commonly made to terminate in ucex, as for example, the names, Rosacex, Valerianaceæ, Rubiaceæ, Caryophyllaceæ and Cucurbitaceæ; but the names Compositæ, Labiatæ and Leguminosæ are exceptions. Order names usually end in ales.

Principal Groups of Plants. We shall treat of the plant kingdom under four great Divisions. These are the

Thallophyta, Bryophyta, Pteridophyta, and Spermatophyta.

It cannot be claimed that this is a strictly natural classification; probably in the present state of our knowledge it is not possible to make one which accurately represents the relations 
of the lower forms of plant life. The future progress of the science will probably show that the Thallophytes include several groups at least as distinct from each other as the Pteridophytes are from the Spermatophytes. But this confessedly imperfect classification may still serve as a scaffolding with which to build the more perfect structure.

It is beyond the scope of this work to give more than a general view of some of the principal types of plants under each Division.

CHAPTER II.

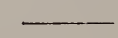 \\ DIVISION I.-THALLOPHYTA. \\ CHARACTERISTICS.—THE MYXOMYCETES.}

The name Thallophyta literally means "thallus-plants," and it alludes to the fact that in this group there is no clear differentiation of the plant-body into root, stem and leaf. It includes a vast number of forms differing widely from each other in structure, appearance and habit, some unicellular and the very simplest and smallest of organisms known, others comparatively complex and of large size. Not even the highest, however, ever possess true roots, though some are provided with root-like organs, called rhizoids, which serve mainly for anchorage or as holdfasts. A few of the higher forms show some differentiation of stem and leaf, but in no case is this distinction as sharp and clear as we find it in most plants belonging to the higher groups, and in the great majority of cases it is entirely wanting. While, also, the internal structure in some of the highest forms attains a considerable complexity, there is never a clear differentiation into epidermal, fundamental and fibro-vascular systems of tissue, such as we find in Ferns and Flowering-plants.

Between the highest and lowest forms of the Thallophytes there are various gradations of structure, and these are not always along the same line of development. Among unicellular forms every gradation may be seen between the simplest possible cells and those of the highest degree of complexity, and among multicellular forms, there are those in which the cells are united in the 
simplest possible way, namely, in a linear series to form filaments, and the cells have so little dependence upon each other that they readily break apart to form distinct organisms." There are those, again, in which the cells are somewhat more intimately united to form cell surfaces or flat expansions consisting of but one layer of cells; and there are still others which by cell-division in three planes, form masses. Among these, also, many gradations may be observed; some are cell-masses in which the component cells are nearly alike, and there is little difference between different parts of the organism; and there are others in which the component cells become developed into tissue-like groups, each differing from the other, but all closely inter-dependent, and where the plant grows into a definite form with a tendency to the development of distinct organs.

In many members of this group, the multicellular forms are, . as in the higher plants, the product of the division of a single cell; in others, however, the mature plant-body is an aggregate of cells which were originally distinct but have come together to form a community.

The great majority of the Thallophytes are at some period in their development endowed with the power of locomotion. Among the lowest forms the possession of this power may last during a considerable part of the life of the plant, while in the higher forms it is confined to the spore-period, or in some is wanting altogether.

Their habits of life are also various; some are aquatic, others terrestrial; some are chlorophyll-bearing, flourishing only in the light and assimilating mineral matters, while others are chlorophylless, indifferent to light, living as saprophytes or as parasites.

They exhibit great variety also in their modes of reproduction. Among some of the lowest forms no mode is known except that of cell-division; in some others sexual reproduction takes place in its simplest form, by the union or conjugation of two similar: sexual cells or gametes; in still others it takes place by the simplest mode of fertilization, which consists in the production of oospores in oogonia, and, lastly, in the highest forms it takes place by that mode of fertilization which results in the production of a fruiting organ, often quite complex in its character, called a sporocarp.

About 80,000 species of Thallophytes are known, of which the Algæ number about 14,000 and the Fungi about 66,000. 


\section{THE MYXomycetes, OR SLIME-Molds.}

These are anomalous plants, so near the border-line between the animal and vegetable kingdoms, that some have regarded them as belonging to the one, and some to the other. They show little evidence of relationship to any other plants. The name is derived from myxos, slime, and mycetes, mold. They are, not uncommon, forming slimy masses amid decaying organic matters, especially decaying wood or leaves, or on forest soil. By far the great majority are saprophytes, while a few, as the curious one that causes the disease called "Club-root" on the Cabbage plant, are parasitic. (Fig. 505.)

During their vegetable life, the typical slime molds consist of a naked, streaming mass of protoplasm known as a plasmodium. This is net-like in structure, containing many nuclei but no chlorophyll. These plasmodia may range in size from a diameter of half an inch to an area of several square feet. They are usually white or yellow in color. They avoid the light, and creep about, amœba-like, among the organic debris on which they feed.

Like the amœba, also, the slime molds surround and engulf particles of food instead of absorbing it in solution as other plants do. At the time of fructification, they creep to the surface and the whole plasmodium takes part in the formation of one or more fructifying masses which may be net-like, irregular and sessile, resembling the plasmodia (plasmodiocarps), or flat and cake-like with rudimentary walls (æthallia), or stalked (sporangia). Each of these, however, produce spores. When the fructification is ripe, it bursts, and very numerous thick-coated spores are discharged, commonly leaving behind a kind of frame-work which, being usually composed of capillary threads, is called a capillitium. When these asexual spores germinate, the naked protoplasts (swarm spores) escape and move about, sometimes at first by means of cilia, and then, losing their cilia, by amœboid movements; more commonly, however, the movements are amœba-like from the very start. The moving particles, after growing considerably, divide, the movements in the meantime continuing. After a while, however, two or more of them come together, and the mass thus formed attracts other of the particles, which move toward it and unite with it, forming a colony of considerable size. The colony then sooner or later begins to develop its fructification. 
But before the fructifying period arrives, if the weather becomes dry and the conditions are not suitable for vegetative growth, the plants become motionless, shrink into compact and more or less rounded forms termed sclerotia, secrete a tough enclosing mem-

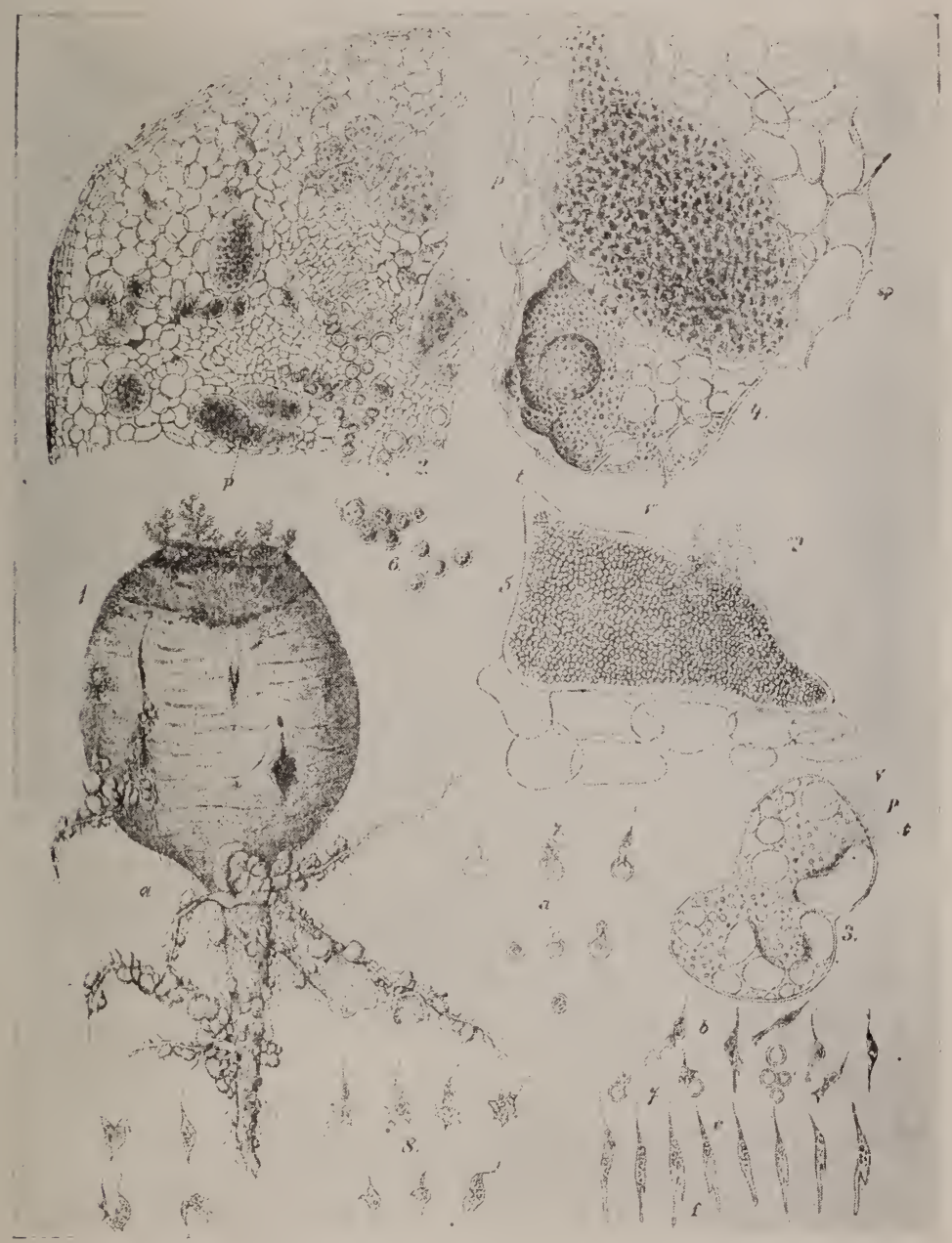

Fig. 505-Club-root of Cabbage, Plasmodiophora brassicae. 1, Turnip with club-root; 2 , section of cabbage root with parenchyma cells filled with slime mold; 3, isolated parenchyma cell, (v) vacuole, ( $t$ ) oil-drops in plasmodium, (p) plasmodium; 4, lower cell with plasmodium, upper cell with spores developing; 5 , parenchyma cell with ripe spores; 6 , isolated ripe spores; 7 , germinating spores; 8, myxamoeba. (Harshberger.) 
brane, and are then able to stand desiccation. When favorable conditions for growth return, the protoplasts escape from their enclosure and resume their activity. Some of the different stages in the development of these plants are represented in Fig. 506.

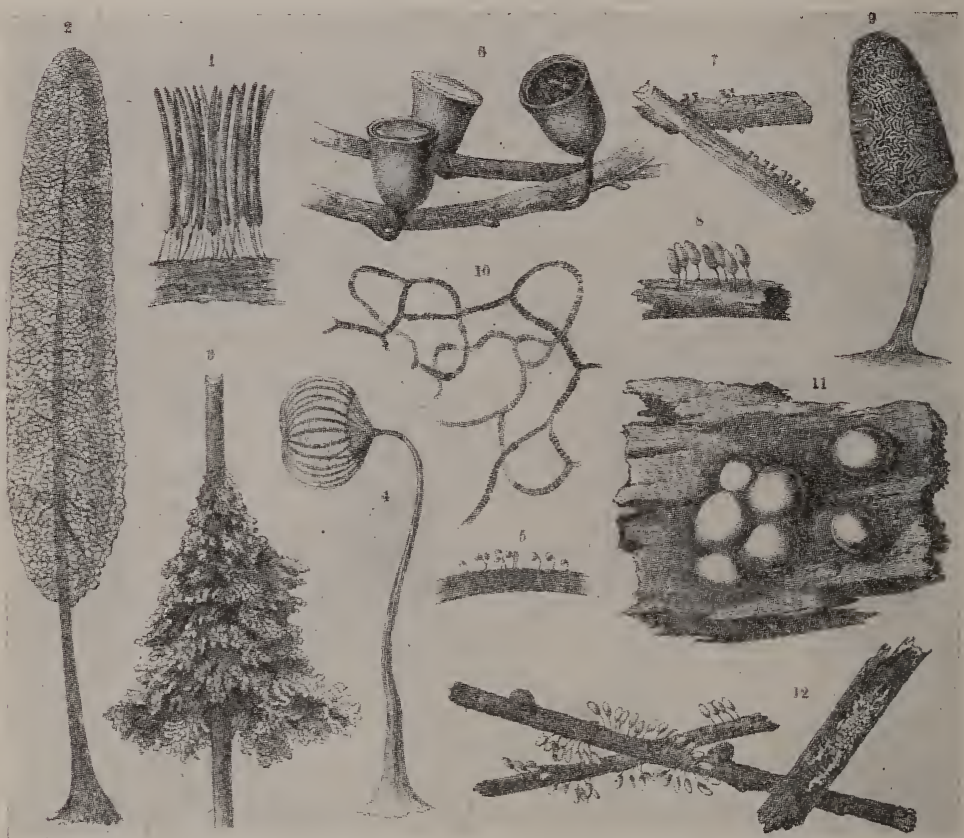

Fig. 506.-Myxomycetes. 1, A group of sporangia of Stemonitis fusca. 2, A single sporangium (x6). 3, Dendritic mass of sporangia of Spumaria alba on a Grass leaf. 4, Sporangium of Dictydium cernuum (x25). 5, A group of sporangia of the same. 6 , and 7 , Sporangia of Croterium minutum $(6, x 25)$. 8. Sporangia of Arcyria punicea. 9 A single sporangium (x10), 10, Part of the net-like capillitium of the same $(x 160)$. 11. Fructification of Lycogala epidendrum on a piece of wood. 12, Leocarpus fragilis; a plasmodium on the right; several sporangia on the left. (Kerner and Oliver.) 
CHAPTER III.-THE SCHIZOMYCETES, OR BACTERIA.

CHAPTER III.-THE THALLOPHYTA (CONTINUED).

\section{THE SCHIZOMYCETES. - THE CYANOPHYCE E. - THE FLAGEILATA.-THE DINOFLAGELLATA.}

\section{THE SCHIZOMYCETES, OR BACTERIA.}

The term Schizomycetes is compounded of two Greek words, meaning literally "fission-fungi," in allusion to the way these plants increase, by fission, and to their fungus-like habits. They are commonly known as Bacteria, and are at once the most abundant and the most minute of organisms. They range in size from 0.1 micron $(1 / 250,000$ of an inch) in diameter up to 20 microns (1/1250 of an inch) in length. It requires for their study, therefore, the highest and best powers of the microscope. They are all chlorophylless organisms, with nearly transparent cell-contents. They are found nearly everywhere, in water, in soil and on plants and animals. In all putrefying fluids, or solutions that contain decaying organic matters, they swarm in myriads. They are, in fact, the inciting cause of putrefaction. Some species of bacteria are harmless or even beneficial to man, while others are the source of some of the most dreaded and most fatal of diseases. A peculiar interest, therefore, attaches to the study of these organisms.

The bacteria agree in having somewhat slimy as well as transparent walls and colorless cell-contents, which are not clearly differentiated into nucleus and cytoplasm. Different species differ considerably in form, size and in conditions and habits of growth. Their usual mode of increase is by fission. In some species the cells, after fission, immediately become independent; in others they remain united for a time to form filaments or chains of various lengths. The rapidity of this cell-division is so great that of some species one individual may produce millions of offspring in twentyfour hours.

Many of the species, in some stage of their development, have the habit of secreting a jelly and increasing rapidly by fission, forming large gelatinous colonies. These are called zoogloa masses. They may be observed as a pellicle on bouillon, or on water in which organic substances are decaying.

Many bacteria are motile, moving about freely, their locomotion being quite different from the Brownian movement. Their motion is usually due to the presence of flagella or cilia located usually at 
the ends of the cells either as a single flagellum or a tuft of them. Other species, perhaps as numerous, possess no flagella and are non-motile.

Under certain unfavorable conditions of temperature, food supply or moisture, some bacteria may pass into a resistant stage in which the protoplasm of the cell shrinks and is enclosed by a heavy inner wall, giving rise to a peculiar spore. These spores are very resistant to heat, cold and dryness, as well as to the action of antiseptics such as would quickly kill the fully-developed bacteria.

Since bacteria live either in or upon their food supply, they have only to change it into soluble form in order to use it. Hence they secrete enzymes, by means of which they are able to assimilate their food, though commonly, as a result of enzyme action, by-products are presently formed which check the multiplication of the bacteria themselves.

There is no group of plants in which it is at present so difficult to define the limits of species. It is difficult to classify them by their forms, because these, under certain conditions, have been found to change into others quite different, and a similar objection applies to classifying them according to their physiological effects, since it has been found that, in some instances at least, an innocent species may, in a different environment, be changed to one of great virulence and, vice versa, a virulent one may be changed to one that is harmless.

Species which closely resemble each other in size and shape may show wide differences in their zoogloa or colony development and in their manner of living. The majority need oxygen for their growth and are termed aërobic, but some grow best away from oxygen and are termed anaërobic. Optional or facultative anaërobes can adapt themselves to either mode of existence.

According to their form, three principal groups of bacteria are distinguished: the coccus or spherical forms, the bacillus or rod-like forms, and the spirillum or spirally bent forms.

In the Coccus group the cells are globular and very small, appearing as minute dots under the microscope. In this group are included the micrococcus, in single, spherical forms exceedingly small; the streptococcus, in loosely united bead-like chains; the diplococcus, in pairs; the staphylococcus, in grape-like clusters, and the sarcina, in cubical clusters. Related to these are the plano- 
sarcina and planococcus, which differ from the preceding groups in being motile.

Among the rod-shaped organisms, the bacilli possess flagella or whip-like cilia and develop endospores, which the bacteria proper do not. The spirilla are motile by flagella at the extremities (polar flagella), but the cells are rigid, while in the spirochæta the spiral cells themselves are flexible.

In the genus Beggiatoa the filaments are thicker and long; in the genus Cladothrix the filaments are branching; and in the genus Crenothrix they are simple but enclosed in a rather thick gelatinous sheath. Some idea of the forms of bacteria may be gained from Fig. 507.

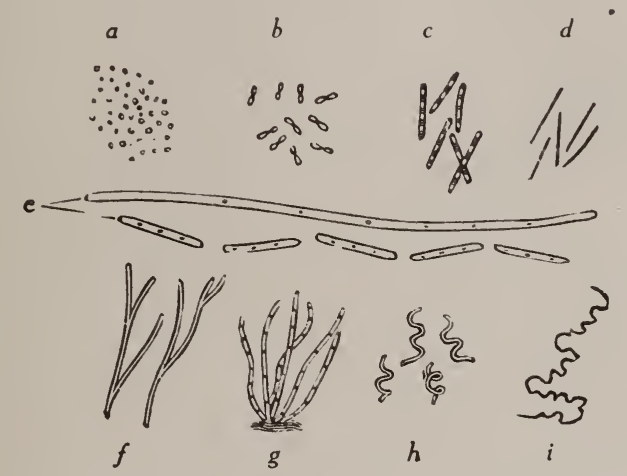

Fif. 507.-Forms of Bacteria. a, Micrococcus, magnified about 1,800 diameters; b, Bacterium termo, magnified about 1,500 diameters: c, Bacillus tuberculosis, magnified about 1,800 diameters; d, Leptothrix buccalis, magnified about 800 diameters; e, Beggiatoa alba, magnified about 600 diameters; f, ("ladothrix dichotoma, magnified about 1,000 diameters; g, Crenothrix Kueliniana, magnified about 500 diameters; h, Spirillum undula, magnified about 800 diameters; $i$, Spirochaete plicatilis, magnified ahout 600 diameters.

A classification according to some striking property or product of the organisn, while not indicating relationship, is of practical value. For example, we may group bacteria as pathogenic or disease-producing, chromogenic or color-producing, zymogenic or ferment-producing, photogenic or light-producing, thermogenic or heat-producing, and saprogenic or decay-producing.

Thus the phosphorescence observed on decaying sea fishes is due to photogenic bacteria; the heating of silage, hay, manure and cotton waste, even giving rise to spontaneous combustion, is due to thermogenic organisms, while characteristically colored colonies are formed on culture media by many chromogenic forms, ranging 
through practically all the colors of the spectrum. Decay-producing bacteria are responsible for the spoiling of poorly preserved foodstuffs and the development in these of the poisonous animal alkaloids known as ptomains. Fermentation bacteria are concerned in the souring of milk, the conversion of cider into vinegar, the ripening of cheese, the curing of tobacco and other important economic operations. Pathogenic bacteria are the inciting cause of a number of infectious diseases, such as typhoid fever, tuberculosis, diphtheria, cholera and leprosy. In their invasion of the human body, very poisonous substances known as toxins are generated, these may be neutralized by the antitoxins formed by the body and resistance to the disease thus secured. Researches along these lines have resulted in the discovery of various methods for combatting or securing immunity from bacterial diseases and have aided in building up the important special science termed Bacteriology, to the text books of which the student is referred for further information on this very important subject.

\section{THE CYANOPHYCEAE, OR BLUE-GREEN ALGE.}

The term is derived from two Greek words, which literally mean "blue-green sea-weed." They contain, in addition to chlorophyll, a blue pigment, phycocyanin, and also, sometimes, reddish coloring matters in their cells. In some species the cells are distinct; in others they are more or less united into chains or filaments.

These plants are distributed widely, forming a bluish-green scum on or near the surface of stagnant water, either fresh or salt, and a slimy bluish-gray coating on wet soil, stones or logs. They are among the simplest plants capable of photo-synthesis and therefore of leading an independent existence. They flourish where there is organic matter, hence prefer sluggish streams and ponds. Some species can withstand high temperatures and thrive in hot springs; others are endophytic in habit, living within the cavities of larger and more highly organized plants. Some become united with Fungi to form Lichens.

The Cyanophycex are of slight economic interest, though at times they become so abundant as to give an offensive odor to drinking water. While in a few of the higher forms of Cyanophycex the protoplast is fairly well organized, in the lower forms there is little or no differentiation into nucleus and cytoplasm and the 
chlorophyll as well as the phycocyanin is diffused throughout the protoplast. Reproduction is entirely by vegetative methods, chiefly cell-division.

The plant body is either an isolated cell, or, more commonly, a group or colony joined to form a filament or a plate. Glœocapsa may be taken as an illustration. Like many of its congeners, it is

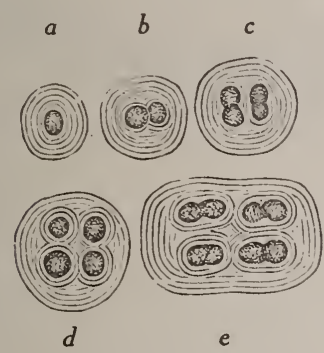

Fig. 508.-Gloeocapsa. a, fully developed cell with gelatinous, greatly thickened and stratified cellwall; b, c, d, e, illustrate mode of multiplication. magnified about 150 diameters.

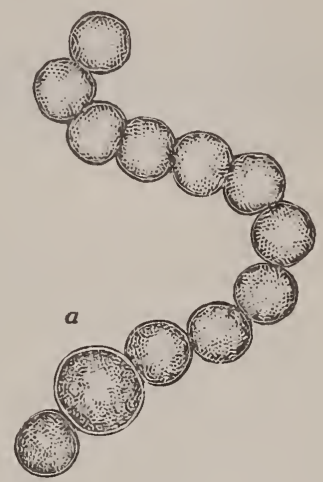

Fig. 509.-Filament of Nostoc magnified about 800 diameters. a, a heterocyst.

found growing on damp rocks adjacent to springs, where they form slimy masses. The cell-walls swell and become converted into a stratified jelly, and in the meantime the cells multiply by fission in different planes within the jelly, forming masses of various sizes. The plant and the way it multiplies are illustrated in Fig. 508. Other forms produce by division in one plane symmetrical, tabular colonies, consisting of four, eight, sixteen, thirty-two or sixty-four rounded cells, held together by a firm gelatinous matrix.

The Nostocs occur as greenish or brownish, tough gelatinous masses, some species of which are as large as walnuts, or even larger. They are common in ponds or slow streams, or on the damp ground bordering rivers, swamps and lakes. If a section be made of one of these masses and examined microscopically, it will be seen to contain, imbedded in the jelly, very numerous serpentine threads, composed of spherical cells loosely attached to each other in chains or moniliform rows. At intervals in the chain of cells occur larger and nearly colorless cells, called heterocysts. Fig. 509 shows one of these threads highly magnified. 
Nostoc is also able to form resting cells, which are larger than the ordinary cells of the plant and are filled with food. Such cells can survive unfavorable conditions, such as cold and drought, and reproduce the plant filaments when conditions again become favorable.

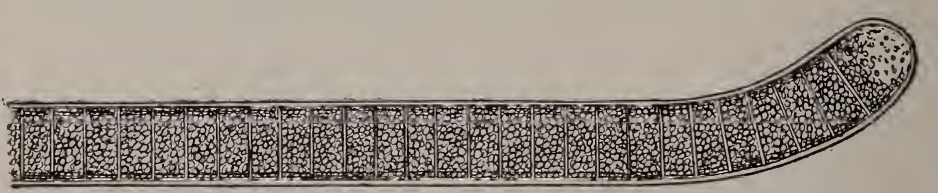

Fig. 510.-Portion of filament of Oscillatoria. magnified about 1.000 diameters.

The Oscillatorias are blue-green or brownish-green filamentous organisms, found abundantly in filthy ditches and ponds. The filaments are slender, usually somewhat coiled, and composed of compactly arranged short cylindrical cells, joined together end to end and provided with a gelatinous covering. The filaments are commonly agglomerated in masses, and each possesses a peculiar writhing or oscillating motion. It is to this that the name, Oscillatoria, is due. Frequently the filaments break up transversely into short segments known as hormogones, each of which, escaping from its jelly-like covering, develops new filaments. Fig. 510 represents a portion of one of the filaments.

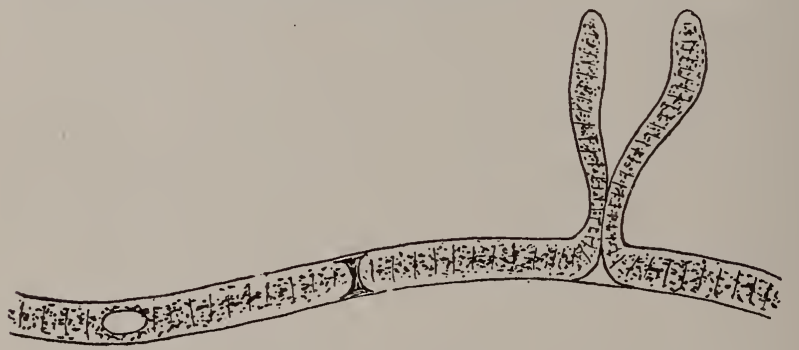
eters.

Fig. 511.-Portion of filament of Scytonema Naegellii, magnified 250 diam-

The Scytonemas are also filamentous greenish or brownish plants, but they branch in a peculiar manner, as shown in the illustration, Fig. 511. Moreover, there are often more than one row of cells side by side, particularly in older filaments, and the cells are enclosed in a thick gelatinous envelope. Besides increasing by ordinary cell-division, they produce heterocysts and hormogones. 
The Rivularias occur as small roundish gelatinous masses of radiating, somewhat branching filaments, each tipped with a transparent whip-like extension. At the opposite or basal end of the filament is a large rounded cell, the heterocyst. The plants, or

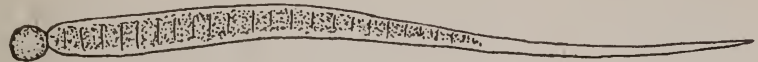

Fig. 512.-Filament of Rivularia dura, magnified about 500 diameters.

rather colonies, either float in the water or are attached to waterweeds, submerged rocks, etc. Fig. 512 shows a filament of one of the species.

\section{THE FLAGLLLATA.}

These are typically unicellular free-swimming fresh-water organisms, microscopic in size and generally regarded as bordering on both the animal and plant kingdoms. They form gelatinous colonies which may be either free-floating or attached, and either globular or branched. They have several characters in common with the unicellular animals (Protozoans); they are endowed with active locomotion by means of fiagella, whence their name; many change their forms like the animal Amoba; they possess contractile vacuoles and red pigment spots, and grade quite perfectly into a distinctly animal group, the ciliate Infusoria. On the other hand, they possess chlorophyll and form thick-walled resting spores, hence are classified with plants. A common flagellate is the Euglena, usually found when fresh-water Algæ are examined under the microscope. Its body is long, slender and one-celled; it bears a long flagellum at one end; it contains a nucleus, several

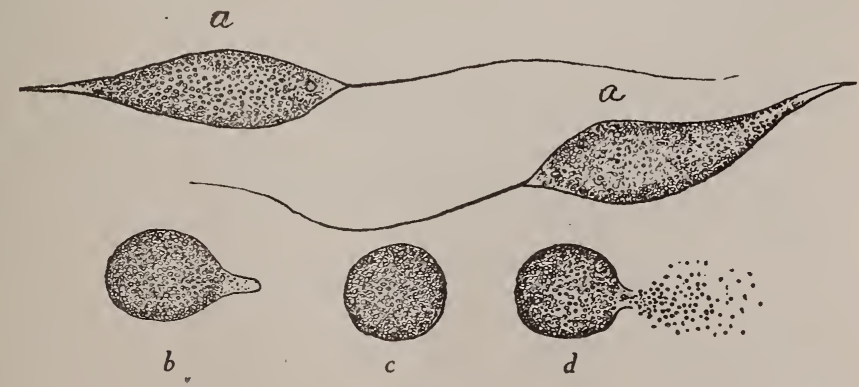

Fig. 513.-Euglena viridis. a, a, motile forms, each provided with a long tlagellum and an "eye-spot"; $b$, one of the cells passing into the encysted stage: $\mathrm{c}$, encysted form: d, encysted form discharging minute swarm-spores. 
elongated chloroplasts, a contractile vacuole and a red pigment spot or "eye spot." Apparently this eye spot is sensitive to light, toward which the organism usually swims. Reproduction is by longitudinal fission, but in the autumn a thick-walled resting spore is formed which survives the winter and in the spring produces one or more new plants. Although ordinarily making its own food by photosynthesis, yet it can also exist in organic solutions as a saprophyte.

Another flagellate, the Uroglena, is of interest because it sometimes collects in water pipes and in decaying imparts an unpleasent oily flavor to water supplies.

\section{THE DINOFLAGELLATA OR PERIDINA.}

Alizd to the Flagellata is this small group of unicellular, freeswimming organisms which are mostly found floating in the sea, and with the Diatoms, constitute an important part of the plankton. (See page 451.) Some are luminous when disturbed and help to form the phosphorescence so often noted at sea. They are unicellular and possess a nucleus, vacuoles and large, brownish-yellow chromatophores. Characteristic of the group is the possession of two long cilia or flagella springing from the ventral surface in a longitudinal furrow. On cilia is directed backward, the other is curved and lies in a transverse furrow. The cell-walls are typically plates of cellulose, perforated and often beautifully sculptured. A few species are destitute of chlorophyll and either live as saprophytes or even surround and enclose their food in the manner of the Amœba. Reproduction by cell-division and by swarm spores is the rule. In the highest types a simple form of sexual reproduction has been met with.

\section{CHAPTER IV.-THE THALLOPHYTA (CONTINUED).}

\section{THE DIATOME ZE.-THE HETEROCONT E.}

\section{THE CHLOROPHYCE $A$.}

\section{THE DIATOMEAE, OR DIATOMS.}

The Diatoms are peculiar in the great variety of their shapes and in the strikingly beautiful sculpturing of their walls. They are in all reality unicellular, though sometimes united in colonies, 
and all are microscopic in size. They possess chlorophyll, but the green color is more or less obscured by the presence of a peculiar brown coloring matter. Many are endowed with the power of locomotion, the movement being a gliding one, but some are pedicelled and attached.

The great distinguishing feature of the group, however, is the peculiar structure of the enclosing membrane. This is a silicious box consisting of two pieces fitting one into the other, like the parts of a common band-box. The two valves, as the parts of the box are called, are usually alike, excepting that one is a trifle larger than the other, so as to fit over it, and both are beautifully and often very delicately and regularly sculptured.

Not less interesting and strange is their mode of reproduction. This takes place by fission, and in many species also sexually by conjugation, but the processes are peculiar. When the process of fission begins, the valves separate slightly from each other, the protoplasm divides into two portions, and each secretes for itself a new valve to fit within the old one that lies adjacent to it, and the plants thus become independent.

It is evident that, as successive divisions take place, there will be a gradual reduction in the size of the plants, since the rigid valves once formed are not capable of expansion; so the process only goes on for a certain number of generations, when it is interrupted by the formation of what is called an auxospore. This may be formed asexually, simply by rejuvenation or the escape of the protoplasm from the old valves, or it may be the result of the conjugation of the protoplasm of two plants and the discarding of the old valves. In either case the new valves which are secreted are of the same size as those with which the first generation started.

Diatoms are exceedingly abundant plants, both in individuals and in species, being found in nearly all waters, both salt and fresh, that are reasonably free from putrid matters. They occur in the tropics, in springs where waters are so hot that few other forms of life are able to survive, and in the ice-cold waters of the polar seas. About 6,000 species are known. Some of the different forms are represented in Figs. 514 to 518, inclusive.

The flinty coverings or valves of the diatoms remain after their living substance is decayed. They even withstand incineration or the attack of strong acids. So-called "diatomaceous earth" is the 
fossil remains of diatoms and is used as a base for many polishing powders as well as for a filtering medium.
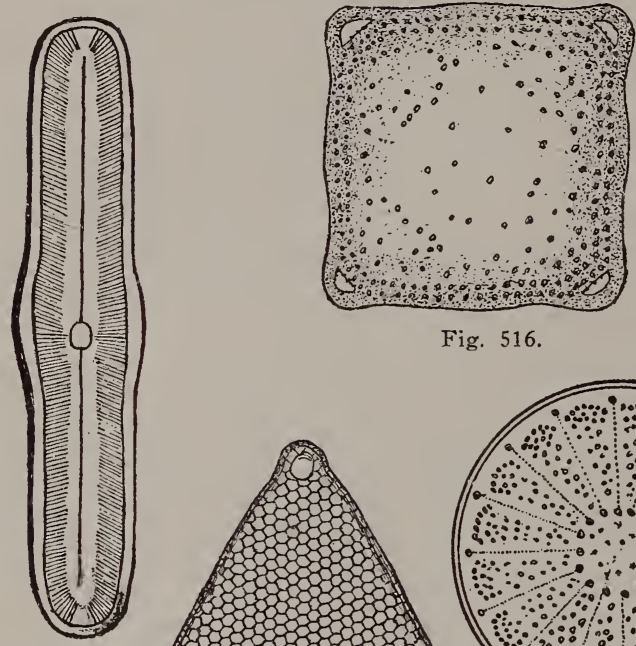

Fig. 516.

Fig. 514
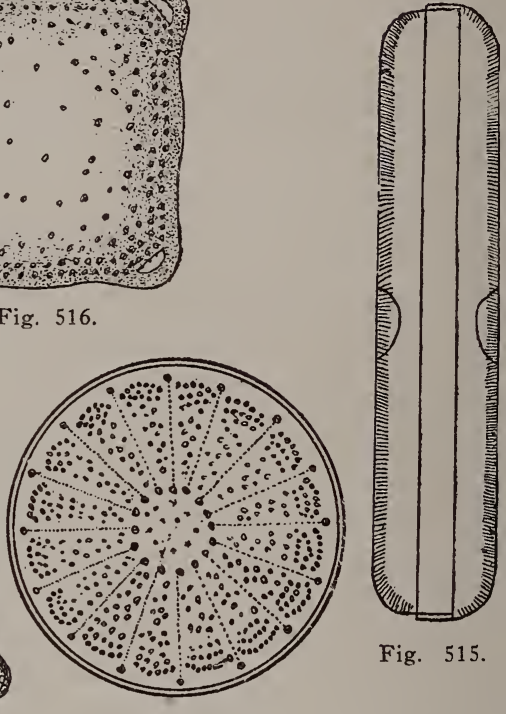

Fig. 515.

Fig. 517.

Fig. 518.

Fig. 514.- Side view of valves of Pinnularia dactylus, magnified about 300 diameters.

Fig. 515.-Front view of the same diatom, showing the way the valves fit together. eters.

Fig. 516.-Valve of Triceratium intermedium, magnified about 500 diam-

Fig. 517.-Triceratium favus, magnified about 150 diameters.

Fig. 518.-Cosmiodiscus Normanianus, magnified about 600 diameters.

THE HETEROCONTAE OR CONFERVA.

This is a small group of green algæ, growing on wet soil or in water, and characterized by a peculiarity of their zoospores, which have cilia of unequal length. They are of little or no economic importance. The lower members of the group are related to the Flagellates, while the higher forms, such as Conferva, resemble the Chlorophyceæ and were formerly included therewith.

Conferva consists of slender, unbranched filaments and is widely distributed in fresh water. Its chloroplasts are yellowishgreen and oil-forming. Reproduction is by the fragmentation of the filaments or by the production of zoospores. 
THE CHLOROPHYCEA, OR GREEN ALGAE.

This group includes quite a variety of forms, some simple in their structure, others comparatively complex. None of them possesses a soluble blue or brown coloring matter in the cells, though the spores of some, when ripe, have portions of the chlorophyll modified into a substance chemically similar to the latter substances, but having a red color. Most

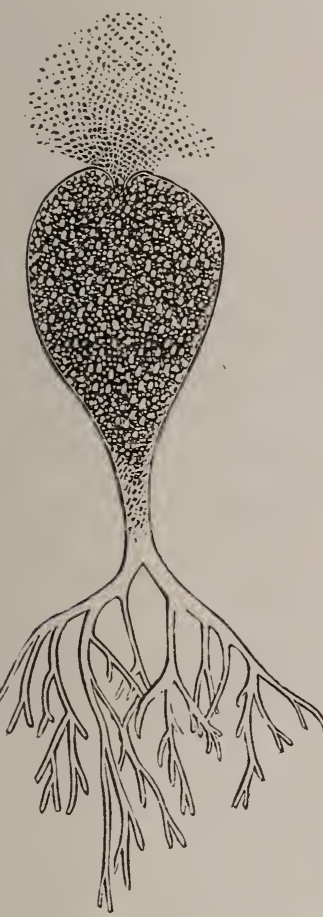

Fig. 519.-Botrydium granulatum, in the act of discharging its zoospores. Mag. nified about 20 diameters. After Wolle. of the forms reproduce not only asexually by some mode of cell-division, but also sexually, either by conjugation or by the production of oogonia or antheridia resulting in the formation of oospores. They present wide diversity in size, shape and habit. Many beautiful forms occur in fresh water and, being easily collected, are favorite subjects of study. About nine thousand species are known, usually grouped in five orders: Siphonales, Protococcales, Volvocales, Confervales, Conjugales and Charales.

Siphonales. These include both marine and fresh-water forms. One of their most distinctive characteristics is the fact that, though often complex in form and attaining a considerable size, they are not divided into cells; each plant, in fact, may be regarded as a single highly elaborated cell. In a few species no sexual reproduction is known, in others it takes place by conjugating zoospores, and in still others, by fertilization and the production of oospores.

Among the simplest forms of the group are the Botrydiums, one of which is represented in Fig. 519. The lower portion forms dichotomously branching root-like bodies or rhizoids, which penetrate the mud and serve for anchorage, while the balloon-shaped upper portion rises into the water above. This is filled with granular protoplasm and contains much chlorophyll. .

The plants multiply in several different ways. When the ponds 
in which they grow begin to dry up, the protoplasm descends into the rhizoids and there breaks up to form numerous rounded cells which are capable of enduring desiccation. When favorable conditions return, these either germinate and form new plants or immediately develop into sporangia.

The upper or bulbous part of the plant, when mature, also becomes a sporangium. The spores discharged by this may be of two kinds; one kind, the zoospore, has but one cilium, and after moving about for a while it comes to rest and develops immediately into a new plant; the other kind, the gamete, possesses two cilia and fuses with another similar gamete (isogamete), forming a zygospore, and this, sooner or later, develops into a new plant. This figure shows the plant in the act of discharging its zoospores.

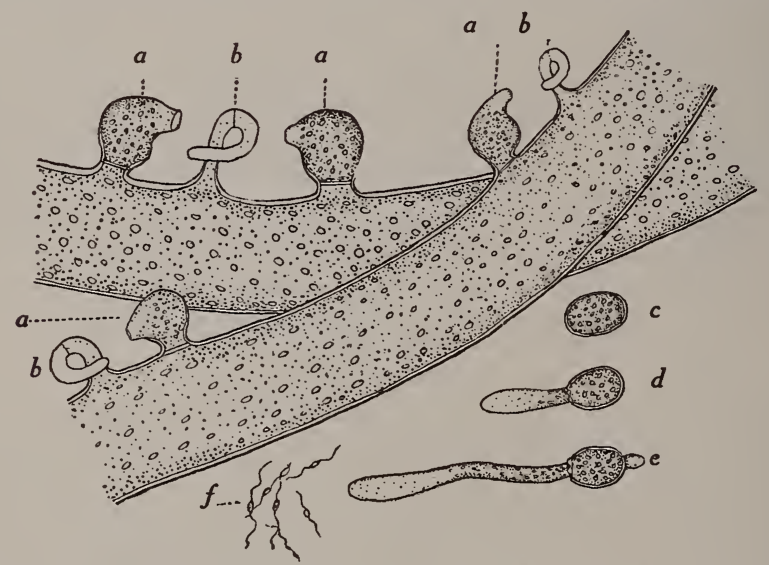

Fig. 520.-Portions of fertile filaments of Vaucheria sessilis, showing mode of sexual reproduction. a, a, a, a, oogonia; b, b, b, antheridia; c, "oospore; $d$, $c$, germinating oospores; $f$, sperms. Magnified about 175 diameters.

The Vaucherias, or Green Felts, occur as dense, felt-like masses in wet soil, on dripping rocks adjacent to springs, and in other similar situations.

The individual filaments in some species attain a length of eight or ten inches. They root in the mud by means of rhizoids similar to those of Botrydium, and the filaments are more or less branching. Besides chlorophyll-bodies, they contain numerous oilglobules distributed through the interior of the tubes. They reproduce asexually by rather large, multiciliate and multinucleate zoospores, formed by the separation of the ends of some of the branches. 
Their mode of sexual reproduction is illustrated in Fig. 520. The oogonium, it will be seen, is an oval body borne laterally on the filament, and cut off from it by a partition. The antheridial branch, which is located adjacent to it, is slender and curved, a transverse partition is formed near its middle, and in the terminal cell thus produced are developed an immense number of very minute, ciliated sperms, which are discharged by a rupture of the cell-walls. Some of them find their way through the terminal opening of an oogonium, and fertilize the contained egg cell. It then develops into an oospore, which, after resting until the succeeding spring, germinates.

The species of Bryopsis, with beautiful feathery fronds; the Acetabularias, curious umbrella-shaped marine forms; and the Caulerpas, sea-shore plants, sometimes attaining a length of several yards, and having rhizoids, creeping stems and leaf-like branches, looking wonderfully like the much more highly organized multicellular plants, which have roots, stems and leaves, are also classed with the Siphonales.

The Protococcales include a number of forms of unicellular, non-motile, green, water algæ, some of which occur as isolated cells, while others consist of cells once distinct, which have grouped to form colonies. These colonies have a definite shape peculiar to the species, and are called cœnobia. Except on reproductive cells, cilia are lacking and the plants are not endowed with the power of locomotion, in this respect differing from the Volvocales. Celldivision occurs usually by internal cell-formation, and the cells always at first become distinct from each other, though they sometimes unite afterwards, as we have seen, to form cœnobia. They reproduce asexually by means of zoospores, and most of them also sexually by the conjugation of zoospores of smaller size.

Some forms live in the interior of other plants, though not parasitically. One of these, called Chlorochytrium Lemnæ, grows in the intercellular spaces of the thallus of the common Duck-weed, Lemna trisulca. Others enter into the formation of Lichens.

Pleurococcus or Protococcus is regarded as the simplest plant of this group. It consists of a single, spherical, non-motile cell, and forms thin, green coatings on damp earth or walls or on the trunks of trees. It has a definite wall, enclosing a lobed chloroplast and a well-defined nucleus. It reproduces by cell-division only. (Fig. 521.)

Scenedesmus, a common fresh-water Alga, forms simple colo- 
nies with the cells, usually four in number, arranged in a row. Its reproduction is effected by the division, lengthwise, of each cell into four daughter cells which, on escaping from the parent cell, form a new colony. (Fig. 522.)

Among the forms which produce mole complex colonies are the Pediastrums and Hydrodictyon. The former are free microscopic forms, found abundantly in most fresh waters. The shapes of

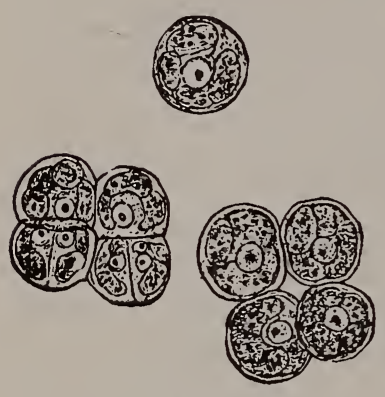

Fig. 521.

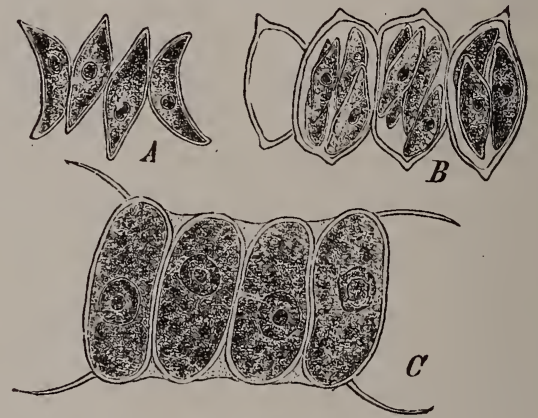

Fig. 522.

Fig. 521.-Pleurococcus vulgaris. Above, a single plant consisting of a single cell with a definite wall, well defined nucleus, and arge lobed chloropast; below, left, plants dividing; and below, right, a group of four separate plants. x 540. (After Strasburger from Martin.)

Fig. 522.-A, Scenedesmus acutus. B. the same, undergoing division; C, Scenedesmus caudatus. (After Senn, x 1000, from Strashurger.)

the colonies are roundish or stellately discoidal. Usually the central cells of the disc are polygonal, and those constituting the outer circle are commonly two-lobed.

The contents of the cells after a time form small ciliated zoospores, which move about for a time on the interior of the cell. They then break through the membrane and escape; they soon come to rest, however, and divide again and again to form a colony, which at first consists of loosely and irregularly aggregated masses of cells. The colony now becomes enclosed in a mass of jelly secreted by its members, and then the latter arrange themselves in one plane as already described. Instead of zoospores, gametes, similar in form but smaller and more numerous, may be formed. These being alike (isogametes) form zygospores and each zygospore upon germinating, develops into a new colony. Fig. 523 represents a plate-like colony of one of these plants.

The Hydrodictyon, or Water-net, is an interesting fresh-water alga, not uncommon in ponds, lakes and slow streams. In the mature form of the plant the cells are arranged to form a quite 
regular net-work, which takes the shape of an elongated purse or bag, sometimes attaining a length of a yard or more. These float freely in quiet water with one end buoyed up by the bubbles of gas caught in it. Asexual reproduction takes place as follows: In the interior of some of the cells composing the mature net, the protoplasts break up and form a multitude of zoospores. These move about actively for a time within the parent cell and then arrange themselves to form minute new nets, which are finally set free by the rupture or solution of the enclosing walls, and in the course of a few weeks attain a size similar to that of the parent colony.

In the sexual mode, numerous similar, but very much smaller ciliated gametes are formed in some of the special cells of the colony; these escape through the mother cell wall, pair and fuse, forming a zygospore. The latter produces zoospores which, after a resting stage, form new nets.

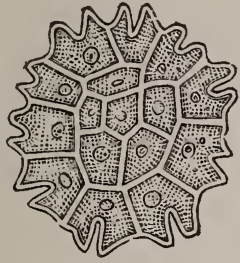

F i g. 523.-Pedias trium Boryanum, mag. nified 350 diameters.

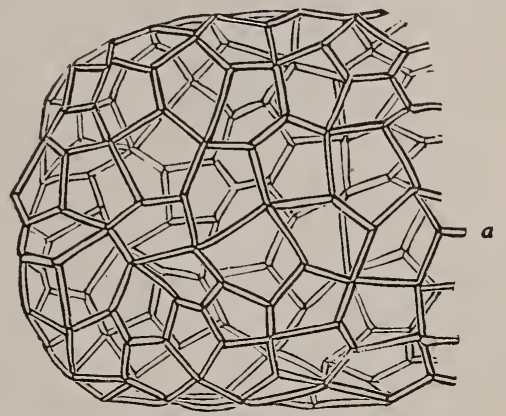

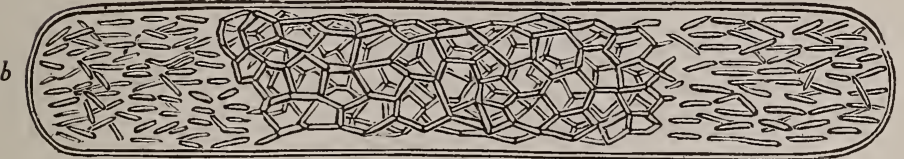

Fig. 524.-The Hydrodictyon or Water-net. a, portion of colony nearly natural size; b, one of the cells of the colony greatly enlarged, showing in the interior minute cells arranging themselves to form a reticulum.

Fig. 524, $a$, represents a portion of a mature Water-net not far from the natural size, and $b$, one of the cells greatly enlarged, showing numerous small cells in the interior, in the act of arranging themselves into a net.

The Volvocales consist of cells, either occurring singly or grouped in colonies, sometimes quite complex in structure. They 
are provided in the vegetative, as well as in the spore stage, with cilia and have the power of locomotion, swimming about like animals. The plants are mostly fresh-water forms, and even the colonies are of small size, most of them microscopic. They multiply asexually by cell-division. The mode of sexual reproduction in some is by the conjugation of gametes, while in the higher forms of the group, the process is that of fertilization, the egg cell being of larger size and quiescent, while the sperm cell is small and provided with cilia.

Among the unicellular forms Chlamydomonas may be taken to illustrate the simplest of the group. This plant is common in fresh
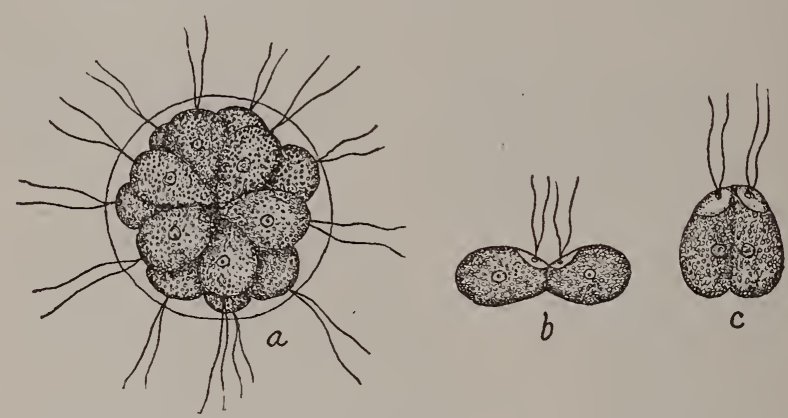

Fig. 525.-Pandorina Morum, a fresh-water alga. a, colony of sixteen cells, each provided with a pair of cilia, by means of which the whole colony moves through the water with a rolling motion; $b$, two zoospores of the same plant in the act of conjugation; $c$, the process nearly completed. Magnified about 150 diameters.

water and, being a free-swimming form, might readily be mistaken for a protozoan. The protoplast is somewhat globular, rlosely surrounded by a thin cell-wall, through which projects, at one end, two long cilia. The protoplast contains a large cup-shaped chloroplast, a protein body, known as the pyrenoid, and usually surrounded by starch bodies, a nucleus, an "eye spot" of red pigment, and contractile vacuoles. Reproduction is effected either by zoospores which are miniatures of the parent plant or by gametes which fuse in pairs to form resting zygospores which, later, germinate and become new plants. "Red snow" observed by traveler's in arctic and alpine regions is produced by a species of Chlamydomonas which secretes a bright red pigment and, when abundant and blown over the surface of the snow, gives rise to this appearance.

Pandorina and Volvox may be taken to illustrate the forms 
which produce colonies. In Pandorina the colony consists of sixteen, or less commonly of eight or thirty-two cells, crowded into a spheroidal mass, and surrounded by a transparent gelatinous envelope. Each cell possesses two cilia which project through the envelope and by which the colony is propelled with a rolling motion through the water. Asexual reproduction takes place by the formation of sixteen zoospore-like cells in the interior of any cell of the colony. These young cells remain together and after a time escape from the parent cell and form independent colonies.

In the sexual reproduction, cell-division takes place as before, but the gametes which are formed escape from their enclosure by the softening of the gelatinous membrane and move about individually by means of their cilia, finally fusing and forming zygospores which, when mature, acquire a brownish-red color. These after a period of rest germinate, produce gametes which pair and fuse, and then divide to form colonies of sixteen cells. See Fig. 525.

Volvox globator is a more highly developed but similar plant also common in our fresh waters. When mature it has a diameter of about half that of an ordinary pin-head, and the cells composing it, which may number thousands, are so arranged as to form a hollow, spherical colony. The cells are chlorophyll-bearing and imbedded in a tough, gelatinous, transparent matrix; they are ordinarily connected with each other by threads of protoplasm, which form a delicate net-work over the surface, and each cell is provided with a pair of cilia which project beyond the enveloping membrane, and by their rhythmic vibrations communicate a rolling motion to the cœnobium.

Asexual reproduction takes place as follows: At first the cells are all alike, but some enlarge and escape from the envelope into the interior of the sphere, where they form miniature colonies similar to the parent one. Often two or three of these colonies can be seen within the parent cœnobium. These continue to grow until the walls of the colony can no longer contain them, when by its rupturing, they escape and become independent.

In the sexual reproduction, which occurs toward the close of the season, two distinct kinds of gametes are involved. Some of the cells enlarge, lose their cilia and develop into egg cells; these are the female gametes; other cells form numerous small, motile, male gametes or sperms. Both forms of gametes escape to the hollow of the spherical colony, where the sperms seek the eggs and fuse 
with them. This is a prototype of fertilization such as occurs in the higher plants.

After the resulting oospores have matured, the walls of the parent colony dissolve away and they are set free. Fig. 526 represents a fertile colony of this species.

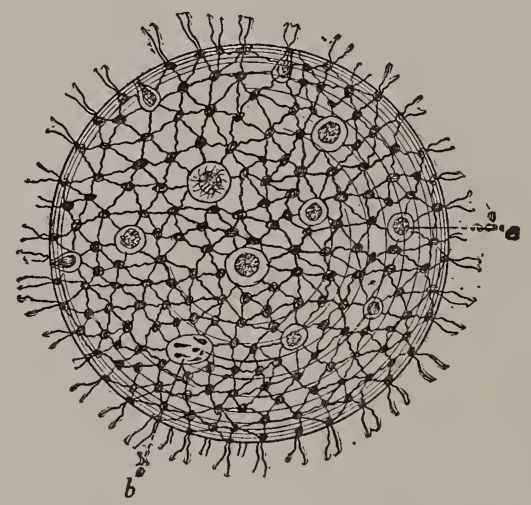

Fig. 526.-Volvox globator, magnifiedabout 75 diameters. a, one of the oogonia; b, one of the antheridia fromwhich most of the sperms have escaped.

The Confervales or Confervoid Algæ. The plants of this group are the largest and most familiar of the Green Algæ, chiefly inhabiting fresh waters. Most of them are either filamentous or they form a flattened thallus, consisting of a single layer, or at most of two layers, of cells. In a few forms the filaments are branching, in a few others, adjacent filaments anastomose, and in some, the component cells secrete a mucilage and become separated from each other, forming a mucilaginous mass, in which the cells multiply by division.

Most of the forms reproduce by asexual zoospores, many reproduce sexually by means of zoospore-like gametes, which fuse together in pairs, forming a zygospore, and this upon germination, forms several zoospores which grow into new filaments; still others produce oogonia containing oospheres, and antheridia which produce ciliated sperms.

The order includes a large number of forms, Ulva, Ulothrix, Cladophora, Edogonium and Coleochæte.

The Ulvas, so common in marine estuaries and salt marshes, are often called Sea-lettuce, from the shape of the bright-green fronds, which consist of thin, flattened or crispate membranous 
expansions, often several inches in breadth, and attached to stones, shells, etc. The fronds consist of two strata of cells, and increase in size by cell-division in two planes. In the early stages of their development, however, they are filamentous, but afterward, by cell-division in two planes, becomes laterally expanded. Fig. 527 represents one of these plants.
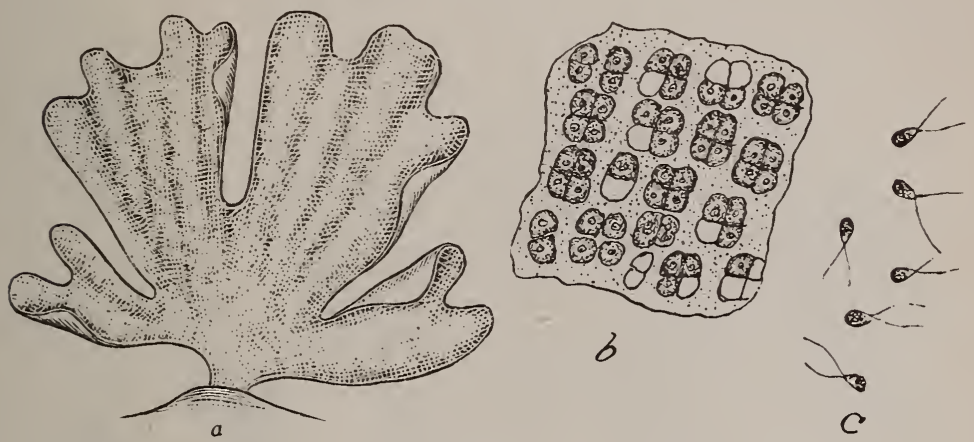

Fig. 52 7 -a. Ulva Lactuca, frond about natural size; $b$, portion of frond magnified, showing arrangement of cells; the unshaded ones are those from which zoospores have escaped; c, biciliated zoospores.

The Edogoniums are filamentous, mostly unbranching freshwater algæ, whose cells are densely packed with chlorophyll-bodies. They are not uncommon in ponds, ditches and slow streams, where they occur in patches, attached by means of root-like processes to sticks, stones, the stems of aquatic plants, etc. There are a large number of species, some of them diœcious. They reproduce asexually, not only by the transverse fission of their cells, but by the production of zoospores. In the latter process, the protoplasm. of the cell becomes aggregated into a rounded or oblong mass, acquires a fringe of cilia at one end, escapes from the cell-wall, and moves through the water for a time, but finally comes to rest, sends out from one end root-like processes, attaches itself to some object in the water, and develops into a filament. See Fig. 528.

In the sexual reproduction, one or more of the cells of the filament become greatly enlarged to form oogonia. When mature, an opening or pore is formed in each oogonium and sperm cells, produced either on another filament or in smaller cells of the same filament, find their way through these openings and fertilize the egg cells, of which there is but one in each oogonium. This is the common mode; in other species, however, small ciliated cells, called 
androspores, are produced either in a male filament, or in other cells of the same filament that produces the oogonia; but these, instead of directly fertilizing the latter, become attached by a root-like process to it or near it, lose their cilia, grow into a short filament, and finally the terminal cell of the latter ruptures, setting free a minute sperm cell, which penetrates the aperture of the oogonium and fertilizes the egg cell. See Fig. 529.

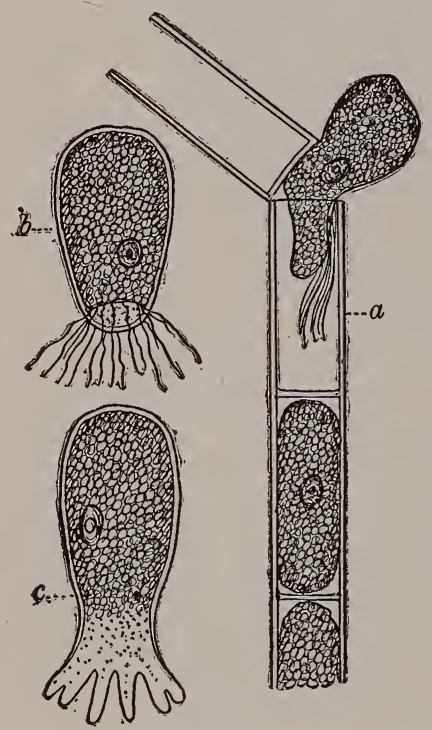

Fig. 528.

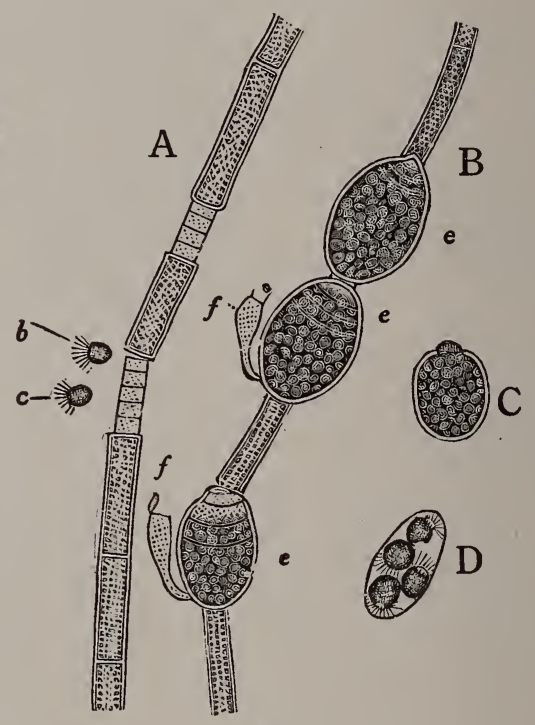

Fig. 529.

Fig. 528.-Edogonium, showing asexual modes of reproduction. a, portion of filament with the protoplasm escaping to become a free, ciliated cell, b; c, the same cell throwing out rhizoids. Magnified about 250 diameters.

Fig. 529.-CEdogonium ciliatum, showing mode of sexual reproduction. A, portion of male filament producing androspores $b$ and $c$. $B$, portion of female filament producing oogonia e, e, e; , f, male plants produced from androspores, which have germinated on the sides of two of the oogonia, and are each discharging a minute sperm. The filament has partially broken apart, leaving an opening in the top of the lower oogonium, so that the sperm cell may enter. This end of the oogonium is filled with mucilage, which slightly protrudes from the opening. $C$, a ripe oogonium, which has separated from the filament. D, represents the production of four ciliated spores from the germinating oospore.

After fertilization, the oospore acquires a thick cell-wall, and in ripening changes to a brown color. The oogonium, with the ripened oospore still enclosed within its walls, now separates from the filament which bore it, and the spore, after a period of rest, 
germinates. It does not, however, immediately develop into a filament, but first forms four ciliated zoospores. These, after moving about for a while, come to rest, and each develops into a filament.

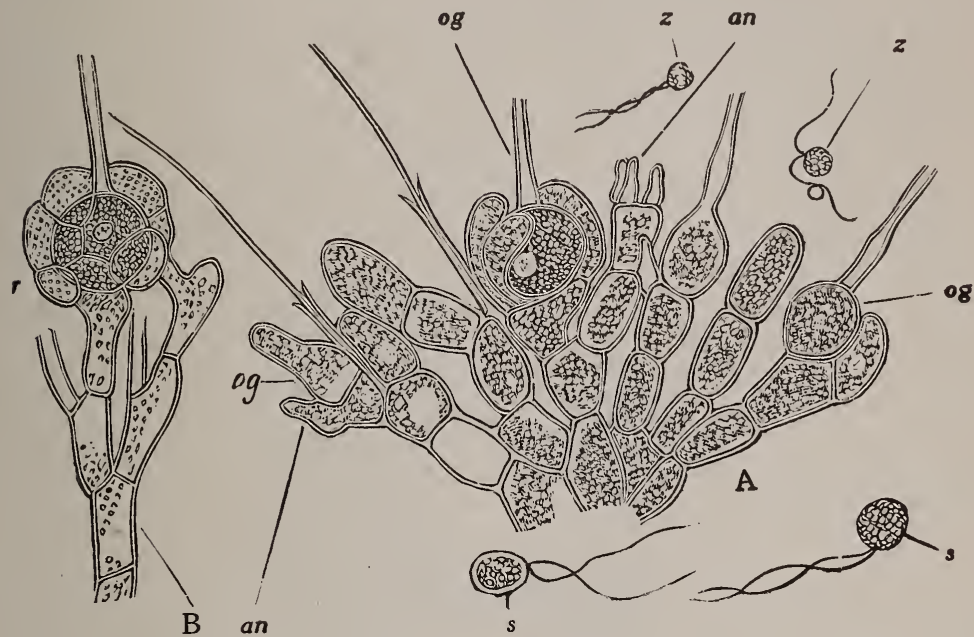

Fig. 530.-A, part of fertile thallus of Coleochaete pulvinata (magnified 350 diameters). og, og, og, oogonia in various stages of development; an, an, antheridia; z, z, sperms; s, s, zoospores; B, ripe oogonium in its cellular rind, $r$. After Pringsheim, from Sachs' Botany.

Coleochæte. We may take Coleochæte pulvinata to illustrate this group. It occurs as small rounded, dark-green or olive-green masses, from $1 / 12$ to $1 / 2$ an inch in diameter, attached to stones, sticks or water-weeds in calcareous spring-waters. Each mass consists of a number of articulated, branching filaments, the cells composing which are oblong, narrower at the basal end, more or less dilated anteriorly, and often provided with a transparent hair or bristle, which has at its base a kind of sheath.

The plants propagate themselves asexually by means of zoospores, which may arise from any of the vegetative cells, and sexually by means of oogonia and antheridia. The former are always modified terminal cells of a branch. The cell becomes swollen at the base and elongated into a tube at its apex, and when ready for fertilization, the tube opens and emits a colorless mucilage. The antheridia are small flask-shaped bodies, borne singly, or two or more together, at the ends of other branches, or on adjacent cells. Each of these when ripe emits a single sperm 
cell. The latter moves about by means of two cilia, and probably finds its way through the mucilage down the tube of the oogonium to the egg cell at its base and fertilizes it. In the course of the ripening of the oogonium, there grows up about it from adjacent cells a cellular rind or protecting sheath. See Fig. 530, $A$ and $B$. The ripe oospore does not immediately develop into the mature form of the plant, but, after a period of rest, first forms zoospores, from which the filaments are finally produced.

The Conjugales or Conjugating Algæ. This group differs from all other algæ in the peculiarly complex structure of their chlorophyll-bodies; from all, except some of the Diatomaceæ, in their

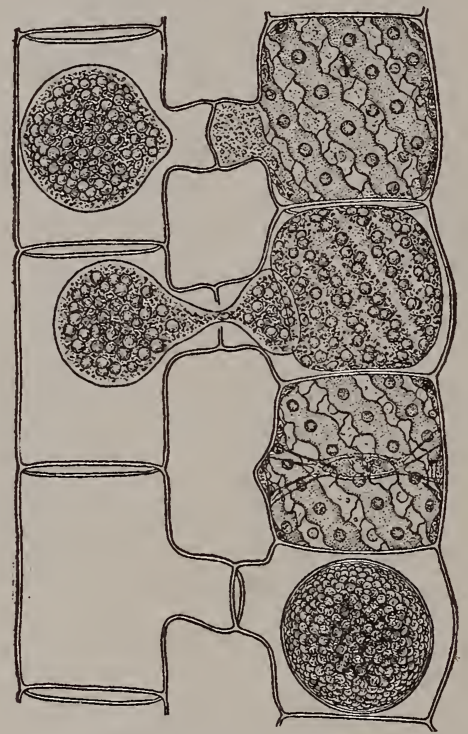

Fig. 531.-Spirogyra species; $\times 300$. The cells of the filament on the left show successive stages in conjugation with the filament on the right, which has one cell in the vegetative condition, and one with a fully formed zygospore. (After L. Kny from Ganong.)

mode of sexual reproduction, which consists in the direct conjugation of ordinary vegetative cells to form zygospores, and from many in not producing zoospores nor swimming gametes. In some of the species the chlorophyll-bodies form plates of definite form and arrangement, in others, star-shaped masses, and in still others, spiral bands. A few of the forms are unicellular, but most of them consist of unbranching filaments. To this group belong a number of genera represented by species common in our fresh 
waters, most important of which are Mesocarpus, the Spirogyras, the Zygnemas and the Desmids.

The Spirogyras are filamentous algæ, very common in ponds and ditches, and they occur in masses of silky, green threads which sometimes attain a length of six or eight inches. The name Spirogyra was given in allusion to the fact that the chlorophyll-bodies form spiral bands winding around the cell adjacent to its interior wall. In some species the bands are single, in others there may be two or more. See Fig. 335, Part II.

In conjugation, the cells of neighboring filaments grow toward one another in tubular projections which unite, forming a passage between the cells of the paired filaments. The protoplasts of one cell travel amœba-like into the other cell of the pair. After fusion, the zygospore thus formed secretes a thick wall and after a rest period is set free by the decay of the old filament, and upon germination forms a new filament. (Fig. 531.)

The Zygnemas differ from the Spirogyras in having the chlorophyll-bodies stellate in form and arranged axillary, a pair of them in each cell. (Fig. 336, Part II.)

In Mesocarpus and some other related forms the zygospore is not formed within either of the conjugating cells but in the space between them, as shown in Fig. 532.

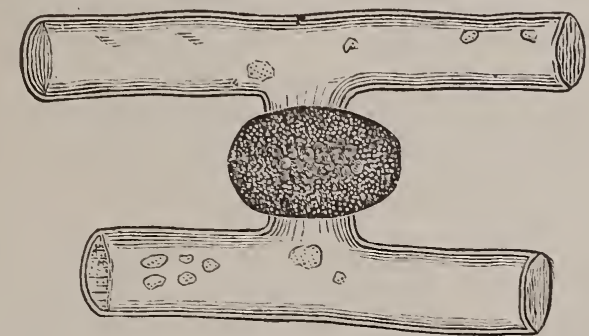

Fig. 532.-Cells of two filaments of Mesocarpus scalaris with zygospore formed between them. Magnified about 350 diameters.

The Desmids are found in great abundance and variety in clear, fresh water. They are mostly unicellular, but in some cases are loosely united into filaments. They have cellulose walls surrounded by a transparent gelatinous substance. They are usually more or less constricted in the middle, and in this isthmus-like, constricted part the nucleus is situated. Each symmetrical half contains a chloroplast and a number of pyrenoids. They contain large green 
chloroplasts, often compound and elaborate. The species are exceedingly numerous; many are lobed, spinose, delicately striated or otherwise ornamented.

Asexual reproduction takes place by division along the plane of symmetry between the halves. The new wall thus formed is double, and on each side of it is formed a new semi-cell. When these reach a size about as great as that of the old semi-cells,

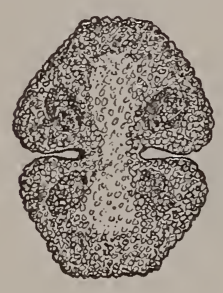

$a$

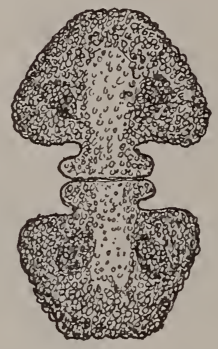

$b$

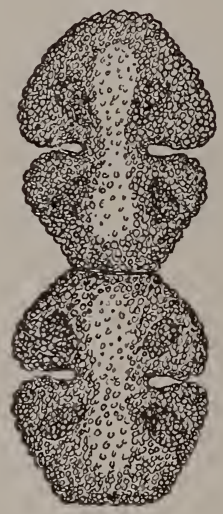

c

Fig. 533.-Cosmarium Botrytis, a Desmid, showing process of division. a, the mature plant; $b$, the plant in any early stage of division, with two new semicells forming between the old ones; c, the process nearly completed. Magnified about 500 diameters.

separation takes place. Each of the new plants thus formed, therefore, consists of an old and a newly-formed semi-cell. This mode of multiplication is illustrated in Fig. 533.

Sexual reproduction takes place usually late in the season, and consists in the conjugation of two cells which come together, their protoplasts escaping through ruptures at the isthmus and fusing to form a zygospore. The zygospore differs considerably in appearance in different species. Sometimes it is smooth and spherical, at others warty or tuberculate, and in still others spiny, as in Fig. 534, which illustrates the sexual reproduction of Cosmarium Botrytis.

In Fig. 535 are represented several other forms of Desmids.

The Charales or Stoneworts. These are submerged fresh-water plants, rooting in the muddy bottoms of ditches, ponds and sluggish streams. They are able to deposit lime from solution and thus become encrusted with it, hence the popular name, Stoneworts. 
They do not possess true roots, but fasten themselves to the mud by means of root-like processes called rhizoids. They bear at intervals on the slender stems whorled appendages, which may be

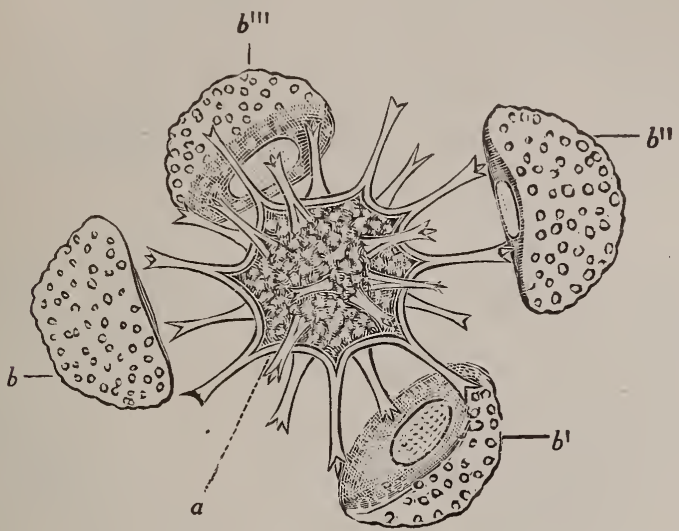

Fig. 534.-Conjugation of Cosmarium Botrytis. a, zygospore; b, b', b', $b^{\prime \prime \prime}$, the empty semi-cells of the two plants. Magnified about 500 diameters.
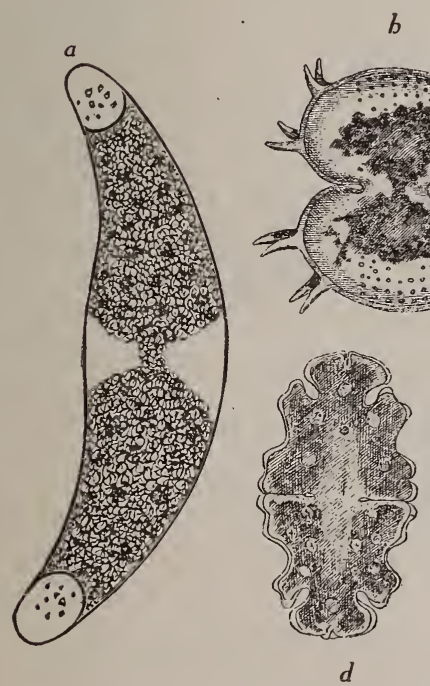

$b$

Fig. 535.-Desmids. a, Closterium Ehrenbergii, magnified 100 diameters
Xanthidium fasciculatum, magnified 500 diameters; c, Micrasterias radiosa, b, Xanthidium fasciculatum, magnified 500 diameters; c, Micrasterias radiosa, marium pardalis (?), magnified 500 diameters; f, Micrasterias pinnatifida, magnified about 400 diameters. 
taken to represent leaves, and in the axils of these, branches occur. See Fig. 536. The stem increases in length by the continual division of the apical cell in a transverse direction, and by the growth in length of some of the cells thus produced. The cells resulting from this division are alternately nodal and internodal cells. The latter become multinucleated and greatly elongated, sometimes several inches in length, but do not again divide. Not so, however, with the nodal cells. These increase but little in length, but divide longitudinally to produce the lateral appendages,-leaves, stems and fruiting organs. From them also originates the cellular cortex which in the genus Chara, but not in the related genus Nitella, covers the internodal cell and keeps pace with its growth. In this mode of growth, as well as in the structure of their fruiting organs, the Stoneworts are peculiar among plants. In complexity of structure, also, they rank highest among Algæ. The plants are abundant in species, and are widely distributed over the world, but they all belong to the two genera already mentioned. Some are of small size, only one or two inches high; other species attain the height of two or three feet. Nearly all are gregarious in their habits.

They agree with the Conjugales in not producing zoospores, their asexual reproduction being by means of tuber-like structures 
borne on the subterranean parts, or by peculiar branches which form rhizoids on their basal nodes and become separated from the parent plant.

They reproduce sexually by means of oogonia and antheridia, both of which have interesting peculiarities in their structure. These organs are, in some species, both borne on the same plant; in others, on different individuals; they occur at the nodes, often close together. The oogonium is at first a single cell, but in the

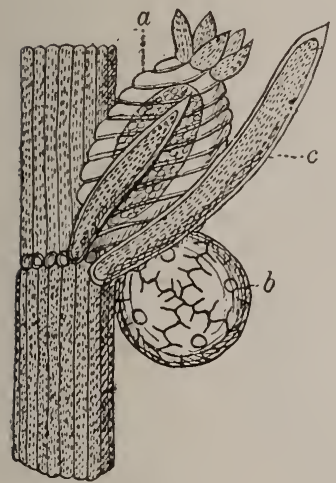

Fig. 537.

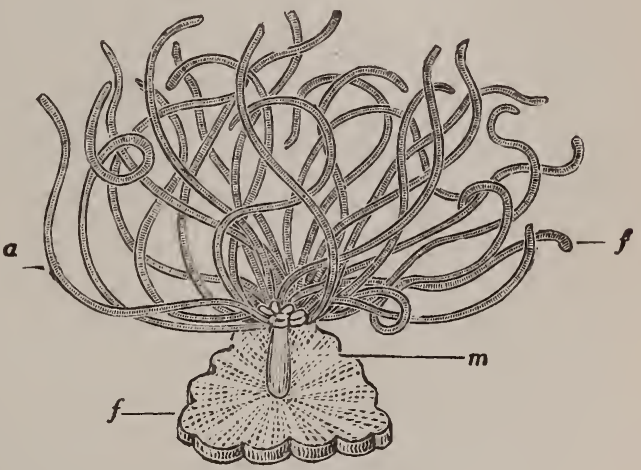

Fig. 538.

Fig. 537.-Small portion of Chara stem. showing one node on which are borne an oogonium, a, and an antheridium, b. c, is a leaf, most of the other leaves having been removed. Enlarged about ten diameters.

Fig. 538.- Segment of Antheridium of Chara. a, one of the wall-cells; $\mathrm{m}$, manubrium; f, f, antheridia! filaments. Magnified about 100 diameters.

course of its development it divides transversely, and the apical cell becomes enlarged and develops into a germ-cell. This soon becomes covered by a layer of cells growing up from the base and coiled spirally around it, and these are surmounted by a crown, which in Chara consists of five and in Nitella of ten smaller cells, which originate from the others by transverse division. Thus, just before maturity, the large egg cell is completely enclosed, but when ready for fertilization, an opening occurs between the cells at the apex, and this becomes filled with mucilage, and the wall of the germ-cell is also converted into mucilage at its apex, permitting the entrance of the sperms. The oogonium, when mature, is oblong or ellipsoidal in form and of a deep orange color. Sce Fig. 537.

The antheridium is a spherical body nearly as large as the 
oogonium, and also orange-colored when ripe. Its walls are composesd of eight triangular cells, whose edges are serrated or wavy, and nicely dovetail into each other. To the centre of each one of these cells, and projecting interiorly, is attached a cylindrical cell, called the manubrium, and this bears at its inner apex a rounded cell called the head-cell. This, in turn, is surmounted by about six smaller cells, from which proceed a number of small, coiled filaments, each made up of about two hundred disc-shaped cells. In all, each antheridium contains from one hundred to two hundred of these filaments. See Fig. 538. When the antheridium is ripe the segments of the wall separate, and from each cell of the filaments there escapes a minute, slender, coiled sperm cell, provided at its smaller end with two long cilia, by means of which it moves actively through the water. Some of them find their way into the oogonia and fertilize them. See Fig. 539. After fertilization the

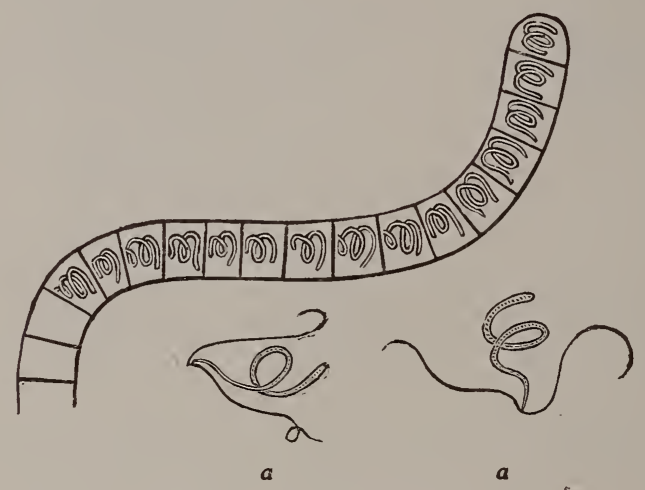

Fig. 539.-Portion of one of the antheridial filaments, magnified about 800 diameters, showing sperms ill all of the cells but two; from these the sperms have escaped, and are shown at a, a.

outer cells of the oogonium harden, forming a protective coat for the oospore.

The ripe spore rests for a time, and then, either in the autumn or early spring, germinates. It does not, however, immediately produce the leafy plant, but develops a filament of cells, called the pro-embiyo. From this the leafy plant springs as a lateral shoot, and the pro-embryo afterwards perishes. 


\section{CHAPTER V.-THE THALLOPHYTA (CONTINUED).}

THE PHAOPHYCEA.-THE RHODOPHYCE $A$.

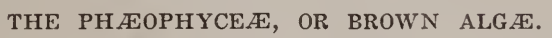

The Phæophyceæ are practically all marine plants, and are among the most abundant as well as the largest plants of the ocean. They reach their greatest size in the colder waters. While some are small, others attain gigantic dimensions, Macrocystis, for instance, having a length of stem which considerably exceeds that of the tallest Australian Eucalyptus trees and California conifers. In complexity of structure, also, the group presents great differences, some being quite simple, others among the most complex of their class, but the simplest are connected with the most complex by almost innumerable gradations.

They all possess, in addition to chlorophyll, a peculiar brown coloring matter, fucoxanthin, related to that found in the Diatoms, and hence they have an olive-green or brownish instead of a brightgreen color. They are, on this account, called Brown Sea-weeds.

There are two principal divisions of the Phæophycer, the Phæosporales, and the Fucales.

The term Phæsporales literally means dusky-spored, and is applied to the group because of the unusually dark color of the sporangia. Many of the species have been observed to produce gemmæ, or to multiply by the separation of branches; but sporereproduction takes place by means of small, ciliated gametes, formed in special cells on the surface of the fronds; the zygospores resulting grow directly into new plants similar to the parents. Some species produce only round, dark-colored, unilocular sporangia; others produce these and also oblong multilocular sporangia.

The most familiar members of the group are the Laminarias or Sea-aprons. These are plants of large size, some attaining a length of twenty to thirty feet. They have cylindrical stems of varying length, and often attaining the diameter of an inch or more. The base is attached firmly to rocks or other marine objects by means of strong, branching rhizoids, and the upper part expands into a flattened, leathery, blade-like organ, which in some species is entire; in others more or less divided. The blade and stem increase in length in a peculiar manner, namely, by the 
formation of new cells at the junction of the two organs, and the stem also increases in diameter by means of a growing layer beneath the rind, reminding us of the growth of the stems of Dicotyledons.

Fig. 540 represents a plant of Laminaria saccharina, about one-thirtieth natural size. To this group also belong the Nereocystis, with its very long stalk, single great float and broad blades, the Postelsia or Sea Palm, and the gigantic Macrocystis.

The Fucales or Rockweeds are dark olive-green algæ of considerable size, and having a cartilaginous consistency. Most of them adhere firmly to rocks by means of branching discs, but a few float free in the ocean waters. The vegetative body consists either of a dichotomously branching, more or less flattened thallus, as in the genus Fucus, or of fairly differentiated stems and leaves, as in Sargassum, the Gulfweed of the Sargasso Sea. Many of the species possess air-bladders, which render the branches buoyant.

They differ from the previous group in their more complex mode of sexual reproduction. This takes place by means of antheridia and oogonia.

We may, take the common Bladder-wrack, Fucus vesiculosus, as the type of the group. A portion of the plant is shown in Fig. 541. It grows attached by discoid holdfasts to rocks, between high and low tide. The frond is flattened, cartilaginous, two or three feet in length, and repeatedly forking. It has a prominent midrib, and on either side of it, at intervals, air-vesicles occur in pairs. The fruiting organs occur at the ends of certain branches, in cavities called conceptacles, which are arranged close together, and consist of globular depressions in the surface. The walls of the conceptacles are lined with hairs, some of which protrude from the narrow opening. Among these hairs, on the-interior of some of the conceptacles, are borne antheridia, and in others oogonia; but in some species, for example, Fucus platycarpus, both are borne in the same conceptacle. A female conceptacle is shown in Fig. 542.

The antheridia are branching filaments, some of the cells of which, when mature, emit numerous bi-ciliated sperm cells. These find their way to the egg cells, which, in the meantime, have escaped from the oogonia, and fertilize them. Fig. 503 shows one of the branching filaments bearing antheridia.

The oogonium begins as a minute papilla-like protuberance on the wall of the conceptacle, and is at first a single cell. This 


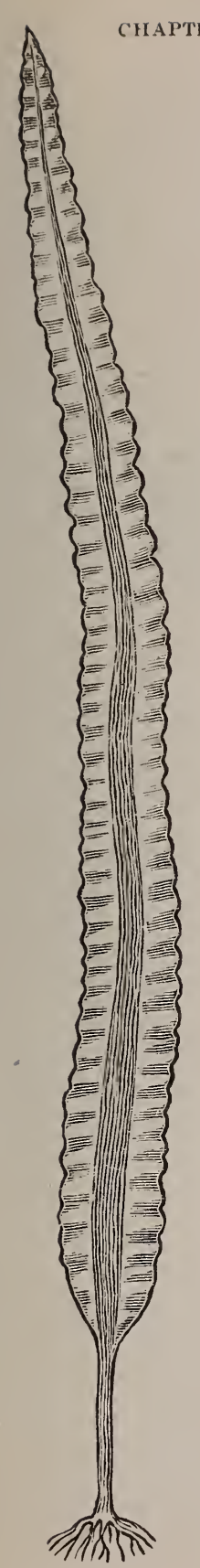

Fig. 540 .

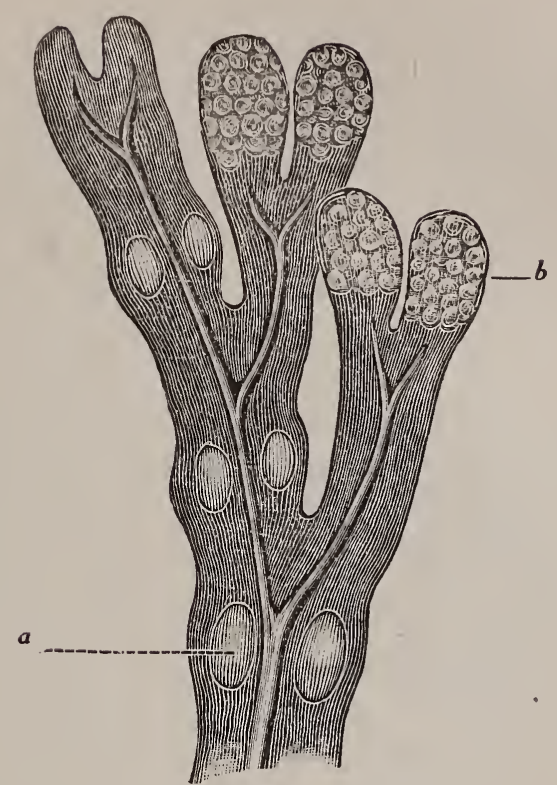

Fig. 541.

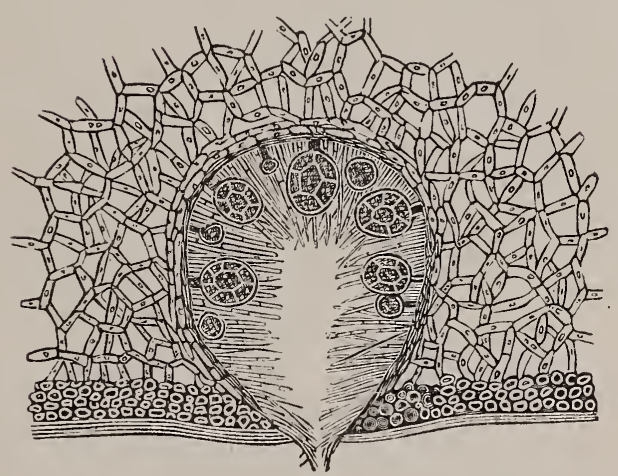

Fig. 542 .

Fig. 540.-Laminaria saccharina, about one-thirtieth natural size.

Fig. 541.-Portion of thallus of Fucus vesiculosus, about natural size; $a$, one of the bladders; b, fruiting organs.

Fig. 542.-Female conceptacle of Fucus vesiculosis, producing on its interior, hairs and oogonia. Magnified about 40 diameters. 
divides transversely into two cells, the lower one constituting the stalk, and the other becoming the ocgonium proper. This becomes relatively large in size and spheroidal in form, and, in this species, the protoplasmic contents break up into eight nearly equal portions, forming as many egg cells. In most other members of the

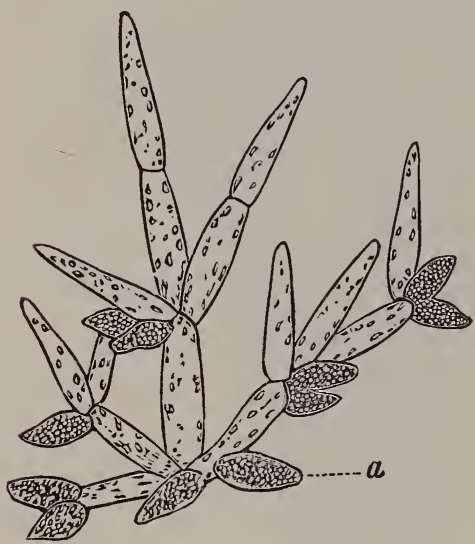

Fig. 543.

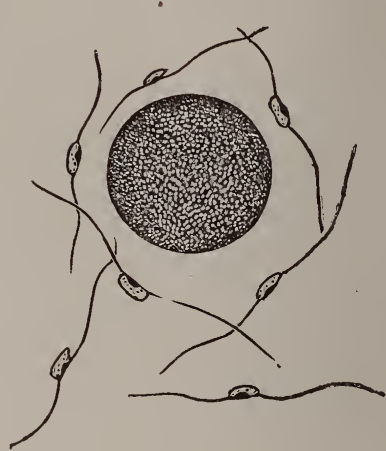

Fig. 544 .

Fig. 543.- One of the branching filaments from a male conceptacle of Fucus vesiculosis bearing antheridia, a. Magnified about 150 diameters.

Fig. 544.-Escaped egg cell from one of the oogonia, with ciliated sperms swarming about it. Magnified about 400 diameters.

order, either no division takes place, and but a single egg cell is formed within the oogonium, or else fewer are formed than in Fucus.

When the egg cells are fully formed, the wall of the oogonium ruptures and they are discharged into the water, and there the sperm cells swarm about them and fertilize them. See Fig. 544. After this process is completed the oospore acquires a cell wall, and soon begins to germinate.

\section{THE RHODOPHYCEAE, OR RED ALGE.}

This group includes the red or violet-colored algæ, popularly known as "Sea-Mosses" or Red Marine Algæ. They are exceedingly numerous in species, and are widely distributed in ocean waters. A few also, as Batrachospermum and Bangia, inhabit fresh waters. The marine forms mostly grow attached to rocks or shells below the level of low tide, some at considerable depths, as far down as light can penetrate-about two hundred feet in 
clear waters. They are chlorophyll-plants, but the proper green color is more or less obscured by the presence of a red or violet coloring matter, phycoerythrin. Some have also a blue pigment, phycocyanin. In the simpler forms the thallus consists of branching filaments; in others it forms a flat expansion, consisting of one or more strata of cells, sometimes with a midrib, giving the structure an appearance something like that of a leaf; in other instances tissue-like structures, often possessing considerable complexity, originate from the growing together of adjacent branches; and in still others true tissues appear to be formed. Some species are quite gelatinous and have some food value, notably Chondrus Crispus and Gigartina mamillosa, which constitute Irish Moss, and several Asiatic species of Gracilaria, Gelidium and Gloiopeltis, from which Agar is extracted. In the majority of cases growth takes place by the division of a single apical cell, but in the Corallines and their relatives, there are usually several initial cells. This group is also distinguished from the rest by the fact that they secrete large quantities of lime in their cells.

The most distinguishing characteristic of the group is their mode of reproduction. In their asexual reproduction they produce non-motile cells, called tetraspores, which, as the name indicates, are usually formed in fours in the mother-cell. This, however, is not always the case; sometimes there are but one or two, occasionally as many as eight. In the forms which consist of branching filaments, the tetraspores are usually formed in the terminal cells of the branches; in other species they are usually imbedded in clusters in the tissues of certain branches, which consequently often acquire a form quite different from the rest. The plant which bears the tetraspores has no sex organs, but the tetraspores upon escaping, germinate and grow into plants that bear sex organs. Fig. 545 represents a small portion of the thallus of a species of Plocamium highly magnified, showing tetraspores.

The sex organs consist of antheridia and rrocarps, the latter. containing the carpogonia. These may both be borne on the same plant, or, as is more commonly the case, on separate plants of the same species. The antheridia occur either singly or in groups at the ends of certain branches, and the sperm cells are minute, rounded, non-ciliated and non-motile particles, and are dependent therefore on water-currents or on animalcula for their conveyance to the procarp. The latter are more complex organs than the oogonia of other algæ. In the course of their development, the 
unicellular or multicellular mass first formed becomes differentiated into two portions, an upper portion, called the trichogyne, usually a straight, hair-like process, and an enlarged basal portion, the carpogonium.

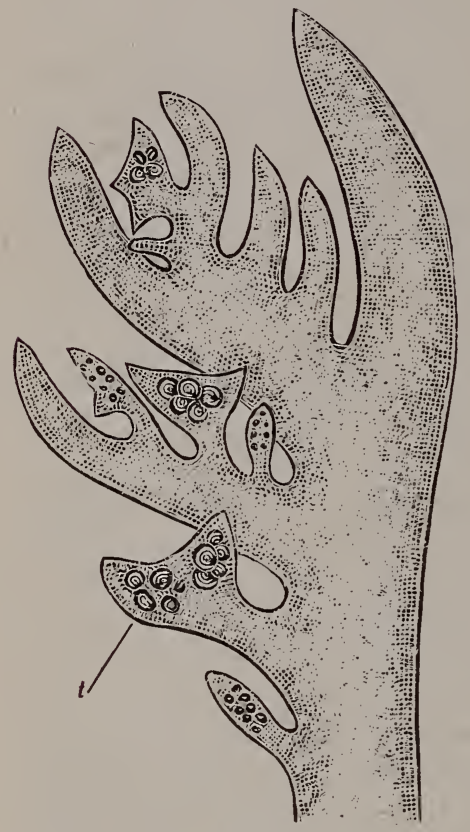

Fig. 545 .

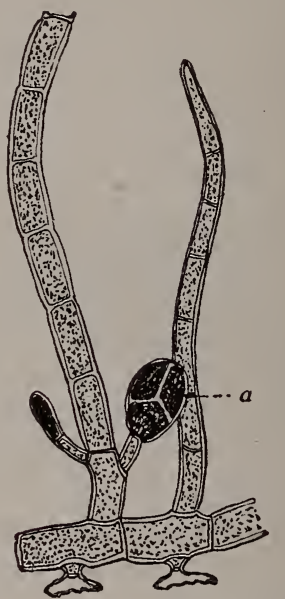

Fig. 546.

Fig. 545.-Small portion of thallus of a species of Plocamium, one of the Red Algæ, showing branches bearing tetraspores, t. Magnified about 75 diameters.

Fig. 546.-Lejosisia mediterranea, one of the Red Marine Algæ; portion of filament, showing asexual reproduction by tetraspores. a, represents tetra. sporangium. Three of the four spores are shown in the figure, the other is concealed behind them.

The part which receives the fertilizing influence of the sperm cells is the trichogyne, but this does not undergo development in consequence, but communicates the influence to the carpogonium, and then soon withers away, while the latter undergoes very considerable changes. These differ considerably in different species, but in all, the fertilization stimulates a considerable vegetative growth, which results in the production of a cystocarp containing a number of asexual spores, called carpospores.

Upon germination, the carpospores produce the sexual plants, thus completing the life cycle. We observe here for the first time the alternation of sexual and asexual generations which is so well established in the higher plants. 
In some cases, as in Nemalion, fertilization results in the outgrowth of several branches from the basal part, which break up into cells, each one of which becomes a carpospore. In other cases, as in Lejolisia, the stimulant influence results in the development

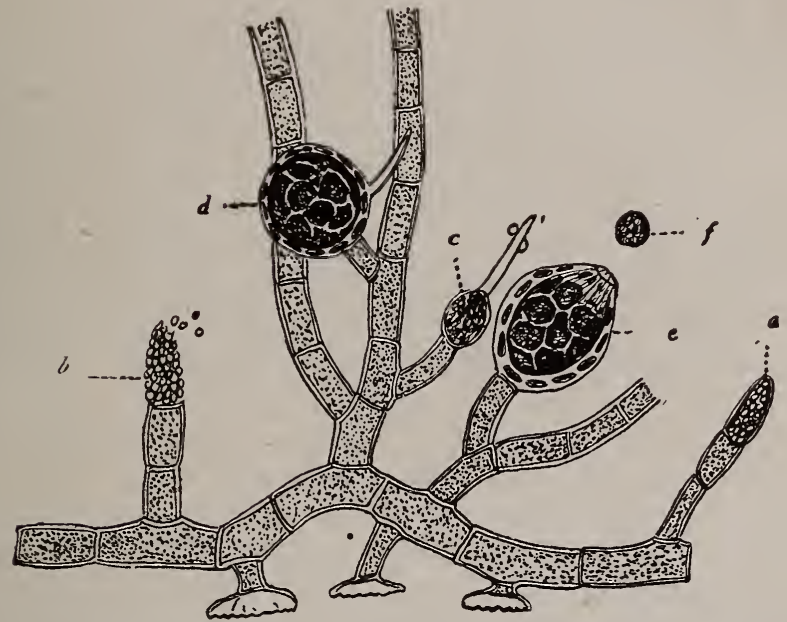

Fig. 547.-Lejolisia mediterranea; portion of fertile filament, showing mode of sexual reprodiction. $a$, antheridium nearly ripe; $b$, ripe antheridium with escaping sperm cells; c, carpogonium, bearing at its apex a trichogyne, to which two sperm cells are attached; $d$, cystocarp, showing carpospores in its interior; $e$, cystocarp discharging one of its carpospores, f. Magnified about 150 diam. eters.

of adjacent cells to form filaments which grow up around the cystocarp, and unite laterally to form an envelope to enclose it. Both the sexual and asexual processes in this plant are illustrated in Figs. 546 and 547.

CHAPTER VI.-THE THALLOPHYTA (CONTINUED).

THE FUNGI.-THE PHYCOMYCETES.THE CHYTRIDIACEA.-THE ASCOMYCETES.

\section{CHARACTERISTICS OF THE FUNGI.}

The Fungi are generally regarded as degenerate descendents of the Algæ, which, having lost their chlorophyll and therefore their power of independent living, have now become parasites or sapro- 
phytes. The distinction between these two groups is not sharply drawn. Thus some parasites are able to exist as saprophytes when occasion requires and are called facultative saprophytes, while others cannot adjust themselves to any other mode of existence and are obligate parasites.

There are several thousand species of fungi. The vegetative body of the fungus consists of a mycelium made up of colorless, branched thread-like cells known as hyphx, which in saprophytes ramify among the decaying organic debris of the substratum or. in parasites invade the living tissue of the plant or animal host and draw nourishment from them. In some instances there are formed club-shaped branches of the mycelia especially fitted to absorb food material. Such branches are termed haustoria. The mycelia of some species of parasitic fungi grow on the surface of the host and are epiphytic, while in other species they live within the tissues of the host and are endophytic.

Some fungi live in symbiotic relations or partnerships with green plants, and this without apparent injury to the latter. Of such nature are the mycorhizas formed in connection with the roots of trees (see also page 276). Lichens, to be later described, are peculiar unions of alga and fungus in which the alga provides the carbonaceous food while the fungus holds fast the plant body to the substratum.

In the simpler mycelial forms, the hyphæ occur singly or more or less interwoven into a tangled felt-work, but they are not gathered into definite forms, and have little or no dependence upon each other; in the higher groups, however, there is more or less division of labor among the hyphæ, and they become consolidated into false tissues, which acquire definite shapes according to the species. Of this character are the fructifying organs or carpospores, which constitute the above-ground parts of the Agarics, Puff-balls, Cup-fungi, etc., and the sclerotium, a compact, hard mass of thick-walled hyphæ, which serves as a resting-stage in the development of some species, as the Ergot of Rye.

In their reproduction, the fungi show resemblances to the green algæ, presumably their ancestors. Asexual spores formed in great numbers are usually responsible for the rapid spread of fungous diseases. Of such nature are conidia, which are merely cells cut off from the ends of certain hyphæ. Similar asexual spores are the uredospores of the rusts and the basidiospores of the mushrooms. Others, formed in spore cases or sporangia, or in special recep- 
tacles of various kinds, will be described in connection with the groups in which they are formed. In some fungi, sexual organs are formed by specially modified hyphæ, and a variety of sexual spores, chief among which are zygospores, oospores and ascospores are thus produced.

Classification of the fungi is difficult, for, owing to their degenerate mode of life, the structures through which their relationship might be traced, have become greatly changed. The names of the principal groups end characteristically in "mycetes" (meaning fungus). Thus we have the Eumycetes or True Fungi, divided into the Phycomycetes or Alga-like Fungi, the Ascomycetes, or Sac-Fungi, and the Basidiomycetes, or Basidia Fungi. The remainder of the fungi, including those whose life histories are incompletely known, are placed in the artificial group of Fungi Imperfecti.

THE PHYCOMYCETES OR ALGAL FUNGI.

The term Phycomycetes literally means "Sea-weed Fungi," and alludes to the resemblance, in the mode of sexual reproduction, between these plants and certain of the Green Algæ. They produce a copious mycelium, which usually consists of unsegmented hyphæ, bear conidia, and most of them reproduce sexually either by zygospores or oospores.

There are three orders, the Zygomycetales, the Peronosporales, and the Saprolegniales.

Of the Zygomycetales, or Conjugating-Fungi, Mucor Mucedo may be taken as an example. This mold is a very common one found growing on various kinds of decaying matters, such as horse-dung, rotten fruits, etc. The mycelium, which is unicellular, extends its finer hyphæ through the nutritive substratum, while its coarser hyphæ form a cobweb-like growth on the surface of the latter. Both are profusely branched.

The fruiting hyphæ, however, are simple, and grow out into the air, each bearing at its tip a globular, blackish sporangium, the wall of which soon ruptures, setting free numerous conidia. This is the asexual mode of reproduction. Sexual reproduction takes place by conjugation of two similar or somewhat dissimilar gametes, which are merely cells cut off from the ends of the hyphæ. These fuse and form large, rounded, thick-walled zygospores, which rest for a time before germinating, and then, if the supply 
of nourishment is sufficient, develop a copious vegetative mycelium; if insufficiently nourished they produce at once aerial hyphæ, bearing sporangia. The modes of reproduction in this plant are illustrated in Fig. 548.

Bread Mold (Rhizopus nigricans) is another member of this order. It produces fluffy mycelia on the surface of bread, fruits

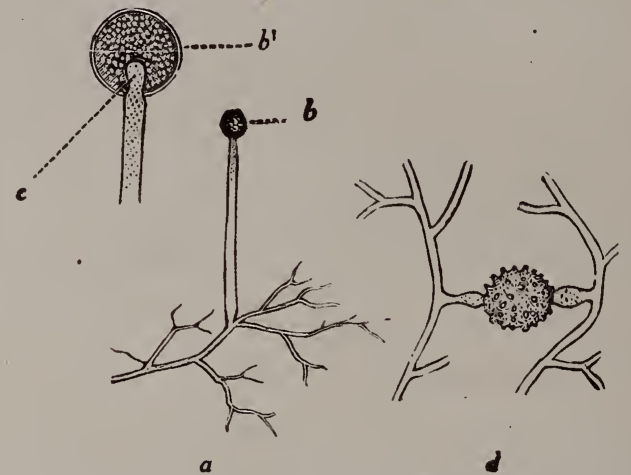

Fig. 548.-Muco mucedo. a, a portion of vegetative mycelium. bearing an aerial hypha, terminated by a sporangium, b; b', sporangium more highly magnified, showing the contained conidia; c, columella; $d$, conjugating mycelial filaments, with a zygospore formed between.

and other favorable substances when these are freely exposed to air. The sporangia are dark in color and give a black appearance to the mature mold.

The Squirting Fungus (Pilobolus crystallinus) hurls its sporangia with considerable force toward the light. It is common on manure.

The Entomophthoracex, which are parasitic upon living insects of various kinds, are also classed here. Of these Empusa muscorum, which infests house-flies, destroying them in large numbers, and Entomophthora sphærosperma, which often destroys the larvae of the Cabbage-butterfly, are common examples. The white sporangia of the former are often seen as a halo around dead flies on window panes.

The Peronosporales or Downy Mildews are mainly parasitic on terrestrial Phanerogams; a few, however, as some of the species of Pythium, are saprophytic, feeding upon dead animal and vegetable matter's. They produce unsegmented hyphæ which ramify in the intercellular spaces of their hosts and, sending haustoria 
into adjacent cells, absorb nourishment from them. The great majority, after a time, send hyphæ to the surface, frequently out through the stomata of the plant, and these bear sporangia which are shed, when ripe, in the same manner as conidia, and hence are commonly so called, though they differ from them in the fact that when they fall into water, the contents break up into several rounded masses which escape as zoöspores. These, after finding a lodgment on the epidermis of the host-plant, come to rest and produce hyphæ, which either penetrate the walls of the epidermal cells or find their way into the interior through the stomata. A few of the forms, however, produce true conidia which give rise to hyphæ directly; a few others neither produce conidia nor sporangia.

Nearly all the species reproduce sexually by means of oögonia and antheridia. The oögonium formed at the end of a hyphal branch is similar in structure to the corresponding organ in the oösporous Algæ, but the antheridia consist of one or more slender, curved out-growths, from the branch beneath the oögonium, or sometimes from adjacent hyphæ. Both oögonium and antheridium are formed within the tissues of the host. In fertilization the antheridium applies itself directly to the surface of the oögonium, and usually a tube from it penetrates to the oöspore and fertilizes it. In most cases the oöspores rest for a considerable period before germinating, and then, in some cases, develop a mycelium directly, in others they first produce a germ-tube which develops one or more sporangia which gives rise to zoöspores, and these, in turn, to a vegetative mycelium.

To the Peronosporales also belong Phytophthora infestans, a blight which attacks the leaves, stems and tubers of the Irish Potato and is very destructive; Plasmopara viticola, the Grapemildew, a most destructive Fungus, and Cystopus candidus, a mildew found on the Shepherd's-purse, and some other Cruciferous plants.

Some idea of the modes of reproduction in this group may be obtained from Figs. 549 and 550.

The Saprolegniales, or Water Molds, are aquatic fungi which form a dense mycelium on the bodies of animals that decay in water, and sometimes also upon submerged regetable matter. They also attack young fish, through the gills, and often cause heavy losses in fish hatcheries. They resemble the Peronosporales in many respects, but differ from them in the fact that the spor- 
angia produce ciliated zoöspores, and that the oögonia produce several egg-cells instead of one.

A curious and suggestive fact connected with some of the species of this group is, that while oögonia and oöspores are produced
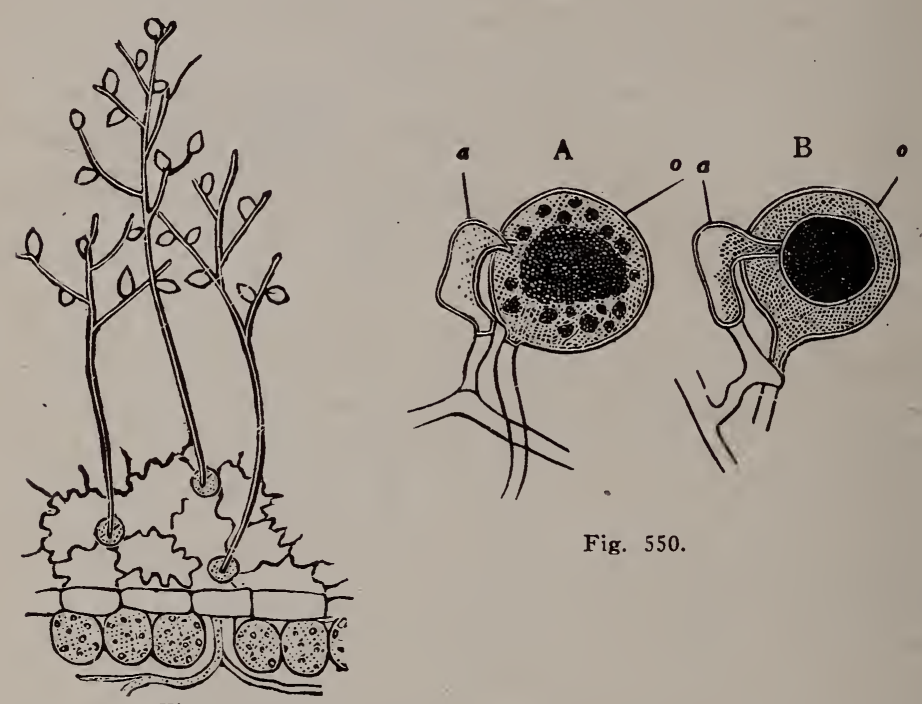

Fig. 550.

Fig. 549.- Portion of epidermis of Potato, showing three stomata with hyphae of Phytophthora infestans issuing from them and bearing sporangia. a, one of the sporangia. Magnification about 100 diameters.

Fig. 550.-Stages in reproduction of Peronospora Alsinearum. A, earlier stage, fertilization-tube of antheridium, a, not yet fully formed; $B$, the tube fully formed and the fertilization of the oogonium, 0 , completed. Magnified about 350 diameters. After DeBary.

as in the rest, either antheridia are not produced at all, or these do not perform the usual function of fertilization. The sexual process has in fact degenerated into an asexual one. This phenomenon is termed parthenogenesis, meaning reproduction by an egg without fertilization, and is particularly observed in the genus Saprolegnia, and, as we shall presently see, is a common one among the higher groups of the Fungi.

Achlya lignicola, which feeds upon decaying, submerged wood, illustrates well the perfect forms of the group. See Fig. 551 A and $\mathbf{B}$.

\section{THE CHYTRIDIACE F.}

In this order are Fungi of the simplest organization, most of 
them being unicellular, and not producing hỹphæ, while a few of the higher forms produce rudimentary hyphæ. They reproduce asexually by means of uniciliated zoöspores. Sexual reproduction has been observed in but one species, and in this instance it takes

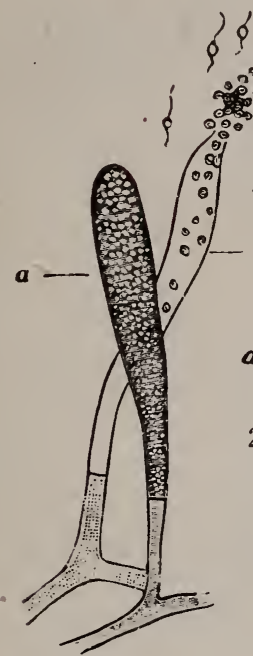

A

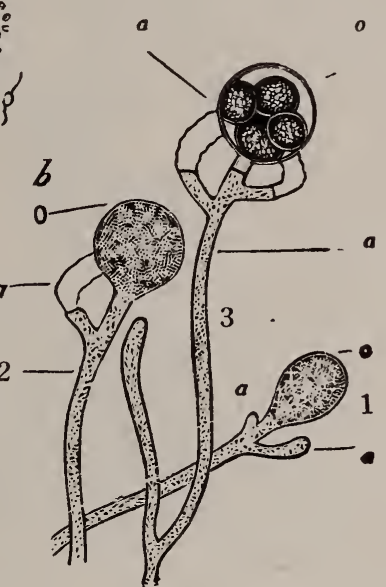

B

Fig. 551.-Achyla lignicola. A, Sporangia; a, sporangium nearly ripe but not et dehiscent; b, sporangium dehiscing; $z$, zoospores; $B$, stages in sexua repriduction. In 1 , the oogonium, 0 , and the antheridia, $a$, a. not yet fully formed; 2, later stages when oogonium is nearly ready for fertilization; 3 , process completed and antheridia withering away. Magnified about 300 diameters.

place by conjugation. In the typical genus Chytridium, the plants are unicellular, and their habitat is the interior of the living or dead tissues of aquatic Fungi and Algæ. The cells, on reaching maturity, become sporangia and emit zoöspores, which again germinate in the same plant, or, escaping, find their way to others and there germinate. See Fig. 552.

\section{THE ASCOMYCETES OR SAC FUNGI.}

This order consists of saprophytic or parasitic hyphal fungi, which produce a multicellular mycelium and on the whole attain a complexity of structure exceeding that of any of the groups alleady described. A few, however, as the Yeast-plant and its allies, are among the simplest of vegetable organisms. Some of 
them reproduce by means of conidia, and these may be formed from hyphæ by the separation of cells in succession from their fren ends, or they may be produced in special receptacles. But their most distinctive characteristic is the production of ascospores. These are spores formed in an ascus or sac. The spores are usually eight in number, but in some species there are but two, and, in others, four or five. They have a thick outer wall and a thin extensible inner one. When placed under conditions favorable for germination, the outer wall bur'sts and the inner extends to form one or more tubes, from which the hyphæ develop.

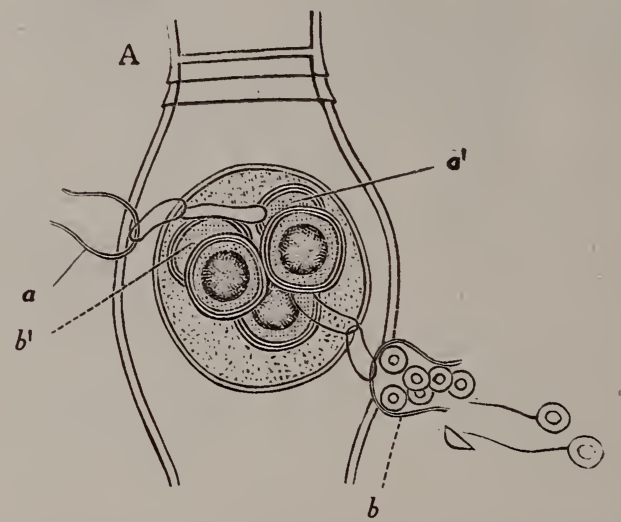

Fig. 552.-Chytridium Olla. A, oogonium of Edogonium rivulare, with an immature oospore killed by the parasite; the oospore contains several restingspores of Chytridium, which ripened in October; three of these spores are still unchanged; two have germinated. By turning the specimen around, it was seen distinctly that the empty sporangium, a, was formed from the resting-spore $a^{\prime}$. and the sporangium $b$, which is ejecting its contents, from $b^{\prime}$; near the mouth of $\mathrm{b}$, are the cast-off lid and two zoospores. Magnified 600 diameters. Figure and description after De Bary.

Ususally the asci are produced in a specially developed orgair or ascocarp, which is often a complex structure constituting the most conspicuous part of the plant, and may be cup-shaped, flaskshaped or globular: but in a few forms the asci are isolated, and not borne in a special fruiting-organ; and in other cases the latter is present, but has the simplest possible structure, sometimes merely the enlarged end of a hypha forming a thin-walled sac. Normally, the production of an ascocarp and ascospores, is the result of an antecedent sexual process analogous to that which occurs' in most Phycomycetes, but this is not always the case; in a large number of instances the organs of sexual reproduction 
either exist only in a rudimentary condition, or have entirely disappeared.

When sexual reproduction occurs, it takes place by means of an ascogonium and an antheridium, the former corresponding to the oögonium of the Peronosporales, but differing from it in the fact that no oöspores are developed within it, as well as in the fact that the collateral growths resulting from fertilization are usually very different.

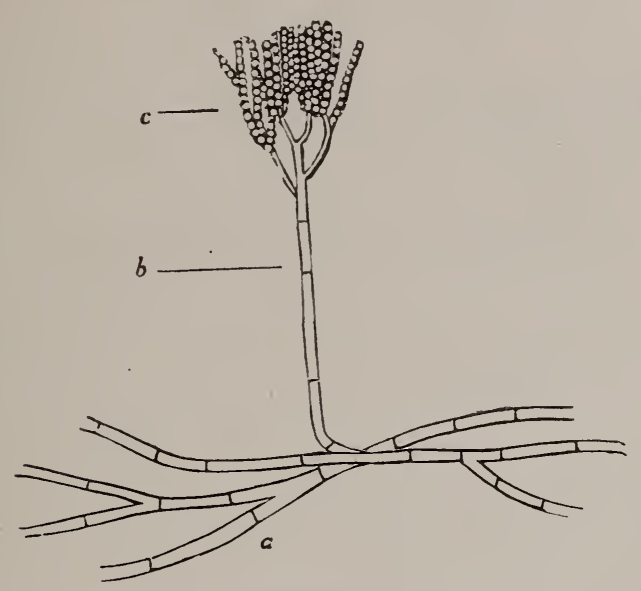

Fig. 553.-Penicillium glaucum. a. mycelium; b, conidia-bearing hypha; c, conidia. Magnified about 150 diameters.

In some of the simpler species, the end of a hyphal branch becomes enlarged and ellipsoidal in form, and is separated from the rest by a septum to form the ascogonium, and an adjacent branch becomes less thickened, has its apical portion separated from the rest by a septum in a similar manner, and becomes an antheridium. In most cases, however, the filament that forms the ascogonium becomes twisted into a spiral, and covered, perhaps, by an out-growth of adjacent hyphæ to form a compact mass. This may be provided with a projecting filament, or trichogyne, which receives the fertilizing influence, or it may be without it.

In the species which do not produce a trichogyne, the antheridium becomes entangled with the coiled filaments of the ascogonium, and thus fertilizes them; in the species that do produce one, the antheridium, when ripe, discharges sperm cells which, by adhering to the trichogyne, fertilize the ascogonium. 
The principal divisions of the Ascomycetes are the Erysiphex, the Plectascales, the Pyrenomycetes, and the Discomycetes. Here also are placed the Saccharomycetes or Yeast-fungi, and the apparently related Exoasci.

The Erysiphea or Perisporiales include the Powdery Mildews, the mycelium of which forms powdery spots, thereby differentiating this fungus from the Downy Mildews belonging to the Phycomycetes. Several species are common on the leaves of lilacs, apples, roses, alders, hops and other plants, and may do considerable damage.

The Plectascales include the Blue Molds an: Green Molds, which superficially resemble the Black Molds (belonging to the Zygomycetales), but which produce greenish instead of blackish sporemasses. They occur along with the Black Molds, but have a wider range and are common upon cheese, leather, fruits and other objects that become "moldy" when damp. Aspergillus is a familiar Green Mold, common on preserved fruits. Its mycelium is loose and spreads through the substratum, sending up hyphæ (conidiophores), which bear conidia in chains at their ends. The sex organs appear later and consist of two short hyphal filaments which come together and intertwine. A cleistothecium, or closed case, results from their fertilization, and this contains asci with eight spores mingled with sterile hyphæ. Upon the decay of the cleistothecium, the ascospores are scattered by the wind.

Blue Mold, Penicillium glaucum, is common upon bread, often mingled with Black Mold. The conidia are borne as shown in Fig. 553. Its ascosporous fructification is similar to Aspergillus. The peculiar flavor of Roquefort, Camembert and other cheeses is due to species of Penicillium.

The Pyrenomycetes are characterized by producing a compact superficial mycelium of dark color suggesting charring by fire, hence the name, literally "burnt fungi." They form the familiar black swelling on Cherry and Plum trees, which they injure severely. The mycelium develops parasitically in the bark and at length breaks through as a black, swollen prominence or sclerotium. Hyphæ arise from this and bear conidia, which are scattered by the wind, thus spreading the infection. In the next stage, the knot bears club-shaped asci in the interior of roundish or flask-shaped ascocarps, or perithecia, and these are distributed early in the spring, thus carrying the disease to new hosts.

Chestnut blight (Endothia parasitica), which was introduced 
into this country a few years ago and has been very destructive to chestnut trees; Cordyceps, whose various species are parasitic upon the bodies of insect larvæ; and Claviceps, whose species produce ergot on various kinds of grasses, belong to this group. Claviceps purpurea, which constitutes, in one stage of its development, Ergot of Rye, may be selected for more particular description. The ascospores of this fungus infect the ovaries of the Rye when it is in flower, and appear as a tangled mass of delicate mycelial threads on the surface of the ovary, also penetrating its tissues.

These mycelial threads develop numerous conidia and at the same time produce a sweet liquid, or "honey dew," which attracts insects, who carry the conidia to other flowers and rapidly spread the disease. There then begins to form, at the base of the diseased ovary, a dense mass of mycelium, which continues to enlarge until it forms the hard, dark-purple, club-shaped sclerotium, the medicinal Ergot.

The remains of the upper part of the ovary and the style are often seen attached to the apex of the sclerotium, even when the latter is mature, but it very soon afterwards falls off. Sometimes as many as twenty sclerotia are produced in a single diseased head of Rye, but more commonly not more than two or three. Each sclerotium consists wholly of a hard and compact mass of mycelium, and contains no part of the original grain of Rye which it has displaced. This sclerotium lies dormant until spring, when, if placed in warm, damp soil, there arise from its interior a number of stalked bodies with rose-colored globular heads. These are the stromata, and each contains just beneath its convex surface numerous flask-shaped perithecia, each of which contains many asci, and each ascus contains several delicate thread-like ascospores.

At maturity the asci rupture and discharge the spores, which, if they find their way to the young flowers of Rye, germinate and produce the mycelium, with which this description started, and so the cycle is completed. The successive steps in the reproduction of this Fungus are illustrated in Figs. 554 to 559, inclusive.

The Discomycetes differ from the rest of the group chiefly in the structure of the hymenium, which is on the surface of a discoid, cup-shaped or club-shaped fructification, which may or may not be the result of an antecedent fertilizing process which takes place in the mycelium growing in the substratum. Some 

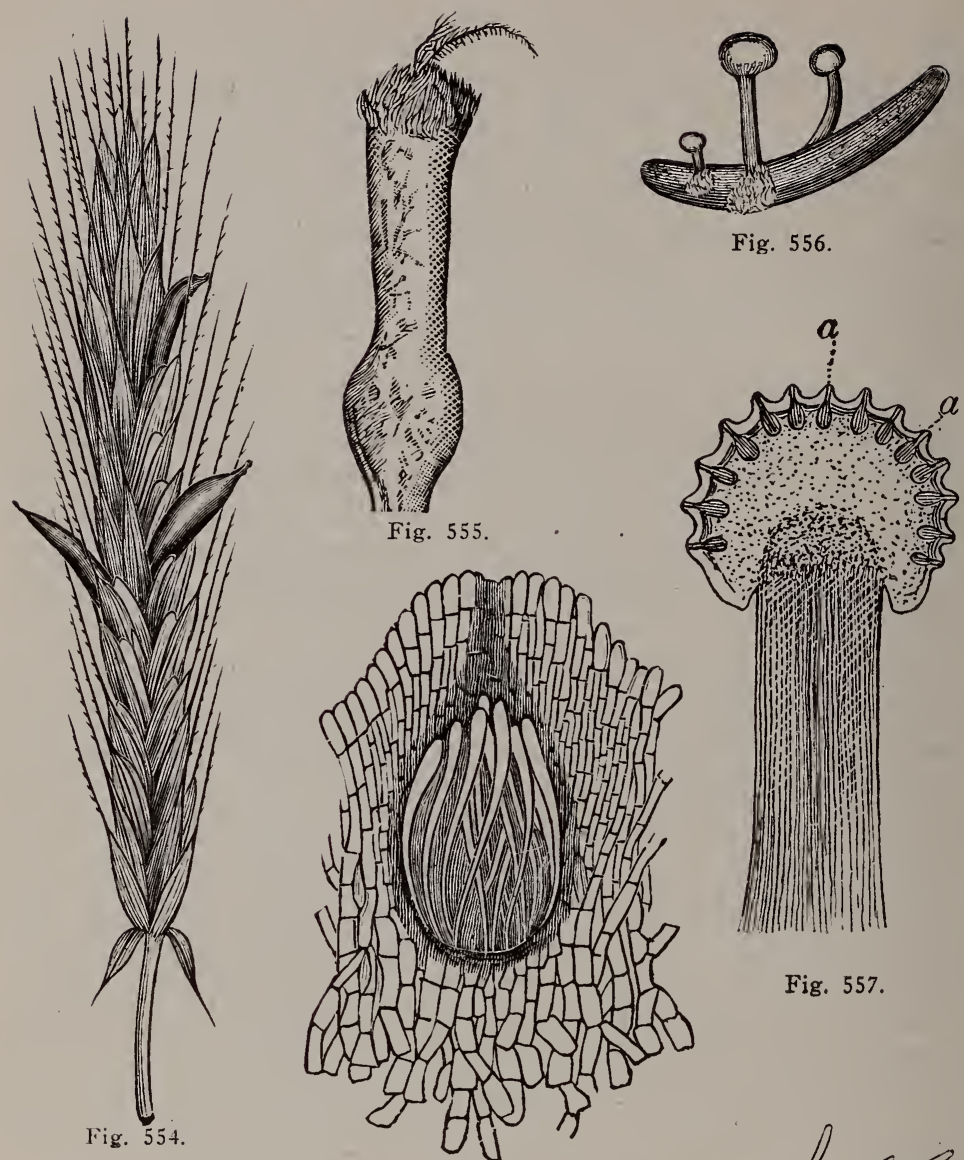

Fig. 556.

Fig. 555 .
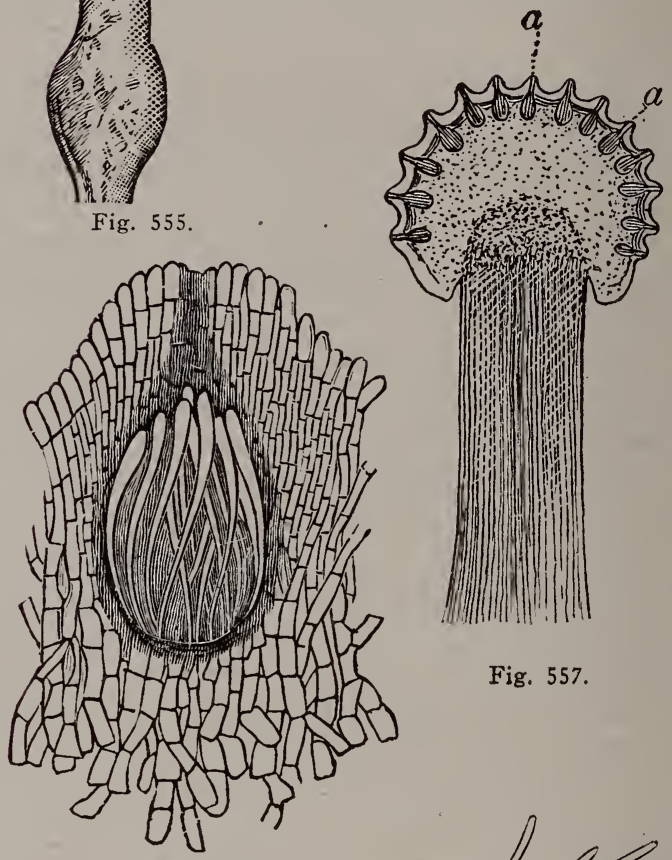

Fig. 557.

Fig. 558.

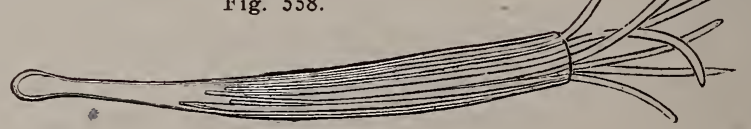

Fig. 559 .

Fig. 554.-Head of Rye, bearing three Ergot-grains.

Fig. 555.--Pistil of Rye attacked by Ergot blight-Claviceps purpurea, in the first or sphacelial stage of development. Somewhat magnified.

Fig. 556.-Ergot-grain after lying orer winter, producing stromata. Nearly natural size.

Fig. 557.-A fructiying organ or stroma of Ergot in longitudinal section. magnified. a, a, perithecia imbedded in the margin.

Fig. 558.-A perithecium much more highly magnified, showing the club. shaped asci in its interior.

Fig. 559.-One of the asci greatly magnified, shown in the act of discharging its ascospores. The discharge really takes place fron the ascus, before it leares the perithecium. 
of the forms are parasitic, others saprophytic. The group includes the largest and most highly developed members of the Ascomycetes. Here belong the Pezizules or Cup-fungi, common in woods, growing upon leaf-mould and producing a cup-shaped apothecium; the Helvellales, including Morchella (see Fig. 566), Helvella, etc., which have large, mostly club-shaped ascocarps, the hymenium of which is borne either on a smooth or on a reticulately indented surface; and the Phacidex, which produce small, blackish, disc-like or roundish fructifications on dead leaves of various kinds.

The fungus parts of most Lichens also belong in this group, but owing to the composite character of these plants they had best be considered separately.

For a fuller illustration of the life history of these plants we may take Pyronema confluans. The mycelium grows in soil rich in organic remains and sends up ascending hyphæ which develop numerous oögonia tipped with stout trichogynes. Into contact with these grow the antheridia developed from other hyphal cells. After the fertilization is effected, the oöspores grow new hyphæ from which are developed the asci, until a mass of considerable size is formed; on the upper surface is developed a hymenial layer of closely compacted erect hyphal branches; the whole apothecium gradually assumes the form of a cup. The ripe ascospores are shed by the rupture of the asci and are disseminated by the wind.
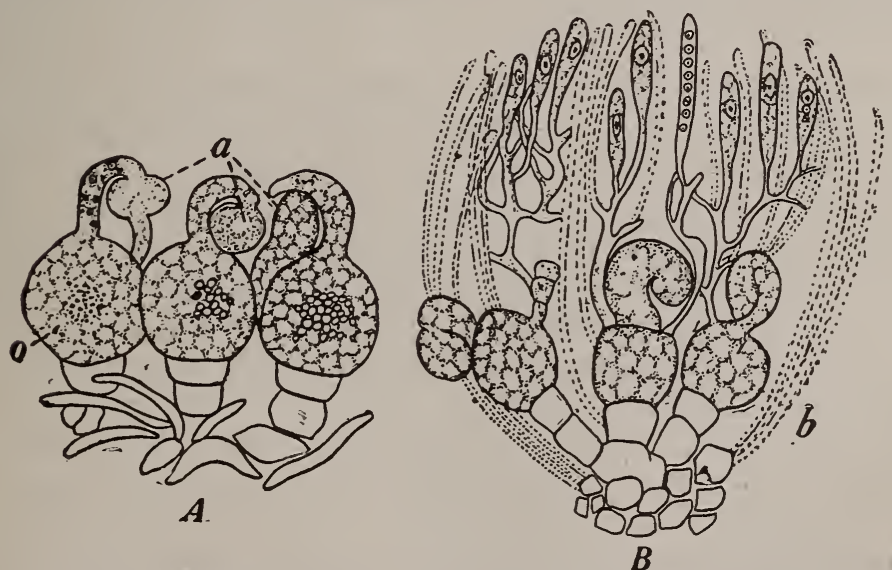

Fig. 560.-Sexual reproduction in Pyronema confluans. A, the sex organs at the time of fertilization, showing the antheridia $(a)$ in contact and fusing with the trichogynes through which the sperms pass to the oogonia (o); $B$, development of apothecium, showing the oogonia developing ascogenous hyphae which are beginning to form asci at the ends of their branches, and the sterile hyphae (b) which grow up among the ascogenous hyphae and form a large part of the wall of the apothecium. Highly magnified. (After Harper from Martin.) 
The Tuberales are, many of them, highly prized for food, under the name of Truffles. They produce subterranean, tuber-like ascocalps from a mycelium that penetrates through the soil, and, in some instances, appears to form a mycorrhiza with the roots of certain trees. The ascocarp is usually spherical, and invested with a tough cortical layer. The ascospores are produced in intricately winding passages in the interior. Each ascus contains from two to four spores, which are set free by the decay of the surrounding parts. Since these tuber-like fructifications are formed underground, they are hunted by means of pigs or dogs, which detect them by their aromatic odor.

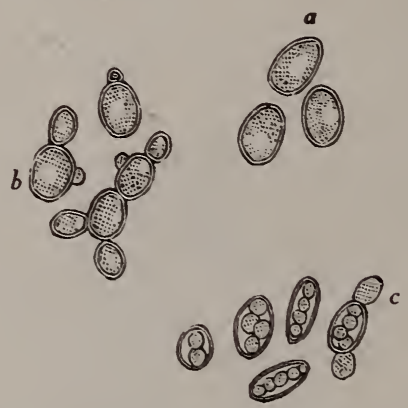

Fig. 561.-Yeast cells. a, cells of Saccharomyces Cerevisiae, not budding: $b$, budding cells of the same plant: $c$. cells of S. ellipsoideus developing ascospores. All magnified about 700 diameters.

The Saccharomycetes, or yeasts, as has already bcen stated, are now classed among the Ascomycetes and are regarded as degenerate members of the group. They include most of the forms which are capable of exciting the alcoholic fermentation in saccharine liquids. They are minute plants of very simple structure, consisting of rounded or ellipsoidal cells, which either occur singly or loosely united into short chains. The cells contain cytoplasm. a nucleus and a vacuole, and, when growing in a suitable medium, they increase rapidly by budding or sprouting. This is their principal and, under ordinary circumstances, their only mode or increase, but when deprived of sufficient nourishment, as for example when wine-ferment is cultivated for several days on a porous tile kept moist under a bell-jar, the cells cease sprouting and the contents break up into four ascospores, which develop thick walls and pass into a resting stage.

In this stage, they are carried through the air, as dust, and are 
found everywhere. Yeasts are readily cultivated on suitable media and, as the flavor of the fermented products depends in large measure on the yeast, pure cultures of certain kinds are much used. In fact, yeast is one of the oldest of cultivated plants. Brewer's yeast (Saccharomyces cerevisix) is familiar, especially as "compressed yeast," in which form it is largely used in making bread. The manufacture of beer, wine and other alcoholic liquids c'epends upon yeasts. Saccharomyces ellipsoideus or wine yeast is a wild yeast which gains access from the skins of the grape to the grape juice. S. albicans is pathogenic, causing the disease known as "thrush." Cells of common yeast are shown in Fig. 561.

The Exoasci are another group of very simple and apparently degenerate Ascomycetes. They possess no ascocarp and the asci are borne exposed. They are parasitic upon Spermatophytes. One species attacks the leaves of the Peach, causing "Peach Curl," another grows on the young ovaries of the Plum, causing the deformity known as "Bladder Plums." A third produces the so-called "Witches Brooms" on some of our deciduous trees. Sexual reproduction is unknown in this group.

\section{CHAPTER VII.-THALLOPHYTA.-FUNGI (CONTINUED).}

\section{THE BASIDIOMYCETES.-THE USTILAGINALES.-THE FUNGI IMPERFECTI.}

THE BASIDIOMYCETES, OR BASIDIA FUNGI.

The distinctive characteristic of this group is the fact that at the ends of the spore-bearing hyphæ, large, club-shaped or oblong cells are produced which bear at their apex delicate processes, two, eight or, more commonly, four in number, each of which is terminated by a rounded or ellipsoidal spore. The cells which bear the spores are called basidia, and the spores, basidiospores. The basidia occur in large numbers compactly arranged, sometimes with intervening sterile filaments called paraphyses, on or in a definite part of the sporocarp, constituting the hymenium. The sporocarp is usually of considerable size, forming much the most 
conspicuous part of the plant, the vegetative mycelium, in fact, being usually concealed in the substratum. The spores in the hymenium all ripen about the same time, and then the sporocarp usually withers away or decays.

The Basidiomycetes are classified scientifically according to the shape of the sporocarp, the position and character of the hymenium, the position of the teleutospores, etc. One species, Exobastdium vaccinii, shows a-very simple fructification, consisting of compactly arranged basidia forming a hymenium directly on the surface of the organs which it attacks. The plant is a parasite on the leaves and stems of Vaccinum vitis-idra. The Basidiomycetes are distributed into four groups: The Uredinales or Rusts, the Ustilaginales or Smuts, the Hymenomycetes or Mushrooms, and the Gasteromycetes or Puffballs.

The Uredinales are popularly known as Rusts, and are parasites, forming yellowish, brownish or blackish spots on the stems and leaves of various plants. Some of them, as the Wheat-rust, are highly destructive to crops. The name Ecidiomycetes, sometimes applied to these fungi, refers to a peculiar form of fructification called "æcidia," which are produced by the species. Ecidia consist of a cup-shaped envelope or peridium, in the bottom of which rows of cells are formed and separated one after the other, by transverse division, forming rounded spores called xcidiospores. They are only a pecular form of conidia, and the whole fructifying organ corresponds, doubtless, to the ascocarp of the Ascomycetes.

In some species, the æcidiospores, on germinating, produce short, few-celled filaments, constituting a promycelium which soon ceases its vegetative growth and bear's small conidia, called sporidia. These, when deposited by the wind or some other agency on a suitable host-plant, germinate and produce tubes which penetrate the epidermis or enter the stomata and develop a mycelium in the interior of the host-plant, and this mycelium again produces æcidia.

In some of the species, however, the life-history is more complex, there being two distinct stages in it that are spent on different host-plants, and in which different sets of reproductive spores are developed. Of this group, the common Wheat Rust, or Black Rust, Puccinia graminis, may be taken as an illustration. This first makes its appearance in the form of rust-colored patches on the stems and leaves of Wheat and other grasses. These spots are due to multitudes of reddish spores, called uredospores or "summer 
spores," produced from a mycelium growing within the plant. These spores are produced abundantly and are dispersed by the wind; if the season is damp and warm the infection rapidly spreads from plant to plant and great damage is done.

Spore production of this kind continues until toward the close of the growing season, when, as the grain is ripening, the rust-like patches change to a darker, almost blackish color. This is due to the development of another kind of spores called teleutospores or. "winter spores," which differ from the other's in being two-celled and having thicker walls. Moreover, they are not capable of developing on a healthy blade of grass, but rest over winter in the straw, and in the spring germinate, producing a promycelium, the branches of which bear the basidiospores, or sporidia. These are wafted away by the winds and germinate on the leaves of the Barberry and, perhaps, on other plants, but not on the Wheat. These immediately produce hyphæ which, penetrating the stomata, for'm a mycelium which derives nourishment from the cells of the leaf, and finally bursts through the epidermis on the under surface of the leaf and forms the rcidia popularly known as "clustercups."

In these little cups are formed multitudes of small, rounded, yellow or orange-colored æcidiospores which the wind scatters. These do not germinate on the Barberry, but those which are conveyed to the leaves of grasses develop hyphæ, which penetrate to the interior of the leaf, and after a time produce the rust-like patches at the surface.

At the same time as the æscidia are produced, there are usually formed on the upper surface of the Barberry leaf, small flaskshaped structures or spermagonia containing functionless spermatic, supposedly representing sexual spores.

Some of the steps in the reproduction of this plant are shown in Fig. 562, A, B and C.

This remarkable life-cycle of Wheat Rust, including four kinds of spores, besides the spermatia, and affecting two host-plants, is of great economic interest. No effective method of combating the rust has been found, for even the destruction of the Barberry does not eradicate the disease. While the uredospores are usually killed by freezing in winter weather, yet they can survive in the young plants, where Winter Wheat is grown, and then reinfect the fields in the spring. The best remedy seems to lie in the selection and cultivation of varieties of Wheat that are resistant or immune to 
the Rust. Black Rust also infects Oats, Rye, Barley and other Grasses.

The phenomenon of alternating stages on different hosts, so

A

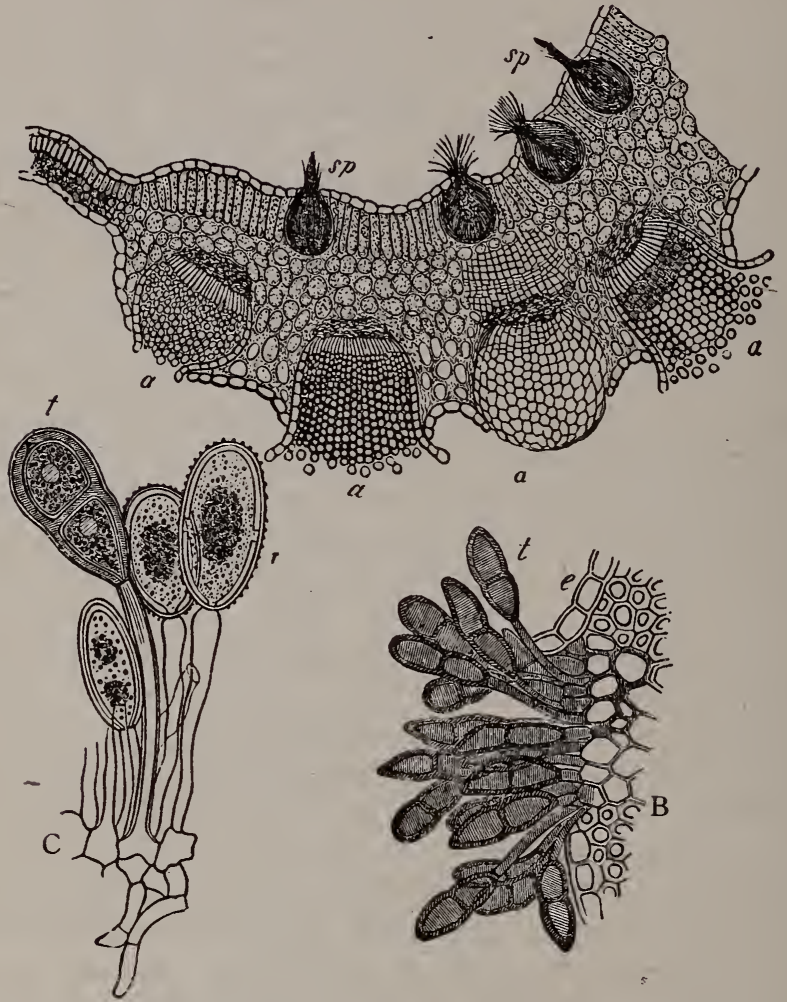

Fig. 562.-Puccinia graminis. A, part of a thin cross-section of Barberry leaf showing four rcidia, a, a, a, a, in various stages of development on the under surface, and four spermagonia, sp, imbedded in the upper surface. B, group of ripe teleutospores bursting through the epidermis, e, of a leaf of Triticum repens. C, Uredospores, $r$, and teleutospore, $t$, more highly magnified. A, slightly magnified; B, magnified about 190 diameters, and C, magnified about 390 diameters. After Sachs.

prominent in this group, also occurs in some others and is likewise exemplified in some of the lower forms of animal life.

Gymnosporangium juniperi-virginianæ produces the gall-like growths knorvs as "Cedar apples" on the leaves of the Red Cedar. Its cluster cups appear on the leaves and fruit of the Apple (Malus) and constitute the disease known as "Apple Rust." Other 
Rusts attack Asparagus, Feach trees, Pine trees and other plants, causing serious damage.

\section{THE USTILAGINALES.}

The Ustilaginales or Smuts, of which the common Corn-smut, Ustilago Maidis, may be taken as the type, are parasitic upon flowering-plants, chiefly on the Grasses, and cause much damage to the cultivated cereals. The slender mycelial threads usually penetrate through the intercellular spaces of the host-plant, and in some species send sucker-like branches (haustoria) into its cells. In some instances the parasite attacks the seedling plant and sends its hyphæ through the whole structure, growing as it grows; in others it attacks the more mature plant, and confines its ravages to certain parts.

At maturity it produces, either at the outside of the host-plant, or in its intercellular spaces, very numerous chlamydospores on tangled mycelial filaments. These most frequently occur on the inflorescence, or on parts adjacent to it, and the spore-masses, together with the abnormal growth caused by it, often assume quite characteristic forms. Corn-smut forms irregular, roundishlobed masses, often attaining a diameter of six inches or more. The masses consist of a translucent gelatinous membrane enclosing innumerable blackish-brown, rounded "brand" spores, having a nodular surface and a thick wall. These chlamydospores survive the winter, either on the ground or in the straw, or in the grain itself. They germinate the following spring, giving rise to a promycelium, regarded as a basidium, and on which basidiospores are produced which develop into a true mycelium.

The Smut of Oats, Stinking Smut of Wheat and Covered Smut of Barley are due to similar fungi.

The Gasteromycetes are distinguished from the rest of the Fungi by the fact that the hymenium is enclosed within the peridium or body of the sporophore. The latter may be uniform or it may be differentiated into two coats, the outer and inner peridium and the interior, known as the gleba, variously subdivided into compartments, on the walls of which the basidia are borne. In many species the number of spores on each basidium is eight, but in some there is the usual number, four.

By reason of the complex structure of their sporophores, the Gasteromycetes are usually considered the highest of the Fungi in development. They are often found growing with the Mush- 
rooms, requiring about the same conditions for growth, and, like the latter also, many species are edible.

The Lycoperdacex, the Hymenogastracex, the Nidulariacex and the Phallacer, form the sub-divisions of the group.

The Lycoperdace include the Puff-balls and Geasters or Earthstars. The rounded sporophores of the former produce innumerable brown spores, which are discharged in clouds by the scaling away of the outer peridium and the rupturing of the inner one. The latter are similar, except that the tough outer peridium sepates hygroscopically into regular segments, which flatten out into a star-like form. (Fig. 565.)

The Hymenogastrace $\boldsymbol{X}$ are subterranean fungi, resembling, in their habits, the Truffles. In most of the other species of the group the walls of the chambers, constituting the supporting frame-work for the hymenium, undergo great changes during the development of the sporocarp, for exaruple, in the Lycoperdons the chambers disappear, leaving only a loose frame-work of threads; but in the species of this group they remain unchanged until the ripening is complete. The spores are finally set free by their decay.

The Nidulariaceæ or Bird's-nest Fungi (see Fig. 564), form small cup-shaped sporophores. When ripe the peridium opens at the top, exposing several rounded hard bodies, peridiola, which look something like eggs in a nest. These bodies are the sporebearing chambers of the gleba which have become isolated in the process of development.

The Phallacex, or Carrion Fungi, are at first rounded, but in development, the peridium, which consists of three layers, bursts and exposes a chambered gleba which is elevated on an elongating stalk. The hymenium soon becomes a dark-colored and foul-smelling mucilaginous mass in which the spores are inclosed. The spores are scattered by carrion-flies, which are attracted to the plants in large number:s by the smell.

The Hymenomycetes include such familiar Fungi as the Mushrooms and Toadstools. They are a numerous and important group, resembling each other in the fact that at the time the spores are ripe, the hymenium, which consists of basidia associated with sterile hyphæ, occupies the outer free surface of the sporophore or fruit-body and not its interior.

The fungi of this group are usually saprophytic in habit, the showy sporophore developing from an invisible mycelium, which may be hidden in the ground or in dead tree trunks. Only a few 
are parasitic and may attack living trees. The species bearing sporophores of umbrella-like form with stalk, cap and gills, are popularly known as Toadstools or, when edible, Mushrooms, although the latter term is often applied to edible fungi of other groups. Some of the Toadstools are very poisonous, others are merely tough and unsuited for food.

According to the shape of the sporophore and the structure of the hymenium, several sub-groups are distinguished, among which are the following:

The Thelephoracex, or Leather Fungi, are, in their structure, the simplest of the group. In all the hymenium is smooth. They form incrustations, in some species of irregular, in others of regular form, on logs, the barks of trees, etc. Exobasidium attacks the ovaries of flowers of the Heath family, producing gall-like growths.

The Clarariacex, Club-fungi or Coral Fungi, a related form (see Fig. 567), have cylindrical or club-shaped, simple or branching sporophores, which may, according to the species, be white, gray, brown or yellow in color. The hymenium occupies the smooth exterior surface, and when the spores are ripe, they communicate to it a dusty appearance.

The Hydnaceæ or Tooth Fungi (see Fig. 568) are distinguished from the rest by the fact that the hymenium consists of prickle-like projections from the surface of the sporophore. There are many species, some of them having a cap or pileus supported by a central stalk, as in the common Mushroom; sometimes the stalk is attached laterally, and sometimes there is no stalk.

The Polyporacex, Pore Fungi, are characterized by producing a hymenium which consists of straight tubes arranged compactly side by side. On the inner surface of these tubes the spores are borne. The hymenium covers the under surface. Some of the species produce fructifications of large size. In the genus Polyporus, the Bracket Fungi, they mostly form lateral, shelf-like projections often seen on dying trees. The mycelium spreading through the wood gradually reduces it to a pulp and kills the tree. In the genus Boletus (see Fig. 569), there is an expanded cap and a stalk, the latter usually placed centrally. The tough, spongy mycelium of Polyporus fomentarius is sometimes used in surgery under the name of Surgeon's Fungus, and, saturated with solution of potassium nitrate and dried, it constitutes what is called Spunk or Punk. Polyporus officinalis, a parasite upon the European Larch, has medicinal properties, and Boletus edulis is one among 
the few of the large genus to which it belongs, that is prized for food.

The Agaricacex, the Agarics or Gill Fungi, produce a sporophore which is commonly expanded and hat-like in form, and in the majority of cases, is supported on a central stalk; but sometimes the latter is inserted to one side of the center, or in a few species is altogether wanting. The most distinctive features of the group, however, consist in the structure of the hymenium, which is composed of lamelliform bodies, or "gills," as they are often called, arranged in a radial manner on the under surface of the expanded umbrella-like portion of the sporophore or pileus. Many of the stalked forms are, in the early stage of their development, invested with a membrane called a velum or veil, which, at a later period, is ruptured; but its parts usually remain in the mature sporophore, forming a sheath at the base of the stalk, or a ring around it higher up, or fringing the border of the pileus. Other forms are destitute of this membrane.

The species are numerous, many of them edible, others useless for food, and still others highly poisonous. Among the latter may be mentioned the Deadly Amanita, from which the alkaloid muscarine is obtained. Several species are brightly and beautifully colored. Some, as the genus Coprinus, produce a very perishable sporophore, others are hard, leathery and enduring. The genus Lactarius is distinguished from the rest, and from most, other thallophytes, by possessing a milky juice. Commonly, the hymenium is borne on the under side of the sporophore and is thus protected from rain.

For further illustration of the group, we may select Agaricus campestris, the common Mushroom. A mass of mycelium called by mushroom growers "spawn," is formed by the germinating spores in the vegetable mold or humus, from which the plant absorbs its food. On this mycelium protuberances of a rounded or nodular form, popularly known as "buttons," sooner or later make their appearance and rise above the soil. These are the young sporophores still invested in their membrane. Presently the membrane or veil ruptures, exposing an upright stalk or stipe composed of compactly arranged hyphæ, which are continued at the top into the pileus. The latter is convex and nearly smooth above, and the numerous radiately arranged, plate-like gills, cover the concave surface below. The gill surfaces are composed partly of large sterile cells, and partly of basidia, and each of the latter 
bears two spores. The spores are minute, and the aggregate number produced by a sporophore is enormous.

In this species a portion of the velum remains as a ring or annulus on the stalk. See Fig. 563, $A, B$ and $C$.

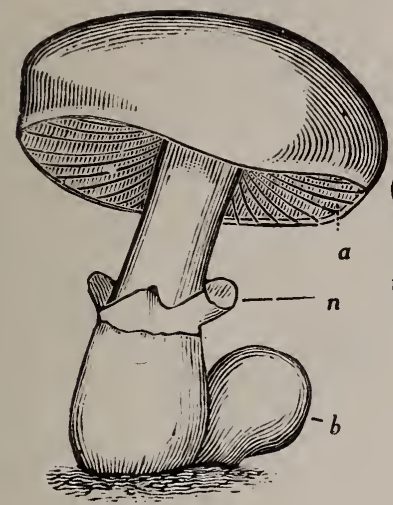

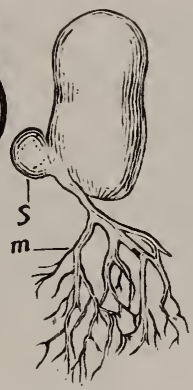

B

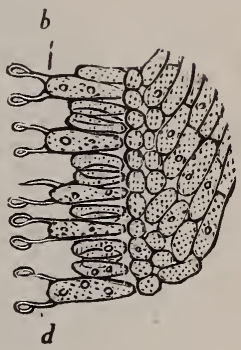

$\mathrm{C}$

\section{A}

Fig. 563.-Agaricus compestris. A, two sporophores, one of them, b, quite young, and still enclosed in its membrane, the other fully matured; a, the "gills" or hymenium; $\mathrm{n}$, the annulus. Somewhat reduced.

B, young sporophores, s, s, of the same species, showing how they originate from the mycelium, $m$.

$C$, a small portion of one side of one of the gills of the same fungus, showing basidia $\mathrm{b}$, and sterigmata, d. Magnified about 325 diameters.

Figs. 564 to 571 illustrate various species of the higher Fungi.

In the genus Amanita the veil covers the whole fruit-body and when it is ruptured during growth the lower part remaining attached to the base of the stalk forms the volva or "death cup." Fig. 570 .

\section{THE FUNGI IMPERFECTI, OR IMPERFECT FUNGI.}

Here are included a large group of Fungi, numbering about 16,000 kinds, whose life histories are imperfectly known. As this group is an artificial one, formed only for convenience in classification, its membership is constantly changing, for as investigation goes on the life histories of its members are worked out and they are properly classified elsewhere. While the group is thus a heterogenous one, its fungi differing greatly in their characteristics, yet their resemblances are chiefly to the Ascomycetes.

Reproduction is commonly from conidiospores and the manner in which these are borne affords the usual basis for the classification of this group. 


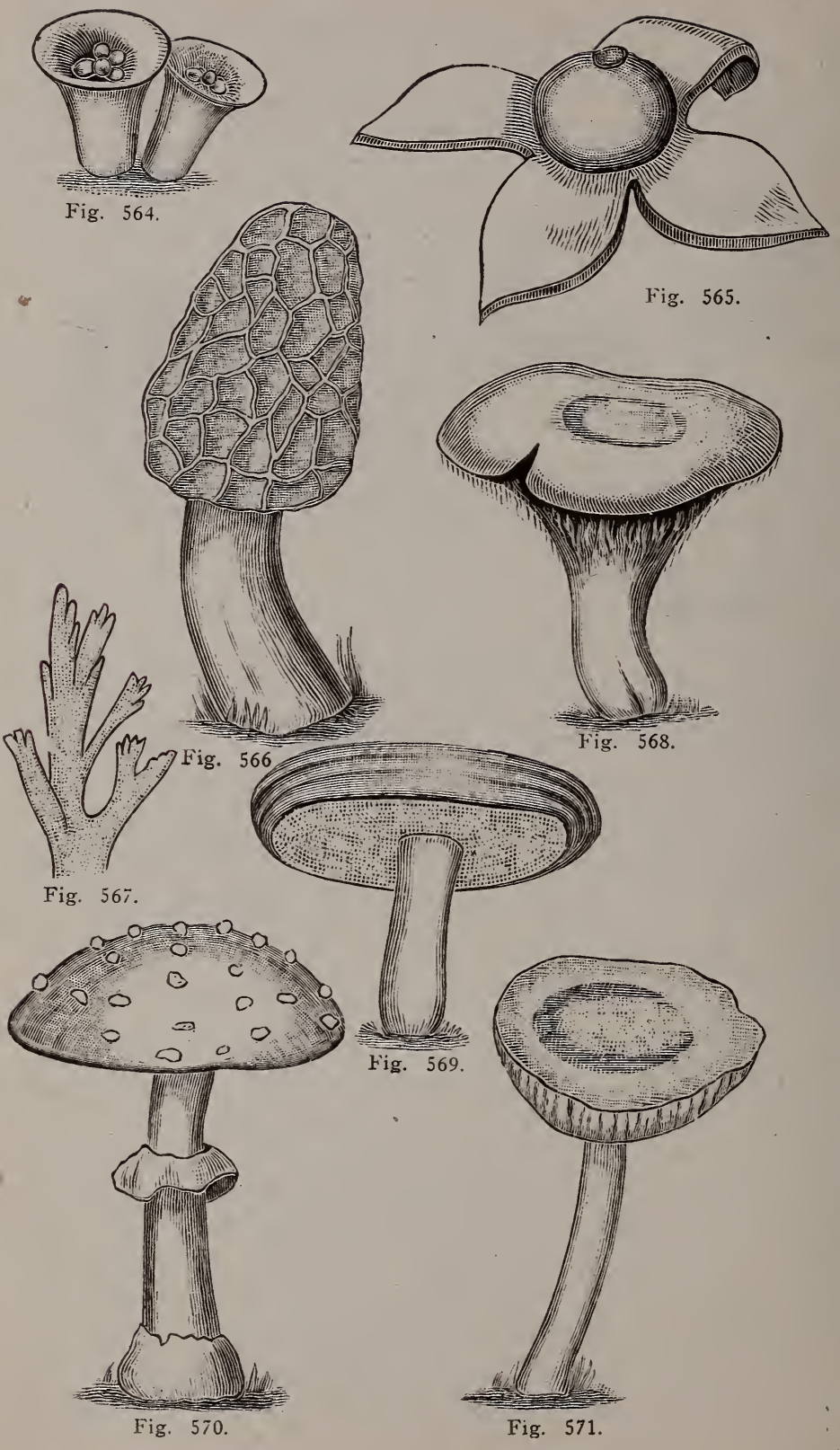


While the larger number are saprophytes, there are also many parasites, some of these producing serious diseases on cultivated plants, such as Apple Blotch, Late Blight of Celery, Leaf Blight of Tomato, Anthracnose of Grape, Early Blight of Potato and Black Rot of Sweet Potato.

\section{CHAPTER VIII.-THALLOPHYTA.-FUNGI (CONINUED).}

THE LICHENES, OR LICHENS.

These plants are here treated as a separate group more for convenience than because there is anything in their structure which warrants the distinction. Each is, in fact, an alga and a fungus living together as host and parasite. Lichens are therefore composite structures. A few of the fungi composing them belong to the Basidiomycetes, but by far the larger portion to the Ascomycetes, and in each case the modes of reproduction are such as characterize these groups respectively.

The algæ mainly belong to the unicellular Green Algæ or some form of the Blue-green Algæ, among others, the Nostocs, the Palmellas, Chroöcoccus, Chroölepus, and, more rarely, the Confervoidæ; and while they do not lose their power of vegetative multiplication by reason of the parasitism, they do lose the power to reproduce by other means, and moreover, frequently undergo important structural modifications. They often occur free from the fungus association, but the lichen fungi are seldom found growing separately.

The parasiticism of the fungus upon the alga, constituting the lichen, has been compared to that of master and slave (Helotism). It seems likely that the alga suffers little injury from the attack

Figs. 564 to $571 .-F u n g i$ of various kinds.

Fig. 564.-Cyathus, one of the Nidularieae or Bird's-nest Fungi, slightly enlarged.

Fig. 565.-Geaster, or Earth-star, nearly natural size.

Fig. 566.-Morchella esculenta, one of the Discomycetes.

Fig. 567.-Portion of Clavaria rugosa, one of the Hymenomycetes.

Fig. 568.-Hydnum repandum, one of the Hymenonycetes, about two-thirds natural size.

Fig. 569.-Boletus edulis, one of the Polyporeae, about half natural size. size.

Fig. 570.-Agaricus muscarius. the Fly Agaric, about two-thirds natural

Fig. 571.-Marasmus oreades, about two-thirds natural size. 
of the fungus and in fact is benefitted to a degree, since the hyphal cells of the latter help to retain water which enables the green algal cells to make carbohydrates under conditions of drought, which other plants could not survive. Lichens are therefore quite independent of food supplies in the substratum and can exist on bare rocks, the barks of trees, fence-rails and other exposed surfaces. They are found everywhere, often acting as pioneers by aiding in the disintegration of rocks and the formation of soil and preparing the way for Mosses and other plants.

Some idea of the character of this association between parasite and host may be gained by the study of Fig. $572 \mathrm{~A}$ and B, taken

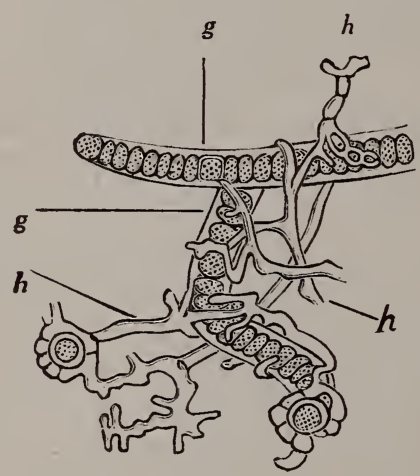

A

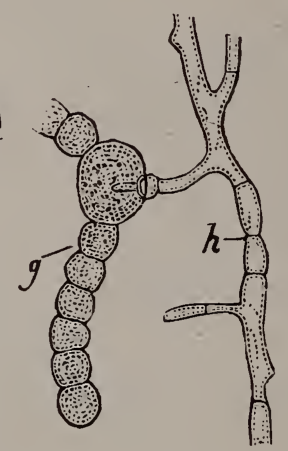

B

Fig. 572.-P'ortions of two Lichens, showing fungi parasitic on Algae. In $A$, the filaments, $g, g$, belong to a species of Scytonema and the hyphae, $h, h, h$, are those of Stereocaulon ramulosus. Magnification about 950 diameters.

In $B$, a hyphal branch, $h$, is entering the cells of a species of Nostoc, $g$. Magnification about 650 diameters. Both after Bornet.

from Bornet's researches on the Lichens. Here portions of tissue from two different Lichens are shown.

It has been determined by experiment that the lichen alga freed from the lichen fungus can lead a normal life and may then be identified, even though this is not possible during its parasitism by the fungus which prevented its normal development. Lichens have been produced artificially by allowing the spores of the lichen fungus to germinate on free algæ. By such synthesis, it has been learned that one algal species may serve several lichen fungi. With perhaps one exception, however, the latter are not able to grow except in symbiosis with their algal hosts.

The colors of lichens vary from almost white to greenish-gray, 
yellow, orange or brown. Examined microscopically, their tissues always show colorless filaments, the fungus hyphæ, and green or red chlorophyll-bearing cells which belong to the Algæ. The latter are technically called gonidia.

In some Lichens the algæ are equally distributed throughout the thallus; in others they are arranged in definite groups or layers. The former kinds are described as homoiomerous, the latter as heteromerous. All the species are capable of enduring dessication without destroying their vitality.

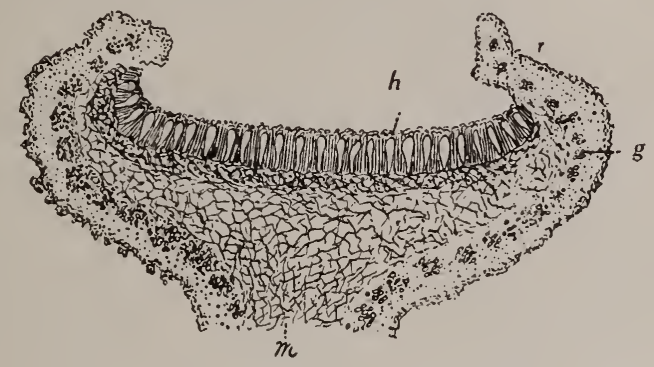

Fig. 573.-Vertical section of apothecium of Anaptychia ciliaris; h, hymenium, producing numerous asci; g, gonidial layer; r, rind, composed of compact hyphae; $m$. medulla, composed of loosely arranged hyphae. Magnified about 50 diameters. After Sachs.

The fructification of Lichens is, as we have seen, that of the fungus and not of the alga. The sex organs suggest those of the Red Algæ.

In the common Tree Lichen, the grayish and radiate thallus or plant body is composed of hyphal cells surrounding green algal cells and sending down thread-like rhizoids which serve to fasten the plant to its substratum, usually the bark of an old tree; as the hyphal cells spread, the algal cells multiply by cell-division and thus keep pace with the growth. On the surface of the thallus, there form many cup-like apothecia in the hymenium of which asci and paraphyses are formed as they are in the Discomycetes. These asci develop ascospores.

In other species the apothecium is closed and the spores, when ripe, escape from a narrow opening, as in the Pyrenomycetes. Fig. 573 represents a perpendicula section of an apothecium of the cup-like kind.

Many of the Lichens also multiply vegetatively by means of soredia. These are gonicia, or groups of them, wrapped about 
with hyphal filaments, which escape from the Lichen thallus, usually in the form of a fine powder, and germinate directly to form new plants.

According to the structure and mode of growth of the thallus, Lichens may be described as:

The Homoiomerous Lichens. The members of this group have for the most part a more or less gelatinous thallus, which is sometimes flattened and lobed, and sometimes filamentous, consisting of an algal filament with fungus hyphæ wrapped about it. Their algæ all belong to the Cyanophyceæ. The remaining groups are Heteromerous or stratified.

The Crustaceous Lichens form a numerous group, having a thallus of indefinite form adhering so closely to the substratum on which they grow, that it is often difficult to distinguish them from it. They grow on rocks, smooth-barked trees, wooden fences, and sometimes on the ground.

The Foliaceous Lichens form flattened leaf-like expansions, which may be variously lobed or crispate on the margins, and adhere, often in the form of rosette-like patches, more or less closely to the substratum. Many of these, as the Parmelias and Stictas, form greenish-gray or yellowish patches on tree-trunks, fences, etc.; others, as the species of Peltigera, grow on damp hillsides among the moss, and bear their apothecia on the lobed borders of the thallus. Still other species, as those of Gyrophora and Umbilicaria, form dark-colored patches on rocks. See Figs. 574 and 575.

The Fruticose Lichens have a shrub-like growth, often branching profusely, and are attached to the substratum only at the base. The branches of the thallus are in some species cylindrical, in others flattened, but even in the latter there is usually little, if any, structural difference between the upper and under surface. For the most part the gonidia are arranged in the form of a hollow cylinder running lengthwise of the branches; the interior of the cylinder is filled with hyphæ, and on the exterior they enclose it as a sheath. Many of the species cling to tree-trunks, logs or rocks, but some grow upon damp earth.

To the forms having cylindrical branches belong the Usneas (see Fig. 576), Roccella tinctoria, a Lichen that constitutes one of the principal sources of Litmus (see Fig. 577), and the familiar Cladonia rangiferina, or Reindeer Lichen; and to those with flattened branches belong the so-called Iceland Moss, Cetraria islandica, 
prized as a food, and used in medicine for its demulcent and tonic properties. (See Fig. 578.) Sereral specics yield red, purple, brown or yellow dyes. None are poisonous.

Since the fungus is the ruling member of the composite struc-
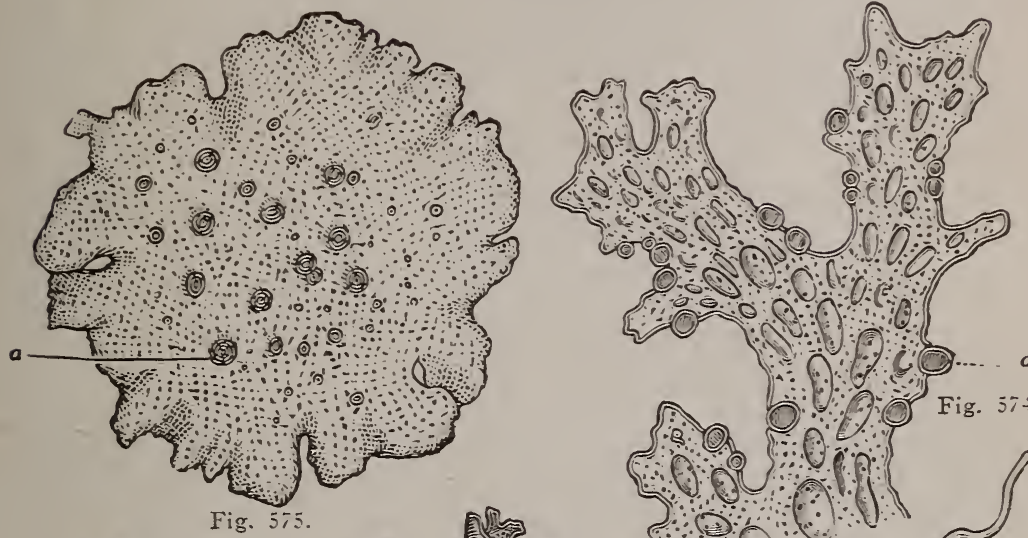

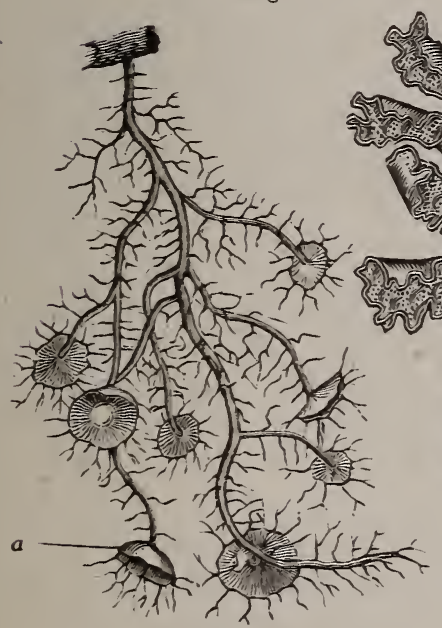

Fig. 576.

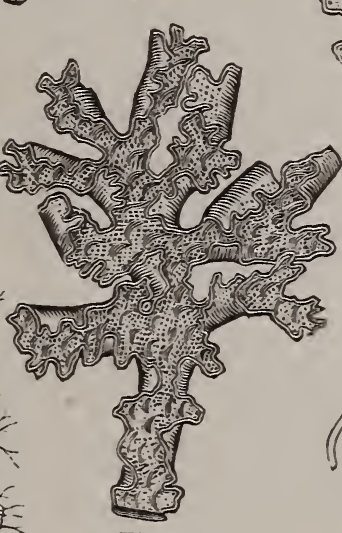

Fig. 578.

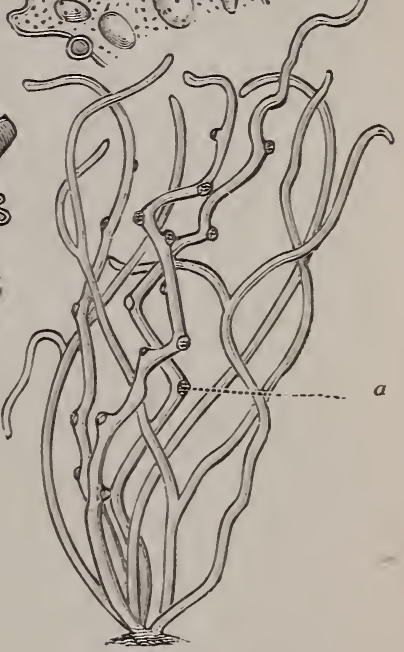

Fig. 577 .

Fig. 574.-Portion of thallus of Sticta pulmonacea, a ioliaceous Lichen. a, apothecium. Natural size.

Fig. 575.- Thallus of Lmbilicaria vellea, a toliaceous Lichen, a, apothecium. Natural size.

Fig. 576.-Thallus of L'snea barbata, a iruticose I,ichen, about natural size. , apothecium.

Fig. 577.-Thallus of Roccella tinctoria, a fruticose Lichen, about natural size. a, apothecium.

Fig. 578.-Portion of Cetraria islandica, a fruticose Lichen with a flattened thallus. About natural size. 
ture, determining the form of growth, the classification of Lichens is usually based on the fungal constiutent and four families are recognized :

Discolichenes, producing asci in apothecia, as in the Discomycetes; Pyrenolichenes, producing asci in perithecia in the manner of the Pyrenomycetes; Basidiolichenes, where the fungus belongs to the Basidiomycetes, and Gasterolichenes, where the fungus belongs to the Gasteromycetes.

\section{CHAPTER IX.-THE BRYOPHYTA, OR MOSS PLANTS.}

\section{THE HEPATICAE.-THE MUSCI.}

\section{CHARACTERISTICS OF THE BRYOPHYTES.}

The Bryophytes, on the whole, show, in the more complete differentiation of their cells into tissues and of the plant body into stem, leaves and root-hairs, as well as in their more complicated reproductive process, a decided advance in structure over the Thallophytes. At first sight the two groups seem sharply distinct, but a closer comparison shows that there are few points in the Bryophytes which have not been clearly anticipated by some of the plants below them. In turn, the Bryophytes anticipate some of the features of the higher plants.

The Bryophytes are the simplest of land plants. They are supposed to have originated from the Algæ and to have been the most primitive of land plants. As contrasted with the Algæ, which soon die when taken from the water, the Mosses are protected by their structure against too rapid transpiration. They are not parasitic and are seldom harmful; they have, however, but slight economic value.

All Moss-plants are chlorophyll-bearing; in all, the plant body consists of true tissues formed by cell-division; all are of small or moderate size, seldom attaining more than a few inches in height, yet none of them at maturity are so small as to be strictly microscopic; none possess true roots, these being replaced by rhizoids, consisting of branched, thread-like cells by means of which they attach themselves to the substratum or absorb nutriment; a few are aquatic; most are either terrestial or epiphytic, but none are either parasitic or saprophytic. 
All the species are characterized by a distinctly-marked alternation of a sexual with an asexual generation. The gametophyte or plant which bears the sexual organs is the more conspicuous; it may be either a leafy-stemmed plant or a thallus.

In the majority of the Bryophytes, the distinction between leaf and stem is clearer than in the Characeæ and other foliose Thallophytes, but the leaves of Mosses are simpler in their structure than those of higher plants. They often consist of a flat expansion composed of a single layer of cells which are all alike, but in a few species the cells are in more than one layer and one or two simple nerves are developed. The stems, of the higher forms at least, have an axial bundle of elongated, thin-walled cells which must be regarded as anticipating the fibro-vascular bundles of the higher plants, though true ressels are never developed.

Mosses differ from most of the higher plants in their branching. The thalloid forms mostly branch dichotomously, and the branches of the foliose forms do not spring from the leaf-axils, but from the side of the leaf, or from a point below it. The stems increase in length by means of a single terminal cell, and in many cases the plants continue to grow at the apex, while dying away at the base.

The organs of reproduction consist of antheridia and archegonia. These are sometimes borne solitary on the gametophytic stem or thallus, but more commonly in groups; sometimes both kinds of organs in the same group, sometimes the different kinds in distinct groups. They are often closely associated with hair-like bodies, called paraphyses, and are not infrequently surrounded with slightly modified leaves, called the perichatium or the perigynium.

The antheridia are short-stalked, multicellular bodies, spherical, oblong, ovate or club-shaped in form, and produce in their interior cells multitudes of minute, slender, spirally-coiled, biciliated sperms. The latter are thicker at one end, and it is to the opposite end that the cilia are attached. (See Figs. 581 and 582.)

The archegonia are flask-shaped, multicellular bodies, with a narrow, elongated neck, and a relatively thick, rounded base. They possess at first an axial row of cells, the one in the dilated base being of larger size than the rest, and constituting the egg cell. Later, the axial cells of the neck dissolve into mucilage, through which the sperms penetrate to the egg cell. The former are discharged from the antheridia when moisture is present, and 
it is through the medium of the water that they find their way to the archegonia. (See Fig. 583.)

The fertilization thus effected initiates an important series of changes resulting in the production of the plant of the asexual

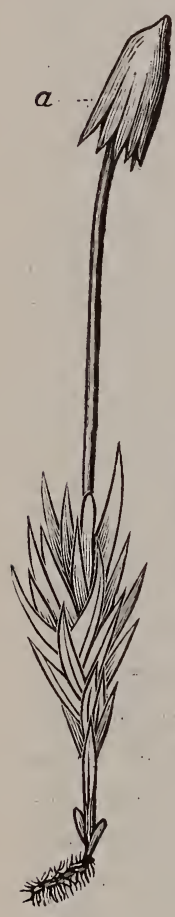

Fig. 579.

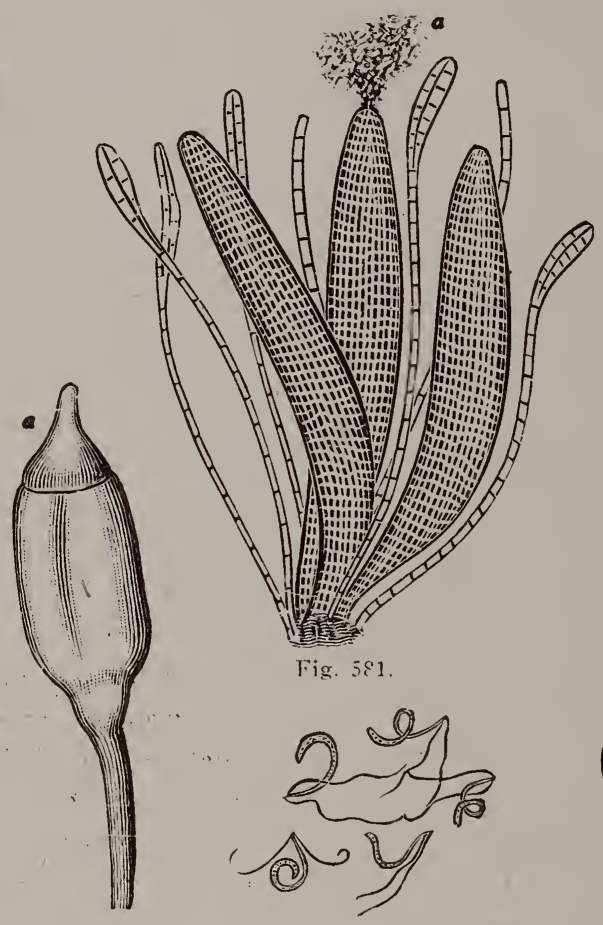

Fig. 582 .

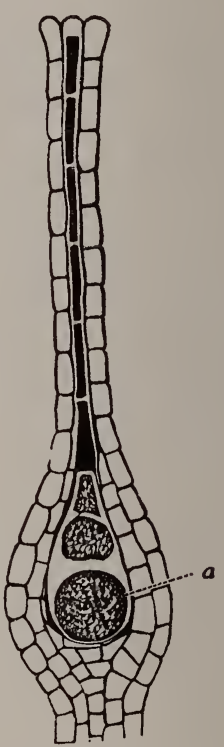

Fig. 583.

Fig. 579. - The common Hair-cap Moss, Polytrichum commune, in fruit. a, stalked sporogonium covered with a calyptra.

Fig. 580.- Sporogonium somewhat magnified, and with the calyptra removed, showing operculum, a.

Fig. 581.-Paraphyses and antheridia, one of the latter emitting sperms. a.

Fig. 582.-Sperms, highly magnified.

Fig. 583.-Female organ. or archeronium. highly magnified. a, egg cell.

generation, the sporophyte, very different in appearance from the gametophyte, but growing up in contact with it, and technically called the sporogonium. The process of development is as follows: The fertilized egg cell, still enclosed within the archegonium, divides repeatedly in different directions, and the lower portion of the cell-mass thus formed penetrates the tissues of the parent plant, and the rest develops outward, stretching and finally rup- 
turing the walls of the archegonium, which, immediately after fertilization, usually increases considerably in size, and then stops growing, while the sporogonium continues its development. As this proceeds, the basal part usually develops into a stalk, sometimes of considerable length, while the apical portion swells into a capsule, which produces in its interior multitudes of minute spores. (See Fig. 584.)

The archegonium, in some species, is ruptured at its apex by

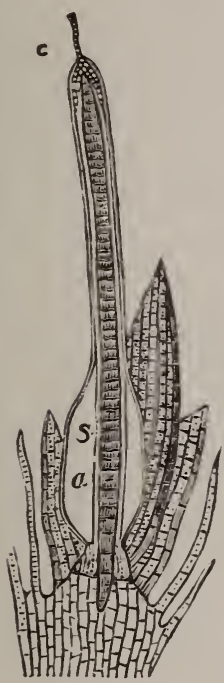

F: ig. 584

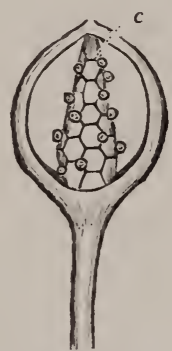

Fig. 585 .

Fig. 584.-Development of sporogonium of Funaria hygrometrica. a, archegonium already much stretched by the development of the sporogonium, s, the lower part of which has penetrated the tissues of the stem, and the upper part of which carries the calyptra, c. Magnified about 50 diameters. After Sachs.

Fig. 585.- Sporogonium of Phascum muticum cut open so as to show the columella, c. to which a few spores are still attached. Magnified.

the growth of the sporogonium, and then its torn remains are seen as a kind of sheath at the base of the stalk; in others, and more commonly, it ruptures near the base, and then is borne like a cap, called the calyptra, at the top of the capsule. (See Fig. 579 , a.)

The sporogonia, when ripe, differ in structure and mode of dehiscence, in ways which are more or less characteristic of the genera. In some, there is developed in the interior of the capsule an axial organ, called a columella, around which the spores are borne (see Fig. 585); in other's, no such organ is present. In the capsules of some, there are developed among the spores peculiar filamentous, usually spirally coiled, bodies, called elaters, which aid in the ejection of the spores after the capsules are ripe; in other species elaters are wanting. 
In some species, the capsule splits, when ripe, longitudinally into two or four valves; in others, the dehiscence is transverse and the upper part, called the operculum, comes off like a lid; in a few forms the dehiscence is irregular, and rarely there is none at all, but the spores are set free by the decay of the capsular walls.

The spores are minute cells with the wall differentiated into two parts, a thicker outer coat, called the exospore, and a thinner interior one, which is very distensible, like the inner coat of a pollen-grain, called the endospore. In germinating, the exospore ruptures, and the endospore becomes distended into a tube, which usually divides transversely and forms a mass of green, branching filaments, which resemble some of the filamentous algæ; this is the protonema, from which either directly or by production of lateral buds, the plant of the sexual generation is developed. (See Fig. 586.)

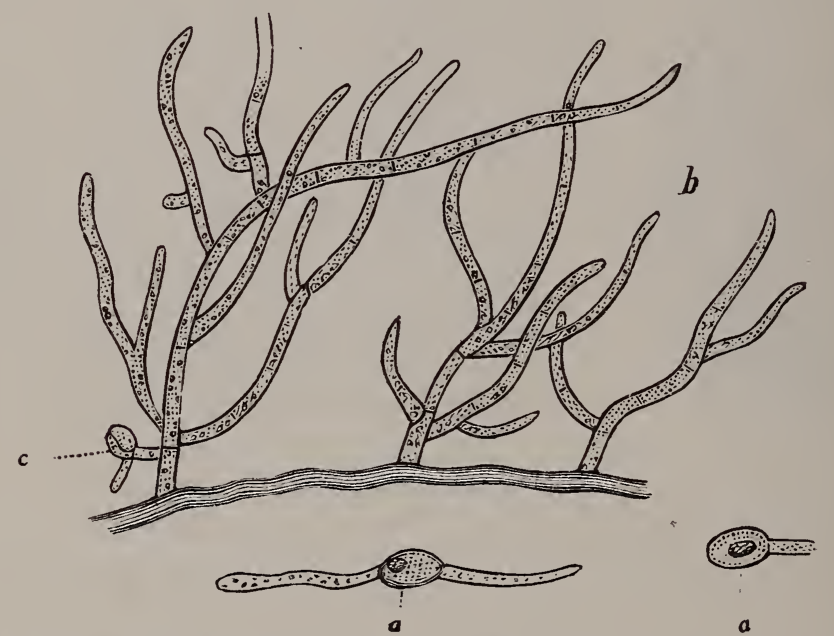

Fig. 586.-Germinating spores and protonema of Moss. a, a, spores in different stages of germination; $b$, filaments of the protonema; $c$, bud on protonema destined to develop into a leafy plant. Magnified about 550 diameters.

The Bryophytes number about 16,000 species and are divided into two classes, the Hepaticæ or Liverworts and the Musci or Mosses.

THE HEPATICAE, OR LIVERWORTS.

The Hepaticæ, or Liverworts, are the lower in organization. A few forms still live in water, thus establishing a connection with 
their supposedly ancestral forms. The majority are land plants but prefer moist or at least shady locations. In some species the thalli are lobed and liver-shaped, and in accord with the old-time "doctrine of signatures" they were assumed to have medicinal value in the treatment of the diseases of the liver-hence the name Liverwort. They include many thalloid forms, and the leafbearing or foliose ones present a simpler structure than the Mosses, proper. Their sporogonia, if they dehisce at all, open lengthwise, usually into four, but sometimes into two, valves. Except in one order, the Anthocerotex, they do not possess a columella. Most of the species are provided with elaters. The remains of the archegonium are never borne on the top of the sporogonium.

In habit of growth, nearly all of the species lie prostrate on the substratum, presenting one side to the light and having the other in shade. The two surfaces accordingly have a different structure, rhizoids being usually developed in great numbers on the shaded but not on the illuminated side; the latter, in the thalloid forms, also often possesses stomata, while the other does not. The flattened forms usually branch dichotomously, and in some of these there is no indication of leaves, while in others, as in the Marchantias, scale-like bodies, doubtless to be regarded as imperfectly developed leaves, occur on the under surface.

In the foliose forms, there are two vertical rows of leaves, very simple in their structure, on opposite sides of the stem, and usually a third row of less perfectly developed ones on the side next the substratum.

There are about 4,000 species, grouped in four orders, as follows:

The Ricciales are thalloid forms which branch dichotomously, and produce their antheridia and archegonia sunken in a groore along the middle line of the upper side of the thallus (gametophyte). The sporophyte is reduced to a globose unstalked sporogonium which does not bear elaters, and does not spontaneously rupture when ripe. It bears many spores. The plants are of small size, and not numerous in species. Some of them, as Riccia fluitans and $R$. natans, are not uncommon in fresh water; others, as Riccia glauca, grow on damp soil.

Anthocerotales is a small order of inconspicuous Liverworts, of which Anthoceros is representative. The gametophyte is a simple, flattened, irregularly-lobed thallus, which is closely attached 
by means of rhizoids to the damp soil in which they grow. The archegonia and antheridia are imbedded in the upper surface of the thallus. After fertilization a sporogonium develops which is remarkable in that it is chlorophyll-bearing and thereby able to make food for itself, though dependent on the gameophyte for its water supply. Accompanying the green tissues are stomata, allowing of an air-supply, while a columella running lengthwise through the sporophyte carries the spore-bearing tissues. The development of a root would make this green sporophyte an independent plant and to this extent it anticipates the two independent generations of some of the Pteridophytes. Anthoceras lavis, one of the most commonly observed species, is illustrated in Fig. 587.

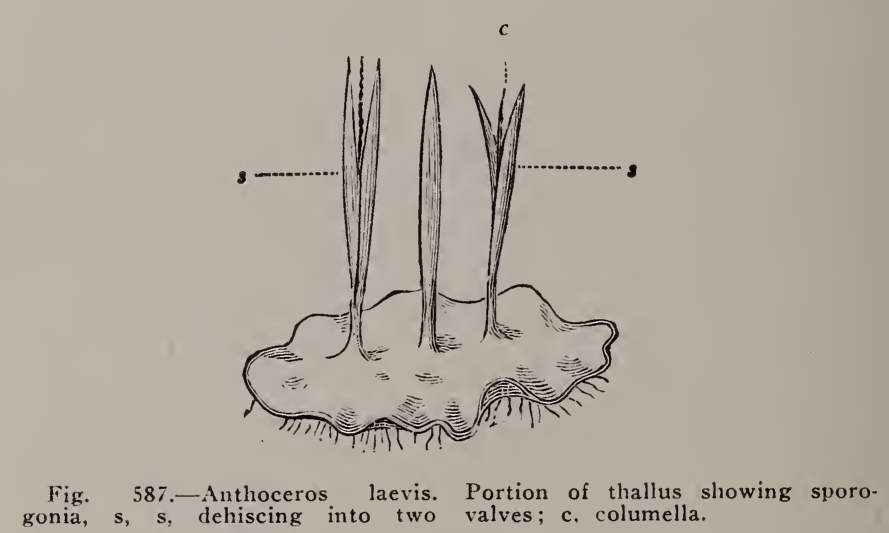

The Marchantiales include the most familiar Liverworts. They have thalloid, dichotomously branching stems, producing numerous well-developed stomata on the upper surface, and abundant rhizoids and two rows of small scale-like leaves on the lower. The antheridia and archegonia are borne in separate, stalked receptacles. The spore-capsules dehisce variously in different species, sometimes by four valves and sometimes irregularly, and the ejection of the spores is aided by spirally,coiled elaters.

Marchantia polymorpha is found everywhere on damp ground, on wet rocks adjacent to springs and waterfalls, and on the damp earth of greenhouses. Fig. 558, $A$, represents a male plant bearing an erect, stalked, wheel-shaped receptacle (gametophore), $a$, in the upper surface of which numerous antheridia are imbedded. 
Fig. 558, $B$, represents a female plant of the same species; bearing a female gametophore which consists of a star-shaped body borne at the summit of an erect stalk. On its under surface, near the base of the rays, when the organ is young, are borne the flaskshaped archegonia.

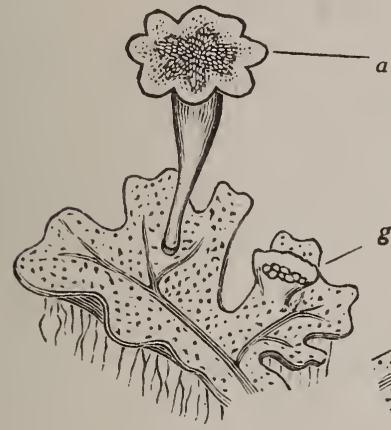

A

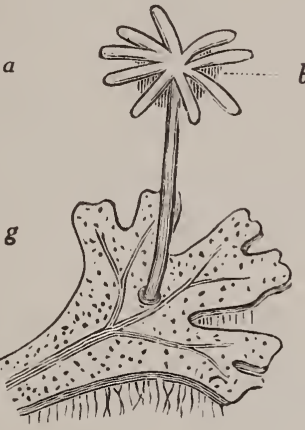

$B$

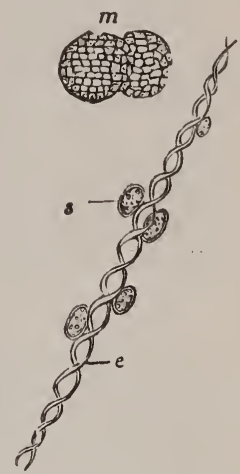

Fig. 588.-Marchantia polymorpha. A, male plant bearing a stalked gametophore; $a$, producing antheridia. B, female plant, bearing a stalked gametophore. $\mathrm{b}$, from which sporogonia have developed on the under surface of the rays; $\mathrm{g}$. one of the receptacles with gemmae; $m$, one of the gemmae magnified; e, elaters highly magnified. and s. a spore clinging to the elaters.

The fertilized egg cell develops into a rounded sporogonium, containing many spores accompanied by elaters. At the base of this stalked sporogonium may be seen the remnants of the archegonium from which it grew. The spore-capsule bursts to discharge the spores, their expulsion being aided by the hygroscopic movements of the elaters. The spores are dispersed by the wind and, upon germinating, produce new thalli.

Vegetative reproduction is provided for by the development, on the thallus, of cups containing gemmæe (Fig. 588, $g$ ), which have the nature of separable buds (Fig. $588, m$ ) and, when washed out or blown by the wind, are able to produce new plants. During the growth of the thallus the older portions may decay, setting free the younger parts and thus giving rise to new plants.

Since the thallus bears the gametes, it is termed the gametophyte, while the sporophyte is represented by sporogonium.

The Jungermanniales constitute the largest order of the Liverworts, numbering about 3,000 species. A few of them have thalloid, but the great majority, foliose stems. They produce solitary sporogonia which ordinarily split into four valves, from the apex 
downwards, and produce numerous spores and spiral elaters. (See Fig. 589.)

In the foliose forms the leaves occur, as has already been described, in three longitudinal rows, and two of the rows are conspicuous and spread out laterally, while the third occurs on the shaded or under side, and its members are not so well developed.

The leaves are very delicate, scale-like, destitute of a midrib and are of but one cell in thickness. The antheridia are usually found among the leaves and the archegonia at the apex of the shoots. These may occur on the same plant (moncecious) or on different plants (diœcious). Many of the species are common in damp soil and on tree trunks. They are plants of wide distribution, occurring both in tropical and temperate climates.

THE MUSCI, OR MOSSES.

The Musci, or Mosses, are all leafy-stemmed plants, and the leaves are all of the same kind and very seldom two-ranked. The spores produce a protonema of felted, green filaments which may increase indefinitely by an apical growth, but sooner or later gives rise to lateral buds which develop into the leafy plant. See Fig. 586. When the sporogonium develops in the archegonium, the latter usually ruptures at the base, and is carried up as a calyptra on the top of the capsule. In the great majority of cases the latter has a circumscissile dehiscence, and the operculum comes off like a lid. The columella is always present, and the capsule never produce elaters. Mosses propagate abundantly by vegetative processes. Most of their cells are able to develop protonemas. Many can provide gemmæ. Shoots separated from the parent plants give rise to new plants and thus the moss carpets frequent in woods and bogs are formed.

There are three orders of Mosses, as follows:

The Sphagnales, or Bog-mosses, which grow in tufted masses in boggy places, about springs and along the banks of mountain brooks, where the supply of water is constant. They are included in one genus, Sphagnum; they have in the shade a bright green or a pale green, but in exposed locations a red color, straight stems growing indefinitely at the ends and producing numerous laterally spreading, fascicled branches, which are covered with closely imbricated leaves. The latter are veinless and consist of a single layer of cells, but these are of two kinds, one large, narrowly linear, chlorophyll-bearing, and forming a net-work, and the other color- 
less, perforated by pores and serving to absorb and hold water by capillarity, whence the notable water-retaining property of Sphagnum. The antheridia are borne on club-shaped or catkin-like axillary branches, and the archegonia are commonly in groups of three or four enclosed in a bud-like involucre at the ends of the upper branches. The spore-capsule is round and operculated, but without a peristome, and pedicelled, but the pedicel, known as the pseudopodium, instead of being a part of the sporogonium, as is usually the case in other Mosses, is a prolongation of the axis of the gametophyte. The germination of the spores produces a flat thallus, like the Liverwort, and not a filamentous protonema such as the higher Mosses possess. One of the Sphagnums is illustrated in Fig. 590, $A$ and $B$.

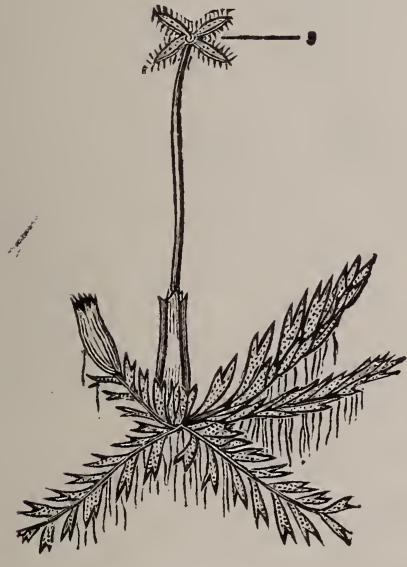

Fig. 589.

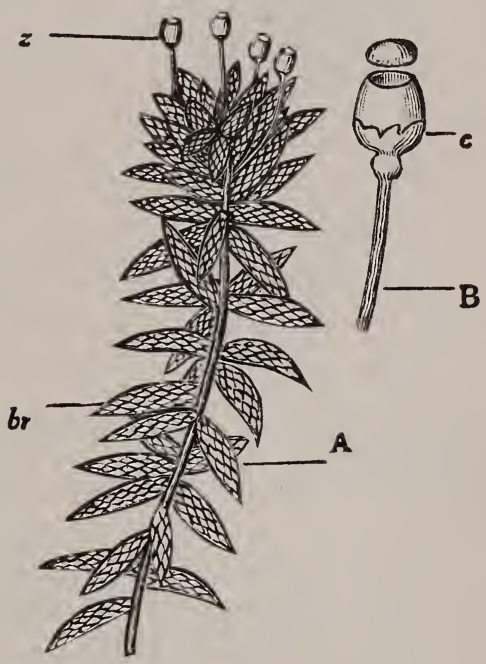

Fig. 590 valves.

Fig. 589.-Jungermannia bidentata. s, sporogonium dehiscent into four

Fig. 590.-Sphagnum cymbifolium. A, mature plant bearing leafy branches, br, and capsules, $z$. B, one of the capsules, considerably magnified, showing operculum; c, is the remnant of the wall of the archegonium.

The Sphagnums are the Mosses that form peat-bogs, and these are, in some countries, an important source of fuel. By reason of its water-holding quality Sphagnum is employed for wrapping and packing living plants for shipment. When properly cleaned and dried it has been employed as a surgical dressing, for which its absorptive power makes it especially useful. 
The Andræales. This is a small order of dark colored, branching mosses, of rather diminutive size, mostly growing on damp rocks in mountainous regions. They produce capsules which have a closely adherent, thin calyptra, and a central columella, which is free at the apex; they dehisce longitudinally into four or rarely six valves. These separate in the middle to shed their spores, but remain united both at the base and apex. See Fig. 591. The capsules are stalked, but the stalks are formed as in the Sphagnums.

The Bryales constitute by far the largest as well as the best
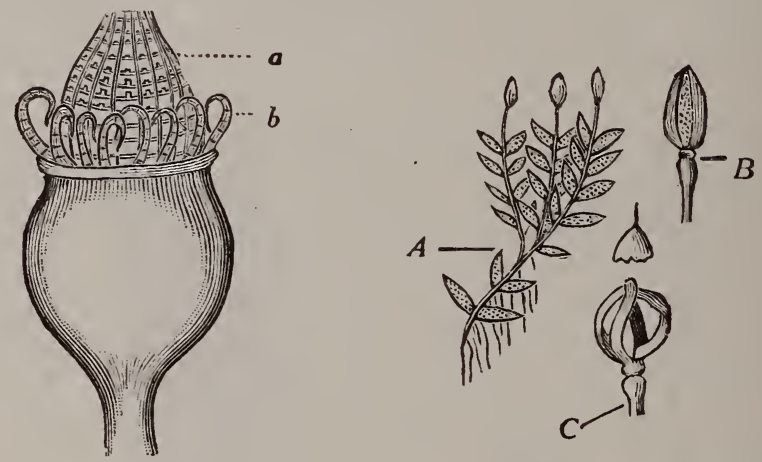

Fig. 591.-Andraea. A, fruiting plant; B, capsule, magnified; C, dehiscent capsule and calyptra.

Fig. 592.-Capsule of Fontinalis, one of the Bryales, with calyptra and operculum removed, showing the double peristome; a, inner, b, outer peristome. Magnified.

developed order of Mosses. It is one of this order that is illustrated in Figs. 579 to 583, inclusive. They are usually, low, tufted plants, with generally cylindrical or rarely slightly compressed or somewhat angular, leafy stems, the gametophytes. The leaves are simple, and, in some species, composed of but one stratum of cells; in others, of more than one; in some, the leaves are nerveless, in others there is a single median nerve, and in still others two small nerves at the base.

$\therefore$ The reproductive organs are, in most cases, enclosed in a perichætium or perigonium. The sporophyte consists simply of the sporogonium or spore-capsule which is traversed perpendicularly by a columella.which is attached both above and below; in a very

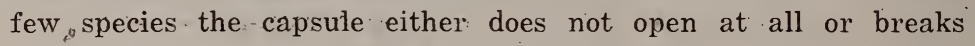
irregularly; in the great majority it dehisces by means of an oper- 
culum. The orifice thus exposed is sometimes naked, but in most cases has a peristome. The latter may either be single or double, having one part within the other. The outer peristome consists of a row or circle of teeth which, in different species, vary in number from four to thirty-two or more. The inner peristome, if present, consists of a yellowish pellucid membrane, which is often latticed, and attached to the inner base of the outer peristome, and is itself segmented or toothed at the top. (See Fig. 592.)

The spores are dispersed by the wind and upon germinating develop into the protonema, already described. From buds on the protonema grow stems (gametophores) and at the tips of these the antheridia and archegonia are borne. Free-swimming sperms of spiral form are given off from the antheridia. Fertilization is effected through water, probably raindrops. The archegonium opens to receive the sperms and the fertilized oöspore develops into the new sporogonium.

\section{CHAPTER X.}

THE PTERIDOPHYTA, OR VASCULAR CRYPTOGAMS.

THE FILICINEÆ.-THE EQUISETINEA.-THE LYCOPODINEA.

The Pteridophyta, like the preceding series, consist entirely of chlorophyll-bearing plants, which are never either parasitic or saprophytic. The word "Pteridophytes" literally means "fernplants," the Ferns being the most numerous as well as the most important members of this division. About 3,500 species are known.

The term "Vascular Cryptogams" is applied because here, for the first time, we find a distinct development of tubes and sieve cells constituting a vascular system and permitting of a growth in height far beyond that of the Bryophytes. In many of the species, in fact, we find a differentiation of tissues almost as complete as that found in flowering-plants. Moreover, the plant-body develops true roots and well-developed stems and shoots, the latter forming, in many species, large and beautiful leaves or fronds.

In the reproductive process, also, great progress is shown over 
that which occurs in the Mosses. They exhibit, like the Bryophytes, a distinct alternation of generations, but while in the latter group the gametophyte is the more conspicuous and better developed, the reverse is the case in the Pteridophytes, the plant producing the sexual organs being, even in those species in which it is best developed, a mere thallus resembling that of some of the lower Hepaticæ, and commonly perishing soon after the fertilization of the egg cell has been effected, while the sporophyte developed from the latter is conspicuous and highly organized. In common with the Bryophytes, the Pteridophytes possess distinctive Archegonia, hence these two divisions are sometimes grouped together as the Archegoniates.

The process of reproduction, briefly outlined, is as follows: The spore borne by the sporophyte germinates and produces the protonema, which through cell-division grows into a tiny flat green body, the prothallium, so called because of its resemblance to a thallus and because it is temporary in its character, a mere forerunner, so to speak, of the plant which is ultimately produced by it.

In the Ferns, Equisetums and other species in which it is most highly developed, the prothallium consists of a flattened body attaching itself to moist soil by means of rhizoids growing from the under surface, and is always insignificant in size compared with the plant which produced the spore. It is composed of chlorophyll-bearing cells, and may continue its growth for some time before bearing fructifying organs. These consist of antheridia and archegonia. The archegonia, like those of the Mosses, are flask-shaped, cellular structures, having an enlarged basal portion which contains the egg-cell or oösphere, and a neck through which the fertilizing sperms penetrate. The basal portion is buried in the the tissues of the thallus, but the neck is free, projecting above the surface. The latter is usually short and composed of four longitudinal rows of cells.

In the interior of the young archegonium, an axial row of three cells is formed, the lower constituting the egg cell, the other two the neck cells, which later are converted into mucilage, the pressure of which forces apart the cells composing the wall of the neck, forming a passage for the sperms. The mucilage which oozes out of the opening seems to have an important influence also in directing the free-swimming sperms to their destination.

The antheridia may be produced on another part of the same prothallium, or on a different one. They are usually rounded 
cellular bodies, with walls composed of a single layer of cells, and borne on the surface of the prothallus. In the interior a number of small rounded cells are produced, each of which contains a spirally coiled sperm, provided at its anterior or small end with numerous vibratile cilia. Both organs are usually borne on the under surface of the prothallus, and the sperms are set free when the surface is bathed in water, and through this medium they swim about, finding their way ultimately to the mucilage discharged at the orifice of the archegonium, and pass through it to the egg cell. The first sperm to reach the egg cell penetrates it, thus completing the act of fertilization, and at once a fertilization membrane is formed about the fertilized egg cell, through which the remaining sperms are unable to enter. The egg now begins to develop in the bottom of the archegonium, and by means of a root-like process which it sends into the tissues of the prothallus, for a time derives nourishment from the latter, but soon forms roots, stems and leaves of its own, and becomes independent.

In the Mosses, under the same circumstances, only a sporogonium, which remains attached to the parent plant, and seems a part of it, is produced; but here it develops into a conspicuous and highly organized plant, usually with an unlimited period of growth, and possessing roots, stem and leaves. This plant at maturity bears, usually either on the ordinary leaves, or on others specially modified for the purpose, a multitude of spores corresponding to those produced in the capsules of Mosses. These are borne in organs called sporangia, and their structure and the way they are borne form a basis for the classification of the members of the Fern group.

Great differences exist in different members of the group, in the degree of development which the prothallus attains. In the Ferns, and other of the lower members, it is comparatively well developed, while in some of the higher forms it tends to disappear entirely, being reduced to one, or a very few cells, which do not emerge from the coats of the germinating spore.

While the life cycle in Ferns is nearly always as above described, yet in some instances the sporophyte may grow out directly from the prothallus without fertilization intervening, a phenomenon known as A pogamy, and, conversely, prothallia sometimes arise directly from the leaves of the Fern plant, without the intervention of spores, a condition known as Apospory.

Some of the species produce but one kind of spores, while 
other's produce two sets, one of large size, called megaspores, which, in germinating, produce prothallia bearing archegonia only, and a smaller, called microspores, whose prothallia produce antheridia only. The former species are called homosporous, the latter, heterosporous.

Three classes are usually recognized: The Filicineæ, the Equisitinex, and the Lycopodinex.

\section{THE FILICINAE, OR FERNS.}

In the Ferns, the sporophyte plants have solid, mostly unbranching, or but sparingly branching stems, which, in our species, are all subterranean; but in some tropical or sub-tropical forms rise above ground and form scaly trunks, sometimes of considerable size. They all increase in length by the division of the cells of a meristematic region at the tip of the stem.

The leaves are more highly developed than in any other group of vascular cryptogams. They are ample, petioled, sometimes stipulate, and commonly, though not always, fork-veined; they usually unfold circinately, increase in length by an apical growth, and often branch into very compound forms.

The roots are true roots, in structure and function like those of the Seed Plants and not rhizoids such as occur in the gametophyte.

The vascular bundles are of the concentric type, and of that variety of it which has the xylem tissues located centrally, and ensheathed by the phloem. In the stems the bundles are usually disposed in a single circle, as has already been explained. (See page 224, Part II.)

The sporangia are always borne on the leaves, either on those of the ordinary form, or on those slightly modified for the purpose. They are either borne at the margins or on the under surface, most commonly in groups or clusters, each called a sorus (plural sori). The sporangia are cellular sacs, whose walls consist of a single layer of cells, and enclose usually a considerable number of spores.

To the Filicinex belong by far the larger part of the existing Pteridophytes. According to the structure of the sporangia the class is divided into two sub-classes, the Eusporangiatæ, with the wall of the sporangium composed of several layers of cells, and Leptosporangiatæ, with the wall of the sporangium composed of but one layer of cells. 
The first sub-class includes but one order, the Ophioglossales, or Adder's Tongue Ferns; the second sub-class includes the Filicales or Ferns Proper, and the Hydropteridales, or Water Ferns.

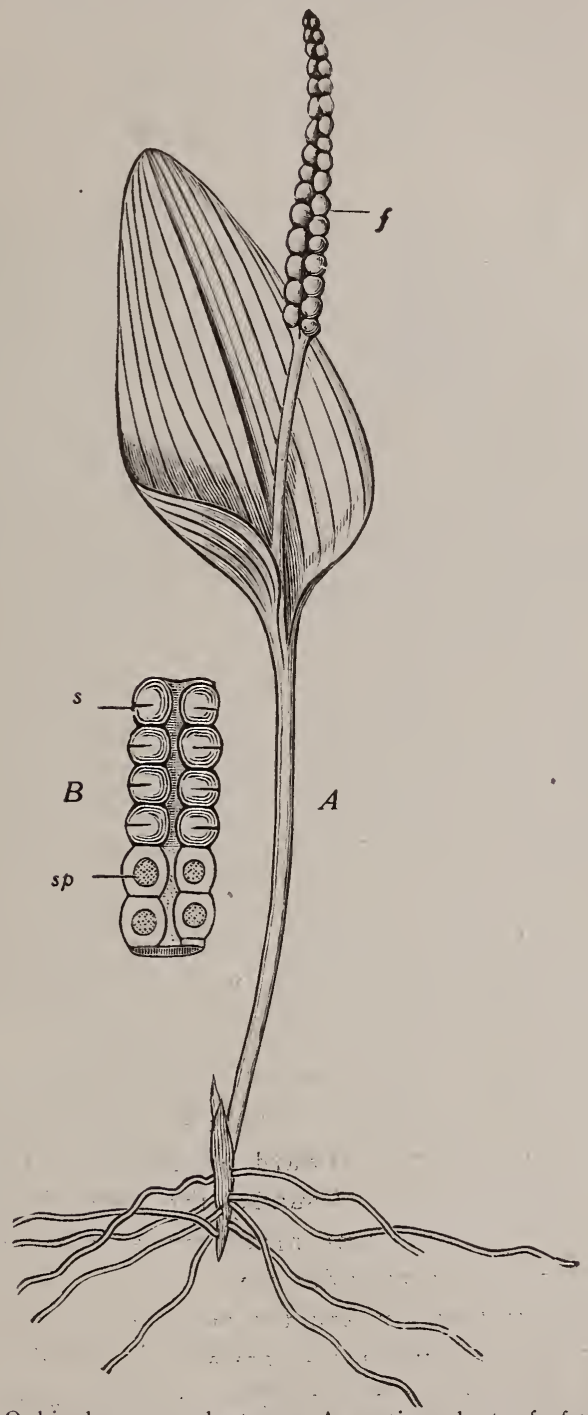

Fig. 593.-Ophioglossum vulgatum. A, entire plant; f, fruiting portion of leaf. B, part of fruiting portion of leaf, magnified. s, rounded portion of margin, containing in its interior a sporangial cavity, as shown below at $\mathrm{sp}$, where a portion has been cut away so as to show the internal structure. 
The Ophioglossales comprise a small order, the members of which consist of a stem, bearing a single leaf, and arising from a fleshy root. This leaf bears a fruiting segment on its upper side, upon which are developed in a spike or panicle, rows of sporangia formed from the inner tissues of the leaf. See Fig. 593. Ophioglossum, or Adder's Tongue Fern, and Botrychium, or Grape Fern, are the common genera. The tropical order Marattiales is related.

Filicales. This constitutes by far the largest order and includes all the plants we ordinarily call Ferns. They have a wide range but reach their highest development in the tropical Tree Ferns.

The spores in germinating produce at first a filament, one end of which soon expands into a flattened tissue consisting of one stratum of cells. By further growth it becomes two-lobed or cordate at the apex, the growing point being located between the lobes, and the middle portion of the prothallus becomes several layered. This is the gametophyte and it is usually better developed and longer lived than in other vascular cryptogams. It consists of a flat, green thallus, attached by one surface to the soil by means of numerous simple rhizoids.

The sexual organs of both sorts are borne on the under surface. The antheridia are rounded bodies usually produced in abundance at the margin and on the posterior surface of the younger prothallus along with the rhizoids. In the majority of cases they consist of a single layer of cells enclosing mother cells, which, by division, form the sperms. The antheridium when ripe absorbs water, which causes it to burst at the apex, and the mother cells containing the sperms are set free. Soon after, the walls of these cells burst, each setting free a sperm which is coiled spirally, and provided at its thinnest end with numerous cilia.

The archegonia are usually borne on the thicker, middle part of the older prothallia. They are flask-shaped bodies with necks rather short, and curved backward or toward the base of the prothallium. See Fig. 594. Usually, the antheridia and archegonia are not ripe on the same prothallus at the same time and cross-fertilization is thus provided for.

The mode of fertilization and the development of gametophyte from the fertilized egg cell are essentially the same in the entire class. It has already been described at the beginning of this chapter. All the Filicales are homosporous.

The stems in a few instances, as in Pteris aquilina, have the 
internodes rather long and not covered by the persistent leaf-bases, but, in most instances, the nodes are crowded together, and the leaf-bases completely obscure the stem, giving it a scaly appearance.

The leaves and stems often bear hairs which are usually flat-
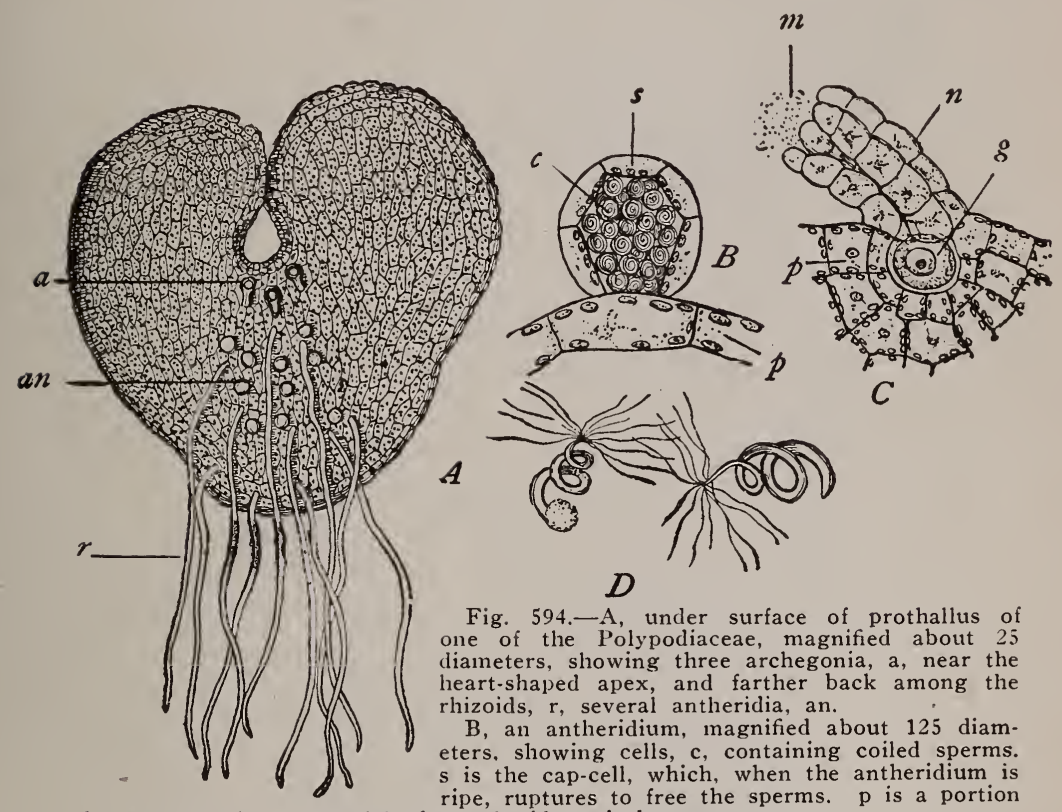

of the prothallium on which the antheriduum is borne.

$\mathrm{C}$, is a ripe archegonium, also magnified about 125 diameters. p, portion of prothallium in which the base of the archegonium is imbedded; $\mathrm{g}$, egg-cell; $\mathrm{n}$, neck of archegonium, consisting of four rows of cells; $\mathrm{m}$, mucilage discharged from neck.

$\mathrm{D}$, sperms, magnified about 500 diameters.

tened and sometimes conspicuous for their size, forming a brownish chaff which, not infrequently, as in the Male Fern, completely invests the young leaves. These hairs are technically called palex.

The sori, in their arrangement, usually bear a definite relation to the venation of the leaves, and as this is different in different groups, it affords an important means of distinguishing genera and species. For example, in Pteris they are borne on the lower margin along the terminations of the veins, and are protected by the revolute margins of the leaf; in Hymenophyllum, they occur on prolongations of the veins; in Polypodium, they are on the 
under surface at the extremities of short veins; and in Acrostichum, they occur anywhere on the lower surface, sometimes covering the greater portion of it.

In some species the sori are naked, that is, not enclosed by a protecting membrane or indusium, but in many, such a membrane is present, and its form and structure often afford characters by which groups are distinguished. In the Shield-ferns, for example, the indusium is shield or kidney-shaped; in the Aspleniums it has one edge attached to a vein while the other is free; and in some of the Cyathace $x$ it is capsular and completely encloses the sporangia.

The sporangia themselves differ considerably in different groups. In the Polypodiacer, the sub-order to which most of our common ferns belong, it has the structure represented in Fig. 595 , B. The upper part, or sporangium proper, has a row of thick-walled cells, $a$, which begins at the upper part of the stalk,

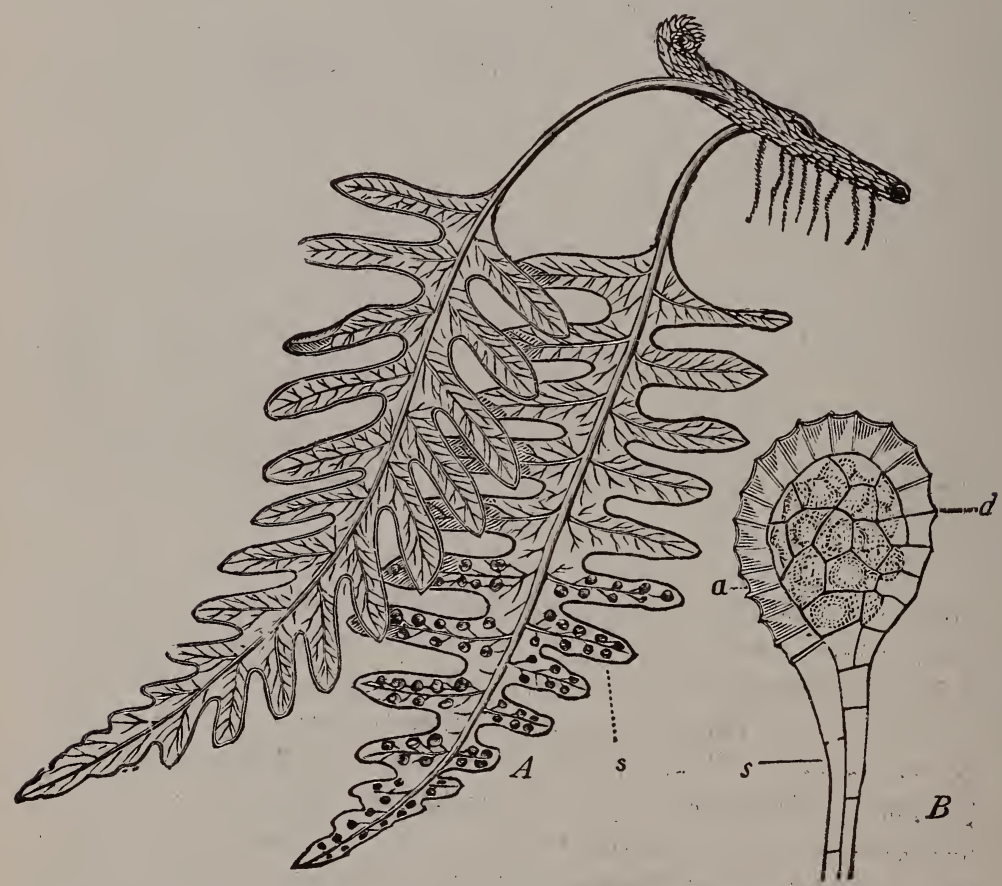

Fig. 595.-Polypodium vulgare. A, rhizome and two leaves, one showing the inferior surface and sori; $s$, is one of the sori. B, a sporangium of one of the Polypodiaceae. a, annulus, composed of thick-walled cells extending vertically around the sporangium to $d$; near $d$, the dehiscence begins; s, stalk of the sporangium. 
$s$, on one side and passes vertically over to the other side, but terminates at $d$ before it again reaches the stalk. This row of cells is called the annulus, and it is at or near where it terminates that the sporangium ruptures when ripe. The dehiscence is transverse, and the spores are ejected by the elastic straightening of
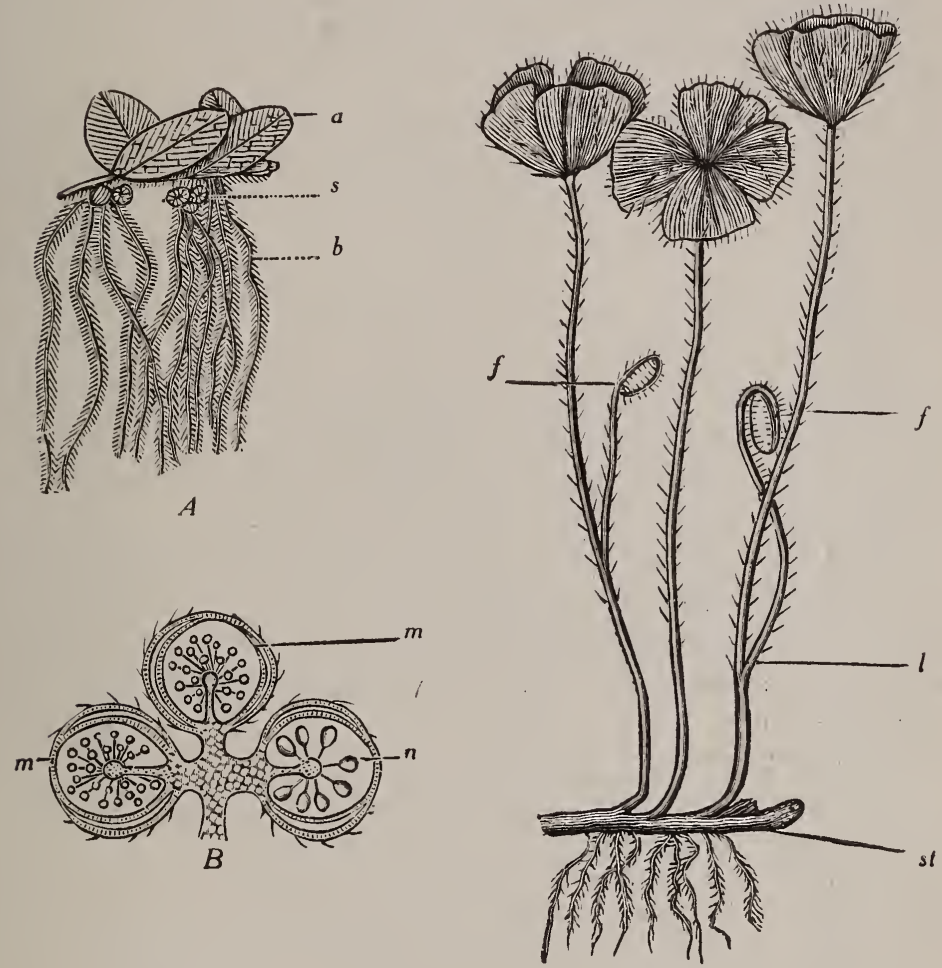

Fig. 596.

Fig. 597.

Fig. 596.-Salvinia natans. A, portion of plant showing aerial leaves, a; sub. merged leaves, b; and sori, s, borne on the submerged leaves. $B$, a cluster of the sori in section, magnified about 10 diameters. 11, a sorus containing macrosporangia, and $\mathrm{m}, \mathrm{m}$, sori containing microsporangia. Partly after Sachs.

Fig. 597.-Marsilea salvatrix. st, stem, bearing roots and leaves; 1, leaf petiole giving off a fructifying branch; f, f, fruits, containing sporangia which bear both macrospores and microspores.

the annulus. In this group, as we have seen, the annulus is incomplete, that is, it does not pass completely around the sporangium; in the Hymenophyllums and in the Cyathacex, however, it is complete. In some other species, as in the Osmundas, it is wanting entirely. 
Hydropteridales. In this order the spores are of two kinds, borne in separate sporangia. Some produce single, large megaspores; others, much smaller microspores in considerable numbers. Both kinds of spores produce very rudimentary prothallia (gametophytes) which project but little from the wall of the germinating spores. The gametophytes developed from microspores produce antheridia only, while those which are developed from megaspores produce archegonia only.

The order is a small one, consisting of two sub-orders, the Salviniacex and the Marsiliacex, each represented by but a few species. The Salvinias are aquatic in habit; the Marsilias grow in marshy places. See Figs. 596 and 597.

\section{THE EQUISETINEAE, OR HORSETAILS.}

The plants of this class are readily distinguished by their hollow, cylindrical, jointed and fluted stems, their sheath-like whorls of united leaves, and their terminal, cone-like fructifications. The internodes of the stem are hollow, but each node is closed by a membrane; the leaf-sheath is broken up into a number of points at its apex, each point corresponding to the tip of a leaf, and for each there is a corresponding fibro-vascular bundle, which at the base of the sheath passes into the stem, thence straight down it to the nade next below, where it forks into two, the branches coalescing with those of the stem.

The stems are all herbaceous and mostly perennial, from creeping, underground stems or rhizomes; the aerial branches are of two kinds, fertile and sterile, and are usually started.at the close of the season, persist over winter and are ready for growth the following spring. The stems are sometimes simple; sometimes they are branching, and the branches, which have their origin on the inside of the base of the leaf-sheath, are arranged in whorls. The stems grow from a terminal, triangular-pyramidal cell.

The fertile branch containing the fruiting cone usually appears first in the spring and commonly bears no side branches or foliage leaves. The cone or strobilus consists of compactly arranged whorls of sporangiophores, each of which is a flattish, usually hexagonal shield, elevated centrally on a short stalk, and bearing around its interior margin the sporangia, usually from five to ten for each shield. The spores produced in the latter are provided with elaters, which being hygroscopic, coil and uncoil as the amount of moisture 
present increases or diminishes, the movements aiding the ejection of the spores from the sporangia. See Figs. 598 and 599 .

All the existing species of Equisetums are homosporous, though some of the fossil members of the class, represented in their fossils in coal and in rock, were heterosporous. Most of the living forms are practically diœcious, some of the spores producing male and others female gametophytes. This, however, is probably not due to any inherent difference in the spores but to difference of nutrition, the gametophytes which are well nourished producing archegonia only or mainly, while those which receive a deficient supply of nutriment bear antheridia only.

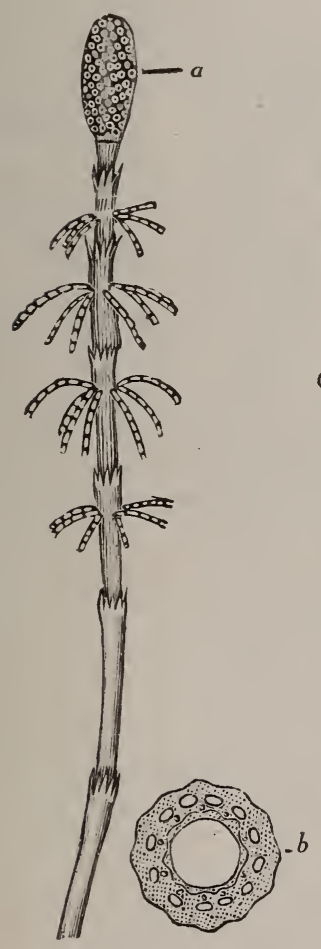

Fig. 598.

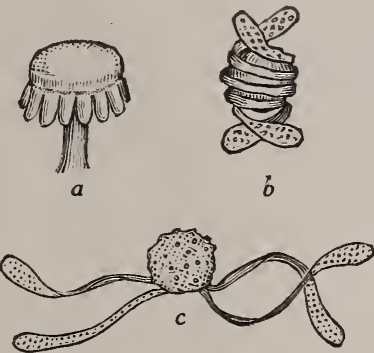

Fig. 599.

Fig. 598.-Portion of Equisetum sylvaticum, showing fruiting cone, a, at the apex of the stem; $b$, transverse section of stem somewhat magnified.

Fig. 599.-Equisetum silvaticum. a, fruiting scale, magnified, showing sporangia: $b$, one of the spores enveloped in the elaters; c, one of the spores with elaters extended.

Fig. 600.-Fruiting plant of Equisetum arvense; $a$ strobilus; b. transverse section of stem, showing hollow and circle of fibro-vas. cular bundles and large intercellular spaces.

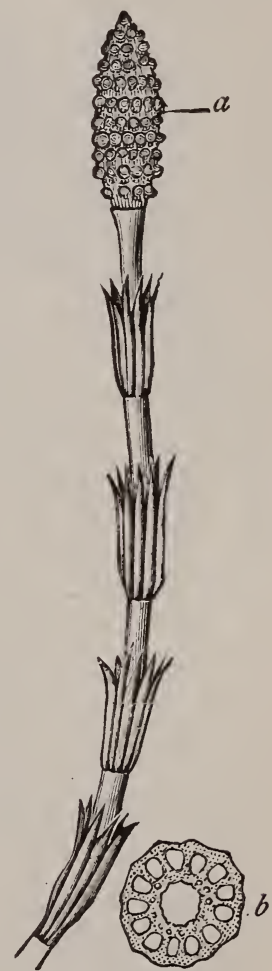

Fig. 600 .

The forms of the prothallia in the Equisetums are usually more irregular than those of Ferns, commonly developing lobes or processes of various sizes. The antheridia are apically or marginally situated, and the archegonia, though first formed on the mar- 
gin, on account of the continued growth of the gametophytes, come to occupy the upper surface. The sperms are of much larger size than those of the Ferns. In other respects, the mode of sexual reproduction in these plants closely resembles that of the Ferns. Fig. 600 represents a fruiting plant of Equisetum arvense, a species common in damp, sandy soil, and which produces from its rhizomes chlorophylless, simple stems that mature their spores early in the spring and then die, and later develop freely branching green stems that continue to grow during the season. Figs. 601 and 602 show, respectively, male and female prothallia of this

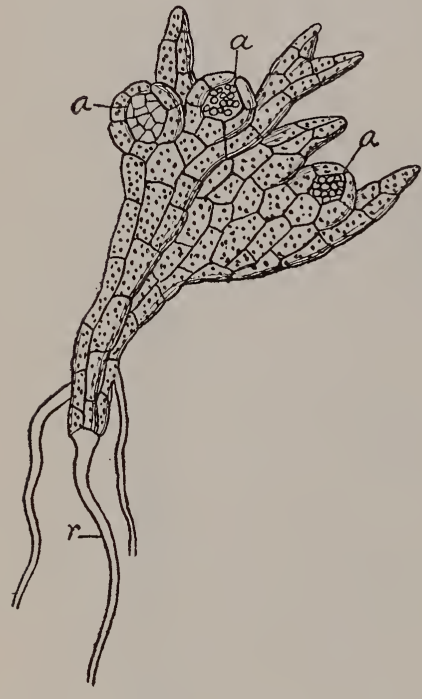

Fig. 601.

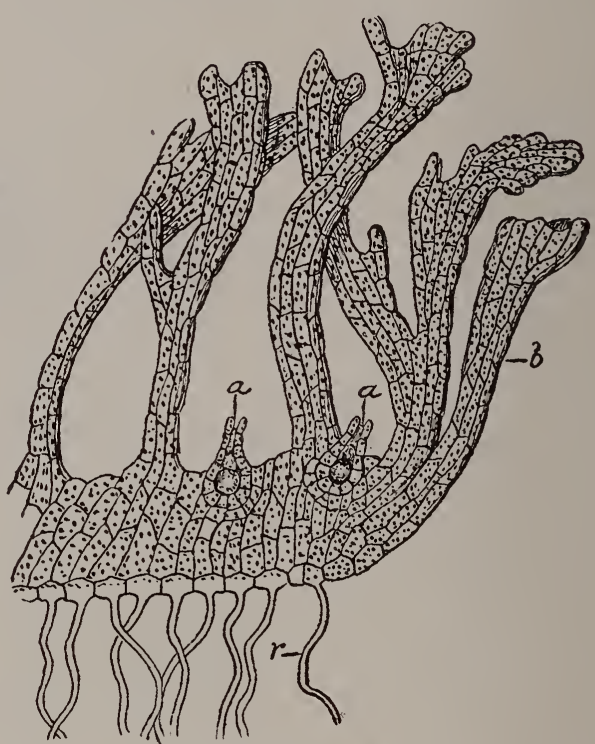

Fig. 602 .

Fig. 601.-Male prothallus of Equisetum arvense: r, rhizoid; a, a, a, antheridia in various stages of development. Magnified alout 300 diameters.

Fig. 602.-Part of female prothallus of Equisetum arvense. a, a, archegonia; $b$, branch of prothallium; $r$, one of the rhizoids. Magnified about 300 diameters.

plant. Both are so small that a lens is needed to identify them. Rather seldom do they survive in our climate and our species of Equisetum are chiefly propagated vegetatively.

The forms of Equisetineæ, at present in existence, are all included under the one genus, Equisetum, and this does not contain a large number of species; the individuals, however, are abundant and widely distributed. Certain species are abundant along rail- 
road embankments and exposed locations, while others are found only in moist or shaded places. In temperate climates they range in height from several inches to a few feet, but one tropical species leaches a height of forty feet. Fossil forms from the carboniferous period are abundant, some attaining the size of trees. Some of the species known as Scouring Rushes are remarkable for the large amount of silica contained in the epidermis.

\section{THE LYCOPODINEE, OR CLUB MIOSSES.}

The plants of this class are, for the most part, small or moderate sized perennial herbs, sometimes with stems erect and rooting at the base, but more commonly creeping, with ascending or erect branches, which, in the majority of cases, originate dichotomously, though in some instances monopodially. With few exceptions, the stems and branches are thickly clothed with leaves. The latter, in the simplicity of their structure, are in strong contrast to those of the Ferns, being mostly of small size, without petioles or stipules, usually provided with but a single vein; which constitutes a mid-rib, and the blade is never branching or compound.

The sporangia are, in the majority of cases, borne on the leaves, but, in some instances, as in Psilotum and Selaginella, on the stem. The spore-bearing leaves may be of the ordinary form, or they may be somewhat modified in structure and crowded together, forming spikes or cones (strobili) at the ends of some of the branches. Some members of the group are homosporous, others are heterosporous.

There are two orders, the Lycopodiales and the Selaginellales.

The Lycopodiales, or Club Mosses Proper, include several hundred species, ranging from the tropics to the frigid zone. Only four genera are known, two of them Australian. All the existing forms of the group are homosporous, but the Lepidodendrons of the Coal Age, which must be regarded as belonging here, were heterosporous. The prothallia are mostly subterranean, tuber-like bodies, which bear both antheridia and archegonia.

The ordinary or spore-bearing plants are all terrestrial, and moss-like in appearance, the stems being thickly clothed with small simple and often narrow leaves. The stems branch in a dichotomous manner by a division of the terminal bud. In habit, the stems may either be creeping, with erect or ascending branches, as in Lycopodium clavatum, or, less commonly, erect from the first, as in Lycopodium Selago. 
The internal structure of the stems is somewhat peculiar. There is a stele or central cylinder containing a large bundle consisting of several strands of xylem, with phloem intermingled and a surrounding sheath.

In the principal genus, Lycopodium, the sporangia, which are one- to three-celled, occur singly in the axils or on the upper surface of leaves (sporophylls). See Fig. 603.

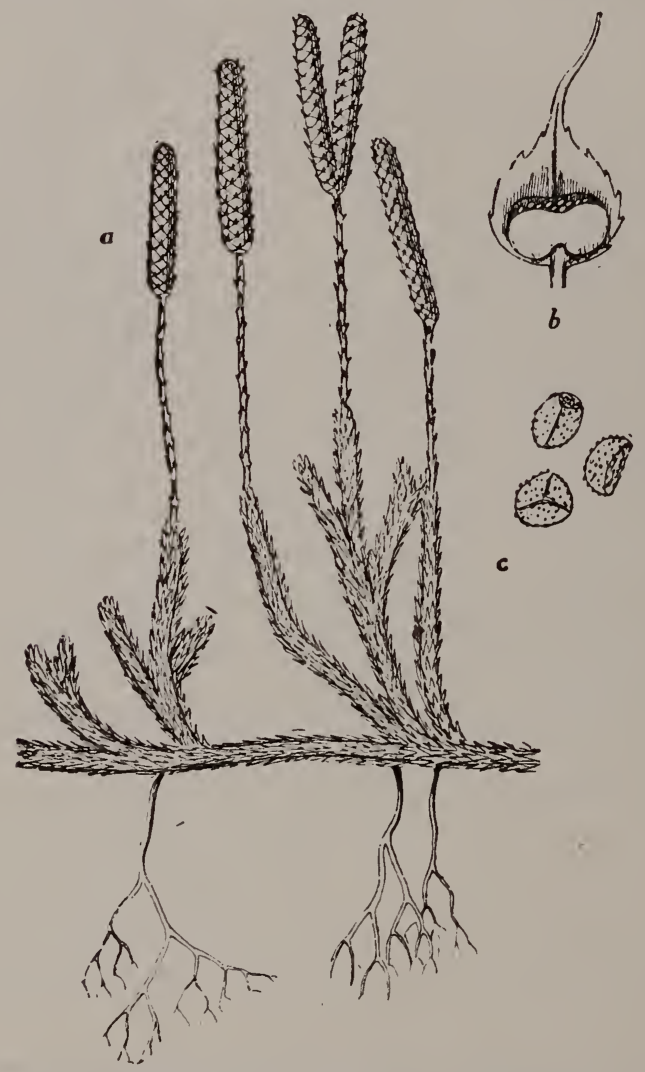

Fig. 603.-Fruiting branches of Lycopodium clavatum, about one-half natural size. $a$, fruiting cone; $b$, one of the scales of a cone, showing inner surface. and one of the sporangia near its base, considerably magnified; $c$, three spores highly magnified.

The sporangia open in a slit-like fashion and shed their spores which are distributed by the wind. These spores are very light and are very inflammable. They are sometimes used in fireworks 
and are known as "vegetable sulphur." They are also employed as a dusting powder for infants and in pharmaceutical practise as an absorbent coating for pills.

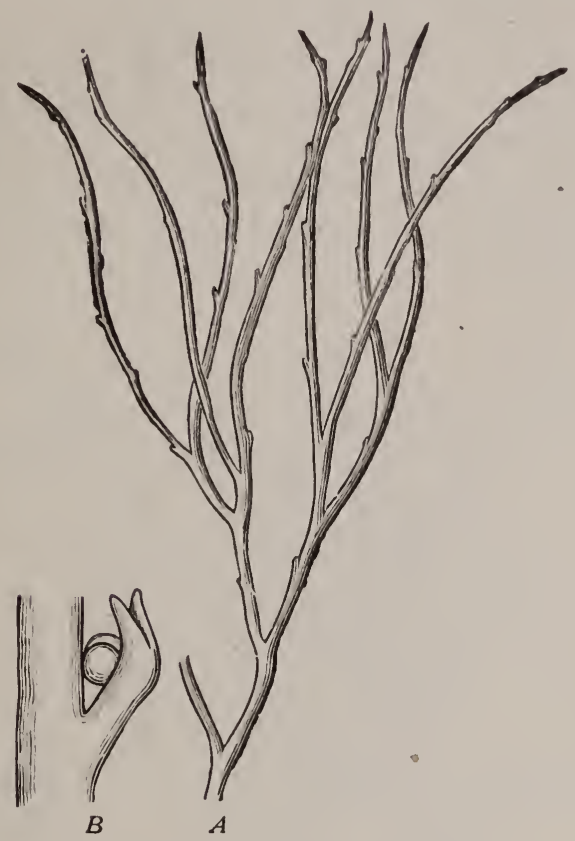

Fig. 604.-Psilotum triquetrum. A, part of plant, natural size. 13, portion of stem, magnified, showing fructifying branch bearing at its apex two sporangia between two small leaves.

Psilotum, a tropical epiphyte belonging to a related family, is illustrated in Fig. 604.

The Selaginellales include two genera, Selaginella and Isoetes.

The Selaginellas, or Little Club Mosses, are widely distributed in nature and are often grown in greenhouses for their decorative effect. In general appearance the sporophytes are delicate plants and bear a considerable resemblance to the species of Lycopodium, but the dichotomous branching is in one plane and not in all planes; the leaves are arranged in four vertical rows, and the members of opposite pairs are dissimilar in size or shape; the roots fork repeatedly, and the secondary branches decussate with the primary, 
the tertiary with the secondary, and so on. The sporangia are borne on the stem immediately above the insertion of the leaves so as to appear in their axils. The sporangia occur singly and are of large size compared with those of Ferns; the megasporangia each contain four spores, while the microsporangia, which are ordinarily borne higher up on the axis, contain numerous microspores.

Both kinds of spores begin to germinate while yet in the sporangia. The microspore grows into the male gametophyte, consisting of a single vegetative cell which bears a simple antheridium. The antheridium contains a few, free-swimming, biciliate sperms which escape through a fissure in the wall of the microspore.

The megaspores are several times larger than the microspores
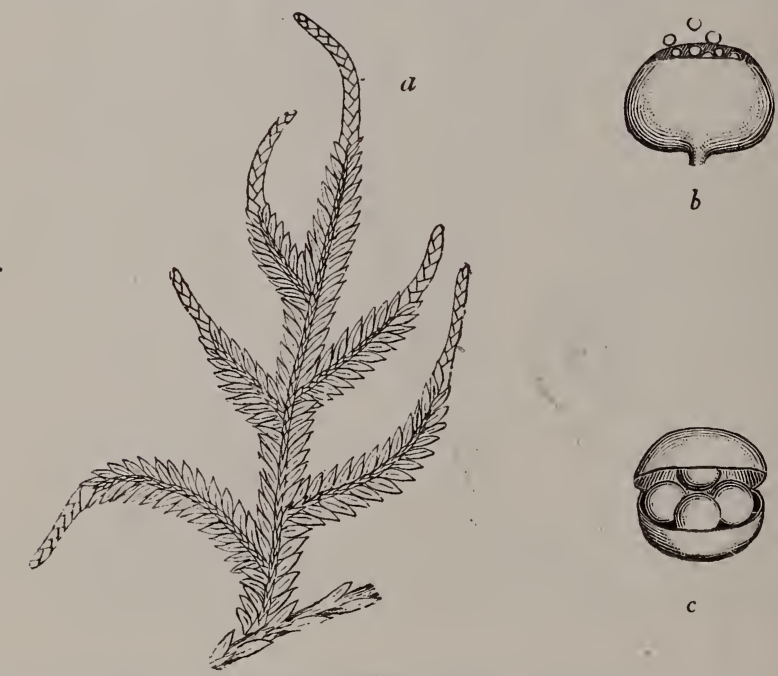

Fig. 605.-Fruiting branches of Selaginella, aiout natural size. a, sporebearing portion; $b$, sporangium containing microspores, from the inner surface of one of the scales; c, sporangium from the inner surface of another scale, containing megaspores.

and each grows into a multicellular prothallus which protrudes through the ruptured spore wall and develops archegonia on the outermost part. In some species, fertilization occurs while the spores are still on the plants. The fertilized egg-cell grows to an embryo having a suspensor and remains for some time imbedded in the prothallus. The development of a suspensor is an important distinction from the True Ferns and marks an advance toward the Seed Plants. Unlike the embryo of the Seed Plants, however, that 
of Selaginella does not go into a resting period, but continues to grow until it protrudes its root and shoot from the prothallus and finally becomes an independent green plant-the sporophyte. Fig. 605 represents a portion of a fructifying stem of a Selaginella with a microsporangium and a megasporangium enlarged.

The Isoetes, or Quillworts. In these species the stem is short, and the numerous leaves with which it is clothed are long and grass-like, and on the upper surface of the sheathing bases occurs a depression or pit in which the sporangia are borne, and just above this is the ligule. The megasporangia contain numerous megaspores, and are borne mostly by the outer leaves of the fascicle, while the

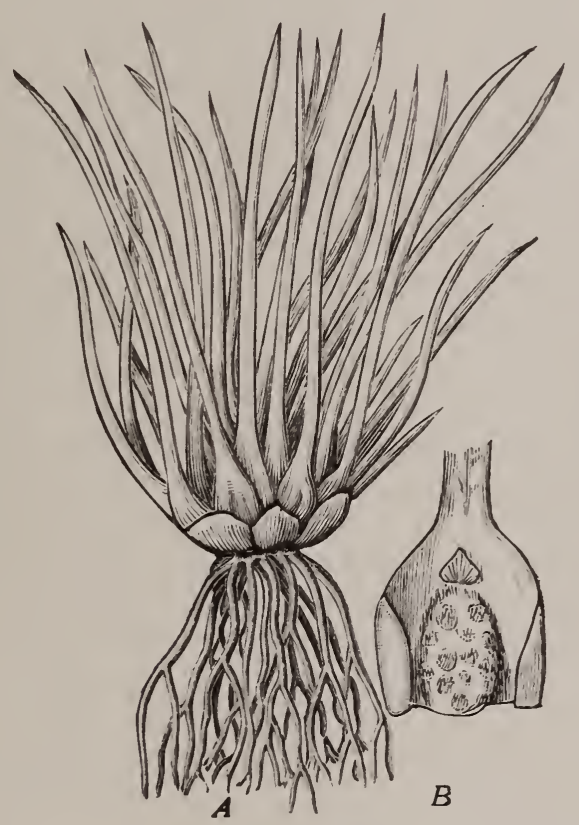

Fig. 606.-Isoetes setacea. A, the entire plant. B, the base of one of the leaves, showing immature sporangium and, above it, the ligule.

microsporangia are borne on the interior ones. Among the spores in both kinds of sporangia are borne cellular filaments or paraphyses. A few of the species are terrestrial or amphibious in their habits, but most are submerged aquatics, growing in water which does not contain much calcareous matter in solution. See Fig. 606. 


\section{CHAPTER XI.}

\section{THE SPERMATOPHYTA, OR SEED PLANTS.}

CHARACTERISTICS.-THE GYMNOSPERMAE.

The Spermatophytes or Seed-Plants are characterized by the production of seeds. The group contains the largest and most highly developed of all vegetable forms; by far the larger proportion of those plants we most admire for their beauty or desire for their usefulness. From them chiefly do we form our conceptions of vegetable life. They do more than any others, or all others combined, to give to the landscape its character and charm.

We have already discussed the gross structure of these plants in Part I and their cellular structure in Part II, gaining thereby some idea of the immense variety of shapes, sizes and habits that occur among them. Some species, as the Wolffia, are mere green specks, barely distinctly visible to the naked eye, while others, as the giant Sequoia, attain the lofty height of more than three hundred feet. Some pass through the complete round of their life-history in a few days, while other's outlive many generations of men; some have a soft, flabby structure, and are easily destroyed, while others are composed chiefly of hard and enduring tissues; some make their homes in the water, others in marshy places, others on dry ground, while still others prefer the arid wastes of the desert; some are parasitic or saprophytic, but the great majority are chlorophyllbearing; some like the shade, others prefer the open sunshine; some flourish only on the borders of eternal snows, while others cannot thrive except in the perpetual warmth of the tropics; and there are indeed few corners of the earth so inhospitable as not to afford some of them a congenial abiding-place.

While it is probably true that, merely in the number of individuals, they are surpassed by some of the Thallophytes, in the number of species, approximately 133,000 , they probably exceed all the other groups of plants put together.

The term Spermatophytes, or Seed-plants, is appropriately applied to the members of the group, because their most distinctive characteristic is the production of seeds. These, as we have 
already seen, are quite complex in their structure, containing within their seed-coats an embryo which is usually so far developed as to possess the rudiments of stem, root and leaves. They often contain also an endosperm or perisperm, whose service is to nourish the growing embryo.

Since none of the lower plants produce seeds, there would seem, at first thought, to be a shar'p line of separation between Seed-plants and all other's, but such is not really the case. The process of seedproduction is closely related to the sexual processes in the higher Pteridophytes, and the progress from the lowest forms of the latter group to the highest forms of Seed-plants, is one of easy gradations.

In both groups the familiar and conspicuous plant is the sporophyie; the reproductive organs are, with a few exceptions, borne upon modified leaves (sporophylls). In the Seed-plants, however, particularly in the higher forms, these leaves, and often also other's indirectly concerned in the reproductive process, are much more strongly modified and form a more or less conspicuous group, which we have already studied as the flower. Moreover, the ovules and pollen-sacs of seed-plants are homologous respectively with the megasporangia and microsporangia of the higher Pteridophytes; the embryo-sac in the ovule corresponds with the megaspore, and the pollen-grain with the microspore.

In the lower Pteridophytes, such as Ferns and Equisetums, we find that the prothallus or gametophyte generation attains a very considerable development, and continues for some time as an independent plant, but in the higher members of the group, as Salvinia, Selaginella, etc., it becomes progressively of less and less importance, in some cases scarcely emerging from the coats of the spore. In Seed-plants the gametophyte is still represented, but its degradation is carried a step farther. The female prothallus or gametophyte consists of a few cells or a tissue formed in the megaspore or embryo-sac, and it never bursts through the walls of the latter, but either remains as a part of the seed, or is afterwards absorbed by the forming embryo. The seed is, in fact, a megasporangium containing a megaspore which, while still in contact with the parent plant and nourished by it, has germinated and produced an internal prothallus or gametophyte (embryo-sac) containing an egg cell, and which, after fertilization, has developed into an embryo (sporophyte) ; and, only after these processes have been accomplished, has it become free.

In like manner, the pollen-grains are microspores, somewhat 
modified in accordance with the changes in the development of the megaspore. They are formed in the pollen-sac in the same way that microspores are in microsporangia, but the male prothallus which they produce in germinating, is, if possible, still more rudimentary, and motile sperms are seldom produced. Instead, the entire pollen-grain, as we have found, is conveyed by the wind, by insects, or by some other agency either to the ovules direct, as in the Pines and their relatives, or to the stigma, which is a portion of a carpel leaf or whorl of carpel leaves enclosing the ovules, as in the higher flowering-plants, and it there germinates and forms a pollen-tube which penetrates to the ovule, and through the micropyle of the latter to the embryo-sac, as was explained in Part I.

Compared with the Pteridophytes, the various organs of vegetation are more complex and better developed, the modifications of form and structure which organs of the same name assume-the multiform adaptations of stems, leaves and roots, for example, to a variety of uses and changes of form to correspond with changed functions-is especially remarkable.

We have now noted two advances made by the Spermatophytes over the preceding groups, both being directly concerned with propagation and of great importance. One of these is the distribution of the microspores (pollen grains) by the wind or by insects, thereby rendering the presence of water unnecessary to fertilization, whereas, in the lower plants, the free-swimming sperms require water to enable them to reach the egg-cells. The second advance is the formation of the embryonic plant, protected by the seed coats and remaining in a resting stage for a considerable period, during which the distribution of the seed occurs. Owing to these and other advantages, the spermatophytes have spread over the earth and have competed successfully with-and often replaced - their less fortunate neighbors, the fern and mosses.

The Spermatophyta is subdivided into two classes, the Gymnospermæ in which the seeds are not enclosed by sporophylls (carpels), and the Angiospermx, in which the seed are enclosed in an ovary consisting of a single carpel or a whorl of carpels.

By far the larger proportion of all Seed-plants are chlorophyllbearing. Only a few have developed parasitic or saprophytic habits.

THE GYMNOSPERMA, OR GYMNOSPERMS.

The plants of this class are, without exception, woody-stemmed, terrestrial and chlorophyll-bearing forms, most of them attaining 
a considerable size, and some of them forming the largest of our forest trees. In the structurc of their stems they show affinities with the highest forms of the Spermatophytes, the Dicotyledons, since they possess a pith, medullary rays and a cambium; but their tissues are less complex, true wood-cells and ducts being largely replaced by an intermediate tissue, the discigerous tracheids. In many other points they show themselves decidedly inferior to the rest of the Spermatophytes, and, in some important respects, closely allied to the Pteridophytes. The strobili or flowers, as a rule, are of very simple structure, consisting of sporophylls much less modified from the ordinary form than in most other flowering plants; they are never showy or nectar-bearing; the stamens and pistils are never found together in the same flower, but all the plants of the Class are either monœcious or diœcious. As implied in the word, gymnospermx, the ovules are not enclosed in an ovary, but are borne on the base of an open carpel, or, more rarely, naked, on the end of a branch, and the cotyledons of the embryo are arranged in whorls, sometimes of two, but often of four, six, or some higher number.

Their alliance to the higher members of the preceding group, the heterosporous Ferns, is especially shown in the fact, that a female prothallus is produced in the megaspore (embryo-sac) previous to fertilization, and bears simple and much-reduced archegonia, and in the fact that the pollen-grain develops a vegetative cell which grows out as a pollen-tube, and an antheridial mother-cell which forms two sperm cells. This structure behaves like, and is really the equivalent of, the rudimentary male gametophyte of Salvinia and Selaginella.

In descent, the Gymnosperms are an older group than the Angiosperms; many fossil species have been determined; their sexual generation indicates a closer relationship with the Ferns; probably an extinct group of the latter known as Seed Ferns (Pteridosperms) were their ancestors.

The Gymnosperms include three orders, which, in appearance and habits of growth, differ widely from each other, but agree essentially in their modes of reproduction. They are the Cycaclales, the Conifercales and the Gnetales.

The Cycadales. The plants of this order have much the aspect of Tree-ferns, with which, in fact, they are more strongly allied than are any other members of their class, having unbranching scaly stems crowned at their summit with ample pinnate leaves. 
They are slow-growing plants which, though once exceedingly abundant and playing an important part in the world's flora, are now rare, consisting of only about eighty species, and these confined to tropical and sub-tropical regions.

The stems, though externally scaly and unbranching, like those of Tree-ferns, more closely resemble in their internal structure those of the Pines and Dicotyledons, having the woody elements arranged in much the same way and growing in substantially the same manner. Compared with the Pines the medullary rays are broader, and the cells composing them thinner-walled and the pith is usually large. The woody elements consist of discigerous, scalariform or reticulate tracheids in the secondary wood, with a few spiral tracheids in the primary wood or medullary sheath, but true tubes are seldom found. The stems also differ from those of Ferns, in being continued downward into a tap-root.

The leaves are arranged on the stem in compact spirals, and consist of two kinds, the ample pinnate ones already mentioned, and more numerous, scale-like, brown, leathery, rudimentary ones. Every year or two the crown of foliage leaves is renewed by the unfolding of the large terminal bud.

The species are all diccious, the male and female flowers being borne on different individuals. Both kinds are borne at the apex of the stem, the staminate ones consisting of leaves modified into shield-shaped scales compactly arranged on a terminal cone, sometimes a foot or more in length. Each scale bears on its under surface numerous pollen-sacs or microsporangia, which are usually collected into groups of from two to five each. See Fig. 607, $B$.

The female flower is also, except in the genus Cycas, spike-like or cone-like in appearance, the cones often being of large size and made up of peltate scales, on the under surface of each of which two ovules or megasporangia are borne. See Fig. 607, C.

The female flowers of the species of Cycas differ from those of other members of the order, in the fact that the ovule-bearing leaves (megasporophylls) form, a rosette, composed of parts similar in shape but smaller in size than the ordinary foliage leaves, and the ovules take the place of the ordinary pinnæ. See Fig. $607, A$. Moreover, the axis that bears the floral leaves does not stop growing, but is continued upward through the flower and bears above the latter both scale-like and ordinary leaves.

The ovules are orthotropous, and each consists of a nucellus 
enclosed in a single thick coat which, at maturity, becomes succulent. They are of large size, the largest in the vegetable kingdom, attaining, in some species, the size of a filbert, before fertilization.

The young megasporangium (ovule) contains four megaspores but only one develops and it remains within the ovule and is nour-

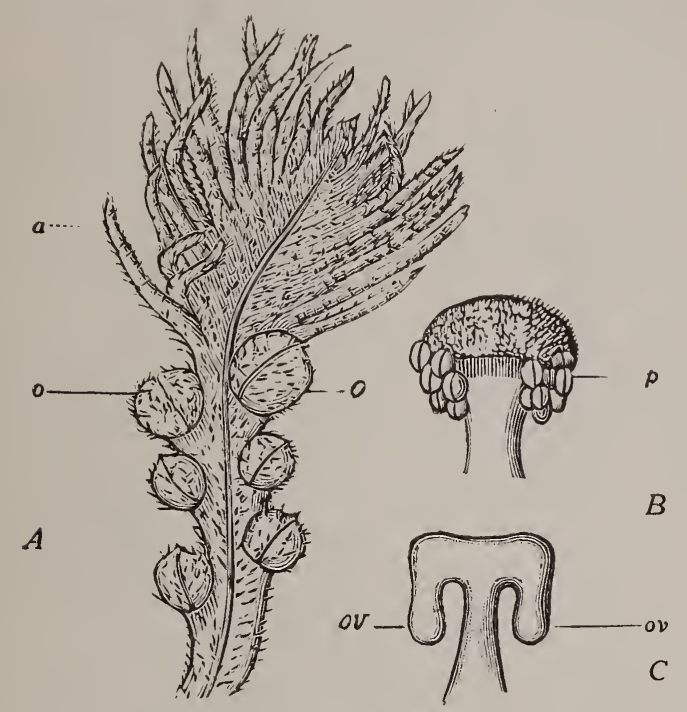

Fig. 607.-A, carpellary leaf (megasporophyll) of Cycas revoluta, about onefourth natural size. a, one of the pinnae of the leaf; o, o, ovules (megaspor. angia) developed in the place of pinnae. B, one of the anther-bearing scales (microsporophylls) from a staminate cone of Zamia, one of the Cycads; p, pollensacs. $C$, one of the carpellary scales from the fertile cone of Zamia, showing two ovules, ov, ov, pendant from the under surface.

ished by the tissues of the nucellus. Several archegonia are formed at the apical end, imbedded in the tissues of the prothallus (endosperm).

The pollen is wind-borne and upon reaching the ovules penetrates the micropyle and enters a chamber between the micropyle and nucellus which is filled with a watery liquid secreted by the tissues. Here the pollen grain develops a short pollen-tube which, upon rupturing, liberates two very large sperms provided with cilia and thus free-swimming. These pass through the open end of the nucellus and fertilize the large egg-cell. Several months may elapse between pollination and fertilization in this species.

The Cycads and the related Ginkgo afford the only instance, 
among Spermatophytes, of free-swimming sperms-a fact pointing strikingly to their connection with the Ferns.

Other points of resemblance between Cycads and Ferns are the coiled (circinate) vernation of the pinnæ, the forked venation of the leaves and the presence of fruiting organs resembling sori rather than flowers. Although forming a true seed, the embryo grows at once into a plant (sporophyte) without an intervening resting period such as ordinarily characterizes seeds.

Cycas revoluta, known sometimes as Sago Palm, is commonly cultivated in hot-houses, and another cycad, Zamia integrifolia. commonly called the Coontie, is native to the United States, growing in southern Florida.

The Coniferales or Conifers constitute by far the largest and most important order of the class. It includes the Pines, Yews, Cypresses, Firs, Larches, Junipers, Araucarias, etc. A few of the species are shrubs, but most are trees of medium or large size; the stems are very commonly excurrent or spire-shaped; branching occurs freely, and the branches spring from the leaf-axils, but not all, or even the larger proportion of the axils, produce buds; the leaves are, with few exceptions, entire, simple-veined and of small size, and are commonly very abundant, in some instances, as in the Arbor Vitæ and Red Cedar, so thickly clothing the branches that the branch itself is completely obscured.

The foliage leaves are usually evergreen, remaining on the plant for an indefinite period-ranging from two to ten years. Many of the species produce, besides the foliage leaves, brown scales, which mainly serve a protective purpose, as bud-scales, etc., as in the Spruces; but in one Australian genus, Phyllocladus, no green leaves are developed, but leaf-like branches springing from the axils of scales, take their place.

In their internal structure and mode of growth, the stems very closely resemble those of Dicotyledons, the most important difference being the fact that the elements of the secondary wood consist almost entirely of discigerous tracheids. (See Fig. 431, Part II.) The larger part of our supply of soft wood timber comes from the coniferous trees, especially the Pines.

Nearly all the species produce terebinthinous secretions, and many valuable resinous and oleo-resinous products are obtained from the order.

The flowers are, in some species, monœcious, in others diœcious. The staminate flowers consist of shield-shaped scales compactly 
arranged along a lengthened axis, forming a strobilus or cone, and each scale bearing on its inferior surface two or more pollen-sacs. These often vary in number on the same plant. In the species of Spruce and Pine, there are two placed side by side on the staminal leaf, very much as in most of the higher flowering-plants; in the common Juniper there are three roundish pollen-sacs; in Taxus baccata (see Fig, 608, C) there are from three to eight, and in the

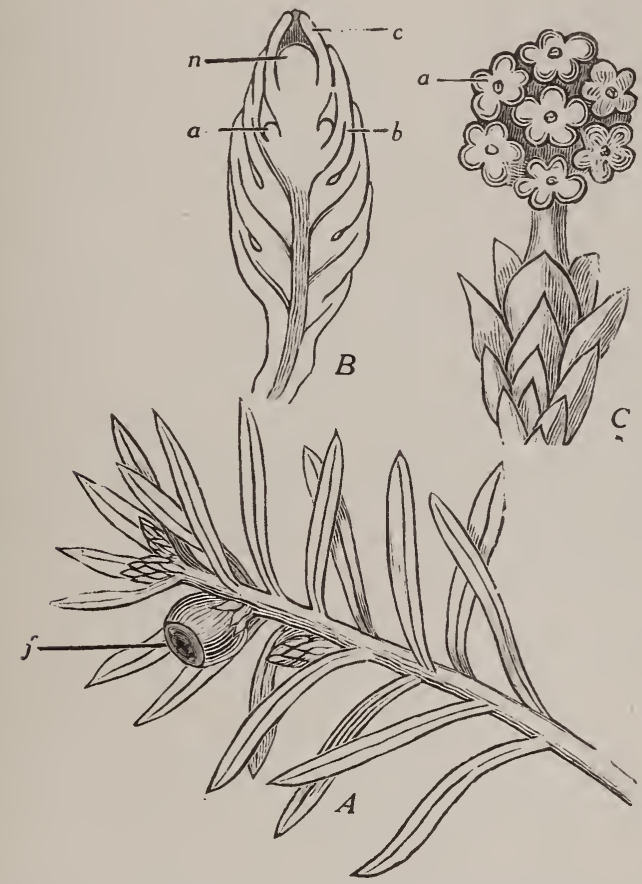

Fig. 608.-The Yew, Taxus baccata, showing flowers and fruit. A, branch, with ripe fruit, $f$, about natural size. B, longitudinal section of female flower, showing terminal ovule; $\mathrm{n}$, nucellus; $\mathrm{c}$, coat of ovule: a, rudiment of aril, whicl later grows up and envelops the seed; b, a bract. Magnified about 20 diameters. $\mathrm{C}$, male flower, showing terminal cone of staminate, shield-shaped scales, each with several pollen-sacs on the inferior surface; a, one of the pollen-sacs. Magnified.

Araucarias of the southern hemisphere, there are a large number of long cylindrical ones pendent from the lower surface of the shield-shaped scales. The staminal scales are nearly always smaller and of a different color from the ordinary ones, but they are arranged in a similar manner on the stem. In this respect they 
show their inferiority to Angiosperms, for in the latter the differentiation between floral and ordinary leaves often extends to the phyllotaxy, the arrangement of the floral leaves frequently being quite different from that of the foliage leaves on the same plant.

The ovulate flowers vary a good deal in the different species, particularly in the position of the ovules. In some, as the Yews, family Taxacex, Fig. 608, $B$, the flower consists of a naked ovule borne at the apex of a short branch; in others, as the Spruces, Pines, Larches and Cedars, family Pinacex, they form cones (strobili) consisting of an axis, along which lateral scales or bracts are compactly arranged in spiral order, and in the axil of each bract, and attached to it only at the base, occurs another carpellary scale, which bears on its upper surface two ovules, whose micropyles point downward (see Fig. 609, A); the Araucarias of the Southern hemisphere have flowers of similar structure, except that the carpellary scale is completely fused with the bract, in whose axil it is borne; in the Taxodiums, represented by the Bald Cypress of our Southern States, the fusion between carpellary scale and subtending bract, has also taken place, but the micropyle of the ovule is directed upward instead of downward; and in the subfamily Cupressinex, to which belong the Juniper, Savin, Red Cedar and Arbor Vitæ, the carpellary scale is completely fused with the bract, the micropyle of the ovule is directed upward, and the bracts are arranged on the axis in whorls instead of spirals.

For illustrating more particularly the mode of reproduction in this group, we may take the Scotch Fir, Pinus sylvestris. This species is monœcious, and the staminate flowers are borne in clusters on the lower parts of shoots of the same season. Each scale produces two pollen-sacs placed longitudinally, side by side, on the lower surface. The pollen-grains are formed early in May and when ripe consist of a central body with two vesicular, winglike air sacs, as is frequently the case with the pollen of Conifers. The pollen-grain (microspore) upon germination divides into four cells, two constituting the prothallus, a third the pollen-tube and the fourth the antheridium mother-cell; usually one of the prothallial cells soon disappears, however, and the mature pollen-grain contains but one.

The ovulate flower is a cone, borne at the apex of a small branch. Each fertile scale bears on either side of a central rib, near its base, two ovules, whose micropyles point obliquely downward. The ovule-bearing scale is in the axil of a bract, and 
slightly attached to it at the base. Each ovule consists of a nucellus enclosed in a single coat, as is most commonly the case in Gymnosperms. Although four megaspores are originally formed in the ovule, only the basal one develops, and the others are disorganized and used by it as food.
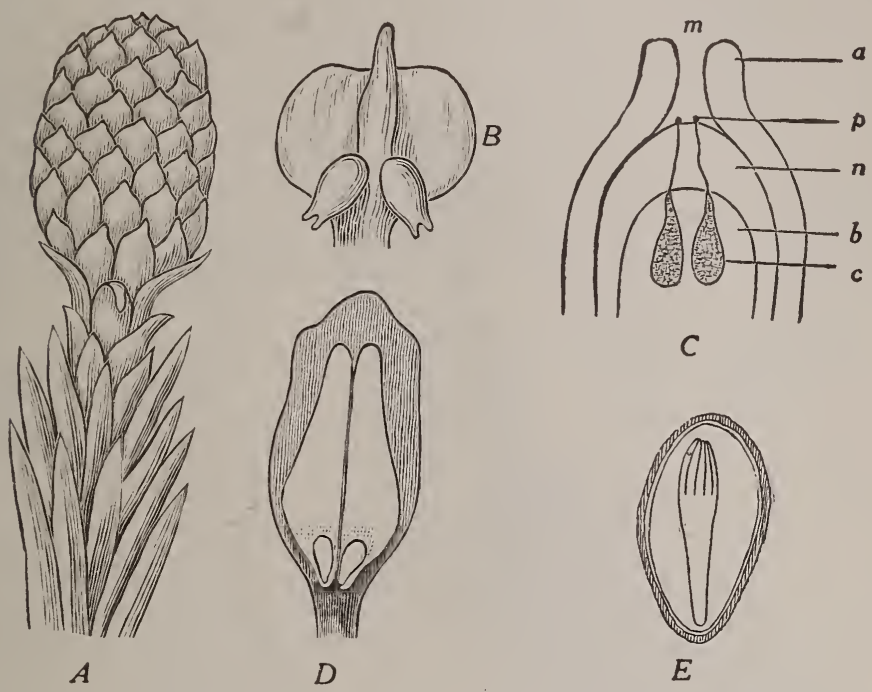

Fig. 609.-Pinus sylvestris. A, female cone somewhat enlarged; B, one of the fruiting scales considerably magnified, showing upper surface and two ovules near its base, pointing obliquely downward. The bract, in the axil of which the fruiting-scale is borne, is concealed behind the latter. C, diagram of upper part of ovule much magnified; $a$, coat of ovule; $\mathrm{m}$, micropyle; $\mathrm{p}$, pollen-grain sending tube into nucellus, $\mathrm{n} ; \mathrm{b}$, embryo-sac filled with endosperm; $\mathrm{c}$, one of the two archegonia. D, scale with ripened seeds; these each possess a prominent wing. $E$, seed with wing removed and cut longitudinally to show albumen and embryo.

When the ripened pollen-sacs begin to open to shed their pollen, the axis of the fertile cone lengthens so as to separate the scales and permit the access of the pollen. The latter, conveyed by the wind and falling upon the ovule-bearing scale, slips down it to the base, being guided in its course partly by the projecting mid-rib, partly by the peculiar formation of the scale, and partly by the appendages of the pollen-grains, until they rest in the micropyles of the ovules. The pollination thus accomplished, the scales of the cone close together at the top, and become agglutinated with resinous matter. At the time this takes place the ovule is very imperfectly developed, and in this species the process of fertiliza- 
tion occupies a long time, not being completed, in fact, until the succeeding year.

When the ovule is fully matured and ready to receive the fertilizing influence of the pollen-tube, a large embryo-sac has been formed in the nucellus, and this has been filled with cells constituting a prothallus (gametophyte), and in this are formed one or more archegonia, which structurally resemble the corresponding organs of the Pteridophytes, possessing a body, which contains an egg-cell, and a neck composed of rows of small cells. The pollentube, formed from the germinating pollen-grain, penetrates the tissues of the nucellus and grows down through them to the neck of the archegonium, and its sperm nucleus unites with the nucleus of the egg-cell. The fertilized egg-cell then begins to develop three
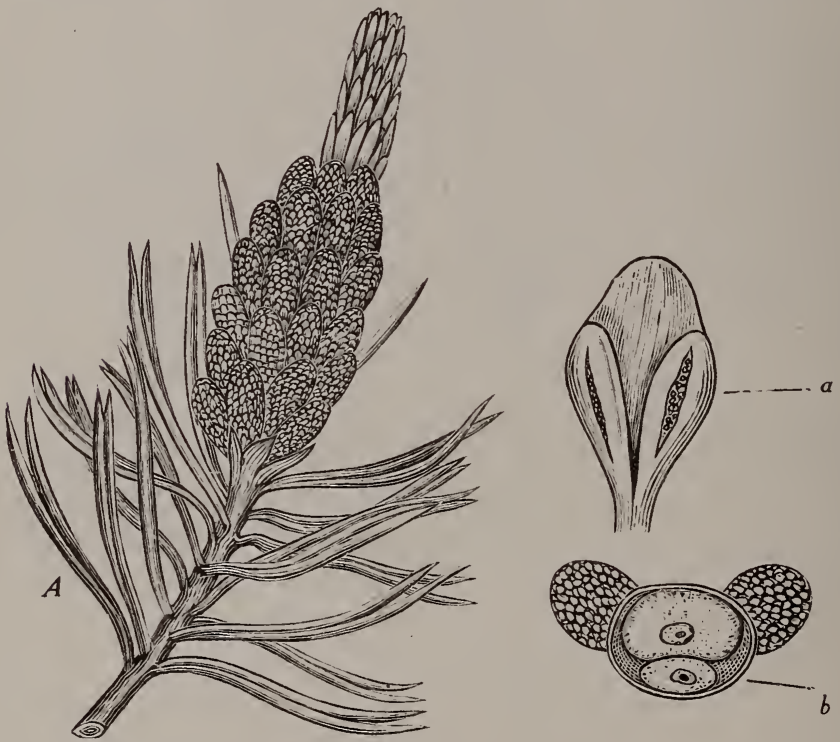

Fig. 610.-Pinus sylvestris. A, branch, showing cluster of staminate cones near its apex; a, one of the staminal leaves magnified, showing two pollen-sacs: b, a pollen-grain highly magnified, showing outer coat with two cellular, winglike appendages. The body of the grain contains two cells, one large and one small one.

structures, known as the pro-embryo, the suspensor and the embryo-sporophyte. A part of the prothallus is used in nourishing the embryo but more is stored as endosperm around it. The time of pollination to the ripening of the seed, comprises, in this and 
many other species of the Conifers, two entire seasons. The embryo, as in many other species of Pinaceæ and in some other Conifers, is polycotyledonous. The reproduction of Pinus sylvestris is illustrated in Figs. 609 and 610.

The Gnetales, or Joint Firs, constitute a small but diversified order of plants, consisting of undershrubs, shrubs, and small or moderate-sized trees. There are only about forty species in all,

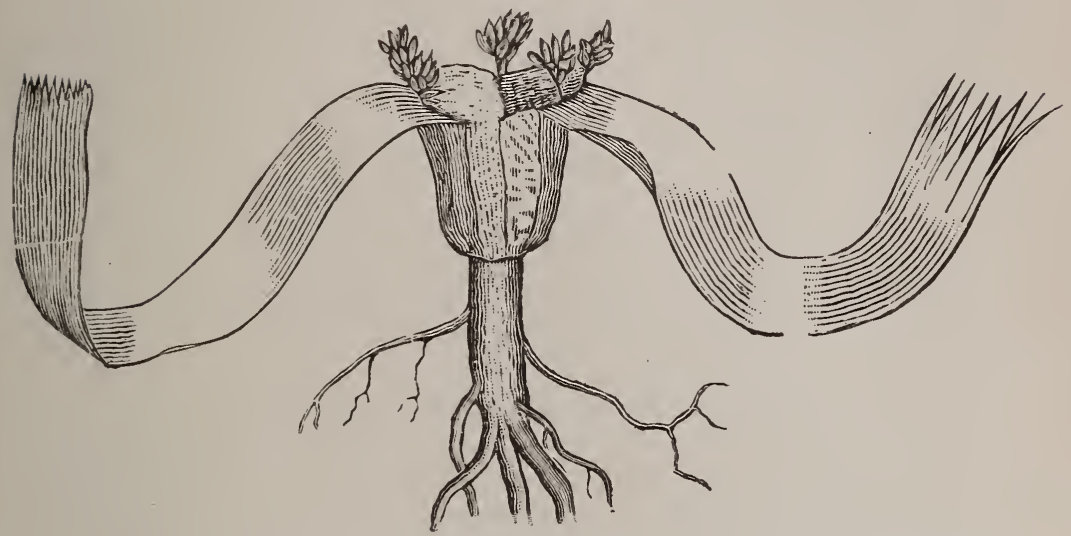

Fig. 611.-Welwitschia mirabilis, entire plant, about one-thirtieth natural size. After Hooker.

and these are distributed into the three genera, Ephedra, Gnetum and Welwitschia, comprised in the family Gnetacex. The Ephedras are shrubs or undershrubs with much the aspect of Equisetums, having slender, cylindrical, jointed branches covered with a green rind, and bearing at the joints a pair of opposite small leaves, which are connate at the base, forming a two-toothed sheath.

The Gnetums also have opposite leaves, but these are large, broadly lanceolate or oval, entire, and pinnately veined. The remarkable genus, Welwitschia, is represented by but one species, Weluitschia mirabilis, a native of South Africa. It has a short, thick stem, which rises but 'a few inches above the soil, and is continued downward into a long tap-root. From opposite sides, just below the summit of the stem, arise two long, strap-shaped persistent foliage leaves, several feet long, and usually more or less fringed and torn at the apex, the only leaves the plant possesses, and from the circumference of the broad apex of the 
stem, just above these, spring the branches of the cymose inflor escence. These arise from the axils of bracts, and are jointed and dichotomously branching. See Fig. 611.

The flowers in some species of the Gnetaceæ are monœcious, in others diœcious, and both male and female flowers are invested and protected by modified leaves, forming a kind of perianth somewhat similar in character to that of the higher flowering-plants. Each stamen bears either two or four pollen-sacs, the ovules, like those of the higher plants, have two coats, and the embryos are dicotyledonous.

The members of the order, unlike the Conifers, are destitute of resinous secretions.

\section{CHAPTER XII.-THE SPERMATOPHYTA (CONTINUED.)}

THE ANGIOSPERM $A$; OR ANGIOSPERMS.

The plants of this class greatly excel the preceding, and in fact all others, in the number of their species, and in the variety of their habits. There are not less than 125,000 species known. They include the great majority of our cultivated plants, most of our forest trees, and nearly all our shrubs, herbs, marsh plants and flowering aquatics. They are the most highly developed members of the plant kingdom and are best adapted to live as land plants. A few among them have acquired parasitic or saprophytic habits, and are destitute of chlorophyll, but these are the rare exceptions; by far the larger part are chlorophyll-bearing.

Their tissues are, on the whole, more complex than those of Gymnosperms, and their vegetative organs, particularly the leaves, are better developed. Their superiority is shown most conspicuously, however, in the structure of their flowers. In the Gymnosperms, as we have seen, the pollen is brought directly in contact with the ovule, but in the Angiosperms the pollen comes in contact first with a receptive surface of the carpel known as the Stigma. While, therefore, the strobili of the Gymnosperms represent flowers in their very simplest form and lack anything resembling a calyx or corolla, in Angiosperms, usually, the floral branch, including the sporophylls which directly bear the pollen-grains 
and ovules, and the floral leaves constituting the perianth, exterior to them, are much more strongly modified or highly specialized, forming a true flower which is more or less conspicuously different from the rest of the plant. The perianth is usually differentiated into calyx and corolla and serves to protect the sporophylls and especially to secure insect pollination. The part of the axis on which the floral leaves are borne, is usually very short, and the leaves themselves compactly arranged either in whorls or spirals. Moreover, the axis nearly ceases its growth after these floral leaves are formed, and does not, except in occasional monstrosities, produce buds in their axils. The short, often expanded, part of the axis, calied the receptacle, that bears the tioral leaves, is irequently prolonged below into a stalk or peduncle, which may either be naked or bear small modified leaves, the bracteoles. In all Gymnosperms, as we have seen, the flowers are either monœcious or diœcious; but while this is the case also with many Angiosperms, the majority are hermaphrodite, or produce both stamens and pistils together in the same flower, the carpellary leaves occupying the center of the flower, while the stamens are borne immediately below or exterior to them. But perhaps the most conspicuous difference between the two Classes, is the fact that, in Angiosperms, the ovules are enclosed, while in Gymnosperms they are naked or unenclosed. While the pollination in the Gymnosperms is exclusively anemophilous, in the higher Angiosperms it is entomophilous.

Other differences, though less conspicuous and less easily detected, but of still greater significance, as showing the relations between the two groups, and the connection of both with the Pteridophytes, are found in the pollen-grains and embryo-sacs.

The megasporophylls, here known as carpels, constitute the pistil. This organ may consist of one carpel (simple pistil) or of a whorl of carpels united together (compound pistil). The ovary, the part of the pistil which contains the ovules, and the stigma, which receives the pollen, are among the characteristic features of the Angiosperms. Within the ovary are borne the megasporangia, here known as ovules. Each ovule consists of a nucellus and two surrounding integuments (already described in Part I). The mother-cell of the megaspores is formed within the nucellus and, like the microspore mother-cell, undergoes two successive divisions, resulting in the formation of four megaspores. Also, at one stage of these divisions, a reduction of the chromosomes to the 
gametophytic number occurs. One of the megaspores enlarges at the expense of the other three, which are used by it as food. The adjoining cells of the nucellus are also digested by the growing megaspore, whose nucleus divides repeatedly until eight nuclei are enclosed within its cell membrane. This constitutes the female gametophyte, here known as the embryo-sac. Two so-called polar nuclei, one from each end of the embryo-sac, move to the centre of the sac and come in contact and may either fuse early or await fertilization before fusing. The three nuclei at the micropylar end become the egg-cell and the two synergids; the other three nuclei comprise the antipodal cells; now the female gametophyte is ready for fertilization. (See Part I, page 107.)

The microsporophylls, better known as the stamens, consist essentially of the microsporangia (pollen-sacs), of which there are usually four in each anther. The microspores (pollen-grains) are usually numerous and are formed before the flower opens. As in the lower plants, the microspores are formed in special cells, known as mother-cells, of which there are many in each pollen-sac. While the flower is yet in the early bud stage, the mother-cells are formed. Each mother-cell divides twice, forming four pollengrains. This division of the mother-cell nuclei is a reduction division as a result of which the daughter-cells (and therefore the pollen-grain nuclei) get only half the number of chromosomes that the parent plant (sporophyte) possessed. Before the pollen-grain is shed, its nucleus divides, forming two nuclei, known as the generative nucleus and the tube nucleus. In this condition the pollen reaches the stigma and there resumes its growth or germination.

In the Angiosperms, the germination of the pollen-grain (microspore) is simpler than in the Gymnosperms, the prothallial cells are absent and the male gametophyte is represented by the pollen-tube containing the tube nucleus and generative nucleus, the latter dividing to form the two sperms. The pollen-tube (male gametophyte) is usually short-lived and exists as a parasite, nourishes by the stigmatic secretion (see page 106, Part I).

The female gametophyte, formed in the embryo-sac of Angiosperms, is much more rudimentary than in Gymnosperms, being represented only by the egg-cell, two synergids, the three antipodal cells and the fusion nucleus. (See Fig. 265, page 107). In fertilization, the stimulus afforded by the union of the second sperm nucleus with the fusion nucleus causes a further growth of the 
prothallus or endosperm, and this with the growing embryo fills the sac. Therefore, it is only after fertilization is effected that an endosperm is developed in this group of plants. It serves the same purpose as the endosperm formed in the embryo-sac of Gymnosperms previous to fertilization, and is called by the same name. It is obviously, however, not the same structure but is rather to be regarded as a new formation.

The efforts of botanists to develop a natural classification of the Angiosperms have been attended with great difficulties and a satisfactory classification is not yet attained. In the attempt to follow the lines of evolution the greatest stress has been laid upon the structure of the flowers. Those flowers which most closely approach the strobili of the Gymnosperms are considered the simplest and, therefore, the lowest in evolutionary sequence. Flowers without perianths rank below those with perianths. Those with the sporophylls arranged spirally are considered simpler than those with a cyclic arrangement. Union of petals or carpels represents an advance over flowers in which these parts are distinct. There is, however, a substantial agreement on the division of the Angiosperms into two markedly distinct sub-classes, the Monocotyledons and the Dicotyledons, in both of which the orders and families are arranged in an ascending series.

\section{CHAPTER XIII.-THE SPERMATOPHYTA.}

THE ANGIOSPERME (CONTINUED).

THE MIONOCOTYLEDONES, OR MONOCOTYLEDONS.

Plants of this sub-class seldom show in their stems any distinction between wood and bark; they are without medullary rays; their fibro-vascular bundles, which are of the closed variety, are not arranged radially about a central pith, as are the bundles in the stems of Gymnosperms and Dicotyledons, but are irregularly imbedded in the fundamental tissue, and there is usually no cambium zone by which the stems increase in thickness. (See Part II, pp. 226.) Only a few tropical species, notably the Palms, become trees, the others are mostly herbaceous. 
The primary root, though present in the embryo, in most cases soon ceases to grow, and soil solutions are absorbed chiefly by adventitious roots, which spring laterally from the stem. Moreover, these roots possess no cambium zone, have no medullary rays, and undergo no important secondary changes as do the roots of Dicotyledons, and the central radial bundle commonly has more numerous xylem and phloem rays, and the endodermis whick encloses it, is usually composed of thick-walled cells.
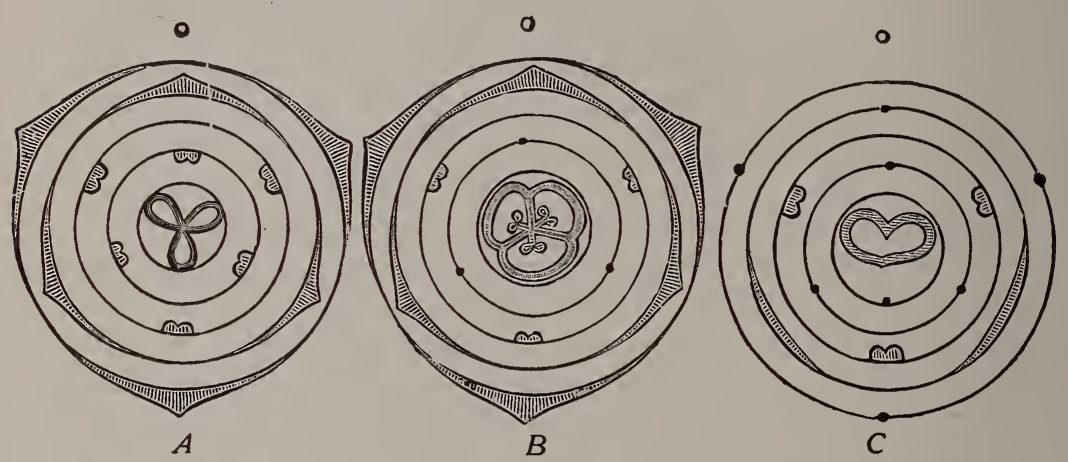

Fig. 612.-Floral diagrams of flowers of Monocotyledons. A, typical flower of Monocotyledon; B, diagram of flower of Iris; C, diagram of flower of a Grass.

The leaves, except those of the Arums, Yams and Smilaxes, are seldom reticulate, but are mostly parallel-veined and the weaker veins are deeply buried in the mesophyll, and do not stand out so prominently on the lower surface as do those of Dicotyledons; they are not often opposite or whorled, but usually arranged on one of the simpler of the alternate plans, as one-half, one-third or one-fourth, though occasionally in a more complex manner; they are less commonly provided with stipules than the leaves of Dicotyledons; they are not usually articulated to the stem but are commonly sheathing at the base and often with no distinction of petiole and blade. . Usually they are entire.

The flowers most commonly have the cycle number of three or six and usually consist of five alternating whorls, one of sepals, one of petals, two of stamens and one of pistils. See Fig. 612, A. In the majority of cases, the perianth whorls, when present, are similar in color.

The seeds, in most cases, possess a copious endosperm, with a relatively small embryo, but in some species, as most Orchidacer, 
no endosperm is formed at all; and in the Alismacex, Naiadacex and Juncacex, it is formed, but very soon disappears; and in the Scitaminales a copious perisperm is developed in its stead.

But perhaps the most distinctive characteristic of the group lies in the structure of the embryo. This is monocotyledonous; that is, instead of an opposite pair of cotyledons, as in many Gymnosperms, and nearly all Dicotyledons, only one embryonic leaf occurs on the first node; if other's are present, they alternate with it, and are enfolded by it. As this is the only conspicuous one, it is called the cotyledon. The embryo is usually straight and cylindrical or obconical, from the thickening of the cotyledon toward its upper end, but in a few cases, as in Potamogeton, it is elongated and coiled. The axial part (caulicle and radicle) is usually very short and nearly enclosed in the relatively large cotyledon, but in Sagittaria, Vallisneria, Hydrocharis, and their relatives, the axis is more conspicuous than the cotyledon. When the seed germinates, in some cases the radicle scarcely grows at all, but is almost immediately displaced functionally by adventitious roots which spring from above it, as in the Grasses; but in most cases it grows vigorously for a short time and then stops, giving way to adventitious roots.

The sub-class includes about nine orders, forty families and upwards of 24,000 species, and comprises about one-fourth of the Angiosperms.

The first five orders are grouped as the Primitive Monocotyledons; their flowers are often destitute of perianth (naked) or have the floral parts indefinite in number and exhibit spiral rather than cyclic arrangements in at least some of their parts.

Order 1. Pandanales. This order includes three families; the Pandanacex, or Screw Pines, the Typhacer, or Cat Tails, and the Sparganiacex, or Bur-reeds. These are the simplest of Monocotyledons. The perianth is absent; the flowers unisexual and the stamens indefinite in number and spirally arranged. The predominant family, the Screw Pines, are tropical, the others chiefly of temperate regions.

Order 2. Heliobales. Here are included about one hundred species of small herbs mostly growing in water (hydrophytes) or in wet places. Among these are the Pondweeds (Potamogeton), Water Plantains (Alisma) and Arrowheads (Sagittaria). They are chiefly anemophilous or hydrophilous: They present a wide range of floral structure, ranking above the Pandanales in that 
respect. Unlike the following order, they have little or no endosperm.

Order 3. Glumales, or Glumiflorae, include two great families, the Grasses (Gramineæ), with nearly 5,000 species, and the Sedges (Cyperacer), with over 2,000. This is among the largest of the Angiospermous orders in number of species and no doubt the very largest in the number of individuals. The flowers are mostly bisexual, destitute of perianth and enclosed by scaly or glumaceous bracts. They are mostly arranged in spikes or panicles. The fruit of the Grasses is a caryopsis, that of the Sedges, an akene.

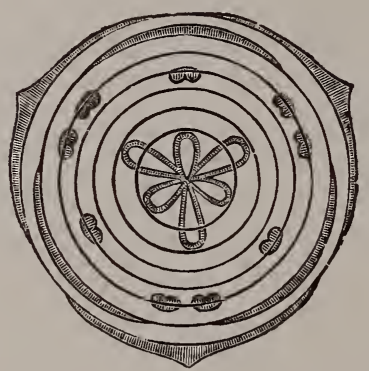

Fig. 613.-Diagram of flower of Butomus, or Flowering.rush, showing a doubling in the outer whorl of stamens, and two whorls, instead of one, of pistils.

The Grasses are the most valuable group of plants from an economic standpoint. Fodder for domestic animals and food for man are afforded by them. The cereals, including Wheat, Corn, Oats, Rice, Rye and Barley, belong here. So also do the Sugar Cane and the tropical Bamboo, the latter the only tree in the group. The Sedges are distinguished by their solid and mostly triangular stems.

Order 4. Palmales, or Principes, is a well-marked tropical or sub-tropical order, including many handsome trees, with upright columnar stems crowned by a tuft of frond-like leaves. The family Palmacex, with about 150 genera and 1,100 species, comprises the group, which yields many products of considerable economic importance: Dates, Cocoanuts, Sago, Palm Oil, Rattan and Vegetable Ivory are among these. In the Palms the perianth is always present, the flowers are rather small and occur in simple or branched spikes and the inflorescence in its early growth is enclosed by a spathe. 
Order 5. Arales comprise chiefly the family Aracex, with about 1,000 species, and the Lemnaceæ, with only 25. Our Jack-inthe-Pulpit or Indian Turnip, the Calla Lily, the Caladiums and Anthuriums of our greenhouses and the Sweet Flag (Acorus calamus) are familiar representatives of the Aroids. The inflorescence is usually fleshy, often bearing unisexual flowers, and is characteristically surrounded by an enveloping bract or spathe, frequently highly colored. In the Lemnaceæ or Duckweeds is included Wolffia, of interest as the smallest of the flowering plants, a tiny green grain scarcely larger than a pin head.

The next two orders are grouped as the Differentiated Monocotyledons, and in these the individual flower takes precedence over the cluster, being larger and more showy than the preceding orders. Likewise, the cyclic arrangement of the floral parts now predominates and these are usually trimerous and pentacyclic, there being commonly three carpels, six stamens (in two whorls) and six perianth parts (in two whorls). The showy perianth is of service in securing insect pollination. The line of development of the group is toward epigyny and zygomorphy.

Order 6. Farinales, or Bromeliales, includes more than 2,000 species, over 900 of them comprised in the principal family Bromeliacex, largely tropical epiphytes. The Pineapple is a terrestrial member of this family. To the Pontederiacer belongs the common Pickerel Weed of shallow waters; the Commelinace yields the Spiderwort and the Day Flower. The mealy endosperm which characterizes this order is a distinction from the Lilies.

Order 7. Liliales, including the Lilies and their kin, some 5,000 species, in nine families, are typical highly developed Monocotyledons. They are chiefly herbaceous perennials, many of them from bulbs. The predominant family is the Liliaceæ. The Lilies have regular flowers with a perianth of six parts and two whorls of three stamens each; the three carpels are united; the flowers are entomophilous and are often large and showy-some of them exceedingly handsome. Lilies, Tulips and Hyacinths belong here, as also Onions and Asparagus among our garden vegetables, and the medicinal Squill, Aloes, Colchicum and Sarsaparilla. The Dragon Tree of the Canary Islands is a liliaceous plant and an example of a monocotyledonous stem that increases in diameter through the formation of new bundles. The related Amaryllidaceæ yields Amaryllis, Narcissus, Snowdrop, Tuberose and other cultivated flowers, as well as the Agave or Century Plant. The Iridaceæ 
is the most highly specialized family in the order and yields our cultivated Fleur-de-Lis, Crocus and Gladiolus, as well as the medicinal Saffron and Orris Root. The Juncacex, including the Rushes, grass-like plants growing in water or wet places, are considered the lowest of the group.

The remaining monocotyl orders are classed as the Specialized Monocotyledons, by reason of the high degree of specialization noticeable in their flower's. The arrangement of the floral parts is cyclic and trimerous, but the number of stamens is much reduced and the ovary is syncarpous and inferior. The conspicuous perianth, usually of six parts, is highly irregular, either zygomorphic or asymmetrical, and shows distinctive adaptations to insect pollination. There are two principal orders.

Order 8. Scitaminales includes the Musacex, Zingiberacex, Cannacex and Marantacex. These are chiefly great herbs of tropical regions with large clusters of showy flowers. They number about 1,200 species. The genus Musa yields the Banana, the most popular tropical fruit. The spices, Ginger, Cardamon and Turmeric, are products of the Zingiberacex. From the fleshy rhizomes of Canna and Maranta species are prepared important food starches, known as East Indian and West Indian Arrowroot, respectively. The Cannas are much grown for ornament.

Order 9. Orchidales, or Microspermæ, includes the family Orchidaceæ, numbering more than 6,000 species and widely known for their beautiful and extremely irregular flowers-many of them wonderfully adapted for insect pollination. Features of the Orchids are: The peculiar lip or labellum, consisting of a large petal; the one or two stamens united with the pistil (gyandrous), the other stamens being reduced to staminodia or absent entirely; the masses of pollen already referred to as pollinia (page 87), and the tiny and very numerous seeds. The tropical Orchids are the most highly specialized and are mostly epiphytic in habit; many of the most prized exotics of our conservatories are among them. The Orchids of temperate regions are mostly terrestrial. Vanilla "beans," the fruit of a tropical species, is the only economic product of importance. Several species of Cypripedium are employed in medicine. 
CHAPTER XIV.-THE SPERMATOPHYTA.

THE ANGIOSPERME (CONTINUED).

THE DICOTYLEDONES, OR DICOTYLEDONS.

The stems of Dicotyledons, like those of Gymnosperms, have the collateral vascular bundles arranged radially about a pith, and separated from each other by medullary rays, and in nearly all cases secondary thickening takes place by means of a cambium which lies between the wood and bark, but their tissues are more complex, particularly those of the secondary wood, which usually consist of wood-cells, wood parenchyma, tracheids and tubes of various kinds, and frequently also of some other tissues. The branching is always monopodial, and nearly always from axillary buds.

The primary root is often strongly developed, and with its branches constitutes the principal root-system of the plant, but adventitious roots are also common, and in some instances early replace functionally the primary roots, as they do in Monocotyledons. The roots in most cases undergo important secondary changes, increasing in thickness by means of a cambium and developing medullary rays resembling those of the stem. The primary radial vascular bundle is usually few-rayed, and the walls of the endodermal cells which enclose it are seldom thickened. (See Part II, page 231.)

The leaves are remarkable for the variety of their forms and modifications; they may be opposite, whorled or alternate, and in many cases the phyllotaxy is quite complex; they are frequently stipulate, often toothed, incised, or branched into compound forms; with very few exceptions, their venation is reticulate, and the veins, except in succulent forms, are prominent on the lower surface. They are most commonly petiolate, seldom sheathing or clasping, and, in most instances, are articulated to the stem.

The flowers present very great diversity both of form and arrangement. In the majority of cases the floral organs consist of four alternate whorls, one of sepals, one of petals, one of stamens and one of pistils. (See Fig. 614, A). The prevailing cycle number is five, but not uncommonly the parts are in fours (see Fig. $614, C)$, less frequently they are in twos, threes or sixes. There 
are, however, numerous deviations from cycle number, due either to the suppression of some of the whorls or a part of them, or to the multiplication of some of them. The corolla, particularly, is liable to be wanting, and the stamens are especially likely to consist of multiple whorls. In the Magnoliacex, the Ranuculacex, the leafy Calycanthacex and the Nymphracex, some or all of the floral organs may be arranged in spirals rather than whorls.
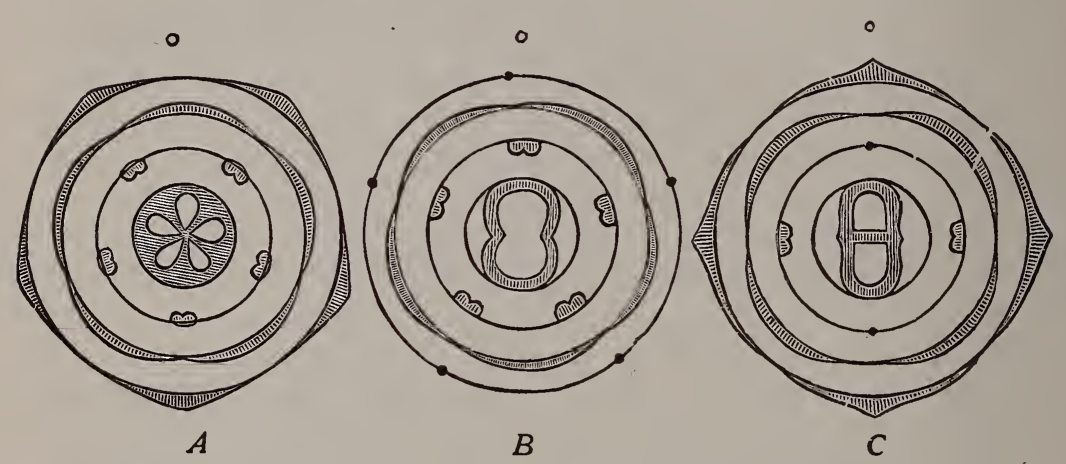

Fig. 614.-Floral diagrams of flowers of Dicotyledons. A, diagram of flower of Aralia, consisting of four whorls of five alternating parts each; B, diagram of flower of Compositae, calyx wanting (or only represented in the pappus), the pistil consisting of two coalesced carpels and five each of the petals and stamens; $\mathrm{C}$, diagram of tetramerous flower of Oleaceae.

When both whorls of the perianth are present, they are seldom alike, but are differentiated into calyx and corolla. Zygomorphic and asymmetrical flowers are more common in Dicotyledons than in Monocotyledons.

The embryos of Dicotyledons are relatively large and well developed. They may be associated in the seed with a copious endosperm, as in the Spurges, Umbelworts and Polygonums, or with one which is relatively small in quantity, as in the Mints and Milkweeds, or the endosperm may be completely absorbed before the seed is ripe, as in the Oaks, Cucumbers, Roses and Cresses. In nearly every case it is formed copiously at first, and usually by internal cell-formation within the embryo-sac. It is rarely the case that the embryo is very rudimentary in the ripe seed, except in chlorophylless parasites and saprophytes, such as Monotropa and the Orobanchacex, where it often consists of a cluster of only a few cells. In the seeds of other species, cotyledons, caulicle, 
radicle and plumule, are usually distinguishable. The plumule, though, is sometimes wanting, even in embryos otherwise well developed, being represented only by the naked apex of the caulicle rising between the bases of the cotyledons, as in the species of Cucurbita. The embryos, in nearly all cases, are strictly dicotyledonous, but, in a few instances, as already explained in Part I, they become falsely monocotyledonous or falsely acotyledonous by the abortion of one or both of the cotyledons, and it rarely happens, on the other hand, that a plant which ordinarily produces a dicotyledonous embryo, develops one with three. This has been known to occur in the Oak and Almond.

In germination, also, the embryo behaves differently from that of Monocotyledons, in the relatively strong growth which the

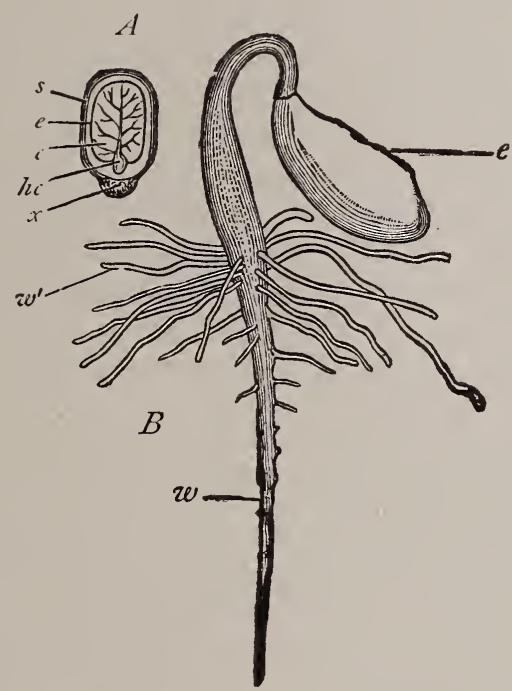

Fig. 615.-Ricinus communis. A, ripe seed laid open longitudinally; s, testa ; e, endosperm; $c$, cotyledon; hc, hypocotyledonary part of caulicle; $x$, strophiole or caruncle. B, regminating seed with the cotyledons still buried in the endo. sperm, e; w, primary root; $w^{\prime}$, secondary roots. After Sachs.

primary root or radicle always makes. It pushes out of the seedcoats and attains a considerable size, even while the rest of the embryo is still contained within the seed. See Fig. 615. The cotyledons may either remain enclosed within the seed-coats and wither, after the nutriment in them has been exhausted, or they 
may be carried above-ground, performing for a time the functions of foliage leaves.

The Dicotyledons are chiefly terrestrial mesophytes. To them belong all the trees except the Pines and their congeners, and nearly all the shrubby plants and a large portion of the herbs that constitute the native flora of the northern United States. They form by far the largest group of flowering plants, much larger, in fact, than all the others combined. About 100,000 species are recognized by botanists. They are divided into three principal divisions, as follows:
A.-The Archichlamyder.
B.-The Polypetalx.
C.-The Sympetalx.

(A) The Archichlamydeæ, or Apetalæ, sometimes termed the Primitive Dictyledons, have usually small and inconspicuous flowers, which are mostly destitute of a corolla, and frequently also of a calyx. When present these parts are usually rudimentary, indefinite in number and spirally arranged.

Order 1 , Verticillales is represented only by the family Casuarinacex, which includes but one genus, Casuarina, and about 20 species, natives of Australia and southeastern Asia. They are trees and shrubs with the aspect of Equisetum. The flowers are very simple; the staminate flowers borne in spikes, the pistillate in heads. No perianth is present. The ovules contain many embryo-sacs instead of one.

Order 2, Piperales include the Saururacex, Piperaceæ and Chloranthaceæ. All are destitute of perianth. The Piperaceæ or Pepper Family is much the largest in the order and is noteworthy for its aromatic properties. Its members are herbs and shrubs with jointed stems, entire leaves, and naked inconspicuous flowers in spikes. Pepper, the most largely used of spices, Cubebs and Ava Kava, used medicinally, are derived from this family.

Order 3, Salicales includes the Salicaceæ or Willow Family. The Willows and Poplars, trees and shrubs of temperate and arctic regions, with soft white wood and bitter bark, belong here. They are diœcious, with both staminate and pistillate flowers in catkins; entomophilous; fruit, a dehiscent many-seeded pod. The barks of several species of Willow and Poplar are used medicinally and as a source of Salicin, a bitter glucoside. Willow and Poplar woods are sources of the medicinal Wood Charcoal.

Order 4, Myricales, as a group resembles the preceding order, 
but the fruit is one-seeded. The Myricacex is the principal family. Myrica cerifera yields the Bayberry wax of commerce. Several species yield aromatic leaves or astringent barks.

Order 5, Juglandales is represented by the family Juglandacex, a small group of trees and shrubs with odd-pinnate leaves and nutlike fruit enclosed in a husk. A number of important food nuts, Black Walnut, English Walnut, Butternut, Hickory and Pecan, belong here, as well as several valuable woods, including black walnut and hickory.

Order 6, Fagales comprises the families Betulaceæ and Fagacex, about 700 species in all, and yields many important timber trees affording hard woods. These are distinguished from the preceding groups by the presence of a calyx in many of the species. In the Fagacex the pistillate flowers are surrounded by an involucre which persists and becomes a "bur" or "cup" in the fruit. The volatile oil from Sweet Birch is known in commerce as Oil of Wintergreen. Chestnuts and Hazelnuts are important food nuts; Beechnuts and Acorns serve as food for animals. Nutgalls and Oak Bark, used as astringents and for tanning, Bottle Cork, used for stoppers, cork floats, etc., are also products of the Oaks.

Order 7, Urticales comprises the families Ulmacex, Moracex, and Urticacex, distinguished from the preceding six orders by not having their flowers in catkins or spikes. The Ulmacex, or Elms, are well-known forest trees or shrubs, often cultivated for ornament. The Moracex, or Mulberries, afford the Fig, Mulberry and Bread Fruit, as well as several important fibers, chief among which is Hemp. Hops, Lupulin and Indian Hemp are drugs derived from the same family. Hempseed yields a bland fixed oil. The Urticacex, or Nettles, are chiefly herbs, the common Stinging Nettle being one of them. Ramie fiber (Bchmeria nivea) is an important economic product.

Order 8, Proteales embraces only the family Proteacex, with about 1,000 species, natives of the Southern Hemisphere. A few are cultivated in our greenhouses for their beautiful flowers.

Order 9, Santales comprises two families: The Lowanthacex, or Mistletoes, which are aerial or tree parasites or half-parasites in mode of life, and the Santalacex, which are often root-parasites, though provided with chlorophyll and therefore at least semiindependent. The East Indian Sandalwood (Santalum album) yields an odorous volatile oil used in medicine and in perfumery.

Order 10, Aristolochiales includes the Rafflesias, giant parasites 
already referred to (page 97), and the Aristolochiacex or Birthworts, the latter chiefly herbs or shrubs with erect or twining stems. Petals are absent but the gamosepalous calyx is often odd in shape and highly colored. Serpentaria and Asarum are official drugs derived from this family. Dutchman's. Pipe is a rather common porch vine.

Order 11, Polygonales is represented only by the Polygonacex, or Buckwheats, comprising about 700 species, including herbs, shruhs and trees, mostly native to the temperate regions of the Northern Hemisphere. The stipular sheaths and orthotropous seeds are distinctive. Buckwheat and Pie Plant among the foods, the medicinal Rhubarb and Rumex, and Canaigre, much used in tanning, are important economic products.

Order 12, Chenopodiales or Centrospermæ includes the families Chenopodiacex, Amarantacex, Phytolaccacex, Nyctaginaceæ, Aizoacex, Portulacacex and Caryophyllacex, which have in common a coiled or curved embryo and the fruit not an akene. Over 3,000 species are embraced in this great order. The Sugar Beet is the most important economic plant in the Chenopodiacex, being the source of about a half the world's supply of sugar. The tops of Spinach, Chard and several other Chenopods are eaten as greens. The drug Chenopodium and the oil distilled from it are valuable vermifuges. The Amarantacex or Amaranth family yields a number of ornamental garden annuals and many weeds of cultivated grounds. The Nyctaginacex or Four-O'Clock Family yields several garden plants, among them the Bougainvillea and Four-O'Clock. The Phytolaccacex is represented in medicine by the Poke, the root of which is employed. Aizoacex includes the Ice Plant (Mesembryanthemum crystullinum), which has leaves covered with hairs bearing a viscid liquid and giving the plant a characteristic frosty appearance. The Portulacacex yields a number of mucilaginous plants, several of them being used as potherbs. The Caryophyllacex, a large and widely distributed family, furnishes several of our cultivated flowers, Dianthus, Gypsophila, Lychnis and Saponaria.

(B) The Polypetalæ, or Dialypetalæ, sometimes termed the Differentiated Dicotyledons, have better developed individual flowers, usually in four whorls, with the calyx green in color, and distinguished thereby from the corolla. The petals are usually five in number and distinct. Entomophily is the prevalent form of pollination. 
Order 13, Ranales is characterized by having, usually, separate petals, sepals, stamens and carpels, the two latter often more numerous than the petals. About 3,000 species are included in the following nine families: Nymphacex, or Water Lily family, aquatic plants, among them the Lotus and White Pond Lily, as well as the Amazonian Victoria regia. Renunculaceæ, or Buttercup Family, which includes several important drugs, notably Hydrastis and Aconite. The Columbine, Larkspur, Anemone, Clematis and Peony are familiar ornamental plants belonging to this family. Berberidacex, or Barberry Family yields the Podophyllum or May Apple, of which the resin from the underground parts is a valuable cathartic, also the ornamental Barberries (Berberis), whose rootbark contains the bitter vellow alkaloid Berberine. Menispermaceæ, or Moonseed Family furnishes Calumba, much used as a bitter tonic, also the poisonous Fish Berries (Anamirta Cocculus). Magnoliaceæ, or Magnolia Family includes the Magnolias and other trees and shrubs with handsome flowers. Calycanthaceæ supplies a number of ornamental shrubs. Anonaceæ, mostly tropical, yields several edible fruits, including the Northern Papaw (Asimina). Myristicaceæ, a small tropical family, furnishes the valuable spices, Nutmeg and Mace, the latter being the aril and the former the kernel from the same fruit. Monimiaceæ, a tropical and subtropical family of trees and shrubs, supplies the medicinal Boldo leaves. Lauracex, or Laurel Family is rich in useful plants. Among its products are Camphor, Cinnamon and Sassafras. The Sweet Bay and the Avocado also belong here.

Order 14, Papaverales, or Rhœadales, comprise more than 2,000 species, mostly herbs, which are distinguished from the preceding order chiefly by their united carpels, forming a compound ovary. Papaveraceæ affords Opium, noted for its sedative and narcotic properties, also Sanguinaria and Celandine, which are medicinal, as well as several varieties of Poppy cultivated for ornament. Fumariacex gives several well-known garden plants, including the Bleeding Heart (Dicentra). Cruciferæ, named from its four petals, which form a cross, yields both black and white Mustard, Cabbage, Turnip, Rutabaga, Radish and other useful products. This family numbers 1,600 species and is characterized by its four petals, six stamens (four long and two short), its pod-like fruit (Silique or Silicle), the peculiarly curved embryo and the acrid, watery juice. Capparidaceæ, closely related to Cruciferæ, furnishes the cultivated Caper (Capparis) and several garden plants. 
Resedacex, or Mignonette Family and Moringaceæ, or Moringa Family are small groups yielding little of importance.

Order 15, Sarraceniales includes a small group of perennial herbs growing in bogs and insectivorous in habit. Among the families are Sarraceniacer, the American Pitcher Plants, Nepenthace $x$, or East Indian Pitcher Plants, and Droserace , or Sundews. Several species are employed in medicine, otherwise they are of little economic importance. (See Figs. 131, 133 and 134, page 53.)

Order 16, Rosales comprises a very large and varied order of about 10,000 species, yielding many important economic products. Crassulacex or Orpine Family is composed chiefly of succulent plants whose water-storing facilities fit them for dry climates. Saxifragace yields the Currants and Gooseberries, as well as the Philadelphus, Hydrangea and other ornamental shrubs and herbs. Pittosporaceæ comprises a group of Australian plants; several species, chiefly evergreen shrubs, are in cultivation. Hamamelidaceæ furnish our Witch Hazel and Sweet Gum tree (Liquidambar); Styrax, a medicinal balsam, is obtained from an Asiatic species of Liquidambar. Platanace $x_{\text {includes the Plane Tree (Platanus) }}$ and the Button-Ball (Cephalanthus).

Rosace $\mathscr{X}$ is a large family of 1,500 species. Many of the flowers resemble those of the Ranunculacex, but are perigynous, the sepals united or confluent with the cup of the receptacle upon which the petals and stamens are borne. The family is usually divided into several sub-families based on the nature of the fruits; one having follicles; another pomes; a third, achenes or separate drupelets, and a fourth, drupes. To the Rosaceæ belong many cultivated fruits, the Apple, Pear, Quince, Cherry, Plum, Peach, Raspberry, Blackberry and Strawberry. Also many ornamental plants, Roses, Hawthorne and Spiræas, and a considerable number of medicinal plants, Wild Cherry, Soapbark, Bitter Almond and others. Leguminos $\mathscr{x}$, one of the largest families in the plant kingdom, comprises about 7,000 species and is widely distributed, though more abundant in the tropics. It is usually divided into three sub-families: Mimosæ, with regular flowers; Cæsalpinæ, with irregular but not papilionaceous flowers, and Papilionacer, with papilionaceous flowers (see Fig. 181, page 79). The common character is the leguminous fruit (see Fig. 226, page 89). The leaves of many of the Leguminosæ are motile (see page 287), and the pollination often quite intricate. The roots often bear tubercles containing nitrogen-fixing bacteria (Fig. 497). Peas and Beans 
among food plants; Clovers and Alfalfa among forage plants; Logwood and Red Saunders among dyestuffs; Acacia and Tragacanth among the gums; Kino and Catechu among astringent medicines, Balsams of Peru and Tolu, Licorice, Copaiba and other drugs, including the very poisonous Calabar Bean (Phystostigma), are a few of the immense number of economic products of this family.

Order 17, Geraniales is another large and varied order including some 8,000 species. It is distinguished from the preceding order by its compound pistils and usually separate sepals. The families embraced in it are: Geraniacex or Geranium Family, to which the Wild Geranium and the house Geranium (Pelargonium) belong; Oxalidaceæ or Oxalis Family; Tropæolaceæ or Nasturtium Family; Linaceæ, which yields Flax, with its valuable fiber and seed-oil; Erythroxylacex, from which the Coca leaf and its habit-forming alkaloid, Cocaine, are obtained; Zygophyllacex, represented in medicine by Lignum Vitæ and its resin, Guaiac; Rutaceæ, yielding the important Citrus fruits, Oranges, Lemons, Limes and Grape Fruit, as well as the medicinal Buchu, Pilocarpus and Prickly Ash; Simarubacex, from which the bitter Quassia wood is obtained; Burseracex, which supplies the fragrant gum-resins Myrrh, Olibanum and Frankincense; Meliacex, furnishing Mahogany and West Indian Cedar as well as the Pride of India and other ornamental southern trees; Polygalacex, affording the medicinal Senega, and Euphorbiaceæ or Spurge Family, in which the apparently single blossoms are really clusters of reduced flowers, often monœcious or diœcious, and surrounded by highly colored bracts which simulate petals (e. g., Poinsettia). The Spurges comprise about 4,000 species and among their valuabie products are India Rubber, Cassava, Castor Oil, Croton Oil and many useful and ornamental plants.

Order 18 , Sapindales embraces about 2,500 species, mostly trees and shrubs belonging to the following families: Buracex, to which the ornamental Box belongs; Empetraceær, or Crowberry Family; Coriariacex, which yields the poisonous Myrtle-leaved Sumach of Southeastern Europe; Limnanthacex; Anacardiaceæ, to which belongs the Pistachio-nut, the Cashew-nut, the Mango, the ornamental Pepper Tree and Sumach, and the Poison Ivy; Aquifoliacex, from which comes the Holly used in Christmas decoration; Celastracex or Staff Tree Family, including several ornamental shrubs with showy arillate seeds; Staphylencex or Bladdernut Family; 
Aceracex, including the Maples; Hippocastanacex, including the Horse-chestnuts; Sapindacex, yielding the Soapberry and the medicinal Guarana, and Balsaminacex, represented by the familiar Touch-me-not and Balsam.

Order 19, Rhamnales includes about 1,000 species, mostly shrubs, small trees or vines. Its families are: Rhamnacex, including the cathartic Cascara and Frangula barks, as well as the Buckthorns, and Vitacex, to which the Grape, the Virginia Creeper and the Boston Ivy belong.

Order 20, Malvales comprises about 2,100 species of herbs, shrubs and trees, including: the tropical family Elrocarpacex; Tiliacex, represented by the Linden or Basswood trees; Malvacex, yielding the invaluable Cotton with its seed-hairs and bland oil; Bombacex, to which belongs the Baobab and the Silk-Cotton trees; and Sterculiacex, furnishing Chocolate and Cacao Butter as well as the caffeine-containing Cola.

Order 21, Parietales, comprising about 3,000 species, is related to the Rosales, from which it differs chiefly in having parietal placentas (Fig. 232, page 91). Many of the species are tropical or subtropical. Among the families of this order are Theacex, or Tea Family; Guttifer $x$, from which the medicinal Gamboge is obtained; Hypericacex, represented by St. John's wort and St. Peter's wort; Tamaricacex, including the cultivated Tamarisk; Cistacex, or Rock Rose Family; Bixacex, which furnishes the Annatto of commerce; Violacex, including the Violets and Pansies; Passifloracex or Passion-flower Family; Caricacex, which yields the tropical Pawpaw containing a pepsin-like ferment in its juice, and Begoniacex, represented by the Begonias, which are among our highly prized ornamental plants.

Order 22, Opuntiales, represented by a single family Cacta$c e x$, including about 1,200 species, nearly all being American. They are fleshy plants with large and showy flowers. Their characteristic spines are modified leaves. The Night Blooming Cereus is grown in greenhouses for its beautiful flowers; its succulent stems are used in medicine. Mescale buttons (Anhalonium) are used as narcotics and intoxicants by certain Indian tribes. The fruits of the Indian Fig are edible. Many species, owing to their waterstoring ability, are adapted to desert conditions.

Order 23, Myrtales includes 7,500 species, chiefly tropical. Among the families represented are: Thymeleacex, yielding the medicinal Mezereum; Elæagnaceæ, furnishing several cultivated 
ornamental shrubs, among them the Shepherdia; Lythraceæ, represented by several garden plants, including the Crape Myrtle, and also yielding Henna, used as a red dye for the hair; Punicacex, from which the Pomegranate is obtained; Lecythidaceæ, yielding the Brazil-nut and other oily edible seeds; Rhizophorace $æ$ or Mangrove Family, remarkable for the ærial roots borne by its members; Combretaceæ, which yields several useful hard woods; Myrtace , a large tropical family rich in aromatic volatile oils, such as Oil of Cajuput and Oil of Bay, and the source of the well-known spices Cloves and Allspice. The Australian genus Eucalyptus yields a variety of volatile oils, as well as astringent extracts and valuable hard-woods. Among the Eucalypts are the tallest trees known. The Guava and Rose Apples, prized in the tropics, are myrtaceous fruits; Melastomacex, another large tropical family, yields little of economic value, though several species are cultivated for the beauty of their flowers; Onagraceæ includes the Fvening Primrose (Enothera), Fuchsia and Willow Herb; Hydrocaryaceæ or Water Chestnut Family, and Haloragidaceæ, a group of aquatic or terrestrial herbs, including Myriophyllum, conclude the order.

Order 24, Umbellales, or Umbellifloræ, numbers about 2,000 species, comprised in three families. Small, epigynous flowers are common to the order. Araliacer yields the Ginseng, so highly prized in Chinese medicine, the English Ivy (Hedera), cultivated for ornament, the Spikenard, and some other medicinal or ornamental Aralias. Umbelliferæ, named from the prevalent flower cluster (see Fig. 154, page 64), is a family of about 1,500 species, distinguished by well-marked characters; the epigynous flower with five petals and five stamens attached to a fleshy epigynous disk. (See Fig. 174, page 76); and the peculiar double fruit (cremocarp) (see Fig. 286, page 117). There are' many useful products of this family. Among the spices are Anise, Caraway, Coriander, Fennel and Dill; among the vegetables, Carrot, Celery and Parsnip; among the drugs, Asafœtida, Ammoniac, Galbanum, Lovage and Sanicle. A few, such as Poison Hemlock (Conium), Fool's Parsley (AEthusa) and Water Hemlock (Cicuta) are sedative poisons. Cornacer is distinguished from the preceding family by not having the flowers in umbels; many species have the flowers in heads surrounded by a large, petaloid involucre. Several species of Cornus (Dogwood) are grown as ornamental shrubs.

(C) The Sympetalæ or Gamopetalæ, is named from the most 
prominent character, the union of the petals; this coherence may, however, be slight, or even lacking in some families. The group is also known as the Metachlamyder or as the Specialized Dicotyledons. The flowers are mostly epigynous or perigynous, with the corolla and stamens attached to the tube of the calyx. They are commonly entomophilous and showy. In the Isocarpic subdivision, the carpels of the compound ovary equal in number the petals and sepals and are half as numerous as the stamens, there being usually five carpels, ten stamens, five petals and five sepals. In the Anisocarpic subdivision there are usually two carpels, five sepals, five petals and five stamens.

Order 25, Ericales includes about 1,800 species, mostly shrubs, many evergreen, and characterized by the stamens being mostly free from the corolla or attached only to its base. Six families are usually distinguished. Clethracex has a superior, three-celled ovary and a corolla of five separate petals. The plants are mostly tall shrubs or small trees with deciduous leaves. A few species are grown for ornament. Pyrolacex is distinguished from the preceding family by the usually four- to five-celled ovary and evergreen foliage. Several species of Chimaphila and Pyrola are used in medicine. Monotropacex is of interest by reason of the saprophytic habit of its members, of which the Indian Pipe (Monotropa uniflora) is representative. Ericacex, or Heath Family is much the largest in the order, comprising about 1,400 species, mostly shrubs, many with evergreen leaves and all (except Ledum) with gamopetalous corollas. The stamens are often appendaged and dehisce by terminal pores (see Fig. 207, page 84). Arctostaphylos Uva-Ursi and related species are used medicinally; Cranberries, Blueberries and Huckleberries are valuable fruits; Rhododendrons are cultivated for their beautiful flowers; Gaultheria procumbens is the source of Oil of Wintergreen, used as a flavor and in medicine; several species of Kalmia contain poisonous principles, Trailing Arbutus (Epigea) is a favorite spring flower. The Heathers (Calluna) and Heaths (Erica) are well-known European genera. The Epacridacex are shrubs or small trees native to Australia and New Zealand. Diapensiacex is a small family of low shrubs, among them the Pyxie or flowering Moss (Pyxidanthera).

Order 26, Primulales comprises about 1,100 species, many tropical, our species being herbs, with regular, perfect flowers, the stamens borne on the corolla and as many as its lobes and opposite 
them. There are three families. Myrsinacex is a tropical family yielding little of importance. Primulacer includes the true Primroses, Cyclamen, 'and several other ornamental plants. Of Plumbaginacex, a few genera are represented by garden flowers, such as Armeria and Statice.

Order 27, Ebenales, about 1,000 species of trees and shrubs, chiefly tropical, includes: Sapotacex, from which Gutta Percha and Chicle Gum are obtained; Ebenacex, yielding the valuable Ebony wood, and the cultivated Japanese Persimmon, as well as the native Persimmon; Styracex, from which is obtained a balsamic resin known as Benzoin, official in our pharmacopeia, and Symplocacex, an East Indian family represented in North America by only one species and yielding little of economic value.

Order 28, Gentianales, or Contortæ, a large group of about 4,400 species, having usually two distinct ovaries or a compound ovary with two cavities; the stamens mostly attached to the corolla tube. There are five families: Oleacex, trees or shrubs, includes the Olive, cultivated from the earliest times for its fruit and its oil; the Manna Ash, the saccharine exudation of which is employed in medicine, and several cultivated ornamental shrubs, among them Lilac, Privet, White Jasmine, Forsythia and Chionanthus. Loganiacex, chiefly tropical, yields several valuable medicines, among them Nux Vomica and Ignatia seeds, both of which contain the very poisonous alkaloid Strychnine; here also belongs Spigelia, employed as a vermifuge, and Gelsemium or Yellow Jasmine, a poisonous drug used as a nervine. Gentianacex, mostly herbs with bitter juice, the ovary one-celled, and the leaves exstipulate, yields the official Gentian, a bitter tonic drug; also Menyanthes, Chirata, Sabbatia and Frasera, used similarly, and our native Gentians, among the most handsome of our wild flowers; A pocyna$c e x$, with a milky juice, sagittate anthers, usually two separate ovaries but with the stigmas and styles united are chiefly tropical; several species yield Rubber, and quite a few are poisonous; the medicinal Strophanthus, a powerful hear't tonic, employed by the African natives as an arrow poison belongs here, also the rhizomes of several species of Apocynum, used medicinally, likewise the bark of the South American tree Aspidosperma Quebrachoblanen. Asclepiadacex, also with a milky juice, are distinguished from the preceding by their distinct styles, monadelphous stamens, and pollinia (see Fig. 221, page 87). Here belong our common 
Milkweeds, Pleurisy Root (Asclepias tuberosa) and the South American Condurango Bark, used medicinally.

Order 29, Polemoniales, or Tubifloræ, a very large group comprises about 13,500 species of herbs, shrubs and trees, having a compound ovary, flowers regular or irregular, stamens mostly adnate to the middle of the corolla tube or beyond. There are eighteen families. Convolvulaceæ yields the powerfully purgative Jalap and Scammony roots, the edible Sweet Potato, the ornamental Moonflower, Morning Glory and Cypress Vine and the parasitic Dodders (Cuscuta) and Bindweeds which do much damage to some crops. Polemoniacex is represented among garden plants by the Phloxes, Cobæa, and Polemonium. Hydrophyllaceæ affords us Yerba Santa, used in medicine, and several ornamental plants. Boraginacex yields many plants which were formerly used in medicine but now have been dropped from use as being of little value. Alkanet root, used as a dye; Heliotrope and Forget-me-not, familiar garden plants, belong here. The Verbenacex includes the Vervain (Verbena hastata) and others used in medicine, though now considered of little value; also several ornamental herbs or shrubs, Lantana, Lippia and Verbena. Labiatæ, comprising herbs or shrubs with square stems, mostly bilabiate corollas, four (didynamous) or only two stamens, and a superior ovary of two carpels, deeply four-celled, are noted for their aromatic volatile oils. Owing to these essential oils and to bitter principles, many are employed in medicine, among them Peppermint, Spearmint, Scutellaria, Thyme, Rosemary, Lavender and Catnip. Thymol, prepared from Oil of Thyme, is a valuable antiseptic and parasiticide. Menthol, from Oil of Peppermint, is a useful anodyne. Sage, Marjoram and Savory are used for culinary purposes. Many species are cultivated for ornament or for their odor and flavor or for medicinal use. Nolanace $x$ is a small South American family. Solanacex is important as the source of the Potato, Tomato, Egg Plant, Cayenne Pepper and Tobacco. It also yields the poisonous drugs Belladonna, Hyoscyamus and Scopola, which contain mydriatic alkaloids and are powerfully sedative. A number of troublesome weeds, Black Nightshade, Jimson Weed and Horse Nettle, belong here. About thirty genera are cultivated either for food, medicine or ornament. Scrophulariaceæ affords many plants of medicinal value; Digitalis, a powerful and poisonous heart tonic, and Leptandra, a cathartic drug, are among them. Many species are cultivated for their showy flowers, notably Snap-dragon, Cal- 
ceolaria, Chelone, Foxglove, Linaria, Mimulus and Veronica. Bignoniacer, mostly tropical woody climbers, are of small economic value; our Catalpa trees and Trumpet Flower belong here. Pedaliace is a small family of herbs, natives of Africa, southern Asia and Australia; the foliage bears mucilage-secreting glands. Oil of Sesame, from the seed of Sesamum indicum, is a fatty oil of considerable importance. Martyniaceæ is a small family, native to tropical and subtropical America and of little or no economic importance. Gesneriacex, though widely distributed, yields little of value except a few ornamental plants. Lentibuliariace $x$ includes the Butterwort (Pinguicula) and Bladderwort (Utricularia) and other insectivorous plants, mostly aquatic. Globulariaceæ is a small family native to the Mediterranean region. Acanthacex, comprising about 1,500 species, yields little of interest excepting a few ornamental herbs and shrubs. Myoporaceæ is a small family of tropical or subtropical shrubs or trees and of little economic interest. Phrymacex comprises a single genus and but one species, an ornamental plant.

Order 30, Plantaginales includes only the Plantain Family (Plantaginace $x$ ), a small but widely distributed group of about 200 species. A few were formerly used in medicine but have been discarded as of little value. The common Plantain (Plantago) is a weed in lawns and dooryards.

Order 31, Rubiales comprises about 5,300 species, mostly tropical and of considerable economic importance. By far the largest family is Rubiace 2 , with 4,500 species. They include herbs, shrubs and trees with epigynous flowers and with stamens and lobes of the calyx and of the corolla, usually four to five. Among its valuable products are Coffee, Cinchona bark and Quinine, Ipecac and Gambir. The family is mostly tropical, but many species are cultivated in greenhouses, one of them being the Gardenia. Among the native species are Buttonbush (Cephalanthus), Cleavers (Galium), Bluets (Houstonia) and Mitchella (see Fig. 255, page 101). Caprifoliaceæ includes the Honeysuckles, Elders and Viburnums, also the Snowberry (Symphoricarpos), Twin Flower (Linnea) and Horse Gentian (Triosteum). Several are used medicinally but are not powerful drugs. Valerianaceæ gives us the antispasmodic drug, Valerian, noted for its peculiar odor. Dipsacex yields the Fuller's Teasel (Dipsacus ferox), the spiny, hooked bracts of which are used in "fulling" cloth.

Order 32, Campanulales include an immense assemblage of over 
13,000 species, highly specialized as regards the consolidation of the parts of the flower. With a few exceptions, the anthers are united (see Fig. 201, page 83). The Cucurbitaceæ are monœcious or diœcious and the flowers are not in heads. These are herbs, or rarely shrubs, tendril-bearing and climbing and with characteristic melon fruits. Here belong the Pumpkin, Squash, Watermelon, Muskmelon and Cucumber, also the Luffa or Vegetable Sponge, the Gourd or Calabash, and a number of powerful cathartic drugs, some of them poisonous. Among these are Colocynth, Bryony and Elaterium. The Campanulacer numbers about 1,500 species, with gamopetalous and epigynous flowers, many ovules and often united stamens. Lobelia inflata is an official drug and is acrid and somewhat poisonous. The Blue Lobelia, the Cardinal Flower, the Balloon Flower (Platycodon) and the Bluebell (Campanula) are among the ornamental plants of this family. The Compositæ is much the largest family, including between 10,000 and 12,000 species, characterized by having their flowers in involucrate heads (see Fig. 150, page 63). The corolla is commonly tubular or ligulate and the five stamens are attached to it and usually have their anthers united in a ring around the style. The calyx is often reduced to a tuft of hair termed a pappus. They are mostly herbs, with a few shrubs. While many of the Compositæ have been employed medicinally, yet the number of valuable drugs is not large. Included in the official list are Dandelion Root (Taraxacum), Lactucarium (from Lactuca virosa), Grindelia, Eupatorium, Pyrethrum, Santonin (from Artemisia pauciflora), Arnica, Lappa, Calendula, Matricaria, Absinthium, Inula, Echinacea and Farfara. Insect powder is the powdered flower heads of two species of Chrysanthemum. Rather few are used for food; Lettuce, Oyster Plant, Chicory, Globe Artichoke and Jerusalem Artichoke are the most important. A large number are cultivated for the beauty of their flowers; Asters, Chrysanthemums, Daisies, Dahlias, Marigold, Cinerarias, Sunflowers, Goldenrods and Zinnias among them. Many are obnoxious weeds; the Thistles, Cockle Burs and Burdocks are the most common.

\section{CHAPTER XV.-EVOLUTION.}

DARWINISM.-VARIATIONS.-MUTATIONS.

In discussing the classification of plants, in the foregoing chapters, it was assumed that relatively simple groups of plants 
preceded those of more complex structure. This view accords with the results of the study of fossil plants as well as living forms. It is not controverted by the fact that some simple forms of plants now existing, have developed from more highly organized ancestors. These changes in living organisms, whether progressive, as in passing from the simpler to the more complex, or regressive, when this order is reversed, constitute what is termed Evolution.

Evolution is, then, a gradual but constant change, in operation since the very beginning of things and still going on. Not only are living organisms, plants and animals, undergoing these changes; they occur as well with inorganic things. Seacoasts are washed away or are added to; mountains are worn down; certain areas of the earth's surface have been elevated and other areas lowered; regions that had in early ages a tropical climate are now temperate or, perhaps, arctic. Even the elements themselves have not sscaped, for modern researches indicate that radio-activity comprises, essentially, changes in the chemical elements, hitherto deemed unchangeable. These changes in the non-living material of the earth, have affected fundamentally the development of plants and animals, so that inorganic evolution and organic evolution have, in a measure, gone on together. In living organisms, such as plants, these changes fall into two classes: those which occur during the course of life of the individual plant, from the spore to the fully developed structure, known as ontogenetic, and those which accompany the development of a group of related plants, phylogenetic changes. Ontogeny, then, considers the life history of the individual; phylogeny traces the ancestral history of the race. There is a remarkable parallel between ontogenetic and phylogenetic changes and it is a well-supported scientific fact that "ontogeny epitomizes phylogeny" and the life history of the individual gives a clue to the development of the race. But while evolution is now accepted universally as a fact, the method by which evolution is effected is still undetermined.

The French naturalist, Lamarck, having made certain observations, such as that the muscles and some of the organs of man and of animals are enlarged and strengthened by use and that through lack of exercise they lessen or even become lost, undertook to explain the manner by which evolution takes place by assuming: that plants and animals have been exposed to a constantly changing environment; that they have undergone changes in structure to fit them for their altered environment; and that these changes 
induced by environment have become hereditary and are intensified in passing from generation to generation. However, the evidence accumulated since Lamarck's time shows that the changes in animals and man, resulting from use or disuse of organs, are not inherited, much less are they added to in passing from parent to offspring. In plants, also, it seems now quite certain that most modifications that result directly from environment, are not inheritable.

Darwinism. Darwin's studies, extending over a period of more than twenty years and culminating in the publication of his great book, the Origin of Species, presented a most convincing argument for evolution and profoundly influenced scientific thought. His fundamental propositions are that evolution is the method of creation, and the method of evolution is based on "natural selection."

His theory of natural selection might well be termed the essence of Darwinism. It is based upon several fundamental facts: First, that parental characters tend to reappear in succeeding generations. The resemblance of children to their parents or grandparents in features or temperament is a familiar observation; evidently there is an inheritance of physical or of mental characters, one or both. Second, that this inheritance is never complete. Always there is some variation. The child resembles but is never the replica of the parent; there may be a resemblance to one ancestor in the color of the eyes and to another in the shape of the face. Among plants, there may be variations in height, in the number of flowers borne by the plant, in the colors of the petals or in the shape of the leaves. Now it may happen that some of these variations are such that they better fit the plant to the conditions of its environment and hence are of direct advantage to it. Other variations, on the contrary, may be detrimental. Those individuals that develop favorable variations have an advantage in maintaining themselves and in propagating their kind. Through successive generations, the advantageous inheritance is intensified and may finally become a character of a new species. Darwin's observations and experiments convinced him that through continuous selection of variants it is possible to secure plants having certain desired characters. In this he was following along lines of plant and animal breeding under domestication. As compared with such artificial selection, Darwin argued that natural causes, notably severe competition between individuals of the same 
species, as well as between different species occupying the same habitats, would give similar results, these he termed natural selection.

The Struggle for Existence. Darwin used this term to include not only the existence of the individual as such but also success in perpetuating its kind. "Two canine animals in time of dearth may be truly said to struggle with each other which shall get food and live. But a plant on the edge of a desert is said to struggle for life against the drought, though more properly it should be said to be dependent on moisture. A plant which annually produces a thousand seeds, of which only one on an average comes to maturity, may be truly said to struggle with other plants of the same and other kinds which already clothe the ground." Darwin showed that "every being, which during its natural lifetime produces several eggs or seeds, must suffer destruction during some period of its life or during some season or occasional year; otherwise, on the principle of geometrical increase, its numbers would quickly become so inordinately great that no country could support the product." Some of our weeds produce annually as many as 25,000 seeds from a single plant. If all of these seeds grew into plants and the same with succeeding generations, their progeny would in a few years be sufficient to cover the inhabitable portion of the earth. Yet, while certain plants may increase very rapidly for a time, in the end their spread is checked and from that time their numbers remain stationary or decrease. Darwin cites the results of observations on a piece of 'ground six square feet in area, dug and cleared, and where, out of 357 seedlings of native weeds as they came up, 295 were destroyed by slugs and insects, and in a little plot of mown turf, 12 square feet in area, nine out of twenty species were killed by the other species being allowed to grow up freely.

Survival of the Fittest. In the severe competition between all living organisms and especially between those of the same kind and habit, the advantage lies ultimately with those whose variations happen to be such as to better fit them for this struggle. Since many more individuals are born than can possibly survive, those having any advantage, however slight, over the others, have the best chance to live and to reproduce their kind. A plant whose variation takes the form of increased height will grow out from the shade of its neighbors and receive more light. Also it will develop a correspondingly more extensive root system and secure 
more water from the soil. So it is, likewise, with plants developing a greater thickness of epidermis, as a defense against too great transpiration, or an unusually heavy growth of hairs, or any of the multitude of floral devices which favor cross-fertilization and hence the production of a more vigorous offspring. The perpetuation and increase of such advantageous variations is comprised in what Darwin called Natural Selection, but which Herbert Spencer forcefully termed "the survival of the fittest." It might more accurately be described as the elimination of the unfit, for it is this process of elimination that leaves room and food supplies for the best-adapted individuals to live and propagate and eventually results in the development of new species.

Objections and Difficulties. The publication of the "Origin of Species" brought upon its author the severe criticism of many theologians who thought that the foundations of religion were endangered. But Darwin disclaimed the intention of shocking the religious feelings of anyone. He called attention to the fact that the discovery of the law of the attraction of gravity had been similarly attacked by Leibnitz as "subversive of natural, and inferentially of revealed religion." He states, "A celebrated author and divine has written to me that he has gradually learned to see that it is just as noble a conception of the Deity to believe that He created a few original forms capable of self-development into other and needful forms, as to believe that $\mathrm{He}$ required a fresh act of creation to supply the voids caused by the action of His laws." Other objections and difficulties have been raised by scientists and some of these have not yet been satisfactorily answered. Among them are the absence of transitional forms or "connecting links" between related species; the inheritance of acquired characters, proposed originally by Lamarck but disputed by many investigators; the difficulty in assuming that by selecting slight variations a new species may eventually be produced,-it has been argued that no one has as yet succeeded in producing a new species artificially in this manner-and finally the causes of the variations which are taken advantage of in natural selection.

Continuous Variations. Foremost among the scientists, who, following Darwin's lead, have applied the experimental method to the study of evolution, is Hugo DeVries, director of the botanical garden at Amsterdam, Holland. His carefully conducted experiments started with the seeds of "pure" strains, that is, unmixed with any other variety and therefore pure with reference to a 
selected character, and extended over a score of year's and as many generations, each generation being self-pollinated and thus kept pure. The plants of each generation were painstakingly studied, photographed and represented by herbarium specimens so as to permit of accurate comparisons. DeVries' results demonstrated the existence of two distinct types of variations, the continuous and the discontinuous. Continuous variation is the usual kind and comprises fluctuations in such characters as size, form, color of the flowers, etc. Thus some of the flowers of a certain species will be a lighter blue and some a darker blue than the average; some of the plants will be taller and some will be shorter; some of the fruits will contain more and some fewer seeds than the norma! number. But these fluctuations are kept within narrow limits. The average for each generation remains practically constant. Thus the wider valiations from the average are few and the smaller departures relatively numerous. Changes in the ecological factors, such as light, water supply, temperature and soil constituents, as well as the freedom from competition which cultivation assures, are chiefly responsible for continuous variations. It has been demonstrated repeatedly that these variations are not transmitted to the succeeding generations. Thus in a pure strain of beans, the largest seeds were selected for sowing and the resulting plants were kept pure by self-fertilization. This was carried on through several generations but no increase in the average size of the seeds was obtained. Again, thougin it is well known that the yield of sugar by sugar-beets has been increased through selecting seed from plants of high sugar content, this advantage is lost as soon as the selection of seed is neglected.

Mutations. Discontinuous variations are those which arise suddenly and result in the formation of new characters, which are then capable of transmission. DeVries was the first to demonstrate their importance and to advance the theory that natural selection depended upon them rather than on continuous variations. DeVries termed discontinuous variations mutations and the plants which give rise to them mutants. Such plants are said to be mutate. Thus it is believed that the common cabbage, kohlrabi, cauliflower and brussels sprouts are mutants or "sports" of the same plant, the wild cliff-cabbage. Thornless cacti, beardless oats and green roses are other instances of mutants. "Bud sports" such as nectarines and seedless oranges have resulted from the mutation of buds. DeVries made the remarkable discovery that a group of 
plants of Lamarck's Evening Primrose (Enothera Lamarckiana) growing in an abandoned potato field near Amsterdam were evidently in mutating condition. Associated with them, he found later two new forms which he judged had grown from them as mutants. From sowings of the seeds of normal plants, pedigreed through a series of generations, DeVries obtained several new forms which bred true and proved to be true mutants. These differed so widely from the parent form as to be entitled to rank as different species. Mutations, unlike continuous variations, are not due directly to variations in environment, although these may have an influence upon mutation. Apparently they are due to fundamental changes arising in the gametes.

\section{CHAPTER XVI.-HEREDITY. \\ SIGNIFICANCE.-MENDELISM.-LAW OF DOMINANCE.-UNIT CHARAC- TERS.-PURITY OF GAMETES.}

Heredity may be defined as the transmission of characters or qualities from parent to offspring. It includes the resemblances of the individual to its ancestors, as contrasted with the variations by which individuality is expressed. Though the inheritance is constant, so that the characters of a species are faithfully reproduced with but little change from generation to generation, yet these resemblances are not expressed in every detail in each individual, and, with plants no less than with animals, two individuals, however closely related, are never exactly alike.

In the lower or unicellular forms of plants, where reproduction consists of simple cell-division, and the parent cell dividing forms two daughter cells which then separate and become distinct individuals, the offspring are merely segments of the parent, the latter terminating its existence as an individual, with the appearance of its offspring. In such instances the inheritance is clearly carried by the protoplasm or living material which has passed from the parental cell into the offspring. But in the higher plants, as we have seen (Reproduction, page 108), only the protoplasm of sperm and the egg are transmitted to the offspring, hence these sex cells or germ cells must bear all the heritable characters. Indeed some biologists hold that this germ plasm is of nature different from the protoplasm of the other living cells of the plant and they distinguish accordingly between the "germ plasm," derived from the sex cells and the organs immeaiately involved in their produc- 
tion, and the "somatoplasm" or body plasm which comprises the protoplasm of the vegetative parts. It is held that changes in the somatoplasm may result from altered environment and such changes may bring about modifications in the vegetative organs of the plant but do not affect the germ plasm and therefore are not heritable. The germ plasm, on the other hand, is continuous from one generation to the next and the only changes experienced by it are due to mutations such as those already described. In vegetative reproduction the somatoplasm only is involved, but here the offspring is simply an isolated part of the parent plant which has become separated and now leads an independent existence.

Mendelism. The experimental studies of Gregor Mendel, an Austrian monk, are among the most important biological investigations ever made. He selected common garden peas as meeting best the requirements for his experiments. These plants afford varieties exhibiting well-marked differences which are constant, or "breed true," from generation to generation. They are self-fertilized and hence of pure strain, that is, without hybrid characters. The plants are easily cultivated, easily protected against the influence of foreign pollen and rapidly complete their life cycle from germination to the production of seed. Some of the varietal characters chosen for observation by Mendel were:

Difference in size, i.e. tallness as contrasted with dwarfness.

Difference in the shape of the ripe seeds, i.e. round and smooth seeds as contrasted with angular and wrinkled seeds.

Difference in color of the cotyledons, i.e. a shade of yelloworange as contrasted with a shade of green.

Other differences noted by him were in the color of the seed coat, the form and color of the ripe pods and the location of the flowers on the stem. Mendel's efforts were directed toward crossfertilizing selected varieties, each showing one or more of the above-mentioned characters, and watching the behavior of the resulting hybrids for several generations so as to determine the recurrence of the parental characters in the offspring. Since the garden pea is normally self-fertilized, it was necessary to remove the stamens from the selected flowers before the pollen was shed and to artificially cross-pollinate them by bringing pollen from the other plant selected as a parent. Then the flowers were protected from foreign pollen by tying paper bags over them.

Mendel crossed varieties, differing in one or more of the prominent characters mentioned above and then carefully bred the 
hybrids for several generations by self-fertilization and recorded his results.

$\mathrm{He}$ found that pairs of contrasting characters were exhibited by the progeny in the same general way and that it made no difference whether the selected character came from the staminate or from the pistillate parent. Thus in experimenting with peas showing in one parent the character of tallness and in the other parent the character of dwarfness, Mendel found that the first generation of offspring, which he termed the $F_{1}$ generation, all exhibited tallness. But in the second or $F_{2}$ generation, obtained from self-fertilized plants of the first generation, some were tall and some were dwarf in the proportion of three tall to one dwarf plant. In the third or $F_{3}$ generation, all the dwarf plants bred true, that is, produced only dwarfs, while only one-third of the tall plants bred true for tallness and the remainder behaved as the $F_{\text {: }}$ generation, producing two-thirds tall and one-third dwarf plants. Succeeding generations acted like the $F_{3}$. Mendel termed the predominating factor, i.e. tallness, a dominant, and the contrasting character, i.e. dwarfness, a recessive. Evidently then, in the $F_{3}$ generation, one-fourth of the plants (the pure dwarfs) carry only the recessive factor, one fourth (the pure talls) only the dominant, and one-half (the impure talls) carry both factors, but exhibit only the dominant.

The pure talls, the impure talls and the pure dwarfs are produced in the $F_{2}$ generation in the ratio of $1: 2: 1$ and the impure talls always produce these three kinds in the same ratio, $1: 2: 1$, or, counting the pure talls and the impure talls together, for there is no apparent difference in the plants themselves but only in the offspring, we get the ratio: $3: 1$, as first observed. When both factors, for tallness and for dwarfness, are present, the dominant character only appears. Therefore, all the plants of the $F_{1}$ generation are tall, and so are all the impure dominants of the succeeding generation, as indicated in the following diagram. (Fig. 616.)

The ratio $1: 2: 1$ recalls the algebraic expression of the square of $a+b$, namely, $\mathrm{a}^{2}+2 \mathrm{ab}+\mathrm{b}^{2}$, assuming that $a$ and $b$ each equal 1 . In plants $(T+d) \times(T+d)=T T+2 T d+d d$, in which $T$ represents the dominant, tallness, and $d$ the recessive, dwarfness.

Law of Dominance. As a result of many similar experiments Mendel formulated the Law of Dominance, as follows: "When pairs of contrasting characters are combined in a cross, one char- 
acter behaves as a dominant over the other, which is a recessive." Such pairs of contrasting character's are known as allelomorphs.

Unit Characters. Mendel held that such characters as tallness, dwarfness, wrinkled seeds, yellow cotyledons, etc., are inherited as independent units and are not affected by other characters or

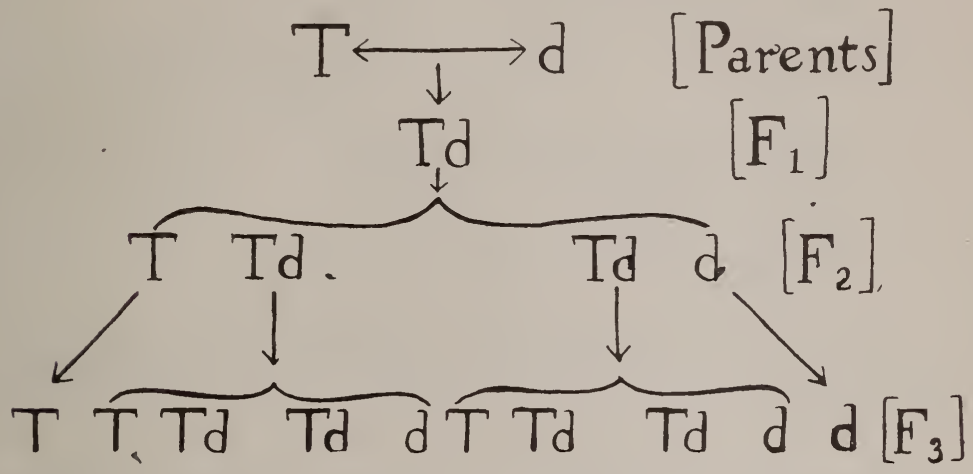

Fig. 616.-Diagram illustrating the inheritance of a dominant character (tallness) indicated by $\mathrm{T}$, and a recessive character (dwarfness) indicated by $\mathrm{d}$, in the first, second and third hybrid generation.

units. Thus hybrids from a tall and a dwarf parent will behave the same in regard to tallness and dwarfness unaffected by other characters such as wrinkled seeds or yellow cotyledons.

Purity of Gametes. Basing his theory upon his conception of unit characters, Mendel argued that a gamete can contain but one of the two allelomorphs, that is, a gamete may bear the gene or unit character for tallness but not the gene for dwarfness, although it may, of course, bear other genes, such as those for wrinkled seed and yellow cotyledons. The hybrid plant of the first generation bears both of the allelomorphs or contrasting unit characters derived fiom its parents, but when this hybrid produces gametes, each gamete bears but one of the allelomorphs. This was Mendel's theses concerning the segregation and purity of gametes. It is confirmed by the observation that pure dwarf and pure tall plants of the second generation and succeeding generations breed true and have evidently no genes for the contrasting characters. The production of the hybrid of the first generation results from the fertilization of the egg cell derived from one parent by the sperm cell from the other parent. If one parent bears the dominant and the other the recessive allelomorph, the hybrid will have. 
both and will be heterozygous. If, on the other hand, each parent bears the same gene or unit character, the offspring will bear a "double dose" of this unit character and none of its contracting

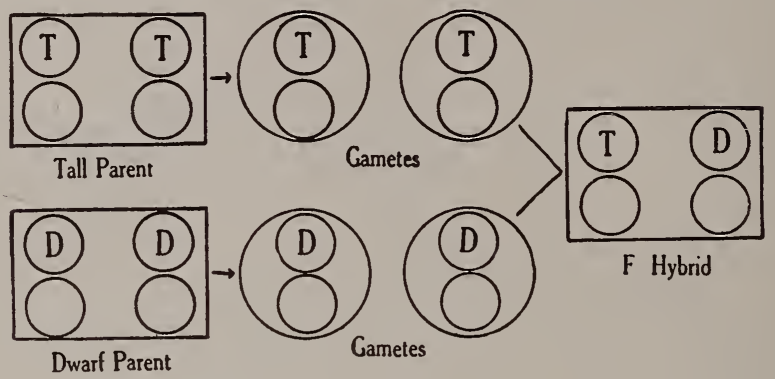

Fig. 617.-Diagram illustrating behavior of chromosomes in Mendel's cross of tall and dwarf peas. Large rectangular figures, nuclei of zygotes or mature individuals; large circles, gametes; small circles within zygotes and gametes, chromosomes; letters on chromosomes, determiners ( $T$, tallness; $D$, dwarfness). From Coulter \& Coulter, Plant Genetics.

character and will therefore be homozygous. Homozygous plants, when self-fertilized, breed true or are pure for a certain unit-character; their gametes, therefore, must be alike in respect to it.

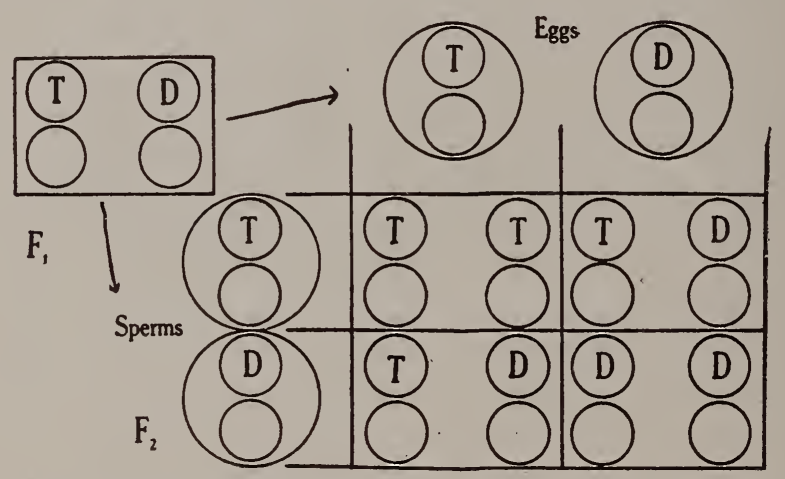

Fig. 618.-Diagram iliustrating the behavior of the first hybrid generation $\left(F_{1}\right)$ when inbred. Illustrates the meaning of "segregation" and "purity of gametes" and how chance matings of $F_{1}$ gametes result in $3: 1$ ratio in $F_{2}$ gen. eration; dwarf individual produced only by zygote in lower right-hand corner. From Coulter \& Coulter, Plant Genetics.

But the gametes of heterozygous plants, in equal proportions, will bear one or the other but never both of the contrasting characters, and their descendants will be equally divided between heterozygous 
and homozygous kinds. Mendel's keen observations and deductions concerning the purity of gametes have been borne out by the later study of the mechanism of cell division, in which it has been determined that each chromosome of the parent cell divides into two equal parts and each daughter cell receives one of these parts. It seems fairly certain that the chromosomes bear the heritable char-

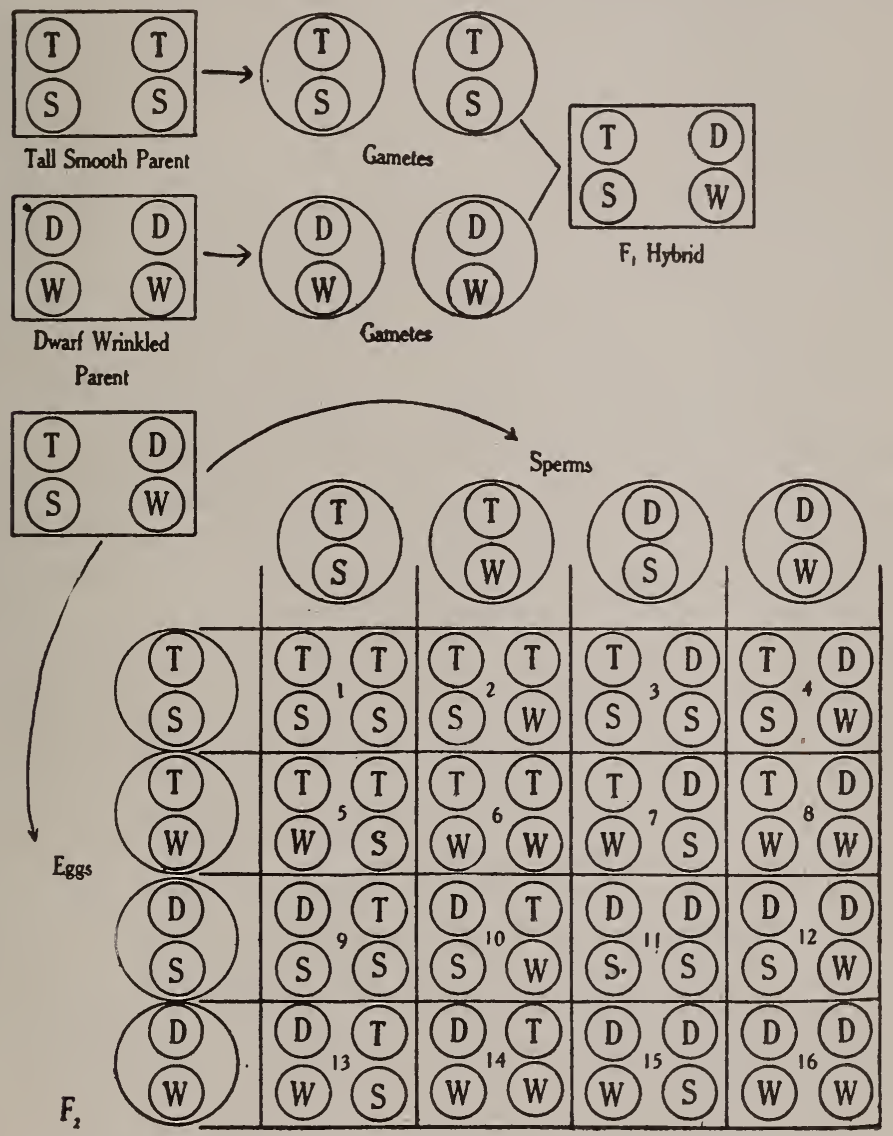

Fig. 619.-Diagram illustrating dihybrid ratio. Upper part shows how original parents were crossed to give $F_{1}$ hybrid; lower part shows $F_{1}$ hybrid producing four kinds of gametes; chance matings among these gametes, when $F_{1}$ is inbred result as indicated in the large set of squares and explains the $9: 3: 3: 1$ ratio in the $F_{2}$ generation. Four phenotypes result in the $F_{2}$ generation, namely: nine tall, smooth individuals (squares numbered $1,2,3,4,5,7,9,10,13$ ); three dwarf smooth $(11,12,15)$; three tall wrinkled $(6,8,14) ;$ and one dwarf wrinkled (16). There are four homozygotes $(1,6,11,16)$; the remainder are heterozygotes. (From Coulter and Coulter, Plant Genetics.) 
acters. When the gametes are produced, reduction division occurs and each gamete receives but one-half of the chromosomes of the individual that produced it. (See page 171.)

The term phenotype has been applied to plants or animals which are alike, whether heterozygous or homozygous, while the term genotype implies organisms that have similar germinal constitution. The Mendelian ratio in the second hybrid generation is $1: 2: 1$ if based on genotypes, but $3: 1$ if based on phenotypes. It will be recalled that there are only two phenotypes, viz., tall and dwarf, but there are three genotypes, viz., pure tall, impure tall and pure dwarf.

So far we have considered but one pair of allelomorphs, selecting tallness and dwarfness. Many such contrasting characters have been observed and can be treated in similar manner. Thus, selecting a tall variety with smooth seed for one parent and crossing with a dwarf variety with wrinkled seed, we have two pairs of allelomorphs to consider. Representing the dominant characters by the capital letters $T$ for tallness and $S$ for smoothness of seed, and the recessive characters by small letters, $d$ for dwarfness and $w$ for wrinkled seed, we will have the algebraic formula $(\mathrm{T}+\mathrm{d}) \times$ $(\mathrm{T}+\mathrm{d})=\mathrm{TT}+2 \mathrm{Td}+\mathrm{dd}$, and similarly $(\mathrm{S}+\mathrm{w}) \times(\mathrm{S}+\mathrm{w})=\mathrm{SS}+2 \mathrm{Sw}$ +ww, and combining these we have TTSS+2SSTd+SSdd+2TTSw $+4 \mathrm{TdSw}+2 \mathrm{Swdd}+\mathrm{TTw}+2 \mathrm{Tdww}+\mathrm{ddww}$. This gives us sixteen individuals, including nine genotypes and four phenotypes, the latter including nine tall smooth individuals, three smooth dwarfs, three tall wrinkled and one dwarf wrinkled, or a 9:3:3:1 ratio. It will also be observed that only four of these individuals are homozygous and will therefore breed true, while the remaining twelve are heterozygous. (See Fig. 619.) This illustrates a dihybrid ratio as compared with the monohybrid ratio earlier considered. Trihybrid ratios involve three pairs of contrasting characters and produce eight phenotypes in sixty-four individuals. Higher and more complex ratios are possible, for a limit would seem to be established only by the number of chromosomes in the cells of the plant. 


\section{CHAPTER XVII.-ECOLOGY.}

SCOPE.-ECOLOGICAL FACTORS.-PLANT SOCIETIES.-PLANT GEOGRAPHY. -IMPORTANCE OF ECOLOGY.

Scope of Ecology. In the preceding chapters, the classification of plants based on their relationship has been considered. By the relationship of plants is understood their phylogeny or their genealogy, in other words relationship based on lines of descent. Such relationship is most clearly indicated by the reproductive organs of the plant. Hence, in assigning the place of the higher plants in taxonomic arrangements, their flowers are chiefly considered. But frequent mention, throughout our text, has also been made of the habits of plants, that is, whether certain plants are parasites, saprophytes or independent plants, and whether they are climbers, epiphytes, aquatic plants, etc. It has been noted that these habits affect chiefly the vegetative organs of the plant. It is a matter of common observation that certain plants may resemble each other in habit (e.g. Wild Grape and Moonseed vines) and yet be very distantly related. Also that plants of similar habits may occur in similar places or surroundings, known as their habitat. Attention has been called to the fact that plants must compete successfully with other plants and with animals, and must survive unfavorable conditions of their environment, such as light and shade, heat and cold, moisture and drought. Only those plants that can successfully adjust themselves to these factors of their environment are able to flourish and to extend their habitat. It is the province of Plant Ecology to study the adjustments of plants to their surroundings as well as the distribution of plants in relation thereto. It may again be pointed out that phylogenetic relationship may have little bearing on ecology; especially is this true of the higher plants (Spermatophytes). Thus it may happen that a tree (the Elm), a vine (the Hop) and an herb (the Nettle), though differing widely in habit, are members of the same order (Urticales) of the phylogenetic classification. In the lower groups the connection is more evident; thus the Fungi show remarkable uniformity in their parasitic or saprophytic habits; practically all the Algæ are water plants; the Mosses are chiefly carpet plants in moist locations, and most of the Ferns are shade-loving.

Some of the problems of plant ecology are: 
To learn what species of plants are associated together in similar locations.

To determine why these species congregate to form plant associations.

To define the special habit and habitat of each species.

To study the relations of plants to their environment; how they adjust themselves to light, shade, water supply, warmth, cold, various kinds of soil, influence of winds, competition with other plants and activities of animals.

To investigate the causes of variation in the structure of plants, as affected by these environmental factors and to arrive at the meaning of the forms of plant organs.

One phase of ecology deals with plants as individuals, with their individual structures, forms and adaptations, and has been considered sufficiently for our purpose in connection with morphology in. Parts I and II of this book. As an instance of the bearing of ecology upon morphology, it may be pointed out that the subject of pollination (Part I, Chapter XII) is largely an ecological one, since it is so closely involved with the adaptations of flowers to secure cross-pollination and especially to make sure of the risits of insects.

Another phase of ecology deals with plants grouped into societies or associations, and will be briefly considered here.

Ecological Factors. The external factors which affect the structure of the plant, and determine its habitat, include light, heat, water, soil, wind, other plants and animals. It is to these factors that the plant must successfully adjust itself in order to survive.

Light. The importance of light in the photosynthetic processes of the plant has already been discussed. (Part III, Chapters III and IV.) So essential is light to the life of the plant, that its intensity and duration play a most important part in the distribution of plants and determine the range of the various species. The effects of light on growth forms, the production of weak and spindly shoots due to insufficient light, and the phenomena of etiolation have already been mentioned. It has been often observed that the light needs of different species vary. Some are especially suited to shade, others flourish only in full sunlight. The efforts of plants to climb, and the development of tall stems are endeavors to secure sufficient light. The fact that individuals growing in shade develop larger leaves than others of the same species growing in sunshine is a form of adjustment to secure the optimum 
amount of light. The full, rounded form of maples or oaks growing in the open, as contrasted with tall, slender and crowned forms of the same tree when growing in forests, is another instance of light effect.

The structure of the leaves of shade-loving and sun-loving plants is also different. The latter are often isolateral or centric or if dorsiventral they have a thickened cuticle, protected stomata (Fig. 620) and may have water storage tissue above the chloren-

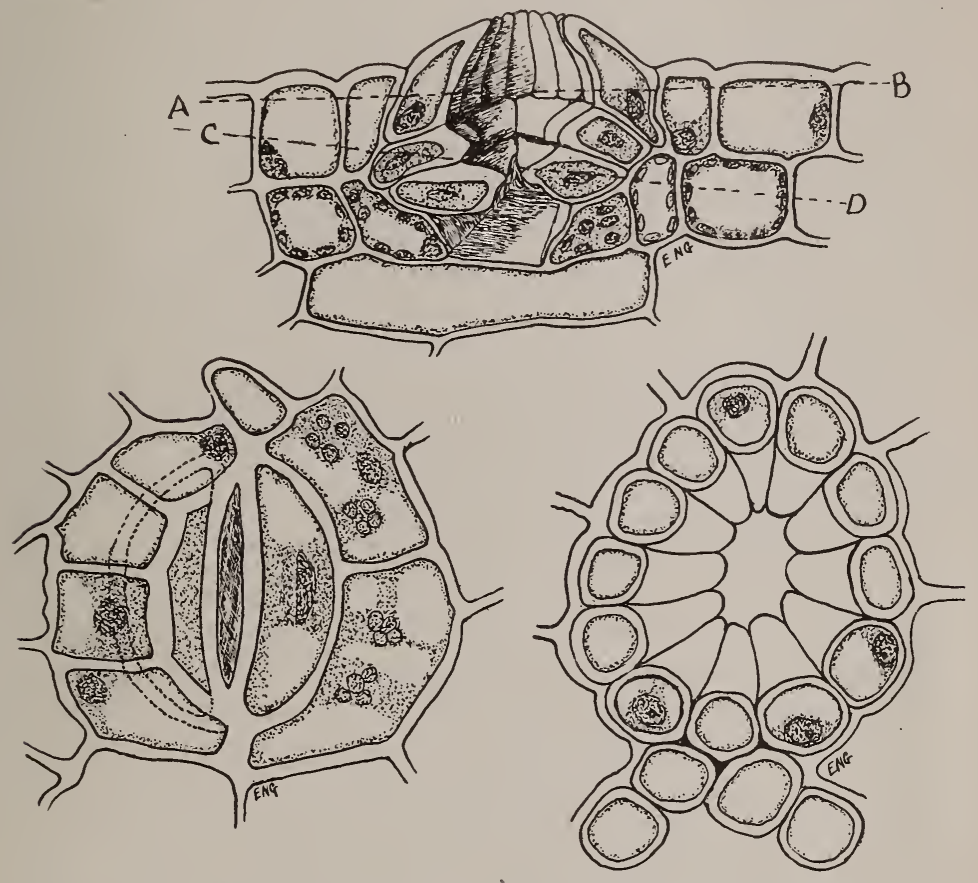

Fig. 620.-Epidermis of the leaf of Cycas revoluta, illustrating the protection of the stoma by a "vestibule." Above-Transverse section partly in perspective; A, ordinary epidermal cell; $\mathrm{B}$, vestibular cell; $\mathrm{C}$, collar cells supporting the vestibule; $D$, suard cells of the stoma. Below, at left.-Tangential section at C-D in upper figure. Below, at right. Tangential section at $\mathrm{A} \perp \mathrm{B}$ in upper figure. Cells of the vestibule cut through near their base.

chyma, while the shade-loving plants bear thin, soft leaves, dorsiventral in structure, deep green in color and usually little divided.

Heat. One of the most important ecological factors is heat. Its effects on growth have already been indicated (Part III, Chapter III). It is well known that the range of each species is deter 
mined by climatic conditions. Thus, owing to its susceptibility to frost, the Orange is limited to warm climates, while Oats and Barley do best in colder climates. Similarly, the zones of temperature, arctic, temperate and tropical, are also distinguished by their characteristic flora. Extreme cold and extreme heat are alike fatal to plant life, hence the ice-bound polar regions and the hot deserts in the tropics are characterized by sparseness of vegetation, though there is scarcely a spot to be found where plants are entirely absent. The succession of flowering plants so familiar to us, as summer succeeds spring and is followed by autumn, is likewise an evidence of the importance of the heat factor. Protection of plants against extremes of heat and cold have already been mentioned; the prostrate forms of arctic plants and the formation of rosettes by the basal leaves are examples of the latter, while certain resistant properties of the protoplasts which are probably due to changes in the condition of the protoplasm itself, explain the immunity to cold of such unicellular plants as the Snow Alga (Sphaerella).

Water. The absolute necessity of water for maintaining life has already been discussed (Part III, Chapter II). The adjustment to water needs varies with different plants, from those that live completely submerged in water to those that are able to withstand the severe drought of deserts. No other ecological factor makes so marked an impression on the structure of the plant as the water supply. As with light and heat, so there is a minimum, optimum and maximum amount of water that each species can use, and an excess of water, as well as a deficiency, may be fatal. A moist climate is on the whole favorable to a longer life for individual plants while dry climates shorten the vegetative period, produce earlier flowering and fruiting and favor the development of annuals or perennials with a marked resting period. More irregular in its distribution than heat and not less necessary to the vital processes of the plant, water takes the first place in the factors which determine the distribution and character of plant associations.

Soil. The nature of the soil, both in regard to its chemical constituents, its physical structure, its air content and especially the amount of water contained in it, is of great importance as a factor in determining the kinds of plants that may grow in any given location. Among the commonly recognized kinds of soil are rock soil, sand soil, clay soil, humus and loam. 
Sand soil is composed chiefly of particles of quartz, but felspar, mica and volcanic products may be present. Sandy soil is loose, and is readily permeated by air and water, but retains water only slightly. It dries quickly and becomes rapidly heated by sunlight but cools with equal rapidity at night, hence may show wide ranges of temperature.

Clay soil, chiefly composed of invisible particles of kaolinhydrated silicate of aluminum--exhibits to a high degree the power of absorbing water. It swells and becomes plastic when moist, but dries to a stony hardness and cracks with drought. It is sticky or "heavy," admits air but poorly and as a subsoil, is almost impermeable to water.

Humus soil is rich in decaying vegetable matter, often with some animal matter, and is black or brown in color. It contains much carbon, and may contain nitrogen. Peat, a bog soil, consists wholly of humus in which the vegetable material is only partly decayed. Of all soils, peat has the greatest capacity for holding water and, since air is virtually excluded, humus acids develop which have an injurious effect on vegetation. Muck is a black soil containing an excessive amount of humus. Loam, the best of garden soils, is an intimate mixture of humus with sand and clay. It rarely contains more than ten per cent of organic matter, is neutral or alkaline in reaction and affords a home for earthworms, insects, fungi, etc.

The amount of water present in the soil is of first importance, when we recall that plants ordinarily secure their water supply entirely through their roots. Since the water in soils is held in the form of films surrounding the soil particles, it is evident that a soil constituted of very fine particles (clay) will retain water. more tenaciously than one composed of coarse particles (sand).

Of scarcely less importance to plants is the presence of air in the soil, for the root cells like other living organisms must respire, and for respiration oxygen is essential. Air ordinarily fills the larger spaces in soils, spaces not occupied by the water films, and is more or less in connection with the atmosphere. When the air becomes charged with carbon dioxide, as a result of respiration, it needs to be replaced, hence the value to crops of moderately heavy rains, with intervening periods of dry weather.

Mineral salts dissolved in the soil water, though needed in but small amount, are necessary to the welfare of plants. Such salts when supplied artificially are known as "fertilizers." They are 
especially compounds containing nitrogen, phosphorus, potassium, calcium, sulphur and magnesium. In nature, they result in part from the disintegration of rocks and in part from the action of living organisms.

Wind. While wind is of value to plants in carrying pollen and aiding in the distribution of seed, yet it may also have an injurious effect in excessively increasing transpiration and in carrying the spores of disease-producing fungi. It also dries the soil and, in cold weather, when the activity of the root is but slight, shoots and branches are killed and deformities of growth are caused. Particularly are the trunks of trees bent and the branches curved away from the windward side, in exposed situations where high winds prevail.

Other Plants and Animals. Competition among different species of plants is a factor in their distribution. A familiar example is that crop plants do poorly under the shade of trees and that "weeds" crowd out garden plants. Many species have spread, as weeds, far from their homes. Thus Datura stramonium, a native of Asia, has spread as a common weed through this country, and Salsoli kali, the so-called "Russian Thistle," a plant of the European seacoast, has become a pest in the wheat fields of our Northwest. We have contributed to the weed list our Waterweed (Elodea canadensis) which now is common in Central Europe, as also is our Canada Fleabane (Erigeron canadensis). Leguminous plants are often helpful neighbors, since their root tubercles afford a home for nitrogen-fixing bacteria, but Bindweeds and Morning Glories, in climbing, break down plants or interfere with their light. On the other hand, plants from many different habitats do well under conditions of cultivation, largely because competition has been removed.

The importance of insects in cross-pollination has already been considered as well as the service of larger animals in aiding in the distribution of seeds. In addition to the foregoing general ecologic factors, there are others of lesser importance in the distribution of plants, such as the influence of the living vegetable covering on the soil and the influence of the non-living covering, such as snow. It is also to be borne in mind that factors act together and not singly and that definite relations exist between the factors themselves. Thus light and heat are interdependent; air movements affect water needs by increasing transpiration, and cold acts to lessen absorption of water from the soil, producing a physiological 
drought. According to their adjustments to these factors of environment, plants are classified into ecologic groups or societies.

\section{PLANT SOCIETIES.}

Water Plants. These include the so-called Hyarophytes, both those that float free and those that are attached by roots or holdfasts.

Among the free-swimming forms are the Flagellata, the Peridinæ and the motile spores of the Algæ. The floating forms include the Desmids and Diatoms and the non-motile spores of Algæ and Fungi. Such microscopic hydrophytes constitute the so-called "phyto-plankton," the ultimate source of food for marine animals and often so abundant as to impart a distinctive blue, blue-green or yellow-green color to the water. Other Algæ, originally attached, but afterward breaking loose, float as "drifting seaweeds" and continue to propagate vegetatively. The Sargasso Sea, characterized by Sargassum in great abundance, is of this nature. Included in the attached hydrophytes are many Cyanophycer, Chlorophycex and Rhodophycex. Here also are the Rockweeds of our seacoasts and the giant Kelps, so abundant as to be harvested as a source of potash and iodine. A few alga-like Spermatophytes such as Elodea canadensis and Vallisneria spiralis as well as the curious Bladderwort (Utricularia) have a similar. habitat.

The peculiar conditions surrounding submerged water plants produce a structure that is characteristic. The necessary gases (oxygen and carbon dioxide) required by all green plants are accessible only through the water, in which relatively small proportions are dissolved. This applies also to the mineral salts. Much-divided leaves and stems with a thin epidermis destitute of water-proof cuticle favor the absorption of these constituents, and since all parts of the plant are in contact with water and can absorb, water-conducting tissue is scarcely needed. The buoyancy afforded by the water lessens the need of mechanical strength and support. Submerged water plants, therefore, as a rule collapse when taken from the water. Anchored forms which are subject to tidal or wave action may have quite a tough structure.

Marsh Plants, such as the Water Lilies, whose leaves float on water but which are attached to submerged rootstocks, differ in habit and structure from the preceding, inasmuch as their supply 
of carbon dioxide and oxygen is drawn chiefly from the atmosphere and only a relatively small part from the water solution. Such plants are Aërophytes rather than Hydrophytes, physiologically. In the Water Lilies the petioles are long and flexible so as to be capable of adjustment to the depth of the water and are provided with large air passages whereby gases secured from the air by the leaf are supplied to the submerged parts. In these plants the leaves are commonly rounded in form, flat, and the upper surface of the leaf sheds water remarkably. In those tiny floating plants, the Duckweeds, the roots, hanging free in the water, prevent the leaves from upsetting.

Swamp societies, comprising Sedges, Rushes, Reeds, Bulrushes, Cat-tails and other plants whose leaves are borne above the surface of the water, are related to the hydrophytes in habit. Associated with those and forming a fringe along the borders of the swamp societies may be found a few trees, notably Alders and Willows.

In bog swamps, certain mosses (Sphagnum) spread as a floating mass which afterwards condenses, forming Peat, upon the surface of which the living mosses are borne.

Normal Plants, or Mesophytes, are those forming the common vegetation. They are suited for ordinary conditions of plant life; a moderate amount of water, fertile soil and free access of air. Hence when swamps are drained or as they gradually fill up owing to the decaying vegetation or other causes, the hydrophytic swamp societies gradually change to the mesophytic forms. These correspond to the plants which we have chiefly discussed in the foregoing parts of this book. They are provided with roots for absorption of water and soil solutions as well as for fixing the plant in place, green leaves for photosynthesis, and supporting stems. The above-ground parts, exposed to the drying influence of the air, are protected by a water-proof covering of epidermis or cork, through which openings for the passage of gases and water vapor are provided by the stomata and lenticels. They have a well developed mechanical system capable of withstanding the strains caused by the wind and the weight of the leaves, flowers and fruit.

Among the many mesophytic plant societies are: the deciduous forests, composed of our common deliquescent trees, such as Maples, Oaks, Elms and Beeches; meadows and prairies, in which grasses and herbs predominate and trees are few or entirely absent; thickets of shrubs and small trees, and rainy tropical for- 
ests, characterized by the abundance of trees, shrubs and vines, forming an almost impenetrable jungle.

Desert Plants, or Xerophytes, are plants which are adapted to conditions of drought, that is, where air and soil are dry the greater part of the year. Xerophytes not only possess features which lessen transpiration, notably smaller leaf surface, sunken stomata, abundant trichomes, and thickened epidermis, but they also have devices for storing water (water storage tissue) and may also reach deep into the soil by means of long tap roots. In most xerophytic areas there is a short wet season during which most of the plant growth occurs. Immediately following this many of the herbs lose their foliage and survive only in their underground rhizomes or tubers. Annuals bridge over the dry season in the form of seeds. Among the xerophytic plant societies are: the evergreen forests, including such trees as Pines, Hemlocks, Spruces and Firs, whose adaptations to the physiological dryness of the long northern winters and to high altitudes also enable them to flourish in dry situations in temperate climates and even to survive mesophytic conditions; the xerophytic thickets, represented by the chapparal of our southwestern states; the desert societies, the extreme types of xerophytes, and including in our country the Cactus and Yucca; the rock societies, chiefly lichens and mosses growing on dry and exposed rocks; and the heaths of northern Europe, where, owing to the acid soil, the predominant vegetation is Ericaceous shrubs.

The Seacoast plants, or Halophytes, grow in habitats where, owing to the proximity of the salt water, there occurs an appreciable amount of salt in the soil. The presence of salt inhibits the absorption of water by the roots and as a result the plants growing in this soil possess the features of xerophytes. In fact many xerophytic grasses and annuals occur in such habitats, along with certain succulents such as Saltwort.

Ecological Plant Geography. The comnection between the topoggraphy of the country and its characteristic vegetation areas is obvious. Even a casual observer recognizes the distinctive plant formations of swamps, prairies, thickets and woods. A more careful inspection discloses that these plant formations contain at least several, and more often, many kinds of plants. Among such plants, the largest and best adapted forms will dominate and lend a distinctive character to the whole formation. Rarely there may be but one of these dominants but usually there are several. Thus 
in the flood plain forests of river "bottoms," Elms and Basswoods are the dominant trees; climbing upon these are the vines, Wild Grape, Greenbrier, Poison Ivy and Virginia Creeper; in the undergrowth are the Haws (Cratægus) and many others, while the spring-flowering herbs, Spring Beauty, Phlox, several Trilliums, Dogtooth Violet, Indian Turnip, the blue and the yellow Violets, Collinsia, etc., form the carpet.

Where there are several dominants in a plant society these are sometimes spoken of as commensals (literally, eating at the same table) and the condition of shared dominance is termed commensalism. This should be distinguished from the relationship between host and parasite, even when this is mutually beneficial (symbiosis).

Plant associations are often designated by their dominant forms; the pine forest, the oak forest, the tamarack swamp and the peat bog are examples.

The Succession of Plant Societies. Among plants, as among animals and men, there is sharp competition. With such nicety are the successful plants adjusted to their surroundings, that every change in the environmental factors puts them at a disadvantage, and may favor a more fortunate competitor. Yet we know that everywhere and without ceasing, these changes go on. Climatic fluctuations, even though they be slight; the occurrence of unusually wet or unusually dry seasons; the activities of man in cultivating fields, clearing forests or draining swamps; the attacks of fungi and of insects; the gradual filling in of shallow lakes by decaying vegetable matter; the erosion caused by streams, as well as the formation of flood plains; the disintegration of rocks with the production of new soil; all of these profoundly affect the plant societies inhabiting the areas in which these changes occur. As swamps are filled, the hydrophytic societies are replaced by mesophytic ones, while the sparse flora of the sand dunes is gradually enriched as the soil becomes fixed through the growth of vegetation until at length xerophytes such as Pines are established, to be succeeded in turn by Oaks and other mesophytes. In general, where climatic conditions permit, the trend is toward the production of conditions suited to mesophytes, to whom both xerophytes and hydrophytes are slowly losing ground.

Importance of Ecology as Related to Medicinal Plants. Ecology has a most important bearing upon the cultivation of medicinal plants, in respect to the variation in the amount of medicinally 
active constituents under different ccological conditions and at different periods of growth. Thus Cinchona, grown under glass in this climate, yields no alkaloid; Belladonna root is richest in alkaloid in the late summer, autumn or early spring; Belladonna leaves are apparently most active medicinally at the time of flowering. Not only the quality but also the quantity of the drug produced may be markedly affected by ecological factors. Digitalis, under favorable environment in Oregon, has attained a height of twelve feet, and Ricinus, an annual herb in our northern states, becomes a tree in the tropics. Both the superior fragrance and the yield of Peppermint oil depend largely upon the moisture and other conditions of the soil upon which the plant is grown.

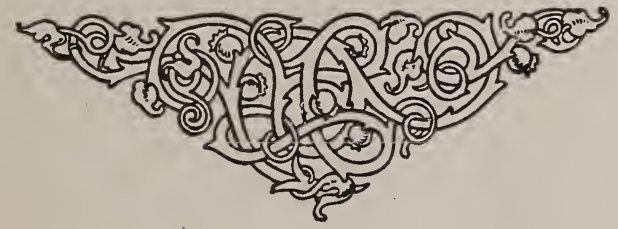





\section{INDEX.}

ABSORPTION of water and soil

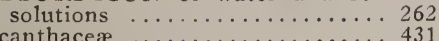
Acanthacer $\ldots \ldots \ldots \ldots \ldots \ldots \ldots \ldots .431$

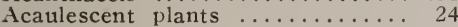

Aceracea .................. 426

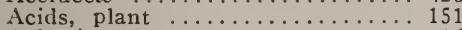

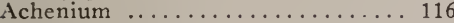

Achlya lignicola ..........344, 345

Acotyledonous embryos ......... 128

Ecidomycetes ............... 354

Ecidiospores ................ 354

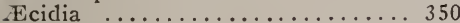

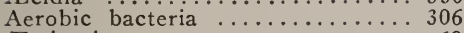

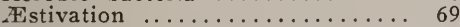

Ethallia of Myxomycetes....... 302

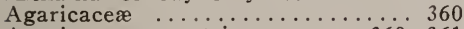

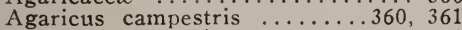

Agaricus muscarius ........... 361

Aggregate fruits ............ 122

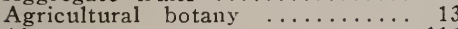

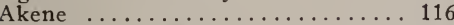

Albuminous seeds ............ 126

Alburnum .................. 235

Aleurone grains ................ 144

Algæ .................... . . 308

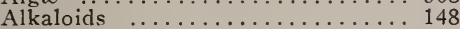

Allelomorphs $\ldots \ldots \ldots \ldots \ldots \ldots \ldots \ldots \ldots .441$

Allogamy .................. 95

Alternation of generations in Ferns 380

Amaryllidaceæ ............... 415

Ament ...................... 63

Anacardiaceæ ............... 425

Anaerobic bacteria .............306

Anæsthetics, effects of on plants.. 290

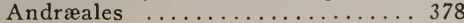

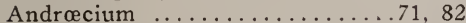

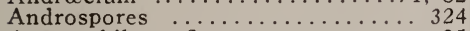

Anemophilous flowers .......... 95

Angiospermæ, classification of..... 411

general characters of 408 reproduction in ... 410

Animals as agents in the disper-

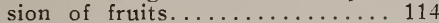

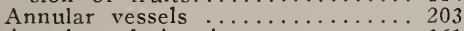

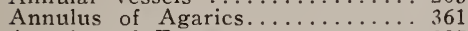

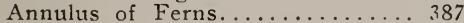

Anonacex ................ 423

Anther ...................... 84

Antheridia of Green Alga........... 315

" of Ferns .......... 380

of Mosses ................ 369

Anthoceros ................... 374

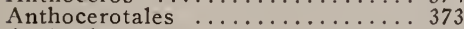

Anthophore .................... 77

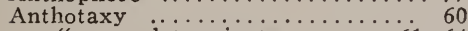
"6

determinate $\ldots \ldots \ldots 61,64$

indeterminate $\ldots \ldots \ldots 61$

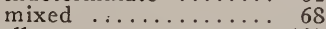

Antipodal cells .................. 107

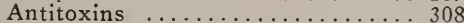

Apetalæ .................. . 420

Apocarpous pistils ........... 89

Apheliotropic plants ............ 283

Apocynaceæ ................. 429

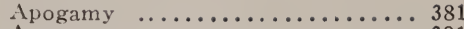

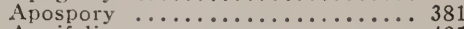

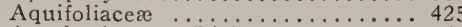

Apothecium of Lichens.......... 365

Arace $\ldots \ldots \ldots \ldots \ldots \ldots \ldots . \ldots 415$

Arales ................... 415

Aralia, flower of............. 418

Araliacer ................. 427

Araucarias, flowers of ............. 403

Archegonia of Mosses.............. 369

Archegoniates .............. 380

Archichlamydex ... . . . . . . . . . 420

Aril .................... 124

Aristolochiales ................ 421

Aristolochiacere ............. 421

Ascent of water in plants........ 266

Ascomycetes, general characters of 345

Ascospores ................341, 346

Ascus .................. 346

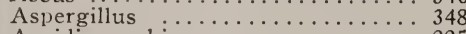

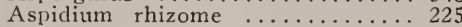

Ash of plants............... 260

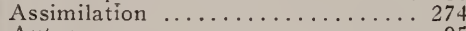

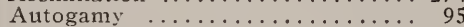

Auxospores ................ 313

BACILLUS ................ 307

Bacteria, classification of............ 306 general characters of... 305

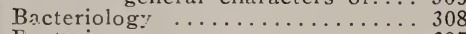

Bacterium ........................ 307

Balsaminacea ............... 426

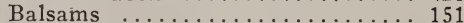

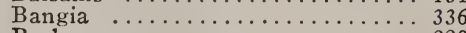

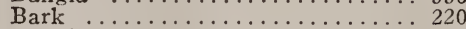

" layers of ...........237, 239

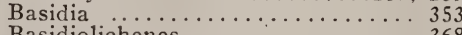

Basidiolichenes ................ . . 368

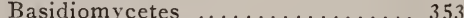

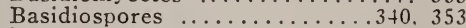

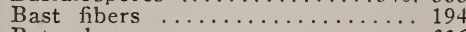

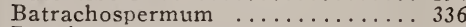

Beggiatoa .................. 307

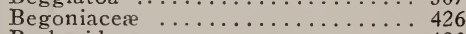

Berberidacere ................... 423

Berry, definition of ......................... 118

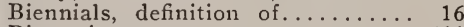

Bignoniace $\ldots \ldots \ldots \ldots \ldots \ldots \ldots .431$

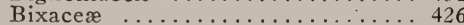

Bladder-wrack .........334, 335, 336

Blue-green Algæ .............. 308

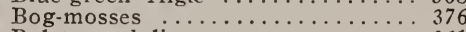

Boletus edulis .............. 361

Bombaceæ ................... 426

Boraginaceæ $\ldots \ldots \ldots \ldots \ldots \ldots \ldots \ldots . \ldots 430$

Bordered pits in Pine Wood...... 199

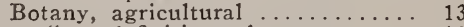

"s definition of $\ldots \ldots \ldots \ldots \ldots .13$

" floricultural $\ldots \ldots \ldots \ldots \ldots \ldots .13$

" geographical .......... 13

" horticultural .......... 13

" medical .............. 13

paleontological ........ 13

pharmaceutical ......... 13 


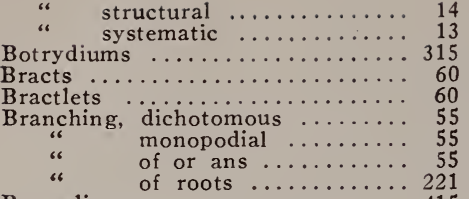

Bromeliacer...$\ldots \ldots \ldots \ldots \ldots \ldots .445$

Bromeliales ............... 415

Brown Sea-weeds ............ 333

Bryales ................. 378

Bryophyta, general characters of. 368

Budding of cells............. 173

Bud scales .................. 22

Buds, kinds of.........21, 22, 23

Buds, their nature $\ldots \ldots \ldots \ldots \ldots . .21$

Bulbs, structure of ............ 29

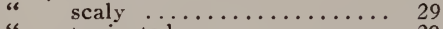

" tunicated ............. 29

Burseraceæ $\ldots \ldots \ldots \ldots \ldots \ldots \ldots 425$

Butomus, floral diagran of ..... 414

Buxacex .................4 425

CACTACEA ............. 426 Caesalpinæ ............... 424

Calcium oxalate ............... 154

Calycanthaceæ ................. 423

Calyptra of Mosses.............. 371

Calyx ..............71, 76, 77

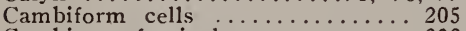

Cambium, fascicular ........... 232

Cambium, inter-fascicular ...... 232

Campanulales .............. 431

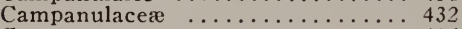

Cannaceæ .............. 416

Capillitium of Mrxomycetes.... 302

Capitulum, or head............ 63

Capparidacere .................. 423

Caprifoliacex .............. 431

Capsule, definition of ............ 119

Capsules, dehiscence of .......... 120

Caricacer ................ 426

Carpels ................... 71

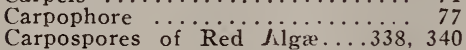

Caruncle ................. 124

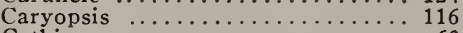

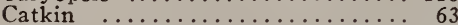

Caulicle or hypocotyl.........126

Celastraceæ ................... 425

Cell, definition of ................ 132

typical, structure of ....... 133

Cells, conjugation of ............. 327

" division of $\ldots \ldots \ldots \ldots \ldots \ldots, 168$

" formation of .............. 168

" shapes of ............. 160 size of $\ldots \ldots \ldots \ldots \ldots \ldots \ldots \ldots \ldots \ldots \ldots 1616$

Cellulose in the cell wall........ 162

Cellulose as reserve material......274

Cell-wall ................134. 157 " cellulose in ........... 162

" chemical changes in..... 162

" cutinization of ........ 163

" lignification of $\ldots \ldots \ldots \ldots 162$

" markings of ........... 159

" mineral crystals in....... 163

" mucilaginous changes in 163

“ stratification of ...... 163

" striation of $\ldots \ldots \ldots \ldots \ldots 164$

Central cylinder or stele.......... 217

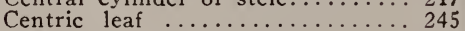

Cereals .................. 414

Cetraria islandica .............. 367
Chara ..............330,331, 332

Charales ...............328, 329

Chlamydomonas ............... 320

Chlamydospores ............. 357

Chlorophyceæ .............. 315

Chlorophyll, functions of ....... 269

Chloroplasts .................. 137

Chondrus crispus ............ 337

Chromatin ................... 135

Chromatophores $\ldots \ldots \ldots \ldots \ldots \ldots \ldots \ldots .136$

Chromogenic bacteria ........ 307

Chromoplasts $\ldots \ldots \ldots \ldots \ldots \ldots \ldots 137$

Chromosomes ................... 169

Chromosomes as bearers of herit-

able characters ............. 443

Chytridiacer $\ldots \ldots \ldots \ldots \ldots \ldots \ldots \ldots .344$

Chytridium .................. 346

Ciliary motion ............. 281

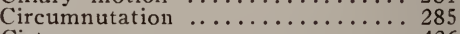

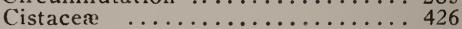

Cladophylla ............... 30

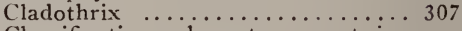

Classification, characters nost im-

portant in .............. 297

Classification of plants.........2 294

Clavariaceæ ................... 359

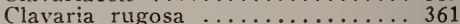

Claviceps purpurea $\ldots \ldots \ldots \ldots . . .349,350$

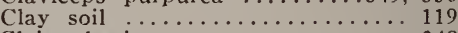

Cleist othecium ............. 348

Clethracex $\ldots . . \ldots \ldots \ldots \ldots . . . .428$

Climbing-plants $\ldots \ldots \ldots \ldots \ldots \ldots \ldots .25$

Closed collateral bundles..........226

Close-fertilization ............ 95

Club-Mosses, general characters of 391

Club-root of Cabbage............. 303

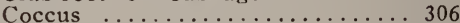

Cochlea ........................... 119

Coenobium ................. 317

Coleochrete ................ 325

Collateral bundles ........220, 226

Collective or multiple fruits..... 122

Collenchyma ................. 178

Colleters .................. 213

Columella of Mosses.........371, 374

Combretace $\ldots \ldots \ldots \ldots \ldots \ldots \ldots 427$

Commelinaceæ ............... 415

Commensals ............... 454

Commensalism $\ldots \ldots \ldots \ldots \ldots \ldots \ldots \ldots \ldots \ldots \ldots 454$

Companion cells .................. 205

Comparative study, value of . . . 294

Compositæ, floral diagram of ...... 418

Compositæ, general description of 432

Concentric bundles ........... 224

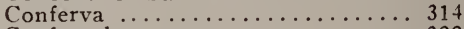

Confervales $\ldots \ldots \ldots \ldots \ldots \ldots \ldots \ldots .322$

Confervoid Algæ ............. 322

Conidia of Fungi............. 340

Coniferales, general characters of 402

Coniferales, mode of reproduction

in ................... 403

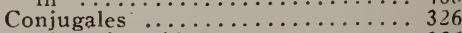

Conjugating Algæ ............ 326

Conjugation of cells............ 327

Connective .................. 86

Constituents of plants............. 259

Constructive metabolism ........ 255

Continuous variations .......... 436

Contortæ ................... 429

Contractility of protoplasm...... 245

Convolvulaceæ ................ 430

Coriariaceæ .................... 425

Corms, characteristics of........ 28

Cornaceæ ................. 427

Cork tissue .................. 191 
Corolla

$71,76,80$

Corollas, choripetalous, forms of. . 80 gamopetalous, forms of. 80

Corona

Cosmarium botrytis .......... 628,329

Cotyledons .................. 126

Crassulacer ...................... 424

Cremocarp ................. 117

Crenothrix ............... 307

Cross-fertilization $\ldots \ldots \ldots \ldots \ldots .95$

Cruciferæ ................... $\begin{array}{r}95 \\ \text { agencies of }\end{array}$

Crustaceous Lichens ......... 366

Crystal fibers ............... 156

Crystal sand ................... 155

Crystals of calcium oxalate..... 155

Crystalloids ................. 144

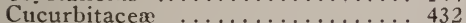

Culm ........................ 65

Cup Fungi .................. 351

Cyanophycea $\ldots . . .308$

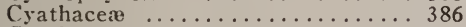

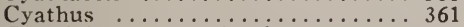

Cycadales, eneral characters of 399

Cycas, fructification of ........ 400

Cycle number .............. 72

Cyme ................... 65

Cyperacea $\ldots \ldots \ldots \ldots \ldots \ldots \ldots \ldots 44$

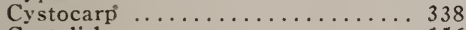

Cystoliths ................ 156

Cytology, definition of............ 13

Cytoplasm ................. 134

DARWINISM .........434, 436

Dehiscence of capsules........ 120

Desert plants, or xerophytes..... 453

Desmids ................... 327

Destructive metabolism ......... 255

Determinate anthotaxy ........ 64

Diapetala .................. 422

Diapensiacer .............. 428

Diatomaceous earth ........... 313

Diatomer .................. 312

Dichogamy in flowers............ 97

Dichotomous branching ........ 55

Diclinism in flowers......... 97

Dicotyledons, classification of ....4420 $\begin{array}{ll}\text { "“ } & \text { embryos of } \ldots 127,418 \\ \text { “ } & \text { flowers of } \ldots \ldots \ldots 418\end{array}$ “ general characters of 418 “ leaves of ....... 417 " number of species of 420 roots of ........4 417

Dicotyledon-type of stem......... 231

Differentiated Monocotyledons ... 415

Diffusion $\ldots . .263$

Digestion in plants............ 274

Dihybrid ratios ............... 443

Dinoflagellata .............. 312

Diøcious plants ............ 97

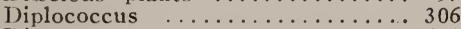

Dipsaceæ ................ 431

Discolichenes ................ 368

Discomycetes $\ldots \ldots \ldots \ldots \ldots \ldots \ldots \ldots \ldots \ldots \ldots \ldots 349$

Disk ................... 76

Diseases produced by Bacteria... 308

Dispersion of fruits........... 113

Distribution of reserve materials.. 273

Division, indirect nuclear....... 168

“ reduction ............ 171

Dominants and recessives......... 440

Dominants in plant associations. 454

Dotted ressels ............... 202

Drupc ...................... 117

Ducts $\ldots \ldots \ldots \ldots \ldots \ldots \ldots, 203$

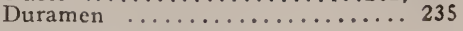

EBENACER ................ 429

Ebenales $\ldots \ldots \ldots \ldots . . . . . . . . .429$

Ecology ................... 445

Ecological factors ........... 446

Ecological plant geography......453

Economic Botany ............... 13

Ectoplasm .................. 135

Egg-apparatus ............... 107

Elaboration of food........... 268

Elæocarpaceæ ............... 426

Elæagnaceæ .................. 426

Elaters of Bryophytes......... 371

“ " Equisetinex ......... 389

Embryo, acotyledonous .......... 128

definition of .......... 126

" formation of $\ldots \ldots \ldots \ldots, 108$

" parts of $\ldots \ldots \ldots \ldots \ldots .126$

" polycotyledonous ........ 128

position of in seed..... 126

Embryo-sac $\ldots \ldots \ldots \ldots \ldots \ldots \ldots, 13$

Embryo, germination of . ........ 127

$\begin{array}{ll}\text { " kinds of } \ldots \ldots \ldots \ldots \ldots \ldots & 126 \\ \text { " of Coniferæ } \ldots \ldots \ldots \ldots & 405 \\ \text { of Dicotyledons } \ldots \ldots \ldots & 418 \\ \text { of Monocotyledons } \ldots \ldots & 413\end{array}$

Embryos of parasites and sapro. phytes

Empetracex .................. 418

Empusa muscorum ............... 425

Endocarp $\ldots \ldots \ldots \ldots \ldots \ldots \ldots \ldots . \ldots \ldots 118,249$

Endodermal tissue ............ 190

Endodermis $\ldots \ldots \ldots \ldots \ldots \ldots \ldots, 218,23$

Endophytic alga $\ldots \ldots \ldots \ldots \ldots \ldots \ldots \ldots \ldots \ldots$

Endophytic bacteria $\ldots \ldots \ldots \ldots \ldots . . \ldots \ldots$

Endopleura ..............124, 249

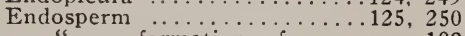

Endospore of Mosses $\ldots \ldots \ldots 108$

Endothia varasitica .............. 348

Entomophthorea $\ldots \ldots \ldots \ldots \ldots \ldots .342$

Entomophilous flowers ........... 96

Entomopthora sphærosperma $\ldots . .342$

Enzymes ................... 146

Epacridacez $\ldots \ldots \ldots \ldots \ldots \ldots \ldots \ldots \ldots \ldots \ldots \ldots \ldots \ldots \ldots \ldots \ldots \ldots$
Epicalyx $\ldots \ldots \ldots \ldots \ldots \ldots \ldots$

Epicarp $\ldots \ldots \ldots \ldots \ldots \ldots \ldots 118,249$

Epidermal tissue $\ldots \ldots \ldots \ldots \ldots \ldots 180$

Epidermis of leaf............... 241

stem ........... 222

Epigeous germination ............ 127

Epiphytes, roots of ............ 17

Epiphytic fungi ............ 340

Equisetum arvense $\ldots \ldots \ldots \ldots \ldots . .390$

Equisetinex $\ldots \ldots \ldots \ldots \ldots \ldots \ldots \ldots \ldots \ldots \ldots \ldots$

Ergot of Rye................... 349

Ericales .................... 428

Ericaceæ ................. 428

Erysipheæ, or Perisporiales...... 348

Erythroxylace $\ldots \ldots \ldots \ldots \ldots \ldots .425$

Euglena ............... 311

Eumycetes, or True Fungi........ 341

Euphorbiaceæ .............. 425

Eusporangiatæ .............. 382

Evolution .................. 432

Exalbuminous seeds $\ldots \ldots \ldots \ldots .126$

Exoasci ................... 353

Exobasidium vaccinii ......... 354

Exospore of Mosses............ 372

FACULTATIVE anaerobes ..... 306

Facultative saprophytes ......... 340 
Fagaceæ .................... 421 Fagales ................... 421 Farinales .................. 415 Fats .................... 143

Fermentation produced by Bacteria 308

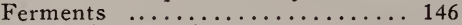

Ferns, leaves of ............. 382 general characters of ..... 382 stems of $\ldots \ldots \ldots \ldots 224,382$

Fertilization, effects of outside of

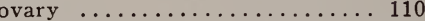

Fertilization of the ovule....94, 105

Fertilizers ................. 449

Fibro-vascular bundles, collateral. 220

Fibro-vascular bundles, concentric 224

Fibro-vascular bundles, radial.... 218

Fibro-vascular bundles of leaf.... 243

Filament

Filicales, general characters of... 384

" reproduction of ........ 384

Filicineæ ................. 382

Fixation of nitrogen........... 272

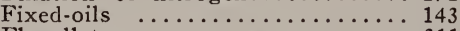

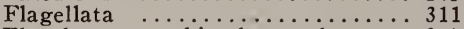

Floral organs, histology of...... 247

Floral parts, absence of........ 74 " " " anteposition of $\ldots .74$ " " $"$ coalescence of $\ldots . .76$ " " multiplication of.... 74

union of $\ldots \ldots \ldots \ldots 75$

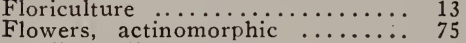

" alloganous $\ldots \ldots \ldots \ldots \ldots . . .65$

anemophilous $\ldots \ldots \ldots . \ldots 95$

" apetalous $\ldots \ldots \ldots \ldots \ldots \ldots .74$ arrangement of on the stem $\ldots \ldots \ldots \ldots \ldots 60$

"6 autogamous $\ldots \ldots \ldots \ldots \ldots . . \ldots 95$

" complete $\ldots \ldots \ldots \ldots \ldots \ldots 73$

"6 cycle numbers of...... 73

" entomophilous ........ 96

"6 diclinous ............ 97

"6 dichogamous ........... 97

" hermaphrodite .......... 73

" heteromorphism in ..... 101

" irregular ............. 75

" naked ........................ 74

6 nature of $\ldots \ldots \ldots \ldots \ldots 6,246$

" nature of $\ldots \ldots \ldots \ldots \ldots 6,246$

" parts of $\ldots \ldots \ldots \ldots \ldots 71,247$

" pistillate ........................... 74

" prefloration of $\ldots \ldots \ldots \ldots 69$

“ proterandrous .......... 97

“ proterogynous ........ 99

" regular $\ldots \ldots \ldots \ldots \ldots \ldots \ldots 73$

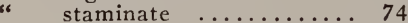

structure of .......... 71

symmetrical .......... 73

typical .................. 72

use of color in ......... 96

use of nectar in ....... 96

use of perfume in..... 96

why interesting to bot-

anist.$\ldots \ldots \ldots \ldots \ldots$

" zygomorphic $\ldots \ldots \ldots \ldots \ldots$

Food, elaboration of ............... 268

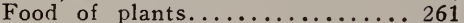

Foliaceous Lichens ............. 366

Follicle ....................... 119

Forestry .................. 13

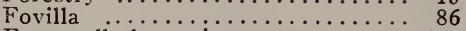

Free cell formation.............. 172

Fructification of Lichens.......... 365

Fruits ...............111, 249
" changes in development of. 111

" classification of ......... 115

" definition of $\ldots \ldots \ldots \ldots \ldots . . \ldots 111$

" dispersion of $\ldots \ldots \ldots \ldots \ldots \ldots . \ldots 113$

structure of $\ldots \ldots \ldots \ldots \ldots \ldots 111$

Fruticose Lichens ................ 366

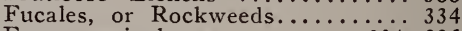

Fucus vesiculosus .................... 336

Fumariacer $\ldots \ldots \ldots \ldots \ldots \ldots \ldots . \ldots 423$

Funaria hygrometrica .............. 371

Fungi, general characteristics of.. 339

GAMETE, female .......... 107

Gamete, male ................... 105

Gametophyte, female ...................... 107

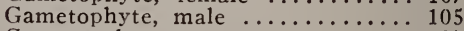

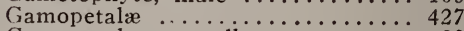

Gamopetalous corolla ...................... 80

Gamosepalous calyx ................ 77

Gases in the plant....................... 267

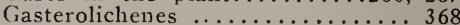

Gasteromycetes ......................... 257

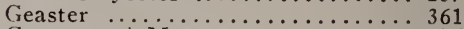

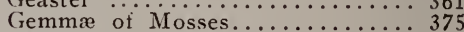

Gemmation of cells.................... 173

Genes, or unit characters........... 442

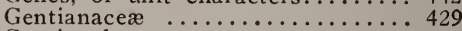

Gentianales .................... 429

Genotypes $\ldots \ldots \ldots \ldots \ldots \ldots \ldots \ldots 444$

Geographical botany .............. 13

Geotropism ................. 282

Geraniacer $\ldots \ldots \ldots \ldots \ldots \ldots \ldots \ldots \ldots . \ldots \ldots . \ldots \ldots 425$

Geraniales .................... 425

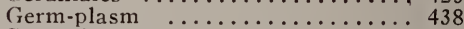

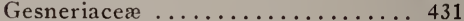

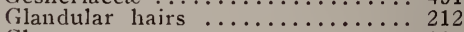

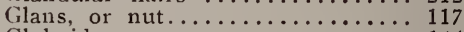

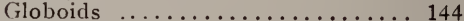

Globulariacere ................ 431

Gloocapsa ................. 309

Glomerule $\ldots \ldots \ldots \ldots \ldots \ldots \ldots \ldots \ldots \ldots 6 . \ldots \ldots$

Glucosides ...................... 148

Glumales .................... 414

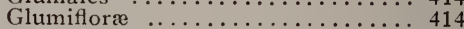

Gnetales, general characters of... 407

Gonidia of Lichens.......... 365

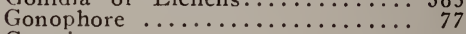

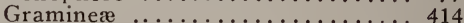

Grasses ................. 412,414

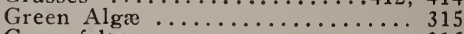

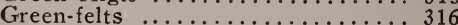

Growing points (meristems).... 277

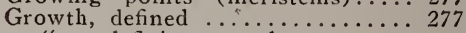

“ definite annual ........... 23

“ grand period of ......... 278

" indefinite annual ......... 23

"influence of temperature

" influence of light on ......... 279

" phases of ........... 277

Gums $\ldots \ldots \ldots \ldots \ldots \ldots \ldots \ldots \ldots \ldots \ldots$

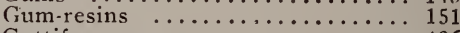

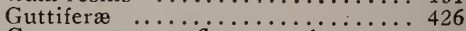

Gymnospermæ, flowers of..........3 398

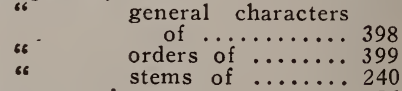

Gymnosporangium $\ldots \ldots \ldots \ldots \ldots \ldots . . \ldots 356$

Gynæcium ...................

Gynandrous stamens .......... 83

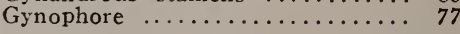

HABENARIA CILIARIS, flower

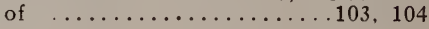


Habitats of plants .......... 445

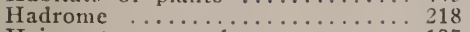

Hairs, structure of . . . . . . . 187

Haloragidacea ................ 427

Halophytes, or seacoast plants... 442

Hamanelidacer ............... 424

Haustoria ................. 340

Head-cell of Chara.............. 332

Head, or capitulum............. 63

Heart-wood ................2 235

Heat, as an ecological factor.... 447

Heliotropism ................. 283

Heliobales ..................4. 413

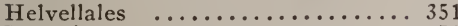

Hepatica ................... 372

Heredity ..................4 438

Hesperidium ................. 118

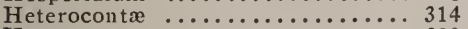

Heterocysts .................. 309

Heteromerous Lichens ........ 365

Heteromorphism of Flowers...... 101

Heterosporous Pteridophyta ...... 382

Heterozygous parents ........4442

Hip fruits ............... 122

Hippocastanaceæ .............. 426

Histology $\ldots \ldots \ldots \ldots \ldots \ldots \ldots \ldots \ldots, 14,131$

Histology of floral organs....... 247

" " leaf ............. 243

" " leaf $\ldots \ldots \ldots \ldots \ldots \ldots . \ldots . \ldots .241$

" " roots $\ldots \ldots \ldots \ldots \ldots .218$

Homoiomerous Lichens .........365, 366

Hormogones ................. 310

Homosporous ferns .......... 382

Homozygous parents ........... 442

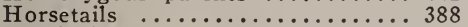

Horticulture $\quad . \ldots \ldots \ldots \ldots \ldots \ldots \ldots, 13$

Host plant .................. 340

Humus soil .................. 449

Hybrids, behavior of ...........441

Hydatodes, or water pores...... 186

Hydnaceæ .................... 359

Hydnum repandum .......... 361

Hydrocaryaceæ ............. 427

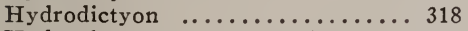

Hydrophytes, or water plants.... 452

Hydropteridales ............. 388

Hydrotropism ................. 285

Hygroscopism, as an agent for the dispersion of fruits...... 113

Hymenium of Fungi............ 353

Hymenogastraceæ ............ 358

Hymenomycetes .............. 358

Hypanthium .............. 78

Hypericaceæ ................4 426

Hyphæ of fungi............. 340

Hypocotyl .................. 126

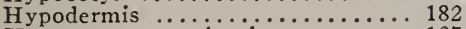

Hypogeous germination ........ 127

INDETERMINATE Anthotaxy.. 61

Inflorescence $1 . \ldots \ldots \ldots \ldots \ldots . . .60$

Influence of light on the plant.. 279

Insectivorous plants ........... 53

Insects and flowers............ 96

Intercellular spaces ........208, 211

Inulin $\ldots \ldots \ldots \ldots \ldots \ldots \ldots \ldots \ldots . . .139$

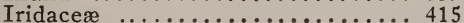

Iris, floral diagram of ......... 412

Irregular flowers ............. 75

Irritability, in plants......255, 288

Isoetes, general characters of .... 395

Isogametes .................. 316
JOINT Firs ............. 407

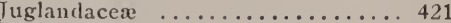

Juglandales .................. 421

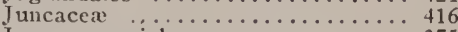

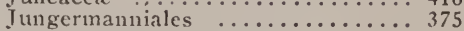

KARYOKINESIS .......... 168

Kernel ................... 125

LABIAT $\ldots \ldots \ldots \ldots \ldots \ldots .430$

Lamarck, on evolution............. 433

Lamina ...................... 437

Laminaria ..................... 333

Latex cells ................. 205

laticiferous vessels $\ldots \ldots \ldots \ldots \ldots 209$

Lauraceæ ..................... 423

Laws, Mendelian ................ 440

Law of dominance............ 440

Leaf, blade of................ 39

centric ................. 245

dorsi-rentral ............. 244

epidermis of $\ldots \ldots \ldots \ldots \ldots \ldots 241$

isolateral ............ 245

fibro-vascular system of.... 241

" histology of .........241.246

Leaf-scars $\ldots \ldots \ldots \ldots \ldots \ldots \ldots{ }_{2}$

Leaflets $\ldots \ldots \ldots \ldots \ldots \ldots \ldots, 50,51$

Leaves, alternate ................ 36 apex forms $\ldots \ldots \ldots \ldots \ldots . . . \ldots \ldots$ arrangement of $\ldots \ldots \ldots .35$ as insect-traps $\ldots \ldots \ldots .53$ base forms ........... 46

cauline ............ 37

compound ........... 50

definition of $\ldots \ldots \ldots .32,240$ duration of $\ldots \ldots \ldots \ldots \ldots, 37$

floral .............. 37

foliage $\ldots \ldots \ldots \ldots \ldots \ldots . \ldots \ldots$

functions of $\ldots \ldots \ldots \ldots \ldots, 32$

general outline ....... 44

marginal indentations ... 46

mode of growth of ....... 32

modifications of ......... 32

opposite ............. 35

parts of $\ldots \ldots \ldots \ldots \ldots \ldots, 37$

perfoliate $\ldots \ldots \ldots \ldots \ldots \ldots . .39$

persistent $\ldots \ldots \ldots \ldots \ldots .37$

position of $\ldots \ldots \ldots \ldots \ldots 37$

radical .............. 37

rameal ............ 37

seminal ............ 37

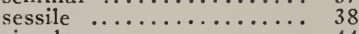

simple $\ldots \ldots \ldots \ldots \ldots \ldots, 44$

structure of $\ldots . .37,41,240$

surface of $\ldots \ldots \ldots \ldots \ldots, 51$

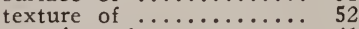

venation of $\ldots \ldots \ldots \ldots \ldots$ 4 4

vernation of ......... 33

whorled ........... 35

Lecythidaceæ $\ldots \ldots \ldots \ldots \ldots \ldots \ldots .427$

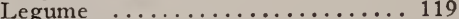

Leguminosæ .................. 424

Lejolisia Mediterranea .......... 338

Lemnaceæ .................4 415

Lentibulariaceæ ............... 431

Lenticels $\ldots \ldots \ldots \ldots \ldots \ldots \ldots \ldots \ldots .238$

Leptome ................ 218

Leptosporangiatæ ........... 382

Leucoplasts ................. 137

Liber ................... 239

Libriform cells .............. 197

Lichen-algæ $\ldots \ldots \ldots \ldots \ldots \ldots \ldots .363$

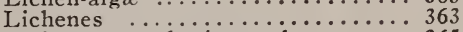

Lichens, apothecium of ....... 365

classification of $\ldots \ldots \ldots 368$ 
" crustaceous ................. 366 foliaceous $\ldots \ldots \ldots \ldots \ldots \ldots . \ldots 366$ fruticose .......... 336 fructification of ...... 365 heteromerous ............. 365 homoiomerous ........ 365 soredia of ............... 365

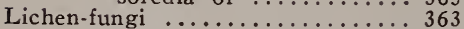

Light, in relation to plant life. 279,446 Ligule

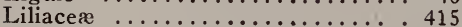

Liliales .................. 415

Limnanthaceæ ................. 425

Linaceæ ................................... 425

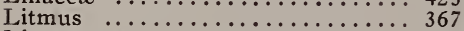

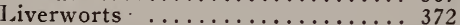

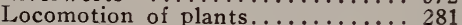

Loganiaceæ ................... 429

Loment .................... 119

Loranthaceæ .................... 421

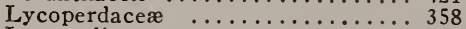

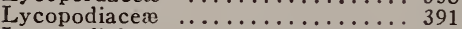

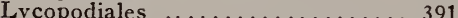

Lycopodinea, general characters of 391

Lycopodium ................ 392

Lysigenous passages .............. 212

Lythraceæ .................. 427

MALVACE $\ldots \ldots \ldots \ldots \ldots \ldots . \ldots . \ldots 426$

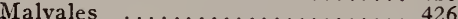

Manubrium $\ldots \ldots \ldots \ldots \ldots \ldots \ldots \ldots \ldots \ldots . \ldots \ldots 332$

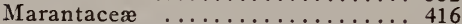

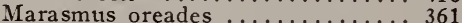

Marchantiaceæ ................ 374

Marchantia polymorphia ............. 374

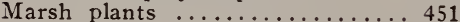

Marsilia .................... 387

Martyniaceæ $\ldots \ldots \ldots \ldots \ldots \ldots \ldots \ldots \ldots . . \ldots 431$

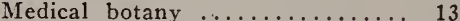

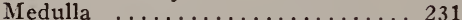

Medullary rays $\ldots \ldots \ldots \ldots \ldots \ldots 220,231$

Megasporangia ............. 106, 394

Megaspore ................106, 394

Melastomaceæ ............... 427

Meliaceæ ..................... . 425

Mendelism ...................... 439

Mendel, researches of..........4440

Meristematic tissue ....................... 176

Meristems, primary ........... 176

"

secondary $\ldots \ldots \ldots \ldots \ldots 176$

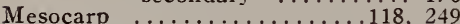

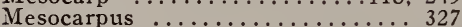

Mesophyll .................

Mestome ............... 204, 205

Mestome strand ............. 231

Mesophytes, or normal plants.... 452

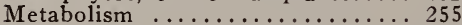

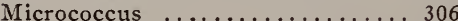

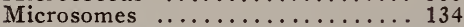

Microsporangia ............ 106, 394

Microspores ........... 105, 382, 394

Midrib ................... 242

Mimosø ................... 424

Mineral substances in cells......... 153

Mitosis .................. 170

Mobility of protoplasm........ 245

Monœcious plants ........... 97

Monimiaceæ................. 423

Monocotyledons, classification of. 413

$\begin{array}{llll}\text { "6 } & \text { embryo of } \ldots \ldots & 413 \\ \text { flowers of } \ldots \ldots & 412 \\ \text { general charac- } & \\ \text { " } & \text { ters of } \ldots 411, & 412\end{array}$

" $4 \begin{aligned} & \text { orders of } \ldots 413.416 \\ & \text { roots of } \ldots 218,412 \\ & \text { seeds of } \ldots \ldots 34,412 \\ & \text { stems of } \ldots .236,412\end{aligned}$

stems of $\ldots 236,412$

Monocotyledon-type of stem...226-231

Monopodial branching ........ 55

Monotropaceæ ..............4428

Morphology ................ 13

Morchella esculenta ............. 361

Mosses $\ldots . . .368,369$

antheridia of ............. 369 archegonia of $\ldots \ldots \ldots \ldots 369$ calyptra of .............. 371

classification of ........... 372

columella of $\ldots \ldots \ldots \ldots . .371$

elaters of $\ldots \ldots \ldots \ldots \ldots \ldots . \ldots 371$

orders of ..........372.378

paraphyses of ....... 369

perichatium of ....... 369

perigynium of ........ 369

protonema of $\ldots \ldots \ldots \ldots 372$

spores of $\ldots \ldots \ldots \ldots \ldots . \ldots 372$

sporogonium of ...... 370

sporophyte of ....... 370

Movements of plants............ 280

Movements, nyctitropic .............286

Tucilage streaming ......... 282

Mucilage-sacs .................. 143

Mucor Mucedo ............341, 342

Musaceæ $\ldots \ldots \ldots \ldots \ldots \ldots \ldots \ldots \ldots \ldots 416$

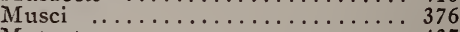

Mutants ................... . 437

Mutations as related to evolution. 437

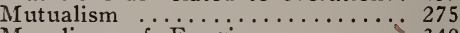

Mycelium of Fungi........... 340

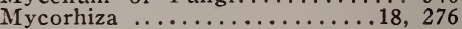

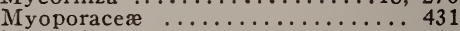

Myricales .................... 420

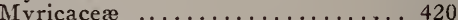

Myrisinaceæ . . . . . . . . . . . . . . . 429

Myristicaceæ $\ldots \ldots \ldots \ldots \ldots \ldots \ldots \ldots \ldots .4 . \ldots . \ldots 423$

Myrtales ................... 426

Myrtacea ................... 427

Myxomycetes ................. 302

NAMES, botanical, origin of. ... 297

Naming of plants............. 297

Negative geotropism ........... 283

Negative heliotropism .......... 283

Nitrogen, fixation of........... 272

Nolanacere ................ 430

Nomenclature, binomial ........ 297

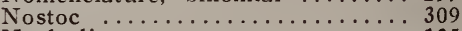

Nucleoli $\ldots \ldots \ldots \ldots \ldots \ldots \ldots \ldots \ldots \ldots \ldots \ldots 135$

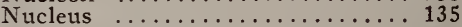

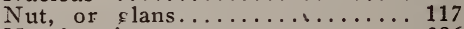

Nyctitropic movements ......... 286

Nymphacer $\ldots \ldots \ldots \ldots \ldots \ldots \ldots \ldots 423$

OBLIGATE Parasites ........ 340

Ocrea ................... 41

CEdogoniums $\ldots \ldots \ldots \ldots \ldots \ldots \ldots . \ldots \ldots 323,324$

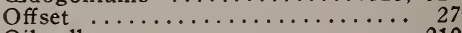

Oil-cells $\ldots \ldots \ldots \ldots \ldots \ldots \ldots \ldots \ldots \ldots \ldots . \ldots \ldots 210$

Oils, fixed $\ldots \ldots \ldots \ldots \ldots \ldots \ldots \ldots \ldots \ldots . \ldots \ldots$

" volatile ................ 150

Oleaceæ ..................... 429

Oleaceæ, floral diagram of........ 418

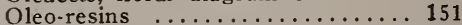

Onagraceæ $\ldots \ldots \ldots \ldots \ldots \ldots \ldots \ldots \ldots \ldots . \ldots \ldots 427$

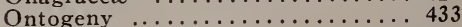

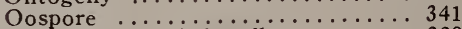

Openore collateral bundles............ 220

Operculum of Mosses............ 370 
Ophioglossum .............. 383

Opuntiales ..................... 426

Orchidales .................. 416

Orchidaceæ ................ +16

Organography, defined ....... 13

Organs of plants, histology oi... 216

Organs of reproduction.......15, 58

Organs of vegetation.........15, 16

Oscillatorias ................. 310

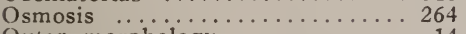

Outer morphology ........... 14

Ovary $\ldots \ldots \ldots \ldots \ldots \ldots \ldots .6,248$

Ovule, fertilization of ........... 107

Ovules, nature of............ 93

" of Gymnosperms ....... 399

" position of .......... 93

" shapes of $\ldots \ldots \ldots \ldots \ldots .949$

Oxalidacere ................. 425

PALE

Paleobotany ............ 13

Palisade tissue ............. 178,245

Palms, useful products of . . . . . 414

Palmales ................ 414

Palmaceæ ..................... 414

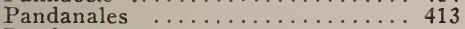

Pandanacea ............... 413

Pandorina ................. 320

Papaverales ............... 423

Papaveraceæ ................. 423

Papilionaceæ ................, 424

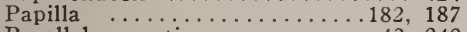

Parallel venation ...........42, 242

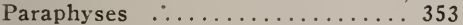

Parasites ................. 275

$\begin{array}{lll}\text { " roots of } \ldots \ldots \ldots \ldots \ldots & 17 \\ \text { Parenchyma }\end{array}$

Parenchyma folded $\ldots \ldots \ldots \ldots \ldots \ldots \ldots \ldots \ldots 178$

" $\quad$ polded $\ldots \ldots \ldots \ldots \ldots, 178,245$

" pitted .............. 178

“ $\quad$ spongy $\cdots \ldots \ldots \ldots 176,245$ stellate. .......... 178

Parenchymatous tissue $\ldots \ldots \ldots \ldots \ldots .177$

Parietales ..................... 425

Passifloraceæ ................ 426

Pedaliaceæ ................. 431

Pediastrum $\ldots \ldots \ldots \ldots \ldots \ldots \ldots \ldots \ldots \ldots \ldots \ldots \ldots \ldots$

Pedicel ................. 60

Peduncle ................ 60

Penicillium slaucum ........347, 348

Pentosides ................... 148

Pepo .................. 118

Perennial herb .............. 25

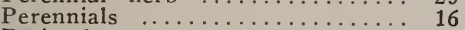

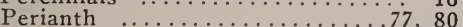

Periblem .................216

Pericarp ..................

Perichætium of Mosses........... 369

Pericycle ................ 224

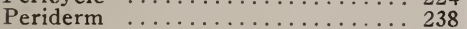

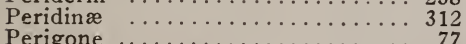

Perigone ............... 77

Perigynium of Mosses.......... 369

Perisperm ................ 109, 251

Perisporiales $\ldots \ldots \ldots \ldots \ldots \ldots \ldots \ldots \ldots . . . \ldots \ldots$

Peronospora alsinearum........ 344

Petals .................... 79

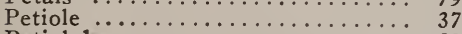

Petiolule .................. 50

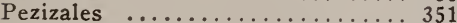

Phacidæ ................. 351

Phæophyceæ, or Brown Algæ.... 333

Phæosporales ............... 333

Pharmaceutical Botany .......... 13
Phascum muticum

Phellogen .............219, 238

Phenotypes ............. 444

Phloem ..........205, 218

Photogenic bacteria .......... 307

Photosynthesis ..........255, 269

Photosynthetic equation ........ 269

Phototropism ............... 283

Phrymacea ............... 431

Phycomycetes ............... 341

Phyllodia ................. 39

Phyllotaxy ............... 35

Phylogenetic relationship ....... 295

Phylogeny ................ 433

Physiology ..........13, 14, 25t

Phytophthora infestans ......343, 344

Pileus of Agarics............. 360

Pinus sylvestris, reproduction in.. $40+$

Piperales ................. 420

Pistils $\ldots \ldots \ldots \ldots \ldots \ldots \ldots \ldots \ldots, 7,4,78$

" angiospermous ......... 88

“ apocarpous ........... 89

a pocarpous $\ldots \ldots \ldots \ldots \ldots \ldots$
compound $\ldots \ldots \ldots \ldots \ldots$

gymnospermous ........ 88

" placentation of ........ 90

syncarpous ............. 89

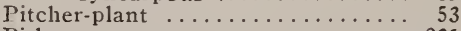

Pith

Pitted tracheids of pine......198, 200

Pitted vessels ............... 202

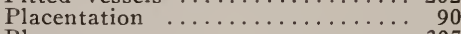

Planococcus .............. 307

Planosarcina .............. 307

Plant breeding .............. 13

" classification ............. 13

" hairs .................... 186

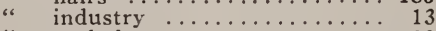

“ pathology ................ 13

societies $\ldots . .451$

Plantaginales ................... 431

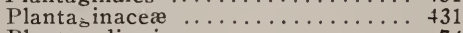

Plants, diøcious ............ 74

" monœcious .......... $7 t$

" polygamous $\ldots \ldots \ldots \ldots \ldots$. 74 principal groups of . . . . . 299

Plasmodia of Myxomycetes...... 302

Plasmolysis ............... 265

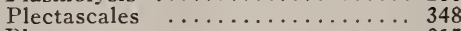

Plerome ..................217

Pleurococcus .............. 317

Plocamium .................... 338

Plumbaginaceæ .............. 429

Plumule ................. 127

Polemoniales .............. 430

Polemoniaceæ ............... 430

Pollen, forms of . . . . . . . . . 86,250

Pollen-tube .............86, 106

Pollinia .................. 87

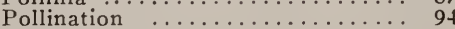

Polygalaceæ .................. 425

Polypetalæ ................ 422

Polypetalous corolla ........... 80

Polypodiaceæ ............... 385

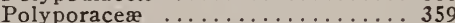

Polyporous fomentarius ........ 359

Polysepalous calyx ............ 77

Polytrichum commune ......... 370

Pome $. . . \ldots \ldots \ldots \ldots \ldots \ldots . \ldots \ldots$

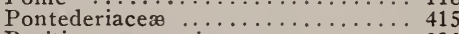

Positive geotropism .......... 283

Positive heliotropism …......... 283

Prefloration $\ldots \ldots \ldots \ldots \ldots \ldots \ldots \ldots .696 .6 \%$

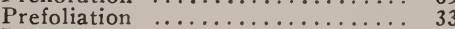

Prickles ................... 189

Primary cortex ............... 216 


\begin{tabular}{|c|c|}
\hline meristems & \\
\hline structure of roots. & \\
\hline “" permanent tissues & 216 \\
\hline 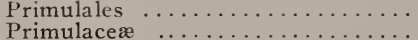 & \\
\hline $\begin{array}{l}\text { Primulaceæ } \ldots . . . . . . . . . \\
\text { Primitive Monocotyledons }\end{array}$ & 413 \\
\hline Primitive Dicotyledons .... & \\
\hline Principal groups of plants... & \\
\hline Procarps $\ldots \ldots \ldots \ldots \ldots \ldots \ldots \ldots$ & \\
\hline 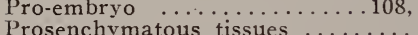 & \\
\hline $\begin{array}{l}\text { Prosenchymatous tissues } \ldots \ldots \ldots \ldots \\
\text { Proterandrous flowers } \ldots \ldots \ldots \ldots\end{array}$ & $\begin{array}{r}194 \\
97\end{array}$ \\
\hline Proterogynous flowers $\ldots \ldots \ldots$ & 97 \\
\hline Proteales $\ldots \ldots \ldots \ldots \ldots \ldots \ldots$ & 421 \\
\hline Proteins $\ldots \ldots \ldots \ldots \ldots \ldots \ldots \ldots$ & 144 \\
\hline Prothallium of Equisetinea........ & \\
\hline Lycopodiacer & \\
\hline Mosses ...... & 380 \\
\hline Pines.. & 406 \\
\hline Protococcales $\ldots \ldots \ldots \ldots \ldots \ldots$ & \\
\hline Protonema of Mosses.......372, & \\
\hline Protoplasm attributes of $\ldots \ldots \ldots \ldots$ & $\begin{array}{l}135 \\
254\end{array}$ \\
\hline Protoderm $\quad . . \ldots \ldots \ldots \ldots \ldots \ldots$ & \\
\hline Protoplasts $\quad \ldots \ldots \ldots \ldots \ldots \ldots$ & \\
\hline $\begin{array}{l}\text { Protoxylem }, \ldots \ldots \ldots \\
\text { Pteridophyta, classes of . . . }\end{array}$ & 382 \\
\hline 1'teridophyta, classes $\begin{array}{l}\text { general characters of } \\
\text { gen }\end{array}$ & \\
\hline " reproduction of $\ldots$ & \\
\hline Ptomains $\quad \therefore .$. & 308 \\
\hline Pteris aquilena & \\
\hline Pteridosperms $\ldots \ldots \ldots \ldots \ldots \ldots$ & \\
\hline Puccinia graminis, life history of. & \\
\hline Pulvinus $\ldots \ldots \ldots \ldots \ldots \ldots \ldots \ldots$ & 39 \\
\hline Punicace P............. & \\
\hline $\begin{array}{l}\text { Purity of Gametes........ } \\
\text { Putrefaction, cause of... }\end{array}$ & \\
\hline Pyrenolichenes ............ & 368 \\
\hline Pyrenoid $\ldots \ldots \ldots \ldots \ldots \ldots \ldots$ & 327 \\
\hline $\begin{array}{l}\text { Pyronema contluans } \ldots \ldots \ldots \ldots \\
\text { Pyrolacex }\end{array}$ & 351 \\
\hline Pyrenomycetes $\ldots \ldots \ldots$. & \\
\hline
\end{tabular}

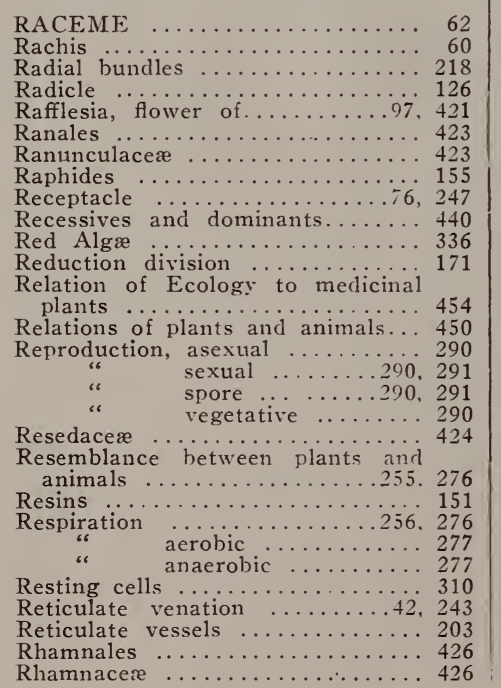

Rhizoids ..............222, 300 Rhizomes distinction from roots.. 27 Rhizophoraceæ ............... 427 Rhodophyceæ ............. 336 Rhœadales ............... 423 Ricciales .................. 373 Ricinus, germination of ........ 419 Rings of growth........... 236 Rivularias $\ldots \ldots \ldots \ldots \ldots \ldots \ldots . \ldots \ldots \ldots$ Roccella tinctoria $\ldots \ldots \ldots \ldots \ldots \ldots .367$ Root, definition of .......... 16

" histology of ........... 216 how it differs from the stem 17 Root-branches. origin of ....... 221 Root-cap ..............17, 217 Root-hairs ............ 218, 216, 263 Root-pressure .............. 266

Roots, absorbing surface of ..... 17 absorption by ............ 265 forms of $\ldots \ldots \ldots \ldots \ldots, 20$ functions of $\ldots \ldots \ldots \ldots 16,20$ of Dicotyledons ....218, 417 Epiphytes ......... 17 “ Monocotyledons ....218, 412 " parasites ........... 17 primary structure of ..... 218 primary .............. 18 secondary changes in..... 219

“ $\quad \operatorname{tap} \ldots \ldots \ldots \ldots \ldots \ldots \ldots . . \ldots 19$ " tuberous ........... 19, 20

Rosaceæ .................4 424

Rosales .................. 424

Rosette crystals .............. 155

Rubiaceæ ................. 431

Rubiales ................. 431

Runner ................... 27

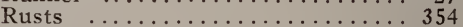

Rutacer ................. 425

SACCHAROMYCES cererisia... 352 Saccharomycetes ............ 342

Sage, flower of .............. 102

Salvinia natans $\ldots \ldots \ldots \ldots \ldots \ldots \ldots . .387$

Salicales .................. 420

Salicaceæ ................ 420

Samara .................... 116

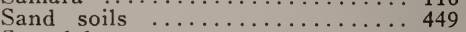

Santalales ............... 421

Santalacea $\ldots \ldots \ldots \ldots \ldots \ldots \ldots, 421$

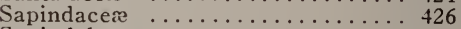

Sapindales ............... 425

Sapotaceæ ................ 429

Saprogenic bacteria ................ 307

Saprophytes ............... 275

Saprolegniales .............. 343

Sap-wood .................... 235

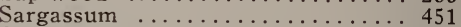

Sarcina ..................... 306

Sarcocarp ................. 118, 249

Sarraceniales $\ldots \ldots \ldots \ldots \ldots \ldots \ldots \ldots, 424$

Sarraceniaceæ .............. 424

Saxifra aceæ . ........... 424

Scalariform vessels $\ldots \ldots \ldots \ldots \ldots .202$

Scape $\ldots \ldots \ldots \ldots \ldots \ldots \ldots \ldots, 60$

Scenedesmus ................. 317

Schizogenous passages ........... 212

Schizomycetes .................. 305

Scitaminales $\ldots \ldots \ldots \ldots \ldots \ldots \ldots, 416$

Sclerenchyma fibers ........... 194

Sclerotia of Myxomycetes........ 303

Sclerotic tissue ............. 180

Sclerotium of Fungi.........340, 348 Scrophulariaceæ .............. 430 Scytonemas $\ldots . . . . . . . . . .310$

Seacoast plants, or Halophytes... 453 
Secondary medullary rays....... 232 “ meristems ......... 176 “ permanent tissues .... 176 “ structure of roots.... 219

Secretion xylem ............ 219

“" passares ............... 212

“ passues $\cdots \cdots \cdots \cdots \ldots .212$

Seed, coats of............123, 249

" definition of $\ldots \ldots \ldots \ldots \ldots \ldots 123$

" number of ............. 129

“ internal structure of ...125, 249

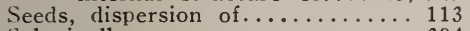

Selaginella ................... 394

Selaginellales, general characters of 393

Semi-parasites ............. 275

Sepals ...................

Sieve plates ................ 204

Sieve tissue .............. 204

Simarubaceæ ................ 425

Siphonales ................... 315

Sleep movements ........... 286

Slime-molds $\ldots \ldots \ldots \ldots \ldots \ldots \ldots 302$

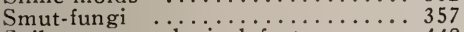

Soil as an ecological factor...... 448

Soils, various kinds of ......... 449

Solanaceæ ................. 430

Soredia of Lichens............... 365

Sorus of Ferns.............. 382

Spadix ................. 63

Sparganiaceæ .............. 413

Specialized Monocotyledons ......4 416

Specialized Dicotyledons ....... 428

Spermagonia of Ascomycetes..... 355

Spermatophyta, classification of ... 398

Spermatophyta, general characters

of ................... 396

Spermatia of Ascomycetes.......... 355

Spermoderm .............124, 249

Sperms, or male gametes........ 105

Sphagnales ................ 376

Sphagnum .................. 377

Spike .................. 62

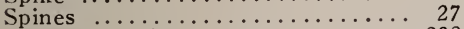

Spiral vessels …........... 202

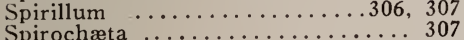

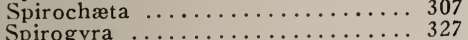

Sporangia of Ferns................ 380

Spore-reproduction ...........290, 291

Sporidia ................... 344,345

Sporogonium of Mosses............. 370

Sporophyte of Mosses.......... 370

Sports, or Mutants...........437

Starch as reserve food-material.138, 271

" formation of .......138, 139

" in chloroplasts $\ldots \ldots \ldots \ldots \ldots 138$ storage of $\ldots \ldots \ldots \ldots \ldots 138$

Starch-grains, forms of .......... 139

"“ " structure of ...... 138

Stamens .............. $71,82,247$

parts of $\ldots \ldots \ldots \ldots \ldots \ldots .82$

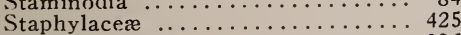

Staphylococcus ............. 306

Starch sheath .............. 218

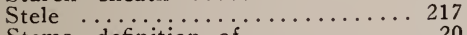

Stems, definition of ............. 20 direction of growth of .... 25 duration of $\ldots \ldots \ldots \ldots \ldots, 25$ habits of growth of ...... 25 how they differ from roots 20 leaf-like $\ldots \ldots \ldots \ldots \ldots \ldots .30$ size of $\ldots \ldots \ldots \ldots \ldots \ldots \ldots .24$ shapes of $\ldots \ldots \ldots \ldots \ldots \ldots$.
“ underground $\ldots \ldots \ldots \ldots \ldots, 27$

Sterculiacere ................ 426

Stereome ................. 180

Sticta pulmonacea ........... 367

Stigma, structure of .......992, 248

Stipules, modification of ........ 37

Stolon .................. 26

Stomata ................. 182

" number to the square inch 184

Stone cells ................ 180

Storage of reserve materials...... 273

Stramonium, fruit of .......... 113

Streaming movements ......... 282

Streptococcus .................. 306

Strobile .................. 63

Strobilus of Equisetums.......... 388

Struggle for existence.......... 435

Style $\ldots . . . . . . . . . . . .692$

Styracex $\ldots \ldots \ldots \ldots \ldots \ldots \ldots . .429$

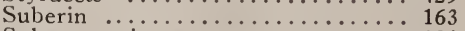

Suberous tissue ............. 191

Substratum ................. 340

Succession of Plant Societies.... 454

Sucker .................. 27

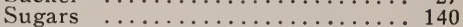

Survival of the fittest......... 435

Sundew .................. 53

Suspensor $\ldots \ldots \ldots \ldots \ldots \ldots \ldots \ldots \ldots \ldots \ldots, 194$

Suture $\ldots \ldots \ldots \ldots \ldots \ldots \ldots, 89$

Swamp societies of plants...... 452

Symbionts ................. 275

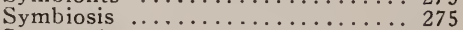

Sympetalæ ................ 427

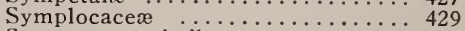

Syncarpous pistils ............... 89

Synergida ................. 107, 410

Synthesis of carbohydrates........ 269

Synthesis of proteins............ 271

Systematic botany ........... 13

TAMARICACE $\mathrm{E}$.......... 426

Taxus baccata, flowers of ...... 403

Taxonomy, vegetable ....13, 14, 294

Teleutospores ...........354, 355

Temperature in relation to plant life 278

Tendrils, nature of ............ 26

Testa ..................124, 129

Tetraspores ................ 337

Thallophyta, general characters of 300

Thallus ................... 30

Theaceæ $\ldots \ldots \ldots \ldots \ldots \ldots \ldots \ldots \ldots \ldots \ldots \ldots \ldots \ldots \ldots, 426$

Thelephoraceæ $\ldots \ldots \ldots \ldots \ldots \ldots \ldots . .359$

Thermogenic bacteria .......... 307

Thermotropism .............. 285

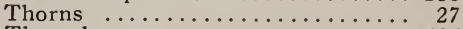

Thymeleaceæ $\ldots \ldots \ldots \ldots \ldots \ldots .426$

Thyrsus .................... 68

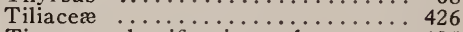

Tissues, classification of ......... 175

origin of $\ldots \ldots \ldots \ldots \ldots 175$

Torus $\ldots \ldots \ldots \ldots \ldots \ldots \ldots \ldots \ldots \ldots \ldots \ldots \ldots \ldots$
Toxins $\ldots \ldots \ldots \ldots \ldots$

Trabecular vessels $\ldots \ldots \ldots \ldots \ldots \ldots \ldots \ldots 203$

Tracheal tubes ............... 201

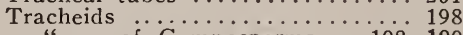

" of Gymnosperms ...198, 199

Transpiration ............. 267

Transverse geotropism .......... 283

Trichogyne of Red Algæ......... 338

Trichomes ................... 186

Tropæolaceæ .................... 425

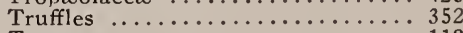

Tryma ........................ 118

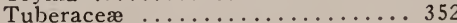

Tubers, characteristics of ........ 28 


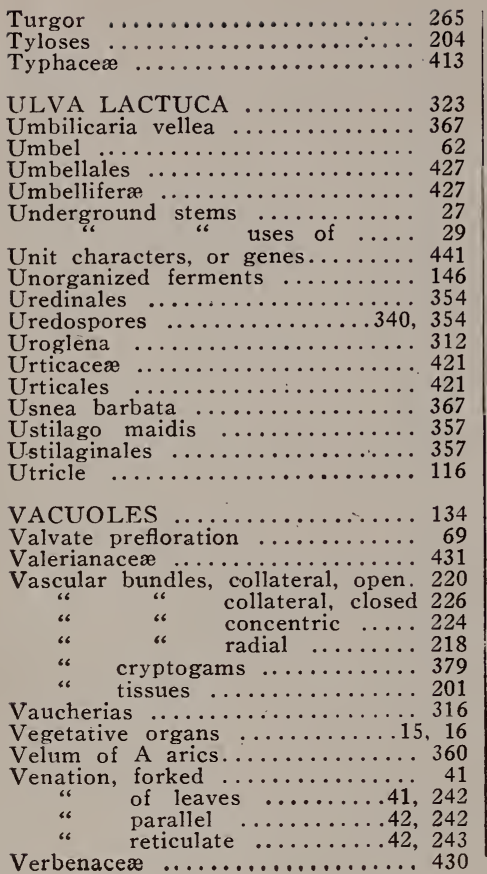

Vernation $\ldots \ldots \ldots \ldots \ldots \ldots \ldots \ldots, 33$

Verticillales ................ 420

Verticillaster $\ldots \ldots \ldots \ldots \ldots \ldots \ldots, 67$

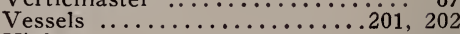

Violaceæ $\ldots \ldots \ldots \ldots \ldots \ldots \ldots \ldots . \ldots, 426$

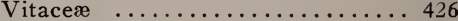

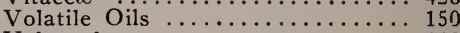

Volvocales ................... 319

Volvox globator ............ 321

WATER, as an ecological factor.. 448

Water plants, or hydrophytes... 451

Water in plants............. 259

Water-pores .................. 186

Waxes .................. 143

Weeds ................... 450

Welwitschia $\ldots \ldots \ldots \ldots \ldots \ldots \ldots \ldots .407$

Wilting of leaves.............. 267

Wind, as an ecological factor.... 450

Wood fibers ................. 197

Wood parenchyma ............... 201

Wound cork .............. 193

XEROPHYTES, or desert plants 453

Xylem .................. 197

“ primary ................. 219

“ secondary ............ 219

YEAST Fungi ............. 352

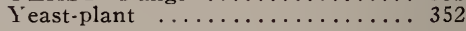

ZINGIBERACE $A$ E ......... 416

Zooglæa-masses of Bacteria........ 305

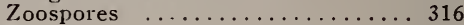

Zygnema .......................... 327

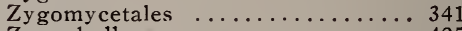

Zygophyllaceæ .............4425

Zygospores $\ldots \ldots . .316,341$

Zymogenic bacteria ............. 307 


$-\gamma$ 


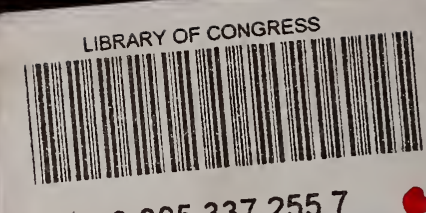
00053372557 